\title{
Maternal Engineered Nanomaterial Inhalation Exposure: Cardiac Molecular Reprogramming in Progeny through Epigenetic and Epitranscriptomic Mechanisms
}

Amina Kunovac

West Virginia University School of Medicine

Follow this and additional works at: https://researchrepository.wvu.edu/etd

Part of the Cardiovascular Diseases Commons, Disorders of Environmental Origin Commons, Genomics Commons, and the Toxicology Commons

\section{Recommended Citation}

Kunovac, Amina, "Maternal Engineered Nanomaterial Inhalation Exposure: Cardiac Molecular Reprogramming in Progeny through Epigenetic and Epitranscriptomic Mechanisms" (2021). Graduate Theses, Dissertations, and Problem Reports. 10255.

https://researchrepository.wvu.edu/etd/10255

This Dissertation is protected by copyright and/or related rights. It has been brought to you by the The Research Repository @ WVU with permission from the rights-holder(s). You are free to use this Dissertation in any way that is permitted by the copyright and related rights legislation that applies to your use. For other uses you must obtain permission from the rights-holder(s) directly, unless additional rights are indicated by a Creative Commons license in the record and/ or on the work itself. This Dissertation has been accepted for inclusion in WVU Graduate Theses, Dissertations, and Problem Reports collection by an authorized administrator of The Research Repository @ WVU.

For more information, please contact researchrepository@mail.wvu.edu. 


\title{
Maternal Engineered Nanomaterial Inhalation Exposure: Cardiac Molecular Reprogramming in Progeny through Epigenetic and Epitranscriptomic Mechanisms
}

\author{
Amina Kunovac \\ Dissertation submitted to the School of Medicine at West Virginia University in partial \\ fulfillment of the requirements for the degree of: \\ Doctor of Philosophy in Exercise Physiology \\ John M. Hollander, Ph.D, Chair \\ Paul D. Chantler, Ph.D. \\ Roberta Leonardi, Ph.D. \\ Timothy R. Nurkiewicz, Ph.D. \\ I. Mark Olfert, Ph.D. \\ Department of Human Performance, Division of Exercise Physiology, West Virginia \\ University, Morgantown, WV, USA - 2021
}

Keywords: Mitochondria, Epitranscriptome, Cardiac, ENM, Fetal, Gestation, m6A. Proteome

Copyright 2021 Amina Kunovac 


\title{
Abstract \\ Maternal Engineered Nanomaterial Inhalation Exposure: Cardiac Molecular Reprogramming in Progeny through Epigenetic and Epitranscriptomic Mechanisms
}

\author{
Amina Kunovac
}

Introduction: Nano-titanium dioxide $\left(\mathrm{TiO}_{2}\right)$, a prominently utilized engineered nanomaterial (ENM), is being employed for its physiochemical properties in several fields including the food industry, manufacturing, and biomedicine. As the prevalence of this ENM, and other particulate matter grows, so does the concern for antagonistic consequences on long-term heart function in vulnerable populations, which until now have not been investigated. Due to the reliance of the heart on the ATP generating capacity of mitochondria for contraction, understanding the role of mitochondrial bioenergetics and structure is pivotal in understanding the repercussions of particulate matter exposure during gestation. As the mass population in cities, where particulate matter exposure is highest, do not have many options for mitigating their exposure, it is of utmost importance that strategies are developed that limit the detriments associated with xenobiotic exposure. Understanding the mechanisms, both epigenetic and epitranscriptomic, that regulate mitochondrial and cardiac function under these circumstances will allow for a better understanding of potential therapeutic or preventative strategies and mitigate the disease burden related to particulate matter exposure each year. The purpose of this compilation of work is to identify the mechanisms contributing to the acute and chronic pathological effects of ENM inhalation exposure during gestation as a prerequisite to developing strategies to reduce risks to public health.

Methods and Results: Using an inhalation exposure paradigm that mimics the lung burden seen in an occupational setting, we first examined the effects of maternal nano- $\mathrm{TiO}_{2}$ inhalation exposure during gestation on the cardiac function of wild type offspring at the fetal (acute) and adult (chronic) stage using both conventional and speckle tracking stress-strain echocardiographic assessments. Cardiac contractile function was decreased in both the fetal (gestational day 15 (GD 15)) and the adult (11 weeks) offspring. Assessment of mitochondrial bioenergetic and electron transport chain (ETC) complex activities revealed a decreased oxygen consumption rate in offspring and decreased ETC Complex IV at both the fetal and adult stage following maternal ENM inhalation exposure during gestation. Furthermore ELISA-based assessment of 5methylcytosine (5mC methylation) and Dnmt expression pointed to the involvement of epigenetic mechanisms in altered mitochondrial and cardiac function. Implementation of a novel breeding strategy, using a transgenic mouse model that overexpresses mitochondrial phospholipid hydroperoxide glutathione peroxidase (mPHGPx), an antioxidant enzyme, determined that enhanced antioxidant expression in the maternal environment can mitigate the effects of gestational nano- $\mathrm{TiO}_{2}$ inhalation exposure on fetal and adult offspring cardiac and mitochondrial function. $\mathrm{N}^{6}$-methyladenosine $\left(\mathrm{m}^{6} \mathrm{~A}\right)$ was implicated as a modulator of altered $\mathrm{mPHGPx}$ activity following maternal ENM exposure in adult offspring, suggesting that epitranscriptomics also has a regulatory role in the adverse effects of particulate matter exposure. 
Conclusions: The work presented in this presentation demonstrates the ability for ENM inhalation exposure during gestation to alter cardiac function through a mechanism that involves altering mitochondrial function and elevating ROS levels. These studies also provide evidence that there is likely overlap and interplay between epitranscriptomic and epigenetic mechanisms that contribute to changes in the mitochondrial proteome that reduces the ability of the mitochondrion to regulate stress in the form of ROS and leads to dysfunction. Limiting ROS levels through mitochondrially-targeted antioxidant defense enhancement provides a potential preventative route that may allow for the evasion of the adverse cardiac outcomes in offspring that are gestationally exposed to xenobiotics. 


\title{
Dedication
}

\author{
To My Parents: Šemsa and Esad Kunovac
}

Without your hard work and perseverance, this would have never been possible. Thank you for your unconditional love and support throughout this whole process and for always taking an interest in my research even when it made no sense at all. We did it.

Additionally, I would like to thank the following people for their constant support and encouragement: Kemal, Sarah, Teta, Kenan, Strina, Adjo, Alma, Lamija, Belmin, and my husband, Quincy. 


\section{LIST OF ABBREVIATIONS AND DEFINITIONS}

5-mC

7-KCh

ACE

Acta1

AMPK $\alpha 2^{-/-}$

Ang II

ANP

AT III

$\mathrm{AT}_{1} \mathrm{R}$

Bax

$\mathrm{BC}$

Bcl-2

BNP

$\beta-\mathrm{MHC}$

C3

$\mathrm{Ca}^{2+}$

CAP

$\mathrm{CaV} 1.2$

CK

$\mathrm{CO}$

Colla1
5-Methylcytosine

7-ketocholesterol

Angiotensin I-converting enzyme

Actin alpha 1 (ACTA1)

AMP-activated protein kinase $\alpha 2$ knockout

Angiotensin II (ANG)

Atrial natriuretic peptide (NPPA)

Antithrombin III (SERPINC1)

Angiotensin II type I receptor (ATGR1)

Bcl-2-associated X protein

Black carbon

B-cell lymphoma 2

Brain natriuretic peptide (NPPB)

$\beta$-myosin heavy chain

Complement factor 3

Calcium

Concentrated ambient particles

Calcium channel, voltage-dependent, L type, alpha $1 \mathrm{C}$ subunit

Creatine kinase

Carbon monoxide

Collagen type I alpha 1 


$\begin{array}{ll}\text { Col3a1 } & \text { Collagen type III alpha 1 } \\ \text { COX-2 } & \text { Cyclooxygenase-2 (PTGS2) } \\ \text { CPT1A } & \text { Carnitine palmitoyltransferase } \\ \text { CREB } & \text { cAMP response element binding protein } \\ \text { CRP } & \text { C-reactive protein } \\ \text { CsA } & \text { Cyclosporin A } \\ \text { cTnI } & \text { Cardiac troponin I } \\ \text { cTnT } & \text { Cardiac troponin T } \\ \text { CVD } & \text { Cardiovascular disease } \\ \text { CXCL1 } & \text { C-X-C motif chemokine ligand 1 } \\ \text { D2D } & \text { D-dimer }\end{array}$

DNMT

DNA methyltransferase

DRP1

Dynamin-related protein 1

EC

Elemental carbon

EGFR

Epidermal growth factor receptor

ENM

Engineered nanomaterials

eNOS

Endothelial nitric oxide synthase

EPC

Endothelial progenitor cells

ER

Endoplasmic reticulum

ET-1

Endothelin-1(EDN1)

F3

Tissue factor III

$\mathrm{FBA} / \mathrm{B} / \mathrm{G}$

Fibrinogen genes

FIS1

Fission 1 
GADD153

GATA

GRP78

GSH-Px

GSK3 $\beta$

GST

GST-P

GTSM1

H3K27me3

H3K4me3

HDL

HDM

HIF

HO-1

HOI

HOMA-IR

HRV

HSP70

ICAM-1

IFN- $\gamma$

IKK

IL

CXCL8
Growth arrest and DNA damage 153

GATA sequence binding protein

Glucose regulated protein 78

Glutathione peroxidase

Glycogen synthase kinase 3 beta

Glutathione S-transferase

Glutathione s-transferase $\mathrm{P}$

Glutathione s-transferase mu 1

Histone 3 lysine 27 trimethyaltion

Histone 3 lysine 4 trimethyaltion

High-density lipoprotein

House dust mite

Hypoxia inducible factor

Heme oxygenase-1(HMOX)

HDL oxidative index

Homeostatic Model Assessment of Insulin Resistance

Heart rate variability

Heat-shock protein $70 \mathrm{kD}$

Intercellular adhesion molecule 1

Interferon gamma (IFNG)

Inhibitor of I $\kappa \mathrm{B}$ kinase-2

Interleukin

Interleukin 8 


\begin{tabular}{|c|c|}
\hline iNOS & Inducible nitric oxide (NOS2) \\
\hline IP-10 & IFN $\gamma$-induced protein 10 \\
\hline IPA & Ingenuity Pathway Analysis \\
\hline Isop & F2-isoprostane \\
\hline JNK & C-Jun $\mathrm{NH}_{2}$-terminal kinase \\
\hline $\mathrm{LDH}$ & Lactate dehydrogenase (LDHB) \\
\hline LDL-C & Low-density lipoprotein cholesterol \\
\hline LINE-1 & Long interspersed nuclear element-1 \\
\hline MAPK & Mitogen activated protein kinase \\
\hline MCP-1 & Monocyte chemoattractant protein 1 \\
\hline MDA & Malondialdehyde \\
\hline Mef2c & Myocyte enhancer factor \\
\hline $\mathrm{MeHg}$ & Methylmercury \\
\hline METTL & Methyltransferase like protein \\
\hline Mfn1 & Mitofusin 1 \\
\hline MIP-1 & Macrophage inflammatory protein \\
\hline MMP9 & Matrix metalloproteinase \\
\hline mPHGPx & Mitochondrial phospholipid hydroperoxide glutathione peroxidase \\
\hline MPO & Myeloperoxidase \\
\hline mPTP & Mitochondrial permeability transition pore \\
\hline MT-RNR1 & Mitochondrial 12s RNA \\
\hline MT-TF & Mitochondrially encoded tRNA phenylalanine \\
\hline $\mathrm{M}^{6} \mathrm{~A}$ & $\mathrm{~N}^{6}$-methyladenosine \\
\hline
\end{tabular}




\begin{tabular}{|c|c|}
\hline NCX & $\mathrm{Na}^{+} / \mathrm{Ca}^{2+}$ exchanger \\
\hline NF-кB & Nuclear factor-kappa beta (NFKB1) \\
\hline $\mathrm{NO}_{2}$ & Nitrogen dioxide \\
\hline NOX-4 & NADPH oxidase 4 \\
\hline NRF2 & Nuclear factor erythroid-derived 2-like 2 \\
\hline $\mathrm{OC}$ & Organic carbon \\
\hline OGG1 & 8-oxoguanine DNA glycosylase \\
\hline OPA1 & Mitochondrial dynamin like GTPase \\
\hline PAH & Polycyclic aromatic hydrocarbons \\
\hline PAI-1 & Plasminogen activator inhibitor-1 \\
\hline PAMR1 & Peptidase domain containing associated with muscle regeneration 1 \\
\hline $\mathrm{Pb}$ & Lead Acetate \\
\hline $\mathrm{PDH}$ & Pyruvate dehydrogenase \\
\hline PF-4 & Platelet factor 4 \\
\hline PlGF & Placental growth factor \\
\hline $\mathrm{PM}$ & Particulate Matter \\
\hline p-PLN & Phosphorylated phospholamban \\
\hline PRDX5 & Peroxiredoxin 5 \\
\hline PRNP & Prion protein \\
\hline PTPRF & Protein tyrosine phosphatase receptor type F \\
\hline ROS & Reactive oxygen species \\
\hline RYR2 & Ryanodine receptor 2 \\
\hline SAA & Serum amyloid A \\
\hline
\end{tabular}


SELP

SERCA2

SHR

SiNP

SIRT

$\mathrm{SO}_{2}$

$\mathrm{SO}_{4}$

SOD

SOS1

STAT

TFPI

TGF $\beta-1$

TIMP3

$\mathrm{TiO}_{2}$

TLR2

TLR4

TNFR2

TNF- $\alpha$

t-PA

TRPA1

UCP2

UFCP

UFP
P-selectin

Sarco/endoplasmic reticulum Ca2+-ATPase (ATP2A2)

Spontaneously hypertensive rats

Silica nanoparticles

Sirtuin

Sulfur dioxide

Sulfate

Superoxide dismutase

SOS Ras/Rac Guanine Nucleotide Exchange Factor 1

Signal transducer and activator of transcription

Tissue factor pathway inhibitor

Transforming growth factor beta 1

Tissue inhibitor of metalloproteinase 3

Titanium dioxide

Toll-like receptor 2

Toll-like receptor 4

Tumor necrosis factor receptor 2 (LTBR)

Tumor necrosis factor alpha

Tissue-type plasminogen activator (PLAT)

Transient receptor potential cation channel A1

Uncoupling protein 2

Ultrafine carbon particles

Ultrafine particles 
VCAM-1

VEGF

vWF

WT
Vascular Cell Adhesion Protein 1

Vascular endothelial growth factor (VEGFA)

Von Willebrand factor

Wild type 


\section{TABLE OF CONTENTS}

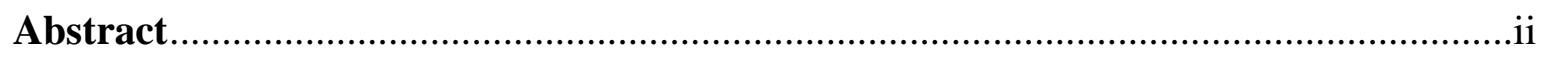

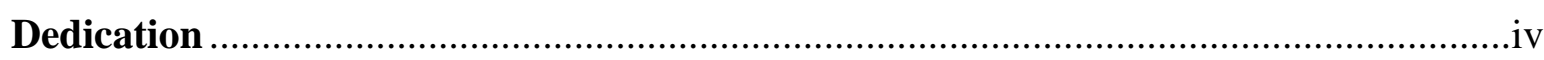

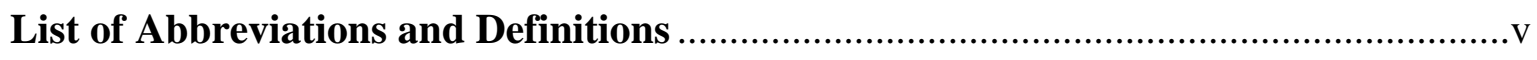

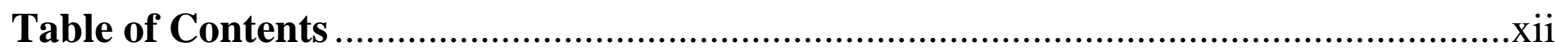

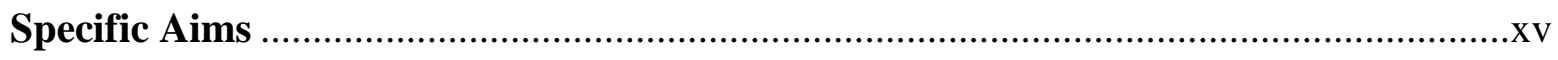

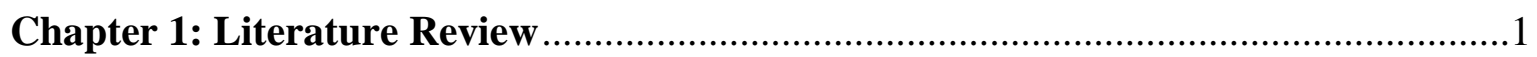

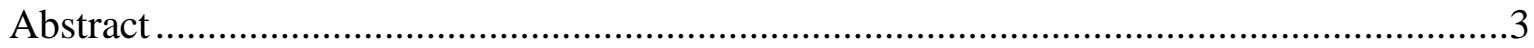

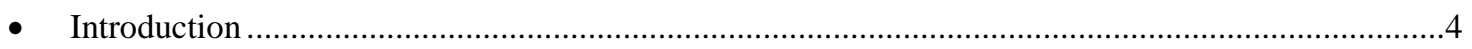

- Summarized Recent Findings Table 1.1 f............................................................................

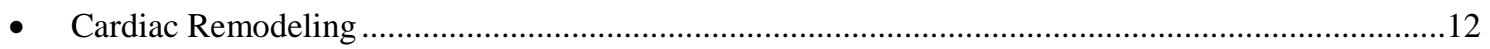

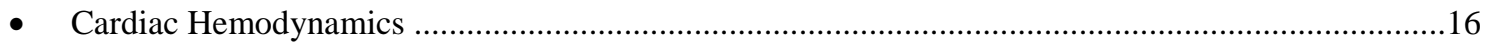

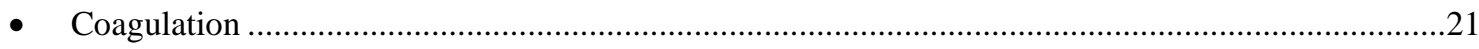

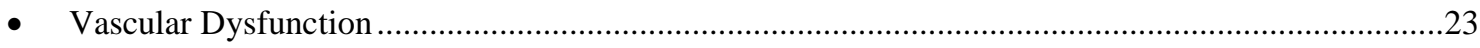

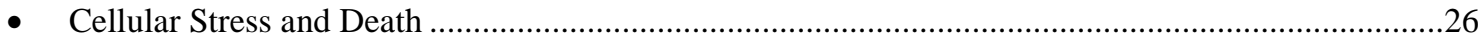

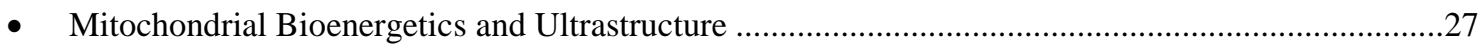

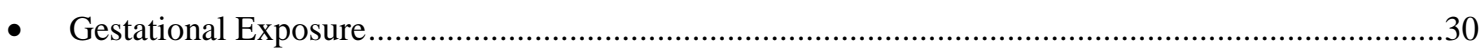

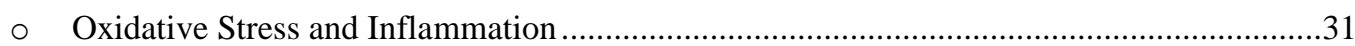

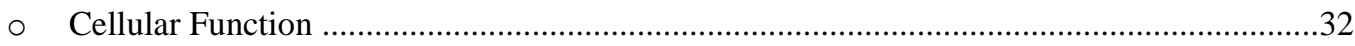

$\circ \quad$ Epigenetics and Transcriptional Regulation ......................................................................

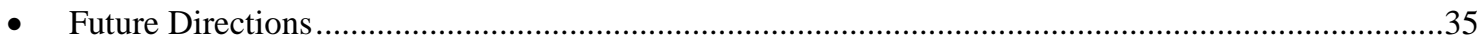

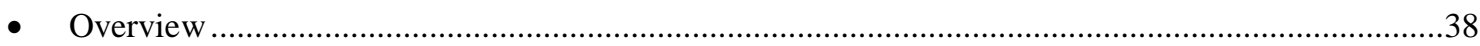

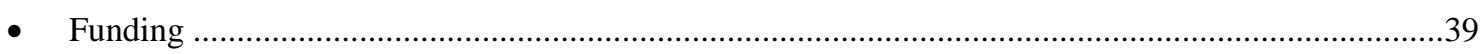

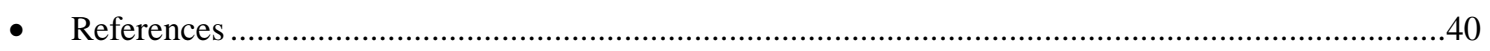

\section{Chapter 2: Specific Aim 1}

ROS Promote Epigenetic Remodeling and Cardiac Dysfunction in Offspring Following Maternal Engineered Nanomaterial (ENM) Exposure …......................................54

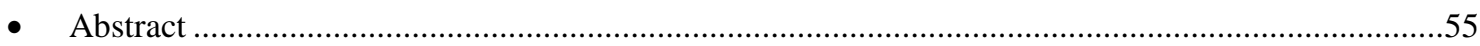

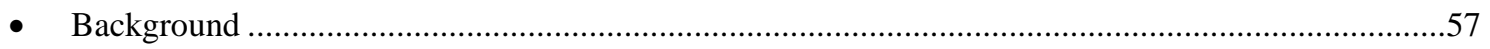




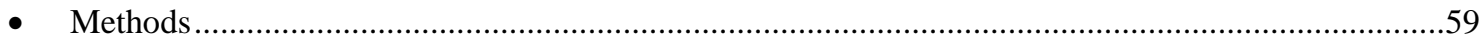

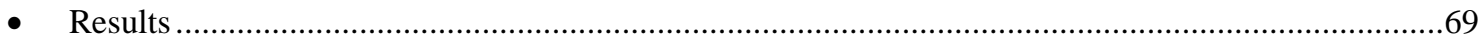

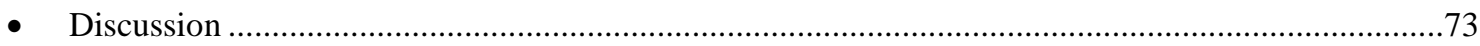

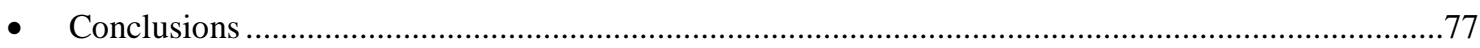

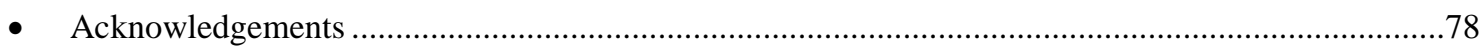

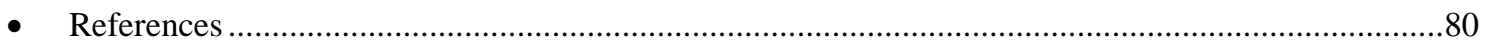

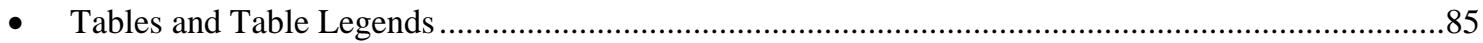

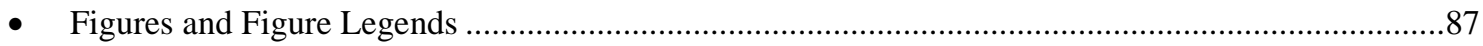

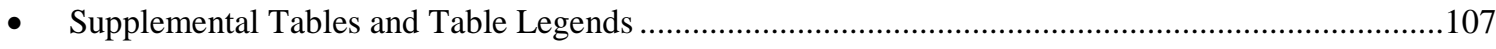

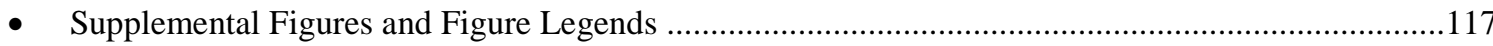

Chapter 3: Specific Aim 2 - Enhanced Antioxidant Capacity Prevents Epitranscriptomic and Cardiac Alterations in Adult Offspring Gestationally-Exposed to ENM ...............124

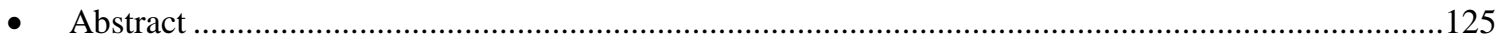

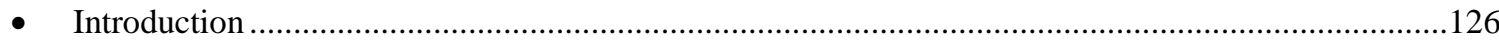

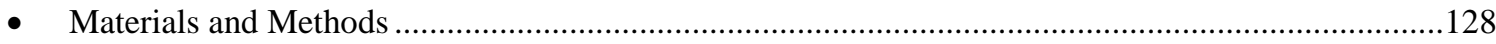

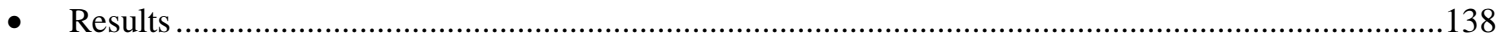

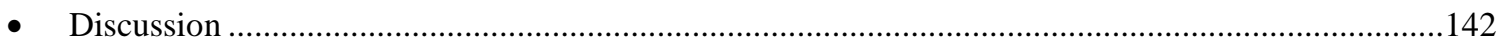

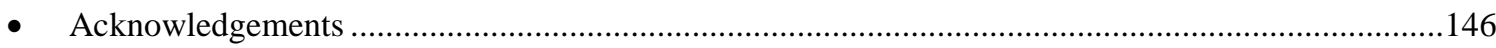

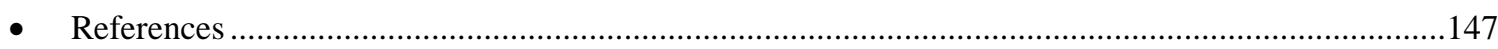

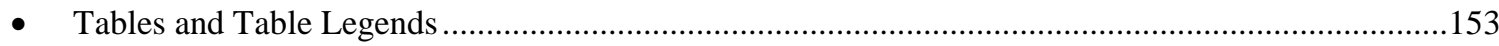

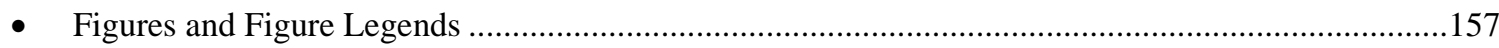

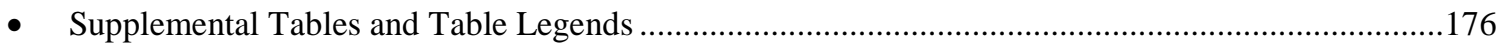

Chapter 4: Specific Aim 3 - Increased $N^{6}$-Methyladenosine in Fetal Offspring following Gestational Nano-TiO2 Inhalation Exposure Decreases Mitochondrial Transcript and

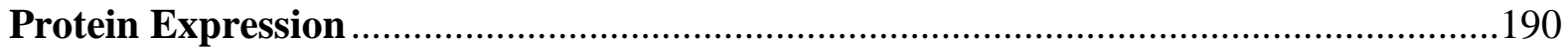

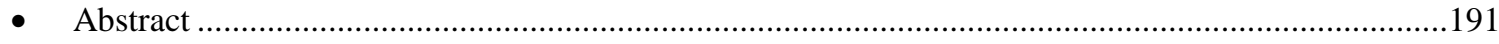

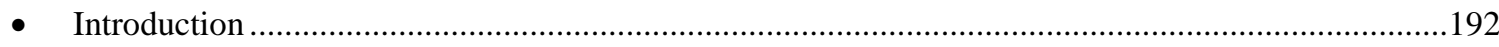

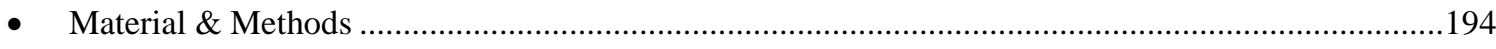

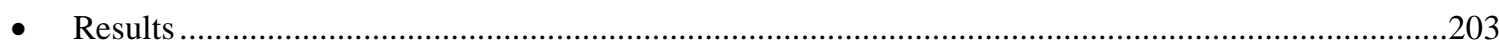

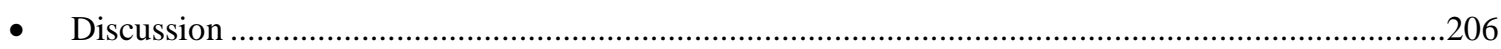

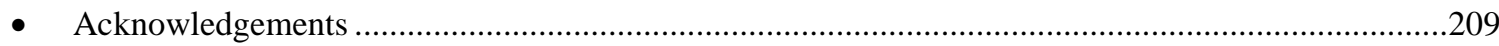

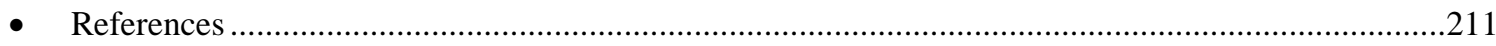




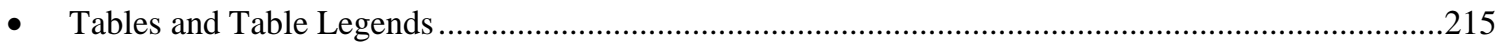

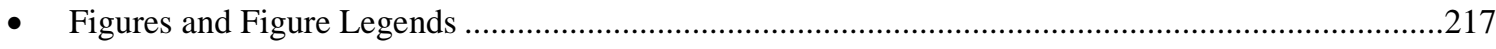

- Supplemental Figures and Figure Legends .............................................................................237

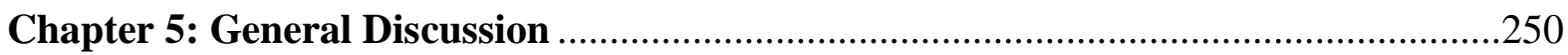

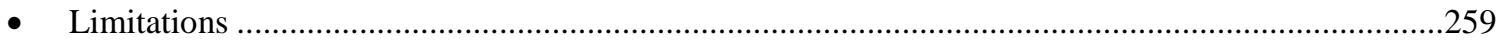

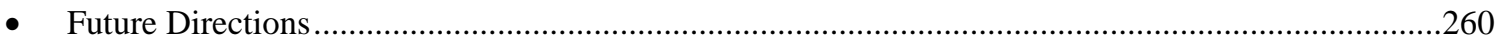

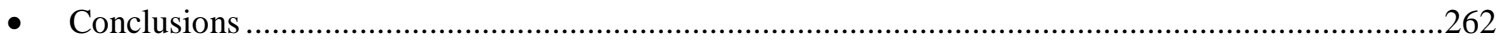

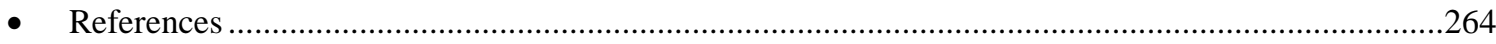

Chapter 6: Supplemental Material: Left Ventricular Segmental Stress-Strain Identifies Unique Myocardial Deformation Patterns Following Intrinsic and Extrinsic Stressors in

Mice .267

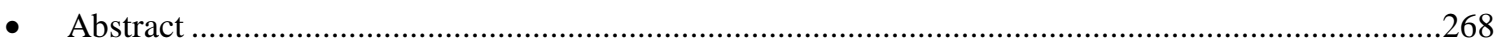

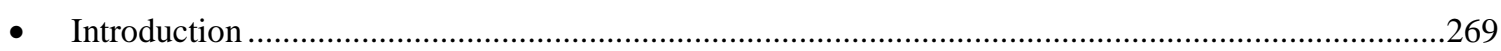

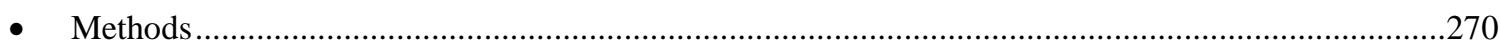

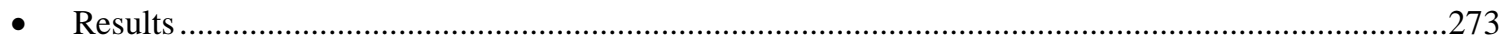

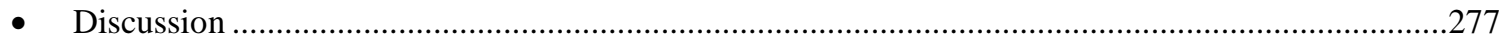

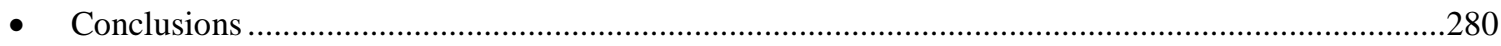

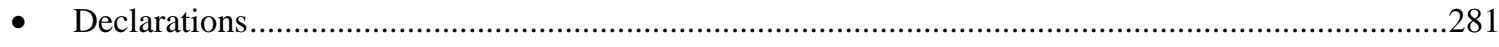

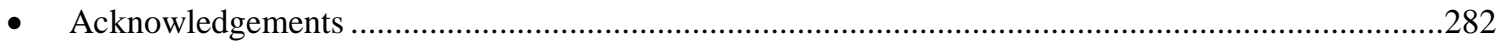

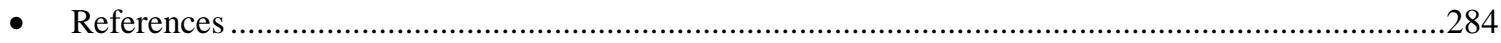

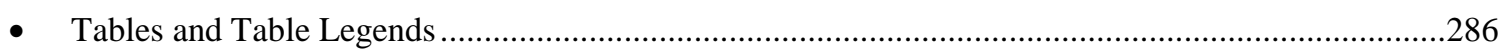

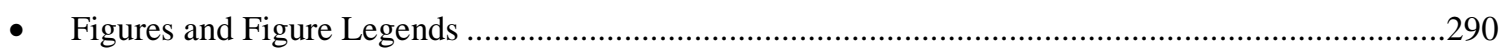

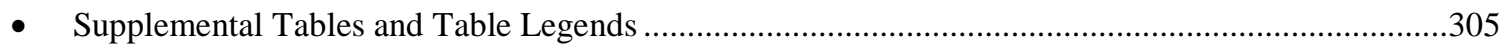

- Supplemental Figures and Figure Legends ……………....................................................................309

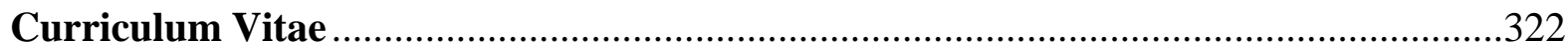




\section{Specific Aims:}

Xenobiotic exposure is a causative agent of cardiovascular dysfunction, ensuing as a result of mitochondrial bioenergetic dysregulation. The implementation of engineered nanomaterials (ENMs) in consumer products, manufacturing processes, and clinical applications is expanding rapidly despite our limited understanding of their impacts on human health. Exposure to ENMs are of particular concern for vulnerable populations such as the developing fetus, which is prone to deleterious effects that can alter the epigenomic profile and result in sustained dysfunction or susceptibility to other metabolic disturbances into adulthood. Our laboratory was the first to evaluate the consequences of maternal ENM inhalation exposure during gestation. The findings of this study indicated that gestational nano- $\mathrm{TiO}_{2}$ exposure has a detrimental impact on cardiac contractile function, mitochondrial respiration and bioenergetics that are sustained into adulthood. The functional deficits seen following ENM inhalation exposure have been attributed to increased production of reactive oxygen species (ROS), that was ameliorated by overexpression of mitochondria phospholipid hydroperoxide glutathione peroxidase (mPHGPx), an antioxidant enzyme that protects cells from oxidative stress. ROS insult has the capacity to induce mRNA epigenetic modifications, such as 5-methylcytosine or epitranscriptomic changes, such as $\mathrm{N}^{6}$ methyladenosine $\left(\mathrm{m}^{6} \mathrm{~A}\right)$, which is predicted to occur in a critical region of the 3' UTR of mPHGPx and can thus alter mRNA stability. However, there is a paucity of information regarding the effects of the altered epigenetic/epitranscriptomic mechanisms and whether they are connected to changes in the mitochondrial proteome in progeny. The studies outlined in this dissertation address these critical gaps in knowledge and are designed to determine if enhanced antioxidant protection can provide a protective role to offspring following maternal ENM inhalation exposure and elucidate the epigenomic remodeling mechanisms that impact development. The long-term goal of these studies is to identify mechanisms contributing to the pathological effects of xenobiotic exposure as a prerequisite to developing strategies for reducing risks to public health.

The objectives of this dissertation are to: (1) determine whether maternal engineered nanomaterial (ENM) inhalation exposure influences progeny cardiac function and epigenomic remodeling (2) elucidate the impact of mPHGPx overexpression in various contexts on contractile function and mitochondrial bioenergetics in offspring following maternal ENM inhalation exposure; and (3) 
determine whether disruption of mitochondrial bioenergetics and cardiovascular dysfunction elicited by maternal exposure can be attributed to epitranscriptomic remodeling that is associated with an altered mitochondrial proteome that is incapable of managing high levels of ROS. My central hypothesis is that changes in the $\mathrm{m}^{6} \mathrm{~A}$ methylome, concomitant with an altered mitochondrial proteome at the fetal stage, precipitate cardiac contractile dysfunction that is sustained into adulthood following maternal ENM inhalation exposure. Sustained dysfunction may be averted through limiting ROS via overexpression of mPHGPx. Preliminary data from our lab indicate that ENM exposure results in altered mitochondrial and cardiac contractile function as a result of elevated ROS levels and diminished antioxidant capacity. Additionally, our laboratory has shown that following exposure, fetal offspring presented with an altered transcriptome and changes in DNA histone modifications. We have chosen nano- $\mathrm{TiO}_{2}$ as a representative ENM because it is widely tested in academic, industrial, and biomedical research. To test our central hypothesis, we propose three Specific Aims:

Specific Aim 1: Elucidate the effects of maternal nano-TiO $\mathrm{O}_{2}$ inhalation exposure on cardiac contractile function and mitochondrial function in fetal offspring and whether these detriments persist into adulthood. We will test our working hypothesis that maternal nano- $\mathrm{TiO}_{2}$ inhalation exposure during gestation may evoke an ROS response resulting in mitochondrial bioenergetic disruption and cardiac contractile dysfunction in offspring that persists into adulthood.

1.1 Evaluate cardiac contractile function using conventional and speckle tracking stressstrain parameters in fetal (gestational day (GD) 15) and adult (11 weeks) offspring following maternal nano- $\mathrm{TiO}_{2}$ inhalation exposure during gestation.

1.2 Examine the effects of inhalation nano- $\mathrm{TiO}_{2}$ during gestation on fetal and adult offspring cardiac mitochondrial bioenergetics and ultrastructure.

1.3 Determine the role of epigenetic modifications and their mediators in modulating mitochondrial function in offspring maternal nano- $\mathrm{TiO}_{2}$ inhalation exposure during gestation.

The expected outcomes of Specific Aim 1 are that cardiac function is negatively altered following gestational ENM inhalation exposure along with mitochondrial dysregulation in fetal and adult offspring, likely as a result of reprogramming that causes changes in ROS levels. 
Specific Aim 2: Determine whether enhanced $m P H G P x$ expression preserves cardiac contractile function and bioenergetics in adult offspring following maternal ENM inhalation exposure, and whether $m^{6} \mathrm{~A}$ methylation contributes to altered antioxidant capacity. We will test our working hypothesis that enhanced antioxidant defense at the level of the dam and fetus will provide the most impactful protection by lessening cardiac contractile dysfunction and bioenergetic disruption in adult offspring following gestational ENM exposure. The enhanced antioxidant defense will mitigate the contractile and mitochondrial dysfunction by evading changes to the $\mathrm{m}^{6} \mathrm{~A}$ methylome.

2.1 Determine whether increasing ROS scavenging through mPHGPx expression in maternal, fetal, or both provides the most protective profile.

2.2 Elucidate whether enhanced antioxidant protection has the ability to mitigate ROS levels such that cardiac function and mitochondrial activity are restored.

2.3 Ascertain whether $\mathrm{m}^{6} \mathrm{~A}$ plays a role in diminished mitochondrial bioenergetics and ROS scavenging ability at the adult stage following maternal ENM inhalation exposure during gestation and whether mPHGPx overexpression ameliorates these consequences.

The expected outcomes of Specific Aim 2 are that overexpression of mPHGPx in the fetus combined with the overexpression of mPHGPx in the pregnant dam will provide the most protective profile, thereby lowering mitochondrial ROS levels, ameliorating mitochondrial dysregulation, and preserving proper cardiac function following maternal ENM inhalation exposure.

Specific Aim 3: Evaluate the epitranscriptomic changes and the mechanism associated with increased ROS following maternal ENM inhalation exposure that contribute to mitochondrial and cardiac dysfunction at the fetal stage. We will test our working hypothesis that nuclear and changes to the epitranscriptome of mitochondrial genes following maternal ENM inhalation exposure contribute to cardiac dysfunction at the fetal stage that persists into adulthood as a result of altered regulator expression. 
3.1 Explicate the repercussions of maternal nano- $\mathrm{TiO}_{2}$ inhalation exposure during gestation on the overall $\mathrm{m}^{6} \mathrm{~A}$ methylome in wild type fetal offspring to determine the role of epitranscriptomics in diminished cardiac function.

3.2 Elucidate how maternal nano- $\mathrm{TiO}_{2}$ inhalation exposure during gestation alters the mitochondrial proteome in wild type fetal offspring and whether these changes are associated with epitranscriptomic reprogramming.

The expected outcomes of Specific Aim 3 are that changes in $\mathrm{m}^{6} \mathrm{~A}$ of crucial nuclear-encoded mitochondrial mRNA will correlate with a deficient mitochondrial proteome that can account for diminished mitochondrial bioenergetics that occurs in fetal offspring following gestational ENM exposure and contributes to the long-term cardiac effects that also persist into adulthood.

With respect to the overall expected outcomes, successful completion of these studies will provide fundamental information concerning the relationship between epigenetic/epitranscriptomic regulation during the critical window of fetal development and the subsequent long-term cardiovascular effects. The information will aid in the design of protective antioxidant strategies and assessment of consumer risks to ensure safer development of nanotechnologies. 


\section{RESEARCH STRATEGY}

SIGNIFICANCE. While nanotechnology has provided important advancements in biomedical engineering, the increased interactions of nanomaterials and biological tissue warrants assessments of associated toxicological effects $(2,4,16)$. Engineered nanomaterials (ENMs) pose occupational and public risks due their abundance in consumer products $(17,20)$ and the primary route of exposure, inhalation, allows particles to enter the bloodstream and systemically impact the body (20). Nano titanium dioxide $\left(\mathrm{TiO}_{2}\right)$, one of the most utilized ENMs, is incorporated into versatile industrial, environmental, and consumer products (17), with application in consumer products escalating by $300 \%$ from 2011 to 2013 (22). Maternal ENM exposure during gestation interferes with fetal development and has long-term consequences for offspring that persist into adulthood $(2,4,11,21)$. Over the last decade, the developmental origins of health and diseases (DOHaD) hypothesis has increased emphasis on understanding how parental exposure to environmental stressors can alter the susceptibility of offspring to various diseases including obesity (24). Currently, $40 \%$ of all adults (over the age of 20) in the United States are obese (8), which is one of the top risk factors for heart disease. Cardiovascular disease is the leading cause of death, accounting for every 1 in 4 deaths in the US (1). Understanding the risk factors that increase the propensity for developing cardiovascular disease and how they can be prevented is critical in lowering the associated death toll.

Previous studies, in conjunction with preliminary data presented in this application, provide the scientific premise for the proposed experimentation. Our laboratory was the first to report sustained (into adulthood) cardiac contractile dysfunction following maternal nano- $\mathrm{TiO}_{2}$ inhalation exposure during gestation $(10,19)$. These effects were associated with disruption to the fetal cardiac epigenome, dysregulated mitochondrial bioenergetics, and decreased mPHGPx expression levels in offspring. Increased reactive oxygen species (ROS) generation indicated oxidative stress following acute ENM inhalation exposure (15), which could be linked to cardiac contractile dysfunction through epigenomic changes such as DNA methylation and posttranslation histone modifications (12). These data support the proposition that targeted interventions lessening ROS during gestation may provide relief from the damaging effects of ENMs. Elevated ROS has also been associated with altered levels of $\mathrm{N}^{6}$-methyladenosine $\left(\mathrm{m}^{6} \mathrm{~A}\right)$, the most prevalent mRNA modification in higher eukaryotes, which regulates transcription and 
translation $(13,23,26)$. Investigation of $\mathrm{m}^{6} \mathrm{~A}$ sites in crucial coding regions of nuclear genomeencoded mitochondrial mRNA that are pivotal in antioxidant defense is therefore pertinent as it will provide insight into the mechanism by which ROS may be controlling mPHGPx protein expression. Further, understanding the repercussions of early-life exposure in terms of susceptibility to obesity and other metabolic diseases, such as diabetes, mellitus is critical, as epigenomic adaptations may alter the ability of an organism to cope with a secondary insult (7). Maternal exposure to particulate matter, as it relates to the susceptibility of offspring to develop obesity, have previously been investigated in several epidemiological studies $(3,5,6,14,24)$. All in all, the previous studies suggest a critical need for understanding the epigenetic mechanisms involved in developmental reprogramming that causes such detriments. Our laboratory has shown that in mice, following a single ENM inhalation exposure, fatty acid metabolism has been impacted $(9,10)$. Additionally, diminished $\mathrm{m}^{6} \mathrm{~A}$ methylation has been demonstrated in diabetic patients, concomitant with elevated fat mass and obesity-associated (FTO) protein expression, a well characterized $\mathrm{m}^{6} \mathrm{~A}$ demethylase $(18,25)$.

The contribution of this work is significant because it will identify epitranscriptomic mechanisms contributing to the cardiovascular deficits elicited by ENM exposure as a prerequisite for assessing consumer and occupational risks. Additionally, this work will determine the benefit of enhanced antioxidant defense in attenuating cardiac dysfunction associated with ENM exposure. This information will be critical as we consider public health risks of nanotechnology, while aiding in the development of biomarkers and prophylactic strategies to lessen cardiovascular complications associated with ENM inhalation exposure. The proposed research is conceptually and mechanistically innovative because it is the first study to propose $\mathrm{m}^{6} \mathrm{~A}$ modifications as a contributing cause of cardiac dysfunction elicited by ENM inhalation exposure. The proposed research is technically innovative in its application of echocardiographic imaging of offspring in utero and application of a transgenic mouse model that overexpresses mPHGPx as an antioxidant protective strategy to prevent mitochondrial and cardiac deficits in progeny following maternal ENM inhalation exposure. Understanding the epitranscriptomic changes that occur and establishing a therapeutic approach that may attenuate elevated ROS and its associated detriments, enhances the impact of the studies. 


\section{References}

1. Benjamin EJ, Muntner P, Alonso A, Bittencourt MS, Callaway CW, Carson AP, Chamberlain AM, Chang AR, Cheng S, Das SR, Delling FN, Djousse L, Elkind MSV, Ferguson JF, Fornage M, Jordan LC, Khan SS, Kissela BM, Knutson KL, Kwan TW, Lackland DT, Lewis TT, Lichtman JH, Longenecker CT, Loop MS, Lutsey PL, Martin SS, Matsushita K, Moran AE, Mussolino ME, O'Flaherty M, Pandey A, Perak AM, Rosamond WD, Roth GA, Sampson UKA, Satou GM, Schroeder EB, Shah SH, Spartano NL, Stokes A, Tirschwell DL, Tsao CW, Turakhia MP, VanWagner LB, Wilkins JT, Wong SS, Virani SS, American Heart Association Council on E, Prevention Statistics C, and Stroke Statistics S. Heart Disease and Stroke Statistics-2019 Update: A Report From the American Heart Association. Circulation 139: e56-e528, 2019.

2. Bommarito PA, Martin E, and Fry RC. Effects of prenatal exposure to endocrine disruptors and toxic metals on the fetal epigenome. Epigenomics 9: 333-350, 2017.

3. Chiu YM, Hsu HL, Wilson A, Coull BA, Pendo MP, Baccarelli A, Kloog I, Schwartz J, Wright RO, Taveras EM, and Wright RJ. Prenatal particulate air pollution exposure and body composition in urban preschool children: Examining sensitive windows and sex-specific associations. Environ Res 158: 798-805, 2017.

4. Crispi F, Miranda J, and Gratacos E. Long-term cardiovascular consequences of fetal growth restriction: biology, clinical implications, and opportunities for prevention of adult disease. Am J Obstet Gynecol 218: S869-S879, 2018.

5. Fleisch AF, Luttmann-Gibson H, Perng W, Rifas-Shiman SL, Coull BA, Kloog I, Koutrakis P, Schwartz JD, Zanobetti A, Mantzoros CS, Gillman MW, Gold DR, and Oken E. Prenatal and early life exposure to traffic pollution and cardiometabolic health in childhood. Pediatr Obes 12: 48-57, 2017.

6. Fleisch AF, Rifas-Shiman SL, Koutrakis P, Schwartz JD, Kloog I, Melly S, Coull BA, Zanobetti A, Gillman MW, Gold DR, and Oken E. Prenatal exposure to traffic pollution: associations with reduced fetal growth and rapid infant weight gain. Epidemiology 26: 43-50, 2015.

7. Foulds CE, Trevino LS, York B, and Walker CL. Endocrine-disrupting chemicals and fatty liver disease. Nat Rev Endocrinol 13: 445-457, 2017.

8. Hales CM, Fryar CD, Carroll MD, Freedman DS, and Ogden CL. Trends in Obesity and Severe Obesity Prevalence in US Youth and Adults by Sex and Age, 2007-2008 to 2015-2016. JAMA 319: 1723-1725, 2018.

9. Hathaway QA, Durr AJ, Shepherd DL, Pinti MV, Brandebura AN, Nichols CE, Kunovac A, Goldsmith WT, Friend SA, Abukabda AB, Fink GK, Nurkiewicz TR, and Hollander JM. miRNA-378a as a key regulator of cardiovascular health following engineered nanomaterial inhalation exposure. Nanotoxicology 1-20, 2019.

10. Hathaway QA, Nichols CE, Shepherd DL, Stapleton PA, McLaughlin SL, Stricker JC, Rellick SL, Pinti MV, Abukabda AB, McBride CR, Yi J, Stine SM, Nurkiewicz TR, and Hollander JM. Maternal-engineered nanomaterial exposure disrupts progeny cardiac function and bioenergetics. Am J Physiol Heart Circ Physiol 312: H446-H458, 2017.

11. Hougaard KS, Campagnolo L, Chavatte-Palmer P, Tarrade A, Rousseau-Ralliard D, Valentino S, Park MV, de Jong WH, Wolterink G, Piersma AH, Ross BL, Hutchison GR, Hansen JS, Vogel U, Jackson P, Slama R, Pietroiusti A, and Cassee FR. A perspective on the developmental toxicity of inhaled nanoparticles. Reprod Toxicol 56: 118-140, 2015. 
12. Kietzmann T, Petry A, Shvetsova A, Gerhold JM, and Gorlach A. The epigenetic landscape related to reactive oxygen species formation in the cardiovascular system. $\mathrm{Br} J$ Pharmacol 174: 1533-1554, 2017.

13. Kmietczyk V, Riechert E, Kalinski L, Boileau E, Malovrh E, Malone B, Gorska A, Hofmann C, Varma E, Jurgensen L, Kamuf-Schenk V, Altmuller J, Tappu R, Busch M, Most P, Katus HA, Dieterich C, and Volkers M. m(6)A-mRNA methylation regulates cardiac gene expression and cellular growth. Life Sci Alliance 2: 2019.

14. Mao G, Nachman RM, Sun Q, Zhang X, Koehler K, Chen Z, Hong X, Wang G, Caruso D, Zong G, Pearson C, Ji H, Biswal S, Zuckerman B, Wills-Karp M, and Wang X. Individual and Joint Effects of Early-Life Ambient Exposure and Maternal Prepregnancy Obesity on Childhood Overweight or Obesity. Environ Health Perspect 125: 067005, 2017.

15. Nichols CE, Shepherd DL, Hathaway QA, Durr AJ, Thapa D, Abukabda A, Yi J, Nurkiewicz TR, and Hollander JM. Reactive oxygen species damage drives cardiac and mitochondrial dysfunction following acute nano-titanium dioxide inhalation exposure. Nanotoxicology 12: 32-48, 2018.

16. Pietroiusti A, Stockmann-Juvala H, Lucaroni F, and Savolainen K. Nanomaterial exposure, toxicity, and impact on human health. Wiley Interdiscip Rev Nanomed Nanobiotechnol 2018.

17. Robichaud CO, Uyar AE, Darby MR, Zucker LG, and Wiesner MR. Estimates of upper bounds and trends in nano-TiO2 production as a basis for exposure assessment. Environ Sci Technol 43: 4227-4233, 2009.

18. Shen F, Huang W, Huang JT, Xiong J, Yang Y, Wu K, Jia GF, Chen J, Feng YQ, Yuan BF, and Liu SM. Decreased N(6)-methyladenosine in peripheral blood RNA from diabetic patients is associated with FTO expression rather than ALKBH5. J Clin Endocrinol Metab 100: E148-154, 2015.

19. Stapleton PA, Hathaway QA, Nichols CE, Abukabda AB, Pinti MV, Shepherd DL, McBride CR, Yi J, Castranova VC, Hollander JM, and Nurkiewicz TR. Maternal engineered nanomaterial inhalation during gestation alters the fetal transcriptome. Part Fibre Toxicol 15: 3, 2018.

20. Stebounova LV, Morgan H, Grassian VH, and Brenner S. Health and safety implications of occupational exposure to engineered nanomaterials. Wiley Interdiscip Rev Nanomed Nanobiotechnol 4: 310-321, 2012.

21. Sun J, Zhang Q, Wang Z, and Yan B. Effects of nanotoxicity on female reproductivity and fetal development in animal models. Int J Mol Sci 14: 9319-9337, 2013.

22. Vance ME, Kuiken T, Vejerano EP, McGinnis SP, Hochella MF, Jr., Rejeski D, and Hull MS. Nanotechnology in the real world: Redeveloping the nanomaterial consumer products inventory. Beilstein J Nanotechnol 6: 1769-1780, 2015.

23. Wang SR, Wang JQ, Zhang XE, Fu BS, Song YY, Ma P, Gu K, Zhou X, Zhang XL, Tian T, and Zhou X. N-6-Methyladenine hinders RNA- and DNA-directed DNA synthesis: application in human rRNA methylation analysis of clinical specimens. Chem Sci 7: 1440-1446, 2016.

24. Xu YY, Wang WJ, Chen MJ, Zhou J, Huang XK, Tao SM, Pan B, Li ZZ, Xie XY, Li WH, Kan HD, and Ying ZK. Developmental programming of obesity by maternal exposure to concentrated ambient PM2.5 is maternally transmitted into the third generation in a mouse model. Particle and Fibre Toxicology 16: 2019. 
25. Yang Y, Shen F, Huang W, Qin S, Huang JT, Sergi C, Yuan BF, and Liu SM. Glucose Is Involved in the Dynamic Regulation of m6A in Patients With Type 2 Diabetes. $J$ Clin Endocrinol Metab 104: 665-673, 2019.

26. Zhong X, Yu J, Frazier K, Weng X, Li Y, Cham CM, Dolan K, Zhu X, Hubert N, Tao Y, Lin F, Martinez-Guryn K, Huang Y, Wang T, Liu J, He C, Chang EB, and Leone V. Circadian Clock Regulation of Hepatic Lipid Metabolism by Modulation of m(6)A mRNA Methylation. Cell Rep 25: 1816-1828 e1814, 2018. 


\section{Chapter 1:}

\section{Literature Review}




\title{
Cardiovascular Adaptations to Particle Inhalation Exposure: Molecular Mechanisms of the Toxicology
}

\author{
Amina Kunovac ${ }^{1,2,3}$, Quincy A. Hathaway ${ }^{1,2,3}$, Mark V. Pinti ${ }^{2,4}$, Andrew D. Taylor ${ }^{1,2}$, and John \\ M. Hollander ${ }^{1,2,3^{*}}$
}

Modified from the following publication: American Journal of Physiology Heart and Circulation Physiology. 2020 June 12; 1;319(2):H282-H305. doi: 10.1152/ajpheart.00026.2020.

\footnotetext{
${ }^{1}$ Division of Exercise Physiology, West Virginia University School of Medicine, Morgantown, WV, USA. ${ }^{2}$ Mitochondria, Metabolism \& Bioenergetics Working Group, West Virginia University School of Medicine, Morgantown, WV, USA. ${ }^{3}$ Center for Inhalation Toxicology (iTOX), West Virginia University School of Medicine, Morgantown, WV, USA. ${ }^{4}$ West Virginia University School of Pharmacy, Morgantown, WV, USA.
}

Running Title: Cardiovascular Molecular Pathways following Exposure

Keywords: Heart, Mitochondria, Gestation, Genomics, Particulate Matter, Engineered Nanomaterial, UFP, $\mathrm{PM}_{2.5}$ 


\begin{abstract}
:
Ambient air, occupational settings, and the use and distribution of consumer products all serve as conduits for toxicant exposure through inhalation. While the pulmonary system remains a primary target following inhalation exposure, cardiovascular implications are exceptionally culpable for increased morbidity and mortality. The epidemiological evidence for cardiovascular dysfunction resulting from acute or chronic inhalation exposure to particulate matter has been well documented, but the mechanisms driving the resulting disturbances remain elusive. In the current review, we aim to summarize the cellular and molecular mechanisms that are directly linked to cardiovascular health following exposure to a variety of inhaled toxicants. The purpose of this review is to provide a comprehensive overview of the biochemical changes in the cardiovascular system following particle inhalation exposure and to highlight potential biomarkers that exist across multiple exposure paradigms. We attempt to integrate these molecular signatures in an effort to provide direction for future investigations. This review also characterizes how molecular responses are modified in at-risk populations, specifically the impact of environmental exposure during critical windows of development. Maternal exposure to particulate matter during gestation can lead to fetal epigenetic reprogramming, resulting in long-term deficits to the cardiovascular system. In both direct and indirect (gestational) exposures, connecting the biochemical mechanisms with functional deficits outlines pathways that can be targeted for future therapeutic intervention. Ultimately, future investigations integrating "omics" based approaches will better elucidate the mechanisms that are altered by xenobiotic inhalation exposure, identify biomarkers, and guide in clinical decision making.
\end{abstract}




\section{Introduction}

Irrespective of diet, physical fitness, or other controllable risk factors, the quality and contents of the air we breathe are often unavoidable. In industrial cities and large metropolitan areas, the most pervasive mode of exposure to aerosolized toxicants is through the ambient air. Long term exposure to ambient air pollution contributes to $7.6 \%$ of global mortality, with $91 \%$ of the world's population residing in places where air quality exceeds the guideline limits put forth by the World Health Organization (WHO) $(31,171,172)$. The number of annual premature deaths as a result of outdoor air pollution are staggering, with projections indicating 6-9 million deaths in 2060 (18, 121). Subsequently, the predicted economic costs are increasing substantially as a repercussion of the illnesses resulting from exposure (121). The importance of lowering ambient fine particulate matter exposure is highlighted specifically by the notion that if all countries met the WHO Air Quality Guidelines, life expectancy could increase by over 7 months (2). This becomes a daunting task with increasing urbanization (171) and implementation of nanoparticles for their advantageous physical, chemical, and biological properties in industrial, commercial and medical sectors (136).

There are numerous factors that contribute to the diminishing air quality including industrial sources, energy power plants, traffic, agriculture, and fires (37, 80, 142). Particulate matter (PM) is the sum of all organic and inorganic compounds dispersed in the solid and liquid phases that can be carried by air $(22,81)$. PM components are typically categorized by particle size including coarse $\left(\mathrm{PM}_{10} ; \leq 10 \mu \mathrm{m}\right.$ in diameter), fine $\left(\mathrm{PM}_{2.5} ; \leq 2.5 \mu \mathrm{m}\right.$ in diameter $)$, and ultrafine (UFP, $\mathrm{PM}_{0.1} ; \leq 0.1 \mu \mathrm{m}$ in diameter) particles. However, the surface area, chemical composition, number, solubility and reactivity are some of the other characteristics that must be considered (16, 22 , 106, 148). Decreasing the size of particulates from $\mathrm{PM}_{10}$ to $\mathrm{PM}_{2.5}$ increases the capacity for the material to travel further into the bronchoalveolar airways and allows for a broader interaction area $(53,175)$. Similar to $\mathrm{PM}_{2.5}$, UFP, also have the capacity to penetrate deeply into the alveoli of the tracheobronchial airways $(117,150)$, but UFP exhibit an increased capacity for interstitialization and can transport systemically throughout the body due to their high surface-tovolume ratios $(22,40,106,117,148)$. Because the bulk of cardiovascular effects originate from fine PM and nanoparticles $(53,144)$, this review will focus on $\mathrm{PM}_{2.5}$, UFP, and engineered nanomaterials (ENM). 
ENM (at least one dimension $\leq 100 \mathrm{~nm}$ in diameter), which are similar in size to UFP, are anthropogenic materials that pose additional risk to public cardiovascular health $(82,125,136$, 146). Nanomaterials represent an ever-increasing vehicle for inhalation toxicology (85). Whether during the manufacturing of nanomaterials (85) or in consumer use (113), production and rate of application continue to rise $(7,68)$. While inhalation studies examining ENMs and UFP typically differ in the number and standardization of compounds found within the mixtures, both share commonality in the nanometer scale that permits similar dispersion within the lungs during inhalation (148). Nanomaterials, similar to UFP, exist exclusively at a biological scale that alters the dynamics of interactions with organic matter $(112,157)$, potentially altering toxicities compared to their micrometer-sized equivalents $(22,53,144,148)$. One example of ENM, is nanotitanium dioxide $\left(\mathrm{TiO}_{2}\right)$, which is predominantly used for its photocatalytic properties, like its ability to refract light and enhance colors. Nano- $\mathrm{TiO}_{2}$ is therefore implemented in products such as paint pigments, sunscreen, paper, pharmaceuticals, tattoo ink, and water purification systems. There are specific physicochemical properties of inhaled particles that determine its applications. The size, composition, pore size, and surface charge and chemistry are some of the main properties that govern the applicability of inhaled particles (60). In the attempt to understand the biological effects of inhaled particles, particularly on the cardiovascular system, these varying properties have posed a challenge such that any attempt to understand an individual particle or co-exposure would require each particle within the exposure to be purified and characterized based on the many relevant particle properties. Our laboratory has specifically focused on understanding the mechanisms associated with nano- $\mathrm{TiO}_{2}$ inhalation exposure. Although the properties of nano- $\mathrm{TiO}_{2}$ may differ from other inhaled particles by size, solubility, porosity, crystallinity, shape, etc., we utilize this particle as a surrogate to focus on the mechanism that is elicited by almost all inhaled particle exposures, increased reactive oxygen species (ROS) (61). It is outside the scope of most studies to identify the unique spectrum of molecular changes that each ENM may produce (14). Using a surrogate particle is beneficial in that it eliminates the variability introduced when a mixture of particles is present that contain particulate matter of varying physicochemical properties.

There are three prevailing theories on the mechanism by which inhaled pollutants result in deleterious effects on the cardiovascular system $(106,107,115,117)$. The first of these theories involves inflammation, whereby particles that reach the lungs initiate an inflammatory response 
that leads to the release of cytokines and other mediators that can then be introduced into the circulation, causing downstream effects (107). The other possibility is that, based on the size of the particles, they may not only enter the systemic circulation but also translocate across the alveolar wall and impact the cardiovascular system directly (typically only applies to ultrafine particles), such as by influencing the vascular endothelium. Lastly, the particles may affect autonomic regulation and alter the parasympathetic: sympathetic balance through sensory receptors on the alveolar surface. This can result in changes in heart rate variability and other parameters of cardiac function. It would be naive to state that one of these specific pathways is solely responsible for the cardiovascular effects induced by inhaled particle exposure. A more likely scenario is that all three pathways work in concert, and likely contribute and exacerbate the effects of each one. For example, an initial inflammatory response may result in tissue damage that increases permeability and makes it easier for particles to translocate and incite further damage. Regardless of the initial response within the lungs, understanding the cardiovascular molecular pathways that exposure mediates is essential for identifying appropriate prophylactic and/or therapeutic strategies. A potential starting point in developing prophylactic and/or therapeutic strategies for limiting particle-induced cardiovascular effects would be limiting reactive oxygen species (ROS) production and dissipation (107). This is instrumental as oxidative stress has the potential to contribute to all three prevailing theories that explain how inhaled particles could cause cardiovascular effects and furthermore likely promotes interactions between the three pathways. Depending on the physicochemical properties of the inhaled particle, the surface chemicals of the particulate matter (such as special coatings that are utilized for its specific effects) or other pollutants in the air may interact and result in redox reactions that produce free radicals. As mentioned previously, inhaled particles can also activate inflammatory cells, which causes a release of cytokines and oxidative mediators. Lastly, oxidative stress can be a response from the particle interaction with tissue enzymes like the stimulation of xanthine oxidase or depletion of antioxidant defenses (107). Due to the high likelihood that ROS is involved in the cardiovascular effects of inhaled particles, increasing antioxidant protection is a promising therapeutic strategy that requires further explication.

According to the WHO, over four million people die every year from outdoor air pollution, with cardiovascular disease accounting for about $40 \%$ of those deaths $(2,91,172)$. While the pulmonary system is considered the primary site of interaction with these particles, secondary 
target organs, such as the heart and circulatory system, may be subject to the most detrimental long-term effects. The overt epidemiological risk of cardiovascular injury following chronic and acute inhalation exposure to $\mathrm{PM}_{2.5}$, UFP, and ENM has been well documented and includes increased propensity for ischemic heart disease, heart failure, out-of-hospital cardiac arrests, arrhythmias, atherosclerosis, and other cardiovascular complications (16, 28, 58, 128-130, 134, 152, 156, 187). The effects of PM inhalation exposure on the heart function of individuals who are susceptible to cardiovascular disease (CVD) have also gained recent interest. One of the main points of concern emanates from the increasing rate of patients with diet-induced obesity and type 2 diabetes (24). These populations with metabolic disorders can have further modifications to insulin-signaling pathways that arise from inhalation exposure, ultimately increasing susceptibility and aggravating underlying pathophysiology $(5,15,26,74,122,124,130)$.

Among those whom are most vulnerable to the repercussions of inhaled particulates, are those exposed at a critical point in development, such as during gestation. While the main focus has been on the effects of toxicant inhalation exposure directly to an individual, recent studies have highlighted the importance of understanding how exposure during gestation impacts future progeny $(12,13,52,87,100,104,108)$. Maternal inhalation exposure to particles can affect offspring through both direct and indirect mechanisms or a combination of the two (41). Direct effects can ensue if the particle size enables the particulate matter to enter the maternal blood, cross the placental barrier, and directly damage fetal tissue via inflammatory and oxidative stress pathways. Indirect mechanisms can occur if the particle inhalation results in deep instillation of the particle in the lower airways that result in oxidative stress and inflammatory responses. Subsequently, this response may trigger the release of inflammatory mediators that can reach the placenta and fetus resulting in short and long-term repercussions. Lastly, it is possible that a similar response occurs if the particles inhaled reach the placental tissue (even if they are unable to cross the barrier) and incite an oxidative stress and inflammatory response that compromises the placental function and thereby causes oxidative stress, inflammation, growth restriction, preterm birth, as well as cardiovascular and behavioral impairments. It is important to recognize that maternal inflammation may not directly indicate that fetal inflammation is occurring, but the placenta may act as a sensor of maternal inflammation and thereby initiate an adaptive response that causes changes to the fetal environment and potentially reprogramming (41). As per the developmental origins of health and diseases (DOHaD) hypothesis, a baleful gestational 
environment results in epigenetic alterations and has a notable influence on the health of the offspring $(11,49)$. Currently, there are limited studies defining the longitudinal cardiovascular effects of offspring exposed to inhaled particles during gestation and whether exposure increases susceptibility to metabolic diseases at a later point in life due to alterations in overlapping pathways $(17,72)$. Delineating the long-term effects of inhaled particle exposure on cardiovascular function, particularly in progeny, along with the molecular mechanisms governing predisposition to CVD is critical for limiting premature mortality rates. One potential way that is being investigated is increasing antioxidant protection to evade the cardiovascular defects that are associated with inhaled particulate matter exposure as the balance of oxidants and antioxidants are critical for physiological homeostasis. Under normal pregnancy conditions, the maternal environment can maintain this balance (41). However, because inhaled particles result in excessive amounts of ROS production through direct and indirect pathways, the intrinsic antioxidant system may not be able to manage these levels and can thereby result in diminished antioxidant capacity and elevated oxidative stress. One of the studies that will be discussed in this dissertation, therefore implements antioxidant protection in different contexts to determine which context will provide the most protective profile for long-term offspring cardiovascular health.

The compilation of the works presented herein serves to examine the molecular pathways that are implicated in cardiovascular adaptions to various inhaled particles and attempts to provide a cohesive framework of how each of these molecular pathways has been evaluated across multiple models. Summarized findings of these molecular mechanisms for various exposures and exposure models are presented in Table 1.1. Furthermore, there are limited studies examining the cardiovascular consequences of gestational PM exposure on progeny. Therefore, this review will also focus on the effects of PM exposure during gestation on the cardiovascular system in progeny and highlight the molecular pathways that PM exposure alters during this critical window of fetal development. The studies discussed also highlight the necessity for unbiased omics approaches in understanding the indirect mechanisms that play a role in long-term cardiovascular health defects following inhaled particle exposure (41). The following sections are divided into categories, with each section interweaving similar molecular pathways/responses to PM inhalation exposure. 


\begin{tabular}{|c|c|c|c|}
\hline \multicolumn{4}{|c|}{$\mathbf{P M}_{2.5}$} \\
\hline (6) & $\begin{array}{l}\text { Fine } \mathrm{PM}_{2.5} \text { and coarse PM decreased Alu and } \\
\text { TLR4 methylation, respectively }\end{array}$ & 15 local participants & $\begin{array}{l}\mathrm{PM}_{2.5} \text { collected in downtown Toronto. Administered } 250 \\
\text { and } 200 \mu \mathrm{g} / \mathrm{m}^{3} \text { per session }\end{array}$ \\
\hline (17) & $\begin{array}{l}\text { No changes seen in inflammatory markers related } \\
\text { to } \mathrm{PM}_{2.5} \text { exposure (monocytes, TNF- } \alpha \text {, IL-10, IL- } \\
6 \text {, IL-8, IL-1 } \beta \text { ) }\end{array}$ & $\begin{array}{l}25 \text { healthy male and female } \\
\text { participants } 18-50 \text { years old }\end{array}$ & $\begin{array}{l}\mathrm{PM}_{2.5} \text { data obtained from Dearborn, Tecumesh, and Dexter, } \\
\text { MI. } 3 \text { sub-acute integrated 5-day-long exposure periods in } \\
\text { Dearborn, MI (mean concentration of } 11.5 \pm 4.8 \mu \mathrm{g} / \mathrm{m}^{-3} \text { ) }\end{array}$ \\
\hline (19) & $\begin{array}{l}\mathrm{PM}_{2.5} \text { exposure was associated with mtDNA D- } \\
\text { Loop methylation in peripheral blood leukocytes }\end{array}$ & 48 male participants & $\begin{array}{l}\mathrm{PM}_{2.5} \text { collected January } 2007 \text { to June } 2012 \text { in Boilermaker } \\
\text { Union Local 29, Quincy, MA }\end{array}$ \\
\hline (30) & $\begin{array}{l}\text { Elemental carbon ( } 48 \text { genes), } \mathrm{PM}_{2.5}(49 \text { genes }) \text {, and } \\
\text { organic carbon ( } 260 \text { genes) differentially effected } \\
\text { the transcriptome }\end{array}$ & $\begin{array}{l}63 \text { pick-up and delivery drivers } \\
\text { and dock workers }\end{array}$ & $\begin{array}{l}\mathrm{PM}_{2.5} \text { collected February } 2009 \text { and October } 2010 \text { from } 10 \\
\text { trucking terminals in the northeastern US (CT, MA, MD, } \\
\text { NJ, NY, and PA). }\end{array}$ \\
\hline (33) & $\begin{array}{l}\mathrm{PM}_{2.5} \text { increased STAT3, which promoted } \\
\text { microRNA-21 expression, leading to decreased } \\
\text { TIMP3 and increased MMP9 }\end{array}$ & $\begin{array}{l}\text { Male Sprague Dawley rats, } 6 \\
\text { wks old }\end{array}$ & $\begin{array}{l}\mathrm{PM}_{2.5} \text { collected in Beijing, China. Trachea drip, } 4 \mathrm{mg} / \mathrm{kg} \\
\text { b.w. every } 3 \text { days for } 36 \text { days }\end{array}$ \\
\hline (38) & $\begin{array}{l}\mathrm{PM}_{2.5} \text { reduced intracellular } \mathrm{Ca}^{2+} \text { via decreased } \\
\text { RYR2 and increased SERCA2a }\end{array}$ & Male Balb/c mice, 6-8 wks old & $\begin{array}{l}\mathrm{PM}_{2.5} \text { collected Hebei, China. Intratracheal instillation of } \\
0.5 \mathrm{mg} \text { at Day } 0 \text { and Day } 2\end{array}$ \\
\hline (39) & $\begin{array}{l}\mathrm{PM}_{2.5} \text { exposure with vitamin } \mathrm{E} \text { and omega-3 } \\
\text { polyunsaturated fatty acid administration } \\
\text { decreased inflammation (TNF- } \alpha, \mathrm{IL}-1 \beta, \mathrm{IL}-6)\end{array}$ & $\begin{array}{l}\text { Sprague Dawley rats, } 6-8 \text { wks } \\
\text { old }\end{array}$ & $\begin{array}{l}\mathrm{PM}_{2.5} \text { collected May-September } 2015 \text { in Shanghai, China. } \\
\text { Intratracheal instillation every other day, for } 6 \text { days at } 10 \\
\mathrm{mg} / \mathrm{kg} \text { b.w or } 1.5 \mathrm{~mL} / \mathrm{kg} \text { b.w. }\end{array}$ \\
\hline (44) & $\begin{array}{l}\text { Increased LINE-1 methylation with increasing } \\
\text { dose of } \mathrm{PM}_{2.5}\end{array}$ & 66 male participants & $\begin{array}{l}\mathrm{PM}_{2.5} \text { collected (pre and post-welding shift) January 2010- } \\
\text { June } 2012 \text { in Boilermaker Union Local 29, Quincy, MA }\end{array}$ \\
\hline (51) & $\begin{array}{l}\mathrm{PM}_{2.5} \text { increasing concentration was associated with } \\
\text { decreasing levels of ET-1 (negatively) and PF-4 } \\
\text { (positively). }\end{array}$ & $\begin{array}{l}15 \text { young, healthy, non- } \\
\text { smoking subjects }\end{array}$ & $\begin{array}{l}\mathrm{PM}_{2.5} \text { ambient air concentrations in Utah Valley from } 2 \\
\text { monitoring sites (Lindon, North Provo) measured daily } \\
\text { (January-March 2009). Blood collections done during high } \\
\left(\mathrm{PM}_{2.5}>40 \mu \mathrm{g} / \mathrm{m}^{3}\right) \text {, moderate }\left(\mathrm{PM}_{2.5} \sim 20-40 \mu \mathrm{g} / \mathrm{m}^{3}\right) \text {, and } \\
\text { low }\left(\mathrm{PM}_{2.5}<10 \mu \mathrm{g} / \mathrm{m}^{3}\right) \text { concentrations. }\end{array}$ \\
\hline (56) & $\begin{array}{l}\text { Exercise during DE }\left(\mathrm{PM}_{2.5}\right) \text { exposure decreased } \\
\text { ET- } 1 \text { and increased NOx, but was not modified by } \\
\text { exercise intensity }\end{array}$ & 18 male participants & $\begin{array}{l}\mathrm{PM}_{2.5} \text { collected a } 5.5-\mathrm{kW} \text { diesel engine under a constant } 2.5 \\
\mathrm{~kW} \text { load. Exposure of } 300 \mu \mathrm{g} / \mathrm{m}^{3} \text { over } 6 / 30 \text {-minute low and } \\
\text { high intensity cycling periods }\end{array}$ \\
\hline (59) & $\begin{array}{l}\mathrm{PM}_{2.5} \text { increased expression of ICAM-1, VCAM, } \\
\text { and CRP in sedentary mice, and increased VCAM } \\
\text { in exercised mice }\end{array}$ & Male ob/ob mice, 12 wks old & $\begin{array}{l}\mathrm{PM}_{2.5} \text { collected Columbus, OH. Average } 32 \mu \mathrm{g} / \mathrm{m}^{3} \text { for } 6 \\
\text { hrs/day, } 5 \text { days/week for } 9 \text { months through a whole-body } \\
\text { inhalation system }\end{array}$ \\
\hline$(62)$ & $\begin{array}{l}\mathrm{PM}_{2.5} \text { decreased VEGF-induced Akt/eNOS } \\
\text { phosphorylation and circulating levels of Flk- } \\
1^{+} / \mathrm{Sca}-1^{+} \text {cells (EPCs) }\end{array}$ & $\begin{array}{l}\text { C57BL/6J male mice, } 8-12 \mathrm{wks} \\
\text { old }\end{array}$ & $\begin{array}{l}\mathrm{PM}_{2.5} \text { collected June } 2009 \text { and December } 2010 \text { in } \\
\text { Louisville, } \mathrm{KY} \text {. Whole-body exposure, } 6 \mathrm{hr} / \text { day for } 4-30 \\
\text { days at } 30-100 \mu \mathrm{g} / \mathrm{m}^{3}\end{array}$ \\
\hline (63) & $\begin{array}{l}\mathrm{PM}_{2.5} \text { reduced insulin stimulated Akt } \\
\text { phosphorylation and circulating levels of Flk- } \\
1^{+} / \mathrm{Sca}-1^{+} \text {cells (EPCs), elevated oxidative stress } \\
\text { (SOD2,GST-P), caused inflammasome activation } \\
\text { (IL-1 } \beta \text {, pro-IL-18 cleavage, activation of Casp-1) }\end{array}$ & $\begin{array}{l}\text { C57BL/6J male mice, } 8 \text { wks old } \\
\text { (control/high-fat diet), } \\
\text { C57BL/6J male mice, } 12 \text { wks } \\
\text { old (control diet, pre-treated } \\
\text { with Metformin/Rosiglitazone }\end{array}$ & $\begin{array}{l}\mathrm{PM}_{2.5} \text { collected June } 2009 \text { and December } 2010 \text { in } \\
\text { Louisville, KY. Whole-body exposure, } 6 \mathrm{hr} / \text { day for } 9 \text { or } 30 \\
\text { days at } 30-120 \mu \mathrm{g} / \mathrm{m}^{3}\end{array}$ \\
\hline$(64)$ & $\begin{array}{l}\mathrm{PM}_{2.5} \text { decreased insulin-stimulated Akt/eNOS } \\
\text { phosphorylation and IKB } \alpha \text {, antioxidant treatment } \\
\text { attenuated vascular insulin resistance and } \\
\text { inflammation }\end{array}$ & $\begin{array}{l}\text { C57BL/6J male mice, } 12 \text { wks } \\
\text { old (control/high-fat diet), pre- } \\
\text { treated with TEMPOL }\end{array}$ & $\begin{array}{l}\mathrm{PM}_{2.5} \text { collected June } 2009 \text { and December } 2010 \text { in } \\
\text { Louisville, } \mathrm{KY} \text {. Whole-body exposure, } 6 \mathrm{hr} / \text { day for } 9 \text { or } 30 \\
\text { days at } 30-120 \mu \mathrm{g} / \mathrm{m}^{3}\end{array}$ \\
\hline (79) & 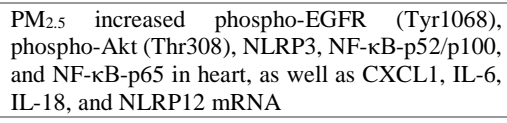 & BALB/c mice, 6-8 wks old & $\begin{array}{l}\mathrm{PM}_{2.5} \text { collected November } 2014 \text { in a major city of central } \\
\text { China. Intratracheal instillation of } 4.0 \mathrm{mg} / \mathrm{kg} \text { b.w. for } 5 \\
\text { consecutive days. }\end{array}$ \\
\hline (93) & $\begin{array}{l}\mathrm{PM}_{2.5} \text { decreased SOS1, CREB, GSK3b, and GRB2 } \\
\text { expression, fucoidan treatment rescued all but } \\
\text { CREB levels. }\end{array}$ & C57BL/6J mice, 8 wks old & $\begin{array}{l}\mathrm{PM}_{2.5} \text { collected November-December } 2016 \text { in Taipei, } \\
\text { Taiwan. } 100 \mu \mathrm{g} / \mathrm{m}^{3}, 28 \text { days, } 6 \mathrm{hrs} / \text { day }\end{array}$ \\
\hline (95) & $\begin{array}{l}\mathrm{PM}_{2.5} \text { caused mitochondrial size/cristae } \\
\text { deformation (increased FIS1, MFN1, MFN2, } \\
\text { DRP1, OPA1), inflammation (increased TNF- } \alpha \text {, } \\
\text { IL-6, IL-1 } \beta \text { ), decreased SOD, increased MDA and } \\
\text { iNOS }\end{array}$ & Sprague Dawley rats & $\begin{array}{l}\mathrm{PM}_{2.5} \text { collected January } 2013 \text { in Taiyuan, China. } \\
\text { Intratracheal instillation of } 0.375,1.5,6.0 \text {, and } 24.0 \mathrm{mg} / \mathrm{kg} \\
\text { b.w. performed } 5 \text { times }\end{array}$ \\
\hline (98) & $\begin{array}{l}\mathrm{PM}_{2.5} \text { increased Caspase- } 3 \text {, Bax, Bcl-2 in heart, } \\
\text { and NF-кB in cardiac myocytes }\end{array}$ & Male C57/BL6 mice, 8 wks old & $\begin{array}{l}\mathrm{PM}_{2.5} \text { was collected in, Nanjing, China. } 10 \mu \mathrm{g} \text { PM } 2.5(10 \mu \mathrm{l}) \\
\text { twice a week/intranasal instillation. }\end{array}$ \\
\hline (99) & $\begin{array}{l}\text { Acute } \mathrm{PM}_{2.5} \text { exposure decreased 5-mC methylation } \\
\text { and DNMT1 mRNA expression in heart and blood. } \\
\text { Chronic } \mathrm{PM}_{2.5} \text { exposure decreased these factors } \\
\text { only in blood }\end{array}$ & C57BL/6J male mice, 7 wks old & $\begin{array}{l}\mathrm{PM}_{2.5} \text { (collection location not stated), whole-body acute } \\
\text { exposure }\left(24 \mathrm{hrs}-\mathrm{PM}_{2.5} \text { dose of } 271.8 \pm 86.8 \mu \mathrm{g} / \mathrm{m}^{3}\right) \text { and } \\
\text { chronic exposure }\left(140 \text { days-PM } \mathrm{PM}_{2.5} \text { dose of } 271.8 \pm 86.8\right. \\
\left.\mu \mathrm{g} / \mathrm{m}^{3}\right)\end{array}$ \\
\hline (103) & $\begin{array}{l}\mathrm{PM}_{2.5} \text { increased inflammation, high intensity } \\
\text { exercise stimulates reduced inflammation } \\
\text { (eHSP70) }\end{array}$ & $\begin{array}{l}\text { Male B6.129SF2/J mice, } 30 \\
\text { days old }\end{array}$ & $\begin{array}{l}\mathrm{PM}_{2.5} \text { collected in São Paulo, Brazil, } 5 \mu \mathrm{g} \text { nasotropic } \\
\text { instillation daily before exercise } 12 \mathrm{wks}\end{array}$ \\
\hline (114) & $\begin{array}{l}\text { DEP }\left(\mathrm{PM}_{2.5}\right) \text { increased PAI-1, fibrinogen, lipid } \\
\text { peroxidation, IL- } 6 \text {. Nootkatone pretreatment } \\
\text { alleviated all and reduced thrombosis with } \\
\text { increased Nrf2 and HO-1 activation. }\end{array}$ & BALB/C mice, 8 wks old & $\begin{array}{l}\text { Diesel exhaust particles (DEP) with a geometric mean } \\
\text { aerodynamic diameter of } 215 \mathrm{~nm} \text { from the National } \\
\text { Institute of Standards and Technology, MD, USA. } \\
\text { Intratracheal instillation of } 30 \mu \mathrm{g} / \text { mouse }\end{array}$ \\
\hline (123) & $\begin{array}{l}\mathrm{PM}_{2.5} \text { exposure in atherosclerosis model increased } \\
\text { MDA and NOX-4 subunits }\left(\mathrm{p} 22^{\text {phox }}, \mathrm{p} 47^{\text {phox }}\right) \text { in } \\
\text { cardiac tissue }\end{array}$ & $\begin{array}{l}\text { Male } \mathrm{ApoE}^{-1-} \mathrm{Tg} \text { mice, } 8 \text { wks } \\
\text { old }\end{array}$ & $\begin{array}{l}\mathrm{PM}_{2.5} \text { collected June-October } 2013 \text { in Shanghai, China } \\
\text { Intratracheal installation at } 0-30 \mathrm{mg} / \mathrm{kg} \text { b.w }\end{array}$ \\
\hline (127) & $\begin{array}{l}\mathrm{PM}_{2.5} \text { exposure was associated with elevated levels } \\
\text { of CD } 14^{+} \text {, CD } 16^{+}, \mathrm{CD} 4^{+}, \mathrm{CD} 8^{+} \text {, endothelial } \\
\text { microparticles (annexin } \mathrm{V}^{+} / \mathrm{CD} 41^{-} / \mathrm{CD} 31^{+} \text {), anti- } \\
\text { angiogenic (TNF } \alpha, \mathrm{IP}-10) \text { and pro-inflammatory } \\
\text { cytokines (MCP-1, MIP-1 } \alpha / \beta \text {, IL- } 6 \text {, IL-1 } \beta \text { ), and } \\
\text { sICAM-1, sVCAM-1 as well as decreased pro- } \\
\text { angiogenic growth factors (EGF, sCD40L, PDGF, } \\
\text { RANTES, GRO } \alpha \text {, and VEGF). }\end{array}$ & $\begin{array}{l}72 \text { young, healthy, non- } \\
\text { smoking subjects } \quad(24 \\
\text { individuals per } 3 \text { winter/ spring } \\
\text { time periods }(2013,2014 \text {, and } \\
2015))\end{array}$ & $\begin{array}{l}\mathrm{PM}_{2.5} \text { ambient air concentrations in Utah Valley from } 3 \\
\text { monitoring sites (Lindon, North Provo, and Spanish Fork) } \\
\text { measured daily. At Lindon and North Provo sites, hourly } \\
\mathrm{PM}_{2.5} \text { concentrations were used to estimate the average } \\
\text { concentration for the } \sim 24 \text {-h period before each blood draw }\end{array}$ \\
\hline (131) & $\begin{array}{l}\mathrm{PM}_{2.5} \text { increased fibrosis } \text { (Col1a1, Col3a1), } \\
\text { oxidative stress (NOX-4), transcription factor } \\
\text { binding (TGF } \beta 1, \text { SMAD3) }\end{array}$ & $\begin{array}{l}\text { Female C57BL/6, } 10 \text { months } \\
\text { and } 4 \text { wks old }\end{array}$ & $\begin{array}{l}\mathrm{PM}_{2.5} \text { collected } 2012 \text { and } 2013 \text { from Taiyuan, Northern } \\
\text { China. } 3 \mathrm{mg} / \mathrm{kg} \text {. b.w. } \mathrm{PM}_{2.5} \text { oropharyngeal aspiration every } \\
\text { other day for } 4 \mathrm{wks}\end{array}$ \\
\hline
\end{tabular}




\begin{tabular}{|c|c|c|c|}
\hline (133) & $\begin{array}{l}\text { CAPs exposure increased } 7-\mathrm{KCh} \text { in plasma and } \\
\text { aortic plaques, and increased CD36 expression in } \\
\text { plaque-macrophages and CD36 uptake of oxidized } \\
\text { lipids }\end{array}$ & $\begin{array}{l}\text { ApoE }{ }^{-/-} \mathrm{Tg} \text { and } \mathrm{LDLR}^{-/-} \mathrm{Tg} \\
\text { mice, } 8 \text { wks old }\end{array}$ & $\begin{array}{l}\text { Concentrated ambient } \mathrm{PM}_{2.5} \text { collected in Columbus, } \mathrm{OH} \text {. } \\
\text { Mice xposed for } 6 \text { months to } 9.1 \pm 7.3 \mu \mathrm{g} / \mathrm{m}^{3}\end{array}$ \\
\hline (135) & $\begin{array}{l}12.4 \% \text { decrease in RHI for every } 10 \mu \mathrm{g} / \mathrm{m}^{3} \text { increase } \\
\text { in } \mathrm{PM}_{2.5} \text {. IsoP, angiopoietin 1, VEGF, PlGF, } \\
\text { MMP-9, ICAM-1 positively associated with } \\
10 \mu \mathrm{g} / \mathrm{m}^{3} \text { increases in } \mathrm{PM}_{2.5} \text {, decreased VCAM- } 1 \text {. }\end{array}$ & $\begin{array}{l}100 \text { male and female } \\
\text { participants }(44 \% \text { had type } 2 \\
\text { diabetes, } 52 \% \text { had diagnosis of } \\
\text { hypertension) }\end{array}$ & $\begin{array}{l}\mathrm{PM}_{2.5} \text { levels obtained from } 5 \text { monitoring stations in } \\
\text { Jefferson County, } \mathrm{KY} \text { (June } 2011 \text {-May 2013) with average } \\
\text { concentration of } 11.45 \mu \mathrm{g} / \mathrm{m}^{3} \text {. }\end{array}$ \\
\hline (140) & $\begin{array}{l}\mathrm{PM}_{2.5} \text { increased Hsp-70, HO-1, MPO in heart as } \\
\text { well as laminin, collagen, and calcium signaling } \\
\text { proteins (181 upregulated, } 178 \text { downregulated } \\
\text { genes) }\end{array}$ & $\begin{array}{l}\text { Male BALB/c mice, } 7-8 \text { wks } \\
\text { old }\end{array}$ & $\begin{array}{l}\mathrm{PM}_{2.5} \text { with high } \mathrm{PAH} \text {, nitrite, and organic carbon levels } \\
\text { collected winter } 2008 \text { in an urban site (Milano, Italy). } \\
\text { Intratracheal instillation on days } 0,3 \text { and } 6 \text {, at } 0.3 \\
\mathrm{mg} / \text { mouse }\end{array}$ \\
\hline (157) & $\begin{array}{l}\text { TRPA1 activation increases } \\
\text { cardiovascular responses to CAPs } \\
\text { through myocardial dyssynchrony. }\end{array}$ & $\begin{array}{l}\text { Trpa } 1^{\mathrm{tm} 1 \mathrm{Kykw} / J} \quad\left(\operatorname{Trpa}^{-/-}\right) \quad \mathrm{Tg} \\
\text { female mice }\end{array}$ & $\begin{array}{l}\mathrm{PM}_{2.5} \text { collected November-December of } 2014 \text { in Triangle } \\
\text { Park, NC. } 3 \text { hrs/day, } 2 \text { days/week, } 8 \text { total whole-body } \\
\text { exposures }\end{array}$ \\
\hline (161) & $\begin{array}{l}\mathrm{PM}_{2.5} \text { exposure increased oxidative stress (PRNP) } \\
\text { and endoplasmic reticulum stress (GRP78). } \\
\text { Nanoparticles found in myocardial ER and in } \\
\text { abnormal mitochondria }\end{array}$ & $\begin{array}{l}30 \text { children and young adults } \\
\sim 20 \text { years old }\end{array}$ & $\begin{array}{l}\mathrm{PM}_{2.5} \text { data obtained in Mexico City Metropolitan Area } \\
1997-2012\end{array}$ \\
\hline (165) & $\begin{array}{l}\mathrm{PM}_{2.5} \text { increased fibrosis and collagen genes, and } \\
\text { oxidative stress (8-OHdg and 4-HNE), reduced } \\
\text { antioxidant genes (PRDX5) }\end{array}$ & $\begin{array}{l}\text { Male AMPK } \alpha 2^{-1-} \text { Tg mice, } 6- \\
8 \text { wks old }\end{array}$ & $\begin{array}{l}\mathrm{PM}_{2.5} \text { collected April-October } 2016 \text { in Beijing, China. } \\
\text { Intratracheal instillation for } 6 \text { months at } 10 \mathrm{mg} / \mathrm{kg} \\
\left(64 \mu \mathrm{g} / \mathrm{m}^{3}\right) \text {. }\end{array}$ \\
\hline (167) & $\begin{array}{l}\mathrm{PM}_{2.5} \text { exposure in hyperlipidemic rats increased } \\
\text { CRP, JNK and P53 phosphorylation, and increased } \\
\text { Bax and Caspase- } 3 \text { in the heart, decreased SOD }\end{array}$ & $\begin{array}{l}\text { Male Wistar rats, } 8 \text { wks old, on } \\
\text { high-fat diet }\end{array}$ & $\begin{array}{l}\mathrm{PM}_{2.5} \text { collected October-December } 2012 \text { in Beijing, China. } \\
\text { Endotracheal instillation of suspension at } 0,4,40 \mathrm{mg} / \mathrm{kg}\end{array}$ \\
\hline (170) & $\begin{array}{l}\text { Higher } \mathrm{PM}_{2.5} \text { resulted in myosin heavy chain } \\
\text { isoform switch (increased } \beta-\mathrm{MHC} \text { ) and decreased } \\
\text { SERCA2a }\end{array}$ & C57BL/6 male mice, 8 wks old & $\begin{array}{l}\text { Concentrated } \mathrm{PM}_{2.5} \text { in Columbus, OH. Mean daily } \\
\text { concentration of } \mathrm{PM}_{2.5} \text { in the exposure chamber was } 85.3 \\
\mu \mathrm{g} / \mathrm{m}^{3} \text {. Mice were exposed for } 6 \mathrm{~h} / \mathrm{d}, 5 \mathrm{~d} / \mathrm{wk} \text {, for } 9 \text { months. }\end{array}$ \\
\hline (173) & $\begin{array}{l}\text { PM } 2.5 \text { increased MDA, iNOS activity, TNF- } \alpha, \text { IL- } \\
1 \beta \text {, along with NOX } 4 \text { and NOX subunits as } \\
\text { p } 67^{\text {phox }}, \text { p } 47^{\text {phox }} \text { and p } 22^{\text {phox }} \text { in the heart and reduced } \\
\text { SOD activity }\end{array}$ & C57BL/6 mice, $6-8$ wks old & $\begin{array}{l}\mathrm{PM}_{2.5} \text { collected September } 2013 \text { in Zhengzhou, Taiwan. } \\
\text { Instilled with } 1.5,3.0,6.0 \mathrm{mg} / \mathrm{kg} \text { BW } 5 \text { days } / \mathrm{wk} \text { for } 2 \text { wks }\end{array}$ \\
\hline (181) & $\begin{array}{l}\mathrm{PM}_{2.5} \text { decreased GSH-Px, increased MDA and } \\
\text { sICAM-1. SeY treatment reduced inflammation } \\
\text { markers (TNF- } \alpha \text {, IL- } 1 \beta \text {, sICM-1) }\end{array}$ & $\begin{array}{l}\text { Male Sprague Dawley rats, } 7 \\
\text { wks old }\end{array}$ & $\begin{array}{l}\mathrm{PM}_{2.5} \text { collected September-November } 2015 \text { in Shanghai, } \\
\text { China. Intratracheal instillation at } 40 \mathrm{mg} / \mathrm{kg}\end{array}$ \\
\hline (185) & $\begin{array}{l}\mathrm{PM}_{2.5} \text { exposure in diabetic model induced NF-KB, } \\
\mathrm{COX}-2 \text {, MAPK in heart, IKB inhibitor restored } \\
\text { function through NF-KB reduction }\end{array}$ & KKay Tg mice, 7 wks old & $\begin{array}{l}\mathrm{PM}_{2.5} \text { collected Polaris in Columbus, Ohio. Intratracheal } \\
\text { instillation for } 6 \mathrm{hr} / \text { day, } 5 \text { day/week, } 8 \text { weeks at dose of } 1.6 \\
\mathrm{mg} / \mathrm{kg}\end{array}$ \\
\hline (186) & $\begin{array}{l}\mathrm{PM}_{2.5} \text { increased DNA damage (increased OGG1 } \\
\text { and GADD153, decreased MTH1and XRCC1) in } \\
\text { the heart and decreased SOD }\end{array}$ & Male Wistar rats & $\begin{array}{l}\mathrm{PM}_{2.5} \text { containing PAHs collected Taiyuan, China. } \\
\text { Intratracheal instillation of } 1.5 \mathrm{mg} / \mathrm{kg} \text { b.w. } \mathrm{PM}_{2.5} \text {, } \\
1.6 \times 10^{-4} \mathrm{mg} / \mathrm{kg} \text { b.w. } 1-\mathrm{NP}, 1.2 \times 10^{-4} \mathrm{mg} / \mathrm{kg} \text { b.w. 9-NA }\end{array}$ \\
\hline (188) & $\begin{array}{l}\text { Higher } \mathrm{PM}_{2.5} \text { correlated with increased blood } \\
\text { TLR2 methylation, flavonoid intake decreased } \\
\text { TLR2 methylation }\end{array}$ & $\begin{array}{l}\text { Normative Aging Study, } 573 \\
\text { participants }\end{array}$ & $\mathrm{PM}_{2.5}$ data collected from Harvard School of Public Health \\
\hline \multicolumn{4}{|c|}{ Gestational } \\
\hline (27) & $\begin{array}{l}\mathrm{PM}_{2.5} \text { exposure increased GATA4, NKX2-5 and } \\
\text { inflammatory markers (TNF- } \alpha \text { and IL-1 } \beta \text { ) } \\
\text { homocysteine exacerbates these effects }\end{array}$ & $\begin{array}{l}\text { Female Sprague Dawley rats, } \\
10 \text { wks old, neonatal progeny }\end{array}$ & $\begin{array}{l}\mathrm{PM}_{2.5} \text { collected Fujian, China. Exposed during gestation } \\
\text { and lactation ( } \sim 42 \text { days) to } 36.5 \mu \mathrm{g} / \mathrm{m}^{3} \text { through a whole- } \\
\text { body inhalation system. }\end{array}$ \\
\hline (57) & $\begin{array}{l}\text { DE } \mathrm{PM}_{2.5} \text { caused promoter methylation of } \\
\text { microRNA-133a-2 in progeny and cardiovascular } \\
\text { stress decreased microRNA 133a- } 2 \text { expression }\end{array}$ & $\begin{array}{l}\text { Female C57BL/6 } 12-14 \text { wks } \\
\text { old, } 12 \text { wk-old progeny }\end{array}$ & $\begin{array}{l}\mathrm{PM}_{2.5} \text { collected a single cylinder Yanmar diesel engine, } \\
\text { operating at } 82 \% \text { load } \sim 300 \mu \mathrm{g} / \mathrm{m}^{3} \text { for } 6 \mathrm{hrs} / \text { day for a total } \\
\text { of } 5 \text { days during pregnancy }\end{array}$ \\
\hline (153) & $\begin{array}{l}\mathrm{PM}_{2.5} \text { preconception exposure increased } \\
\text { inflammatory markers (IL-6, IL-15, NFKB, CRP, } \\
\text { CD26E, CD26P, VCAM-1, MCP-1), fibrosis } \\
\text { (Col3a1), Ca2+ regulation (SERCA2a, p-PLN), } \\
\text { and altered epigenetics (DNMT1 } \downarrow \text {, SIRT1 } \uparrow \text {, } \\
\text { SIRT2 } \uparrow \text { ) }\end{array}$ & $\begin{array}{l}\text { Paternal and maternal FVB } \\
\text { mice exposure - male } 12 \text { wk- } \\
\text { old progeny }\end{array}$ & $\begin{array}{l}\mathrm{PM}_{2.5} \text { collected Columbus, OH. Average } 38.58 \mu \mathrm{g} / \mathrm{m}^{3} \text { for } 6 \\
\text { hrs/day, } 5 \text { days/week for } 3 \text { months through a whole-body } \\
\text { inhalation system preconception }\end{array}$ \\
\hline (154) & $\begin{array}{l}\mathrm{PM}_{2.5} \text { induced changes in calcium dynamics by } \\
\text { decreasing NCX and Cav1.2 }\end{array}$ & $\begin{array}{l}\text { Female FVB mice, } 12 \text { wks old } \\
\text { 14-day old progeny }\end{array}$ & $\begin{array}{l}\mathrm{PM}_{2.5} \text { collected Columbus, Ohio. Exposed } 6 \mathrm{hr} / \text { day, } 5 \\
\text { days/week, average } 91.78 \mu \mathrm{g} / \mathrm{m}^{3} \text { through a whole-body } \\
\text { inhalation system during pregnancy }\end{array}$ \\
\hline (155) & $\begin{array}{l}\text { PM }_{2.5} \text { decreased SIRT1, SIRT2, increased } \\
\text { DNMT1, DNMT3a, DNMT3b, decreased } \mathrm{Ca}^{2+} \\
\text { markers (NCX, p-PLN, SERCA2a) and increased } \\
\text { IL-1 } \beta, \text { IL-6, Col-1, MMP9, MMP13A }\end{array}$ & $\begin{array}{l}\text { Female FVB mice, } 12 \text { wks old } \\
12 \text { wk-old progeny }\end{array}$ & $\begin{array}{l}\mathrm{PM}_{2.5} \text { collected Columbus, OH. } 6 \mathrm{hr} / \mathrm{day}, 7 \text { days/week } \\
\text { throughout pregnancy, average } 73.61 \mu \mathrm{g} / \mathrm{m}^{3} \text { through a } \\
\text { whole-body inhalation system }\end{array}$ \\
\hline (164) & $\begin{array}{l}\mathrm{PM}_{2.5} \text { caused a dose-dependent increase of OPA1, } \\
\text { MFN1, DRP1, and FIS1 in progeny. }\end{array}$ & $\begin{array}{l}\text { Female Wistar rats, } 10-12 \text { wks } \\
\text { old, 1-day old progeny }\end{array}$ & $\begin{array}{l}\mathrm{PM}_{2.5} \text { collected September } 2014 \text { to March } 2016 \mathrm{in} \mathrm{Harbin} \text {, } \\
\text { China. Administered dropwise, } 3 \text { doses }(0.375 \mathrm{mg} / \mathrm{kg}, 1.5 \\
\mathrm{mg} / \mathrm{kg} \text {, and } 6.0 \mathrm{mg} / \mathrm{kg}) \text { during pregnancy }\end{array}$ \\
\hline (174) & $\begin{array}{l}\mathrm{PM}_{2.5} \text { increased histone acetyltransferase } \\
(\mathrm{H} 3 \mathrm{~K} 9 \mathrm{ac}) \text {, GATA4, and MEF2c. Exposure also } \\
\text { increased histone acetylation of GATA4/MEF2c } \\
\text { promoters }\end{array}$ & $\begin{array}{l}\text { Female C57BL/6 mice, } 12 \text { wks } \\
\text { old, } 1 \text { day and } 16 \text { wk-old } \\
\text { progeny }\end{array}$ & $\begin{array}{l}\mathrm{PM}_{2.5} \text { collected Chongqing, China. Gestational exposure } \\
\text { by ultrasonic nebulization, } 2 \text { hours a day during pregnancy, } \\
\text { at } \sim 300 \mu \mathrm{g} / \mathrm{m}^{3}\end{array}$ \\
\hline \multicolumn{4}{|c|}{ UFP } \\
\hline (4) & $\begin{array}{l}\text { UFP exposure increased } \mathrm{AT}_{1} \mathrm{R} \text { protein along with } \\
\text { Acta } 1 \text { and Col3al in the heart, with decreased } \mathrm{HO} \text { - } \\
1 \text { expression }\end{array}$ & Male Sprague-Dawley rats & $\begin{array}{l}\text { UFP collected north of Mexico City (May-July 2009). } \\
\text { Acute ( } 3 \text { days, } 5 \mathrm{hr} / \text { day) and sub-chronic ( } 8 \text { weeks, } \\
\text { days/week, } 5 \mathrm{hr} / \text { day) exposure to varying concentrations. }\end{array}$ \\
\hline (36) & $\begin{array}{l}\text { UCAPs exposure decreased blood plasminogen } \\
\text { and thrombomodulin, increased CRP and SAA. } \\
\text { GSTM1 null participants had worse outcomes }\end{array}$ & $\begin{array}{l}34 \text { participants with metabolic } \\
\text { syndrome, } \sim 48 \text { years old }\end{array}$ & $\begin{array}{l}\text { UCAPs collected at US EPA facility Chapel Hill, NC. } \\
\text { Whole-body exposure for 2-hrs at average particle } \\
\text { concentration of } 189,000 \text { particles } / \mathrm{cm}^{3} \text {. }\end{array}$ \\
\hline
\end{tabular}




\begin{tabular}{|c|c|c|c|}
\hline (70) & $\begin{array}{l}\text { UFP exposure cause mitochondrial mPTP deficits, } \\
\text { Cyclosporin A resulted in attenuation }\end{array}$ & Male Sprague-Dawley rats & $\begin{array}{l}\text { UFP collected US EPA facility Chapel Hill, NC. } 100 \mu \mathrm{g} \\
\text { UFP laryngopharynx instillation }\end{array}$ \\
\hline (90) & $\begin{array}{l}\text { TAA-PNC of UFP was positively associated with } \\
\text { CRP and TNFR2 in white non-Hispanic } \\
\text { participants }\end{array}$ & $\begin{array}{l}408 \text { individuals aged } 40- \\
91 \text { years old }\end{array}$ & $\begin{array}{l}\text { UFP (near-highway, long-term exposure) Dorchester, } \\
\text { South Boston, Chinatown (Boston) }\end{array}$ \\
\hline (147) & $\begin{array}{l}\text { Elemental carbon UFP exposure increased platelet } \\
\text { CD40L and vWF, and decreased circulating } \\
\text { CD40L }\end{array}$ & $\begin{array}{l}19 \text { type } 2 \text { diabetics, } 30-60 \text { years } \\
\text { old, never smoked }\end{array}$ & $\begin{array}{l}\text { UFP particles were generated at } 32 \mathrm{~nm} \text {. Elemental carbon } \\
\text { UFP through mouth piece for } 2 \mathrm{hr} \text { at } 50 \mu \mathrm{g} / \mathrm{m}^{3}\end{array}$ \\
\hline (159) & $\begin{array}{l}\text { UFCP exposure increased CRP and fibrinogen in } \\
\text { systemic circulation }\end{array}$ & $\begin{array}{l}\text { Male spontaneously } \\
\text { hypertensive rats (SHRs), 12- } \\
13 \text { months old }\end{array}$ & UFCP exposure at $180 \mu \mathrm{g} / \mathrm{m}^{3}$ in a 24 -hour time frame \\
\hline (183) & $\begin{array}{l}\text { Increasing UFCP concentrations prevented the } \\
\text { beneficial effects of captopril in reducing AngII. }\end{array}$ & $\begin{array}{l}\text { Spontaneously hypertensive } \\
\text { rats (SHRs), } 10 \text { wks old }\end{array}$ & $\begin{array}{l}\text { UFP collected Beijing, China. Intratracheal instillation of } \\
\text { UFCP }(0.15 \mathrm{mg} / \mathrm{kg}, 0.45 \mathrm{mg} / \mathrm{kg} \text { and } 1.35 \mathrm{mg} / \mathrm{kg}) \text { and } \\
\text { captopril administration. }\end{array}$ \\
\hline \multicolumn{4}{|c|}{ Gestational } \\
\hline (109) & $\begin{array}{l}\text { UFP exposure induced placental HSD11B2 DNA } \\
\text { methylation, elevated IL-1 } 1 \beta \text {, IL- } 6 \text { and MCP- } 1 \text {, and } \\
\text { caused increased activation of AT } \mathrm{T}_{1} \mathrm{R} \text { and ACE }\end{array}$ & $\begin{array}{l}\text { Female C } 57 \mathrm{BL} / 6 \mathrm{~J} \\
6 \text { un } / p^{\text {un }} \text { mice, } \\
\text { progeny }\end{array}$ & $\begin{array}{l}\text { UFP collected in northern Mexico City (April-June 2016). } \\
\text { Intratracheal instillation of } 12 \mu \mathrm{g} \text { or } 400 \mu \mathrm{g} / \mathrm{kg} \text { during } \\
\text { pregnancy }\end{array}$ \\
\hline (139) & $\begin{array}{l}\text { UFP exposure caused higher serum levels of IL-10 } \\
\text { in C67BL/6 progeny }\end{array}$ & $\begin{array}{l}\text { Female C57BL/6 and BALB/C } \\
\text { mice. Progeny } 0-4 \text { wks old }\end{array}$ & $\begin{array}{l}\text { UFP generated with average mass concentration of } 101.94 \\
\mu \mathrm{g} / \mathrm{m}^{3} .24-\mathrm{h} \text { daily mean dose of } 25 \mu \mathrm{g} / \mathrm{m}^{3} \text { during pregnancy }\end{array}$ \\
\hline \multicolumn{4}{|c|}{ Engineered Nanomaterials and Advanced Materials } \\
\hline (54) & $\begin{array}{l}\text { Carbon nanoparticle-inhalation, compared to intra- } \\
\text { arterial injection, was more detrimental to cardiac } \\
\text { tissue with perturbation of inflammatory and } \\
\text { endothelial/epithelial pathways }\end{array}$ & $\begin{array}{l}\text { Female BALB/cJ mice, } 10-12 \\
\text { wks old }\end{array}$ & $\begin{array}{l}\text { Carbon nanoparticles with primary particle diameter of } 10 \\
\pm 2 \mathrm{~nm} \text {. Administered through intra-arterial infusion } \\
\left(30 \mathrm{~mm}^{2} \text { per animal) and inhalation (lung deposited dose }\right. \\
\left.10,000 \mathrm{~mm}^{2}\right) \text {. Whole body exposure for } 4 \text { or } 24 \text { hours }\end{array}$ \\
\hline (65) & $\begin{array}{l}\text { Nano- } \mathrm{TiO}_{2} \text {-exposed microRNA-378a Tg mice had } \\
\text { higher MFN1 levels (fusion), and preserved } \\
\text { metabolic profiles and ultrastructure in the heart }\end{array}$ & $\begin{array}{l}\text { FVB and miRNA-378a } \\
\text { knockout Tg mice aged 14-18 } \\
\text { wks old }\end{array}$ & $\begin{array}{l}\text { Nano-TiO } 2 \text {, particle size }(21 \mathrm{~nm}) / \text { surface area }\left(48.08 \mathrm{~m}^{2} / \mathrm{g}\right) \text {. } \\
\text { Whole-body inhalation exposure at a dose of } 11.09 \mathrm{mg} / \mathrm{m}^{3} \\
\text { for } 4 \mathrm{hrs}\end{array}$ \\
\hline (71) & $\begin{array}{l}\text { Nano-TiO }_{2} \text { exposure increased inflammatory } \\
\text { markers (NF- } \mathrm{BB} \text {, TNF- } \alpha \text {, IL-4, IL-6, TGF- } \beta \text {, CK, } \\
\mathrm{CRP}, \text { IFN- } \gamma \text { ) and transcriptional regulators } \\
\text { (STAT1, STAT3, STAT6, GATA3, GATA4) }\end{array}$ & $\begin{array}{l}\text { CD-1 (ICR) male mice, } 4 \text { wks } \\
\text { old }\end{array}$ & $\begin{array}{l}\text { Nano- } \mathrm{TiO}_{2} \text { prepared through hydrolysis of } \mathrm{Ti}(\mathrm{OBu})_{4} \text {. } \\
\text { Administered via nasal instillation of mice every other day } \\
\text { for } 6 \text { months. Treatment of } 1.25-5 \mathrm{mg} / \mathrm{kg} \mathrm{TiO} 2 \mathrm{NPs}\end{array}$ \\
\hline (77) & $\begin{array}{l}\mathrm{Nano}^{-\mathrm{TiO}_{2}} \text { exposure caused blood specific } \\
\text { activation of } \mathrm{C} 3 \text {, and heart-specific activation of } \\
\text { the complement cascade }\end{array}$ & $\begin{array}{l}\text { Female C57BL/6 mice, } 8 \text { wks } \\
\text { old }\end{array}$ & $\begin{array}{l}\text { Nano-TiO } \\
\text {, UV-Titan } \mathrm{L} 181.6 .0 \mathrm{mg} \mathrm{Ti} / \mathrm{m}^{3}-10 \mathrm{mg} \mathrm{TiO}_{2} / \mathrm{m}^{3} \\
\text { administered through intratracheal instillation }\end{array}$ \\
\hline (116) & $\begin{array}{l}\text { Nano- } \mathrm{TiO}_{2} \text {-exposed mPHGPx } \mathrm{Tg} \text { mice had } \\
\text { reduced ROS and preserved electron transport } \\
\text { chain complex constituents in the heart }\end{array}$ & $\begin{array}{l}\text { Male FVB and male mPHGPx } \\
\text { Tg mice } 10-12 \text { wks }\end{array}$ & $\begin{array}{l}\text { Nano- } \mathrm{TiO}_{2} \text {, particle size }(21 \mathrm{~nm}) / \text { surface area }\left(48.08 \mathrm{~m}^{2} / \mathrm{g}\right) \text {. } \\
11.58 \pm 0.27 \mu \mathrm{g} \text { lung deposition, whole-body inhalation } \\
\text { exposure for } 6 \mathrm{hrs}\end{array}$ \\
\hline \multicolumn{4}{|c|}{ Gestational } \\
\hline (66) & $\begin{array}{l}{\mathrm{Nano}-\mathrm{TiO}_{2}}_{2} \text { exposure } \\
\text { mitochondrial proton leak (UCP2), and fatty acid } \\
\text { metabolism (increased CPT1A and PDH } \\
\text { phosphorylation) }\end{array}$ & $\begin{array}{l}\text { Female Sprague Dawley rats } \\
10-12 \text { wks, } 12 \text { wk-old progeny }\end{array}$ & $\begin{array}{l}\text { Nano- }-\mathrm{TiO}_{2} \text {, particle size }(21 \mathrm{~nm}) / \text { surface area }\left(48.08 \mathrm{~m}^{2} / \mathrm{g}\right) \text {. } \\
7.79 \pm 0.26 \text { days, } 5 \mathrm{hr} / \text { day, } 10.35 \pm 0.13 \mathrm{mg} / \mathrm{m}^{3} \text { through a } \\
\text { whole-body inhalation system during pregnancy }\end{array}$ \\
\hline (87) & $\begin{array}{l}\text { Nano-TiO }{ }_{2} \text { exposure increased } \mathrm{ROS}\left(\mathrm{H}_{2} \mathrm{O}_{2}\right) \text {, global } \\
5-\mathrm{mC} \text { methylation, DNMT1 protein expression, } \\
\text { and HIF- } 1 \alpha \text { activity and downregulated mPHGPx } \\
\text { in the heart }\end{array}$ & 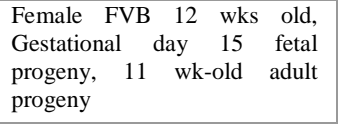 & $\begin{array}{l}\text { Nano-TiO } 2 \text {, particle size }(21 \mathrm{~nm}) / \text { surface area }\left(48.08 \mathrm{~m}^{2} / \mathrm{g}\right) \text {. } \\
\text { Whole-body inhalation exposure at a dose of } \\
12.09 \pm 0.26 \mathrm{mg} / \mathrm{m}^{3} \text { for } 6 \text { days (over 8-day period), } 6 \mathrm{hr} / \mathrm{day} \text {, } \\
\text { starting from gestational day } 5\end{array}$ \\
\hline (143) & $\begin{array}{l}{\mathrm{Nano}-\mathrm{TiO}_{2} \text { exposure resulted in cardiac }} \\
\text { mitochondrial epigenomic remodeling (increased } \\
\mathrm{H} 3 \mathrm{~K} 4 \mathrm{Me} \text { ) and decreased transcriptomic immune } \\
\text { response }\end{array}$ & $\begin{array}{l}\text { Female Sprague Dawley rats } \\
10-12 \text { wks old, Gestational day } \\
20 \text { fetal progeny }\end{array}$ & $\begin{array}{l}\text { Nano- }-\mathrm{TiO}_{2} \text {, particle size }(21 \mathrm{~nm}) / \mathrm{surface} \text { area }\left(48.08 \mathrm{~m}^{2} / \mathrm{g}\right) \text {. } \\
\text { Whole-body inhalation exposure at a dose of } 10.35 \pm 0.13 \\
\mathrm{mg} / \mathrm{m}^{3} \text { for } 7.79 \pm 0.26 \text { days during gestation }\end{array}$ \\
\hline (145) & $\begin{array}{l}\mathrm{Nano}_{-} \mathrm{TiO}_{2} \text { exposure decreased State } 3 \text { and State } 4 \\
\text { mitochondrial respiration }\end{array}$ & $\begin{array}{l}\text { Female Sprague Dawley rats, } \\
\text { female } 11-16 \text { wk old progeny }\end{array}$ & $\begin{array}{l}\text { Nano-TiO } 2 \text {, particle size }(21 \mathrm{~nm}) / \text { surface area }\left(48.08 \mathrm{~m}^{2} / \mathrm{g}\right) \text {. } \\
\text { Whole-body inhalation exposure at a dose of } 10.6 \pm 0.3 \\
\mathrm{mg} / \mathrm{m}^{3} \text { for } 6.8 \pm 0.5 \text { days during gestation }\end{array}$ \\
\hline \multicolumn{4}{|c|}{ Multi-component Exposure } \\
\hline (9) & $\begin{array}{l}\text { Higher } \mathrm{PM}_{2.5} \mathrm{BC} \text {, and mass } \mathrm{PM}_{2.5} \text { exacerbated } \\
\text { hypomethylation of IFN- } \gamma \text { and ICAM- } 1\end{array}$ & $\begin{array}{l}\text { Normative Aging Study, } 777 \\
\text { elderly men }\end{array}$ & $\begin{array}{l}\mathrm{PM}_{2.5} \text { mass concentration and } \mathrm{PM}_{2.5} \mathrm{BC} \text { concentration } \\
\text { measured hourly at the Harvard supersite Boston, } \mathrm{MA}\end{array}$ \\
\hline (10) & $\begin{array}{l}\text { Higher black carbon concentration associated with } \\
12 \% \text { reduction in F3 methylation }\end{array}$ & $\begin{array}{l}\text { Normative Aging Study, } 777 \\
\text { elderly men }\end{array}$ & $\begin{array}{l}\mathrm{PM}_{2.5}, \mathrm{BC}, \mathrm{SO}_{4} \text {, and ozone concentrations of ambient air } \\
\text { collected from Boston, MA were measured hourly }\end{array}$ \\
\hline (32) & $\begin{array}{l}\text { Increases in } \mathrm{PM}_{2.5}, \mathrm{BC} \text {, and UFP concentrations } \\
\text { were positively associated with inflammation } \\
\text { (CRP and fibrinogen) and coagulation, but not } \\
\text { endothelial dysfunction, Delta-C increasing } \\
\text { concentrations assoiciated positively with } \\
\text { fibrinogen and negatively with MPO }\end{array}$ & $\begin{array}{l}135 \text { patients undergoing cardiac } \\
\text { catheterization }\end{array}$ & $\begin{array}{l}\text { Ambient air pollution, Delta-C (wood-smoke), } \mathrm{PM}_{2.5}, \mathrm{BC} \text {, } \\
\text { UFP collected from New York State Department of } \\
\text { Environmental Conservation (DEC) site in Rochester, NY }\end{array}$ \\
\hline (43) & $\begin{array}{l}\mathrm{PM}_{2.5} \text { levels, but not UFP, were positively } \\
\text { associated with hsa-miR-197-3p and hsa-miR-99a- } \\
5 \mathrm{p}\end{array}$ & $\begin{array}{l}59 \text { volunteers ( } 20 \text { were healthy, } \\
20 \text { had COPD, } 19 \text { had ischemic } \\
\text { heart disease) }\end{array}$ & $\begin{array}{l}\text { Ambient air pollution exposure (personal exposure level } \\
\text { measurements of } \mathrm{PM}_{10} \text { and } \mathrm{PM}_{2.5} \text {, UFP, nitrogen oxides, } \\
\mathrm{BC}, \mathrm{CO} \text { ) during 2-hour walk. Oxford Street or Hyde Park, } \\
\text { London, England }\end{array}$ \\
\hline (48) & $\begin{array}{l}\text { SiNP and Pb co-exposure elevated markers of heart } \\
\text { failure (ANP and BNP), inflammation (CRP, IL-6, } \\
\text { TNF- } \alpha \text { ) in heart and increased ANGII and ET-1in } \\
\text { serum. T-PA, TFPI, AT III decreased while } \\
\text { fibrinogen and D2D increased with co-exposure }\end{array}$ & Sprague Dawley rats, 6 wks old & $\begin{array}{l}\text { Stöber technique was used to synthesize SiNPs. Intra- } \\
\text { tracheal instillation of } 2 \mathrm{mg} / \mathrm{kg} \text { body SiNPs and/ or } 0.25 \\
\mathrm{mg} / \mathrm{kg} \text { of lead acetate }(\mathrm{Pb}) \text { for } 30 \text { days. }\end{array}$ \\
\hline
\end{tabular}




\begin{tabular}{|c|c|c|c|}
\hline (84) & $\begin{array}{l}54 \text { circulating miRNAs were correlated with dose } \\
\text { of exposure and pollution type }\end{array}$ & 24 non-smoking adults & $\begin{array}{l}\mathrm{PM}_{2.5}, \mathrm{NO}_{2}, \mathrm{UFP}, \mathrm{BC}, \mathrm{PM}_{10} \text { collected on Oxford Street in } \\
\text { London, 2-hour exposure }\end{array}$ \\
\hline (86) & $\begin{array}{l}\mathrm{UFP}, \mathrm{CO}, \mathrm{SO}_{2} \text { exposure was associated with } \\
\text { increased inflammatory markers (IL-6, IL-8, ET-1) } \\
\text { in blood }\end{array}$ & $\begin{array}{l}52 \text { men and women } 18-34 \text { years } \\
\text { old }\end{array}$ & $\begin{array}{l}\text { UFP, } \mathrm{CO}, \mathrm{SO}_{2} \text { concentrations collected in Sault Ste. Marie, } \\
\text { Ontario, Canada (Summer of 2010). Occupational air } \\
\text { pollution }\end{array}$ \\
\hline (96) & $\begin{array}{l}\mathrm{PM}_{2.5} \text { and } \mathrm{SO}_{4} \text { increases associated with CRP } \\
\text { levels, } \mathrm{NO}_{x} \text { positively associated with IL-6, BC, } \\
\text { sulfate, ozone positively associated with TNFR2 }\end{array}$ & $\begin{array}{l}\text { 3,996 non-smoking participants } \\
\text { Framingham Offspring cohort } \\
\text { cycle } 7 \text { and } 8 \text { and Third } \\
\text { Generation cohort } 1\end{array}$ & $\begin{array}{l}\mathrm{PM}_{2.5}, \mathrm{BC}, \mathrm{SO}_{4}^{2-} \text {, nitrogen oxides, and ozone collected at } \\
\text { the Boston Harvard Supersite and assessed as 7-day } \\
\text { moving average }\end{array}$ \\
\hline (97) & $\begin{array}{l}\text { Higher } \mathrm{PM}_{2.5} \text { and } \mathrm{BC} \text { concentrations were } \\
\text { associated with lower P-selectin levels }\end{array}$ & $\begin{array}{l}3,820 \text { non-smoking participants } \\
\text { Framingham Offspring cohort } \\
\text { cycle } 7 \text { and } 8 \text { and Third } \\
\text { Generation cohort } 1\end{array}$ & $\begin{array}{l}\mathrm{PM}_{2.5}, \mathrm{BC}, \mathrm{SO}_{4}^{2-} \text {, nitrogen oxides, and ozone collected at } \\
\text { the Boston Harvard Supersite and assessed as 7-day } \\
\text { moving average }\end{array}$ \\
\hline (101) & $\begin{array}{l}\text { Nickel, barium, and silver levels were positively } \\
\text { correlated with VEGF, UCHL1, and cortisol }\end{array}$ & $\begin{array}{l}53 \text { healthy participants, } 18- \\
60 \text { years old }\end{array}$ & $\begin{array}{l}\text { Particulate matter collected in downtown Toronto, Canada. } \\
\text { 130-min exposure to } \mathrm{PM}_{10}\left(213 \mu \mathrm{g} / \mathrm{m}^{3}\right), \mathrm{PM}_{2.5}\left(238 \mu \mathrm{g} / \mathrm{m}^{3}\right) \text {, } \\
\text { and/or concentrated UFP }\left(213 \mu \mathrm{g} / \mathrm{m}^{3}\right)\end{array}$ \\
\hline (102) & $\begin{array}{l}\text { Higher } \mathrm{BC} \text { is associated with decreased } \\
\text { methylation of Alu and both increased } \mathrm{SO}_{4} \text { and } \mathrm{BC} \\
\text { resulted in decreased methylation of } \mathrm{LINE}^{-1}\end{array}$ & $\begin{array}{l}\text { Normative Aging Study, } 706 \\
\text { individuals }\end{array}$ & $\begin{array}{l}\mathrm{PM}_{2.5}, \mathrm{BC}, \mathrm{SO}_{4} \text { data collected from Harvard School of } \\
\text { Public Health during January } 1995 \text { to November } 2007\end{array}$ \\
\hline (110) & $\begin{array}{l}\mathrm{PM}_{2.5} \text { concentration was positively associated with } \\
69 \text { differentially methylated regions, } 13 \mathrm{CpG} \text { sites, } \\
\text { including altered methylation of KNDC } 1 \text { and } \\
\text { FAM50B. UFP was also associated with } 15 \\
\text { differentially methylated regions }\end{array}$ & 157 non-smoking adults & $\begin{array}{l}\mathrm{PM}_{2.5} \text { and UFP levels collected in personal and ambient air } \\
\text { pollution, measured in 24-hour intervals, part of } \\
\text { EXPOsOMICS project conducted in } 4 \text { European countries } \\
\text { (December 2013-February 2015) }\end{array}$ \\
\hline (118) & $\begin{array}{l}\text { BC was associated with sVCAM-1, sICAM-1, and } \\
\text { vWF. PM } 2.5 \text { was associated with sVCAM-1 and } \\
\text { sICAM- } 1 \text { in patients not taking statins. In smokers, } \\
\text { PM } 2.5 \text { and BC were positively associated with } \\
\text { sVCAM-1 }\end{array}$ & $\begin{array}{l}60 \text { male and } 37 \text { female } \\
\text { participants with type } 2 \\
\text { diabetes (smokers and non- } \\
\text { smokers) }\end{array}$ & $\begin{array}{l}\mathrm{PM}_{2.5}(1998-2002) \text { and } \mathrm{BC}(1999-2002) \text { measured hourly } \\
\text { and } \mathrm{SO}_{4}^{2-} \text { measured daily (1999-2002) at the Harvard } \\
\text { School of Public Health (Boston, MA) }\end{array}$ \\
\hline (132) & $\begin{array}{l}\mathrm{PM}_{2.5} \text { mass concentration shower positive trend } \\
\text { with HDL-oxidant index (HOI). Changes not seen } \\
\text { with ozone co-exposure. }\end{array}$ & 30 participants, $19-37$ years old & $\begin{array}{l}\mathrm{PM}_{2.5}\left(149 \mu \mathrm{g} / \mathrm{m}^{3}\right) \text {, ozone }\left(221 \mu \mathrm{g} / \mathrm{m}^{3}\right) \text {, and } \mathrm{PM}_{2.5} \text { and ozone } \\
\text { data collected from Toronto, Canada as part of Clean Air } \\
\text { Research Center Project. }\end{array}$ \\
\hline (158) & $\begin{array}{l}\mathrm{PM}_{2.5} \text { and quasi-ultrafine particles }<0.50 \mu \mathrm{m} \\
\text { dysregulated parasympathetic response and } \\
\text { increased IFN- } \gamma \text { methylation in blood }\end{array}$ & 12 healthy participants & $\begin{array}{l}\text { Particulate matter collected Milan, Italy. Inhalation to } \\
\text { mixture }\left(\mathrm{PM}_{10}, \mathrm{PM}_{2.5}, \mathrm{PM}_{1.0} \text { and } \mathrm{PM}_{0.5} \mu \mathrm{m}\right) \text { over } 2 \text { sessions }\end{array}$ \\
\hline (160) & $\begin{array}{l}\mathrm{PM}_{2.5} \text { exposure was associated with higher } \\
\text { inflammation (CRP) and coagulation (platelet } \\
\text { count in blood) }\end{array}$ & 3275 participants & $\begin{array}{l}\text { Ambient air pollution } \mathrm{PM}_{10} \text { and } \mathrm{PM}_{2.5} \text { levels from the } \\
\text { German Heinz Nixdorf Recall Study, three adjacent cities } \\
\text { (Essen, Mülheim, Bochum) }\end{array}$ \\
\hline (163) & $\begin{array}{l}\text { Co-exposure potentiated increases in CRP, IL-6, } \\
\text { CK, LDH, and MDA, and decreased SOD }\end{array}$ & $\begin{array}{l}\text { Male Wistar rats (age not } \\
\text { defined) }\end{array}$ & $\begin{array}{l}\mathrm{PM}_{2.5} \text { (varying doses), ozone }(0.81 \mathrm{ppm}), \mathrm{PM}_{2.5} \text { and ozone } \\
\text { collected June-October } 2011 \text { in Shanghai, China. } \\
\text { Administered as whole-body inhalation exposure (ozone) } \\
\text { and intratracheal instillation }\left(\mathrm{PM}_{2.5}\right)\end{array}$ \\
\hline (169) & $\begin{array}{l}\mathrm{BC}, \mathrm{CO}, \mathrm{NO}_{x} \text {, and PAHs positively associated with } \\
\mathrm{IL}-6 \text { and TNF- } \alpha \text {, quasi-ultrafine particles }<0.25 \mu \mathrm{m} \\
\text { were also associated with IL- } 6 \text {. Associations were } \\
\text { stronger for haplotype } \mathrm{H} \text { than haplotype } \mathrm{U}\end{array}$ & 36 participants, $\sim 84$ years old & $\begin{array}{l}\text { Particulate matter (PM-varying sizes), nitrogen oxides } \\
\left(\mathrm{NO}_{\mathrm{x}}\right) \text {, carbon monoxide (CO), organic and elemental } \\
\text { carbon (OC and EC), collected from four retirement } \\
\text { communities in the Los Angeles air basin }\end{array}$ \\
\hline (176) & $\begin{array}{l}\text { SiNP and } \mathrm{MeHg} \text { co-exposure caused cardiac injury } \\
\text { through changes in serum biomarker activity } \\
\text { including increased SERCA2, cTnT, ANP, and } \\
\text { BNP }\end{array}$ & Sprague Dawley rats, 6 wks old & $\begin{array}{l}\text { Silica nanoparticles (SiNPs) and methylmercury }(\mathrm{MeHg}) \\
\text { administered through intratracheal instillation } 10 \text { times } \\
\text { over } 30 \text { days at doses of } 0.25 \mathrm{mg} / \mathrm{kg}(\mathrm{MeHg}) \text { and } 2 \mathrm{mg} / \mathrm{kg} \\
\text { (SiNPs) }\end{array}$ \\
\hline (184) & $\begin{array}{l}\text { Co-exposure }\left(\mathrm{PM}_{2.5}, \mathrm{SO}_{2} \text {, and } \mathrm{NO}_{2}\right) \text { causes } \\
\text { endothelial dysfunction (increased ET-1 and } \\
\text { decreased eNOS) and inflammation (increased } \\
\text { COX-2, iNOS, TNF- } \alpha, \text { IL- } 6 \text { ) }\end{array}$ & Male C57BL/6 mice, $6-8$ wks & $\begin{array}{l}\mathrm{PM}_{2.5}, \mathrm{SO}_{2} \text {, and } \mathrm{NO}_{2} \text {, collected Taiyuan, China. Intranasal } \\
\text { instillation every other day for } 6 \mathrm{hrs} / 28 \text { days. } 0.5 / 3.5 \mathrm{mg} / \mathrm{m}^{3} \\
\mathrm{SO}_{2}, 0.2 / 2 \mathrm{mg} / \mathrm{m}^{3} \mathrm{NO}_{2}, 1 / 10 \mathrm{mg} / \mathrm{kg} \mathrm{PM} \mathrm{PM}_{2.5}\end{array}$ \\
\hline
\end{tabular}

Table 1.1: Summarized Recent Findings. Summarized findings of the molecular mechanisms contributing to cardiovascular complications following particle inhalation exposure. Studies are organized by exposure $\left(\mathrm{PM}_{2.5}, \mathrm{UFP}\right.$, ENM, and Multi-component), including subsections for gestational and preconception exposures. All abbreviations are defined in the Glossary of Abbreviations provided.

\section{Cardiac Remodeling}

While inhalation exposure directly impacts the lungs, the subsequent downstream adaptations of the heart can lead to sustained cardiac remodeling. This remodeling can be presented 
in the form of fibrosis, hypertrophy, and other structural changes to both the cardiomyocyte and the surrounding connective tissue of the heart. In understanding how this process occurs, examining the biochemical signature linked to cardiac remodeling changes associated with toxicant inhalation exposure can provide insight for future investigations into prevention and treatment. The reported cardiovascular adaptations that occur as a result of toxicant inhalation exposure are depicted in Figure 1.1.

Figure 1.1: Cardiovascular Changes following Exposure.

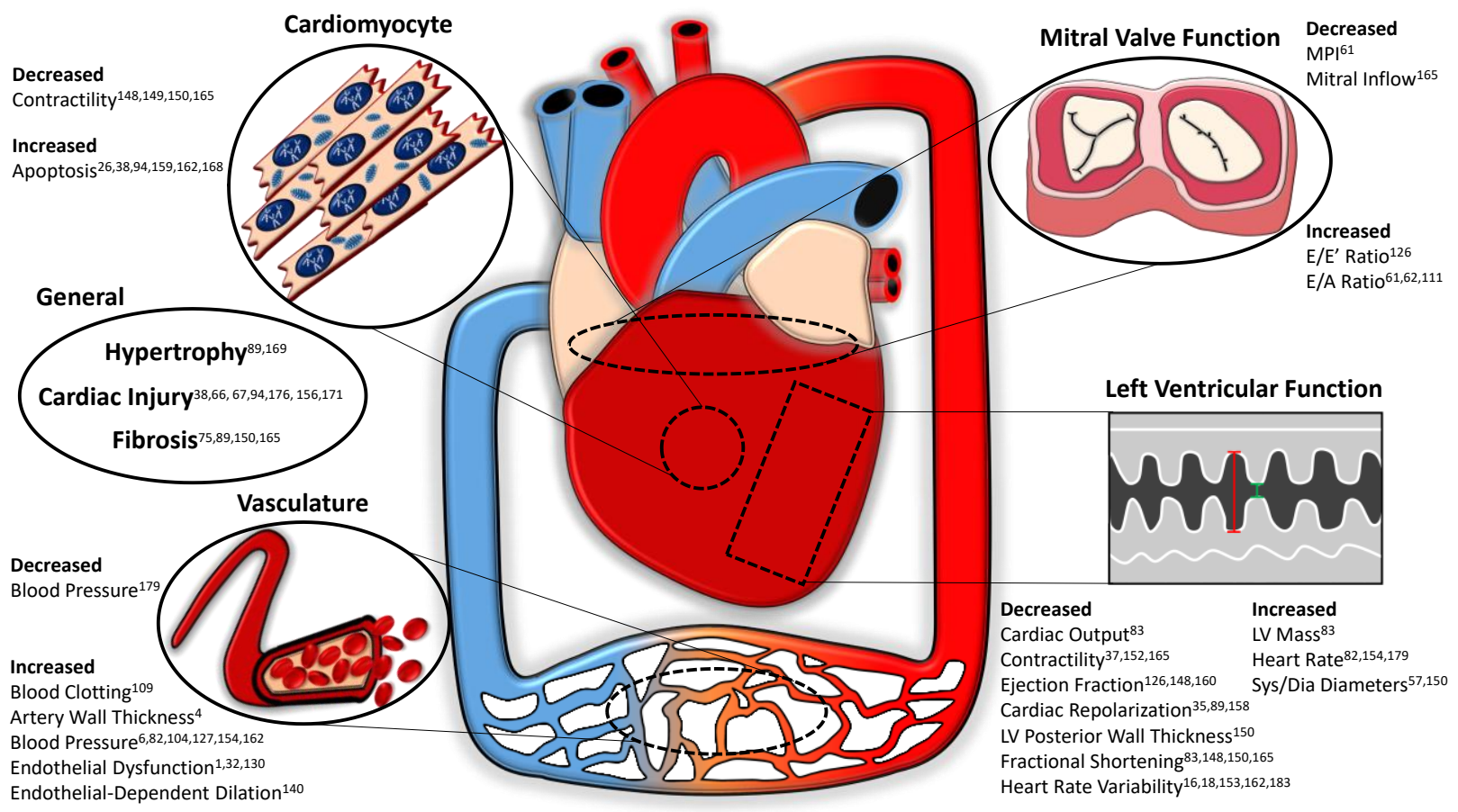

Figure 1.1: Summary of the cardiovascular changes following particulate inhalation exposures and the associated studies detailing these findings. Sys $=$ systolic, Dia $=$ diastolic, $\mathrm{LV}=$ left ventricular, $\mathrm{MPI}=$ myocardial performance index.

Cardiac fibrosis involves the imbalance of extracellular matrix production and degradation, which results in accumulation of scar tissue. Cardiac fibrosis, which occurs as a result of PM 
exposure, therefore decreases compliance, impairing the ability of the heart to contract and relax properly. $\mathrm{PM}_{2.5}$ exposure results in elevation of several genes linked to collagen deposition (collagen type I alpha 1 (Col1a1) and collagen type III alpha 1 (Col3a1)) and the fibrogenic growth factor, transforming growth factor beta 1 (TGF $\beta-1)$ ) (131). Simultaneously, NADPH oxidase (NOX-4) is increased, matching the resultant cardiac dysfunction and prooxidative environment found in the heart following PM exposure. Of note, Qin et al. also further demonstrated that the effects of $\mathrm{PM}_{2.5}$ are worse in older mice, making them more susceptible to prolonged cardiac systolic dysfunction marked by decreased ejection fraction and increased E/E' ratio when compared to juveniles (131). $\mathrm{PM}_{2.5}$-induced fibrosis is also related to cardiac inflammation in the hearts of mice, which show elevated expression of inflammatory genes including interleukin (IL) -6, IL-18, and C-X-C motif chemokine ligand 1 (CXCL1) (79). Inflammation and fibrosis in the heart may be attributed to increased phosphorylation and therefore activation of epidermal growth factor receptor (EGFR)/Akt signaling and increased expression of nuclear factor-kappa beta (NF$\mathrm{KB}$ ) following inhalation exposure. NF-кB expression in the heart is likewise increased as a result of $\mathrm{PM}_{2.5}$ exposure in diabetic mice, along with cyclooxygenase-2 (COX-2) and mitogen activated protein kinase (MAPK), indicating high oxidative stress and inflammation (185). Intracerebroventricular injection of an inhibitor of IкB kinase-2 (IKK) analog (IMD-0354), which regulates the nuclear translocation of $\mathrm{NF}-\mathrm{KB}$, can remediate the inflammatory response that occurs following PM exposure. While NF-кB plays an important role in the cardiovascular effects of PM inhalation exposure, other inflammatory markers contribute to cardiac remodeling. Cardiac injury and inflammation that occurred following $\mathrm{PM}_{2.5}$ exposure were attenuated with supplementation of vitamin $\mathrm{E}$ and omega-3 polyunsaturated fatty acids prior to the exposure in rats by decreasing expression of tumor necrosis factor- $\alpha$ (TNF- $\alpha$ ), IL-1 $\beta$, and IL-6 (39). In addition to TNF- $\alpha$ and IL$1 \beta, \mathrm{PM}_{2.5}$ exposure also induces soluble intercellular adhesion molecule 1 (ICAM-1) (181). Together, these inflammatory markers can form a positive feedback loop with NF-кB, amplifying PM-induced cardiac fibrosis and remodeling. Selenium yeast (SeY) supplementation can similarly serve as a pretreatment protective strategy, as reported in Sprague Dawley rats that were subsequently exposed to $\mathrm{PM}_{2.5}$ (181). PM-exposed rats who were administered SeY pretreatment had lower levels of pro-inflammatory markers and significantly higher total antioxidant capacity, total superoxide dismutase (SOD) and total glutathione peroxidase (GSH-Px), compared to the $\mathrm{PM}_{2.5}$-exposed group without pretreatment (181). The ability of antioxidant therapy to thwart the 
perpetuation of inflammatory signaling associated with cardiac remodeling highlights the essential role of oxidative stress in the development of cardiac pathology following ambient air exposure. Understanding the proteins involved in the regulation of reactive oxygen species (ROS) may provide insight into long-term remodeling of the heart. While most population-derived analyses assess cardiovascular impact in blood samples, a study of the effects of UFP urban air pollution utilized post-mortem ventricular autopsies of 30 children and young adults to substantiate that early and prolonged cardiac stress can result in irreversible consequences (161). Compared to clean air controls, long-term UFP exposure results in significant upregulation of proteins involved in oxidative (prion protein (PRNP)) and endoplasmic reticulum (ER) (glucose regulated protein 78 (GRP78)) stress. These response markers of stress were disproportionately upregulated in the left, compared to right, ventricle. Along with abnormal left-ventricular histopathology, increased oxidative and ER stress markers suggest a compensation by the heart to attenuate the inflammatory effects of air pollution in response to UFP exposure (161). GRP78 elevation in cardiomyocytes is sufficient to promote myocyte growth, potentially through stimulation of cardiac-specific transcriptional factor GATA sequence binding protein 4 (GATA4) (182). Similar to UFP, nano$\mathrm{TiO}_{2}$ exposure in outbred mice can lead to an increase in cardiac lesions and a significant change in inflammation markers, including changes in transcription factors (signal transducer and activator of transcription (STAT) $1 / 3 / 6$ and GATA 3/4) in the heart (71). The ability for oxidative and inflammatory proteins to activate transcription factors such as GATA4 is therefore notable, particularly following UFP/ENM exposure, as they appear to have strong correlations with cardiac hypertrophy. Fine PM exposures can also lead to sustained detrimental effects in the heart by altering the transcription factor profile. One example of this has been shown previously in a cohort of $\mathrm{PM}_{2.5}$-exposed mice (93). Cardiac remodeling through hypertrophy, QT interval prolongation, and fibrosis were correlated with elevated cAMP response element binding protein (CREB), as well as SOS Ras/Rac Guanine Nucleotide Exchange Factor 1 (SOS1), and glycogen synthase kinase 3 beta (GSK3 $\beta$ ) expression. Measuring biomarkers associated with myocardial infarction can also provide information on the extent of cardiac tissue dysfunction and death. An examination of the cardiovascular effects of a co-exposure model using silica nanoparticles (SiNP) and methylmercury (MeHg) has shown increases in myocardial edema, myocardial gap expansion, and myofibril disorder, as well as increases in activities of myocardial enzymes including cardiac troponin $\mathrm{T}(\mathrm{cTnT}$ ), atrial natriuretic peptide (ANP) and brain natriuretic peptide (BNP) compared 
to the serum of single exposure and sham-exposed rats (176). The authors also report increased sarco/endoplasmic reticulum Ca2+-ATPase (SERCA2), a potential marker of endoplasmic reticulum stress (69), in the co-exposure cohort along with oxidative stress. Similar to the preceding studies mentioned, co-exposures can induce cardiac remodeling by increasing oxidative and ER stress, and elevating prominent markers of heart failure. PM exposures, including UFP, ENM, and multi-component exposure, all have the ability to alter the transcription factor profile in the heart and lead to sustained detrimental effects on cardiac structure. The molecular adaptations to particle exposures that result in cardiac remodeling center around a theme of inflammation and oxidative stress, which may ultimately be regulated by a greater transcriptional and epigenetic adaptation following toxicant inhalation exposure.

\section{Cardiac Hemodynamics}

The performance of the heart can highlight both the acute and chronic effects of toxicant inhalation exposure. Although cardiac remodeling provides an informative diagnostic standard for assessing the impacts of PM exposure, more immediate changes are captured in measures of heart function. Whether there is a sustained or transient perturbation to the heart is likely determined by the molecular cascades involved, such as transcriptional or epigenetic reprogramming.

Controlled studies on human exposure to PM allow for the most relevant simulation of pollutant exposure, while also limiting interference of confounding factors. Measurements of blood methylation levels in 15 healthy participants revealed that both fine and coarse concentrated ambient particle (CAP) exposures induce hypomethylation of the Alu repetitive transposable element and toll-like receptor 4 (TLR4) (6). Decreased methylation of the short interspersed nucleotide element, Alu, and TLR4 was also associated with higher systolic blood pressure postexposure, which is similar to previous findings that have shown a role for hypomethylation in atherosclerosis (23). Other studies have reported similar findings with specific components of $\mathrm{PM}_{2.5}$, including with black carbon (BC). Over a 90-day period, increased BC levels correlated with decreased methylation of Alu, while both carbon black and sulfate $\left(\mathrm{SO}_{4}\right)$ were associated with decreased methylation of long interspersed nuclear emlement-1 (LINE-1) (102). Interestingly, in a study examining occupational exposure to $\mathrm{PM}_{2.5}$, methylation of LINE-1 was significantly increased in peripheral blood leukocytes of participants, but was not directly associated with 
declining heart rate variability (HRV) (44). When DNA methylation is altered, it has the potential to activate pro-inflammatory factors or repress anti-inflammatory factors, and can therefore activate pathways that are prevalent in the development of cardiovascular diseases. The discrepancy of whether toxicant exposure results in hypo- or hypermethylation can likely be attributed to different exposure environments (controlled or ambient), duration and concentration. The concentration of $\mathrm{PM}_{2.5}$ during exposure was positively associated with toll-like receptor 2 (TLR2) methylation in older adults, further suggesting potentiation of the inflammatory response (188). Flavonoid supplementation can potentially limit TLR2 methylation, as correlations indicate, and ameliorate $\mathrm{PM}_{2.5}$-induced low frequency HRV. Another study that aimed to address the epigenetic regulation of inflammatory markers by PM exposure utilized young, healthy subjects who inhaled an array of PM compositions ( $\mathrm{PM}_{10}, \mathrm{PM}_{2.5}, \mathrm{PM}_{1.0}$ and $\mathrm{PM}_{0.5}$ ) over two sessions (158). These subjects presented with decreased HRV indicating a stress response, which is consistent with previous studies of PM exposure. Furthermore, $\mathrm{PM}_{2.5}$ as well as quasi-ultrafine particles $<0.50 \mu \mathrm{m}$ were significantly associated with increased pro-inflammatory cytokine (interferon gamma (IFN- $\gamma)$ ) methylation, correlating with alterations in the parasympathetic nervous system as an adaptive response (158). Bind and colleagues however, reported that both $\mathrm{PM}_{2.5} \mathrm{BC}$ and $\mathrm{PM}_{2.5}$ mass concentrations were associated with significantly lower methylation of immunoregulatory genes, IFN- $\gamma$ and intercellular adhesion molecule 1 (ICAM-1) in individuals with low methylation levels prior to exposure (9). The main contributing factor that is likely responsible for these contradictory findings is the population that was studied. While Tobaldini et al. conducted a more controlled experiment with healthy, young males $(n=12)$, Bind et al. utilized a large cohort $(n=777)$ of elderly men with varying health conditions $(9,158)$. Other studies address epigenetic alterations of the cardiovascular system following PM inhalation exposure as well $(99,110)$, though without direct functional associations. Although the studies outlined provide a link between epigenetic mechanisms and cardiac function, specifically HRV, it remains unclear if epigenetic reprogramming is a primary mechanism for sustaining adaptations to PM exposures or if it is transiently changed with exposure. MicroRNA-378A, as well as other microRNAs, are potential molecular mediators of metabolic and cardiac dysfunction that ensue following ENM exposure (65). Nano- $\mathrm{TiO}_{2}$ inhalation exposure induced diastolic dysfunction, E/A ratio elevation, and decreased myocardial performance indices, which were preserved in a microRNA knockout transgenic mouse model (microRNA-378A). The authors pointed to regulation of mitofusin 1 
(Mfn1) expression through microRNA-378A as a mechanism for controlling mitochondrial dynamics following exposure (65). While the preceding studies examined epigenetic changes, the mechanisms of action were not elucidated. Multi-faceted assessments of how pollutants impact the epigenome and inflammation-associated genes are critical as both are implicated in processes mediating cardiovascular function impairment.

Inflammation plays a key role in pollutant exposure response in both individual particulate exposures and multi-component exposures. Co-exposure of sulfur dioxide $\left(\mathrm{SO}_{2}\right)$, nitrogen dioxide $\left(\mathrm{NO}_{2}\right)$, and $\mathrm{PM}_{2.5}$, typical air pollutants produced as a result of coal combustion, results in an enhanced inflammatory response with upregulation of COX-2, inducible nitric oxide synthase (iNOS), TNF- $\alpha$, and IL-6 (184). The co-exposure contributed to decreased blood pressure and increased heart rate when compared to $\mathrm{PM}_{2.5}$ alone. Similarly, IL-6, IL-8, and endothelin-1 (ET1) were significantly associated with rises in carbon monoxide (CO), UFP and $\mathrm{SO}_{2}$ concentrations in healthy individuals near a steel mill (86). The precursor for ET-1 (BET-1) was positively correlated with systolic blood pressure, while C-reactive protein (CRP) was correlated with increased heart rate. Protein ontology revealed a significant elevation of inflammation specific pathways (86). Combined high-dose $\mathrm{PM}_{2.5}$ and ozone exposure also promotes cardiovascular functional injuries that are presented as abnormal electrocardiogram (ECG) results (extended QRS complex and depression of ST-segment) (163). The addition of ozone to the exposure paradigm propagated inflammatory and oxidative stress responses with elevated CRP, IL-6, creatine kinase (CK), lactate dehydrogenase (LDH), and malondialdehyde (MDA). These studies highlight the importance of controlled co-exposure studies for delineating the risk of ambient pollutants and combustion materials on cardiovascular hemodynamics and the associated inflammatory and oxidative stress mechanisms.

Co-exposure to CAPs and acrolein causes myocardial dyssynchrony, though through a less understood mechanism involving the activation of transient receptor potential cation channel A1 (TRPA1), which the authors report may act to increase cardiac risk, specifically in exposures with heterogeneous compositions (157). Along with channel proteins affecting cardiac conduction, modifications in the uptake and clearance of calcium can alter contractility within cardiomyocytes, further dysregulating the cardiac cycle. One of the more studied pathways is through SERCA2a. $\mathrm{PM}_{2.5}$ exposure increased intracellular free calcium $\left(\mathrm{Ca}^{2+}\right)$ that was associated with increased 
ryanodine receptor 2 (RYR2) and decreased SERCA2a, which are responsible for shuttling $\mathrm{Ca}^{2+}$ from the sarcoplasmic reticulum to the cytoplasm and back, respectively (38). The changes in calcium handling may be a direct result of $\mathrm{PM}_{2.5}$-induced oxidative stress, thereby contributing to contractile dysfunction in cardiomyocytes. In response to long-term exposure to $\mathrm{PM}_{2.5}$, others have reported decreased fractional shortening, impaired mitral inflow patterns, depressed contractile reserve, along with decreased peak shortening and relengthening of isolated cardiomyocytes in C57BL/6 mice (170). Downregulation of SERCA2a in $\mathrm{PM}_{2.5}$-exposed mice revealed abnormal $\mathrm{Ca}^{2+}$ cycling, as previously seen, but also elevation of $\beta$-myosin heavy chain ( $\beta$-MHC) indicative of heart failure. Apart from contractility, tone of the vasculature within the heart can alter cardiac hemodynamics. A study of acute and sub-chronic inhalation exposure of Sprague Dawley rats to $\mathrm{PM}_{2.5}$ and $\mathrm{PM}_{0.1}$ separately elevated angiotensin II type 1 receptor $\left(\mathrm{AT}_{1} \mathrm{R}\right)$ mRNA (4). The subchronic exposure to both sizes of $\mathrm{PM}$ further increased $\mathrm{AT}_{1} \mathrm{R}$ protein levels, expression of markers for myocardial adaptive response to damage (actin alpha 1 (Acta1) and Col3a) and IL-6, while decreasing antioxidant heme-oxygenase 1 (HO-1). The authors suggest that angiotensin overexpression can promote coronary artery wall thickness, which is likely to influence blood pressure in exposure models (4). Another study aimed to elucidate the effects of toxicant exposure on the regulation of blood pressure using 12-13 month-old spontaneously hypertensive rats (SHRs), which were exposed to ultrafine carbon particles (UFCP) (159). UFCP inhalation exposure resulted in increased blood pressure and heart rate, which was correlated with increased levels of serum CRP, plasma fibrinogen, and levels of ET-1 in the heart. UFCP exposure-induced hypertension in SHRs is also associated with elevated angiotensin II (AngII) in the blood, with increasing doses of UFCP diminishing the effectiveness of captopril, an angiotensin converting enzyme inhibitor (183). The diminished effectiveness of captopril suggests that increasing doses of UFP, may activate a variety of pathways outside of angiotensin to induce changes in blood pressure. These data suggest that regulation of blood pressure, like other cardiovascular responses, is a multifactorial pathway that is influenced by other circumstances, including genetic makeup and various environmental influences.

One of these environmental influences, high-fat diet feeding, is often used to model hyperlipidemia. Hyperlipidemic rats exposed to $\mathrm{PM}_{2.5}$ are susceptible to higher blood pressure, lower HRV, and higher levels of cardiomyocyte apoptosis, accompanied by decreased expression of antioxidant proteins, including SOD (167). Markedly, high-fat diet exposed mice, compared to 
high fat diet alone, also revealed increased myocardial death through increased levels of cardiac troponin I (cTnI), LDH and CK. Animal models with a high propensity for metabolic dysfunction, such as AMP-activated protein kinase $\alpha 2$ knockout (AMPK $\alpha 2^{-/-}$) mice that lack this crucial gene for fatty acid oxidation, are critical for understanding how $\mathrm{PM}_{2.5}$ inhalation exposure impairs cardiovascular function in vulnerable populations (165). $\mathrm{PM}_{2.5}$ exposure diminished left ventricular ejection fraction in $\mathrm{AMPK} \alpha 2^{-/-}$mice and promoted an oxidative and inflammatory environment through decreased expression of peroxiredoxin 5 (PRDX5), and increased expression of NF-кB and TNF- $\alpha$. These studies highlight the importance of understanding the molecular changes that occur and the downstream effects on oxidative stress regulation in susceptible populations exposed to PM. UFP inhalation exposure in human subjects with metabolic syndrome can be specifically detrimental to cardiac repolarization, as demonstrated by the QRS complexity in those without the glutathione s-transferase mu 1 (GTSM1) protein, a pivotal antioxidant gene (36). In the complete cohort (participants with and without the GTSM1 mutation), UFP exposure elevated CRP and serum amyloid A (SAA) with subsequent decreases in plasminogen and thrombomodulin within blood, indicating an upregulation of inflammatory pathways and the critical role of antioxidant genes. On the contrary, sub-acute exposure to $\mathrm{PM}_{2.5}$ in healthy adults was not correlated with increased inflammatory markers or altered vascular function (17). However, a $10 \mu \mathrm{g} / \mathrm{m}^{3}$ increase in exposure was associated with decreased HRV, correlating to increased homeostatic model assessment of insulin resistance (HOMA-IR). This suggests the possibility that chronic periods of exposure to $\mathrm{PM}_{2.5}$ could reduce insulin sensitivity and thus potentiate susceptibility to diabetes mellitus, though inflammation may not be the etiology implicated by this study (17). Particularly concerning is the notion that in obese mice, chronic exposure to $\mathrm{PM}_{2.5}$ can prevent the beneficial effects of exercise on cardiac function and antiinflammatory pathways (59). Sedentary mice that were exposed to $\mathrm{PM}_{2.5}$ presented with increased left ventricular diameter (systolic and diastolic) that was not ameliorated in the exercised group. Moreover, $\mathrm{PM}_{2.5}$ exposure enhanced CRP, ICAM-1, and vascular cell adhesion protein 1 (VCAM1), which were elevated in the $\mathrm{PM}_{2.5}$ exercised group as well (59). These results are similar to those seen in a previous study that reported the inability of moderate aerobic exercise to provide antiinflammatory protection in mice exposed to $\mathrm{PM}_{2.5}$ (103), which may be linked to expression of heat-shock protein 70 kilodalton (HSP70) $(103,140)$. The advantages of moderate exercise on cardiovascular function in obese mice $(111,126,149)$, but not in obese mice exposed to $\mathrm{PM}_{2.5}$ 
(59), emphasizes the consequential results of $\mathrm{PM}_{2.5}$ exposure in vulnerable populations. However, the use of a high-fat diet induced obesity model may be more relevant in substantiating whether fine particulate exposure hinders the ability of exercise to mitigate the detrimental cardiovascular effects in diabetic models, as the ob/ob model may have impaired exercise capacity (59).

\section{Coagulation}

Within the lungs, the circulatory system provides a necessary pathway for mediation of the inflammatory response. Due to this close association of the pulmonary and circulatory systems, changes arising in blood have the potential to alter homeostasis within blood vessels. Alterations in the coagulation pathway, specifically through fibrinogen, have been reported following PM exposure.

Levels of a pollutant from wood smoke, Delta-C, are positively correlated with fibrinogen and negatively correlated with myeloperoxidase (MPO), an enzyme involved in the inflammatory pathway and platelet activation (32). The study also demonstrated that $\mathrm{PM}_{2.5}$ and UFP retain a positive correlation with fibrinogen as well as CRP, sharing a similarity in the effects on blood coagulation with effects of Delta-C. In a co-exposure model of SiNPs and lead acetate $(\mathrm{Pb})$, Feng et al. reported alterations to the blood clotting cascade evidenced by decreased tissue-type plasminogen activator (t-PA), tissue factor pathway inhibitor (TFPI), and antithrombin III (AT III), as well as elevated fibrinogen and D-dimer (D2D) (48). Following co-exposure, serum analyses revealed leukocytosis and thrombocytopenia, concomitant with increased expression of inflammatory markers (CRP, IL-6, and TNF- $\alpha$ ) and markers of heart failure (ANP and BNP). Overlap found between studies of varying particle sizes can help identify critical biomarkers of increased blood clotting that are a product of multi-component exposure in both human and animal models. Furthermore, others have shown that levels of fibrinogen can be increased by other ambient air pollution constituents (8). Specific associations between $\mathrm{PM}_{2.5} \mathrm{BC}$ and altered epigenetic modification status of tissue factor III (F3) were later reported by this group, indicating alterations to extrinsic blood coagulation (10). Decreased methylation of F3, which likely leads to increased transcription of the gene, can provide the initial stimulus for altering the response of thrombin and fibrinogen thereby increasing coagulation (29). Similarly, in a meta-population study, including 3275 participants, long-term rises in $\mathrm{PM}_{2.5}$, but not $\mathrm{PM}_{0.1}$, were matched with 
significantly increased CRP and platelet count (160), suggesting an increased propensity for blood clotting.

Interestingly, annual average UFP exposure levels and fibrinogen were negatively associated, though not significantly, in human blood samples (90), which may have been a result of micro-environment compared to ambient concentrations. To better elucidate the dynamic relationship between ambient exposure and the time/concentration of the exposure in terms of their effects on the cardiovascular system, Lane et al. examined biomarkers in patients with varying levels of microenvironment exposures (time-activity adjusted) in addition to the annual average particle number concentration of UFPs. There were significant positive associations between time/concentration of exposure and inflammatory pathway genes in blood, including CRP and tumor necrosis factor receptor 2 (TNFR2) (90). These findings illustrate the significance of monitoring personal exposure levels, which may account for the differences seen in fibrinogen expression between studies that solely use annual outdoor particle concentrations and those that consider varying levels of individual microenvironment exposure. Modifying the coagulation pathway in individuals who are continuously exposed to high levels of pollutants through ambient air may provide a potential a potential prophylactic strategy to prevent the inevitable high risk of CVD. Nootkatone, a sesquiterpenoid in grapefruit has potential as a pretreatment strategy for $\mathrm{PM}_{2.5}$ diesel exhaust exposure through its ability to reduce blood clotting by decreasing plasminogen activator inhibitor-1 (PAI-1) and fibrinogen, and restoring thrombotic occlusion time in arterioles (114). The authors suggest that the pretreatment strategy activated nuclear factor erythroid-derived 2-like 2 (NRF2), which plays a key role in initiating HO-1, to provide protection from oxidative injury (114). While the studies discussed thus far have primarily utilized healthy cohorts, it is important to understand how the coagulation pathway is altered in at-risk populations as well. Elemental carbon UFP inhalation exposure modifies platelet activation in type 2 diabetic patients by increasing CD40 ligand (CD40L) expression in platelets, with a resulting decrease in soluble CD40 (sCD40) in blood (147). Higher CD40L levels, as a result of UFP exposure, exerted a stimulatory role on von Willebrand factor (vWF) and elevated its expression. Though this study revealed the adaptations of those with diabetes mellitus, it did not provide a control cohort to elucidate whether these effects of PM on coagulation are exaggerated in the at-risk population. Nonetheless, genes involved in the activation of pathways involving fibrinogen and platelet 
activation are potential early biomarkers of increased CVD risk in healthy and vulnerable populations and require further clarification.

\section{Vascular Dysfunction}

Along with mediating the blood clotting cascade, particulate exposure has the capacity to modify the integrity of vascular tissue, thus interfering with blood flow and cellular metabolism directly within the vasculature. Through direct damage to the vasculature, or mediation of the inflammatory response, particulate matter can cause blood vessels to become predisposed to ultrastructural changes. Atherosclerosis, which involves the build-up of fatty acids and cholesterol within the intima layer of arteries, is linked to PM exposure.

In an atherosclerotic transgenic mouse model $\left(\mathrm{ApoE}^{-/-}\right), \mathrm{PM}_{2.5}$ exposure causes cardiac autonomic nervous system dysfunction concomitant with oxidative stress (123). Of note, the highfat diet fed, atherosclerotic mice displayed a greater proclivity for oxidative damage, suggesting, once again, the impairment of cellular protective mechanisms in those who already have an altered metabolic profile. Similarly, concentrated $\mathrm{PM}_{2.5}$ exposure significantly altered high-density lipoprotein (HDL) anti-oxidant and anti-inflammatory capacity (HDL oxidative index (HOI)), along with increased systolic blood pressure (132). However, ozone exposure in addition to the $\mathrm{PM}_{2.5}$ exposure in this study did not exacerbate these effects, suggesting that short-term CAP and ozone co-exposure may not induce overt changes that are suggestive of atherosclerosis progression. On the other hand, long-term CAP exposure does contribute to the progression of atherosclerosis. Rao, et al. discovered that $\mathrm{PM}_{2.5}$ exposure increased abnormal accumulation of an oxidized variant of cholesterol, 7-ketocholesterol (7-KCh), in macrophages and the aortic wall (133). $\mathrm{PM}_{2.5}$-exposed mice also presented with increased CD36 expression in plaquemacrophages, implicating CD36 in the accumulation of oxidized lipids, promoting atherogenesis. By reducing the number of CD36-positive macrophages, internalization of 7-KCh can be limited and therefore the oxidized lipids can be efficiently cleared from the vasculature (133). Along with altered macrophage clearance, other immune responses have been implicated in vascular maladaptation following particle exposure including changes to the innate immune response. ENM inhalation exposure resulted in translocation of nanomaterials to the heart, which initiated the complement cascade, setting off a local immune response, indicated by global complement factor 
3 (C3) upregulation in the blood (77). This study demonstrates that alterations to the innate immune response may be a direct effect of translocated particles, but both studies $(77,133)$ highlight the importance of the inflammatory response and part of its role in altering vascular function. $\mathrm{PM}_{2.5}$ exposure can impact vascular endothelial cell permeability pathways by causing an inflammatory response, which is a hallmark of increased vascular permeability. A recent study has demonstrated that long-term changes in vascular permeability are promoted specifically by IL- 6 and sustained in-part by STAT3 phosphorylation (1). In rats, $\mathrm{PM}_{2.5}$ exposure induced phosphorylation and subsequently expression of STAT3, which upregulated microRNA-21 expression (33). Increased microRNA-21 expression reduced tissue inhibitor of metalloproteinase 3 (TIMP3) expression and enhanced matrix metalloproteinase 9 (MMP9) expression. Ultimately, vascular endothelial dysfunction was linked to extracellular matrix remodeling propagated by STAT3 (33), which was likely promoted by the PM-induced inflammatory response. Changes in the composition of the vascular matrix could result in alterations to immune cell binding and further changes to diapedesis leading to vascular dysfunction.

In a 3820 non-current smoking patient population that was part of the Framingham Heart Study, acute $\mathrm{PM}_{2.5}$ and $\mathrm{BC}$ exposure concentrations were inversely correlated with expression of P-selectin, suggesting decreased endothelial-surface cell adhesion (97). Along with changes to vascular structure, the ability for the endothelium to regenerate and adapt to pollutant exposure can be compromised. Typically, this occurs through the production of endothelial progenitor cells (EPCs) in response to vascular injury (50). However, $\mathrm{PM}_{2.5}$ exposure diminishes circulating EPC levels, which may occur as a result of vascular endothelial growth factor (VEGF)-induced Akt and endothelial nitric oxide synthase (eNOS) phosphorylation $(50,62)$. Short-term CAP exposure in mice fed a control diet remarkably induced vascular insulin resistance, indicated by decreased Akt phosphorylation, and suppressed circulating levels of EPCs through activation of the NF- $\mathrm{KB}$ inflammatory pathway (63). Increasing insulin sensitivity prevented activation of these pathways, substantiating that $\mathrm{PM}_{2.5}$ exposure can lead to insulin resistance and therefore type 2 diabetes in healthy populations (50). Furthermore, CAP-induced vascular insulin resistance was accompanied by increased vascular oxidative stress marked by mitochondrial SOD2 and glutathione stransferase-P (GST-P) mRNA levels, and expression of protein-HNE adducts (63). Interestingly, 9-day CAP-exposure did not exacerbate high-fat diet induced changes in vascular insulin resistance (63), but a 30-day CAP exposure significantly aggravated systemic insulin resistance, 
elevating glucose intolerance and HOMA-IR in high-fat diet-fed mice (64). In aortic tissue, both 9-day and 30-day CAP exposures resulted in decreased insulin-stimulated phosphorylation of Akt

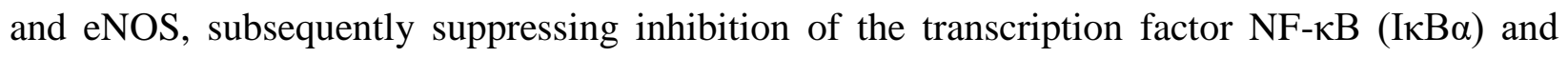
promoting an inflammatory response (64). By treating with an antioxidant, 4-hydroxy-2,2,6,6tetramethylpiperidine-1-oxyl (TEMPOL), CAP-induced inflammation and the associated vascular insulin resistance were alleviated in high-fat diet fed mice leading to the conclusion that short-term exposure to $\mathrm{PM}_{2.5}$ triggers a pulmonary oxidative stress response that is able to elicit downstream vascular insulin resistance and inflammation (64).

Compounding environmental factors can further propagate the effects of particulate exposure. A study in type 2 diabetic Boston residents provided evidence that both $\mathrm{PM}_{2.5}$ and $\mathrm{BC}$ are significantly associated with increased VCAM-1 and vWF in participants who have smoked in the past (118). These data indicate that prior exposure to smoking-related particulates, may exacerbate the inflammatory response seen with ambient $\mathrm{PM}_{2.5}$ exposure, creating a greater risk for endothelial dysfunction and cardiovascular damage in type 2 diabetic patients. In an attempt to directly assess the physiological impact of $\mathrm{PM}_{2.5}$ exposure on vasculature in a CVD at-risk population, Riggs et al. assessed individuals' reactive hyperemia index as a measure of endothelial function (135). Increasing concentrations of $\mathrm{PM}_{2.5}$ significantly reduced the reactive hyperemia index and were associated with angiogenic signaling and inflammation markers, angiopoietin 1, placental growth factor (PIGF), VEGF, ICAM-1, and MMP9 and negatively associated with VCAM-1 and urinary F2-isoprostane (Isop), a measure of oxidative stress (135). Interestingly, incremental increases of $\mathrm{PM}_{2.5}$ by $10 \mathrm{ug} / \mathrm{m}^{3}$, were also associated with increased pro-inflammatory cytokines including, monocyte chemoattractant protein 1 (MCP-1), macrophage inflammatory protein $1 \alpha / \beta(\mathrm{MIP}-1 \alpha / \beta)$ and IFN $\gamma$-induced protein 10 (IP-10) in a cohort of young, healthy individuals with low CVD risk (127). Together, these studies indicate that $\mathrm{PM}_{2.5}$ initiates changes in cytokines and growth factors, which lead to endothelial injury and an immune response that may result in acute cardiovascular events in both high-risk and low-risk CVD populations (127, 135). Furthermore, $\mathrm{PM}_{2.5}$ exposure, in a subset of the same cohort, revealed an inverse association with ET-1, but a positive association with platelet factor 4 (PF-4) (51). Additionally, ET-1 was negatively associated with PF-4 following $\mathrm{PM}_{2.5}$ exposure, which the authors conclude may be the result of an anti-angiogenic effect of the exposure that could also suppress endothelial repair (51, 127). Though this is contrary to previous studies reporting positive correlations between PM and 
ET-1 (48, 86, 184), another acute exposure reported similar findings (56). Conversely, chronic exposure paradigms appear to cause elevated ET-1 levels $(48,86,184)$. Current literature provides convincing evidence that particulate matter exposure causes a remarkable maladaptive vascular response that can lead to increased risk of CVD. However, understanding the genome-wide effects of exposure may provide a better understanding of the molecular mechanisms that are responsible for these alterations.

\section{Cellular Stress and Death}

PM inhalation exposure-induced changes to the cardiovascular system can eventually trigger cell death pathways through varying mechanisms including oxidative stress (94). These pathways include apoptosis and necrosis, leading to programmed or uncontrolled cell death and subsequently cardiovascular hypertrophy.

One of the mechanisms that initiates the cell death pathways is damage to nuclear DNA. Assessment of blood from trucking industry participants revealed that 48 (elemental carbon (EC)), 260 (organic carbon (OC)), and $49\left(\mathrm{PM}_{2.5}\right)$ differentially regulated genes were associated with each of the exposure; these expression profiles implicate genes regulating apoptosis, DNA and metal binding, and chronic heart and lung disease pathways (30). Consistent with these findings, exposure to $\mathrm{PM}_{2.5}$ containing polycyclic aromatic hydrocarbons (PAHs), increased DNA damage and DNA damage response genes in a rodent model (186). These genes included 8-oxoguanine DNA glycosylase (OGG1) and growth arrest and DNA damage 153 (GADD153). PM exposure also altered genes involved in ROS regulation (glutathione S-transferase (GST) and SOD) (186). An increased expression of GST and decreased expression of SOD may promote a high oxidative environment with reduced ability to scavenge ROS, which may help propagate the effects of DNA damage. NOX4 is a prominent contributor of oxidative stress in the failing heart, and is associated with initiating increased DNA damage through this mechanism (89). $\mathrm{PM}_{2.5}$ exposure in mice enhances not only inflammatory markers as previously reported (TNF- $\alpha$ and IL-1 $\beta$ ), but also myocardial apoptosis, NOX4, and NOX4 associated subunits, suggesting that the progression of cardiovascular disease may be dictated by ROS generation and the modification of antioxidant protein-levels, which are initially regulated by $\mathrm{PM}_{2.5}$ exposure (173). While unregulated levels of ROS may function through multiple pathways to cause cell death, programmed cell death through 
apoptosis has been linked to PM inhalation exposure through other channels. Hyperlipidemic rats exposed to $\mathrm{PM}_{2.5}$ are more prone to cardiac apoptosis (167) that is mediated through c-Jun $\mathrm{NH}_{2}-$ terminal kinase (JNK), P53 phosphorylation and downstream activation of (Bcl-2-associated X) Bax and Caspase-3 (167). The expression of both GST and JNK are modified following PM exposure, which implies the presence of an overlap among these pathways that mediate apoptosis as previously suggested (55). Similar results are seen in other vulnerable models such as mice that were challenged with myocardial infarction (98). PM inhalation exposure exacerbated left ventricular dysfunction and increased infarct size, with increased myocardial apoptosis through Caspase-3, Bax and B-cell lymphoma 2 (Bcl-2). Moreover, PM exposure may not immediately stimulate cell death, but rather result in reprogramming of the cell, making it susceptible to future insult. One way reprogramming may be occurring is through changes in microRNAs, which are associated with $\mathrm{PM}_{2.5}$, but not UFP, in the blood of individuals residing in multiple urban regions (43). Specifically, $\mathrm{PM}_{2.5}$ is correlated with increased hsa-miR-197-3p and hsa-miR-99a-5p, which play roles in cell death and cancer $(43,180)$. $\mathrm{PM}_{2.5}$ inhalation exposure was also linked to microRNAs involved in cardiovascular function, including decreased expression of microRNA133a, 145-5p and 499a-5p in plasma (84). Overall, these studies outline some of the potential mechanisms that initiate myocardial apoptosis and eventually lead to cardiovascular abnormalities due to particulate exposure.

\section{Mitochondrial Bioenergetics and Ultrastructure}

In the cardiovascular system, slight perturbations to mitochondrial health could result in significant detriments and sustained pathology. The energy needed for the heart to contract is derived primarily through oxidative phosphorylation of mitochondrion ( 95\%) (189). Alterations to mitochondrial function are therefore implicated as a primary pathway for cardiovascular dysfunction and disease (117).

The integrity of mitochondrial DNA defines its respiratory potential, allowing for separation of individuals into a variety of haplogroups (138). Ambient air pollution has the potential to differentially effect individuals with diverse haplotype backgrounds (169).

Haplogroup H (high ROS production) compared to haplogroup U (low ROS production) is more susceptible to quasi-ultrafine particle $<0.25 \mu \mathrm{m}$ exposure. Quasi-ultrafine particle exposure 
induced inflammation to a greater extent in haplogroup $\mathrm{H}$ than $\mathrm{U}$, demonstrated by increased IL6 and TNF- $\alpha$ (169). Furthermore, high doses of $\mathrm{PM}_{2.5}$ result in cardiac mitochondrial ultrastructure (size and cristae formation) changes in addition to increased inflammation (95). These ultrastructural changes are supported by increases in mitochondrial fission 1 (FIS1), MFN1, MFN2, dynamin-related protein 1 (DRP1), and mitochondrial dynamin like GTPase (OPA1), which suggest alterations to the fission/fusion pathway (95). UFP exposure has also been linked to mitochondrial dysfunction (70). Exposure to UFP exacerbated ischemia/reperfusion damage in the isolated hearts of rats. Isolated cardiac mitochondria of UFP-exposed rats displayed decreased $\mathrm{Ca}^{2+}$ buffering prior to the mitochondrial permeability transition pore (mPTP) opening, which indicates that exposure can increase $\mathrm{mPTP} \mathrm{Ca}^{2+}$ sensitization and therefore mitochondrial permeability (70). The alterations to fission/fusion proteins (95) and mitochondrial permeability (70) showcase changes to the composition and functionality of mitochondrion following exposure, which can propagate oxidative damage and initiate mPTP-associated cell death pathways to instigate cardiac damage. A single dose of ENM through inhalation exposure in mice, has the ability to trigger cardiac functional changes and mitochondrial dysregulation (116). However a transgenic mouse model for mitochondrial phospholipid hydroperoxide glutathione peroxidase (mPHGPx) was used to restore cardiac function, mitochondrial respiratory function, and abrogate ROS levels following nano- $\mathrm{TiO}_{2}$ exposure. By increasing antioxidant defense through mPHGPx overexpression, proteomics revealed that changes in mitochondrial composition, including individual electron transport chain complex constituents, were protected from the detrimental effects of exposure (116). This study further validates the importance of antioxidant protection in preservation of mitochondrial structure and function, and should therefore be investigated as a potential protective approach.

PM exposure can modify the transcriptional capacity of the mitochondrion and likewise incite dysfunction through this approach. Boilermakers exposed to $\mathrm{PM}_{2.5}$ were utilized in a study that aimed to elucidate the exposure-induced changes in methylation of mitochondrial DNA (19). Methylation of specific mitochondrially transcribed genes involved in ATP synthesis, including mitochondrially encoded tRNA phenylalanine (MT-TF) and mitochondrial 12s RNA (MT-RNR1), were not associated with $\mathrm{PM}_{2.5}$ exposure. However, methylation of the mitochondrial promoter DLoop was associated with $\mathrm{PM}_{2.5}$ exposure. Participants with mitochondrial DNA hypermethylation were more vulnerable to the effects of $\mathrm{PM}_{2.5}$ exposure on HRV (19). Inhalation of toxicant particles 
may exert its effects on overall mitochondrial structure and function, and thus cardiovascular function, through ROS regulated and inflammatory pathways as the preceding studies indicate. Both increased inflammation and ROS have the ability to recruit methyltransferases, such as DNA methyltransferase 1 (DNMT1), and alter the methylome of various genes implicated in CVD, causing repression of the associated genes (83).

Though the molecular mechanisms behind cardiovascular impairment associated with particulate matter exposure vary based on the particle size, constituents, and physiochemical properties, there are common overlapping genes that appear to be modulated by multiple toxicants present in air pollution. Figure 1.2, created using Ingenuity Pathway Analysis (IPA), provides an interaction network of genes that are dysregulated following particulate inhalation exposure. IPA included genes that were upregulated, downregulated, or had diverse expression following more than one type of particulate exposure mentioned throughout this review. These genes can serve as potential early biomarkers of cardiovascular damage as a result of inhaled toxicant exposure. 
Figure 1.2: Ingenuity Pathway Analysis (IPA).

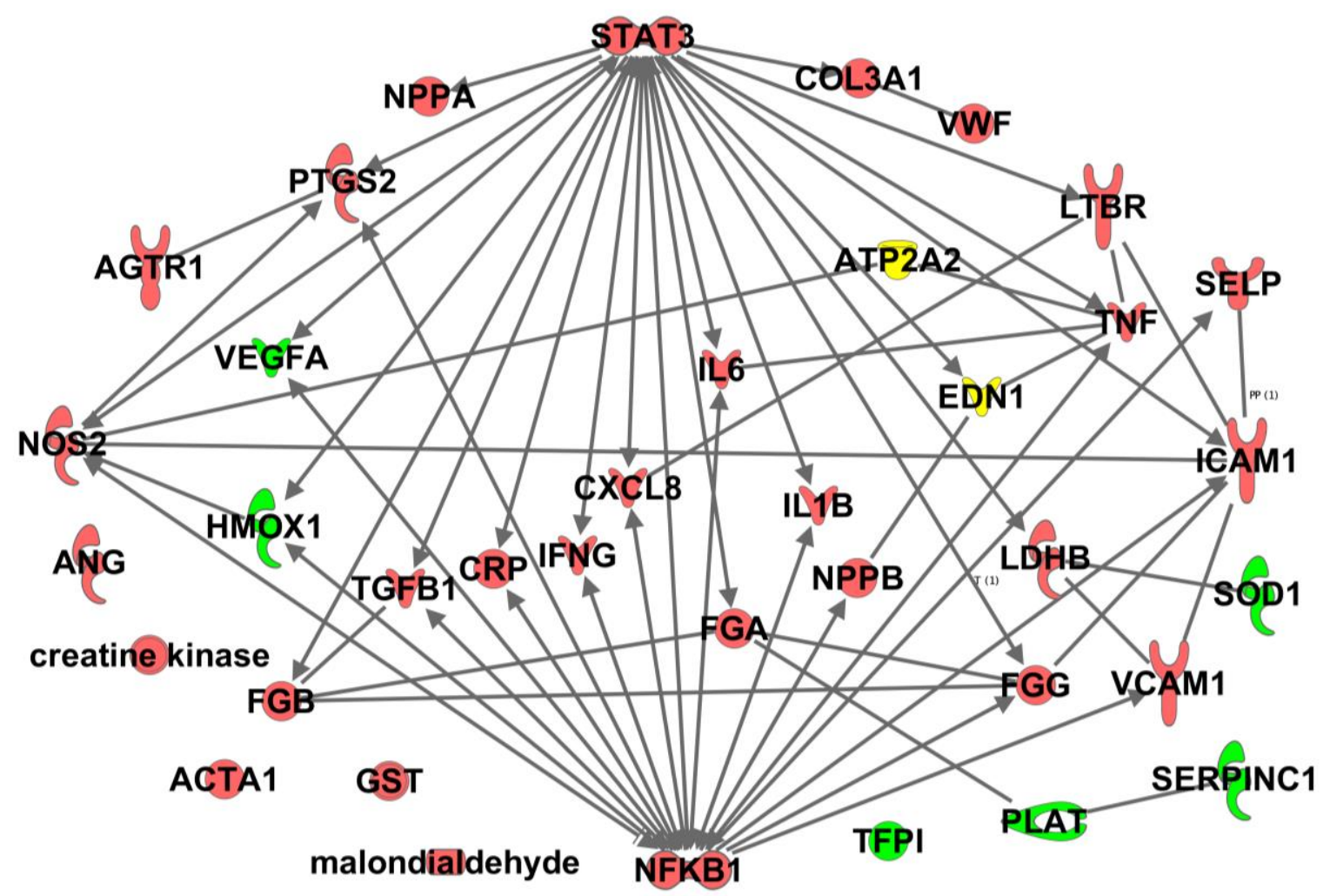

Figure 1.2: Ingenuity pathway depicting the interaction network of genes that are dysregulated following particulate inhalation exposure. The genes included in the interaction network were associated with more than one type of particulate exposure. The interactions represent direct, validated experimental associations between genes that were increased (red), decreased (green), or found to have a diverse expression profile (yellow) following exposures. All abbreviations are defined in the Abbreviations section provided.

\section{Gestational Exposures}

There has been an increasing volume of literature investigating how particulate exposure can affect vulnerable populations, including women during pregnancy. Due to the coinciding metabolic changes prompted by both diabetes/obesity and air pollution, particularly related to oxidative stress and inflammation, understanding the dynamics of both pathologies is critical in determining how pollutant exposure can alter the metabolome (117). Particulate exposure during gestation is a major risk-factor for gestational diabetes $(105,179)$. However, the effects of pollutant insult in utero on the offspring remain a critical gap in knowledge $(11,78,100)$. This is particularly 
concerning for fine and ultrafine particles that have the ability to enter circulation and reach the fetal side of the human placenta (12). Recent studies indicate that maternal toxicant inhalation exposure during gestation is a predisposing factor for CVD in offspring.

\section{Oxidative Stress and Inflammation}

$\mathrm{PM}_{2}$ exposure results in activation of oxidative and inflammatory pathways, as has been described in the previous sections. Preconception toxicant exposure, predisposes future offspring to the development of cardiac dysfunction (153). $\mathrm{PM}_{2.5}$ preconception exposure in both parents decreases ejection fraction, fractional shortening, and cardiomyocyte contractility in 3-month old progeny (153). Inflammatory and oxidative pathways are thereby activated, resulting in increased IL-6, IL-15, NFқB, and CRP along with elevated fibrosis (Col3a1), similar to the results found in many direct exposure studies. Notably, calcium handling proteins, SERCA2a and phosphorylated phospholamban (p-PLN) are elevated in preconception $\mathrm{PM}_{2.5}$ exposed offspring, as increased p-

PLN loses its ability to inhibit SERCA2a. While PM-induced inflammation and oxidative stress are common in both direct and preconception exposures, SERCA2a is contrarily decreased in direct exposures $(38,170)$. One potential reason for this discrepancy may be that preconception exposure results in an adaptive response. Similar to direct and preconception exposure, $\mathrm{PM}_{2.5}$ exposure during gestation also results in cardiac remodeling with associated inflammation (increased IL-6 and IL-1ß) (155). Furthermore, extracellular matrix remodeling, marked by increased collagen-1, MMP9, and MMP13 expression, is also present in neonates following gestational exposure, but was not assessed into adulthood. Nevertheless, long-term maternal exposure to $\mathrm{PM}_{2.5}$, throughout gestation and lactation, enhanced activation of the inflammatory markers and myocardial apoptosis in both neonatal and weanling Sprague Dawley rats (27). UFP exposure to pregnant $\mathrm{C} 57 \mathrm{BL} / 6 \mathrm{~J}$ dams led to fetal reabsorption and increased blood pressure in adult progeny (109). Increases in maternal serum inflammation during gestation, along with $\mathrm{AT}_{1} \mathrm{R}$ and angiotensin I-converting enzyme (ACE) activation in the lungs are suggested to contribute to progeny cardiovascular dysfunction both short and long-term. The notion that maternal and paternal exposure activates an inflammatory response in progeny from early life into adulthood is therefore well established, but whether the changing maternal environment (109), particle 
translocation, or a combination of such factors are culpable in altering progeny development and metabolic function remains elusive.

In addition to inflammatory pathways, immune responses and oxidative stress pathways are changed in progeny who are exposed during gestation. Challenging progeny immune systems with house dust mite (HDM) allergen revealed a decreased immune response through lower IL-13 and IL-17, with higher serum levels of IL-10 following UFP exposure (139). This has also been demonstrated with UFP containing persistent free radicals (MCP230), which suppressed the T helper and T regulatory cells found within the lungs of offspring (166). Maternal ENM exposure during gestation may however, modulate a regulatory axis involving enhanced hypoxia inducible factor (HIF)-1 $\alpha$ activity and decreased mPHGPx expression, which are critical in the regulation of ROS in fetal and young adult cardiac development (87). Understanding how gestational exposure, as opposed to direct exposure, effects individuals will contribute in the development of preventative measures for vulnerable populations, including pregnant women and children, and promote safer limits of exposure thereby mitigating susceptibility to metabolic diseases and CVD in offspring.

\section{Cellular Function}

Calcium regulated contraction is significantly affected throughout development in progeny exposed to particulate matter during gestation. Assessment of fourteen-day old progeny whose dams were exposed to $\mathrm{PM}_{2.5}$ during gestation, revealed decreased cardiomyocyte contractility through calcium dynamics, with changes to proteins involved in calcium flux in the heart, SERCA2a, p-PLN, $\mathrm{Na}^{+} / \mathrm{Ca}^{2+}$ exchanger (NCX), calcium channel, voltage-dependent, L type, and alpha 1C subunit (CaV1.2) (154, 155). Offspring whose dams were exposed during gestation also present with major cardiac anomalies present into adulthood as a result of ENM-induced mitochondrial dysfunction. Nano- $\mathrm{TiO}_{2}$ gestational exposure decreased diastolic cardiac function, marked by a $15 \%$ increase in E/A ratio, and diminished mitochondrial respiration in young adult progeny (66). These results were simultaneous with mitochondrial proton leak and increased uncoupling protein 2 (UCP2), as well as upregulation of mitochondrial metabolism proteins, carnitine palmitoyltransferase 1A (CPT1A) and pyruvate dehydrogenase (PDH) phosphorylation. ENM exposure during gestation also affects mitochondrial bioenergetics by limiting state 3 respiration 
in the left ventricle of young adult progeny, coinciding with impaired endothelium dependent dilation in coronary and uterine arterioles (145). $\mathrm{PM}_{2.5}$ gestational exposure can trigger myocardial apoptosis in a dose-dependent manner, as has been revealed in one day-old neonatal offspring from Wistar rats (164). Myocardial cell death likely occurred due to alterations in mitochondrial fission/fusion through OPA1, MFN1, DRP1, and FIS1 following $\mathrm{PM}_{2.5}$ exposure during gestation (164). Utilizing functional genomics in addition to mitochondrial structural and bioenergetic assessment, may provide insight into the mechanisms driving the deficits observed in progeny whose dams were exposed to particulate matter during gestation.

\section{Epigenetics and Transcriptional Regulation}

Studies in progeny exposed to particulate exposure during a critical point in development such as gestation, reveal that cellular regulatory networks are substantially altered, likely contributing to sustained detrimental effects into adulthood. These regulatory systems include epigenetic remodeling as well as non-coding RNA networks, which can act to reprogram the basal cellular function in progeny and cause predisposition to metabolic disorders that modulate analogous pathways. Maternal $\mathrm{PM}_{2.5}$ exposure during gestation can promote long-term cardiac remodeling and causes cardiac hypertrophy in young adult progeny, with an increase in both total histone acetylation and promoter acetylation of hypertrophy genes, GATA4 and myocyte enhancer factor 2C (Mef2c) (174). This further suggests the ability of gestational PM exposure to induce global epigenetic remodeling through transcriptional activation of acetylated regions in offspring. Supporting these findings, multiple additional studies have reported a cardiac hypertrophic/fibrotic phenotype, cardiac functional changes, and epigenetic reprogramming in early development due to gestational PM exposure $(153,155,174)$. Preconception exposure in both parents to $\mathrm{PM}_{2.5}$ resulted in progeny with decreased ejection fraction, fractional shortening, and cardiomyocyte contractility at twelve weeks of age (153). Epigenetic assessments suggested changes that were indicative of reprogramming induced by the particulate exposure, with decreased expression of the maintenance methyltransferase DNMT1, but increased histone deacetylase sirtuin (SIRT) 1/2. This pattern of expression may be explained by the ability of SIRT to regulate DNMTs and alter their activity. Similar to preconception exposure, $\mathrm{PM}_{2.5}$ exposure during gestation also impaired cardiac function of progeny at twelve weeks of age, revealed by decreased fractional shortening and left 
ventricular posterior wall thickness, and increased left ventricular systolic/diastolic diameters and collagen deposition in cardiac tissue (155). Epigenetic regulation likely contributed substantially to persistent cardiac detriments as seen in the preceding study. In contrast with preconception PM exposure (153), gestational exposure decreased SIRT1/2 and increased DNMT1, DNMT3a, and DNMT3b expression (155). Although there are differences in expression profiles of these epigenetic regulators that likely stem from the time of exposure (preconception vs. gestation), both are representative of profiles that can cause sustained biological detriments and/or susceptibility to pathologic insult. ENM inhalation exposure during gestation causes similar changes to DNA methylation machinery (87). Maternal exposure to nano- $\mathrm{TiO}_{2}$ during gestation decreases cardiac output and increases left ventricular mass with a subsequent decrease in fractional shortening in progeny. These functional alterations were linked to elevated levels of 5-methylcytosine (5-mC), a marker of global DNA methylation, DNMT1 protein expression, and HIF-1 $\alpha$ activity (87). Along with DNA methylation, changes in the histone composition of DNA can contribute to modified gene expression profiles. Chromatin immunoprecipitation sequencing for histone 3 lysine 4/27 trimethyaltion ( $\mathrm{H} 3 \mathrm{~K} 4 \mathrm{me} 3$ and $\mathrm{H} 3 \mathrm{~K} 27 \mathrm{me} 3)$, coupled with the transcriptomic profiling of fetal cardiac tissue from dams exposed to ENM during gestation, has revealed significant changes to major pathways including immune adaption and organismal growth (143). The authors suggest that cardiovascular outcomes at the young adult stage may actually be linked to liver and fetal development, evidenced through IPA protein ontology. MicroRNAs have also been implicated in metabolic changes in offspring as a result of gestational particulate exposure (57). Diesel exhaust exposure in utero decreased methylation of microRNA133a-2 at the promoter region in isolated neonatal cardiomyocytes (57). As the progeny aged, introducing stress, such as transverse aortic constriction, enhanced microRNA-133a-2 and decreased protein tyrosine phosphatase receptor type F (PTPRF) and peptidase domain containing associated with muscle regeneration 1 (PAMR1) expression, which mediate adult sensitivity to heart failure by inducing pathologic hypertrophic signaling or preventing antihypertrophic signaling (57). Currently longitudinal studies on the effects of maternal exposure to various pollutants on offspring cardiovascular function are limited. Figure 1.3 provides a summary of the factors involved in epigenetic regulation that have been discussed in this review, in the context of preconception/gestational particulate inhalation exposure. Functional genomics studies that combine transcriptomic, proteomic, and metabolomic data in cohorts presenting with particulate-induced cardiovascular alterations will provide a more 
thorough understanding of early epigenetic remodeling and its involvement in contributing to CVD predisposition later in life.

Figure 1.3: Epigenetic Alterations.

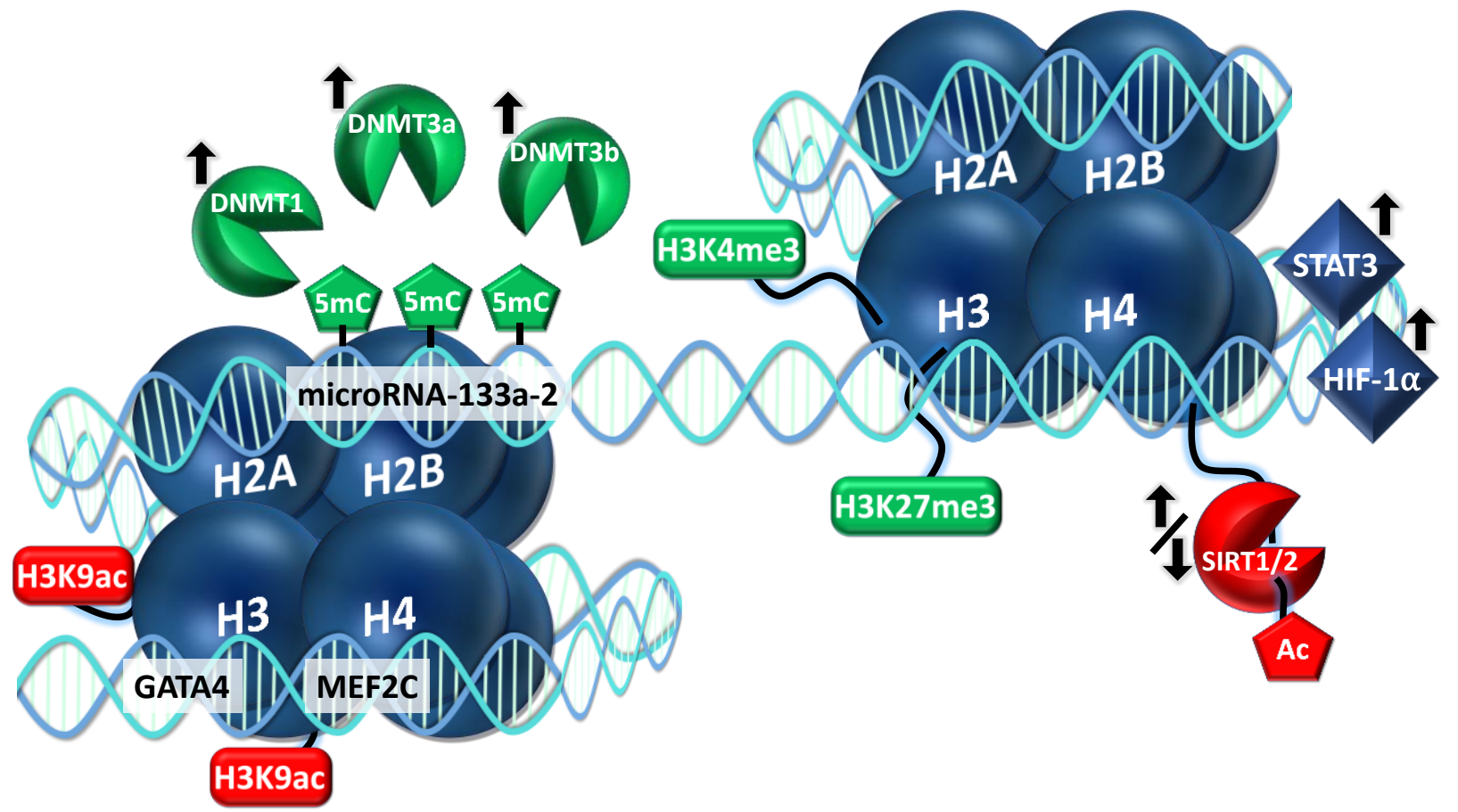

Figure 1.3: Epigenetic alterations observed following gestational and/or preconception particulate inhalation exposures. Gene expression of GATA4 and MEF2C are increased through promoter acetylation at H3K9. MicroRNA133a-2 expression is repressed through elevated 5mC. DNA methyl transferases (DNMT1, DNMT3a, and DNMT3b) are all increased following exposure, along with increased expression of transcription factors (STAT3 and HIF-1 $\alpha$ ). H3K4me3 and H3K27me3 alterations are observed at promoter regions throughout the genome. The histone deacetylases, SIRT1/2, reveal a dysregulated expression profile in progeny exposed during gestation. All abbreviations are defined in the Abbreviations section provided.

\section{Future Directions}

From a morning commute, to an occupational setting, to our very homes, exposure to particulates remains a central issue for debate and therapeutic/lifestyle interventions. 
Industrialization and increased urbanization will continue to exacerbate issues concerning air quality and human health, unless better defined guidelines and limits are introduced. Although we provide a summary of the molecular mechanisms propagating cardiovascular decline following exposure in human and animal models, areas of research that are crucial in driving the field of molecular inhalation cardiovascular toxicology forward, still remain uncharted. Future investigations should aim to address understudied populations.

There are limited studies investigating whether increased particulate matter exposure is associated with higher rates of cardiac arrest. One study that aimed to assess this association in New York City reported that a $10 \mu \mathrm{g} / \mathrm{m}^{3}$ increase in $\mathrm{PM}_{2.5}$ one day before and day of the event significantly increased the relative risk for a cardiac arrest in the warm season (141). Similar results were seen in Melbourne (35), Copenhagen (168), Indianapolis (137), and Houston (42). Contrarily, a study done in Stockholm (134) and several studies by a group in Washington $(25,92,151)$, report no association between PM exposure and out-of-hospital cardiac arrests. Nonetheless, due to the high mortality rate associated with cardiac arrests, future studies should attempt to further clarify these associations through assessment of molecular markers.

There has been a growing body of literature exploring the adverse outcomes of PM exposure during gestation, including associations with metabolic dysregulation and cardiovascular deficits. In addition to a necessity for a better understanding of how particles induce specific changes during embryonic and fetal development, evaluation of the long-term effects is essential. This is particularly important for determining whether particulate exposure during gestation elicits alterations to the epigenome of offspring that can cause increased susceptibility to prevalent metabolic disorders, including diabetes mellitus (100). Notably, recent research has revealed the ability for prenatal and perinatal PM exposure to alter glucose metabolism (108) and elevate lowdensity lipoprotein cholesterol (LDL-C) (104), suggesting an increased risk of diabetes and atherosclerosis. However, the molecular mechanisms were not evaluated. In order to address these gaps in knowledge, focus must turn to the epigenetic effects following particle exposure during intrauterine and early childhood development concomitantly with metabolic assessments, which are currently meager $(49,78)$.

As we continue to shift the paradigm of cardiovascular research in inhalation toxicology, much of the cellular and molecular mechanisms are yet to be discerned. Cell culture models of 
exposure interactions can help provide a foundational understanding of cell and organelle function that cannot be fully captured through in vivo inhalation studies. While it remains outside the scope of this review, in vitro models can provide a very granular, and controlled approach to mechanistic evaluations. Of note, authors have recently investigated the effects of $\mathrm{PM}_{2.5}$ exposure (20, 34, 46, $73,177,178,184)$, as well as the toxicology of nanomaterials and advanced materials $(47,75,76$, 176) in cells. Additionally, in vitro studies can provide preliminary data for determining how complex and dynamic mixtures of particulate and gaseous substances affect cardiomyocytes, establishing potential molecular mechanisms and thus setting a path for future in vivo experiments $(3,67,120)$.

Most of the current research is focused on ambient $\mathrm{PM}_{2.5}$ exposure, but with standards being set based on mass, UFP concentration is not accounted for thoroughly due to their low mass. However, the high surface area of UFP and ENM makes them considerably detrimental to health, potentially even more than fine and coarse PM (148). As most ambient PM exposures are performed by collection and monitoring of PM in different regions, the problem of variable PM composition in these regions also arises. Integration of ENM exposure with UFP and PM multicomponent studies on both humans and mice, will allow for a more thorough interpretation of the direct molecular mechanisms by which pollutants induce toxicity, while also allowing the most relevant elucidation of overall health effects (148). Though co-exposure studies are becoming more common in exploring the effects of present-day air pollution constituents on cardiac function in healthy and metabolically-challenged systems $(21,45,88,119,162)$, there is limited research assessing both cardiac function and the associated molecular mechanisms, leaving a critical gap in knowledge (3). This is one of the main limitations in many studies that could be addressed with the identification of altered candidate genes via functional genomic approaches.

A clear necessity exists for more encompassing "omics" based approaches. While investigators have begun to examine molecular modulators of the responses to inhalation exposure in the heart, including protein and gene markers for inflammation, few studies have examined the complete cellular protein, gene, or metabolic regulatory networks that coincide with the functional and structural changes. The integration of transcriptomics, epigenomics, proteomics, and other holistic approaches will provide a comprehensive understanding of cellular reprogramming, which can be impacted by the size, source and duration of particle inhalation exposure (Figure 1.4). The 
implementation of these approaches will outline early biomarkers induced by particulate exposure, ultimately encouraging exposure limits and standards that more precisely prevent the adverse effects of inhaled toxicants.

\section{Figure 1.4: Overview of Factors Contributing to Cardiovascular Response to Toxicant} Inhalation Exposure.

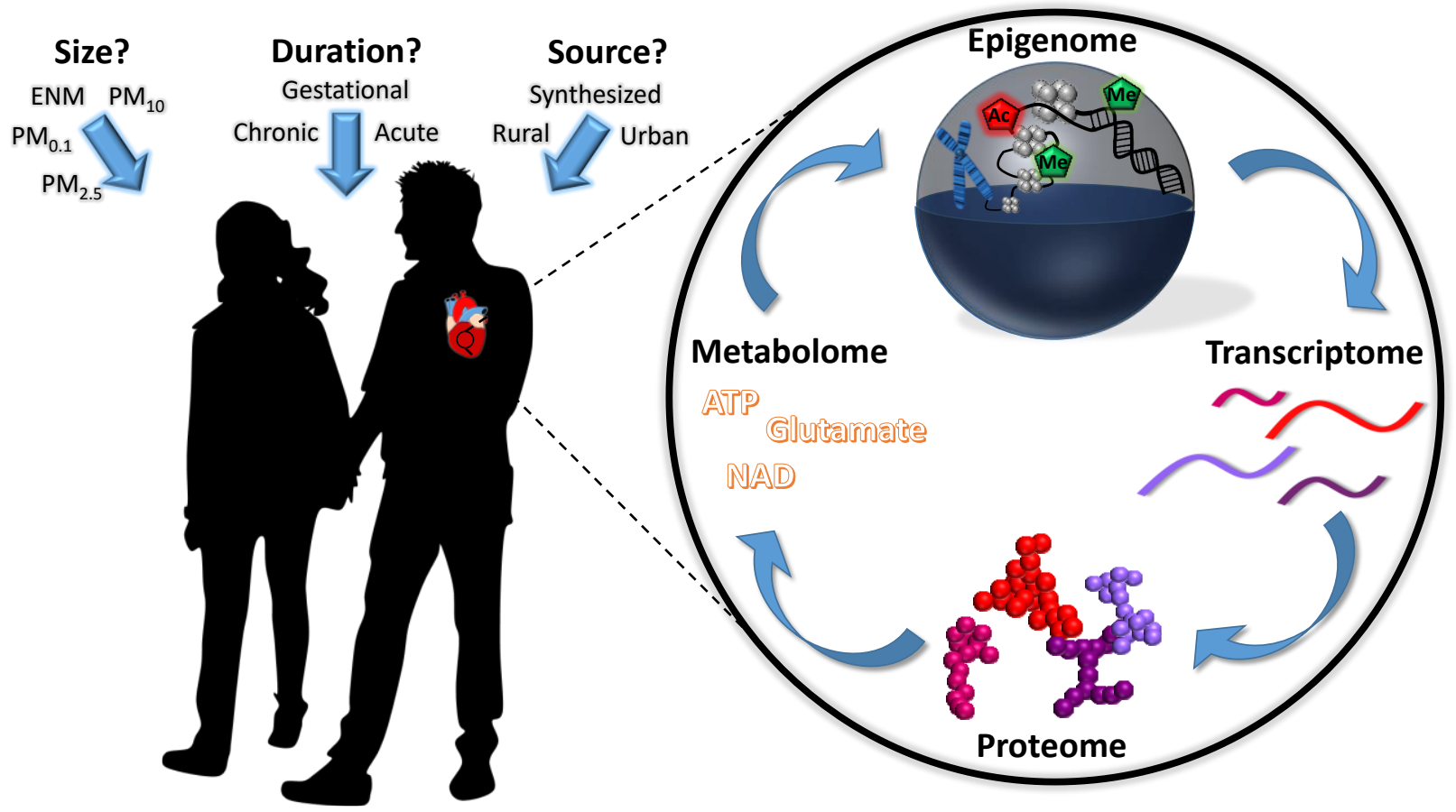

Figure 1.4: An overview of various contributing factors that can differentially alter the cardiovascular responses to toxicant inhalation exposure is provided. Current gaps in knowledge are outlined, including the lack of systemic integration of omics data across varying inhalation exposure paradigms. 


\section{Funding}

This work was supported by: The National Heart Lung Blood Institute (NHLBI) [R01 HL-128485] (JMH), American Heart Association [AHA-20PRE35080170] (AK), American Heart Association [AHA-17PRE33660333] (QAH), and the Community Foundation for the Ohio Valley Whipkey Trust.

\section{Disclosure Statement}

No potential conflict of interest was reported by the authors. 


\section{References:}

1. Alsaffar H, Martino N, Garrett JP, and Adam AP. Interleukin-6 promotes a sustained loss of endothelial barrier function via Janus kinase-mediated STAT3 phosphorylation and de novo protein synthesis. Am J Physiol Cell Physiol 314: C589-C602, 2018.

2. Apte JSB, M Cohen, A.J. Ezzati, M., and Pope CA, 3rd. Ambient PM2.5 Reduces Global and Regional Life Expectancy. Environ Sci Technol Lett 5: 546-551, 2018.

3. Aragon MJ, Chrobak I, Brower J, Roldan L, Fredenburgh LE, McDonald JD, and Campen MJ. Inflammatory and Vasoactive Effects of Serum Following Inhalation of Varied Complex Mixtures. Cardiovasc Toxicol 16: 163-171, 2016.

4. Aztatzi-Aguilar OG, Uribe-Ramirez M, Arias-Montano JA, Barbier O, and De Vizcaya-Ruiz A. Acute and subchronic exposure to air particulate matter induces expression of angiotensin and bradykinin-related genes in the lungs and heart: Angiotensin-II type-I receptor as a molecular target of particulate matter exposure. Part Fibre Toxicol 12: 17, 2015.

5. Basner M, Riggs DW, and Conklin DJ. Environmental Determinants of Hypertension and Diabetes Mellitus: Sounding Off About the Effects of Noise. J Am Heart Assoc 9: e016048, 2020 .

6. Bellavia A, Urch B, Speck M, Brook RD, Scott JA, Albetti B, Behbod B, North M, Valeri L, Bertazzi PA, Silverman F, Gold D, and Baccarelli AA. DNA hypomethylation, ambient particulate matter, and increased blood pressure: findings from controlled human exposure experiments. J Am Heart Assoc 2: e000212, 2013.

7. Bierkandt FS, Leibrock L, Wagener S, Laux P, and Luch A. The impact of nanomaterial characteristics on inhalation toxicity. Toxicol Res (Camb) 7: 321-346, 2018.

8. Bind MA, Baccarelli A, Zanobetti A, Tarantini L, Suh H, Vokonas P, and Schwartz J. Air pollution and markers of coagulation, inflammation, and endothelial function: associations and epigene-environment interactions in an elderly cohort. Epidemiology 23: 332-340, 2012.

9. Bind MA, Coull BA, Peters A, Baccarelli AA, Tarantini L, Cantone L, Vokonas PS, Koutrakis P, and Schwartz JD. Beyond the Mean: Quantile Regression to Explore the Association of Air Pollution with Gene-Specific Methylation in the Normative Aging Study. Environ Health Perspect 123: 759-765, 2015.

10. Bind MA, Lepeule J, Zanobetti A, Gasparrini A, Baccarelli A, Coull BA, Tarantini L, Vokonas PS, Koutrakis P, and Schwartz J. Air pollution and gene-specific methylation in the Normative Aging Study: association, effect modification, and mediation analysis. Epigenetics 9: 448-458, 2014.

11. Bommarito PA, Martin E, and Fry RC. Effects of prenatal exposure to endocrine disruptors and toxic metals on the fetal epigenome. Epigenomics 9: 333-350, 2017.

12. Bove H, Bongaerts E, Slenders E, Bijnens EM, Saenen ND, Gyselaers W, Van Eyken P, Plusquin M, Roeffaers MBJ, Ameloot M, and Nawrot TS. Ambient black carbon particles reach the fetal side of human placenta. Nat Commun 10: 3866, 2019.

13. Bowdridge EC, Abukabda AB, Engles KJ, McBride CR, Batchelor TP, Goldsmith WT, Garner KL, Friend S, and Nurkiewicz TR. Maternal Engineered Nanomaterial Inhalation During Gestation Disrupts Vascular Kisspeptin Reactivity. Toxicol Sci 169: 524-533, 2019.

14. Braakhuis HM, Park MV, Gosens I, De Jong WH, and Cassee FR. Physicochemical characteristics of nanomaterials that affect pulmonary inflammation. Part Fibre Toxicol 11: 18, 2014. 
15. Brook RD, Cakmak S, Turner MC, Brook JR, Crouse DL, Peters PA, van Donkelaar A, Villeneuve PJ, Brion O, Jerrett M, Martin RV, Rajagopalan S, Goldberg MS, Pope CA, 3rd, and Burnett RT. Long-term fine particulate matter exposure and mortality from diabetes in Canada. Diabetes Care 36: 3313-3320, 2013.

16. Brook RD, Rajagopalan S, Pope CA, 3rd, Brook JR, Bhatnagar A, Diez-Roux AV, Holguin F, Hong Y, Luepker RV, Mittleman MA, Peters A, Siscovick D, Smith SC, Jr., Whitsel L, Kaufman JD, American Heart Association Council on E, Prevention CotKiCD, Council on Nutrition PA, and Metabolism. Particulate matter air pollution and cardiovascular disease: An update to the scientific statement from the American Heart Association. Circulation 121: 2331-2378, 2010.

17. Brook RD, Xu X, Bard RL, Dvonch JT, Morishita M, Kaciroti N, Sun Q, Harkema J, and Rajagopalan S. Reduced metabolic insulin sensitivity following sub-acute exposures to low levels of ambient fine particulate matter air pollution. Sci Total Environ 448: 66-71, 2013.

18. Burnett R, Chen H, Szyszkowicz M, Fann N, Hubbell B, Pope CA, 3rd, Apte JS, Brauer M, Cohen A, Weichenthal S, Coggins J, Di Q, Brunekreef B, Frostad J, Lim SS, Kan H, Walker KD, Thurston GD, Hayes RB, Lim CC, Turner MC, Jerrett M, Krewski D, Gapstur SM, Diver WR, Ostro B, Goldberg D, Crouse DL, Martin RV, Peters P, Pinault L, Tjepkema M, van Donkelaar A, Villeneuve PJ, Miller AB, Yin P, Zhou M, Wang L, Janssen NAH, Marra M, Atkinson RW, Tsang H, Quoc Thach T, Cannon JB, Allen RT, Hart JE, Laden F, Cesaroni G, Forastiere F, Weinmayr G, Jaensch A, Nagel G, Concin H, and Spadaro JV. Global estimates of mortality associated with long-term exposure to outdoor fine particulate matter. Proc Natl Acad Sci U S A 115: 9592-9597, 2018.

19. Byun HM, Colicino E, Trevisi L, Fan T, Christiani DC, and Baccarelli AA. Effects of Air Pollution and Blood Mitochondrial DNA Methylation on Markers of Heart Rate Variability. $J$ Am Heart Assoc 5: 2016.

20. Cai C, Huang J, Lin Y, Miao W, Chen P, Chen X, Wang J, and Chen M. Particulate matter 2.5 induced arrhythmogenesis mediated by TRPC 3 in human induced pluripotent stem cellderived cardiomyocytes. Arch Toxicol 2019.

21. Carll AP, Crespo SM, Filho MS, Zati DH, Coull BA, Diaz EA, Raimundo RD, Jaeger TNG, Ricci-Vitor AL, Papapostolou V, Lawrence JE, Garner DM, Perry BS, Harkema JR, and Godleski JJ. Inhaled ambient-level traffic-derived particulates decrease cardiac vagal influence and baroreflexes and increase arrhythmia in a rat model of metabolic syndrome. Part Fibre Toxicol 14: 16, 2017.

22. Cassee FR, Heroux ME, Gerlofs-Nijland ME, and Kelly FJ. Particulate matter beyond mass: recent health evidence on the role of fractions, chemical constituents and sources of emission. Inhal Toxicol 25: 802-812, 2013.

23. Castro R, Rivera I, Struys EA, Jansen EE, Ravasco P, Camilo ME, Blom HJ, Jakobs C, and Tavares de Almeida I. Increased homocysteine and S-adenosylhomocysteine concentrations and DNA hypomethylation in vascular disease. Clin Chem 49: 1292-1296, 2003.

24. Center_for_Disease_Control_and_Prevention. National Diabetes Statistics Report, 2020. Atlanta,GA: Centers for Disease Control and Prevention, U.S. Dept of Health and Human Services, 2020.

25. Checkoway H, Levy D, Sheppard L, Kaufman J, Koenig J, and Siscovick D. A casecrossover analysis of fine particulate matter air pollution and out-of-hospital sudden cardiac arrest. Res Rep Health Eff Inst 5-28; discussion 29-32, 2000. 
26. Chen H, Burnett RT, Kwong JC, Villeneuve PJ, Goldberg MS, Brook RD, van Donkelaar A, Jerrett M, Martin RV, Brook JR, and Copes R. Risk of incident diabetes in relation to long-term exposure to fine particulate matter in Ontario, Canada. Environ Health Perspect 121: 804-810, 2013.

27. Chen H, Chen X, Hong X, Liu C, Huang H, Wang Q, Chen S, Chen H, Yang K, and Sun Q. Maternal exposure to ambient PM2.5 exaggerates fetal cardiovascular maldevelopment induced by homocysteine in rats. Environ Toxicol 32: 877-889, 2017.

28. Chin MT. Basic mechanisms for adverse cardiovascular events associated with air pollution. Heart 101: 253-256, 2015.

29. Chu AJ. Tissue factor, blood coagulation, and beyond: an overview. Int J Inflam 2011: 367284, 2011.

30. Chu JH, Hart JE, Chhabra D, Garshick E, Raby BA, and Laden F. Gene expression network analyses in response to air pollution exposures in the trucking industry. Environ Health 15: 101, 2016.

31. Cohen AJ, Brauer M, Burnett R, Anderson HR, Frostad J, Estep K, Balakrishnan K, Brunekreef B, Dandona L, Dandona R, Feigin V, Freedman G, Hubbell B, Jobling A, Kan H, Knibbs L, Liu Y, Martin R, Morawska L, Pope CA, 3rd, Shin H, Straif K, Shaddick G, Thomas M, van Dingenen R, van Donkelaar A, Vos T, Murray CJL, and Forouzanfar MH. Estimates and 25-year trends of the global burden of disease attributable to ambient air pollution: an analysis of data from the Global Burden of Diseases Study 2015. Lancet 389: 1907-1918, 2017.

32. Croft DP, Cameron SJ, Morrell CN, Lowenstein CJ, Ling F, Zareba W, Hopke PK, Utell MJ, Thurston SW, Thevenet-Morrison K, Evans KA, Chalupa D, and Rich DQ. Associations between ambient wood smoke and other particulate pollutants and biomarkers of systemic inflammation, coagulation and thrombosis in cardiac patients. Environ Res 154: 352-361, 2017.

33. Dai J, Chen W, Lin Y, Wang S, Guo X, and Zhang QQ. Exposure to Concentrated Ambient Fine Particulate Matter Induces Vascular Endothelial Dysfunction via miR-21. Int J Biol Sci 13: 868-877, 2017.

34. Dai J, Sun C, Yao Z, Chen W, Yu L, and Long M. Exposure to concentrated ambient fine particulate matter disrupts vascular endothelial cell barrier function via the IL-6/HIF-1alpha signaling pathway. FEBS Open Bio 6: 720-728, 2016.

35. Dennekamp M, Akram M, Abramson MJ, Tonkin A, Sim MR, Fridman M, and Erbas B. Outdoor air pollution as a trigger for out-of-hospital cardiac arrests. Epidemiology 21: 494-500, 2010.

36. Devlin RB, Smith CB, Schmitt MT, Rappold AG, Hinderliter A, Graff D, and Carraway MS. Controlled exposure of humans with metabolic syndrome to concentrated ultrafine ambient particulate matter causes cardiovascular effects. Toxicol Sci 140: 61-72, 2014.

37. Donaldson K, Tran L, Jimenez LA, Duffin R, Newby DE, Mills N, MacNee W, and Stone V. Combustion-derived nanoparticles: a review of their toxicology following inhalation exposure. Part Fibre Toxicol 2: 10, 2005.

38. Dong L, Sun W, Li F, Shi M, Meng X, Wang C, Meng M, Tang W, Liu H, Wang L, and Song $\mathbf{L}$. The harmful effects of acute PM2.5 exposure to the heart and a novel preventive and therapeutic function of CEOs. Sci Rep 9: 3495, 2019.

39. Du X, Jiang S, Bo L, Liu J, Zeng X, Xie Y, He Q, Ye X, Song W, and Zhao J. Combined effects of vitamin $\mathrm{E}$ and omega-3 fatty acids on protecting ambient PM2.5-induced cardiovascular injury in rats. Chemosphere 173: 14-21, 2017. 
40. Du Y, Xu X, Chu M, Guo Y, and Wang J. Air particulate matter and cardiovascular disease: the epidemiological, biomedical and clinical evidence. J Thorac Dis 8: E8-E19, 2016.

41. Dugershaw BB, Aengenheister L, Hansen SSK, Hougaard KS, and Buerki-Thurnherr T. Recent insights on indirect mechanisms in developmental toxicity of nanomaterials. Part Fibre Toxicol 17: 31, 2020.

42. Ensor KB, Raun LH, and Persse D. A case-crossover analysis of out-of-hospital cardiac arrest and air pollution. Circulation 127: 1192-1199, 2013.

43. Espin-Perez A, Krauskopf J, Chadeau-Hyam M, van Veldhoven K, Chung F, Cullinan P, Piepers J, van Herwijnen M, Kubesch N, Carrasco-Turigas G, Nieuwenhuijsen M, Vineis P, Kleinjans JCS, and de Kok T. Short-term transcriptome and microRNAs responses to exposure to different air pollutants in two population studies. Environ Pollut 242: 182-190, 2018.

44. Fan T, Fang SC, Cavallari JM, Barnett IJ, Wang Z, Su L, Byun HM, Lin X, Baccarelli AA, and Christiani DC. Heart rate variability and DNA methylation levels are altered after shortterm metal fume exposure among occupational welders: a repeated-measures panel study. BMC Public Health 14: 1279, 2014.

45. Farraj AK, Walsh L, Haykal-Coates N, Malik F, McGee J, Winsett D, Duvall R, Kovalcik K, Cascio WE, Higuchi M, and Hazari MS. Cardiac effects of seasonal ambient particulate matter and ozone co-exposure in rats. Part Fibre Toxicol 12: 12, 2015.

46. Feng L, Yang X, Asweto CO, Wu J, Zhang Y, Hu H, Shi Y, Duan J, and Sun Z. Genome-wide transcriptional analysis of cardiovascular-related genes and pathways induced by PM2.5 in human myocardial cells. Environ Sci Pollut Res Int 24: 11683-11693, 2017.

47. Feng L, Yang X, Asweto CO, Wu J, Zhang Y, Hu H, Shi Y, Duan J, and Sun Z. Lowdose combined exposure of nanoparticles and heavy metal compared with PM2.5 in human myocardial AC16 cells. Environ Sci Pollut Res Int 24: 27767-27777, 2017.

48. $\quad$ Feng L, Yang X, Shi Y, Liang S, Zhao T, Duan J, and Sun Z. Co-exposure subacute toxicity of silica nanoparticles and lead acetate on cardiovascular system. Int J Nanomedicine 13: 7819-7834, 2018.

49. Ferrari L, Carugno M, and Bollati V. Particulate matter exposure shapes DNA methylation through the lifespan. Clin Epigenetics 11: 129, 2019.

50. Finch J, and Conklin DJ. Air Pollution-Induced Vascular Dysfunction: Potential Role of Endothelin-1 (ET-1) System. Cardiovasc Toxicol 16: 260-275, 2016.

51. Finch J, Riggs DW, O'Toole TE, Pope CA, 3rd, Bhatnagar A, and Conklin DJ. Acute exposure to air pollution is associated with novel changes in blood levels of endothelin-1 and circulating angiogenic cells in young, healthy adults. AIMS Environ Sci 6: 265-276, 2019.

52. Fong KC, Di Q, Kloog I, Laden F, Coull BA, Koutrakis P, and Schwartz JD. Relative toxicities of major particulate matter constituents on birthweight in Massachusetts. Environ Epidemiol 3: e047, 2019.

53. Franck U, Odeh S, Wiedensohler A, Wehner B, and Herbarth O. The effect of particle size on cardiovascular disorders--the smaller the worse. Sci Total Environ 409: 4217-4221, 2011. 54. Ganguly K, Ettehadieh D, Upadhyay S, Takenaka S, Adler T, Karg E, Krombach F, Kreyling WG, Schulz H, Schmid O, and Stoeger T. Early pulmonary response is critical for extra-pulmonary carbon nanoparticle mediated effects: comparison of inhalation versus intraarterial infusion exposures in mice. Part Fibre Toxicol 14: 19, 2017.

55. Ghosh Dastidar S, Jagatheesan G, Haberzettl P, Shah J, Hill BG, Bhatnagar A, and Conklin DJ. Glutathione S-transferase P deficiency induces glucose intolerance via JNK- 
dependent enhancement of hepatic gluconeogenesis. Am J Physiol Endocrinol Metab 315: E1005E1018, 2018.

56. Giles LV, Tebbutt SJ, Carlsten C, and Koehle MS. The effect of low and high-intensity cycling in diesel exhaust on flow-mediated dilation, circulating NOx, endothelin-1 and blood pressure. PLoS One 13: e0192419, 2018.

57. Goodson JM, Weldy CS, MacDonald JW, Liu Y, Bammler TK, Chien WM, and Chin MT. In utero exposure to diesel exhaust particulates is associated with an altered cardiac transcriptional response to transverse aortic constriction and altered DNA methylation. FASEB J 31: 4935-4945, 2017.

58. Gordon T, and Reibman J. Cardiovascular toxicity of inhaled ambient particulate matter. Toxicol Sci 56: 2-4, 2000.

59. Grimmer JA, Tanwar V, Youtz DJ, Adelstein JM, Baine SH, Carnes CA, Baer LA, Stanford KI, and Wold LE. Exercise does not ameliorate cardiac dysfunction in obese mice exposed to fine particulate matter. Life Sci 239: 116885, 2019.

60. Gubala V, Johnston LJ, Krug HF, Moore CJ, Ober CK, Schwenk M, and Vert M. Engineered nanomaterials and human health: Part 2. Applications and nanotoxicology (IUPAC Technical Report). Pure and Applied Chemistry 90: 1325-1356, 2018.

61. Gubala V, Johnston LJ, Liu Z, Krug H, Moore CJ, Ober CK, Schwenk M, and Vert M. Engineered nanomaterials and human health: Part 1. Preparation, functionalization and characterization (IUPAC Technical Report). Pure and Applied Chemistry 90: 1283-1324, 2018.

62. Haberzettl P, Lee J, Duggineni D, McCracken J, Bolanowski D, O'Toole TE, Bhatnagar A, and Conklin DJ. Exposure to ambient air fine particulate matter prevents VEGFinduced mobilization of endothelial progenitor cells from the bone marrow. Environ Health Perspect 120: 848-856, 2012.

63. Haberzettl P, McCracken JP, Bhatnagar A, and Conklin DJ. Insulin sensitizers prevent fine particulate matter-induced vascular insulin resistance and changes in endothelial progenitor cell homeostasis. Am J Physiol Heart Circ Physiol 310: H1423-1438, 2016.

64. Haberzettl P, O'Toole TE, Bhatnagar A, and Conklin DJ. Exposure to Fine Particulate Air Pollution Causes Vascular Insulin Resistance by Inducing Pulmonary Oxidative Stress. Environ Health Perspect 124: 1830-1839, 2016.

65. Hathaway QA, Durr AJ, Shepherd DL, Pinti MV, Brandebura AN, Nichols CE, Kunovac A, Goldsmith WT, Friend SA, Abukabda AB, Fink GK, Nurkiewicz TR, and Hollander JM. miRNA-378a as a key regulator of cardiovascular health following engineered nanomaterial inhalation exposure. Nanotoxicology 1-20, 2019.

66. Hathaway QA, Nichols CE, Shepherd DL, Stapleton PA, McLaughlin SL, Stricker JC, Rellick SL, Pinti MV, Abukabda AB, McBride CR, Yi J, Stine SM, Nurkiewicz TR, and Hollander JM. Maternal-engineered nanomaterial exposure disrupts progeny cardiac function and bioenergetics. Am J Physiol Heart Circ Physiol 312: H446-H458, 2017.

67. Helfenstein M, Miragoli M, Rohr S, Muller L, Wick P, Mohr M, Gehr P, and RothenRutishauser B. Effects of combustion-derived ultrafine particles and manufactured nanoparticles on heart cells in vitro. Toxicology 253: 70-78, 2008.

68. Hendren CO, Mesnard X, Droge J, and Wiesner MR. Estimating production data for five engineered nanomaterials as a basis for exposure assessment. Environ Sci Technol 45: 25622569, 2011. 
69. Hojmann Larsen A, Frandsen A, and Treiman M. Upregulation of the SERCA-type $\mathrm{Ca} 2+$ pump activity in response to endoplasmic reticulum stress in PC12 cells. BMC Biochem 2: 4, 2001.

70. Holland NA, Fraiser CR, Sloan RC, 3rd, Devlin RB, Brown DA, and Wingard CJ. Ultrafine Particulate Matter Increases Cardiac Ischemia/Reperfusion Injury via Mitochondrial Permeability Transition Pore. Cardiovasc Toxicol 17: 441-450, 2017.

71. Hong F, Wang L, Yu X, Zhou Y, Hong J, and Sheng L. Toxicological effect of TiO2 nanoparticle-induced myocarditis in mice. Nanoscale Res Lett 10: 1029, 2015.

72. Hougaard KS, Campagnolo L, Chavatte-Palmer P, Tarrade A, Rousseau-Ralliard D, Valentino S, Park MV, de Jong WH, Wolterink G, Piersma AH, Ross BL, Hutchison GR, Hansen JS, Vogel U, Jackson P, Slama R, Pietroiusti A, and Cassee FR. A perspective on the developmental toxicity of inhaled nanoparticles. Reprod Toxicol 56: 118-140, 2015.

73. Hu H, Wu J, Li Q, Asweto C, Feng L, Yang X, Duan F, Duan J, and Sun Z. Fine particulate matter induces vascular endothelial activation via IL-6 dependent JAK1/STAT3 signaling pathway. Toxicol Res (Camb) 5: 946-953, 2016.

74. Huang W, Zhu T, Pan X, Hu M, Lu SE, Lin Y, Wang T, Zhang Y, and Tang X. Air pollution and autonomic and vascular dysfunction in patients with cardiovascular disease: interactions of systemic inflammation, overweight, and gender. Am J Epidemiol 176: 117-126, 2012.

75. Huerta-Garcia E, Ramos-Godinez MDP, Lopez-Saavedra A, Alfaro-Moreno E, Gomez-Crisostomo NP, Colin-Val Z, Sanchez-Barrera H, and Lopez-Marure $R$. Internalization of Titanium Dioxide Nanoparticles Is Mediated by Actin-Dependent Reorganization and Clathrin- and Dynamin-Mediated Endocytosis in H9c2 Rat Cardiomyoblasts. Chem Res Toxicol 2019.

76. Huerta-Garcia E, Zepeda-Quiroz I, Sanchez-Barrera H, Colin-Val Z, Alfaro-Moreno E, Ramos-Godinez MDP, and Lopez-Marure R. Internalization of Titanium Dioxide Nanoparticles Is Cytotoxic for H9c2 Rat Cardiomyoblasts. Molecules 23: 2018.

77. Husain M, Wu D, Saber AT, Decan N, Jacobsen NR, Williams A, Yauk CL, Wallin $\mathbf{H}$, Vogel U, and Halappanavar S. Intratracheally instilled titanium dioxide nanoparticles translocate to heart and liver and activate complement cascade in the heart of C57BL/6 mice. Nanotoxicology 9: 1013-1022, 2015.

78. Janssen BG, Madhloum N, Gyselaers W, Bijnens E, Clemente DB, Cox B, Hogervorst J, Luyten L, Martens DS, Peusens M, Plusquin M, Provost EB, Roels HA, Saenen ND, Tsamou M, Vriens A, Winckelmans E, Vrijens K, and Nawrot TS. Cohort Profile: The ENVIRonmental influence ON early AGEing (ENVIRONAGE): a birth cohort study. Int $J$ Epidemiol 46: 1386-1387m, 2017.

79. Jin Y, Wu Z, Wang N, Duan S, Wu Y, Wang J, Wu W, and Feng F. Association of EGF Receptor and NLRs signaling with Cardiac Inflammation and Fibrosis in Mice Exposed to Fine Particulate Matter. J Biochem Mol Toxicol 30: 429-437, 2016.

80. Jorgensen RB, Buhagen $\mathbf{M}$, and Foreland S. Personal exposure to ultrafine particles from PVC welding and concrete work during tunnel rehabilitation. Occup Environ Med 73: 467473, 2016.

81. Katsouyanni K. Ambient air pollution and health. Br Med Bull 68: 143-156, 2003.

82. Kessler R. Engineered nanoparticles in consumer products: understanding a new ingredient. Environ Health Perspect 119: a120-125, 2011. 
83. Kietzmann T, Petry A, Shvetsova A, Gerhold JM, and Gorlach A. The epigenetic landscape related to reactive oxygen species formation in the cardiovascular system. $\mathrm{Br} J$ Pharmacol 174: 1533-1554, 2017.

84. Krauskopf J, Caiment F, van Veldhoven K, Chadeau-Hyam M, Sinharay R, Chung KF, Cullinan P, Collins P, Barratt B, Kelly FJ, Vermeulen R, Vineis P, de Kok TM, and Kleinjans JC. The human circulating miRNome reflects multiple organ disease risks in association with short-term exposure to traffic-related air pollution. Environ Int 113: 26-34, 2018. 85. Kuhlbusch TAJ, Wijnhoven SWP, and Haase A. Nanomaterial exposures for worker, consumer and the general public. Nanoimpact 10: 11-25, 2018.

86. Kumarathasan P, Vincent R, Blais E, Bielecki A, Guenette J, Filiatreault A, Brion O, Cakmak S, Thomson EM, Shutt R, Kauri LM, Mahmud M, Liu L, and Dales R. Cardiovascular and inflammatory mechanisms in healthy humans exposed to air pollution in the vicinity of a steel mill. Part Fibre Toxicol 15: 34, 2018.

87. Kunovac A, Hathaway QA, Pinti MV, Goldsmith WT, Durr AJ, Fink GK, Nurkiewicz TR, and Hollander JM. ROS promote epigenetic remodeling and cardiac dysfunction in offspring following maternal engineered nanomaterial (ENM) exposure. Part Fibre Toxicol 16: 24, 2019.

88. Kurhanewicz N, McIntosh-Kastrinsky R, Tong H, Walsh L, Farraj AK, and Hazari MS. Ozone co-exposure modifies cardiac responses to fine and ultrafine ambient particulate matter in mice: concordance of electrocardiogram and mechanical responses. Part Fibre Toxicol 11: 54, 2014.

89. Kuroda J, Ago T, Matsushima S, Zhai P, Schneider MD, and Sadoshima J. NADPH oxidase 4 (Nox4) is a major source of oxidative stress in the failing heart. Proc Natl Acad Sci U S A 107: 15565-15570, 2010.

90. Lane KJ, Levy JI, Scammell MK, Peters JL, Patton AP, Reisner E, Lowe L, Zamore W, Durant JL, and Brugge D. Association of modeled long-term personal exposure to ultrafine particles with inflammatory and coagulation biomarkers. Environ Int 92-93: 173-182, 2016.

91. Lelieveld J, Klingmuller K, Pozzer A, Poschl U, Fnais M, Daiber A, and Munzel T. Cardiovascular disease burden from ambient air pollution in Europe reassessed using novel hazard ratio functions. Eur Heart J 40: 1590-1596, 2019.

92. Levy D, Sheppard L, Checkoway H, Kaufman J, Lumley T, Koenig J, and Siscovick D. A case-crossover analysis of particulate matter air pollution and out-of-hospital primary cardiac arrest. Epidemiology 12: 193-199, 2001.

93. Li KL, and Lin YC. PM2.5 induced cardiac hypertrophy via CREB/GSK3b/SOS1 pathway and metabolomics alterations. Oncotarget 9: 30748-30760, 2018.

94. Li N, Sioutas C, Cho A, Schmitz D, Misra C, Sempf J, Wang M, Oberley T, Froines $\mathbf{J}$, and Nel A. Ultrafine particulate pollutants induce oxidative stress and mitochondrial damage. Environ Health Perspect 111: 455-460, 2003.

95. Li R, Kou X, Geng H, Xie J, Tian J, Cai Z, and Dong C. Mitochondrial damage: an important mechanism of ambient PM2.5 exposure-induced acute heart injury in rats. J Hazard Mater 287: 392-401, 2015.

96. Li W, Dorans KS, Wilker EH, Rice MB, Ljungman PL, Schwartz JD, Coull BA, Koutrakis P, Gold DR, Keaney JF, Jr., Vasan RS, Benjamin EJ, and Mittleman MA. ShortTerm Exposure to Ambient Air Pollution and Biomarkers of Systemic Inflammation: The Framingham Heart Study. Arterioscler Thromb Vasc Biol 37: 1793-1800, 2017.

97. Li W, Dorans KS, Wilker EH, Rice MB, Ljungman PL, Schwartz JD, Coull BA, Koutrakis P, Gold DR, Keaney JF, Jr., Vasan RS, Benjamin EJ, and Mittleman MA. Short- 
term exposure to ambient air pollution and circulating biomarkers of endothelial cell activation: The Framingham Heart Study. Environ Res 171: 36-43, 2019.

98. Li X, Geng J, Chen Y, Chen F, Liu C, Xu Q, Zhao J, Hu J, Xie J, and Xu B. Exposure to particulate matter induces cardiomyocytes apoptosis after myocardial infarction through NFkappaB activation. Biochem Biophys Res Commun 488: 224-231, 2017.

99. Li Z, Li N, Guo C, Li X, Qian Y, Wu J, Yang Y, and Wei Y. Genomic DNA methylation signatures in different tissues after ambient air particulate matter exposure. Ecotoxicol Environ Saf 179: 175-181, 2019.

100. Lim CC, and Thurston GD. Air Pollution, Oxidative Stress, and Diabetes: a Life Course Epidemiologic Perspective. Curr Diab Rep 19: 58, 2019.

101. Liu L, Urch B, Szyszkowicz M, Evans G, Speck M, Van Huang A, Leingartner K, Shutt RH, Pelletier G, Gold DR, Brook JR, Godri Pollitt K, and Silverman FS. Metals and oxidative potential in urban particulate matter influence systemic inflammatory and neural biomarkers: A controlled exposure study. Environ Int 121: 1331-1340, 2018.

102. Madrigano J, Baccarelli A, Mittleman MA, Wright RO, Sparrow D, Vokonas PS, Tarantini L, and Schwartz J. Prolonged exposure to particulate pollution, genes associated with glutathione pathways, and DNA methylation in a cohort of older men. Environ Health Perspect 119: 977-982, 2011.

103. Mai AS, Dos Santos AB, Beber LCC, Basso RDB, Sulzbacher LM, Goettems-Fiorin PB, Frizzo MN, Rhoden CR, Ludwig MS, and Heck TG. Exercise Training under Exposure to Low Levels of Fine Particulate Matter: Effects on Heart Oxidative Stress and Extra-to-Intracellular HSP70 Ratio. Oxid Med Cell Longev 2017: 9067875, 2017.

104. McGuinn LA, Coull BA, Kloog I, Just AC, Tamayo-Ortiz M, Osorio-Yanez C, Baccarelli AA, Wright RJ, Tellez-Rojo MM, and Wright RO. Fine particulate matter exposure and lipid levels among children in Mexico city. Environ Epidemiol 4: e088, 2020.

105. Melody SM, Ford JB, Wills K, Venn A, and Johnston FH. Maternal exposure to fine particulate matter from a large coal mine fire is associated with gestational diabetes mellitus: A prospective cohort study. Environ Res 183: 108956, 2020.

106. Miller MR, and Newby DE. Air pollution and cardiovascular disease: car sick. Cardiovasc Res 116: 279-294, 2020.

107. Miller MR, Shaw CA, and Langrish JP. From particles to patients: oxidative stress and the cardiovascular effects of air pollution. Future Cardiol 8: 577-602, 2012.

108. Moody EC, Cantoral A, Tamayo-Ortiz M, Pizano-Zarate ML, Schnaas L, Kloog I, Oken E, Coull B, Baccarelli A, Tellez-Rojo MM, Wright RO, and Just AC. Association of Prenatal and Perinatal Exposures to Particulate Matter With Changes in Hemoglobin A1c Levels in Children Aged 4 to 6 Years. JAMA Netw Open 2: e1917643, 2019.

109. Morales-Rubio RA, Alvarado-Cruz I, Manzano-Leon N, Andrade-Oliva MD, UribeRamirez M, Quintanilla-Vega B, Osornio-Vargas A, and De Vizcaya-Ruiz A. In utero exposure to ultrafine particles promotes placental stress-induced programming of reninangiotensin system-related elements in the offspring results in altered blood pressure in adult mice. Part Fibre Toxicol 16: 7, 2019.

110. Mostafavi N, Vermeulen R, Ghantous A, Hoek G, Probst-Hensch N, Herceg Z, Tarallo S, Naccarati A, Kleinjans JCS, Imboden M, Jeong A, Morley D, Amaral AFS, van Nunen E, Gulliver J, Chadeau-Hyam M, Vineis P, and Vlaanderen J. Acute changes in DNA methylation in relation to $24 \mathrm{~h}$ personal air pollution exposure measurements: A panel study in four European countries. Environ Int 120: 11-21, 2018. 
111. Musman J, Pons S, Barau C, Caccia C, Leoni V, Berdeaux A, Ghaleh B, and Morin D. Regular treadmill exercise inhibits mitochondrial accumulation of cholesterol and oxysterols during myocardial ischemia-reperfusion in wild-type and ob/ob mice. Free Radic Biol Med 101: 317-324, 2016.

112. Nature_Nanotechnology. Nanoplastic should be better understood. Nat Nanotechnol 14: 299, 2019.

113. Nazarenko Y, Zhen H, Han T, Lioy PJ, and Mainelis G. Nanomaterial inhalation exposure from nanotechnology-based cosmetic powders: a quantitative assessment. $J$ Nanopart Res 14: 2012.

114. Nemmar A, Al-Salam S, Beegam S, Yuvaraju P, and Ali BH. Thrombosis and systemic and cardiac oxidative stress and DNA damage induced by pulmonary exposure to diesel exhaust particles and the effect of nootkatone thereon. Am J Physiol Heart Circ Physiol 314: H917-H927, 2018.

115. Nemmar A, Holme JA, Rosas I, Schwarze PE, and Alfaro-Moreno E. Recent advances in particulate matter and nanoparticle toxicology: a review of the in vivo and in vitro studies. Biomed Res Int 2013: 279371, 2013.

116. Nichols CE, Shepherd DL, Hathaway QA, Durr AJ, Thapa D, Abukabda A, Yi J, Nurkiewicz TR, and Hollander JM. Reactive oxygen species damage drives cardiac and mitochondrial dysfunction following acute nano-titanium dioxide inhalation exposure. Nanotoxicology 12: 32-48, 2018.

117. Niemann B, Rohrbach S, Miller MR, Newby DE, Fuster V, and Kovacic JC. Oxidative Stress and Cardiovascular Risk: Obesity, Diabetes, Smoking, and Pollution: Part 3 of a 3-Part Series. J Am Coll Cardiol 70: 230-251, 2017.

118. O'Neill MS, Veves A, Sarnat JA, Zanobetti A, Gold DR, Economides PA, Horton ES, and Schwartz J. Air pollution and inflammation in type 2 diabetes: a mechanism for susceptibility. Occup Environ Med 64: 373-379, 2007.

119. Occelli F, Lanier C, Cuny D, Deram A, Dumont J, Amouyel P, Montaye M, Dauchet $\mathbf{L}$, Dallongeville J, and Genin M. Exposure to multiple air pollutants and the incidence of coronary heart disease: A fine-scale geographic analysis. Sci Total Environ 714: 136608, 2020.

120. Okayama Y, Kuwahara M, Suzuki AK, and Tsubone H. Role of reactive oxygen species on diesel exhaust particle-induced cytotoxicity in rat cardiac myocytes. J Toxicol Environ Health A 69: 1699-1710, 2006.

121. Organisation_for_Economic_Co-operation_and_Development. The Economic Consequences of Outdoor Air Pollution Paris: OECD Publishing, 2016.

122. Pearson JF, Bachireddy C, Shyamprasad S, Goldfine AB, and Brownstein JS. Association between fine particulate matter and diabetes prevalence in the U.S. Diabetes Care 33: 2196-2201, 2010.

123. Pei Y, Jiang R, Zou Y, Wang Y, Zhang S, Wang G, Zhao J, and Song W. Effects of Fine Particulate Matter (PM2.5) on Systemic Oxidative Stress and Cardiac Function in ApoE(-/-) Mice. Int J Environ Res Public Health 13: 2016.

124. Peters A, Hampel R, Cyrys J, Breitner S, Geruschkat U, Kraus U, Zareba W, and Schneider A. Elevated particle number concentrations induce immediate changes in heart rate variability: a panel study in individuals with impaired glucose metabolism or diabetes. Part Fibre Toxicol 12: 7, 2015. 
125. Pietroiusti A, Stockmann-Juvala H, Lucaroni F, and Savolainen K. Nanomaterial exposure, toxicity, and impact on human health. Wiley Interdiscip Rev Nanomed Nanobiotechnol 2018.

126. Pons S, Martin V, Portal L, Zini R, Morin D, Berdeaux A, and Ghaleh B. Regular treadmill exercise restores cardioprotective signaling pathways in obese mice independently from improvement in associated co-morbidities. J Mol Cell Cardiol 54: 82-89, 2013.

127. Pope CA, 3rd, Bhatnagar A, McCracken JP, Abplanalp W, Conklin DJ, and O'Toole T. Exposure to Fine Particulate Air Pollution Is Associated With Endothelial Injury and Systemic Inflammation. Circ Res 119: 1204-1214, 2016.

128. Pope CA, 3rd, Burnett RT, Thurston GD, Thun MJ, Calle EE, Krewski D, and Godleski JJ. Cardiovascular mortality and long-term exposure to particulate air pollution: epidemiological evidence of general pathophysiological pathways of disease. Circulation 109: 7177, 2004.

129. Pope CA, 3rd, Muhlestein JB, May HT, Renlund DG, Anderson JL, and Horne BD. Ischemic heart disease events triggered by short-term exposure to fine particulate air pollution. Circulation 114: 2443-2448, 2006.

130. Pope CA, 3rd, Turner MC, Burnett RT, Jerrett M, Gapstur SM, Diver WR, Krewski D, and Brook RD. Relationships between fine particulate air pollution, cardiometabolic disorders, and cardiovascular mortality. Circ Res 116: 108-115, 2015.

131. Qin G, Xia J, Zhang Y, Guo L, Chen R, and Sang N. Ambient fine particulate matter exposure induces reversible cardiac dysfunction and fibrosis in juvenile and older female mice. Part Fibre Toxicol 15: 27, 2018.

132. Ramanathan G, Yin F, Speck M, Tseng CH, Brook JR, Silverman F, Urch B, Brook RD, and Araujo JA. Effects of urban fine particulate matter and ozone on HDL functionality. Part Fibre Toxicol 13: 26, 2016.

133. Rao X, Zhong J, Maiseyeu A, Gopalakrishnan B, Villamena FA, Chen LC, Harkema JR, Sun Q, and Rajagopalan S. CD36-dependent 7-ketocholesterol accumulation in macrophages mediates progression of atherosclerosis in response to chronic air pollution exposure. Circ Res 115: 770-780, 2014.

134. Raza A, Bellander T, Bero-Bedada G, Dahlquist M, Hollenberg J, Jonsson M, Lind T, Rosenqvist M, Svensson L, and Ljungman PL. Short-term effects of air pollution on out-ofhospital cardiac arrest in Stockholm. Eur Heart J 35: 861-868, 2014.

135. Riggs DW, Zafar N, Krishnasamy S, Yeager R, Rai SN, Bhatnagar A, and O'Toole TE. Exposure to airborne fine particulate matter is associated with impaired endothelial function and biomarkers of oxidative stress and inflammation. Environ Res 180: 108890, 2020.

136. Robichaud CO, Uyar AE, Darby MR, Zucker LG, and Wiesner MR. Estimates of upper bounds and trends in nano-TiO2 production as a basis for exposure assessment. Environ Sci Technol 43: 4227-4233, 2009.

137. Rosenthal FS, Carney JP, and Olinger ML. Out-of-hospital cardiac arrest and airborne fine particulate matter: a case-crossover analysis of emergency medical services data in Indianapolis, Indiana. Environ Health Perspect 116: 631-636, 2008.

138. Ruiz-Pesini E, Mishmar D, Brandon M, Procaccio V, and Wallace DC. Effects of purifying and adaptive selection on regional variation in human mtDNA. Science 303: 223-226, 2004.

139. Rychlik KA, Secrest JR, Lau C, Pulczinski J, Zamora ML, Leal J, Langley R, Myatt LG, Raju M, Chang RC, Li Y, Golding MC, Rodrigues-Hoffmann A, Molina MJ, Zhang R, 
and Johnson NM. In utero ultrafine particulate matter exposure causes offspring pulmonary immunosuppression. Proc Natl Acad Sci U S A 116: 3443-3448, 2019.

140. Sancini G, Farina F, Battaglia C, Cifola I, Mangano E, Mantecca P, Camatini M, and Palestini P. Health risk assessment for air pollutants: alterations in lung and cardiac gene expression in mice exposed to Milano winter fine particulate matter (PM2.5). PLoS One 9: e109685, 2014.

141. Silverman RA, Ito K, Freese J, Kaufman BJ, De Claro D, Braun J, and Prezant DJ. Association of ambient fine particles with out-of-hospital cardiac arrests in New York City. Am J Epidemiol 172: 917-923, 2010.

142. Simkhovich BZ, Kleinman MT, and Kloner RA. Air pollution and cardiovascular injury epidemiology, toxicology, and mechanisms. J Am Coll Cardiol 52: 719-726, 2008.

143. Stapleton PA, Hathaway QA, Nichols CE, Abukabda AB, Pinti MV, Shepherd DL, McBride CR, Yi J, Castranova VC, Hollander JM, and Nurkiewicz TR. Maternal engineered nanomaterial inhalation during gestation alters the fetal transcriptome. Part Fibre Toxicol 15: 3, 2018 .

144. Stapleton PA, Minarchick VC, McCawley M, Knuckles TL, and Nurkiewicz TR. Xenobiotic particle exposure and microvascular endpoints: a call to arms. Microcirculation 19: 126-142, 2012.

145. Stapleton PA, Nichols CE, Yi J, McBride CR, Minarchick VC, Shepherd DL, Hollander JM, and Nurkiewicz TR. Microvascular and mitochondrial dysfunction in the female F1 generation after gestational TiO2 nanoparticle exposure. Nanotoxicology 9: 941-951, 2015.

146. Stebounova LV, Morgan H, Grassian VH, and Brenner S. Health and safety implications of occupational exposure to engineered nanomaterials. Wiley Interdiscip Rev Nanomed Nanobiotechnol 4: 310-321, 2012.

147. Stewart JC, Chalupa DC, Devlin RB, Frasier LM, Huang LS, Little EL, Lee SM, Phipps RP, Pietropaoli AP, Taubman MB, Utell MJ, and Frampton MW. Vascular effects of ultrafine particles in persons with type 2 diabetes. Environ Health Perspect 118: 1692-1698, 2010. 148. Stone V, Miller MR, Clift MJD, Elder A, Mills NL, Moller P, Schins RPF, Vogel U, Kreyling WG, Alstrup Jensen K, Kuhlbusch TAJ, Schwarze PE, Hoet P, Pietroiusti A, De Vizcaya-Ruiz A, Baeza-Squiban A, Teixeira JP, Tran CL, and Cassee FR. Nanomaterials Versus Ambient Ultrafine Particles: An Opportunity to Exchange Toxicology Knowledge. Environ Health Perspect 125: 106002, 2017.

149. Stoyell-Conti FF, Irigoyen MC, Sartori M, Ribeiro AA, Dos Santos F, Machi JF, Figueroa DMT, Rodrigues B, and De Angelis K. Aerobic Training Is Better Than Resistance Training on Cardiac Function and Autonomic Modulation in Female ob/ob Mice. Front Physiol 10: 1464, 2019.

150. Sturm R. Local lung deposition of ultrafine particles in healthy adults: experimental results and theoretical predictions. Ann Transl Med 4: 420, 2016.

151. Sullivan J, Ishikawa N, Sheppard L, Siscovick D, Checkoway H, and Kaufman J. Exposure to ambient fine particulate matter and primary cardiac arrest among persons with and without clinically recognized heart disease. Am J Epidemiol 157: 501-509, 2003.

152. Sun Q, Hong X, and Wold LE. Cardiovascular effects of ambient particulate air pollution exposure. Circulation 121: 2755-2765, 2010.

153. Tanwar V, Adelstein JM, Grimmer JA, Youtz DJ, Katapadi A, Sugar BP, Falvo MJ, Baer LA, Stanford KI, and Wold LE. Preconception Exposure to Fine Particulate Matter Leads to Cardiac Dysfunction in Adult Male Offspring. J Am Heart Assoc 7: e010797, 2018. 
154. Tanwar V, Adelstein JM, Grimmer JA, Youtz DJ, Sugar BP, and Wold LE. PM2.5 exposure in utero contributes to neonatal cardiac dysfunction in mice. Environ Pollut 230: 116124, 2017.

155. Tanwar V, Gorr MW, Velten M, Eichenseer CM, Long VP, 3rd, Bonilla IM, Shettigar V, Ziolo MT, Davis JP, Baine SH, Carnes CA, and Wold LE. In Utero Particulate Matter Exposure Produces Heart Failure, Electrical Remodeling, and Epigenetic Changes at Adulthood. J Am Heart Assoc 6: 2017.

156. Tanwar V, Katapadi A, Adelstein JM, Grimmer JA, and Wold LE. Cardiac pathophysiology in response to environmental stress: a current review. Curr Opin Physiol 1: 198205, 2018.

157. Thompson LC, Walsh L, Martin BL, McGee J, Wood C, Kovalcik K, Pancras JP, Haykal-Coates N, Ledbetter AD, Davies D, Cascio WE, Higuchi M, Hazari MS, and Farraj AK. Ambient Particulate Matter and Acrolein Co-Exposure Increases Myocardial Dyssynchrony in Mice via TRPA1. Toxicol Sci 167: 559-572, 2019.

158. Tobaldini E, Bollati V, Prado M, Fiorelli EM, Pecis M, Bissolotti G, Albetti B, Cantone L, Favero C, Cogliati C, Carrer P, Baccarelli A, Bertazzi PA, and Montano N. Acute particulate matter affects cardiovascular autonomic modulation and IFN-gamma methylation in healthy volunteers. Environ Res 161: 97-103, 2018.

159. Upadhyay S, Stoeger T, George L, Schladweiler MC, Kodavanti U, Ganguly K, and Schulz H. Ultrafine carbon particle mediated cardiovascular impairment of aged spontaneously hypertensive rats. Part Fibre Toxicol 11: 36, 2014.

160. Viehmann A, Hertel S, Fuks K, Eisele L, Moebus S, Mohlenkamp S, Nonnemacher M, Jakobs H, Erbel R, Jockel KH, Hoffmann B, and Heinz Nixdorf Recall Investigator G. Long-term residential exposure to urban air pollution, and repeated measures of systemic blood markers of inflammation and coagulation. Occup Environ Med 72: 656-663, 2015.

161. Villarreal-Calderon R, Franco-Lira M, Gonzalez-Maciel A, Reynoso-Robles R, Harritt L, Perez-Guille B, Ferreira-Azevedo L, Drecktrah D, Zhu H, Sun Q, Torres-Jardon R, Aragon-Flores M, Calderon-Garciduenas A, Diaz P, and Calderon-Garciduenas L. Upregulation of mRNA ventricular PRNP prion protein gene expression in air pollution highly exposed young urbanites: endoplasmic reticulum stress, glucose regulated protein 78 , and nanosized particles. Int J Mol Sci 14: 23471-23491, 2013.

162. Wagner JG, Allen K, Yang HY, Nan B, Morishita M, Mukherjee B, Dvonch JT, Spino C, Fink GD, Rajagopalan S, Sun Q, Brook RD, and Harkema JR. Cardiovascular depression in rats exposed to inhaled particulate matter and ozone: effects of diet-induced metabolic syndrome. Environ Health Perspect 122: 27-33, 2014.

163. Wang G, Zhen L, Lu P, Jiang R, and Song W. [Effects of ozone and fine particulate matter (PM2.5) on rat cardiac autonomic nervous system and systemic inflammation]. Wei Sheng Yan Јіи 42: 554-560, 2013.

164. Wang H, Peng X, Cao F, Wang Y, Shi H, Lin S, Zhong W, and Sun J. Cardiotoxicity and Mechanism of Particulate Matter 2.5 (PM2.5) Exposure in Offspring Rats During Pregnancy. Med Sci Monit 23: 3890-3896, 2017.

165. Wang H, Shen X, Tian G, Shi X, Huang W, Wu Y, Sun L, Peng C, Liu S, Huang Y, Chen X, Zhang F, Chen Y, Ding W, and Lu Z. AMPKalpha2 deficiency exacerbates long-term PM2.5 exposure-induced lung injury and cardiac dysfunction. Free Radic Biol Med 121: 202-214, 2018. 
166. Wang P, You D, Saravia J, Shen H, and Cormier SA. Maternal exposure to combustion generated PM inhibits pulmonary Th1 maturation and concomitantly enhances postnatal asthma development in offspring. Part Fibre Toxicol 10: 29, 2013.

167. Wang Q, Gan X, Li F, Chen Y, Fu W, Zhu X, Xu D, Long M, and Xu D. PM2.5 Exposure Induces More Serious Apoptosis of Cardiomyocytes Mediated by Caspase3 through JNK/ P53 Pathway in Hyperlipidemic Rats. Int J Biol Sci 15: 24-33, 2019.

168. Wichmann J, Folke F, Torp-Pedersen C, Lippert F, Ketzel M, Ellermann T, and Loft S. Out-of-hospital cardiac arrests and outdoor air pollution exposure in Copenhagen, Denmark. PLoS One 8: e53684, 2013.

169. Wittkopp S, Staimer N, Tjoa T, Gillen D, Daher N, Shafer M, Schauer JJ, Sioutas C, and Delfino RJ. Mitochondrial genetic background modifies the relationship between trafficrelated air pollution exposure and systemic biomarkers of inflammation. PLoS One 8: e64444, 2013.

170. Wold LE, Ying Z, Hutchinson KR, Velten M, Gorr MW, Velten C, Youtz DJ, Wang A, Lucchesi PA, Sun Q, and Rajagopalan S. Cardiovascular remodeling in response to longterm exposure to fine particulate matter air pollution. Circ Heart Fail 5: 452-461, 2012.

171. World_Health_Organization. Ambient air pollution: a global assessment of exposure and burden of disease. World Health Organization, 2016.

172. World_Health_Organization. Exposure to ambient air pollution from particulate matter for 2016 World Health Organization, 2018.

173. Wu F, and Zhang J. The involvement of Nox4 in fine particulate matter exposure-induced cardiac injury in mice. J Toxicol Sci 43: 171-181, 2018.

174. Wu X, Pan B, Liu L, Zhao W, Zhu J, Huang X, and Tian J. In utero exposure to PM2.5 during gestation caused adult cardiac hypertrophy through histone acetylation modification. $J$ Cell Biochem 120: 4375-4384, 2019.

175. Xing YF, Xu YH, Shi MH, and Lian YX. The impact of PM2.5 on the human respiratory system. J Thorac Dis 8: E69-74, 2016.

176. Yang X, Feng L, Zhang Y, Hu H, Shi Y, Liang S, Zhao T, Cao L, Duan J, and Sun Z. Co-exposure of silica nanoparticles and methylmercury induced cardiac toxicity in vitro and in vivo. Sci Total Environ 631-632: 811-821, 2018.

177. Yang X, Feng L, Zhang Y, Hu H, Shi Y, Liang S, Zhao T, Fu Y, Duan J, and Sun Z. Cytotoxicity induced by fine particulate matter (PM2.5) via mitochondria-mediated apoptosis pathway in human cardiomyocytes. Ecotoxicol Environ Saf 161: 198-207, 2018.

178. Yang X, Feng L, Zhang Y, Shi Y, Liang S, Zhao T, Sun B, Duan J, and Sun Z. Integrative analysis of methylome and transcriptome variation of identified cardiac diseasespecific genes in human cardiomyocytes after PM2.5 exposure. Chemosphere 212: 915-926, 2018. 179. Ye B, Zhong C, Li Q, Xu S, Zhang Y, Zhang X, Chen X, Huang L, Wang H, Zhang Z, Huang J, Sun G, Xiong G, Yang X, Hao L, Yang N, and Wei S. The Association of Ambient Fine Particulate Matter Exposure During Pregnancy with Blood Glucose Levels and Gestational Diabetes Mellitus Risk: A Prospective Cohort Study in Wuhan, China. Am J Epidemiol 2020.

180. Yoshimura A, Sawada K, Nakamura K, Kinose Y, Nakatsuka E, Kobayashi M, Miyamoto M, Ishida K, Matsumoto Y, Kodama M, Hashimoto K, Mabuchi S, and Kimura T. Exosomal miR-99a-5p is elevated in sera of ovarian cancer patients and promotes cancer cell invasion by increasing fibronectin and vitronectin expression in neighboring peritoneal mesothelial cells. BMC Cancer 18: 1065, 2018. 
181. Zeng X, Liu J, Du X, Zhang J, Pan K, Shan W, Xie Y, Song W, and Zhao J. The protective effects of selenium supplementation on ambient PM2.5-induced cardiovascular injury in rats. Environ Sci Pollut Res Int 25: 22153-22162, 2018.

182. Zhang G, Wang X, Bi X, Li C, Deng Y, Al-Hashimi AA, Luo X, Gillette TG, Austin

RC, Wang Y, and Wang ZV. GRP78 (Glucose-Regulated Protein of $78 \mathrm{kDa}$ ) Promotes Cardiomyocyte Growth Through Activation of GATA4 (GATA-Binding Protein 4). Hypertension 73: 390-398, 2019.

183. Zhang X, Chen Y, Wei H, Qin Y, Hao Y, Zhu Y, Deng F, and Guo X. Ultrafine carbon black attenuates the antihypertensive effect of captopril in spontaneously hypertensive rats. Inhal Toxicol 26: 853-860, 2014.

184. Zhang Y, Ji X, Ku T, and Sang N. Inflammatory response and endothelial dysfunction in the hearts of mice co-exposed to SO2, NO2 , and PM2.5. Environ Toxicol 31: 1996-2005, 2016.

185. Zhao J, Liu C, Bai Y, Wang TY, Kan H, and Sun Q. IKK inhibition prevents PM2.5exacerbated cardiac injury in mice with type 2 diabetes. J Environ Sci (China) 31: 98-103, 2015.

186. Zhao L, Zhang L, Chen M, Dong C, Li R, and Cai Z. Effects of Ambient Atmospheric PM2.5, 1-Nitropyrene and 9-Nitroanthracene on DNA Damage and Oxidative Stress in Hearts of Rats. Cardiovasc Toxicol 2018.

187. Zheng Q, Liu H, Zhang J, and Chen $\mathbf{D}$. The effect of ambient particle matters on hospital admissions for cardiac arrhythmia: a multi-city case-crossover study in China. Environ Health 17: 60, 2018.

188. Zhong J, Colicino E, Lin X, Mehta A, Kloog I, Zanobetti A, Byun HM, Bind MA, Cantone L, Prada D, Tarantini L, Trevisi L, Sparrow D, Vokonas P, Schwartz J, and Baccarelli AA. Cardiac autonomic dysfunction: particulate air pollution effects are modulated by epigenetic immunoregulation of Toll-like receptor 2 and dietary flavonoid intake. J Am Heart Assoc 4: e001423, 2015.

189. Zhou B, and Tian R. Mitochondrial dysfunction in pathophysiology of heart failure. $J$ Clin Invest 128: 3716-3726, 2018. 


\title{
Chapter 2: Specific Aim 1
}

\section{ROS Promote Epigenetic Remodeling and Cardiac Dysfunction in Offspring Following Maternal Engineered Nanomaterial (ENM) Exposure}

\author{
Amina Kunovac ${ }^{1,2,4}$, Quincy A. Hathaway ${ }^{1,2,4}$, Mark V. Pinti ${ }^{3}$, William T. Goldsmith ${ }^{4,5}$, Andrya \\ J. Durr ${ }^{1,2}$, Garrett K. Fink, ${ }^{1}$, Timothy R. Nurkiewicz ${ }^{4,5}$, and John M. Hollander ${ }^{1,2,4}$
}

As published in Part Fibre Toxicol. 2019 Jun 18;16(1):24. doi: 10.1186/s12989-019-0310-8.

\begin{abstract}
${ }^{1}$ Division of Exercise Physiology, West Virginia University School of Medicine, Morgantown, WV, USA. ${ }^{2}$ Mitochondria, Metabolism \& Bioenergetics Working Group, West Virginia University School of Medicine, Morgantown, WV, USA. ${ }^{3}$ West Virginia University School of Pharmacy, Morgantown, WV, USA. ${ }^{4}$ Center for Inhalation Toxicology (iTOX), West Virginia University School of Medicine, Morgantown, WV, USA. ${ }^{5}$ Department of Physiology \& Pharmacology, Morgantown, WV, USA.
\end{abstract}

Amina Kunovac; ak0086@mix.wvu.edu, Quincy A. Hathaway; qahathaway@mix.wvu.edu, Mark V. Pinti; mpinti@mix.wvu.edu, William T. Goldsmith; wgoldsmi@hsc.wvu.edu, Andrya J. Durr; ajdurr@mix.wvu.edu, Garrett K. Fink; gkf0001@mix.wvu.edu, Timothy R. Nurkiewicz; tnurkiewicz@hsc.wvu.edu, John M. Hollander; jhollander@hsc.wvu.edu

Corresponding Author:

John M. Hollander, Ph.D., F.A.H.A.

Division of Exercise Physiology

West Virginia University School of Medicine

PO Box 9227

1 Medical Center Drive

Morgantown, WV 26506

Tel: 1-(304) 293-3683

Fax: 1-(304) 293-7105

Email: jhollander@hsc.wvu.edu 


\begin{abstract}
Background: Nano-titanium dioxide (nano- $\mathrm{TiO}_{2}$ ) is amongst the most widely utilized engineered nanomaterials (ENMs). However, little is known regarding the consequences maternal ENM inhalation exposure has on growing progeny during gestation. ENM inhalation exposure has been reported to decrease mitochondrial bioenergetics and cardiac function, though the mechanisms responsible are poorly understood. Reactive oxygen species (ROS) are increased as a result of ENM inhalation exposure, but it is unclear whether they impact fetal reprogramming. The purpose of this study was to determine whether maternal ENM inhalation exposure influences progeny cardiac development and epigenomic remodeling.
\end{abstract}

Results: Pregnant FVB dams were exposed to nano- $\mathrm{TiO}_{2}$ aerosols with a mass concentration of $12.09 \pm 0.26 \mathrm{mg} / \mathrm{m}^{3}$ starting at gestational day five (GD 5), for 6 hours over 6 non-consecutive days. Aerosol size distribution measurements indicated an aerodynamic count median diameter (CMD) of $156 \mathrm{~nm}$ with a geometric standard deviation (GSD) of 1.70. Echocardiographic imaging was used to assess cardiac function in maternal, fetal (GD 15), and young adult (11 weeks) animals. Electron transport chain (ETC) complex activities, mitochondrial size, complexity, and respiration were evaluated, along with 5-methylcytosine, Dnmt1 protein expression, and Hifl $\alpha$ activity. Cardiac functional analyses revealed a $43 \%$ increase in left ventricular mass and $25 \%$ decrease in cardiac output (fetal), with an 18\% decrease in fractional shortening (young adult). In fetal pups, hydrogen peroxide $\left(\mathrm{H}_{2} \mathrm{O}_{2}\right)$ levels were significantly increased ( 10 fold) with a subsequent decrease in expression of the antioxidant enzyme, phospholipid hydroperoxide glutathione peroxidase (GPx4). ETC complex activity IV was decreased by $68 \%$ and $46 \%$ in fetal and young adult cardiac mitochondria, respectively. DNA methylation was significantly increased in fetal pups following exposure, along with increased Hifl $\alpha$ activity and Dnmt1 protein expression. Mitochondrial ultrastructure, including increased size, was observed at both fetal and young adult stages following maternal exposure.

Conclusions: Maternal inhalation exposure to nano- $\mathrm{TiO}_{2}$ results in adverse effects on cardiac function that are associated with increased $\mathrm{H}_{2} \mathrm{O}_{2}$ levels and dysregulation of the Hif1 $\alpha /$ Dnmt1 regulatory axis in fetal offspring. Our findings suggest a distinct interplay between ROS and epigenetic remodeling that leads to sustained cardiac contractile dysfunction in growing and young adult offspring following maternal ENM inhalation exposure. 
Keywords: Inhalation; Mitochondria; Bioenergetics; Methylation; GPx4; Hydrogen Peroxide 


\section{Background}

An elevated risk of postnatal cardiovascular disease has been imputed to a toxic gestational environment, when the fetus is at a critical point of development $(9,15)$. The adverse effects of maternal prenatal disease and environment on future progeny were proposed as early as the 1990's with Barker's contribution of the Developmental Origins of Health and Disease hypothesis $(4,29)$. Recent studies have focused on the consequences of a baleful gestational environment, which include endocrine disruptors, toxic metals, and the subsequent increase in progeny developing cardiovascular, cancer, reproductive, immunological, and neurological diseases $(5,21,36,41,64)$. However, investigation into organ dysfunction and the molecular consequences of maternal inhalation exposure to engineered nanomaterial (ENM) on developing offspring is lacking.

Titanium dioxide $\left(\mathrm{TiO}_{2}\right)$ is one of the most widely used ENM, being incorporated into toothpaste, cosmetic products, food, paint, and in clinical settings for drug delivery due to its photocatalytic capabilities (47). Although $\mathrm{TiO}_{2}$ has provided a wealth of benefits in these applications, the potential for adverse effects on manufacturers, consumers, and the environment raise safety concerns that warrant elucidation. $\mathrm{Nano}-\mathrm{TiO}_{2}$ exposure has been shown to have detrimental effects on mitochondrial bioenergetics and cardiovascular function, which are associated with increased levels of reactive oxygen species (ROS) (26). Mitochondrial and cardiac dysfunction are often related due in part to the cardiomyocytes' dependence on mitochondrial ATP generation necessary for maintaining contractile function. Mitochondria are a primary target of oxidant stress due to ROS generation that arises from the electron transport chain (ETC), which can lead to peroxidation of biomembranes and impairment of ATP production (55). As a result, antioxidant defenses are critical for mitochondrial functional preservation.

Using transcriptomics, we had previously found that maternal nano- $\mathrm{TiO}_{2}$ inhalation exposure induces epigenetic remodeling in offspring through histone modifications (56). Interestingly, an antioxidant defense protein, phospholipid hydroperoxide glutathione peroxidase (GPx4), was the most significantly downregulated transcript ( 9 fold) following exposure, when evaluating proteins that are involved in mitochondrial functional processes (PRJNA513051). GPx4 is an antioxidant enzyme that is a primary defense mechanism against oxidation of mitochondrial biomembranes. We have previously reported that overexpression of a mitochondrially-targeted GPx4, also known as mPHGPX, in a transgenic mouse model, was capable of ameliorating $\mathrm{H}_{2} \mathrm{O}_{2}$ levels and improving mitochondrial and cardiac function in an acute 
nano- $\mathrm{TiO}_{2}$ inhalation exposure model (39), suggesting that it may be of particular relevance during ENM exposure.

The adverse health effects of gestational ENM exposure on developing offspring have among others been attributed to epigenetic alterations $(26,56)$. DNA methylation of cytosine, forming 5methylcytosine $(5 \mathrm{mC})$, was one of the first epigenetic modifications identified and it predominantly occurs at 5-C-phosphate-G-3' (CpG sites). The maintenance DNA methyltransferase, DNMT 1, is responsible for mediating epigenetic memory by propagating the initial signal, whereas DNMT 3A/3B are responsible for de novo methylation (32). An increase in $5 \mathrm{mC}$ at regulatory regions often results in gene repression and silencing (31). The cell alters $\mathrm{CpG}$ methylation in an attempt to respond to environmental factors (28). During maternal ENM exposure, toxic metals can interact with the uterine environment and cross the placental barrier causing direct fetal exposure or indirectly eliciting a maternal immune response (9, 24). Additionally, a direct effect on the fetus may be occurring as a result of changes in maternal-fetal hemodynamics following maternal ENM inhalation exposure (1). ENM exposure during gestation may affect fetal cardiac methylation transiently or permanently, resulting in epigenetic reprogramming.

Previous studies have reported cardiovascular changes and epigenetic alterations in fetalstage offspring of rats exposed to inhaled nano- $\mathrm{TiO}_{2}$ during gestation, though the mechanisms remain elusive $(26,56)$. We hypothesized that maternal nano- $\mathrm{TiO}_{2}$ exposure during gestation may evoke epigenetic remodeling in the fetus initiated through oxidative stress, diminishing cardiac bioenergetics and contractile function. In the current study, we utilized a mouse model of maternal ENM inhalation exposure to explicate the interrelation between $\operatorname{ROS}\left(\mathrm{H}_{2} \mathrm{O}_{2}\right)$ and pathogenesis to cardiac bioenergetic and contractile dysfunction at the acute stage (fetal) and chronic stage (young adult) in progeny. Our study is the first to implement a mouse model in the molecular examination of cardiac alterations elicited by maternal ENM inhalation exposure and the findings suggests that the persistent deleterious consequences observed at the fetal stage may involve sustained epigenetic reprogramming in the heart. 


\section{Methods}

\section{Animal Model}

The West Virginia University Animal Care and Use Committee approved all animal studies which conformed to the most current National Institutes of Health (NIH) Guidelines for the Care and Use of Laboratory Animals manual. Friend Virus B NIH Jackson (FVB/NJ) mice (32 females, 12 males at 7 weeks) were purchased from Jackson Laboratory (Bar Harbor, ME). Because FVB mice have prominent pronuclei and reliably large litter sizes, this strain is useful in creating artificial models that are capable of overexpressing or knocking out specific genes, which could be useful in future investigations (65). Male and female FVB mice were housed in the West Virginia University Health Sciences Center Animal Facility and given access to a rodent diet and water ad libitum. Before mating, mice were acclimated for a minimum of 48 hours. Identification of the vaginal plug was used to verify pregnancy ( $\sim 5$ days) before the pregnant dams were placed randomly into either the Sham (15 pregnant dams) or nano- $\mathrm{TiO}_{2}$ exposure (11 pregnant dams) group at approximately gestational day $5\left(\mathrm{Sham}=\mathrm{GD} 4.4\right.$, nano- $\left.\mathrm{TiO}_{2}=\mathrm{GD} 4.7\right)(6$ exposure times). Echocardiographic assessments were performed on Sham and nano- $\mathrm{TiO}_{2}$ exposed pregnant dams, as well as in the fetal (Sham $=$ GD 14.4, nano- $\mathrm{TiO}_{2}=$ GD 13.8) and young adult (Sham = 10.6 weeks, nano- $\mathrm{TiO}_{2}=10.5$ weeks) offspring. Pregnant dams were euthanized ( 8 Sham and 6 nano- $\mathrm{TiO}_{2}$ exposed), and the pups were removed from the uterus of the Sham and nano- $\mathrm{TiO}_{2}$ exposed mothers. On average, pups and maternal tissue, were harvested at gestational days 15.4 (average of 9 pups per mom) and 14.8 (average of 10 pups per mom) from Sham and nano- $\mathrm{TiO}_{2}$ dams, respectively. The specific gestational days may vary by +1 due to plug checks being administered every 24 hours. Each fetal sample contained all of the pooled tissue from one individual mother separated by heart, lung, and liver. Mothers (7 Sham and 5 nano- $\mathrm{TiO}_{2}$ exposed) belonging to the portion of the cohort to be used for the young adult study were placed back in their individual cages after echocardiographic assessment. The offspring were born with the singly-housed mothers. Lactation was allowed to occur without intervention and offspring were weaned at 23.9 (Sham) and 22 (nano- $\left.\mathrm{TiO}_{2}\right)$ days, housed with offspring from the same mother, and separated by male and female, with no more than 5 animals per cage. Young adult offspring were euthanized, on average, at 10.8 weeks (Sham) and 10.7 weeks (nano- $\mathrm{TiO}_{2}$ ), followed by tissue collection. One, randomly selected young adult was assessed from each mother (7 Sham and 5 nano- $\mathrm{TiO}_{2}$ exposed) for both groups, with 4 females, 3 males in the Sham group and 2 females, 
3 males in the nano- $\mathrm{TiO}_{2}$ group. The number of samples used per study may vary due to limitations in variability of heart size between fetuses, resulting in lower amounts of protein content.

\section{Engineered Nanomaterial Inhalation Exposure}

Nano- $\mathrm{TiO}_{2} \mathrm{P} 25$ powder containing anatase $(80 \%)$ and rutile $(20 \%) \mathrm{TiO}_{2}$ was purchased from Evonik (Aeroxide $\mathrm{TiO}_{2}$, Parsipanny, $\mathrm{NJ}$ ) and prepared by drying, sieving, and storing as previously described $(35,42)$. The primary particle size $(21 \mathrm{~nm})$, the specific surface area $(48.08$

$\left.\mathrm{m}^{2} / \mathrm{g}\right)$, and the Zeta potential $(-56.6 \mathrm{mV})$ have been previously reported $(39,42,48)$. The use of the nanoparticle aerosol generator for rodent inhalation exposure has been previously described (25). Aerosol characterization of nano- $\mathrm{TiO}_{2}$ data are shown in Figure 2.1. To model the lung burden of nano- $\mathrm{TiO}_{2}$ exposure during manufacturing, a target aerosol mass concentration of 12 $\mathrm{mg} / \mathrm{m}^{3}$ of engineered nano- $\mathrm{TiO}_{2}$ for a period of 360 minutes per day for 6 non-consecutive days was chosen. Figure 2.1A shows the mass concentration measurements over a typical exposure day; final measurements indicated a daily 360-minute equivalent average mass concentration of $12.09 \pm 0.26 \mathrm{mg} / \mathrm{m}^{3}$. A high-resolution electrical low-pressure impactor (ELPI+; Dekati, Tampere, Finland), a scanning particle mobility sizer (SMPS 3938; TSI Inc., St. Paul, MN), and an aerodynamic particle sizer (APS 3321; TSI Inc., St. Paul, MN) were used to measure the size of the nano- $\mathrm{TiO}_{2}$ aerosols. A log-normal fit of the data from the ELPI+ indicated an aerodynamic aerosol size distribution with a CMD of $156 \mathrm{~nm}$ and GSD of 1.70 (Figure 2.1B). A log-normal fit of the combined data from the SMPS and APS indicated a sized distribution with a CMD of 184 $\mathrm{nm}$ and GSD of 2.01 (Figure 2.1C). Scanning and transmission electron micrographs (SEM and TEM) of nano- $\mathrm{TiO}_{2}$ aerosolized particles, sampled from the exposure chamber, are shown in

Figure 2.1D. The dose required to match the appropriate lung deposition was calculated based on previously described mouse methodology (39). The formula $D=F \times V \times C \times T$, where $\mathrm{F}$ is the deposition fraction (10\%), $\mathrm{V}$ is the minute ventilation based on body weight $(36.4 \mathrm{ml})(46), \mathrm{C}$ is the mass concentration $\left(12.09 \mathrm{mg} / \mathrm{m}^{3}\right.$ ) and $\mathrm{T}$ is the exposure duration (360 minutes), was employed $(42,57)$. This resulted in a daily deposited nano- $\mathrm{TiO}_{2}$ lung dose of $15.85 \mu \mathrm{g}$ (total six exposure dose $=95.10 \mu \mathrm{g}$ ). Bedding material soaked with water was used in the exposure chamber to maintain a comfortable humidity during the exposure. Control animals were exposed to HEPA filtered air only with similar chamber conditions in terms of temperature and humidity. The last 
exposure was conducted 48 hours prior to sacrifice and tissue harvesting. A timeline for the study can be seen in Figure 2.1E.

\section{Echocardiography}

Echocardiographic assessments were carried out as previously described (26, 39, 40, 52), in both nano- $\mathrm{TiO}_{2}$ exposed $(\mathrm{n}=11)$ and Sham filtered-air exposed pregnant dams $(\mathrm{n}=15)$ as well as in the pups at both the fetal (GD 14) and young adult (11 weeks) time points. Echocardiography was analyzed for one fetal pup (first pup in either the right or left horn ( $\mathrm{n}=15$ Sham, $\mathrm{n}=11$ nano$\left.\mathrm{TiO}_{2}\right)$ and one young adult $\left(\mathrm{n}=7\right.$ Sham, $\mathrm{n}=5$ nano- $\left.\mathrm{TiO}_{2}\right)$ from each mother that was exposed during gestation. Each mouse was anesthetized with inhalant isoflurane, which was then maintained at or below $1 \%$ isoflurane to ensure a physiologically relevant heart rate throughout the experiment and reduce the anesthetic-induced effects on cardiac function. Motion mode (Mmode) echocardiographic and Pulse Wave Doppler images were obtained using the Vevo 2100 Imaging System (Visual Sonics, Toronto, Canada).

In maternal and young adult animals, grayscale M-mode parasternal short-axis images at the mid-papillary level of the left ventricle (LV) were used for conventional echocardiographic analysis. In M-mode, interventricular septal, inner, and posterior wall measurements were taken to determine LV thickness on adjacent end-systolic and diastolic peaks in relation to LV trace analysis. Mitral valve Doppler echocardiography was used to assess diastolic function by taking measurements of E- and A- wave velocity, deceleration time, intraventricular relaxation/contraction time, E-wave-to-A-wave ratio, mitral valve area, etc. In fetal pups, cardiac function was also assessed using M-mode and B-mode stress strain by visualizing individual pups in the uterine horn (53). Pulse Wave Doppler echocardiography (Vascular Package) was also used to assess umbilical and uterine flow in pregnant dams using measures of peak systolic velocity, end diastolic velocity, and velocity-time integral (30). These measurements were calculated over three cardiac cycles and averaged. All echocardiographic measurements were acquired by one analyst blinded to the animal exposure group.

\section{Speckle-Tracking-Based Strain}

Speckle-tracking-based strain assessments were completed using short and long axis Bmode images as previously described by our laboratory $(26,40,52)$. During each cardiac cycle, 
measures of strain (total deformation length divided by the original length of a segment, strain rate, displacement length, and velocity) were obtained $(8,44)$. Endocardium walls were traced and analyzed for three cardiac cycles using a speckle-tracking algorithm in Visual Sonics VevoStrain software (Toronto, Canada). Time-to-peak analysis for curvilinear data, allowing strain and strain rate to be determined, were generated. For maternal and young adult cohorts, speckle-tracking was performed on both long and short axis B-mode images, while fetal groups were only assessed in the short axis. All speckle-tracking-based strain analyses were completed by the same blinded analyst.

\section{Fetal Cardiomyocyte Isolation}

Pregnant dams were euthanized one day after echocardiographic assessment, and pups were removed at GD 15 from the nano- $\mathrm{TiO}_{2}$ exposed and Sham mouse uteri. Maternal and fetal hearts were removed through a midsagittal cut in the thoracic cavity and fetal hearts were pooled (one fetal heart from each exposed mother; Sham $=6$ dams, nano- $\mathrm{TiO}_{2}=5$ dams) as previously described $(26,54)$. The hearts were chopped up and initially washed with $1 \mathrm{X}$ ADS buffer $(0.1 \mathrm{M}$ $\mathrm{NaCl}, 1.2 \mathrm{mM} \mathrm{NaH} 2 \mathrm{PO}_{4}, 0.8 \mathrm{mM} \mathrm{MgSO}_{4}, 5.4 \mathrm{mM} \mathrm{KCl}$, and $5 \mathrm{mM}$ glucose at $\mathrm{pH}$ 7.4). Digestive solution, comprised of $2 \mathrm{mg}$ pancreatin (Sigma Aldrich, St. Louis, MO) and $2 \mathrm{mg}$ of collagen type II (Worthington Biochemical, Lakewood, NJ), mixed with $2 \mathrm{~mL}$ of physiological 1X ADS buffer per heart digested, was used to isolate cells. The supernatant was removed from the tissue debris and centrifuged at $180 \mathrm{x}$ g for 7 minutes after each saved digestion. The supernatant was discarded, and $2 \mathrm{ml}$ of newborn calf serum were added to the cell suspension and stored in a $37^{\circ} \mathrm{C}$ incubator.

A Percoll gradient was made in a $15 \mathrm{~mL}$ conical tube for separation of cardiomyocytes from other cells of the heart as previously described $(26,54)$. The Percoll gradient (density $=1.130$ $\mathrm{g} / \mathrm{ml}$ ) was made of two layers: clear (top, density $=1.059 \mathrm{~g} / \mathrm{ml}$ ) and red (bottom, density $=1.082$ $\mathrm{g} / \mathrm{ml}$ ). After all cell collection steps, cells were centrifuged at $180 \mathrm{x} \mathrm{g}$ and resuspended in $2 \mathrm{ml}$ of $1 \mathrm{X}$ ADS buffer, per five hearts. The 2 milliliters of cells were added to the top of the Percoll gradient and centrifuged at 1,620 x g for 30 minutes, with 9-min acceleration and deceleration time. The non-myocardial mesenchymal cells were aspirated, and the cardiac cells were extracted from the middle layer, washed with newborn calf serum, and placed in plating media (with fetal 
bovine serum). Two hours after placing in plating media, cells were changed to maintenance media (no fetal bovine serum). Cells were counted using a hemocytometer.

\section{Mitochondrial Isolation}

Young adult mice (one from each exposed mother; $\mathrm{Sham}=7$, nano- $\mathrm{TiO}_{2}=5$ )) were sacrificed, and hearts were excised through a midsagittal cut in the thoracic cavity. Using differential centrifugation, isolation of mitochondrial, cytosolic, and nuclear fractions was achieved. Subsarcolemmal and interfibrillar mitochondrial subpopulations were isolated as previously described (43) with modifications by our laboratory $(6,7,18)$. Due to the limited amount of subpopulation-specific mitochondria, the two subpopulations were combined. The isolated mitochondria were then resuspended in $\mathrm{KME}$ buffer $(100 \mathrm{mM} \mathrm{KCl}, 50 \mathrm{mM}$ MOPS and 0.5mM EGTA pH 7.4). Protein concentrations were determined using the Bradford method with bovine serum albumin as a standard (10).

\section{Mitochondrial Respiration}

Freshly isolated mitochondria (from young adults) were used to analyze state 3 and state 4 respiration as previously described $(16,60)$, with modifications by our laboratory (25). Once isolated, mitochondria were resuspended in KME buffer and protein concentrations were determined. Mitochondrial protein was added to respiration buffer $(80 \mathrm{mM} \mathrm{KCl}, 50 \mathrm{mM}$ MOPS, $1 \mathrm{mmol} / \mathrm{l}$ EGTA, $5 \mathrm{mmol} / \mathrm{l} \mathrm{K \textrm {K } _ { 2 }} \mathrm{PO}_{4}$ and $1 \mathrm{mg} / \mathrm{ml} \mathrm{BSA}$ ) and placed into a respiration chamber connected to a multi-unit (8 channel) Oxytherm Peltier Electrode apparatus (Hansatech Instruments, Norfolk, England). Glutamate $(5 \mathrm{mM})$ and malate $(5 \mathrm{mM})$ were used to initiate maximal complex I-mediated respiration. State 3 (250 mM ADP) and state 4 (ADP-limited) respiration data were expressed as nmol of oxygen consumed/min/mg protein.

\section{Cellular and Tissue Bioenergetics}

Fetal isolated cardiomyocytes were plated on F96 V3 cell culture microplates and the Seahorse XF96 was used for analysis (Agilent Technologies, Santa Clara, CA) (26, 51). The pooled samples of fetal cardiomyocytes from the pups of Sham (one pup from each of 6 dams, $\mathrm{n}=1$ ) and nano- $\mathrm{TiO}_{2}$-exposed (one pup from each of 5 dams, $\mathrm{n}=1$ ) females were analyzed 5 hours 
after plating and normalized to cell number. With the pooled samples, 5-6 replicates per animal group were plated. Isolated cardiac tissue from the young adult offspring were plated on F24 V7PS cell culture microplates. Oxygen consumption rate, extracellular acidification rate, and proton production rate were measured using oligomycin, carbonyl cyanide- $p$ trifluoromethoxyphenylhydrazone, antimycin A, and rotenone as previously described (66). Mitochondrial respiration measurements included ATP production, proton leak, basal respiration, maximal respiration, and spare capacity.

\section{Mitochondrial Size and Internal Complexity}

Size and internal complexity were analyzed in mitochondria isolated from young adult offspring hearts using flow cytometry, as previously described $(16,18,19,25,63)$. Isolated mitochondria were loaded with the fluorescent probe Mitotracker Deep Red 633 (Invitrogen) for assessment of mitochondrial size and internal complexity, utilizing the forward scatter (FSC), side scatter (SSC), and Sphero AccuCount Blank Particles, $2.0 \mu \mathrm{m}$ (Spherotech Inc., Lake Forest, IL) sizing beads. Sizing beads allowed for absolute measurement of mitochondrial size through FSC. All flow cytometric measures were captured using the LSRFortessa (BD Biosciences, Franklin Lakes, NJ) at the West Virginia University Flow Cytometry \& Single Cell Core Facility. To process data, FCS Express Flow Research Edition (De Novo Software, Glendale, CA) was implemented.

\section{Electron Transport Chain (ETC) Complex Activities}

ETC Complex activities (I, III, IV, V) were measured in maternal, fetal, and young adult hearts, placenta, and fetal and young adult liver and lung as previously described $(6,16,26,51)$. For the maternal, fetal, and young adult analyses, whole tissue was homogenized using the Polytron PowerGen 500 S1 tissue homogenizer (Fisher Scientific, Hampton, NH) in RIPA buffer (Life Technologies, Grand Island, NY). The Bradford assay provided normalization of samples by protein content (10). Complex I (reduction of decyclubiquinone), complex III (reduction of cytochrome $c$ ), complex IV (oxidation of reduced cytochrome C), and complex V (pyruvate kinase and phosphoenolpyruvate and ATP production) activities were measured. Final values were expressed as nanomoles consumed per minute per milligram of protein, which was equal to the nanomoles of NADH oxidized per minute per milligram of protein. 


\section{Hydrogen Peroxide $\left(\mathrm{H}_{2} \mathrm{O}_{2}\right)$ Production}

Cardiac $\mathrm{H}_{2} \mathrm{O}_{2}$ production was analyzed in maternal, fetal, and young adult hearts, placenta, and in fetal and young adult liver and lung using Amplex Red fluorescent dye in the presence of Horse Radish Peroxidase (HRP). The Amplex Red fluorescent dye reacts with $\mathrm{H}_{2} \mathrm{O}_{2}$ producing resorufin, a red fluorescent oxidation product. Experiments were carried out using the manufacturer's protocol with minor modifications (39). Cardiac protein was incubated with HRP and Amplex Red dye was added, followed by initiation of mitochondrial $\mathrm{H}_{2} \mathrm{O}_{2}$ production using glutamate and malate as substrates. The Flex Station 3 fluorescent plate reader (Molecular Devices, Sunnyvale, CA) was used to assess changes in fluorescence over time and allowed for quantification of $\mathrm{H}_{2} \mathrm{O}_{2}$ production normalized per milligram of protein. Due to its electrical neutrality providing the ability to infiltrate out of the mitochondrial membrane, measuring $\mathrm{H}_{2} \mathrm{O}_{2}$ as a method of assessing mitochondrial ROS production is a well-established method, along with being more quantitative than methods used to detect other ROS (58). Additionally, assessment of $\mathrm{H}_{2} \mathrm{O}_{2}$ levels is particularly important due to its high reactivity towards imperative cellular targets, as compared to using other methods of determining ROS levels such as measuring superoxide, which is not as reactive (58).

\section{Western Blot Analyses}

4-12\% gradient Bis-Tris gels were used in SDS-PAGE as previously described $(3,6,7,18$, 40, 60). Protein sample concentrations were standardized with bovine serum albumin using the Bradford method (10). The primary antibodies used included the following: GPx4 (product no.: 10005258, Cayman Chemical, Ann Arbor, MI), Hif1 $\alpha$ (product no.: sc53546, Santa Cruz Biotechnology INC., Dallas, TX), Dnmt1 (product no.: sc271729, Santa Cruz Biotechnology), and Dnmt3b (product no.: ab2851, Abcam, Cambridge, MA). The anti-GAPDH primary antibody (product no.: ab8245, Abcam) was used to normalize protein levels for each blot. Secondary antibodies used included the following: goat anti-mouse IgG HRP conjugate (product no.: 31430; Pierce Biotechnology, Rockford, IL) and goat anti-rabbit IgG HRP conjugate (product no.: 10004301; Cayman Chemical). Pierce enhanced chemiluminescence Western blotting substrate (Pierce Biotechnology) was used to detect signal per manufacturer's instructions. The G:Box Bioimaging system (Syngene, Frederick, MD) was used to detect signals, and data were captured 
using GeneSnap/GeneTools software (Syngene). Image J Software (NIH, Bethesda, MD) was used to analyze densitometry. All values were expressed as optical density with arbitrary units.

\section{5-mC DNA Analyses}

$20 \mathrm{mg}$ of fetal and young adult tissue was cut into $2 \mathrm{~mm}^{3}$ and the DNeasy Blood \& Tissue Kit (Qiagen, Hilden, Germany) was used, per manufacturer's instructions, to isolate total DNA. DNA methylation (5-methylcytosine; 5-mC) levels were quantified in the fetal and young adult using a 5-mC DNA ELISA kit (Catalog no: D5326: Zymo Research Corp., Irvine, CA), per manufacturer's instructions. Briefly, $100 \mathrm{ng}$ of DNA was run per well in duplicate on a 96-well plate. DNA was denatured and bound to the 96-well plates. An anti-5-Methylcytosine monoclonal antibody was used with a secondary antibody and HRP developer. Absorbance was measured using the Flex Station 3 fluorescent plate reader (Molecular Devices, Sunnyvale, CA) at 450nm. Using a logarithmic second-order regression equation, total percent (\%) methylation was determined.

\section{Hif1 $\alpha$ Transcription Factor Analyses}

Hif $1 \alpha$ transcription factor activity was assessed in maternal and fetal hearts, placenta, and fetal lung and liver tissue samples using the Hif $1 \alpha$ Transcription Factor Assay kit (Catalog no: 10006910: Cayman Chemical, Ann Arbor, MI), per manufacturer's instructions. Briefly, fetal nuclear extracts were run, $10 \mu \mathrm{L}$ per well, in duplicate on a 96-well plate, with the Hif1 $\alpha$ response element immobilized. Hif $1 \alpha$ binds to the response element forming an active HIF transcription factor, which was detected using a Hif $1 \alpha$ primary antibody and a secondary antibody conjugated to HRP. Colorimetric analysis was performed using the Flex Station 3 fluorescent plate reader (Molecular Devices, Sunnyvale, CA) at $450 \mathrm{~nm}$. The Hif1 atranscription factor activity was normalized using the Bradford method and reported per microgram of protein (10).

\section{DNMT Activity Analyses}

DNMT activity in fetal heart was measured using a colorimetric assay kit (Catalog no: P3009: Epigentek Group Inc., Farmingdale, NY), per manufacturer's instructions. Nuclear extracts were loaded onto a 48-well microplate with Adomet, a universal DNMT substrate, and incubated

allowing the DNMT enzymes in the protein sample to transfer methyl groups from Adomet to 
cytosine, methylating DNA. The wells were washed, and the methylated DNA was captured using an anti-5-mC antibody, then detected using a secondary antibody and enhancer solution. Absorbance was measured using the Flex Station 3 fluorescent plate reader (Molecular Devices, Sunnyvale, CA) at a wavelength of $450 \mathrm{~nm}$ and DNMT activity was proportional to the optical density intensity measured. Samples were normalized using the Bradford method and reported per microgram of protein (10).

\section{Ex Vivo Micro-CT}

Microcomputed tomography (micro-CT) was used to examine the anatomy of the fetal mouse circulatory system as previously described (67). Briefly, one fetus was dissected from a nano- $\mathrm{TiO}_{2}$ exposed dam and fixed in $10 \%$ formalin for 24 hours before being stained with Lugol (product no.: L6146: Sigma Aldrich) solution containing iodine for one week. The fetus was then taken out of the Lugol solution and transferred to a $0.1 \mathrm{~N}$ iodine solution (product no.: SI861: Fisher Scientific, Hampton, NH) for one week. After staining, the sample was embedded in agar to be imaged on a high-resolution micro-CT scanner. Imaging, which took approximately six hours, was done with the scanner set to a voltage of $100 \mathrm{kV}$ and current at $100 \mu \mathrm{A}$.

\section{Transmission Electron Microscopy}

Mitochondrial ultrastructure was analyzed in four whole fetal hearts, two from each a Sham and nano- $\mathrm{TiO}_{2}$ exposed mother, after being processed and imaged at the WVU Electron Microscopy Histopathology and Tissue Bank. Due to their small size, the whole fetal hearts were fixed in EM Primary Fixative (3\% glutaraldehyde buffered with 0.1 M Cacodylate buffer) for 48 hours. After rinsing in $0.1 \mathrm{M}$ Cacodylate buffer, the samples were fixed in $1 \%$ osmium tetroxide/ $0.8 \%$ potassium ferricyanide solution for 1.5 hours, followed by an additional series of 0.1 M Cacodylate buffer washes. Samples were dehydrated through graded alcohols (50\%, 75\%, $95 \%, 100 \%$ ) and acetone, and tissue were infiltrated with a mixture of acetone/resin for one hour each at decreasing ratios $(2: 1,1: 1,1: 2)$ followed by 2 infiltrations with pure resin for an hour each under vacuum. The whole fetal hearts were embedded into flat embedding molds and cured at $70^{\circ} \mathrm{C}$ overnight. 15. Samples were then cut into $85 \mathrm{~nm}$ sections on a LEICA UCT 9 Ultramicrotome (Leica Microsystems, Wetzler, Germany) and mounted on copper-coated 200 mesh VELCO grids ( 2 per sample). The grids were stained with uranyl acetate and lead citrate solutions and imaged 
using the JEOL 1010 TEM with side-mount AMT digital camera (JOEL, Akishima, Tokyo, Japan). Semi-quantitative analyses of mitochondrial size were processed through Fiji (NIH). Six to eight randomly selected TEM images of mitochondria per group were used to perform analyses. Mitochondria were quantified through black \& white thresholding using the Shanbhag method (50), through individual tracings, color inversion, and quantification.

\section{Statistics}

All statistical analyses were performed using GraphPad Prism SoftwareVersion 7 for Windows (GraphPad Software, La Jolla CA). To determine statistical significance between Sham and nano- $\mathrm{TiO}_{2}$-exposed groups, a two-tailed Student's t-test was used. Statistical difference was defined by $P \leq 0.05=*, P \leq 0.01=* *, P \leq 0.001=* * *$. All data are presented as the mean \pm the standard error (SEM) of the mean. 


\section{Results}

\section{Cardiac Function in Maternal, Fetal, and Young Adult Animals}

Although nano- $\mathrm{TiO}_{2}$ inhalation exposure has been shown to negatively impact cardiac function in murine models $(26,56)$, it is not known if these effects are mimicked following maternal exposure in the fetus. In pregnant dams and fetal and young adult offspring, M-mode (Table 2.1) was used to assess cardiac function. Both diastolic diameter and volume were significantly decreased in the nano- $\mathrm{TiO}_{2}$ exposed pregnant dams as well as stroke volume and cardiac output. Pulse Wave Doppler indices revealed a significant decrease in the Mitral Valve (MV)-A velocity and a significant increase in MV deceleration - acceleration, MV deceleration time, and E/A ratio in the nano- $\mathrm{TiO}_{2}$ exposed mothers (Figure 2.2A-D). Pulse Wave Doppler revealed no significant changes in uterine flow (Supplemental Table 1), but a significant decrease in umbilical end-diastolic velocity (Figure 2.2E). This effect may be occurring as a result of increased vascular resistance in the in utero circulation, which has been shown to reduce placental perfusion (1) and could increase the rate of perinatal mortality (20).

To better understand how maternal exposure alters fetal circulation, a micro-CT was performed in a maternal nano- $\mathrm{TiO}_{2}$ exposed progeny (Figure 2.2F). The umbilical vein, whose diameter can be measured as way of determining vascular resistance, is also illustrated (Figure 2.2F). Figure 2.2G shows a representative image of the uterine horn with two pups closest to the cervix, as well as an illustration of how fetal cardiac tissue was gated. In order to assess fetal cardiac function, each individual pup was visualized in the uterine horn and echocardiographic scans were performed in utero to determine the effects of maternal ENM inhalation exposure. In the fetal pups, M-mode measurements revealed a significant decrease in cardiac output and a decrease in LV mass, indicating a decrease in heart size (Table 2.1). Following maternal ENM inhalation exposure, young adult offspring showed a significant decrease in ejection fraction and

fractional shortening compared to controls, indicating changes in LV pump (Table 2.1). Pulse Wave Doppler measurements were also taken at the young adult stage and indicated a significant decrease in MV deceleration - acceleration and deceleration time (Figure 2.2H-I).

Speckle-tracking stress strain assessments of the pregnant dams and fetal and young adult offspring are included (Supplemental Table 2.2-2.5). The maternal stress-strain measurements indicated diastolic dysfunction by an increase in long axis diastolic radial velocity and strain rate, with a significant decrease in long axis systolic radial displacement, radial velocity, and short axis 
circumferential strain. Short axis systolic radial strain rate and circumferential displacement were both significantly decreased in the fetal offspring of ENM-exposed dams. Short axis diastolic radial displacement was significantly decreased in the young adult and diastolic longitudinal displacement was significantly increased.

\section{Mitochondrial Bioenergetics}

In order to elucidate whether the cardiac dysfunction seen in the offspring of ENM-exposed dams was associated with dysregulation of mitochondrial bioenergetics, mitochondrial respiration was assessed in isolated cardiomyocytes of the fetal pups as well as in isolated mitochondria and whole tissue from young adult progeny. Basal and maximal respiration and ATP production were decreased in the fetal pups of nano- $\mathrm{TiO}_{2}$ exposed dams as compared to those of Sham-exposed dams (Figure 2.3A). No changes in state 3 and state 4 respiration, using both glucose and fatty acid-mediated metabolism, were observed between the Sham- and nano- $\mathrm{TiO}_{2}$ exposed young adult offspring (Supplemental Figure 2.1A), though in isolated cardiac tissue from the young adult, an overall decrease in oxygen consumption rate was observed (Figure 2.3B). ETC complex activities were evaluated in the fetal (Figure 2.3C) and young adult (Figure 2.3D) progeny heart with additional measurements made in the maternal heart, placenta, and fetal and young adult lung and liver (Supplemental Figure 2.1B-E). Interestingly, in the placenta, there was a significant decrease in complexes III, IV and V activities in the nano- $\mathrm{TiO}_{2}$ exposed dams. ETC complex IV activity (Figure 2.3C-D) was significantly decreased in both the fetal and young adult offspring heart of ENM-exposed dams, further supporting alterations to mitochondrial bioenergetics (37).

\section{$\mathrm{H}_{2} \mathrm{O}_{2}$-Mediated Pathways}

$\mathrm{H}_{2} \mathrm{O}_{2}$ production was assessed in maternal, fetal, and young adult hearts, placenta, as well as in fetal and young adult liver and lung. There was a significant increase in $\mathrm{H}_{2} \mathrm{O}_{2}$ content in the fetal hearts of pups whose dams were exposed to nano- $\mathrm{TiO}_{2}$ (Figure 2.4A), with a decrease in $\mathrm{H}_{2} \mathrm{O}_{2}$ content in the liver (Supplemental Figure 2.2A). There were no significant changes in $\mathrm{H}_{2} \mathrm{O}_{2}$ content in the young adult offspring heart (Figure 2.4A) or other young adult tissues (Supplemental Figure 2.2A). Hif $1 \alpha$ activity was measured to assess how $\mathrm{H}_{2} \mathrm{O}_{2}$ may influence the transcription factor activity and binding. Hif $1 \alpha$ activity was significantly increased in the hearts of fetal offspring whose dams were exposed to nano- $\mathrm{TiO}_{2}($ Figure $\mathbf{2 . 4 B})$ as well as in the maternal 
heart (Supplemental Figure 2.2B). Intriguingly, there was a decrease in activity in the fetal lung and liver tissues following nano- $\mathrm{TiO}_{2}$ inhalation exposure (Supplemental Figure 2.2B).

Because Hifl $\alpha$ is a regulator of Dnmt1 expression, we determined whether $\mathrm{H}_{2} \mathrm{O}_{2}$, induced through nano- $\mathrm{TiO}_{2}$ inhalation exposure, was concomitant with increased transcription of Dnmt1 and, ultimately, DNA methylation patterns. Dnmt1 protein expression in the fetal heart reveled a significant increase in pups whose dams were exposed to nano- $\mathrm{TiO}_{2}$ (Figure 2.4C). Although there was an increase in Dnmt1 protein expression following exposure, Dnmt activity was not significantly altered (Supplemental Figure 2.2C). Additionally, we found that Dnmt3b expression was not changed, following maternal inhalation exposure to ENM in fetal offspring (Supplemental Figure 2.2D). Global DNA methylation levels displayed a significant increase in the hearts of the pups whose dams were exposed to nano- $\mathrm{TiO}_{2}$ (Figure 2.4D). While we observed an increase in 5-mC DNA methylation in fetal pups whose dams were exposed to nano- $\mathrm{TiO}_{2}$, development into adulthood revealed an inverse relationship, with a significant decrease in global DNA methylation (Supplemental Figure 2.2E). Augmented 5-mC DNA methylation levels at the fetal stage indicate that maternal nano- $\mathrm{TiO}_{2}$ exposure during gestation potentially results in the repression of vital genes, which could lead to detrimental dysfunction. Furthermore, cardiac DNA methylation at the fetal and young adult stages reveal an aberrant DNA methylation pattern, which may be attributed to the Hifl $\alpha /$ Dnmt 1 regulatory axis.

\section{GPx4 Expression and Mitochondrial Structure}

We next determined whether enhanced $\mathrm{H}_{2} \mathrm{O}_{2}$ levels are associated with the repression of GPx4 protein expression. A significant diminution of GPx4 protein expression was revealed in the fetal hearts of pups whose dams were exposed to nano- $\mathrm{TiO}_{2}$ during gestation (Figure 2.4E), while GPx4 protein levels were unchanged in the young adult offspring (Figure 2.4F).

To determine if exposure to nano- $\mathrm{TiO}_{2}$ affected fetal mitochondrial ultrastructure, TEM was implemented to assess mitochondrial size and complexity (Figure 2.5A). Using a semiquantitative approach, mitochondrial area and internal complexity were shown to be similar between the Sham and nano- $\mathrm{TiO}_{2}$ groups, while mitochondrial roundness revealed a decrease in the hearts of the maternal nano- $\mathrm{TiO}_{2}$ exposed fetal offspring (Figure 2.5B). To gain insight into the impact of gestational nano- $\mathrm{TiO}_{2}$ exposure on mitochondrial ultrastructure at the young adult stage, mitochondrial size (Figure 2.5C) and complexity (Figure 2.5D) were evaluated through 
flow cytometry. FSC (size) and SSC (internal complexity) were significantly increased in young adult offspring whose dams were exposed to nano- $\mathrm{TiO}_{2}$ during gestation. These data are suggestive of an alteration to mitochondrial ultrastructure as a result of gestational nano- $\mathrm{TiO}_{2}$ exposure; the altered shape of fetal mitochondria could potentially influence the chronic changes to mitochondrial size and internal complexity in the young adults, precipitating sustained bioenergetic and cardiac dysfunction into adulthood. 


\section{Discussion}

The use of nanotechnology continues to increase in both the variety of applicable fields, as

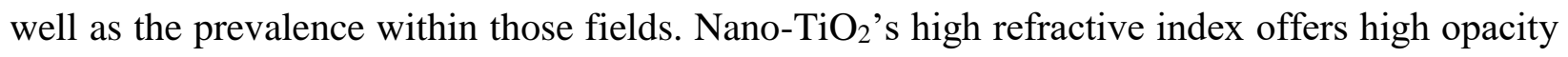
and resistance to corrosion making it beneficial in the industries of paints, inks, papers, and plastics (47). Unfortunately, the repercussions of the rampant use of ENMs remain unclear, along with the mechanisms and solutions to the potential negative consequences. In order to determine how the current exposure paradigm, which achieved a lung burden of $95.10 \mu$ g over 6 days, reflects ENM occupational exposure in humans in a manufacturing setting, alveolar surface area was used as previously described $(2,26,56,59)$. The mouse alveolar surface area is $0.05 \mathrm{~m}^{2}(59)$. Therefore, the mouse lung burden of $95.10 \mu \mathrm{g}$ would result in $1,902 \mu \mathrm{g} / \mathrm{m}^{2}$. Since the human alveolar surface area is $102 \mathrm{~m}^{2}$, the human lung burden with this exposure paradigm would be $194.0 \mathrm{mg}$. Furthermore, the number of working days it would take to achieve this lung burden in humans was calculated:

$$
\begin{gathered}
\text { nano }- \text { TiO2 aerosol concentration } \cdot \text { minute ventilation } \\
\cdot \text { exposure duration } \cdot \text { deposition fraction, }
\end{gathered}
$$

with the following values:

$$
\begin{gathered}
194.0 \mathrm{mg}=\text { nano }- \text { TiO2 aerosol concentration } \\
\cdot 7600 \mathrm{ml} / \mathrm{min} \cdot(8 \mathrm{hrs} / \mathrm{day} \cdot 60 \mathrm{~min} / \mathrm{hr}) \cdot 14 \%
\end{gathered}
$$

therefore:

$$
\begin{gathered}
194.0 \mathrm{mg}=\text { nano }- \text { TiO2 aerosol concentration } \\
\cdot 0.51 \mathrm{~m}^{3} / \text { day } \\
76 \text { days }=194.0 \mathrm{mg} /\left(\left(5 \mathrm{mg} / \mathrm{m}^{3}\right) \cdot 0.51 \mathrm{~m}^{3}\right) \text { nano- } \mathrm{TiO}_{2} .
\end{gathered}
$$

The National Institute for Occupational Safety and Health (NIOSH) Recommended Exposure Limit for nano- $\mathrm{TiO}_{2}$ aerosol concentration is $0.3 \mathrm{mg} / \mathrm{m}^{3}$, while the Permissible Exposure Limit set by the Occupational Safety and Health Administration is $5 \mathrm{mg} / \mathrm{m}^{3}$ (56). Consequently, it would require 76 days for a human to achieve analogous lung burdens with the exposure paradigm used in this study. Thus, the findings are of practical relevance for those exposed in an occupational context. Importantly, our results demonstrate that $\mathrm{H}_{2} \mathrm{O}_{2}$-induced stress from maternal nano- $\mathrm{TiO}_{2}$ inhalation exposure impacts global DNA methylation remodeling, and is associated with sustained mitochondrial bioenergetic and cardiac contractile dysfunction. 
Functioning mitochondria are necessary for providing the immense energy requirement that drives cardiac contraction and relaxation. Thus, mitochondrial dysfunction has been widely implicated as a precipitator of cardiac contractile dysfunction. $\mathrm{ROS}$, such as $\mathrm{H}_{2} \mathrm{O}_{2}$, are a by-product of oxidative phosphorylation, and as a result, the mitochondrion is an initial site of generation and damage. Pathological conditions, such as those presented by ENM exposure, have been associated with enhanced ROS production and mitochondrial dysfunction in cardiac tissue that may precede contractile dysfunction (39). $\mathrm{H}_{2} \mathrm{O}_{2}$ accumulation in the heart following maternal inhalation exposure to ENMs was significantly associated with negative consequences in the growing fetus, but the direct link between maternal exposure and increased progeny cardiac $\mathrm{H}_{2} \mathrm{O}_{2}$ is unknown. One theory suggests that changes in the placental environment, through changes in circulatory flow or inflammation, can trigger tissue specific alterations in the progeny (17).

In the current study we have shown that umbilical blood flow, through a reduction in enddiastolic velocity, was significantly altered (Figure 2.2E). Following an ENM exposure paradigm similar to the paradigm used for the current study, an increase in placental vascular resistance was reported, substantiating the antagonistic effects of nano- $\mathrm{TiO}_{2}$ exposure during gestation (1). Valentino et al. further validate placental circulatory remodeling through a significant decline in placental flow in rabbits, which was observed following gestational exposure to diesel exhaust (61). Additionally, they report decreased vascularization of the placental bed contributing to the effect. Along with diminished maternal-to-fetal blood flow following inhaled gases and particulates, an inflammatory response promoted through the vasculature could also be a contributing factor in untoward cardiovascular events in the growing progeny. Interleukin 1 beta (IL-1 $\beta$ ), IL-6, and monocyte chemoattractant protein-1 (MCP-1) were shown to be significantly elevated in maternal serum following inhalation exposure to ultrafine particulate matter (38). While the direct link between cardiac ROS production/accumulation and alterations to the placental environment are currently unknown, a strong link between placental mitochondrial health (Supplemental Figures 2.1C-E) and fetal cardiovascular outcomes is undoubtedly present. Following maternal ENM inhalation exposure, direct interaction of the ENM with the fetus, maternal immune responses, or other responses involving alterations in blood supply or content could all contribute to increased ROS in the cardiac tissue of the growing fetus. This increased fetal ROS, which is returned to baseline in the young adult, likely contributes to sustained cellular 
consequences, such as abnormal mitochondrial bioenergetics and ultrastructure which have been observed following ENM exposure, as well as disruption to the epigenome $(25,56)$.

Under normal conditions, oxygen-dependent prolyl hydroxylases target Hif1 $\alpha$ for proteasomal degradation; however, during hypoxic conditions, such as when ROS levels are elevated, prolyl hydroxylase activity is limited by the lack of oxygen and therefore results in the stabilization of Hif $1 \alpha$ permitting dimerization with Hif1 $\beta$, which is constitutively expressed (13, $22,34,49)$. This promotes the formation of an active HIF transcription factor complex (14). The Dnmt1 and Dnmt3b promoter regions contain the hypoxia response element (HRE), a consensus sequence for a Hif1 $\alpha$ binding site (62). We found a significant increase in Dnmt1 protein expression, but not activity, further substantiating our hypothesis that in a high ROS environment, elevated Hifl $\alpha$ activity leads to hypermethylation by causing an increase in Dnmt1 protein expression through promoter binding. DNA hypermethylation can cause enhanced profibrotic gene expression and the hypermethylation of $\mathrm{CpG}$ islands of vital genes, causing loss of gene expression (62). This could in turn propagate mitochondrial dysfunction and increased size associated with ENM exposure and increased ROS.

While the direct effects of ROS, such as disruption of protein structure and function, pose a significant threat to cellular health, indirect effects, such as ROS-mediated epigenetic remodeling, can have equal, if not more pronounced, ramifications. In melanoma cells, detachment from the plating surface revealed an increase in ROS, including $\mathrm{H}_{2} \mathrm{O}_{2}$, as well as an increase in global DNA methylation and Dnmt1 expression (11). When introducing an antioxidant, global DNA hypermethylation and Dnmt1 increased expression was shown to be prevented. Outside of global methylation, ROS can induce site-specific methylation profiles. $\mathrm{H}_{2} \mathrm{O}_{2}$ has been shown to increase DNMT1 expression, resulting in hypermethylation and decreased expression of runt domain transcription factor 3 (RUNX3) (33). Additionally, increased $\mathrm{H}_{2} \mathrm{O}_{2}$ has been linked to DNA hypermethylation and silencing of miRNAs, which regulate the expression of multiple genes and gene pathways in the cell (27). ROS have been linked to epigenetic modification of the promoter region of other glutathione peroxide family members (GPX3) (45).

The schema provided in Figure 2.6 encompasses the overall mechanism hypothesized based on the data in the current study. At the fetal stage, cardiac function is negatively impacted through increased $\mathrm{H}_{2} \mathrm{O}_{2}$ levels, which can have negative consequences on mitochondrial function and bioenergetics. The increased $\mathrm{H}_{2} \mathrm{O}_{2}$ can also lead to an activation of Hif1 $\alpha$ activity, which is 
then able to transcriptionally activate the promoter region of a variety of genes, including Dnmt1 and other epigenetic machinery. Augmenting Dnmt1 expression would lead to a global or sitespecific increase in methylation, and in turn repress pivotal genes such as GPx4. By decreasing antioxidant defenses (GPx4), a futile cycle would be propagated through a decreased ability to scavenge ROS such as $\mathrm{H}_{2} \mathrm{O}_{2}$, resulting in a further increase in ROS. Cardiac and mitochondrial dysfunction are therefore sustained into adulthood due to epigenomic remodeling that occurred at the fetal stage.

The role of epigenetic remodeling has been investigated in terms of the intrauterine environment and external stressors may have negative implications on the growing fetus $(23,64)$. The offspring of mothers who had diabetes mellitus or were obese during gestation showed increased incidence of epigenetic changes and an increased risk of type 2 diabetes mellitus and other metabolic disorders that can lead to cardiovascular dysfunction (12). Alterations in the epigenome of young adult offspring were also shown as a potential result of ENM exposure in pregnant rats, which could enhance susceptibility to future insult (56). The demonstration of such changes in a mouse model, as detailed in this study, opens up the possibility of examining the fetal and young adult offspring epigenome using genetic manipulations $(25,39)$.

This study suggests potential mechanisms such as ROS, that can contribute to epigenomic remodeling of the fetus, in utero, but the study is limited in unveiling larger pathways associated with increased genome methylation. We provide a mechanism whereby ROS scavenging is decreased, leading to the accumulation of ROS and ultimately methylation of the genome, but it is likely that this pathway is more dynamic with other epigenetic machinery and transcription factors that are altered. Future experimentation into the specific genes and regulatory pathways that are hypermethylated may provide better insight into the mechanisms contributing to the sustained mitochondrial and cardiac dysfunction observed. 


\section{Conclusions}

This study highlights disruptions in cardiac and mitochondrial function in offspring of nano- $\mathrm{TiO}_{2}$ exposed mice during gestation. These dysfunctions are sustained into adulthood and are most likely due to epigenetic reprogramming, mediated through enhanced $\mathrm{H}_{2} \mathrm{O}_{2}$ which occurs during gestation in the growing fetus. Increased methylation and decreased GPx4 levels suggest repression of important antioxidant proteins, thus perpetuating the inability to control elevated ROS levels and leading to mitochondrial and cardiac dysfunction. 


\section{Declarations}

Ethics approval and consent to participate

The West Virginia University Animal Care and Use Committee approved all animal studies, which conformed to the most current National Institutes of Health (NIH) Guidelines for the Care and Use of Laboratory Animals manual.

\section{Consent for publication}

Not applicable

\section{Availability of data and material}

All data generated or analyzed during this study are included in this published article [and its supplementary information files].

\section{Competing interests}

The authors declare that they have no competing interests

\section{Funding}

R01 HL-128485 (JMH), R01 ES-015022 (TRN), AHA-17PRE33660333 (QAH), DGE-1144676 (QAH, TRN), WV-INBRE support by NIH Grant P20GM103434, WVU Flow Cytometry \& Single Cell Core supported by MBRCC CoBRE Grant GM103488 and Fortessa S10 Grant OD016165, and the Community Foundation for the Ohio Valley Whipkey Trust (JMH).

\section{Authors' contributions}

AK, QAH, TRN, and JMH conceptualized the project and experimental measures. WTG managed the nano- $\mathrm{TiO}_{2}$ exposure paradigm. AK, QAH, and AJD handled animals, including management and tissue dissection. AK, QAH, MVP, AJD, and GKF performed experimentation. AK and QAH analyzed and processed results. AK, QAH, MVP, WTG, TRN, and JMH contributed to the writing and editing of the manuscript.

\section{Acknowledgements}


We would like to thank Sherri A. Friend and the National Institute for Occupational Safety and Health, Morgantown, WV, USA for providing scanning and transmission electron micrographs of nano- $\mathrm{TiO}_{2}$ aerosolized particles. 


\section{References:}

1. Abukabda AB, Bowdridge EC, McBride CR, Batchelor TP, Goldsmith WT, Garner KL, Friend S, and Nurkiewicz TR. Maternal titanium dioxide nanomaterial inhalation exposure compromises placental hemodynamics. Toxicol Appl Pharmacol 367: 51-61, 2019.

2. Abukabda AB, McBride CR, Batchelor TP, Goldsmith WT, Bowdridge EC, Garner KL, Friend S, and Nurkiewicz TR. Group II innate lymphoid cells and microvascular dysfunction from pulmonary titanium dioxide nanoparticle exposure. Part Fibre Toxicol 15: 43, 2018.

3. Adiotomre PN, Johnstone FD, and Laing IA. Effect of absent end diastolic flow velocity in the fetal umbilical artery on subsequent outcome. Arch Dis Child Fetal Neonatal Ed 76: F3538, 1997.

4. Almond D, and Currie J. Killing Me Softly: The Fetal Origins Hypothesis. J Econ Perspect 25: 153-172, 2011.

5. Bakshi MV, Azimzadeh O, Merl-Pham J, Verreet T, Hauck SM, Benotmane MA, Atkinson MJ, and Tapio S. In-Utero Low-Dose Irradiation Leads to Persistent Alterations in the Mouse Heart Proteome. PLoS One 11: e0156952, 2016.

6. Baseler WA, Dabkowski ER, Jagannathan R, Thapa D, Nichols CE, Shepherd DL, Croston TL, Powell M, Razunguzwa TT, Lewis SE, Schnell DM, and Hollander JM. Reversal of mitochondrial proteomic loss in Type 1 diabetic heart with overexpression of phospholipid hydroperoxide glutathione peroxidase. Am J Physiol Regul Integr Comp Physiol 304: R553-565, 2013.

7. Baseler WA, Dabkowski ER, Williamson CL, Croston TL, Thapa D, Powell MJ, Razunguzwa TT, and Hollander JM. Proteomic alterations of distinct mitochondrial subpopulations in the type 1 diabetic heart: contribution of protein import dysfunction. Am $J$ Physiol Regul Integr Comp Physiol 300: R186-200, 2011.

8. Blessberger $\mathbf{H}$, and Binder $\mathbf{T}$. Two dimensional speckle tracking echocardiography: clinical applications. Heart 96: 2032-2040, 2010.

9. Bommarito PA, Martin E, and Fry RC. Effects of prenatal exposure to endocrine disruptors and toxic metals on the fetal epigenome. Epigenomics 9: 333-350, 2017.

10. Bradford MM. A rapid and sensitive method for the quantitation of microgram quantities of protein utilizing the principle of protein-dye binding. Anal Biochem 72: 248-254, 1976.

11. Campos AC, Molognoni F, Melo FH, Galdieri LC, Carneiro CR, D'Almeida V, Correa M, and Jasiulionis MG. Oxidative stress modulates DNA methylation during melanocyte anchorage blockade associated with malignant transformation. Neoplasia 9: 1111-1121, 2007.

12. Cerychova R, Bohuslavova R, Papousek F, Sedmera D, Abaffy P, Benes V, Kolar F, and Pavlinkova G. Adverse effects of Hifla mutation and maternal diabetes on the offspring heart. Cardiovasc Diabetol 17: 68, 2018.

13. Chandel NS, McClintock DS, Feliciano CE, Wood TM, Melendez JA, Rodriguez AM, and Schumacker PT. Reactive oxygen species generated at mitochondrial complex III stabilize hypoxia-inducible factor-1alpha during hypoxia: a mechanism of O2 sensing. J Biol Chem 275: 25130-25138, 2000.

14. Chang TC, Huang CJ, Tam K, Chen SF, Tan KT, Tsai MS, Lin TN, and Shyue SK. Stabilization of hypoxia-inducible factor-1\{alpha\} by prostacyclin under prolonged hypoxia via reducing reactive oxygen species level in endothelial cells. J Biol Chem 280: 36567-36574, 2005. 
15. Crispi F, Miranda J, and Gratacos E. Long-term cardiovascular consequences of fetal growth restriction: biology, clinical implications, and opportunities for prevention of adult disease. Am J Obstet Gynecol 218: S869-S879, 2018.

16. Croston TL, Thapa D, Holden AA, Tveter KJ, Lewis SE, Shepherd DL, Nichols CE, Long DM, Olfert IM, Jagannathan R, and Hollander JM. Functional deficiencies of subsarcolemmal mitochondria in the type 2 diabetic human heart. Am J Physiol Heart Circ Physiol 307: H54-65, 2014.

17. D'Errico JN, and Stapleton PA. Developmental onset of cardiovascular disease-Could the proof be in the placenta? Microcirculation e12526, 2018.

18. Dabkowski ER, Baseler WA, Williamson CL, Powell M, Razunguzwa TT, Frisbee JC, and Hollander JM. Mitochondrial dysfunction in the type 2 diabetic heart is associated with alterations in spatially distinct mitochondrial proteomes. Am J Physiol Heart Circ Physiol 299: H529-540, 2010.

19. Dabkowski ER, Williamson CL, Bukowski VC, Chapman RS, Leonard SS, Peer CJ, Callery PS, and Hollander JM. Diabetic cardiomyopathy-associated dysfunction in spatially distinct mitochondrial subpopulations. Am J Physiol Heart Circ Physiol 296: H359-369, 2009.

20. Gagnon R, Van den Hof M, Diagnostic Imaging Committee E, Council of the Society of $\mathbf{O}$, and Gynaecologists of C. The use of fetal Doppler in obstetrics. J Obstet Gynaecol Can 25: 601-614; quiz 615-606, 2003.

21. Gauthier TW, Ping XD, Gabelaia L, and Brown LA. Delayed neonatal lung macrophage differentiation in a mouse model of in utero ethanol exposure. Am J Physiol Lung Cell Mol Physiol 299: L8-16, 2010.

22. Gerald D, Berra E, Frapart YM, Chan DA, Giaccia AJ, Mansuy D, Pouyssegur J, Yaniv M, and Mechta-Grigoriou F. JunD reduces tumor angiogenesis by protecting cells from oxidative stress. Cell 118: 781-794, 2004.

23. Gluckman PD, Hanson MA, Buklijas T, Low FM, and Beedle AS. Epigenetic mechanisms that underpin metabolic and cardiovascular diseases. Nat Rev Endocrinol 5: 401-408, 2009.

24. Grafmueller S, Manser P, Diener L, Diener PA, Maeder-Althaus X, Maurizi L, Jochum W, Krug HF, Buerki-Thurnherr T, von Mandach U, and Wick P. Bidirectional Transfer Study of Polystyrene Nanoparticles across the Placental Barrier in an ex Vivo Human Placental Perfusion Model. Environ Health Perspect 123: 1280-1286, 2015.

25. Hathaway QA, Durr AJ, Shepherd DL, Pinti MV, Brandebura AN, Nichols CE, Kunovac A, Goldsmith WT, Friend SA, Abukabda AB, Fink GK, Nurkiewicz TR, and JM aH. miRNA-378a as a key regulator of cardiovascular health following engineered nanomaterial inhalation exposure. Nanotoxicology 1-20, 2019.

26. Hathaway QA, Nichols CE, Shepherd DL, Stapleton PA, McLaughlin SL, Stricker JC, Rellick SL, Pinti MV, Abukabda AB, McBride CR, Yi J, Stine SM, Nurkiewicz TR, and Hollander JM. Maternal-engineered nanomaterial exposure disrupts progeny cardiac function and bioenergetics. Am J Physiol Heart Circ Physiol 312: H446-H458, 2017.

27. He J, Xu Q, Jing Y, Agani F, Qian X, Carpenter R, Li Q, Wang XR, Peiper SS, Lu Z, Liu LZ, and Jiang BH. Reactive oxygen species regulate ERBB2 and ERBB3 expression via miR-199a/125b and DNA methylation. EMBO Rep 13: 1116-1122, 2012.

28. He Z, Zhang R, Jiang F, Hou W, and Hu C. Role of genetic and environmental factors in DNA methylation of lipid metabolism. Genes Dis 5: 9-15, 2018. 
29. Heindel JJ, and Vandenberg LN. Developmental origins of health and disease: a paradigm for understanding disease cause and prevention. Curr Opin Pediatr 27: 248-253, 2015. 30. Hernandez-Andrade E, Ahn H, Szalai G, Korzeniewski SJ, Wang B, King M, Chaiworapongsa T, Than NG, and Romero R. Evaluation of utero-placental and fetal hemodynamic parameters throughout gestation in pregnant mice using high-frequency ultrasound. Ultrasound Med Biol 40: 351-360, 2014.

31. Jang HS, Shin WJ, Lee JE, and Do JT. CpG and Non-CpG Methylation in Epigenetic Gene Regulation and Brain Function. Genes (Basel) 8: 2017.

32. Jin B, and Robertson KD. DNA methyltransferases, DNA damage repair, and cancer. Adv Exp Med Biol 754: 3-29, 2013.

33. Kang KA, Zhang R, Kim GY, Bae SC, and Hyun JW. Epigenetic changes induced by oxidative stress in colorectal cancer cells: methylation of tumor suppressor RUNX3. Tumour Biol 33: 403-412, 2012.

34. Kim GH, Ryan JJ, and Archer SL. The role of redox signaling in epigenetics and cardiovascular disease. Antioxid Redox Signal 18: 1920-1936, 2013.

35. Knuckles TL, Yi J, Frazer DG, Leonard HD, Chen BT, Castranova V, and Nurkiewicz TR. Nanoparticle inhalation alters systemic arteriolar vasoreactivity through sympathetic and cyclooxygenase-mediated pathways. Nanotoxicology 6: 724-735, 2012.

36. Leung YK, Govindarajah V, Cheong A, Veevers J, Song D, Gear R, Zhu X, Ying J, Kendler A, Medvedovic M, Belcher S, and Ho SM. Gestational high-fat diet and bisphenol A exposure heightens mammary cancer risk. Endocr Relat Cancer 24: 365-378, 2017.

37. Li Y, Park JS, Deng JH, and Bai Y. Cytochrome c oxidase subunit IV is essential for assembly and respiratory function of the enzyme complex. J Bioenerg Biomembr 38: 283-291, 2006.

38. Morales-Rubio RA, Alvarado-Cruz I, Manzano-Leon N, Andrade-Oliva MD, UribeRamirez M, Quintanilla-Vega B, Osornio-Vargas A, and De Vizcaya-Ruiz A. In utero exposure to ultrafine particles promotes placental stress-induced programming of reninangiotensin system-related elements in the offspring results in altered blood pressure in adult mice. Part Fibre Toxicol 16: 7, 2019.

39. Nichols CE, Shepherd DL, Hathaway QA, Durr AJ, Thapa D, Abukabda A, Yi J, Nurkiewicz TR, and Hollander JM. Reactive oxygen species damage drives cardiac and mitochondrial dysfunction following acute nano-titanium dioxide inhalation exposure. Nanotoxicology 12: 32-48, 2018.

40. Nichols CE, Shepherd DL, Knuckles TL, Thapa D, Stricker JC, Stapleton PA, Minarchick VC, Erdely A, Zeidler-Erdely PC, Alway SE, Nurkiewicz TR, and Hollander JM. Cardiac and mitochondrial dysfunction following acute pulmonary exposure to mountaintop removal mining particulate matter. Am J Physiol Heart Circ Physiol 309: H2017-2030, 2015.

41. Nilsson E, Larsen G, Manikkam M, Guerrero-Bosagna C, Savenkova MI, and Skinner MK. Environmentally induced epigenetic transgenerational inheritance of ovarian disease. PLoS One 7: e36129, 2012.

42. Nurkiewicz TR, Porter DW, Hubbs AF, Cumpston JL, Chen BT, Frazer DG, and Castranova V. Nanoparticle inhalation augments particle-dependent systemic microvascular dysfunction. Part Fibre Toxicol 5: 1, 2008.

43. Palmer JW, Tandler B, and Hoppel CL. Biochemical properties of subsarcolemmal and interfibrillar mitochondria isolated from rat cardiac muscle. J Biol Chem 252: 8731-8739, 1977. 
44. Pavlopoulos H, and Nihoyannopoulos P. Strain and strain rate deformation parameters: from tissue Doppler to 2D speckle tracking. Int J Cardiovasc Imaging 24: 479-491, 2008.

45. Peng DF, Hu TL, Schneider BG, Chen Z, Xu ZK, and El-Rifai W. Silencing of glutathione peroxidase 3 through DNA hypermethylation is associated with lymph node metastasis in gastric carcinomas. PLoS One 7: e46214, 2012.

46. R. W. Bide SJA, E. Yee. Estimation of Human Toxicity from Animal Inhalation Toxicity Data: 1. Minute Volume - Body Weight Relationships Between Animals and Man. edited by Suffield DRE. Alberta, Canada: National Defence, 1997.

47. Robichaud CO, Uyar AE, Darby MR, Zucker LG, and Wiesner MR. Estimates of upper bounds and trends in nano-TiO2 production as a basis for exposure assessment. Environ Sci Technol 43: 4227-4233, 2009.

48. Sager TM, Kommineni C, and Castranova V. Pulmonary response to intratracheal instillation of ultrafine versus fine titanium dioxide: role of particle surface area. Part Fibre Toxicol 5: 17, 2008.

49. Salceda S, and Caro J. Hypoxia-inducible factor 1alpha (HIF-1alpha) protein is rapidly degraded by the ubiquitin-proteasome system under normoxic conditions. Its stabilization by hypoxia depends on redox-induced changes. J Biol Chem 272: 22642-22647, 1997.

50. Shanbhag AG. Utilization of Information Measure as a Means of Image Thresholding. Cvgip-Graph Model Im 56: 414-419, 1994.

51. Shepherd DL, Hathaway QA, Pinti MV, Nichols CE, Durr AJ, Sreekumar S, Hughes KM, Stine SM, Martinez I, and Hollander JM. Exploring the mitochondrial microRNA import pathway through Polynucleotide Phosphorylase (PNPase). J Mol Cell Cardiol 110: 15-25, 2017.

52. Shepherd DL, Nichols CE, Croston TL, McLaughlin SL, Petrone AB, Lewis SE, Thapa D, Long DM, Dick GM, and Hollander JM. Early detection of cardiac dysfunction in the type 1 diabetic heart using speckle-tracking based strain imaging. J Mol Cell Cardiol 90: 7483, 2016.

53. Spurney CF, Lo CW, and Leatherbury L. Fetal mouse imaging using echocardiography: a review of current technology. Echocardiography 23: 891-899, 2006.

54. Sreejit P, Kumar S, and Verma RS. An improved protocol for primary culture of cardiomyocyte from neonatal mice. In Vitro Cell Dev Biol Anim 44: 45-50, 2008.

55. Srinivasan S, and Avadhani NG. Cytochrome c oxidase dysfunction in oxidative stress. Free Radic Biol Med 53: 1252-1263, 2012.

56. Stapleton PA, Hathaway QA, Nichols CE, Abukabda AB, Pinti MV, Shepherd DL, McBride CR, Yi J, Castranova VC, Hollander JM, and Nurkiewicz TR. Maternal engineered nanomaterial inhalation during gestation alters the fetal transcriptome. Part Fibre Toxicol 15: 3, 2018.

57. Stapleton PA, Minarchick VC, Cumpston AM, McKinney W, Chen BT, Sager TM, Frazer DG, Mercer RR, Scabilloni J, Andrew ME, Castranova V, and Nurkiewicz TR. Impairment of coronary arteriolar endothelium-dependent dilation after multi-walled carbon nanotube inhalation: a time-course study. Int J Mol Sci 13: 13781-13803, 2012.

58. Starkov AA. Measurement of mitochondrial ROS production. Methods Mol Biol 648: 245$255,2010$.

59. Stone KC, Mercer RR, Gehr P, Stockstill B, and Crapo JD. Allometric relationships of cell numbers and size in the mammalian lung. Am J Respir Cell Mol Biol 6: 235-243, 1992.

60. Thapa D, Nichols CE, Lewis SE, Shepherd DL, Jagannathan R, Croston TL, Tveter KJ, Holden AA, Baseler WA, and Hollander JM. Transgenic overexpression of mitofilin 
attenuates diabetes mellitus-associated cardiac and mitochondria dysfunction. J Mol Cell Cardiol 79: 212-223, 2015.

61. Valentino SA, Tarrade A, Aioun J, Mourier E, Richard C, Dahirel M, RousseauRalliard D, Fournier N, Aubriere MC, Lallemand MS, Camous S, Guinot M, Charlier M, Aujean E, Al Adhami H, Fokkens PH, Agier L, Boere JA, Cassee FR, Slama R, and ChavattePalmer P. Maternal exposure to diluted diesel engine exhaust alters placental function and induces intergenerational effects in rabbits. Part Fibre Toxicol 13: 39, 2016.

62. Watson CJ, Collier P, Tea I, Neary R, Watson JA, Robinson C, Phelan D, Ledwidge MT, McDonald KM, McCann A, Sharaf O, and Baugh JA. Hypoxia-induced epigenetic modifications are associated with cardiac tissue fibrosis and the development of a myofibroblastlike phenotype. Hum Mol Genet 23: 2176-2188, 2014.

63. Williamson CL, Dabkowski ER, Baseler WA, Croston TL, Alway SE, and Hollander JM. Enhanced apoptotic propensity in diabetic cardiac mitochondria: influence of subcellular spatial location. Am J Physiol Heart Circ Physiol 298: H633-642, 2010.

64. Wolstenholme JT, Edwards M, Shetty SR, Gatewood JD, Taylor JA, Rissman EF, and Connelly JJ. Gestational exposure to bisphenol a produces transgenerational changes in behaviors and gene expression. Endocrinology 153: 3828-3838, 2012.

65. Wong K, Bumpstead S, Van Der Weyden L, Reinholdt LG, Wilming LG, Adams DJ, and Keane TM. Sequencing and characterization of the FVB/NJ mouse genome. Genome Biol 13: R72, 2012.

66. Yoshida S, Tsutsumi S, Muhlebach G, Sourbier C, Lee MJ, Lee S, Vartholomaiou E, Tatokoro M, Beebe K, Miyajima N, Mohney RP, Chen Y, Hasumi H, Xu W, Fukushima H, Nakamura K, Koga F, Kihara K, Trepel J, Picard D, and Neckers L. Molecular chaperone TRAP1 regulates a metabolic switch between mitochondrial respiration and aerobic glycolysis. Proc Natl Acad Sci U S A 110: E1604-1612, 2013.

67. Zhou YQ, Cahill LS, Wong MD, Seed M, Macgowan CK, and Sled JG. Assessment of flow distribution in the mouse fetal circulation at late gestation by high-frequency Doppler ultrasound. Physiol Genomics 46: 602-614, 2014. 
Table 2.1: M-Mode Echocardiography

\begin{tabular}{|c|c|c|c|c|c|c|}
\hline \multirow[b]{2}{*}{ Parameter } & \multicolumn{2}{|c|}{ Maternal } & \multicolumn{2}{|c|}{ Fetal } & \multicolumn{2}{|c|}{ Young Adult } \\
\hline & Sham & Ex & Sham & Ex & Sham & Ex \\
\hline $\begin{array}{l}\text { Heart Rate } \\
\text { (BPM) }\end{array}$ & $\begin{array}{c}672.05 \pm \\
8.30\end{array}$ & $\begin{array}{c}685.39 \pm \\
7.01\end{array}$ & $\begin{array}{c}134.28 \pm \\
8.72\end{array}$ & $\begin{array}{c}118.94 \pm \\
3.40\end{array}$ & $\begin{array}{c}649.49 \pm \\
23.72\end{array}$ & $\begin{array}{c}601.87 \pm \\
65.46\end{array}$ \\
\hline $\begin{array}{l}\text { Diameter;s } \\
(\mathbf{m m})\end{array}$ & $\begin{array}{c}0.58 \pm \\
0.05\end{array}$ & $\begin{array}{c}0.59 \pm \\
0.08\end{array}$ & $\begin{array}{c}0.25 \pm \\
0.02\end{array}$ & $\begin{array}{c}0.24 \pm \\
0.02\end{array}$ & $\begin{array}{c}0.38 \pm \\
0.05\end{array}$ & $\begin{array}{l}0.73 \pm \\
0.13^{*}\end{array}$ \\
\hline $\begin{array}{l}\text { Diameter;d } \\
\quad(\mathrm{mm})\end{array}$ & $\begin{array}{c}2.70 \pm \\
0.08\end{array}$ & $\begin{array}{l}2.43 \pm \\
0.05^{*}\end{array}$ & $\begin{array}{c}0.71 \pm \\
0.02\end{array}$ & $\begin{array}{c}0.69 \pm \\
0.03\end{array}$ & $\begin{array}{c}1.95 \pm \\
0.13\end{array}$ & $\begin{array}{c}2.25 \pm \\
0.15\end{array}$ \\
\hline $\begin{array}{l}\text { Volume;s } \\
\text { (uL) }\end{array}$ & $\begin{array}{c}0.64 \pm \\
0.16\end{array}$ & $\begin{array}{c}0.53 \pm \\
0.16\end{array}$ & $\begin{array}{c}0.05 \pm \\
0.01\end{array}$ & $\begin{array}{c}0.04 \pm \\
0.01\end{array}$ & $\begin{array}{c}0.14 \pm \\
0.06\end{array}$ & $\begin{array}{l}0.58 \pm \\
0.13 * *\end{array}$ \\
\hline $\begin{array}{c}\text { Volume;d } \\
\text { (uL) }\end{array}$ & $\begin{array}{c}27.60 \pm \\
1.92\end{array}$ & $\begin{array}{c}21.15 \pm \\
1.13 * *\end{array}$ & $\begin{array}{c}0.85 \pm \\
0.08\end{array}$ & $\begin{array}{c}0.79 \pm \\
0.08\end{array}$ & $\begin{array}{c}12.64 \pm \\
2.21\end{array}$ & $\begin{array}{c}14.50 \pm \\
0.58\end{array}$ \\
\hline $\begin{array}{c}\text { Stroke } \\
\text { Volume } \\
\text { (uL) }\end{array}$ & $\begin{array}{c}26.96 \pm \\
1.83\end{array}$ & $\begin{array}{c}20.43 \pm \\
1.08^{*}\end{array}$ & $\begin{array}{c}0.80 \pm \\
0.07\end{array}$ & $\begin{array}{c}0.74 \pm \\
0.07\end{array}$ & $\begin{array}{c}12.46 \pm \\
2.17\end{array}$ & $\begin{array}{c}13.92 \pm \\
0.48\end{array}$ \\
\hline $\begin{array}{c}\text { Ejection } \\
\text { Fraction } \\
(\%)\end{array}$ & $\begin{array}{c}97.84 \pm \\
0.43\end{array}$ & $\begin{array}{c}96.72 \pm \\
0.99\end{array}$ & $\begin{array}{c}95.16 \pm \\
0.84\end{array}$ & $\begin{array}{c}94.79 \pm \\
0.67\end{array}$ & $\begin{array}{c}98.84 \\
0.33\end{array}$ & $\begin{array}{c}94.65 \pm \\
1.53 *\end{array}$ \\
\hline $\begin{array}{c}\text { Fractional } \\
\text { Shortening } \\
(\%)\end{array}$ & $\begin{array}{c}78.56 \pm \\
1.67\end{array}$ & $\begin{array}{c}75.89 \pm \\
2.95\end{array}$ & $\begin{array}{c}65.68 \pm \\
2.31\end{array}$ & $\begin{array}{c}65.62 \pm \\
1.56\end{array}$ & $\begin{array}{c}80.80 \pm \\
1.89\end{array}$ & $\begin{array}{c}68.38 \pm \\
3.14^{* * *}\end{array}$ \\
\hline $\begin{array}{l}\text { Cardiac } \\
\text { Output } \\
\text { (mL/min) }\end{array}$ & $\begin{array}{c}18.17 \pm \\
1.31\end{array}$ & $\begin{array}{c}13.79 \pm \\
0.67^{*}\end{array}$ & $\begin{array}{c}0.10 \pm \\
0.01\end{array}$ & $\begin{array}{l}0.08 \pm \\
0.01 *\end{array}$ & $\begin{array}{c}8.30 \pm \\
1.68\end{array}$ & $\begin{array}{c}9.35 \pm \\
0.34\end{array}$ \\
\hline $\begin{array}{l}\text { LV Mass } \\
\text { (mg) }\end{array}$ & $\begin{array}{c}88.03 \pm \\
4.89\end{array}$ & $\begin{array}{c}75.53 \pm \\
8.13\end{array}$ & $\begin{array}{c}0.42 \pm \\
0.04\end{array}$ & $\begin{array}{l}0.74 \pm \\
0.13^{*}\end{array}$ & $\begin{array}{c}83.42 \pm \\
7.13\end{array}$ & $\begin{array}{c}79.05 \pm \\
5.59\end{array}$ \\
\hline
\end{tabular}


Table 2.1: M-mode echocardiography imaging following maternal nano- $\mathrm{TiO}_{2}$ inhalation exposure. Measurements were taken for a minimum of 3 consecutive systolic and diastolic peaks and troughs for maternal ( $\mathrm{n}=15$ Sham, $\mathrm{n}=11 \mathrm{Ex})$, fetal $(\mathrm{n}=15$ Sham, $\mathrm{n}=11 \mathrm{Ex})$, and young adult $(\mathrm{n}=7$ Sham, $\mathrm{n}=5 \mathrm{Ex})$. Sham $=$ control filtered air exposed, Ex $=$ nano- $\mathrm{TiO}_{2}$ exposed, Maternal $(M)=12$ week old pregnant dams, Fetal $(\mathrm{F})=\mathrm{GD}(15)$, Young Adult $(\mathrm{YA})=11$ weeks, Diameter; $\mathrm{d}=$ diastolic diameter, Diameter;s = systolic diameter, LV Mass = left ventricular mass, $\mathrm{V} ; \mathrm{d}=$ volume during diastole, $\mathrm{V} ; \mathrm{s}=$ volume during systole. All data are presented as the mean \pm standard error of the mean (SEM). $*=P \leq 0.05, * *=P \leq 0.01, * * *=P \leq 0.001$ for Ex vs. Sham. 
Figure 2.1: Exposure Paradigm
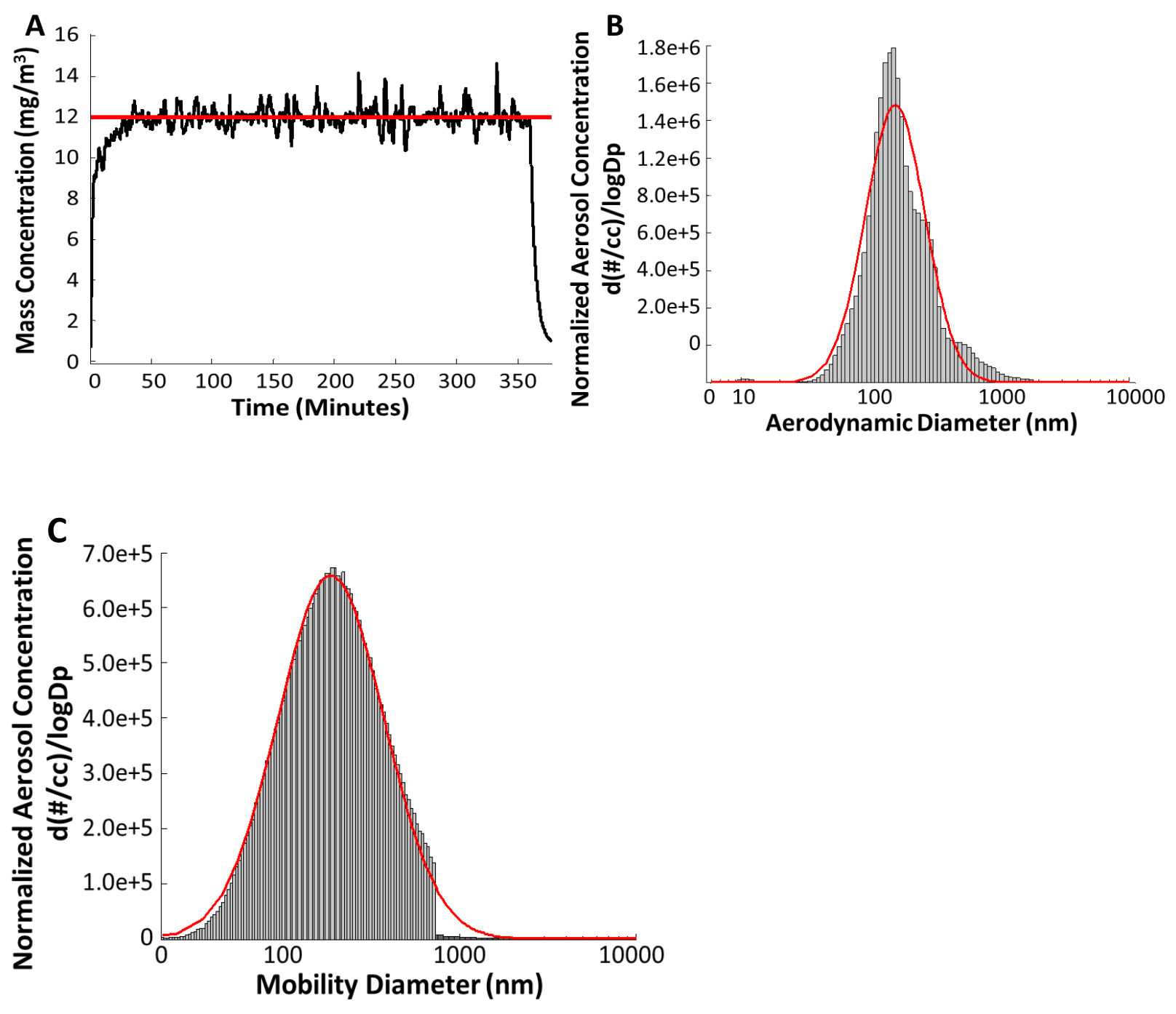
Figure 2.1:

D
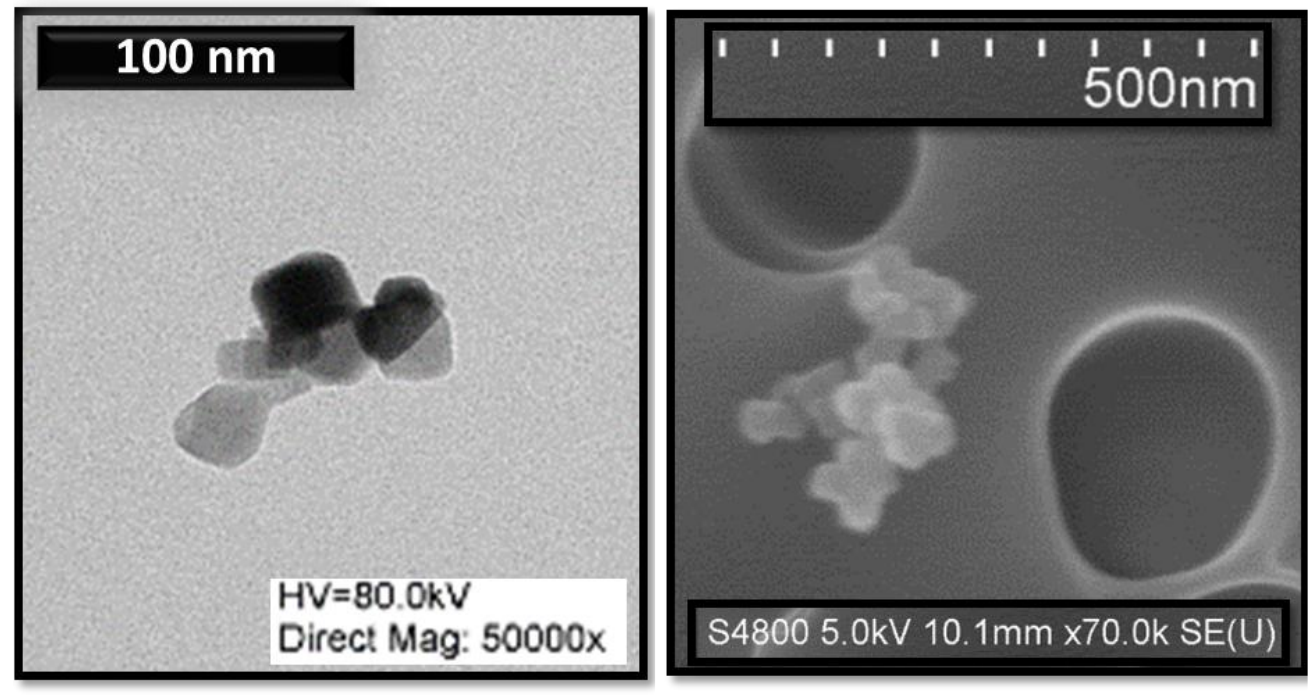

E

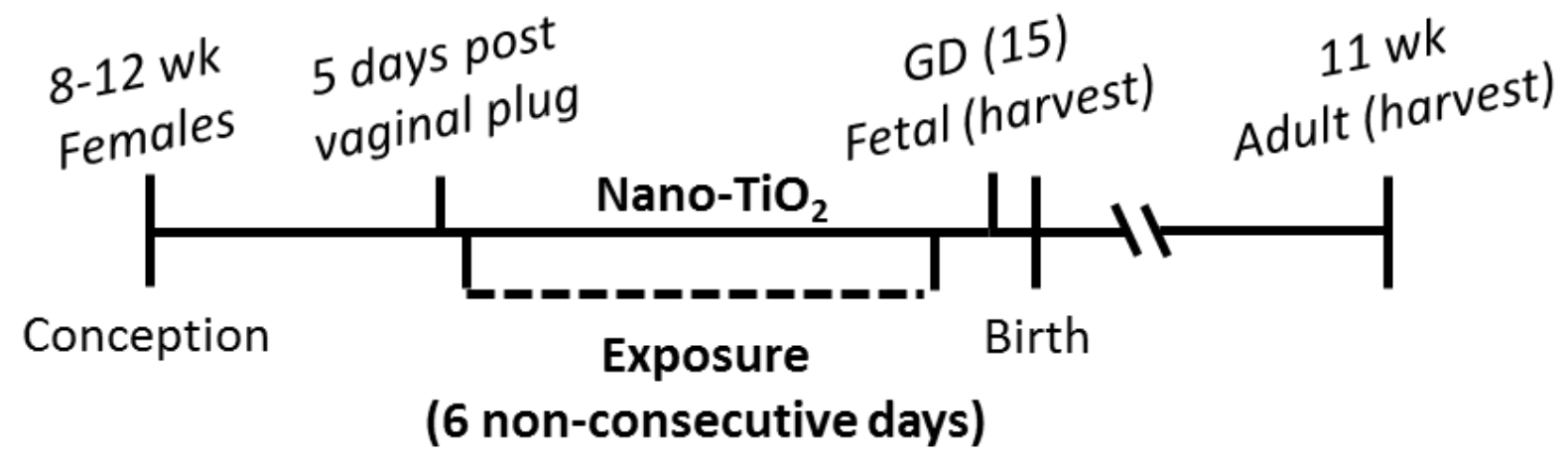


Figure 2.1: Maternal nano- $\mathrm{TiO}_{2}$ inhalation exposure paradigm. (A) Real-time aerosol mass concentration measurements of engineered nano-TiO2 during a typical maternal exposure with the target concentration indicated by the red line (12mg/m3). (B) Aerodynamic diameter of nano- $\mathrm{TiO}_{2}$ $(\mathrm{CMD}=156 \mathrm{~nm})$ measured by high resolution electric low-pressure impactor (ELPI+). (C) Diameter of nano- $\mathrm{TiO}_{2}(\mathrm{CMD}=184 \mathrm{~nm})$ measured by combining scanning mobility particle sizer (SMPS) and aerodynamic particle sizer (APS) measurements. Red line indicates log-normal fit. (D) Transmission and scanning electron micrographs of nano- $\mathrm{TiO}_{2}$ aerosolized particles. (E) A timeline of the study. $\mathrm{CMD}=$ Count Median Diameter. All data are presented as the mean \pm standard error of the mean (SEM). 
Figure 2.2: Pulse Wave Doppler and the Fetal Environment
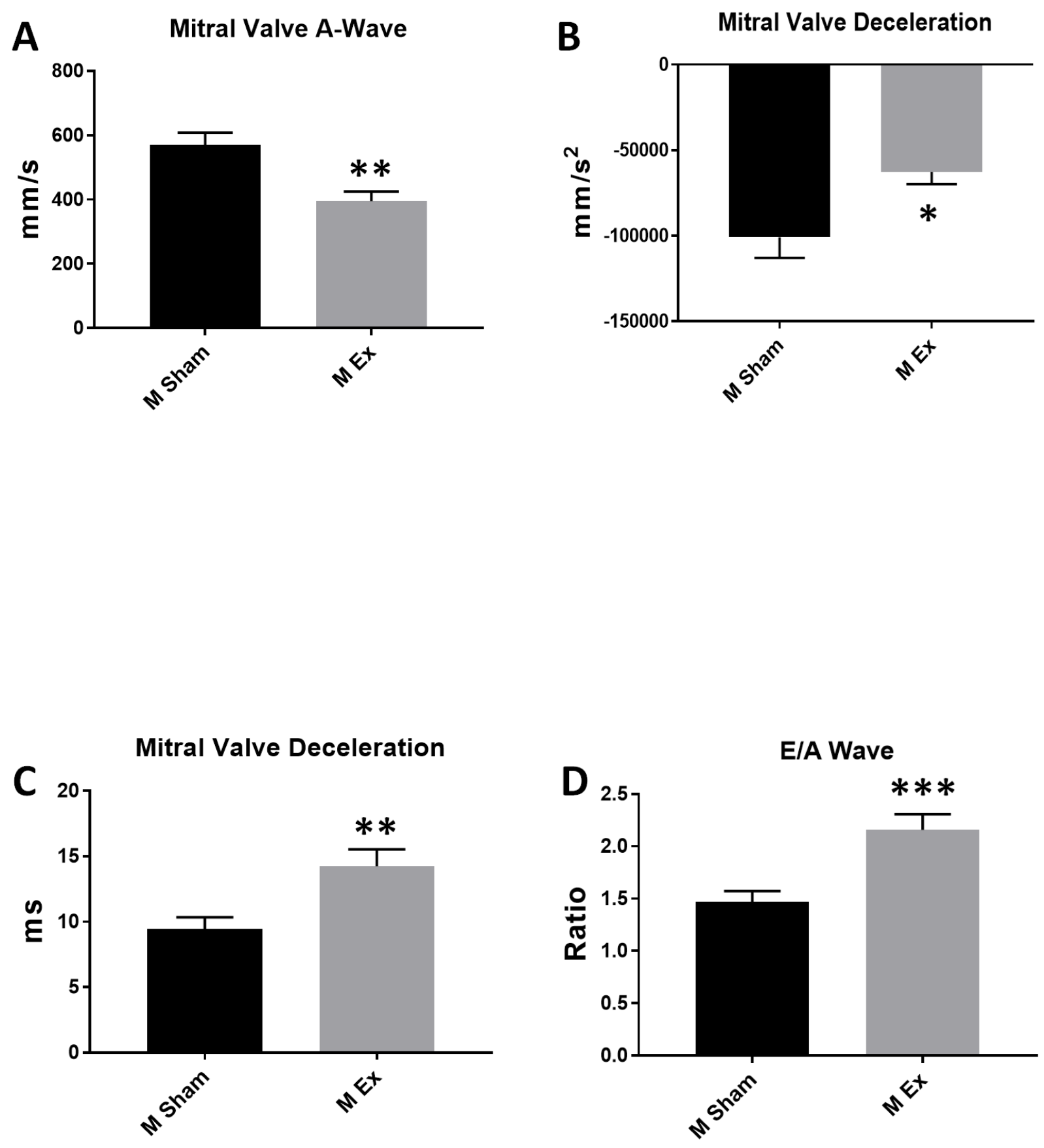
Figure 2.2:
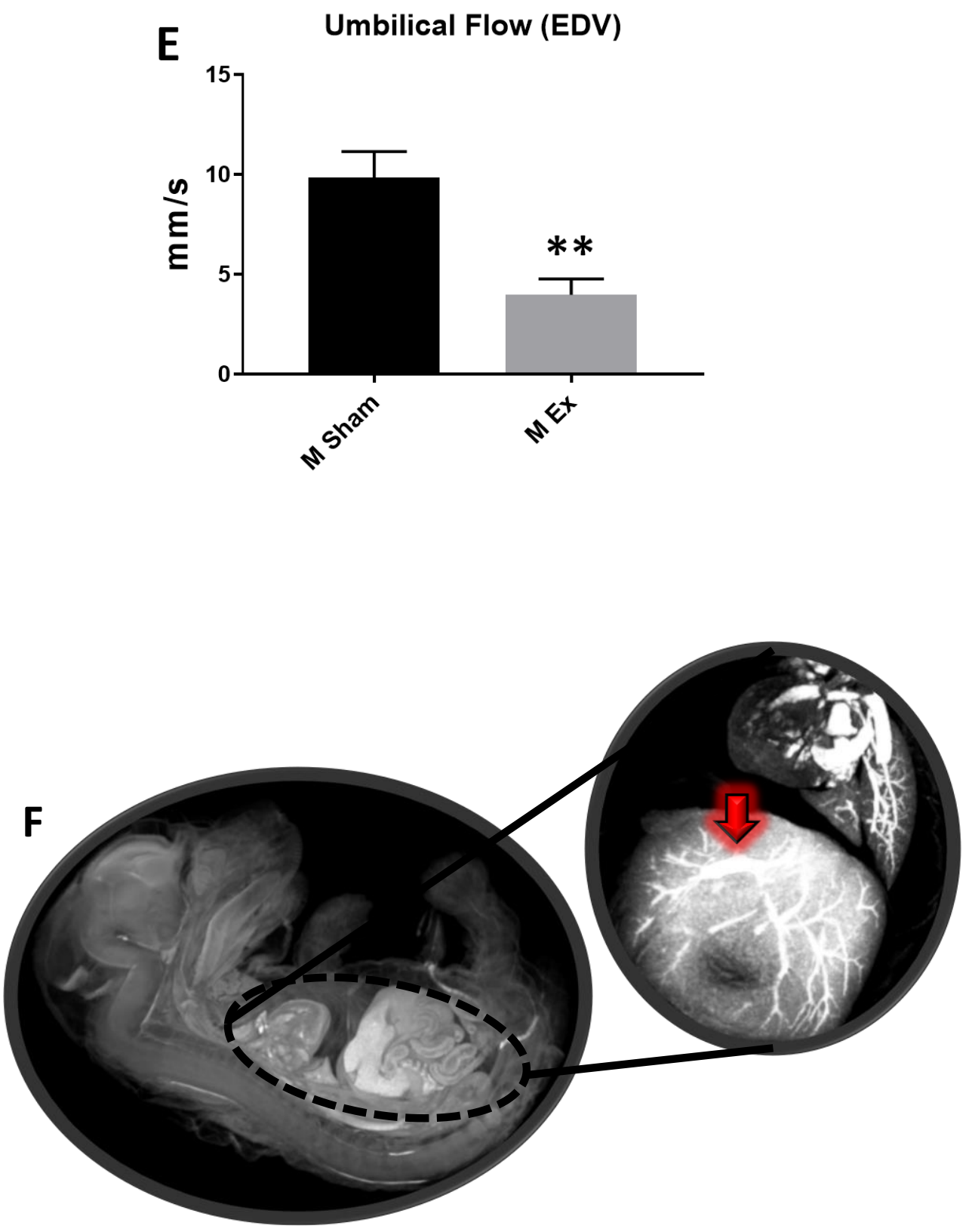
Figure 2.2:
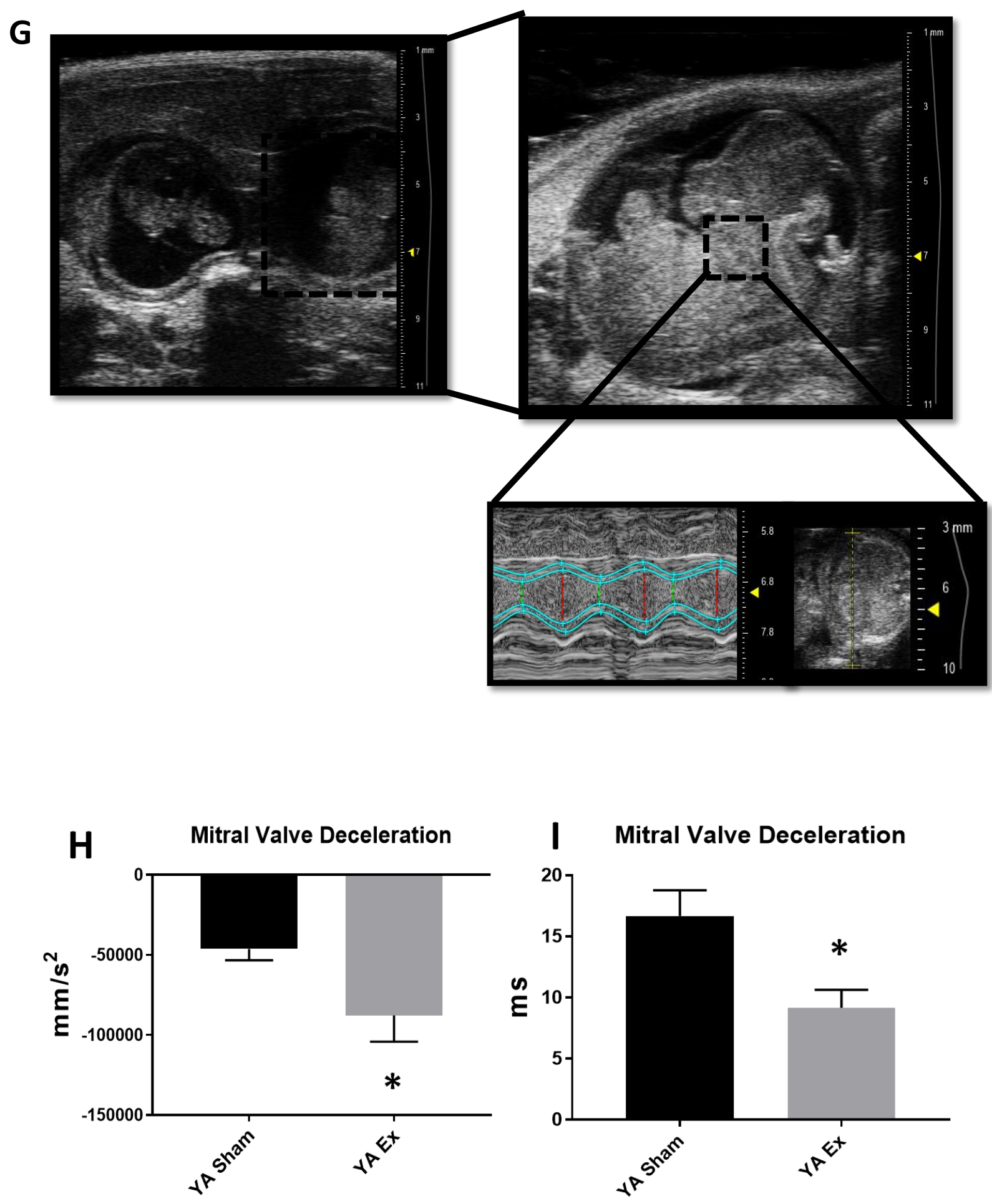
Figure 2.2: Pulse Wave Doppler assessment of Sham vs. nano- $\mathrm{TiO}_{2}$ exposed dams and their offspring. (A) Maternal ( $\mathrm{n}=15$ Sham, $\mathrm{n}=11$ Ex) Pulse Wave Doppler-Mitral Valve imaging illustrating changes in MV-A velocity. (B) Maternal ( $n=15$ Sham, $n=11$ Ex) Pulse Wave Doppler-Mitral Valve imaging illustrating changes in MV Deceleration speed. (C) Maternal ( $\mathrm{n}=$ 15 Sham, $\mathrm{n}=11$ Ex) Pulse Wave Doppler-Mitral Valve imaging illustrating changes in MV Deceleration time. (D) Maternal ( $\mathrm{n}=15$ Sham, $\mathrm{n}=11 \mathrm{Ex}$ ) Pulse Wave Doppler-Mitral Valve imaging illustrating changes in E/A ratio. (E) Pulse Wave Doppler-Flow indices revealed a change in umbilical EDV. (F) Representative micro-CT image illustrating fetal organ complexity at GD 15 and the umbilical vein (circled in red). (G) Ultrasound image showing uterine horn containing two fetal pups, a single fetal pup, and echocardiographic gating of the fetal with a representative M-mode measurement. (H) Pulse Wave Doppler-Mitral Valve of young adult ( $n=7$ Sham, $n=5$ Ex) following maternal exposure indicating changes in MV Deceleration speed. (I) Pulse Wave Doppler-Mitral Valve of young adult $(n=7$ Sham, $n=5$ Ex $)$ following maternal exposure indicating changes in MV Deceleration time. Sham $=$ control filtered air exposed, Ex $=$ nano- $\mathrm{TiO}_{2}$ exposed, Maternal $(M)=12$-week-old pregnant dams, Fetal $(F)=$ GD $(15)$, Young Adult $(Y A)=$ 11 weeks, $\mathrm{MV}=$ Mitral Valve, $\mathrm{EDV}=$ End Diastolic Velocity, micro-CT $=$ micro computed tomography. All data are presented as the mean \pm standard error of the mean (SEM). * $=\mathrm{P} \leq 0.05$, $* *=\mathrm{P} \leq 0.01, * * *=\mathrm{P} \leq 0.001$ for Ex vs. Sham. 
Figure 2.3: Fetal and Young Adult Bioenergetics

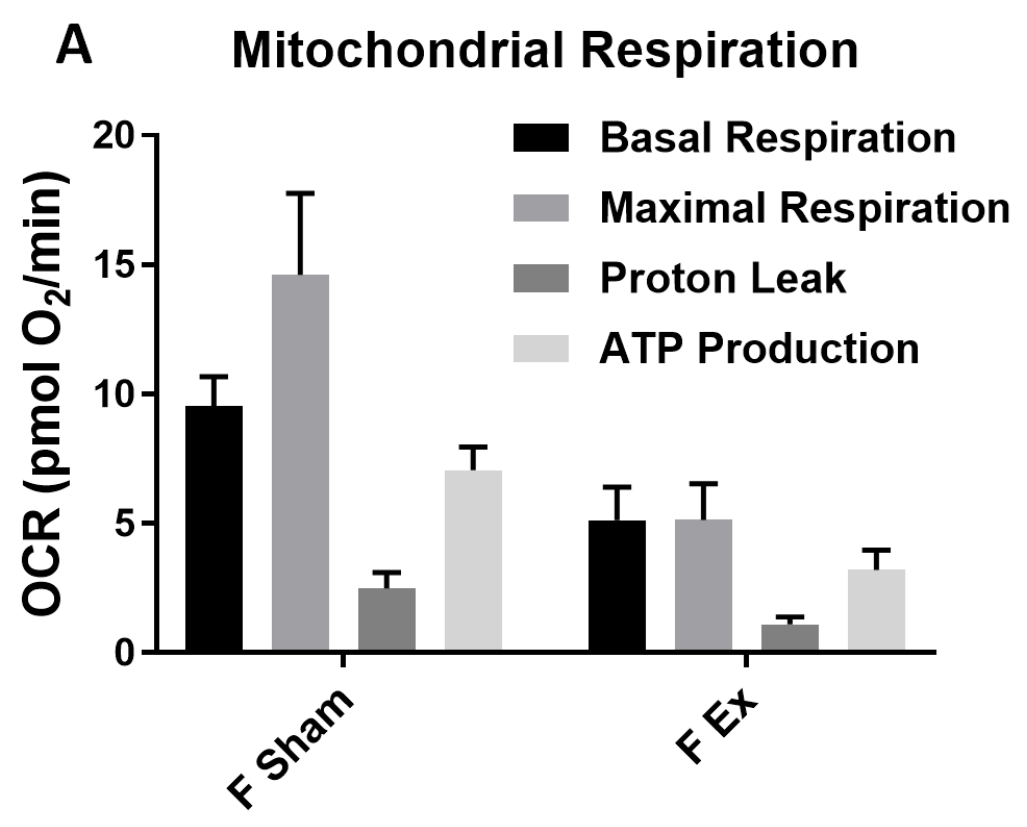

Mitohcondrial Respiration

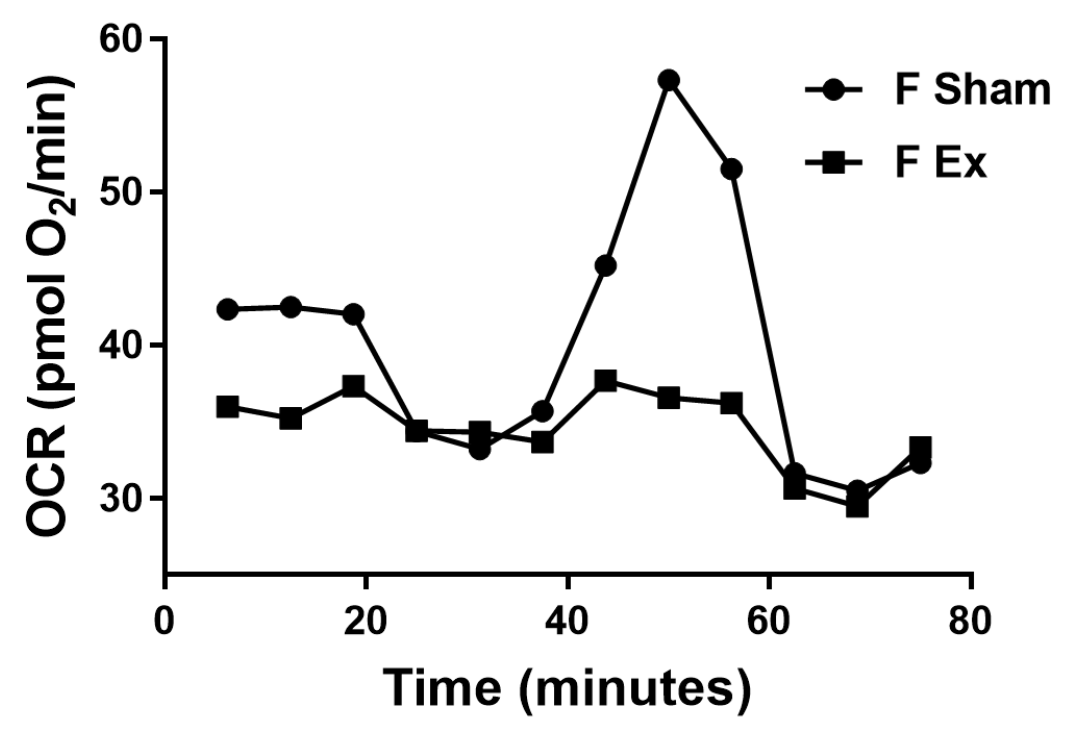


Figure 2.3:

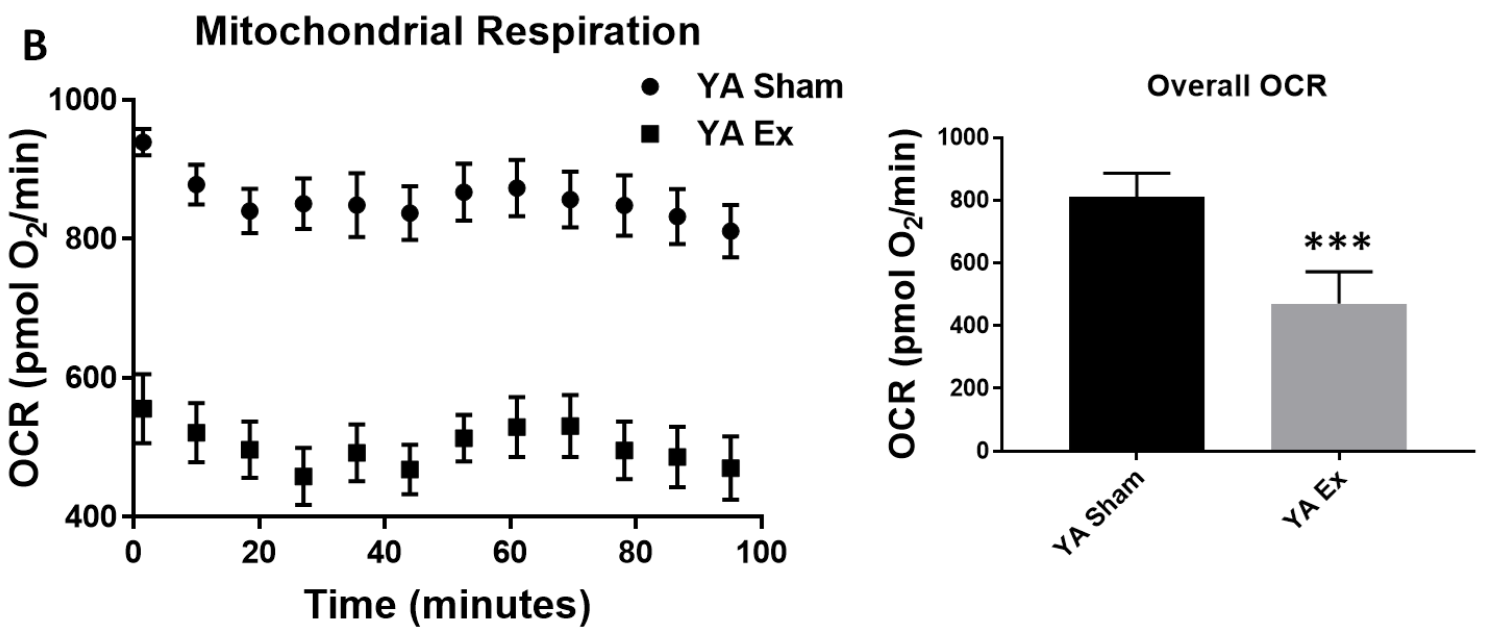

C

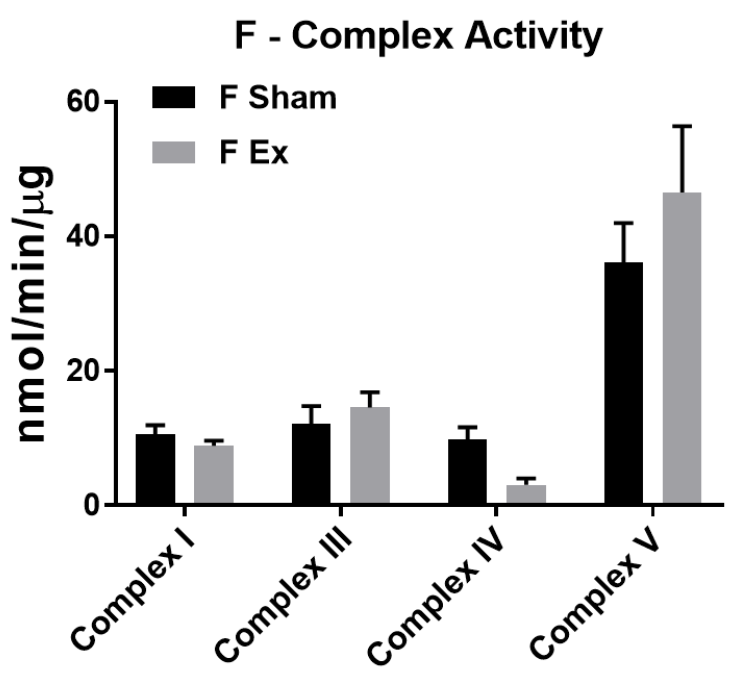

D

YA - Complex Activity

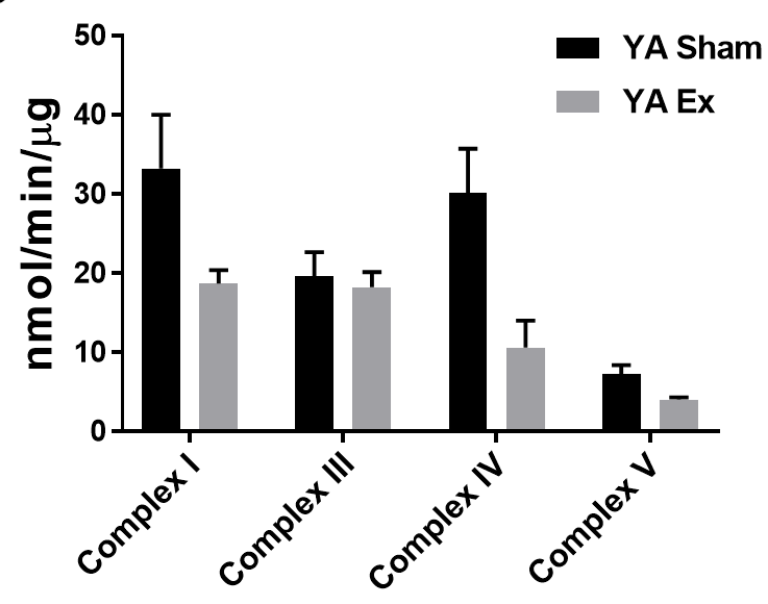


Figure 2.3: Mitochondrial bioenergetics from fetal and young adult offspring following maternal nano- $\mathrm{TiO}_{2}$ inhalation exposure. (A) Seahorse analyses of cardiomyocytes at the fetal stage $(\mathrm{n}=1$ Sham (one fetal heart from each of 6 dams pooled), $\mathrm{n}=1$ Ex (one fetal heart from each of 5 dams pooled) plated as 5-6 replicates) indicating changes in ATP production and basal and maximal respiration. (B) Seahorse analysis of young adult $(n=7$ Sham, $n=5$ Ex) animals demonstrating a significant change in overall OCR. (C) ETC Complex Activities for complexes I, III, IV, V (ATP synthase) in fetal offspring ( $n=6$ Sham, $n=5$ Ex). (D) ETC Complex Activities for complexes I, III, IV, V (ATP synthase) in young adult offspring ( $n=7$ Sham, $n=5$ Ex). Sham $=$ control filtered air exposed, $\mathrm{Ex}=$ nano- $\mathrm{TiO}_{2}$ exposed, Maternal $(\mathrm{M})=12$-week-old pregnant dams, Fetal $(\mathrm{F})=$ GD $(15)$, Young Adult $(\mathrm{YA})=11$ weeks, $\mathrm{OCR}=$ Oxygen Consumption Rate, ETC $=$ Electron Transport Chain. Complex V is measured as $\mathrm{nmol} / \mathrm{min} / \mathrm{mg}$ of tissue. All data are presented as the mean \pm standard error of the mean (SEM). ${ }^{*}=\mathrm{P} \leq 0.05, * *=\mathrm{P} \leq 0.01, * * *=\mathrm{P} \leq$ 0.001 for Ex vs. Sham. 
Figure 2.4: Fetal and Young Adult ROS and Methylation
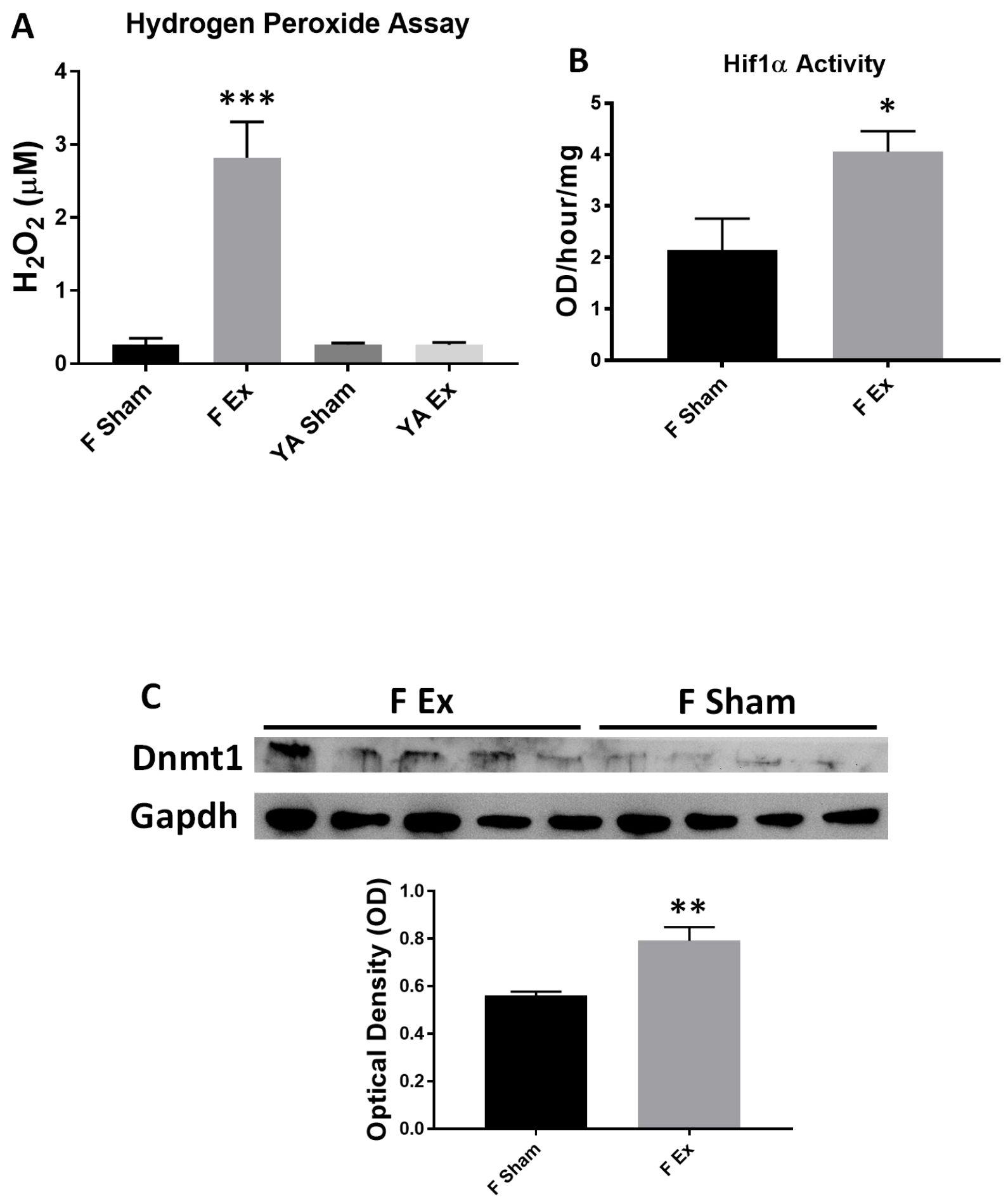
Figure 2.4:
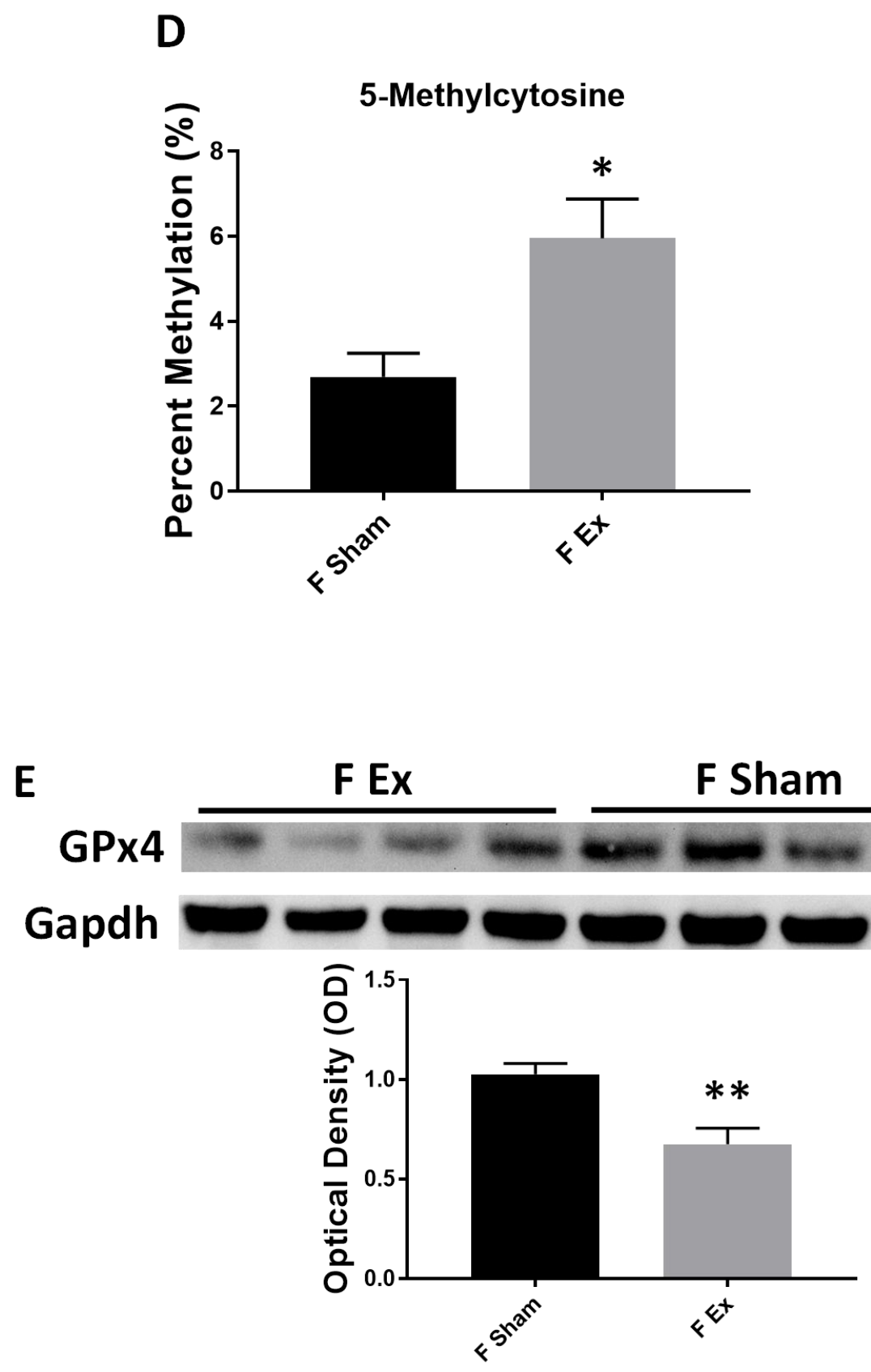
Figure 2.4:
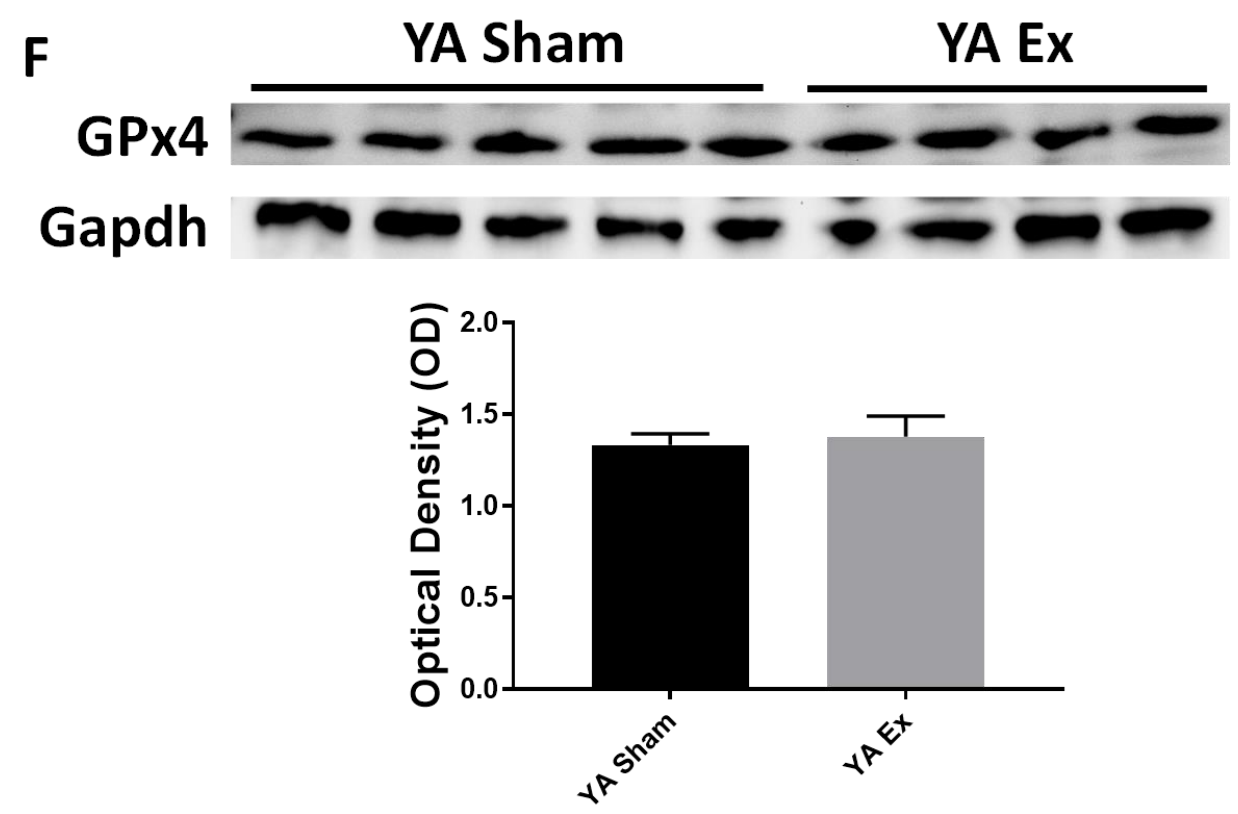
Figure 2.4: Mechanisms governing cardiac and mitochondrial dysfunction following maternal nano- $\mathrm{TiO}_{2}$ inhalation exposure. (A) Hydrogen peroxide $\left(\mathrm{H}_{2} \mathrm{O}_{2}\right)$ concentration in fetal $(n=6$ Sham, $n=5$ Ex $)$ and young adult $(n=7$ Sham, $n=5$ Ex $)$ animals, normalized to protein content. (B) Hif1 $\alpha$ activity was measured in fetal ( $n=4$ Sham, $n=5$ Ex) heart and normalized to protein content. (C) Dnmt1 protein expression was assessed in fetal $(n=4$ Sham, $n=5$ Ex $)$ heart and normalized using anti-Gapdh primary antibody. (D) Global 5-methylcytosine (5-mC) DNA methylation levels were evaluated in fetal ( $n=6$ Sham, $n=5$ Ex $)$ hearts, normalized to DNA concentration. (E) GPx4 levels were assessed in fetal $(n=4$ Sham, $n=4$ Ex $)$ and (F) young adult $(\mathrm{n}=4$ Sham, $\mathrm{n}=5$ Ex $)$ animals and normalized using anti-Gapdh primary antibody. Sham $=$ control filtered air exposed, $\mathrm{Ex}=$ nano- $\mathrm{TiO}_{2}$ exposed, Maternal $(\mathrm{M})=12$-week old pregnant dams, Fetal $(\mathrm{F})=\mathrm{GD}(15)$, Young Adult $(\mathrm{YA})=11$ weeks, Hif1 $\alpha=$ Hypoxia-inducible factor 1-alpha, Dnmt1 $=$ DNA (cytosine-5)-methyltransferase $1, \mathrm{GPx} 4=$ Glutathione peroxidase 4 . All data are presented as the mean \pm standard error of the mean (SEM). $*=\mathrm{P} \leq 0.05$, ** $=\mathrm{P} \leq 0.01, * * *=\mathrm{P} \leq 0.001$ for Ex vs. Sham. 
Figure 2.5: Mitochondrial Ultrastructure

A
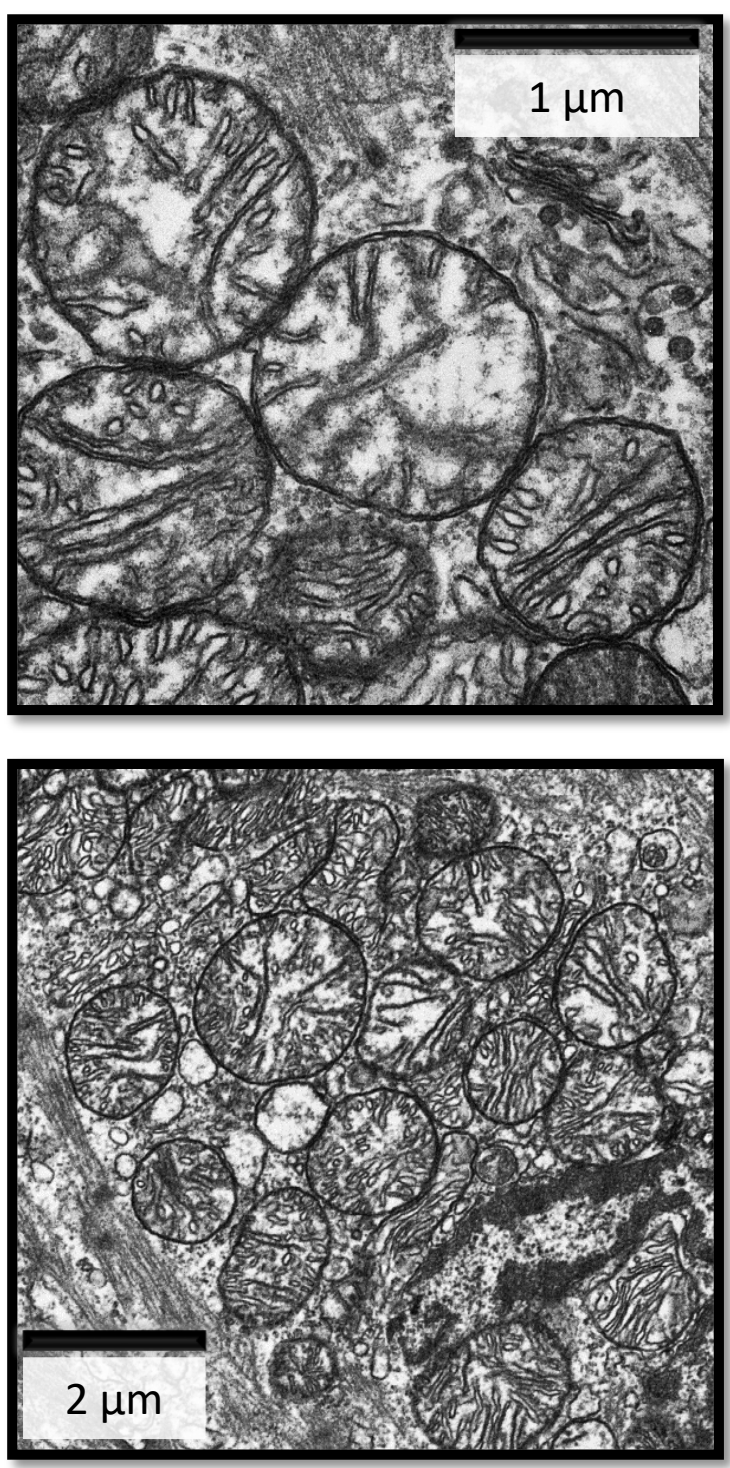

F Ex
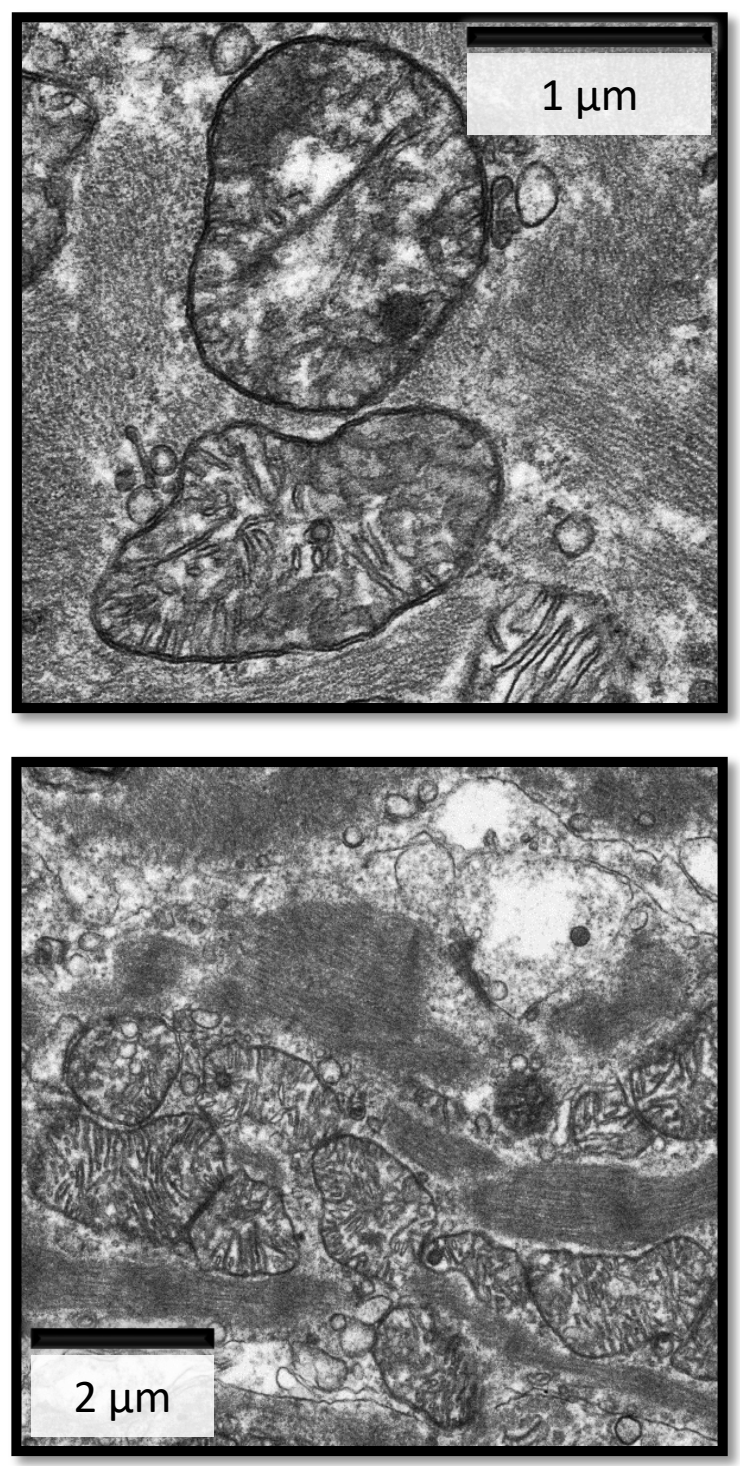
Figure 2.5:

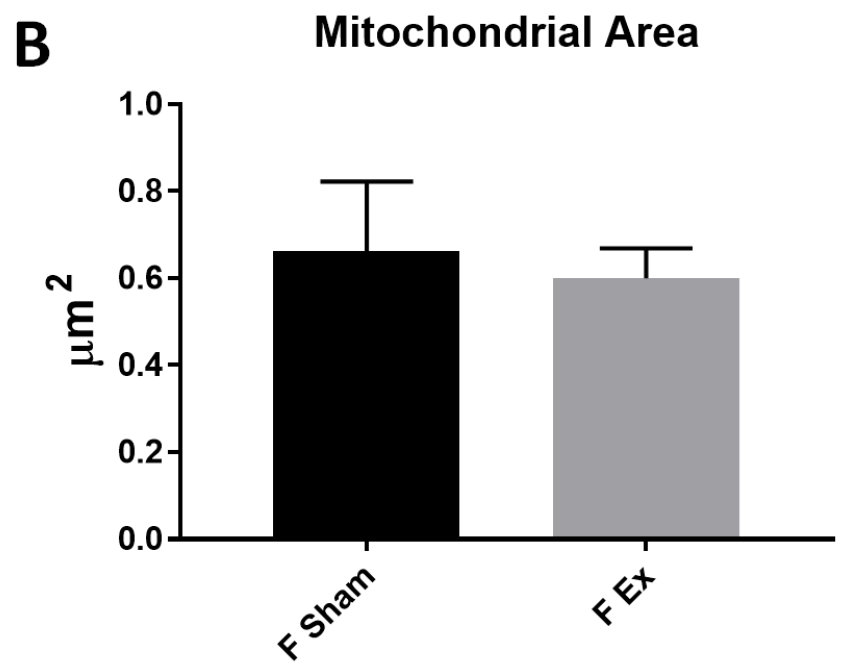

Internal Complexity

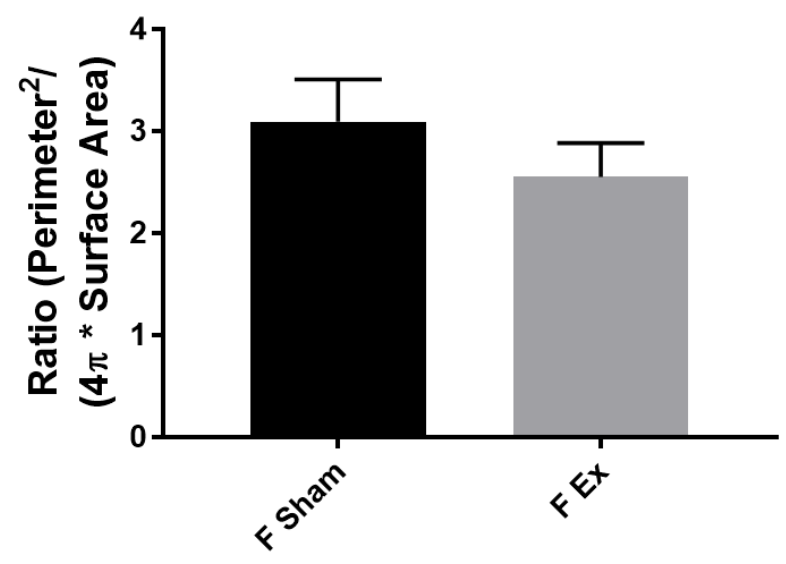

Roundness

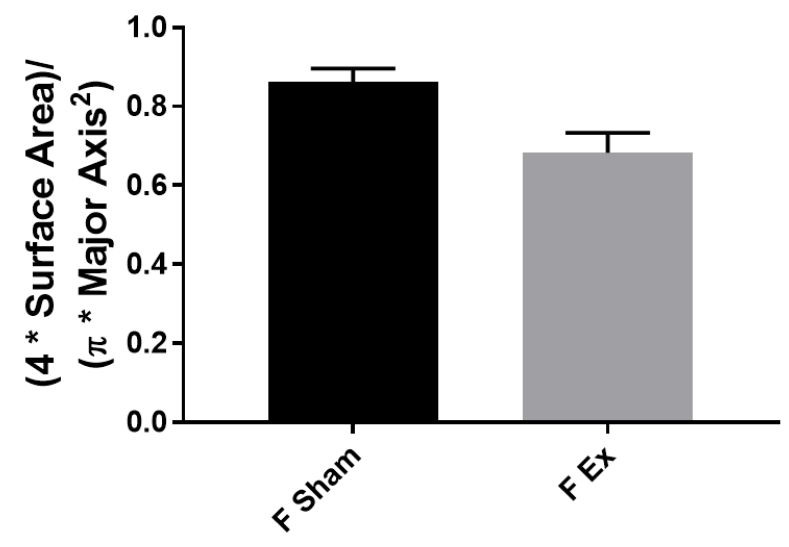


Figure 2.5:
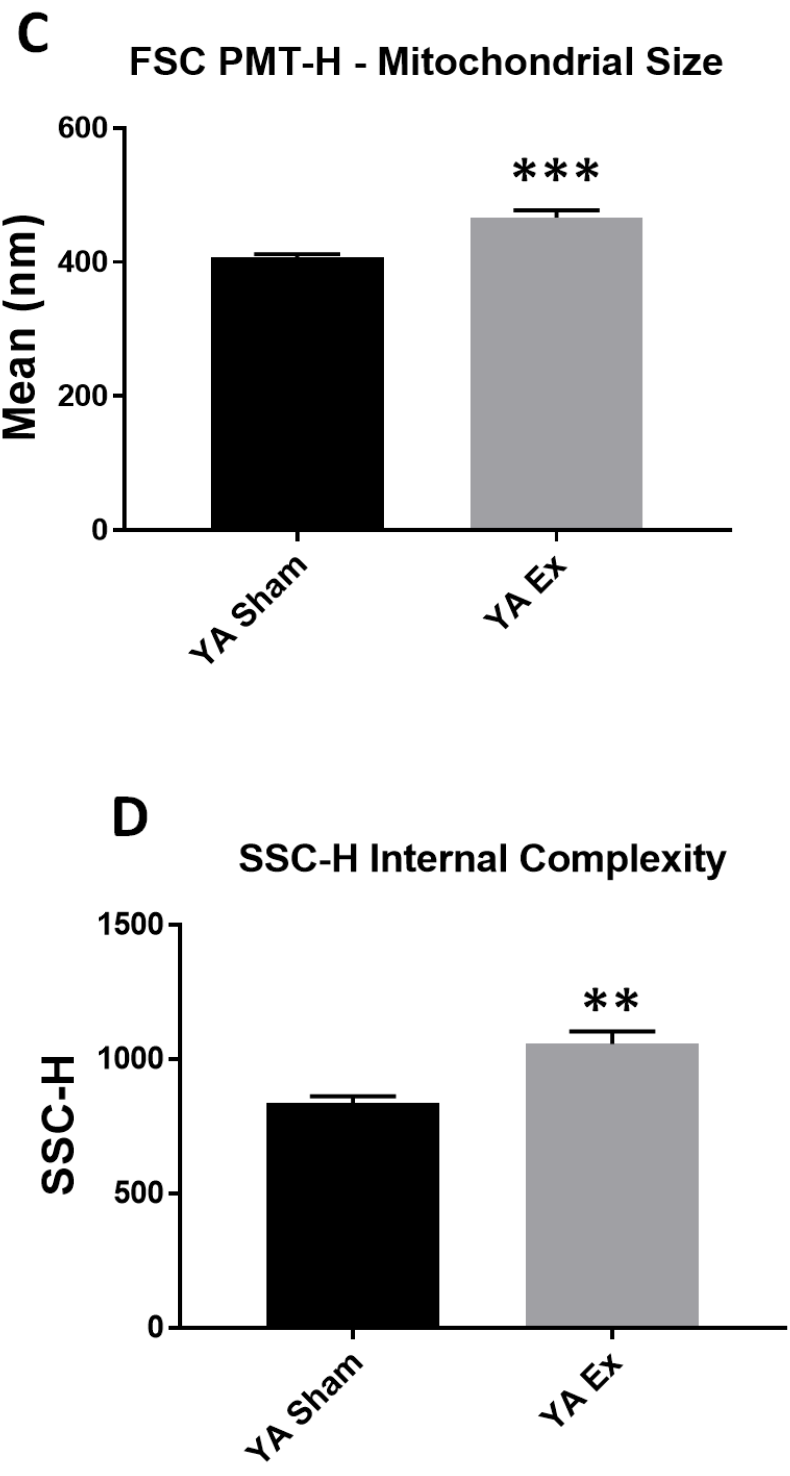
Figure 2.5: Mitochondrial ultrastructure following maternal nano- $\mathrm{TiO}_{2}$ inhalation exposure. (A) Transmission electron micrographs (TEM) of fetal cardiac tissue following Sham and nano$\mathrm{TiO}_{2}$ maternal inhalation exposure. (B) Mitochondrial area, internal complexity (form factor), and roundness $(0-1$, where 1 = perfect spheroid) were assessed through TEM $(n=2$ Sham, $n=2$ Ex $)$. (C) Mitochondrial size and (D) internal complexity were determined in young adult ( $\mathrm{n}=7$ Sham, $\mathrm{n}=5 \mathrm{Ex}$ ) animals through FSC and SSC gating, staining mitochondria with MitoTracker ${ }^{\mathrm{TM}}$ Deep Red FM/633. Sham $=$ control filtered air exposed, $\mathrm{Ex}=$ nano- $\mathrm{TiO}_{2}$ exposed, Maternal $(\mathrm{M})=12-$ week old pregnant dams, Fetal $(\mathrm{F})=$ GD $(15)$, Young Adult $(Y A)=11$ weeks, FSC = Forward Scatter, SSC $=$ Side Scatter. All data are presented as the mean \pm standard error of the mean $(\mathrm{SEM})$. $*=\mathrm{P} \leq 0.05, * *=\mathrm{P} \leq 0.01, * * *=\mathrm{P} \leq 0.001$ for Ex vs. Sham. 
Figure 2.6: Overview

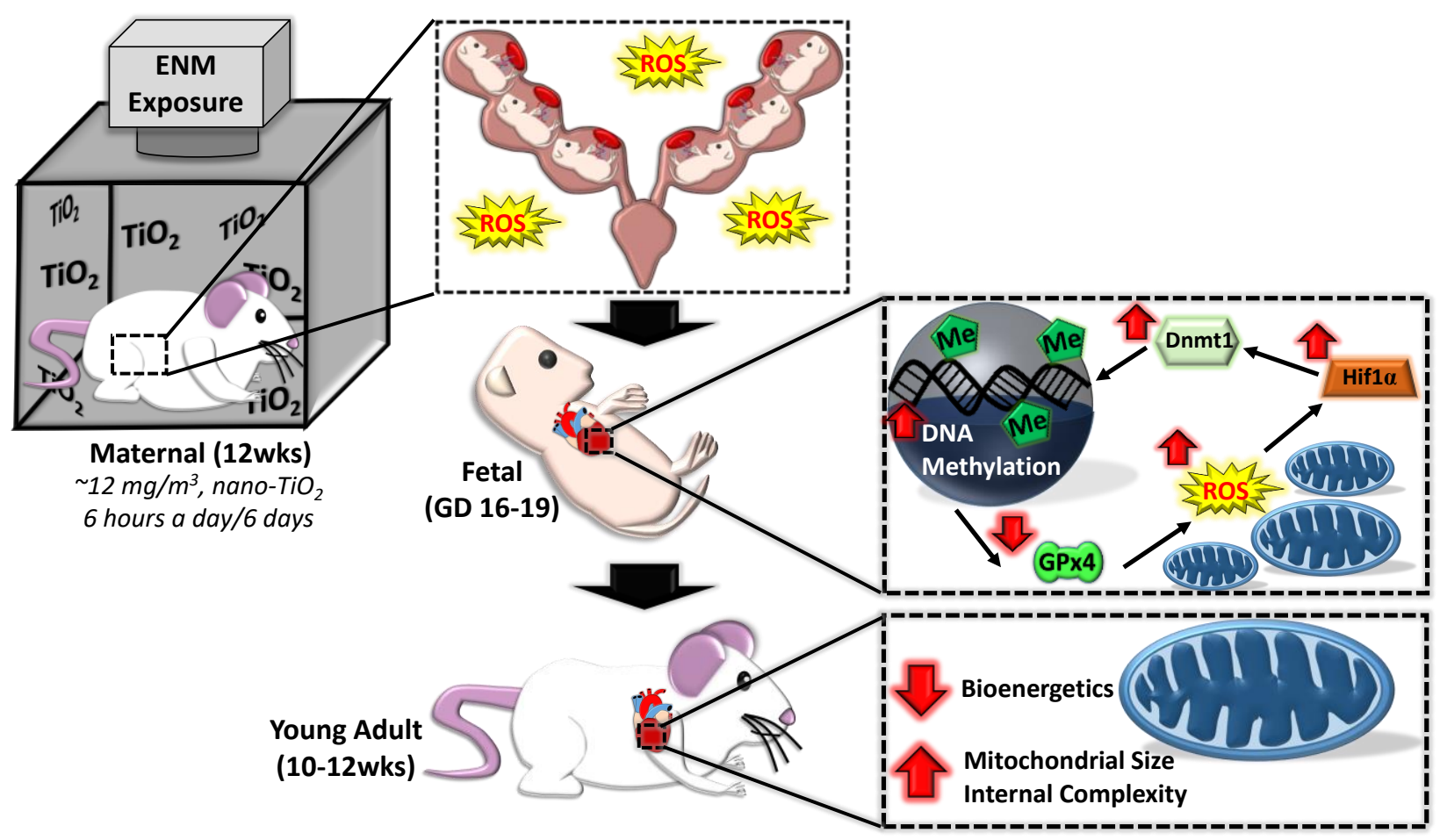


Figure 2.6: Illustration of molecular pathways altered during maternal nano- $\mathrm{TiO}_{2}$ inhalation exposure and physiological ramifications. Following maternal exposure, increased ROS in fetal cardiac tissue and decreased mitochondrial ROS scavenging through GPx4 perpetuates a positive feedback-loop where increased Hifl $\alpha$ activity acts to transcriptionally activate Dnmt1 and ultimately increase global 5-methylcytosine levels. While ROS returns to control levels in the young adult animals, fetal insult negatively influences mitochondrial and cardiac function in maternal nano-TiO2 inhalation exposed progeny into adulthood. Maternal $(\mathrm{M})=12$-week-old pregnant dams, Fetal $(\mathrm{F})=\mathrm{GD}(15)$, Young Adult $(\mathrm{YA})=11$ weeks, ROS $=$ reactive oxygen species, GPx4 = Glutathione peroxidase 4, Hifl $\alpha=$ Hypoxia-inducible factor 1 -alpha, Dnmt $1=$ DNA (cytosine-5)-methyltransferase 1, Me = 5-methylcytosine. 
Supplemental Table 2.1: Pulse-Wave Doppler Maternal Flow

\begin{tabular}{|c|c|c|c|c|c|}
\hline Parameters & Units & $\begin{array}{l}\text { M Sham } \\
\text { Uterine }\end{array}$ & M Ex Uterine & $\begin{array}{l}\text { M Sham } \\
\text { Umbilical }\end{array}$ & $\begin{array}{c}\text { M Ex } \\
\text { Umbilical }\end{array}$ \\
\hline $\begin{array}{c}\text { End-Diastolic } \\
\text { Velocity }\end{array}$ & $\mathrm{mm} / \mathrm{s}$ & $46.66 \pm 4.203$ & $45.31 \pm 6.686$ & $9.864 \pm 1.287$ & $\begin{array}{l}3.994 \pm \\
0.792 * *\end{array}$ \\
\hline $\begin{array}{c}\text { Peak-Systolic } \\
\text { Velocity }\end{array}$ & $\mathrm{mm} / \mathrm{s}$ & $129.3 \pm 14.26$ & $112.6 \pm 11.57$ & $84.04 \pm 10.20$ & $78.03 \pm 7.367$ \\
\hline $\begin{array}{l}\text { Velocity Time } \\
\text { Integral }\end{array}$ & (VTI) $\mathrm{mm}$ & $8.252 \pm 0.786$ & $8.296 \pm 1.192$ & $9.433 \pm 0.907$ & $8.012 \pm 0.924$ \\
\hline $\begin{array}{c}\text { Velocity Time } \\
\text { Integral }\end{array}$ & $\begin{array}{c}\text { (Mean Vel) } \\
\mathrm{mm} / \mathrm{s}\end{array}$ & $81.54 \pm 8.967$ & $74.12 \pm 8.954$ & $36.83 \pm 4.997$ & $33.81 \pm 3.237$ \\
\hline $\begin{array}{c}\text { Velocity Time } \\
\text { Integral }\end{array}$ & $\begin{array}{c}\text { (Mean Grad) } \\
\text { mmHg }\end{array}$ & $0.025 \pm 0.004$ & $0.024 \pm 0.005$ & $0.007 \pm 0.002$ & $0.005 \pm 0.001$ \\
\hline $\begin{array}{l}\text { Velocity Time } \\
\text { Integral }\end{array}$ & $\begin{array}{c}\text { (Peak Vel) } \\
\mathrm{mm} / \mathrm{s}\end{array}$ & $124.8 \pm 12.46$ & $118.79 \pm 12.88$ & $84.43 \pm 10.15$ & $78.14 \pm 7.381$ \\
\hline $\begin{array}{c}\text { Velocity Time } \\
\text { Integral }\end{array}$ & $\begin{array}{c}\text { (Peak Grad) } \\
\text { mmHg }\end{array}$ & $0.077 \pm 0.017$ & $0.061 \pm 0.012$ & $0.033 \pm 0.008$ & $0.026 \pm 0.004$ \\
\hline
\end{tabular}


Supplemental Table 2.1: Pulse Wave Doppler-Flow echocardiography for umbilical and uterine flow following maternal nano-TiO 2 exposure. Maternal $(n=12 \mathrm{Sham}, \mathrm{n}=8 \mathrm{Ex})$. Sham $=$ control filtered air exposed, $\mathrm{Ex}=$ nano- $\mathrm{TiO}_{2}$ exposed, Maternal $(\mathrm{M})=12$-week old pregnant dams. All data are presented as the mean \pm standard error of the mean $(\mathrm{SEM}){ }^{*}=P \leq$ $0.05, * *=P \leq 0.01, * * *=P \leq 0.001$ for Ex vs. Sham. 
Supplemental Table 2.2: Stress-Strain Analysis - Short Axis - Diastole

\begin{tabular}{|c|c|c|c|c|c|c|c|}
\hline Parameters & Units & M Sham & M Ex & F Sham & F Ex & YA Sham & YA Ex \\
\hline Heart Rate & $\begin{array}{c}\text { beats/ } \\
\text { min }\end{array}$ & $670.1 \pm 9.4$ & $684.2 \pm 9.1$ & $\begin{array}{c}123.6 \pm \\
8.186\end{array}$ & $\begin{array}{c}123.9 \pm \\
9.679\end{array}$ & $\begin{array}{c}632.1 \pm \\
24.78\end{array}$ & $\begin{array}{c}689.3 \pm \\
8.156\end{array}$ \\
\hline $\begin{array}{c}\text { Radial Velocity } \\
\text { (Endo) }\end{array}$ & $\begin{array}{c}\mathrm{Pk} \\
\mathrm{cm} / \mathrm{s}\end{array}$ & $\begin{array}{c}-3.913 \pm \\
0.13\end{array}$ & $\begin{array}{c}-3.336 \pm \\
0.324\end{array}$ & $\begin{array}{c}-0.227 \pm \\
0.033\end{array}$ & $\begin{array}{c}-0.163 \pm \\
0.011\end{array}$ & $\begin{array}{c}-2.210 \pm \\
0.262\end{array}$ & $\begin{array}{c}-2.481 \pm \\
0.366\end{array}$ \\
\hline $\begin{array}{l}\text { Radial } \\
\text { Displacement } \\
\text { (Endo) }\end{array}$ & $\mathrm{Pk} \mathrm{mm}$ & $\begin{array}{c}-0.004 \pm \\
0.001\end{array}$ & $\begin{array}{c}-0.008 \pm \\
0.002\end{array}$ & $\begin{array}{c}-0.005 \pm \\
0.005\end{array}$ & $\begin{array}{c}-0.011 \pm \\
0.004\end{array}$ & $\begin{array}{c}-0.0002 \pm \\
0.0001\end{array}$ & $\begin{array}{c}-0.020 \pm \\
0.009 *\end{array}$ \\
\hline $\begin{array}{l}\text { Radial Strain } \\
\quad \text { (Endo) }\end{array}$ & $\mathrm{Pk} \%$ & $\begin{array}{l}-4.192 \pm \\
1.288\end{array}$ & $\begin{array}{c}-2.497 \pm \\
0.536\end{array}$ & $\begin{array}{c}-29.80 \pm \\
7.744\end{array}$ & $\begin{array}{c}-13.28 \pm \\
3.711\end{array}$ & $\begin{array}{c}-2.687 \pm \\
1.264\end{array}$ & $\begin{array}{c}-8.834 \pm \\
4.281\end{array}$ \\
\hline $\begin{array}{l}\text { Radial Strain } \\
\text { Rate (Endo) }\end{array}$ & $\mathrm{Pk} 1 / \mathrm{s}$ & $\begin{array}{c}-29.26 \pm \\
4.182\end{array}$ & $\begin{array}{c}-22.28 \pm \\
1.672\end{array}$ & $\begin{array}{c}-54.07 \pm \\
4.292\end{array}$ & $\begin{array}{c}-60.89 \pm \\
4.576\end{array}$ & $\begin{array}{c}-16.58 \pm \\
2.631\end{array}$ & $\begin{array}{c}-30.13 \pm \\
10.87\end{array}$ \\
\hline $\begin{array}{l}\text { Circumferential } \\
\text { Velocity (Endo) }\end{array}$ & $\begin{array}{c}\mathrm{Pk} \\
\mathrm{deg} / \mathrm{s}\end{array}$ & $\begin{array}{c}-698.1 \pm \\
94.69\end{array}$ & $\begin{array}{c}-811.1 \pm \\
155.1\end{array}$ & $\begin{array}{c}-444.17 \pm \\
83.60\end{array}$ & $\begin{array}{c}-398.8 \pm \\
51.49\end{array}$ & $\begin{array}{c}-608.8 \pm \\
67.48\end{array}$ & $\begin{array}{c}-473.5 \pm \\
1215.5\end{array}$ \\
\hline $\begin{array}{l}\text { Circumferential } \\
\text { Displacement } \\
\text { (Endo) }\end{array}$ & Pk deg & $\begin{array}{c}-2.101 \pm \\
0.603\end{array}$ & $\begin{array}{c}-3.930 \pm \\
1.974\end{array}$ & $\begin{array}{c}-6.367 \pm \\
1.440\end{array}$ & $\begin{array}{l}-16.62 \pm \\
3.183 * *\end{array}$ & $\begin{array}{l}-6.108 \pm \\
2.036\end{array}$ & $\begin{array}{c}-6.623 \pm \\
4.394\end{array}$ \\
\hline $\begin{array}{c}\text { Circumferential } \\
\text { Strain (Endo) }\end{array}$ & $\mathrm{Pk} \%$ & $\begin{array}{c}5.644 \pm \\
1.792\end{array}$ & $\begin{array}{c}2.076 \pm \\
0.646\end{array}$ & $\begin{array}{c}9.881 \pm \\
4.341\end{array}$ & $\begin{array}{c}7.888 \pm \\
2.411\end{array}$ & $\begin{array}{c}22.89 \pm \\
21.61\end{array}$ & $\begin{array}{c}15.58 \pm \\
8.565\end{array}$ \\
\hline $\begin{array}{c}\text { Circumferential } \\
\text { Strain Rate } \\
\text { (Endo) }\end{array}$ & $\mathrm{Pk} 1 / \mathrm{s}$ & $\begin{array}{c}47.67 \pm \\
2.911\end{array}$ & $\begin{array}{c}51.29 \pm \\
3.699\end{array}$ & $\begin{array}{c}12.660 \pm \\
1.975\end{array}$ & $\begin{array}{c}10.58 \pm \\
1.394\end{array}$ & $\begin{array}{c}38.43 \pm \\
2.817\end{array}$ & $\begin{array}{c}47.02 \pm \\
11.50\end{array}$ \\
\hline
\end{tabular}


Supplemental Table 2.2: Diastole cardiac stress-strain in the short axis. B-Mode images were used to examine radial and circumferential stress-strain parameters in the short axis during diastole in maternal $(n=11$ Sham, $n=15$ Ex $)$, fetal $(n=9$ Sham, $n=9$ Ex $)$, and young adult $(n=$ 7 Sham, $\mathrm{n}=5 \mathrm{Ex}$ ) animals. Sham $=$ control filtered air exposed, $\mathrm{Ex}=$ nano- $\mathrm{TiO}_{2}$ exposed, Maternal $(M)=12$-weekold pregnant dams, Fetal $(F)=$ GD $(15)$, Young Adult $(Y A)=11$ weeks All data are presented as the mean \pm standard error of the mean (SEM). $*=P \leq 0.05, * *=P \leq$ $0.01, * * *=P \leq 0.001$ for Ex vs. Sham. 
Supplemental Table 2.3: Stress-Strain Analysis - Short Axis - Systole

\begin{tabular}{|c|c|c|c|c|c|c|c|}
\hline Parameters & Units & M Sham & M Ex & F Sham & F Ex & $\begin{array}{c}\text { YA } \\
\text { Sham }\end{array}$ & YA Ex \\
\hline Heart Rate & beats/min & $\begin{array}{c}670.1 \pm \\
9.4\end{array}$ & $\begin{array}{c}684.2 \pm \\
9.1\end{array}$ & $\begin{array}{l}123.6 \pm \\
8.186\end{array}$ & $\begin{array}{l}123.9 \pm \\
9.679\end{array}$ & $\begin{array}{c}632.1 \pm \\
24.78\end{array}$ & $\begin{array}{l}689.3 \pm \\
8.156\end{array}$ \\
\hline Radial Velocity (Endo) & $\mathrm{Pk} \mathrm{cm} / \mathrm{s}$ & $\begin{array}{c}2.951 \pm \\
0.133\end{array}$ & $\begin{array}{c}2.854 \pm \\
0.170\end{array}$ & $\begin{array}{c}0.194 \pm \\
0.035\end{array}$ & $\begin{array}{c}0.173 \pm \\
0.014\end{array}$ & $\begin{array}{c}2.404 \pm \\
0.258\end{array}$ & $\begin{array}{c}2.754 \pm \\
0.317\end{array}$ \\
\hline $\begin{array}{c}\text { Radial Displacement } \\
\text { (Endo) }\end{array}$ & $\mathrm{Pk} \mathrm{mm}$ & $\begin{array}{c}0.769 \pm \\
0.022\end{array}$ & $\begin{array}{c}0.700 \pm \\
0.049\end{array}$ & $\begin{array}{c}0.143 \pm \\
0.012\end{array}$ & $\begin{array}{c}0.128 \pm \\
0.009\end{array}$ & $\begin{array}{c}0.549 \pm \\
0.060\end{array}$ & $\begin{array}{c}0.629 \pm \\
0.057\end{array}$ \\
\hline Radial Str & $\mathrm{Pk} \%$ & \begin{tabular}{|c|}
$39.26 \pm$ \\
3.328
\end{tabular} & $\begin{array}{c}52.37 \pm \\
4.428 *\end{array}$ & $\begin{array}{c}10.76 \pm \\
0.960\end{array}$ & $\begin{array}{c}11.82 \pm \\
2.382\end{array}$ & $\begin{array}{c}35.49 \pm \\
2.510\end{array}$ & $\begin{array}{l}39.28 \pm \\
19.79\end{array}$ \\
\hline $\begin{array}{c}\text { Radial Strain Rate } \\
\text { (Endo) }\end{array}$ & $\mathrm{Pk} 1 / \mathrm{s}$ & $\begin{array}{c}19.35 \pm \\
2.023\end{array}$ & $\begin{array}{c}19.47 \pm \\
1.664\end{array}$ & $\begin{array}{c}54.07 \pm \\
9.664\end{array}$ & $\begin{array}{l}8.464 \pm \\
1.889 * *\end{array}$ & $\begin{array}{c}27.10 \pm \\
6.571\end{array}$ & $\begin{array}{c}25.22 \pm \\
8.153\end{array}$ \\
\hline $\begin{array}{l}\text { Circumferential } \\
\text { Velocity (Endo) }\end{array}$ & $\mathrm{Pk}$ deg/s & $\begin{array}{c}695.5 \pm \\
104.4\end{array}$ & $\begin{array}{c}810.9 \pm \\
113.9\end{array}$ & $\begin{array}{c}404.25 \pm \\
68.07\end{array}$ & $\begin{array}{l}356.7 \pm \\
37.99\end{array}$ & $\begin{array}{c}724.9 \pm \\
143.5\end{array}$ & $\begin{array}{c}440.85 \pm \\
46.91\end{array}$ \\
\hline $\begin{array}{c}\text { Circumferential } \\
\text { Displacement (Endo) }\end{array}$ & Pk deg & $\begin{array}{c}6.384 \pm \\
0.652\end{array}$ & $\begin{array}{c}4.883 \pm \\
0.817\end{array}$ & $\begin{array}{c}11.62 \pm \\
2.265\end{array}$ & $\begin{array}{l}2.954 \pm \\
0.724 * *\end{array}$ & $\begin{array}{c}3.190 \pm \\
0.899\end{array}$ & $\begin{array}{c}4.512 \pm \\
1.424\end{array}$ \\
\hline $\begin{array}{l}\text { Circumferential Strain } \\
\text { (Endo) }\end{array}$ & $\mathrm{Pk} \%$ & $\begin{array}{c}-38.54 \pm \\
4.448\end{array}$ & $\begin{array}{l}-54.51 \pm \\
2.811 *\end{array}$ & $\begin{array}{c}-27.86 \pm \\
2.405\end{array}$ & $\begin{array}{l}-25.12 \pm \\
3.225\end{array}$ & $\begin{array}{c}-39.90 \pm \\
7.110\end{array}$ & $\begin{array}{c}-39.94 \pm \\
8.000\end{array}$ \\
\hline $\begin{array}{c}\text { Circumferential Strain } \\
\text { Rate (Endo) }\end{array}$ & $\mathrm{Pk} 1 / \mathrm{s}$ & $\begin{array}{c}-44.57 \pm \\
4.357\end{array}$ & $\begin{array}{c}-46.94 \pm \\
4.056\end{array}$ & $\begin{array}{c}-12.63 \pm \\
1.676\end{array}$ & $\begin{array}{c}-8.919 \pm \\
0.432\end{array}$ & $\begin{array}{c}-45.53 \pm \\
4.426\end{array}$ & $\begin{array}{c}-45.22 \pm \\
12.34\end{array}$ \\
\hline
\end{tabular}


Supplemental Table 2.3: Systolic cardiac stress-strain in the short axis. B-Mode images were used to examine radial and circumferential stress-strain parameters in the short axis during systole in maternal $(n=11$ Sham, $n=15$ Ex $)$, fetal $(n=9$ Sham, $n=9$ Ex $)$, and young adult $(n=$ $7 \mathrm{Sham}, \mathrm{n}=5 \mathrm{Ex}$ ) animals. Sham $=$ control filtered air exposed, $\mathrm{Ex}=$ nano- $\mathrm{TiO}_{2}$ exposed, Maternal $(\mathrm{M})=12$-week old pregnant dams, Fetal $(\mathrm{F})=\mathrm{GD}(15)$, Young Adult $(\mathrm{YA})=11$ weeks. All data are presented as the mean \pm standard error of the mean (SEM). $*=P \leq 0.05, * *$ $=P \leq 0.01, * * *=P \leq 0.001$ for Ex vs. Sham. 
Supplemental Table 2.4: Stress-Strain Analysis - Long Axis - Diastole

\begin{tabular}{|c|c|c|c|c|c|}
\hline Parameters & Units & M Sham & M Ex & YA Sham & YA Ex \\
\hline Heart Rate & beats/min & $681.3 \pm 11.66$ & $708.0 \pm 11.75$ & $581.9 \pm 54.00$ & $679.1 \pm 4.952$ \\
\hline $\begin{array}{l}\text { Radial Velocity } \\
\text { (Endo) }\end{array}$ & $\mathrm{Pk} \mathrm{cm} / \mathrm{s}$ & $-2.640 \pm 0.146$ & $\begin{array}{l}-2.152 \pm \\
0.128 *\end{array}$ & $-1.691 \pm 0.043$ & $-1.736 \pm 0.121$ \\
\hline $\begin{array}{c}\text { Radial Displacement } \\
\text { (Endo) }\end{array}$ & $\mathrm{Pk} \mathrm{mm}$ & $-0.006 \pm 0.002$ & $-0.002 \pm 0.001$ & $-0.003 \pm 0.001$ & $-0.007 \pm 0.003$ \\
\hline Radial Strain (Endo) & $\mathrm{Pk} \%$ & $-1.047 \pm 0.234$ & $-0.782 \pm 0.213$ & $-1.413 \pm 0.280$ & $-0.725 \pm 0.282$ \\
\hline $\begin{array}{c}\text { Radial Strain Rate } \\
\text { (Endo) }\end{array}$ & $\mathrm{Pk} 1 / \mathrm{s}$ & $-14.25 \pm 0.980$ & $\begin{array}{c}-10.94 \pm \\
0.933 *\end{array}$ & $-9.768 \pm 0.949$ & $-9.205 \pm 1.083$ \\
\hline $\begin{array}{l}\text { Longitudinal Velocity } \\
\text { (Endo) }\end{array}$ & $\mathrm{Pk}$ deg/s & $-1.579 \pm 0.246$ & $-1.690 \pm 0.152$ & $-1.105 \pm 0.119$ & $-0.873 \pm 0.169$ \\
\hline $\begin{array}{c}\text { Longitudinal } \\
\text { Displacement (Endo) }\end{array}$ & Pk deg & $-0.021 \pm 0.006$ & $-0.034 \pm 0.010$ & $-0.140 \pm 0.034$ & $\begin{array}{c}-0.036 \pm \\
0.016 *\end{array}$ \\
\hline $\begin{array}{l}\text { Longitudinal Strain } \\
\text { (Endo) }\end{array}$ & $\mathrm{Pk} \%$ & $4.654 \pm 1.262$ & $0.933 \pm 0.352 *$ & $2.209 \pm 0.737$ & $1.841 \pm 0.528$ \\
\hline $\begin{array}{l}\text { Longitudinal Strain } \\
\text { Rate (Endo) }\end{array}$ & $\mathrm{Pk} 1 / \mathrm{s}$ & $9.834 \pm 1.207$ & $11.89 \pm 1.223$ & $9.890 \pm 1.586$ & $9.867 \pm 2.347$ \\
\hline
\end{tabular}


Supplemental Table 2.4: Diastolic cardiac stress-strain in the long axis. B-Mode images were used to examine longitudinal and circumferential stress-strain parameters in the long axis during diastole in maternal $(\mathrm{n}=11$ Sham, $\mathrm{n}=15$ Ex $)$, fetal $(\mathrm{n}=9$ Sham, $\mathrm{n}=9$ Ex $)$, and young adult $(\mathrm{n}=7$ Sham, $\mathrm{n}=5 \mathrm{Ex})$ animals. Sham $=$ control filtered air exposed, $\mathrm{Ex}=$ nano- $\mathrm{TiO}_{2}$ exposed, Maternal $(\mathrm{M})=12$-week old pregnant dams, Fetal $(\mathrm{F})=\mathrm{GD}(15)$, Young Adult $(\mathrm{YA})=$ 11 weeks. All data are presented as the mean \pm standard error of the mean (SEM). $*=P \leq 0.05$, $* *=P \leq 0.01, * * *=P \leq 0.001$ for Ex vs. Sham. 
Supplemental Table 2.5: Stress-Strain Analysis - Long Axis - Systole

\begin{tabular}{|c|c|c|c|c|c|}
\hline Parameters & Units & M Sham & M Ex & YA Sham & YA Ex \\
\hline Heart Rate & beats/min & $681.3 \pm 11.66$ & $708.0 \pm 11.75$ & $581.9 \pm 54.00$ & $679.1 \pm 4.952$ \\
\hline $\begin{array}{l}\text { Radial Velocity } \\
\text { (Endo) }\end{array}$ & $\mathrm{Pk} \mathrm{cm} / \mathrm{s}$ & $2.054 \pm 0.091$ & $1.787 \pm 0.060 *$ & $2.003 \pm 0.142$ & $1.954 \pm 0.070$ \\
\hline $\begin{array}{l}\text { Radial Displacement } \\
\text { (Endo) }\end{array}$ & $\mathrm{Pk} \mathrm{mm}$ & $0.574 \pm 0.023$ & $\begin{array}{l}0.469 \pm \\
0.022 * *\end{array}$ & $0.468 \pm 0.037$ & $0.479 \pm 0.038$ \\
\hline Radial Strain (Endo) & $\mathrm{Pk} \%$ & $33.33 \pm 2.797$ & $27.53 \pm 2.388$ & $27.39 \pm 3.189$ & $27.33 \pm 0.595$ \\
\hline $\begin{array}{l}\text { Radial Strain Rate } \\
\text { (Endo) }\end{array}$ & $\mathrm{Pk} 1 / \mathrm{s}$ & $12.07 \pm 1.203$ & $10.94 \pm 1.357$ & $9.365 \pm 0.809$ & $10.49 \pm 0.621$ \\
\hline $\begin{array}{c}\text { Longitudinal } \\
\text { Velocity (Endo) }\end{array}$ & $\mathrm{Pk} \mathrm{deg} / \mathrm{s}$ & $1.245 \pm 0.131$ & $1.466 \pm 0.092$ & $0.997 \pm 0.215$ & $0.923 \pm 0.248$ \\
\hline $\begin{array}{c}\text { Longitudinal } \\
\text { Displacement (Endo) }\end{array}$ & Pk deg & $0.237 \pm 0.040$ & $0.247 \pm 0.035$ & $0.065 \pm 0.011$ & $0.100 \pm 0.022$ \\
\hline $\begin{array}{l}\text { Longitudinal Strain } \\
\text { (Endo) }\end{array}$ & $\mathrm{Pk} \%$ & $-7.070 \pm 1.597$ & $-10.40 \pm 1.741$ & $-12.15 \pm 2.510$ & $-16.87 \pm 2.052$ \\
\hline $\begin{array}{l}\text { Longitudinal Strain } \\
\text { Rate (Endo) }\end{array}$ & $\mathrm{Pk} 1 / \mathrm{s}$ & $-7.309 \pm 2.845$ & $\begin{array}{c}-11.80 \pm \\
1.789 *\end{array}$ & $-10.40 \pm 1.282$ & $-8.526 \pm 1.306$ \\
\hline
\end{tabular}


Supplemental Table 2.5: Systolic cardiac stress-strain in the long axis. B-Mode images were used to examine longitudinal and circumferential stress-strain parameters in the long axis during systole in maternal $(n=11$ Sham, $n=15$ Ex $)$, fetal $(n=9$ Sham, $n=9$ Ex $)$, and young adult $(n=$ 7 Sham, $\mathrm{n}=5 \mathrm{Ex}$ ) animals. Sham = control filtered air exposed, Ex = nano- $\mathrm{TiO}_{2}$ exposed, Maternal $(\mathrm{M})=12$-week old pregnant dams, Fetal $(\mathrm{F})=\mathrm{GD}(15)$, Young Adult $(\mathrm{YA})=11$ weeks. All data are presented as the mean \pm standard error of the mean $(\mathrm{SEM}) . *=P \leq 0.05, * *$ $=P \leq 0.01, * * *=P \leq 0.001$ for Ex vs. Sham. 
Supplemental Figure 2.1: Bioenergetics

A Glutamine

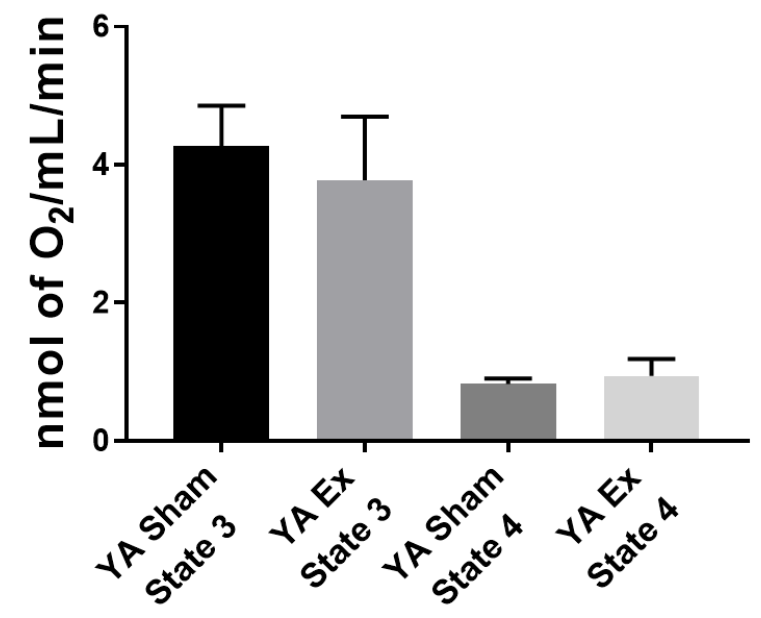

P-Carnitine

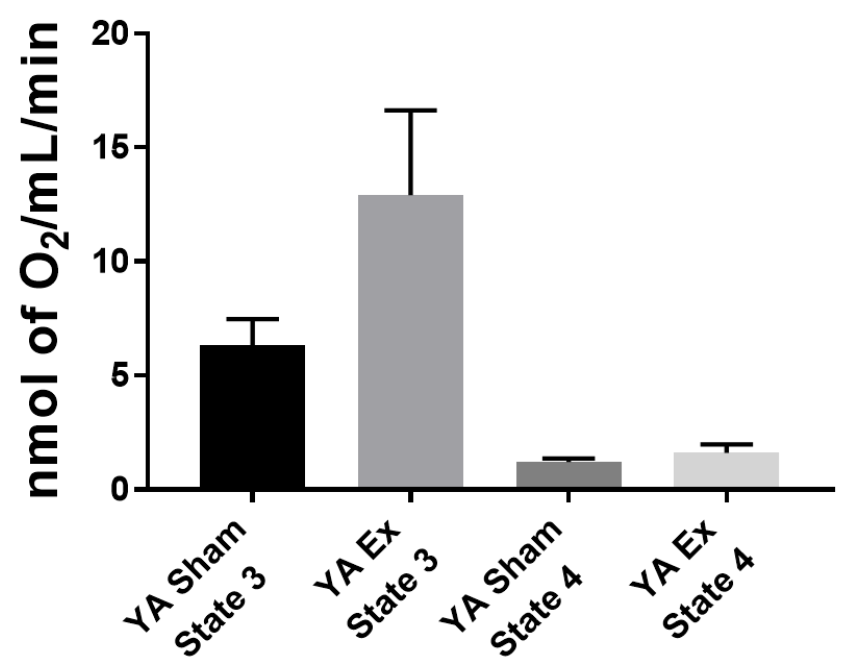


Supplemental Figure 2.1:
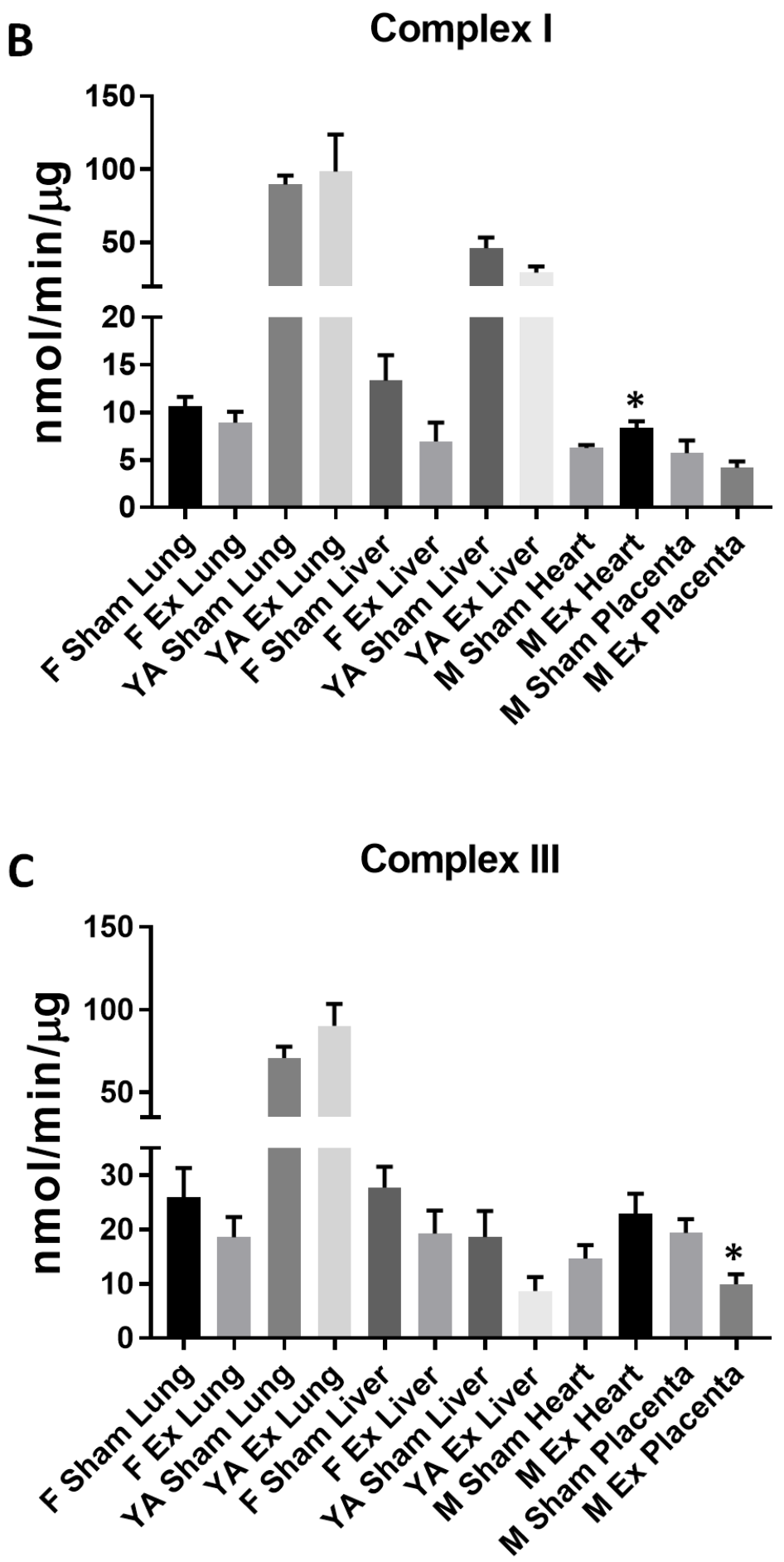
Supplemental Figure 2.1:

D

Complex IV

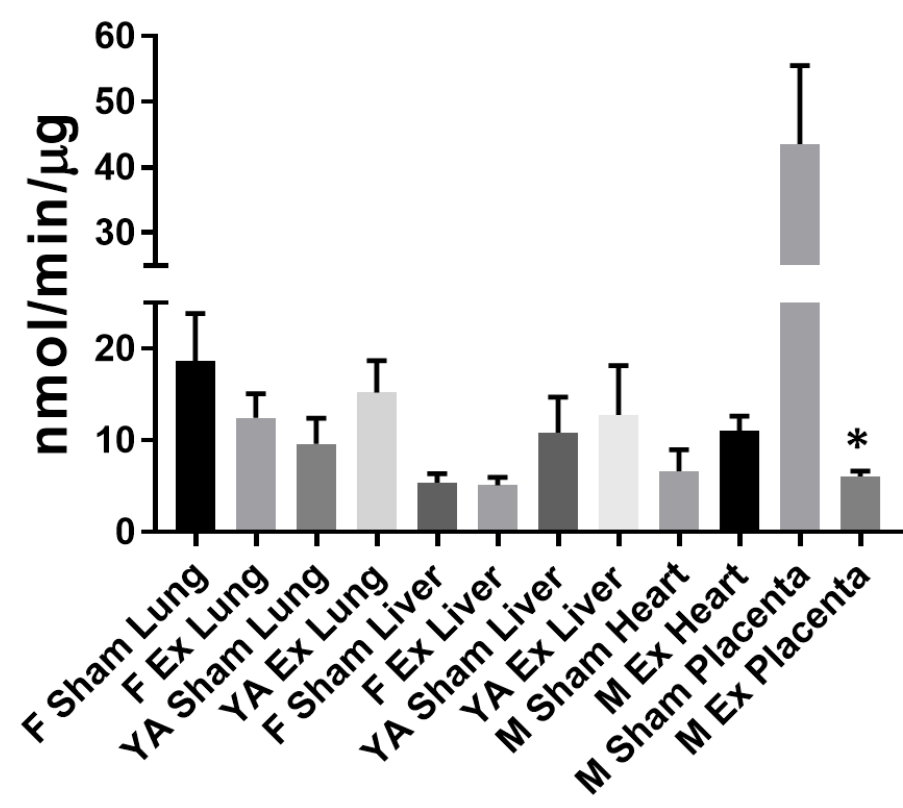

E

Complex V

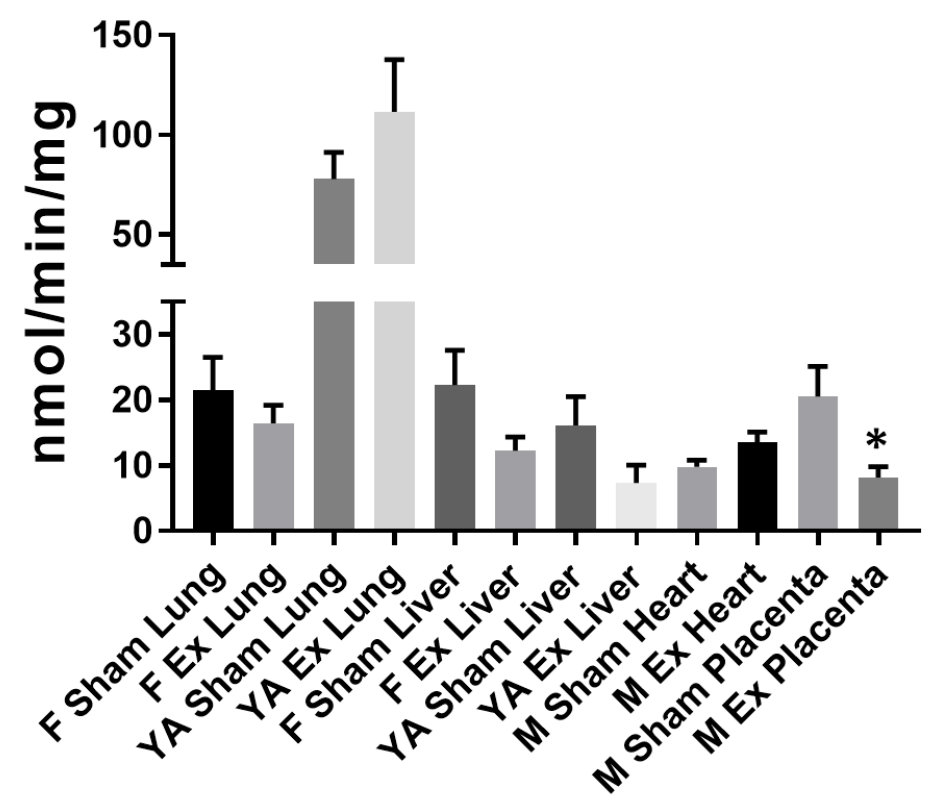




\section{Supplemental Figure 2.1: Mitochondrial bioenergetics of other tissues and organ systems.}

(A) In young adult ( $\mathrm{n}=7$ Sham, $\mathrm{n}=5 \mathrm{Ex})$ animals state 3 and state 4 respiration was assessed using glucose (glutamine) and fatty-acid-mediated pathways (palmitoyl carnitine), normalized to number of mitochondria. (B) ETC complex activities for complex I in fetal, young adult, and maternal tissues. (C) ETC complex activities for complex III in fetal, young adult, and maternal tissues. (D) ETC complex activities for complex IV in fetal, young adult, and maternal tissues. (E) ETC complex activities for complex V (ATP synthase) in fetal, young adult, and maternal tissues. Sham $=$ control filtered air exposed, $\mathrm{Ex}=$ nano- $\mathrm{TiO}_{2}$ exposed, Maternal $(\mathrm{M})=12$-week old pregnant dams, Fetal $(\mathrm{F})=$ GD $(15)$, Young Adult $(Y A)=11$ weeks, P-Carnitine $=$ palmitoyl carnitine. All data are presented as the mean \pm standard error of the mean (SEM). $*=P \leq 0.05, * *$ $=P \leq 0.01, * * *=P \leq 0.001$ for Ex vs. Sham. 
Supplemental Figure 2.2: ROS-Mediated Effects

A

Hydrogen Peroxide Assay

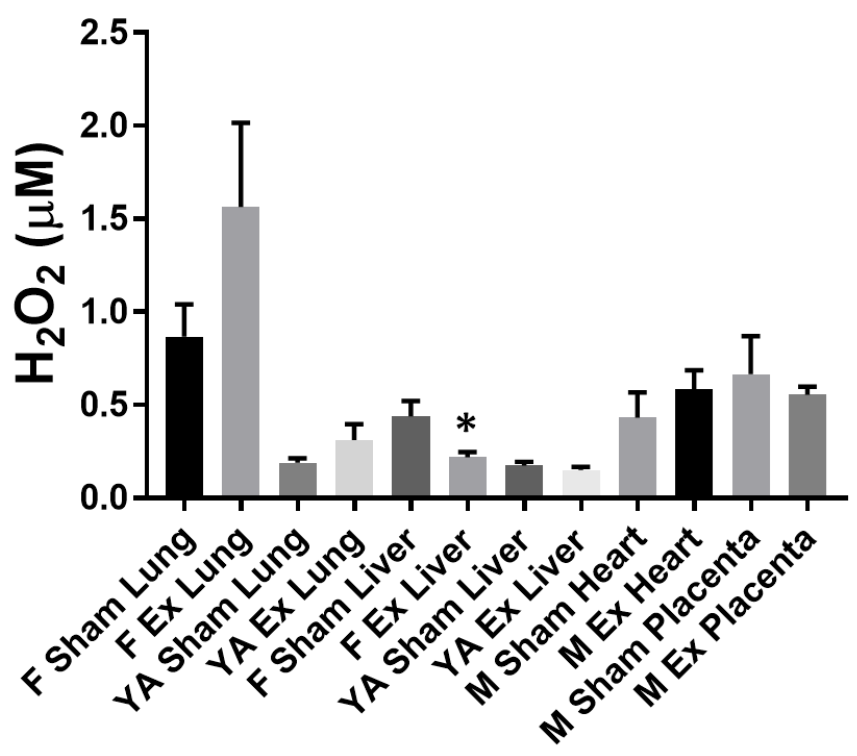

B

Hif1 $\alpha$ Activity

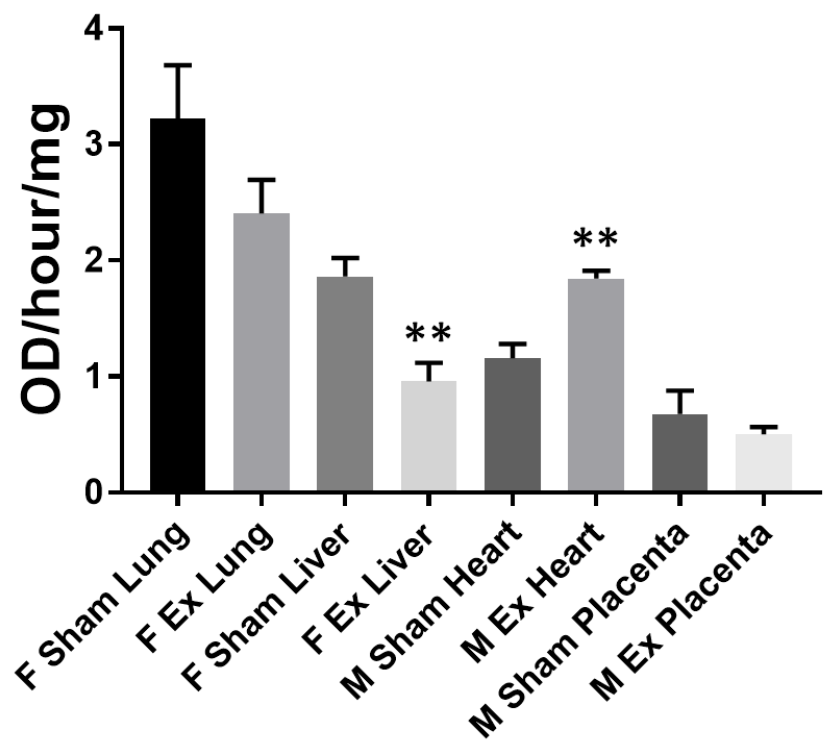


Supplemental Figure 2.2:

C

Dnmt Activity
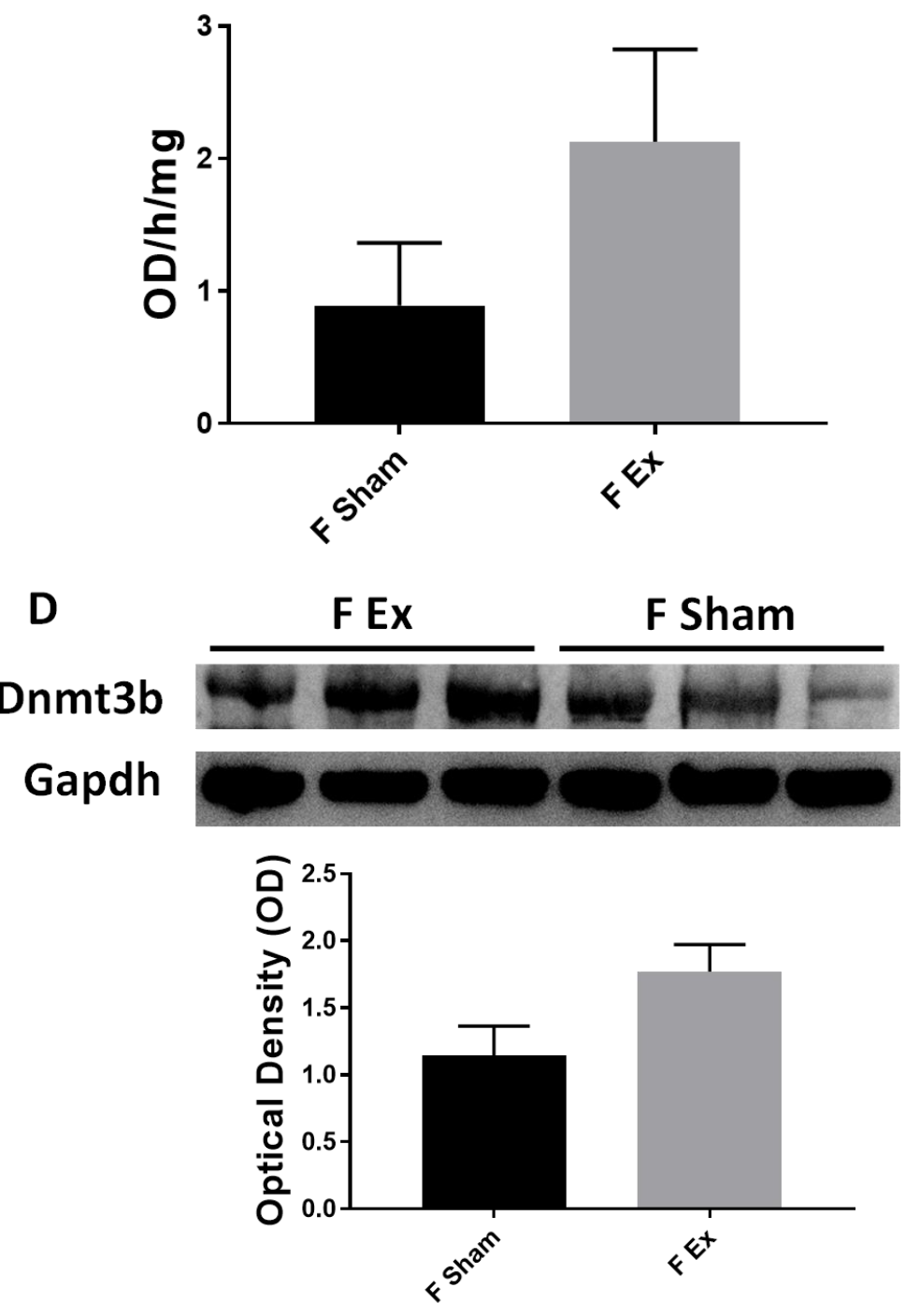

E

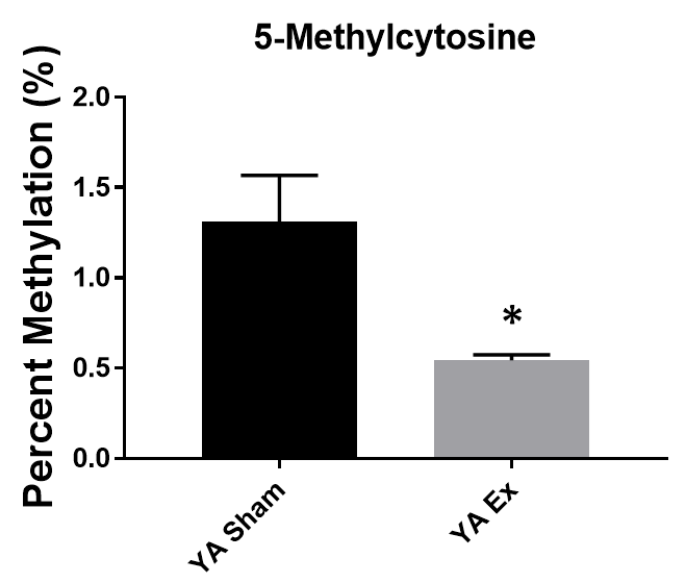


Supplemental Figure 2.2: ROS-mediated pathways in other tissues and organ systems. (A) Hydrogen peroxide $\left(\mathrm{H}_{2} \mathrm{O}_{2}\right)$ concentration in fetal, young adult, and maternal tissues normalized to protein content. (B) Hif1 $\alpha$ activity was measured in fetal and maternal tissues and normalized to protein content. (C) Activity of DNA methyltransferases (Dnmts) in fetal ( $n=4$ Sham, $n=5$ Ex) heart tissue, normalized to protein content. (D) Dnmt3b expression levels were assessed in young adult $(\mathrm{n}=3$ Sham, $\mathrm{n}=3$ Ex) animals and normalized using anti-Gapdh primary antibody. (E) Global 5-mC DNA methylation levels were evaluated in young adult $(n=7$ Sham, $n=5$ Ex) hearts, normalized to DNA concentration. Sham $=$ control filtered air exposed, $\mathrm{Ex}=$ nano- $\mathrm{TiO}_{2}$ exposed, Maternal (M) = 12-week old pregnant dams, Fetal (F) = GD (15), Young Adult (YA) = 11 weeks, Hifl $\alpha=$ Hypoxia-inducible factor 1-alpha. Dnmt3b = DNA (cytosine-5)-methyltransferase 3b. All data are presented as the mean \pm standard error of the mean $(\mathrm{SEM}) . *=P \leq 0.05, * *=P \leq 0.01$, $* * *=P \leq 0.001$ for Ex vs. Sham. 


\title{
Chapter 3: Specific Aim 2
}

\section{Enhanced Antioxidant Capacity Prevents Epitranscriptomic and Cardiac Alterations in Adult Offspring Gestationally-Exposed to ENM}

\author{
Amina Kunovac ${ }^{1,2,3}$, Quincy A. Hathaway ${ }^{1,2,3}$, Mark V. Pinti ${ }^{2,4}$, Andrya J. Durr ${ }^{1,2}$, Andrew D. Taylor ${ }^{1,2}$, William T. \\ Goldsmith $^{3,5}$, Krista L. Garner ${ }^{3,5}$, Timothy R. Nurkiewicz ${ }^{3,5}$, and John M. Hollander ${ }^{1,2,3}$
}

As published in Nanotoxicology. 2021 May 8:1-20. doi: 10.1080/17435390.2021.1921299. Online ahead of print.

\begin{abstract}
${ }^{1}$ Division of Exercise Physiology, West Virginia University School of Medicine, Morgantown, WV, USA.
${ }^{2}$ Mitochondria, Metabolism \& Bioenergetics Working Group, West Virginia University School of Medicine, Morgantown, WV, USA. ${ }^{3}$ Center for Inhalation Toxicology (iTOX), West Virginia University School of Medicine, Morgantown, WV, USA. ${ }^{4}$ West Virginia University School of Pharmacy, Morgantown, WV, USA. ${ }^{5}$ Department of Physiology \& Pharmacology, West Virginia University School of Medicine, Morgantown, WV, USA.
\end{abstract}

Amina Kunovac; ak0086@mix.wvu.edu, Quincy A. Hathaway; qahathaway@mix.wvu.edu, Mark V. Pinti; mpinti@mix.wvu.edu, Andrya J. Durr; ajdurr@mix.wvu.edu, Andrew D. Taylor; adt0023@ mix.wvu.edu, Krista L. Garner; kg0048@mix.wvu.edu, William T. Goldsmith; wgoldsmi@hsc.wvu.edu, Timothy R. Nurkiewicz; tnurkiewicz@ hsc.wvu.edu, and John M. Hollander; jhollander@hsc.wvu.edu

Corresponding Author:

John M. Hollander, Ph.D., F.A.H.A.

Division of Exercise Physiology

West Virginia University School of Medicine

PO Box 9227

1 Medical Center Drive

Morgantown, WV 26506

Tel: 1-(304) 293-3683

Fax: 1-(304) 293-7105

Email: jhollander@hsc.wvu.edu 


\begin{abstract}
Maternal engineered nanomaterial (ENM) exposure during gestation has been associated with negative long-term effects on cardiovascular health in progeny. Here we evaluate an epitranscriptomic mechanism that contributes to these chronic ramifications and whether overexpression of mitochondrial phospholipid hydroperoxide glutathione peroxidase (mPHGPx) can preserve cardiovascular function and bioenergetics in offspring following gestational nanotitanium dioxide $\left(\mathrm{TiO}_{2}\right)$ inhalation exposure. Wild-type (WT) and mPHGPx (Tg) dams were exposed to nano- $\mathrm{TiO}_{2}$ aerosols with a mass concentration of $12.01 \pm 0.50 \mathrm{mg} / \mathrm{m}^{3}$ starting from gestational day (GD) 5 for a period of 360 mins/day for 6 non-consecutive days over an 8-day period. Echocardiography was performed in pregnant dams, adult (11-week old) and fetal (GD 14) progeny. Mitochondrial function and global $\mathrm{N}^{6}$-methyladenosine $\left(\mathrm{m}^{6} \mathrm{~A}\right)$ content were assessed in adult progeny. MPHGPx enzymatic function was further evaluated in adult progeny and $\mathrm{m}^{6} \mathrm{~A}-$ RNA immunoprecipitation (RIP) was combined with RT-qPCR to evaluate $\mathrm{m}^{6} \mathrm{~A}$ content in the 3'UTR. Following gestational ENM exposure, global longitudinal strain (GLS) was 32\% lower in WT adult offspring of WT dams, with preservation in WT offspring of Tg dams. MPHGPx activity was significantly reduced in WT offspring (29\%) of WT ENM-exposed dams, but preserved in progeny of Tg dams. M ${ }^{6} \mathrm{~A}-\mathrm{RIP}-\mathrm{qPCR}$ for the SEC insertion sequence region of mPHGPx revealed hypermethylation in WT offspring from ENM-exposed WT dams, which was thwarted in the presence of the maternal transgene. Our findings implicate that $\mathrm{m}^{6} \mathrm{~A}$ hypermethylation of $\mathrm{mPHGPx}$ may be culpable for diminished antioxidant capacity and resultant mitochondrial and cardiac deficits that persist into adulthood following gestational ENM inhalation exposure.
\end{abstract}

Keywords: Environmental exposure, GPx4, Mitochondria, $\mathrm{N}^{6}$-methyladenosine, $\mathrm{M}^{6} \mathrm{~A}$ 


\section{Introduction}

While engineered nanomaterials (ENMs) and advance materials, have enabled important innovations in biomedical engineering, the increased potential for their interactions with biological tissues warrants assessment of their ability to elicit undesirable toxicological effects $(11,15,52)$. The application of nano-titanium dioxide (nano- $\mathrm{TiO}_{2}$ ), a commonly utilized ENM, escalated by $300 \%$ from 2011-2013 in consumer products (72). The primary route of exposure is inhalation, which allows particles to enter the bloodstream and systemically impact the body (66). The size of these particles ( $\geq 1$ dimension that is $\leq 100 \mathrm{~nm}$ in diameter), plays a critical role in their ability to access systemic circulation and promote cardiovascular damage $(32,36,52,55,66)$. Nano- $\mathrm{TiO}_{2}$ has been implicated in alterations to cardiovascular hemodynamics and mitochondrial dysregulation $(23,24,45)$. Exposure to ENMs are of particular concern for vulnerable populations such as the developing fetus $(11,21)$. Although research relating to particulate matter exposure during gestational development and the associated detriments are receiving more attention, therapeutic interventions are limited and the identification of mechanisms responsible for long term effects remain undefined.

Initial studies from our laboratory have determined that maternal ENM inhalation exposure during gestation elicits cardiac contractile dysfunction and bioenergetic disruption in the developing fetus (35), which are sustained into adulthood $(24,35)$. At the fetal stage, the functional deficits were attributed to an increased production of reactive oxygen species (ROS) (marked by hydrogen peroxide $\left(\mathrm{H}_{2} \mathrm{O}_{2}\right)$ levels) and downregulation of mitochondria phospholipid hydroperoxide glutathione peroxidase (mPHGPx) (35), an antioxidant enzyme that protects cells from oxidative stress. Because mPHGPx scavenges hydroperoxides, limiting diffusion of $\mathrm{H}_{2} \mathrm{O}_{2}$ from the mitochondrion into other cellular regions, its expression is critical for decreasing ROS influence on nuclear genome regulation. MPHGPx has the ability to mitigate cardiac dysfunction and bioenergetic dysregulation in several contexts $(6,16,26)$, including acute nano- $\mathrm{TiO}_{2}$ exposure (45). However, whether enhanced antioxidant capacity can provide a protective role to fetal and adult offspring following maternal ENM inhalation exposure during gestation remains unexplored.

In a previous study from our laboratory, we reported mitochondrial and cardiac contractile decrements in the fetal stage that were sustained into adulthood following maternal ENM inhalation exposure (35). Though the mechanism by which these detriments are sustained is 
unclear, epitranscriptomic modifications resulting from maternal ENM exposure may be contributing to the persistent cardiac mitochondrial dysfunction observed. Of interest was our observation of increased ROS and concomitant diminution of mPHGPx protein expression at the fetal stage which may have been associated with epigenetic reprogramming that occurs following particulate exposure $(11,21,29,33,35,63,71)$. Specifically, epitranscriptomic mechanisms may be responsible for degradation of mRNA and/or functional deficits in proteins $(19,37,44)$. $\mathrm{N}^{6}$ methyladenosine $\left(\mathrm{m}^{6} \mathrm{~A}\right)$ is the most prevalent post-transcriptional mRNA modification in eukaryotes and has been associated with various pathologies (13, 14, 19, 39, 56, 77). Elevated stress levels have the ability to alter $\mathrm{m}^{6} \mathrm{~A}$ machinery and therefore modulate transcript stability by adding and removing methylation marks $(9,19,37,61,77) . \mathrm{M}^{6} \mathrm{~A}$ sites are known to be enriched near stop codons and in 3'-untranslated regions (UTR) of mRNA (73), thereby influencing translation (43). Investigation of $\mathrm{m}^{6} \mathrm{~A}$ sites in crucial coding regions of nuclear genome-encoded mitochondrial mRNAs that are pivotal for antioxidant defense maintenance is of particular interest, as it may provide insight into mechanisms that result in the longitudinal outcomes of maternal ENM exposure during gestation.

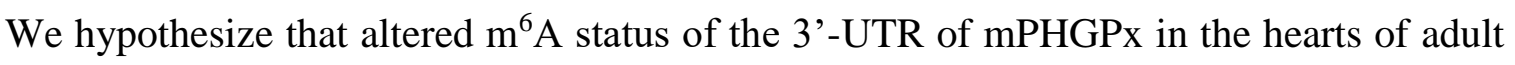
offspring contributes to mitochondrial and cardiac functional deficits and that overexpression of mPHGPx (in the mother or pup) can preserves these functional alterations following maternal ENM inhalation exposure. Through the use of differential breeding strategies, we were able to determine that the maternal transgene is protective for the fetus and the benefit is sustained in adult offspring, regardless of whether the progeny also possessed the transgene. Following gestational ENM inhalation exposure, mPHGPx enzymatic activity was entirely preserved only in offspring whose dams were mPHGPx transgenic. $\mathrm{M}^{6} \mathrm{~A}$ methylation was highly enriched in the 3'-UTR of mPHGPx in wild-type (WT) offspring exposed in utero to nano- $\mathrm{TiO}_{2}$, but maternal mPHGPx overexpression prevented this modification. Our findings suggest that enhancing antioxidant defense in the pregnant dam may provide offspring with the most protection from epitranscriptomic remodeling and subsequent long-term cardiovascular repercussions that arise following gestational nano- $\mathrm{TiO}_{2}$ inhalation exposure. 


\section{Materials and Methods}

\section{Animal Model}

The West Virginia University Animal Care and Use Committee approved all animal studies which conform to the most current National Institutes of Health (NIH) Guidelines for the Care and Use of Laboratory Animals ( $8^{\text {th }}$ edition) manual. Male and female transgenic (mPHGPx $\left.(+/+)\right)$ and wild-type (mPHGPx (-/-)) mice with a FVB/NJ genetic background were housed in the West Virginia University Health Sciences Center Animal Facility. All animals were given access to a rodent diet and water ad libitum. The mPHGPx transgenic mouse model has been previously described by our laboratory $(6,16)$. Briefly, to achieve overexpression of mPHGPx, the gene was placed under the control of the cytomegalovirus promoter, which provides robust transgene expression. Transgene screening was performed on tail clip DNA of 3-week old mice using a qPCR approach in which we probed for mPHGPx using a fluorometric probe (Product no. Mm00515041_m1, Applied Biosystems, Foster City, CA). Increased mPHGPx protein content and improved scavenging ability for phosphatidylcholine hydroperoxide (PCOOH) and hydrogen peroxide $\left(\mathrm{H}_{2} \mathrm{O}_{2}\right)$ in the mPHGPx transgenic mice indicated a functionally active enzyme (16). MPHGPx overexpression as an antioxidant protective strategy was tested in multiple contexts utilizing complementary breeding strategies (Figure 3.1A-B). Because mPHGPx mice are heterozygous transgenic, the transgene status of the donor parent (paternal vs. maternal) impacts the nature of the protective strategy provided to the offspring. Presence of the paternal mPHGPx

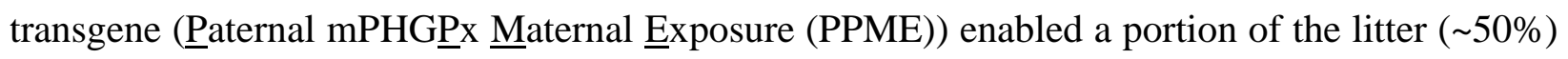
to be mPHGPx transgenic positive (Figure 3.1A, right panel) and thus presented the opportunity to determine whether fetal mPHGPx transgene presence is protective in utero and adult offspring.

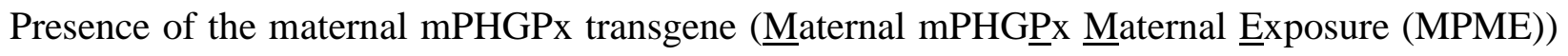
enabled a portion of the litter $(\sim 50 \%)$ to be mPHGPx transgenic $(\mathrm{Tg})$ as well, but with the added benefit of the maternal mPHGPx transgene (Figure 3.1A, left panel). This breeding strategy allowed us to delineate whether mPHGPx transgene presence in the environment provided by the dam is beneficial to non-transgenic progeny or additional benefit to transgenic progeny. Pregnancy was verified by identifying the vaginal plug. Approximately 5 days after identification of the vaginal plug (gestational day 5 (GD 5)), the pregnant dams were designated into either sham or nano- $\mathrm{TiO}_{2}$ exposure groups. Echocardiographic assessments were performed on adult offspring 
(11 weeks old), as well as pregnant dams (12 weeks old) and fetal-stage progeny (GD 14). For the adult offspring study, pups remained with the singly-housed dams until weaning age (19 days) at which point they were housed with littermates and separated by sex, with no more than 5 animals per cage. Adult progeny were euthanized at $\sim 11$ weeks of age and hearts were excised for further analyses. From each adult litter, one animal of each genotype (WT/Tg) was randomly selected and designated $\mathrm{N}=1$, alternating selection of male and female offspring to control for sex as a biological variable. All offspring were genotyped using the qPCR method described above. Pregnant dams were euthanized one day following echocardiographic imaging (GD 15), the pups were removed and tail clips were collected for genotyping. Adult offspring and pregnant dams were euthanized through sedation with $5 \%$ isoflurane and subsequent cervical dislocation. A timeline of the study is provided in Figure 3.1C.

\section{Engineered Nanomaterial Inhalation Exposure}

The ENM inhalation exposure paradigm utilized in the current study has been previously described (23). Nano- $\mathrm{TiO}_{2} \mathrm{P} 25$ powder containing anatase $(80 \%)$ and rutile $(20 \%) \mathrm{TiO}_{2}$ was purchased from Evonik (Aeroxide $\mathrm{TiO}_{2}$, Parsipanny, $\mathrm{NJ}$ ) and prepared by drying, sieving, and storing $(23,34,47)$. The primary particle characteristics have been previously reported including the size $(21 \mathrm{~nm})$, the specific surface area $\left(48.08 \mathrm{~m}^{2} / \mathrm{g}\right)$, and the Zeta potential $(-56.6 \mathrm{mV})(45,47$, 58). Nano- $\mathrm{TiO}_{2}$ was aerosolized with a high-pressure acoustical generator (HPAG; IEStechno, Morgantown, WV), and has been detailed in previous studies (23) involving rodent inhalation exposure. Figure 3.2 provides data outlining the aerosol characterization of nano- $\mathrm{TiO}_{2}$. In order to recapitulate a lung burden typically seen in a manufacturing setting exposure (35), a target aerosol mass concentration of $12 \mathrm{mg} / \mathrm{m}^{3}$ of engineered nano- $\mathrm{TiO}_{2}$ was chosen, for a period of 360 minutes per day for 6 non-consecutive days over an 8-day period, with a whole-body exposure chamber. This level was based on human equivalent alveolar doses during pregnancy and is explained in more detail later in the manuscript. The real-time $\mathrm{TiO}_{2}$ aerosol mass concentration readings (pDR-1500; Thermo Environmental Instruments Inc., Franklin, MA) over a typical exposure day were sampled from an exposure chamber (Figure 3.2A) and verified by gravimetric measurements during each exposure. Final gravimetric measurements indicated a daily 360minute equivalent average mass concentration of $12.01 \pm 0.50 \mathrm{mg} / \mathrm{m}^{3}$. A high-resolution electrical 
low-pressure impactor (ELPI+; Dekati, Tampere, Finland), a scanning particle mobility sizer (SMPS 3938; TSI Inc., St. Paul, MN), and a Nano Micro-Orifice Uniform Deposit Impactor (MOUDI 115R; MSP Corp, Shoreview, MN) were used to measure the size of the nano- $\mathrm{TiO}_{2}$ aerosols. A log-normal fit of the data from the ELPI+ indicated a geometric count median diameter (CMD) of $0.163 \mu \mathrm{m}$ with a geometric standard deviation (GSD) of 1.77 (Figure 3.2B). A lognormal fit of the data from the SMPS indicated a CMD of $0.190 \mu \mathrm{m}$ with a GSD of 1.97 (Figure 3.2C). A $\log$ normal fit of the data from the MOUDI indicated a mass median aerodynamic diameter (MMAD) of $0.968 \mu \mathrm{m}$ with a GSD of 2.56 (Figure 3.2D). Transmission and scanning electron micrographs (TEM and SEM) of nano- $\mathrm{TiO}_{2}$ aerosolized particles, sampled from the exposure chamber have been previously published (35). The dose required to match the appropriate lung deposition was calculated based on previously described mouse methodology modified to reflect alveolar deposition only (45). The formula $\mathrm{D}=\mathrm{F} \times \mathrm{V} \times \mathrm{C} \times \mathrm{T}$, where $\mathrm{F}$ is the alveolar deposition fraction (4.40\%) ((Multiple Path Particle Dosimetry Model (MPPD v3.04)) (2), $\mathrm{V}$ is the minute ventilation based on body weight $(36.4 \mathrm{ml})(10), \mathrm{C}$ is the mass concentration $\left(12.01 \mathrm{mg} / \mathrm{m}^{3}\right)$ and $\mathrm{T}$ is the exposure duration (6 hours), was employed $(47,64)$. This resulted in a daily deposited nano- $\mathrm{TiO}_{2}$ alveolar dose of $6.92 \mu \mathrm{g}$ (total six exposure dose $=41.55 \mu \mathrm{g}$ ). When this alveolar burden is normalized with respect to alveolar surface area $\left(\right.$ mouse $_{\mathrm{sa}}=0.05 \mathrm{~m}^{3}$, human $_{\mathrm{sa}}$ $=102 \mathrm{~m}^{3}$ ) and matched to a human breathing the same aerosol, it corresponds to a human alveolar deposition of $84.76 \mathrm{mg}$. This is equivalent to an approximately 79 day exposure at the NIOSH recommended exposure limit (REL) of $2.4 \mathrm{mg} / \mathrm{m}^{3}$ for fine $\mathrm{TiO}_{2}$ established in 2011 (17) (F = $12.24 \%$ (MMPD), V = 7.6 L). Since factory workers are exposed to airborneTiO2 levels of $\sim 0.65$ $\mathrm{mg} / \mathrm{m}^{3}(51)$ and the human gestational period is 9 months, we feel that our exposure concentration levels are highly relevant to the female worker population. To maintain a comfortable humidity during the exposure, bedding material was soaked in water and placed in the exposure chamber. Control animals (sham) were exposed to HEPA filtered air, rather than nano- $\mathrm{TiO}_{2}$, in a designated chamber with similar chamber conditions. The final exposure was administered 48 hours prior to sacrifice and tissue harvesting.

\section{Echocardiography}


Cardiac contractile function was assessed in adult offspring (11 weeks old) using the Vevo2100 High Frequency Ultrasound system (Visual Sonics, Toronto, Canada) to obtain Motion mode (M-mode) images as previously described (35). Anesthesia was induced using inhalant isoflurane, which was then maintained at $\sim 1.5 \%$ in order to achieve a physiologically relevant heart rate. Images were acquired with a linear array transducer at $32-40 \mathrm{MHz}$, with a frame rate of 233-401 frames/second. M-mode images were also obtained for pregnant dams (12 weeks old) and their fetal progeny (GD 14). For fetal echocardiographic imaging, pups in the right and left uterine horns were imaged sequentially, which allowed us to correlate the assessed cardiac function with the genotype of that specific pup. For adult offspring analyses, one animal of each genotype (WT/Tg) from each exposed (sham/nano-TiO 2 ) dam (PPME (WT mom) or MPME (Tg mom) was selected at random. Measurements were calculated over three cardiac cycles and averaged.

Speckle-tracking-based strain evaluations were performed using parasternal long and short axis B-mode images as previously described by our laboratory $(24,35,46,59)$. A speckle-tracking algorithm in Visual Sonics VevoStrain software (Toronto, Canada) was employed to trace the endocardium and epicardium walls. Data were analyzed for three cardiac cycles using time-topeak analysis for curvilinear data. Measures of systolic strain including deformation, strain rate, displacement, and velocity were obtained. For adult progeny, speckle-tracking was performed on both long- and short-axis images. For fetal progeny, speckle-tracking was performed on short-axis images. All echocardiographic measurements were acquired by one analyst blinded to the animal exposure group and genotype.

\section{Electron Transport Chain (ETC) Complex Activities}

ETC Complex activities (I, III, IV, and V) were measured in hearts of adult offspring as previously described $(4,6,24)$. Whole tissue was homogenized using the Polytron PowerGen 500 S1 tissue homogenizer (Fisher Scientific, Hampton, NH) in NP-40 buffer (20mM Tris, 137mM $\mathrm{NaCl}, 10 \%$ Glycerol, $1 \%$ Triton x100, 2mM EDTA) (25). Samples were centrifuged for 10 minutes at $10,000 \mathrm{xg}\left(4^{\circ} \mathrm{C}\right)$ and the supernatant was used for the activity assays. The protein homogenates were used to measure activities of ETC complexes I, III, IV, and V (ATP synthase). ETC complex I and III activities were determined by measuring the reduction of decylubiquinone (I) and 
cytochrome c (III) in cardiac protein lysate of adult offspring. ETC complex IV activity was determined by measuring the oxidation of reduced cytochrome $\mathrm{c}$, while complex $\mathrm{V}$ activity was determined by measuring oligomycin-sensitive ATPase activity through pyruvate kinase and phosphoenolpyruvate in cardiac protein lysate of adult offspring. The Molecular Devices Flex Station 3 Multi-Mode microplate reader (Sunnyvale, CA) was used to measure all assays spectrophotometrically. Protein content was normalized using the Bradford method, with bovine serum albumin protein assay standards. Final values were expressed as Unit/nanogram (I-IV) or milligram $(\mathrm{V})$ of protein, where Unit $=$ nanomoles of substrate oxidized $\cdot \operatorname{minute}{ }^{-1}$.

\section{Total Glutathione Peroxidase (GPx) Activity}

Total GPx activity was measured using a GPx Activity Kit from Cayman Chemical (item no. 703102, Ann Arbor, MI). The Cayman Chemical GPx Activity Kit determines all glutathionedependent peroxidase activity indirectly through a coupled reaction with glutathione reductase (GR). The cumene hydroperoxide in this assay is reduced by GPx producing oxidized glutathione (GSSG), which can then be recycled to its reduced state by GR and NADPH. The oxidation of NADPH results in a decrease in absorbance at 340nm that is proportional to the GPx activity, when it is the rate limiting factor. The experiment was carried out using the manufacturer's protocol, with minor modifications: Heart lysate (in NP-40) samples were diluted with sample buffer and $20 \mu \mathrm{l}$ of the diluted heart lysate was used for the assay. Absorbance was read once every minute for 6 minutes at $340 \mathrm{~nm}$ using the Molecular Devices Flex Station 3 Multi-Mode microplate reader. Absorbance values were retrospectively normalized to protein content with the Bradford assay (12).

\section{MPHGPx Activity}

To determine mitochondrial phospholipid hydroperoxide glutathione peroxidase (GPx4) activity, phosphatidylcholine hydroperoxide (PCOOH), a specific substrate of mPHGPx, was synthesized as previously described (67). L- $\alpha$-Phosphatidylcholine Type III/S (PC) (item no. P3782; Sigma-Aldrich, St. Louis, MO) was slowly added to a Tris/Base buffer (0.2 M, pH 8.8, 3mM sodium deoxycholate (item no. D6750, Sigma-Aldrich)) while stirring at medium-high 
speed. Once a cloudy emulsion of small droplets was visible, additional Tris/Base buffer was introduced with continuous stirring until the solution was clear. A volume of soybean lipoxidase Type V (item no. L6632, Sigma-Aldrich) was added that equaled 250,000 U to initiate the synthesis reaction followed with continuous stirring for 1hour. A Sep-Pak C-18 cartridge (item no. 020515, Waters, Milford, MA) was activated with methanol and equilibrated with $\mathrm{ddH}_{2} \mathrm{O}$, then used to purify the PCOOH with a $30 \mathrm{ml}$ glass syringe (item no. Z314374, Sigma-Aldrich). The cartridge was washed with water to remove water-soluble substances and the PCOOH was eluted from the $\mathrm{C} 18$ resin with methanol. The concentration of $\mathrm{PCOOH}$ was determined at $\mathrm{A}_{234}$ using the NanoDrop ND-100 (Thermo Fisher Scietific, Waltham, MA) and diluted to a desired concentration with methanol. The $\mathrm{PCOOH}$ was immediately used as the substrate (in place of cumene hydroperoxide) with the Glutathione Peroxidase Assay Kit (Cayman) as described above, with absorbance readings every 30 seconds for 6 minutes at 340nm with the Molecular Devices Flex Station 3 Multi-Mode microplate reader. All samples were blanked with background wells (no sample) and normalized to protein content.

\section{Mitochondrial Isolation}

Adult progeny were sacrificed at 11 weeks of age, and hearts were excised through a midsagittal cut in the thoracic cavity. Isolation of mitochondrial subpopulations was achieved through differential centrifugation as previously described $(6,48)$. The two subpopulations were combined and utilized as a total mitochondrial fraction for subsequent analyses. KME buffer (100mM KCl, 50mM MOPS and 0.5mM EGTA pH 7.4) was used to resuspend isolated mitochondria. Protein concentrations were determined using the Bradford method with bovine serum albumin as a standard (12).

\section{Hydrogen Peroxide $\left(\mathrm{H}_{2} \mathrm{O}_{2}\right)$ Production}

Hydrogen peroxide $\left(\mathrm{H}_{2} \mathrm{O}_{2}\right)$ production was evaluated in total tissue lysate and isolated mitochondria from adult offspring in order to determine mitochondrial ROS production $(35,45$, 65). The Invitrogen ${ }^{\mathrm{TM}}$ Amplex ${ }^{\mathrm{TM}}$ Red Hydrogen Peroxide Assay Kit (product no. A2218; Thermo Fisher) was utilized per manufacturer's instructions and assays performed spectrophotometrically. 
In the presence of horseradish peroxidase (HRP), the Amplex ${ }^{\mathrm{TM}}$ Red reagent produces a red fluorescent oxidation product when the reagent reacts with $\mathrm{H}_{2} \mathrm{O}_{2}$. The oxidation product, resorufin, was detected spectrophotometrically at $560 \mathrm{~nm}$ and data were normalized to protein content.

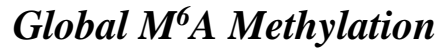

Total RNA was purified from heart samples that were digested with QIAzol lysis reagent (item no. 79306, Qiagen, Hilden, Germany) from one adult offspring of each genotype (WT/Tg) from each dam (PPME/MPME) from each exposure group (sham/nano- $\mathrm{TiO}_{2}$ ) using the miRNeasy Mini Kit (item no. 217004, Qiagen). Global $\mathrm{m}^{6} \mathrm{~A}$ methylation was quantified in total RNA using the EpiQuik ${ }^{\mathrm{TM}} \mathrm{m}^{6} \mathrm{~A}$ RNA Methylation Quantification Kit (item no. P-9005; EpiGentek, Farmingdale, NY) per manufacturer's instructions. Briefly, total RNA samples were diluted to a standard concentration of $200 \mathrm{ng}$ with IDTE buffer. Dilution of the provided positive control allowed for the generation of a standard curve. RNA was bound to the assay wells through incubation with the binding solution. An optimized $\mathrm{m}^{6} \mathrm{~A}$ capture antibody was added to the wells, incubated, and washed, followed by addition of the detection antibody and enhancer solution. The color developing solution was then introduced and incubated for 2 minutes, until the color changed to blue, at which point the stop solution was added. Absorbance was read at $450 \mathrm{~nm}$ using the Molecular Devices Flex Station 3 Multi-Mode microplate reader. A standard curve was used to determine global $\mathrm{m}^{6} \mathrm{~A}$ levels in each sample.

\section{Immunoprecipitation $\left(m^{6} A-R I P\right)$}

Total RNA was purified from whole heart samples from PPME and MPME WT adult offspring from each exposure group (sham/nano- $\mathrm{TiO}_{2}$ ) using the miRNeasy Kit (Qiagen) described above.

\section{RNA Fragmentation}

Before the immunoprecipitation was carried out, the RNA samples were fragmented using the NEBNext Magnesium RNA Fragmentation kit (item no. E6150s; New England Biolabs) (5, 
76). To determine the necessary length of incubation to achieve desired fragmentation ( 130 nt), samples were incubated for $1-10$ minutes at $94^{\circ} \mathrm{C}$. The 10 samples were analyzed with the Bioanalyzer 2100 (Agilent Technologies, Santa Clara, CA) to determine the size distribution of the fragments.

\section{$M^{6} A-R I P$}

The EpiMark N6-Methyladenosine Enrichment Kit (item no. E1610S; New England Biolabs, Ipswich, MA) was used to enrich $\mathrm{m}^{6} \mathrm{~A}$ modified RNA per manufacturer's instructions, with minor modifications. RNA samples were fragmented at $94^{\circ} \mathrm{C}$ for 3 minutes (5). Dynabeads ${ }^{\mathrm{TM}}$ Protein G magnetic beads from Thermo Fisher Scientific (product no. 10003D) were washed and resuspended in Reaction Buffer. An anti-N6-Methyladenosine $\left(\mathrm{m}^{6} \mathrm{~A}\right)$ rabbit monoclonal antibody (product no. 56593, Cell Signaling Technology, Danvers, MA) was bound to the beads, followed by the addition of the fragmented total RNA (100ng) and RNasin ${ }^{\circledR}$ Plus RNase Inhibitor (product no. N2611; Promega, Madison, WI). The normal Rabbit IgG control (product no. 2729, Cell Signaling Technology), an unconjugated rabbit polyclonal antibody, was used as a non-specific IgG control for the immunoprecipitation. After the immunoprecipitation, RNA was eluted with Buffer RLT (product no. 79216; Qiagen) then cleaned and concentrated using Dynabeads ${ }^{\mathrm{TM}}$ MyOne ${ }^{\mathrm{TM}}$ Silane (product no. 37002D; Life Technologies, Carlsbad, CA). The RNA samples from both input and immunoprecipitated samples were examined by RT-qPCR to quantify $\mathrm{m}^{6} \mathrm{~A}$ enrichment.

\section{$R T-q P C R$}

WT adult offspring heart samples (from $\mathrm{WT} / \mathrm{Tg}$ and sham $/$ nano- $\mathrm{TiO}_{2}$ exposed dams) were prepared for downstream analysis by reverse-transcribing the input and immunoprecipitated RNA using the Applied Biosystems High Capacity cDNA Reverse Transcription Kit (product no. 4368814; Thermo Fisher Scientific) per manufacturer's protocol. RT-qPCR was utilized to evaluate $\mathrm{m}^{6} \mathrm{~A}$ enrichment of the mPHGPx $3^{\prime}$-UTR, specifically the region containing the crucial selenocysteine (Sec) insertion sequence (SECIS) $(13,28)$. Primers for mPHGPx and a control, GAPDH, were designed using Primer3Plus (7) and the sequences are listed in Supplemental 
Table 3.1 (Additional file 3.1). Quantification was achieved with $\mathrm{SYBR}^{\circledR}$ Green master mix (product no. A25742, Thermo Fisher Scientific) using the Applied Biosystems 7500 Fast RealTime PCR system. Samples were run in triplicate. Enrichment fold was calculated using the $\Delta \mathrm{Ct}$ value of the IP normalized to the $\Delta \mathrm{Ct}$ of the input, relative to the dilution factor (20\% input; dilution factor $=5$ ), and normalized to GAPDH, as illustrated below (42).

$$
\begin{gathered}
\Delta C t[\text { Normalized IP }]=C t[I P]-(C t[\text { Input }]-\log 2(\text { Dilution Factor })) \\
\Delta \Delta C t=\Delta C t\left[\text { Normalized } I P_{(m P H G P x)}\right]-\Delta C t[\text { Normalized IP }(\text { GAPDH })] \\
\text { Fold enrichment }=2^{(-\Delta \Delta C t)}
\end{gathered}
$$

\section{Statistics}

All statistical analyses were performed using GraphPad Prism Software Version 8 for Windows (GraphPad Software, La Jolla CA). For adult offspring analyses, from each MPME or PPME cohort, one animal of each genotype (WT/Tg) from a given exposure (sham and nano- $\mathrm{TiO}_{2}$ ) was randomly selected and designated $\mathrm{N}=1$. For fetal analyses, each pregnant dam that was exposed (sham/nano- $\mathrm{TiO}_{2}$ ) was considered one observation, with each genetic group (WT/Tg) considered as $\mathrm{N}=1$. Data were analyzed using a two-way analysis of variance (ANOVA) method to evaluate mPHGPx presence and nano- $\mathrm{TiO}_{2}$ maternal exposure. Normality was determined using the D'Agostino-Pearson test. Tukey's multiple comparison method was performed following the two-way ANOVA to evaluate effects within the PPME and MPME groups. Statistical difference was defined by $P \leq 0.05$. The presence of a letter above a specific group denotes statistical significance between those two groups as determined by Tukey's multiple comparisons test. For functional assays performed using adult hearts, a two-tailed Student's t-test was also employed to evaluate whether maternal nano- $\mathrm{TiO}_{2}$ inhalation exposure during gestation elicited a change between offspring of the same genotype. The presence of a dagger ( $\dagger$ ) above a given group indicates statistical significance between WT Sham and $\mathrm{WT} \mathrm{TiO}_{2}$ or $\mathrm{Tg}$ Sham and $\mathrm{Tg} \mathrm{TiO}_{2}$ of the same maternal genetic group (MPME or PPME). For qPCR data, a one-way ANOVA was employed followed by a Tukey's multiple comparisons test to determine significant differences in 
$\mathrm{m}^{6} \mathrm{~A}$ fold enrichment across WT offspring groups. All data are presented as the mean \pm the standard error of the mean (SEM). 


\section{Results}

\section{Cardiac Function}

Deleterious changes in cardiac structure and function have previously been identified in offspring following maternal nano- $\mathrm{TiO}_{2}$ inhalation exposure during gestation (24, 35). Conventional M-mode evaluations determined that adult offspring of WT dams (PPME) who were gestationally-exposed to nano- $\mathrm{TiO}_{2}$ presented with higher systolic diameter and volume, as well as lower ejection fraction and fractional shortening than those whose dams were sham-exposed (Table 3.1). Additionally, adult offspring whose dams were mPHGPx Tg (MPME) overall had significantly lower diastolic diameter and volume, stroke volume, and cardiac outputs than PPME offspring regardless of exposure (Table 3.1). Adult offspring heart rates were unchanged regardless of exposure or genotype (Additional file 3.1: Supplemental Table 3.2).

When examining the dams, WT nano- $\mathrm{TiO}_{2}$-exposed mice had significantly decreased diastolic diameter and volume when compared to WT sham-exposed dams, as well as reduced pump function indicated by stroke volume and cardiac output reductions (Additional file 3.1: Supplemental Table 3.3). Furthermore, relative wall thickness was significantly increased following ENM exposure in WT dams, but not in the mPHGPx Tg dams (Additional file 3.1: Supplemental Table 3.3). Maternal heart rate remained unchanged between all exposure groups (Additional file 3.1: Supplemental Table 3.4). At the fetal stage, in order to correlate the assessed cardiac function with the genotype of that specific pup, pups in the right and left uterine horns were sequentially imaged (Figure 3.3A). A representative trace of the fetal pup's left ventricle (LV) in M-mode is shown in Figure 3.3B. A group-dependent effect was found, with the MPME fetal offspring demonstrating higher diastolic diameter and volume, as well as higher stroke volume and cardiac output than the PPME offspring (Additional file 3.1: Supplemental Table 3.5). MPME fetal offspring also had significantly higher heart rates (Additional file 3.1: Supplemental Table 3.2). Decreased function in the PPME WT offspring following gestational ENM exposure confirms previous findings (35) and substantiate the susceptibility of WT offspring to cardiovascular changes due to maternal nano- $\mathrm{TiO}_{2}$ exposure, which may be a result of limited antioxidant capacity.

Speckle-tracking based stress strain assessments were performed during systole in fetal and adult offspring groups of all dams (Table 3.2 and Additional file 3.1: Supplemental Table 3.6- 
7). Long-axis measurements in adult offspring demonstrated that endocardial global longitudinal strain (GLS) was significantly lower in PPME WT offspring whose dams were exposed to nano$\mathrm{TiO}_{2}$ compared to sham-exposed (Table 3.2). The PPME WT pups also had a significantly lower GLS than PPME Tg adults, who were both progeny of nano- $\mathrm{TiO}_{2}$ exposed dams. (Table 3.2). A group dependent effect was seen with MPME progeny having higher radial and longitudinal strain rates, and diminished longitudinal displacement compared to PPME progeny. Group dependent effects were also observed in the parasternal short axis between the MPME (Additional file 3.1: Supplemental Table 3.6). Figures 3.3 $\mathbf{C}$ and $\mathbf{D}$ provide representative B-mode images of a fetal pup in utero during end diastole and end systole, respectively, as well as speckle-tracking traces correlating to each of these frames (Figure 3.3 E-F). At the fetal stage, short-axis radial and circumferential strain rates were significantly lower in both the PPME WT and Tg groups whose dams were exposed to nano- $\mathrm{TiO}_{2}$ than the pups of the same respective genotype whose dams were sham-exposed (Additional file 1: Supplemental Table 3.7). Further, these data also revealed a group dependent effect based on maternal genotype (MPME vs PPME). Overall, these changes appear to suggest that enhanced maternal antioxidant protection may provide sufficient protection to thwart cardiac maladaptation that is precipitated by ENM exposure.

\section{ETC Complex Activities}

ETC complex activity assays were performed on protein lysate samples of adult offspring (Figure 3.4). Two-way ANOVA analysis revealed no significant difference between PPME and MPME offspring for complex I (Figure 3.4A) and complex III activities (Figure 3.4B), but MPME offspring had significantly higher activities for both complex IV (Figure 3.4C) and V (Figure 3.4D). Individual t-tests were implemented to better delineate exposure specific differences between offspring of the same genotype (WT or Tg) and same cohort (PPME or MPME). The PPME WT offspring of ENM-exposed dams had significantly diminished complex I (Figure 3.4A) and IV (Figure 3.4C) activities than PPME WT offspring whose dams were shamexposed. These findings are consistent with previously published data from our laboratory (35).

\section{GPx Activity and $\mathrm{H}_{2} \mathrm{O}_{2}$ Production}


Total GPx enzymatic activity (including all isoforms) was measured in adult offspring. MPME offspring had a significantly higher level of total GPx activity than the PPME offspring (Figure 3.5A). Within the PPME group, Tg offspring of sham-exposed dams had elevated enzymatic activity compared to their WT littermates (Figure 3.5A). To assess specific mPHGPx activity, phosphatidylcholine $(\mathrm{PCOOH})$ was used as a substrate. Within the PPME group, the Tg sham adult offspring had the highest level of mPHGPx activity and was significantly higher than the other three PPME groups, including the PPME Tg offspring whose dams were nano- $\mathrm{TiO}_{2}$ exposed (Figure 3.5B). In the MPME group, the $\mathrm{Tg}$ sham and $\mathrm{Tg}$ nano- $\mathrm{TiO}_{2}$ groups were both significantly higher than their littermate controls (Figure 3.5B). Student's t-tests were used to delineate exposure specific differences between offspring with the same genotype from the same cohort (PPME or MPME). These analyses revealed that in the PPME group, gestational exposure to ENM resulted in lower mPHGPx activity regardless of the offspring's genotype (Figure 3.5B).

Previously published data from our laboratory have indicated that maternal ENM exposure during gestation resulted in increased $\mathrm{H}_{2} \mathrm{O}_{2}$ levels at the fetal stage, which was not sustained into adulthood (35). In the current study, $\mathrm{H}_{2} \mathrm{O}_{2}$ levels were unchanged in adult offspring (Figure 3.5C), which was consistent with our previous findings. $\mathrm{H}_{2} \mathrm{O}_{2}$ levels were also evaluated in isolated mitochondria. $\mathrm{H}_{2} \mathrm{O}_{2}$ levels were elevated in PPME WT adult offspring whose dams were gestationally-exposed to ENM when compared to PPME WT adult offspring whose dams were gestationally-sham-exposed (Figure 3.5D). These data overall indicate that maternal exposure to nano- $\mathrm{TiO}_{2}$ during gestation results in decreased hydroperoxide scavenging and increased ROS, while maternal antioxidant protection has the potential to prevent these detriments.

\section{Global and mPHGPx $M^{6} A$ Methylation}

Alterations in the relative abundance of $\mathrm{m}^{6} \mathrm{~A}$ modifications can affect RNA metabolism and are associated with various diseases, including metabolic diseases affecting the heart (38). The SEC insertion sequence (SECIS), which is present in the 3'-UTR of mPHGPx and allows for the insertion of the crucial selenocysteine, contains potential $\mathrm{m}^{6} \mathrm{~A}$ sites $(40,75)$. To investigate whether altered total $\mathrm{m}^{6} \mathrm{~A}$ methylation plays a role in the diminished $\mathrm{mPHGPx}$ activity in offspring whose dams were exposed to nano- $\mathrm{TiO}_{2}$, we quantified global $\mathrm{m}^{6} \mathrm{~A}$ in RNA isolated from the hearts of adult offspring (Figure 3.6A). Initial analyses indicated that global $\mathrm{m}^{6} \mathrm{~A}$ status was 
statistically unchanged between the groups, but individual t-tests revealed that MPME Tg offspring whose dams were exposed to nano- $\mathrm{TiO}_{2}$ had significantly lower levels of $\mathrm{m}^{6} \mathrm{~A}$ methylation than MPME Tg offspring whose dams were sham-exposed (Figure 3.6A).

In order to evaluate the SEC region of mPHGPx in WT offspring, RNA was fragmented and used to perform an $\mathrm{m}^{6} \mathrm{~A}$ RNA immunoprecipitation, followed by qPCR for a specific region of the mPHGPx 3'-UTR. RNA fragmentation incubation time was determined using the Bioanalyzer 2100. A 3-minute incubation was deemed the most appropriate in order to achieve $\sim 130 \mathrm{nt}$ fragments (Figure 3.6B) (5). RMBase v2.0 software predicted the presence of $\mathrm{m}^{6} \mathrm{~A}$ sites at the 3'-UTR of mPHGPx mRNA specifically within the SECIS region (Figure 3.6C). RT-qPCR revealed that PPME WT adult offspring whose dams were exposed to nano- $\mathrm{TiO}_{2}$ had significantly higher $\mathrm{m}^{6} \mathrm{~A}$ levels in the $3^{\prime}$-UTR region of mPHGPx than the control group (PPME WT sham) (Figure 3.6D), as well as both the sham and nano- $\mathrm{TiO}_{2}$ MPME WT groups. These data indicate that gestational exposure in WT dams, has the ability to modulate epitranscriptome reprogramming that is present in offspring at adulthood. The increase in $\mathrm{m}^{6} \mathrm{~A}$ enrichment in the PPME WT offspring of ENM-exposed dams may be responsible for the persistent mitochondrial bioenergetic and cardiac functional detriments. Additionally enhanced maternal antioxidant capacity may provide protection from the initial stimuli responsible for the altered $\mathrm{m}^{6} \mathrm{~A}$ status of mPHGPx. 


\section{Discussion}

With the inevitable increase in production and application of ENM-enabled products in manufacturing, biomedicine, and general consumer use, a thorough understanding of the longitudinal repercussions is necessary for the development of preventative and protective strategies for workers and consumers. This is of particular importance during fetal growth, where a toxicological insult may elicit immediate and long-term deleterious effects. In this study, we have demonstrated that increased antioxidant defense in the maternal environment is capable of providing preservation to cardiac contractile function potentially through the maintenance of mitochondrial bioenergetics. Furthermore, the presence of the maternal transgene preserved $\mathrm{m}^{6} \mathrm{~A}$ status at the 3'-UTR of mPHGPx in offspring despite gestational ENM inhalation exposure. Our data point to a maladaptation in the epitranscriptomic signature as the mechanism responsible for diminished bioenergetics and cardiac contractile deficits in adult offspring following maternal exposure.

Left ventricular ejection fraction (LVEF) has been widely used as a key measure of cardiac contractile function and as a prognostic tool for heart failure (53). The dependence of this parameter on load, can limit reproducibility, necessitating a more reliable marker of cardiac function (1, 30). Global longitudinal strain (GLS), a measure of myocardial deformation, is the most commonly utilized clinical application of strain imaging $(20,41)$. GLS appears to be a better predictor of cardiovascular outcomes than LVEF, with better reproducibility $(3,31)$. Decreases in GLS, as seen in the PPME WT offspring following exposure, highlight the susceptibility of this group to future cardiovascular events (Table 3.2). The preservation of GLS in the MPME group is therefore noteworthy as the antioxidant protective strategy provided by the mother was able to sufficiently protect her offspring from long-term adverse cardiovascular complications.

Maternal ENM exposure during gestation interferes with fetal development and has longterm consequences for offspring that persist into adulthood $(11,15,27,69)$. The importance of the maternal environment are outlined by the developmental origins of health and disease (DOHaD) hypothesis and supported by an increasing number of studies (70). The current study highlights how amplifying antioxidant capacity in the maternal environment can deter the maladaptive cardiovascular changes that persist into adulthood, regardless of the progeny's genotype. Although transgenic expression provides a limitation to clinical uses of maternal antioxidant protection, we 
establish a basis for investigating other potential antioxidant protective strategies. One example is mitoquinone mesylate (MitoQ), a mitochondrial-targeted antioxidant that has showed promise in improving mitochondrial dysfunction, reducing hydrogen peroxide production, and antioxidant enzyme activity $(50,54)$. MitoQ also has the ability to prevent the long-term impacts of maternal cigarette smoke exposure on progeny by mitigating renal total ROS in the mothers and offspring at adulthood (68). Future investigations should aim to determine whether supplementation with antioxidant-boosting therapeutics during pregnancy can provide the same protective effect to progeny as maternal mPHGPx overexpression.

As a relatively new area of research in ENM inhalation exposure toxicology, there are few studies that investigate the detailed epitranscriptomic mechanisms associated with the exposures. However, a recent study demonstrated that in A549 cells, global $\mathrm{m}^{6} \mathrm{~A}$ was decreased following particulate matter exposure as a result of altered $\mathrm{m}^{6} \mathrm{~A}$ modulator genes (14). Although this study was performed using lung epithelial cells, it is one of the first studies to highlight the concept that exposure to environmental toxicants has the ability to alter $\mathrm{m}^{6} \mathrm{~A}$ RNA methylation profiles. $\mathrm{M}^{6} \mathrm{~A}$ has previously been established to preferentially occur around stop codons, with high enrichment in 3'-UTRs of human and mouse transcriptomes $(18,43)$. Further, the 3'-UTR of mPHGPx is a critical region as it is the location of the Sec incorporation machinery, which enables the catalytic activity of this peroxide scavenging protein (28). To ensure proper function of mPHGPx as a peroxide scavenger, proper selenocysteine ( $\mathrm{Sec}$ ) incorporation is required, which involves the recoding of a UGA codon from "Stop" to "Sec" via a complex that is assembled at a specific region of the 3'-UTR known as the SECIS $(28,60)$. Recoding occurs through an eEFSec/Sec-tRNASec complex binding to Sec binding protein 2 (SBP2), which is anchored to the SECIS in the 3'-UTR. Alterations to the SECIS region, may affect the efficiency of Sec incorporation and thus alter the catalytic activity and/or expression of mPHGPx by retaining the premature termination codon, potentially resulting in decay $(60,62)$. Modulation of this critical region may be the mechanism that results in the persistent adverse outcomes of maternal ENM inhalation exposure into adulthood.

Early studies of $\mathrm{m}^{6} \mathrm{~A}$ modifications determined that $\mathrm{m}^{6} \mathrm{~A}$ primarily occurs in two possible sequences, $\mathrm{Gm}^{6} \mathrm{AC}$ or $\mathrm{Am}^{6} \mathrm{AC}(74)$, but have further been specified as RRACH (R = A/G and H $=\mathrm{A} / \mathrm{C} / \mathrm{U})(8,18,75)$. Interestingly, RMBase v2.0 software, which was utilized as a way of 
scanning for RRACH motifs, predicted $\mathrm{m}^{6} \mathrm{~A}$ sites at the 3'-UTR of mPHGPx mRNA specifically within the SECIS region (75), as demonstrated in Figure 3.6C. The presence of $\mathrm{m}^{6} \mathrm{~A}$ sites in this region was also confirmed in a recent study that aimed to assess the methylome of human and mouse tissue (40). Papp et al. reported that inefficient selenoprotein synthesis can increase sensitivity to oxidative stress, which is one potential explanation for the alterations seen at the fetal stage following gestational ENM inhalation exposure (49). Moreover, increased methylation, shown in Figure 3.6, may alter Sec incorporation by changing the secondary structure of the SECIS hairpin (57) and preventing SBP2 from anchoring the incorporation complex to the RNA (22). This in turn may be leading to inefficient mPHGPx hydroperoxide scavenging (28) at the adult stage. The decrease in mPHGPx protein expression at the fetal stage compared to the maintenance of expression, but diminution of mPHGPx activity at the adult stage, will require further investigation. A possible explanation is that the epitranscriptomic remodeling occurring at the adult stage may differ from the initial reprogramming that occurred in utero following maternal nano- $\mathrm{TiO}_{2}$ inhalation exposure.

Figure 3.7 provides an overview of the mechanisms involved in the long-term ramifications of maternal ENM inhalation exposure during gestation on offspring. Overexpression of mPHGPx in the pregnant dam limits $\mathrm{H}_{2} \mathrm{O}_{2}$ (ROS) production, thereby mitigating changes to mitochondrial bioenergetics and cardiac contractile function in adult progeny. However, without the overexpression of mPHGPx in the maternal environment, ROS production is not controlled following nano- $\mathrm{TiO}_{2}$ exposure during gestation, resulting in downstream effects on cardiac function and mitochondrial bioenergetics. This occurs, in part, as a result of elevated $\mathrm{m}^{6} \mathrm{~A}$ methylation at the SECIS region of mPHGPx, which disrupts Sec incorporation and diminishes mPHGPx catalytic activity. The current study highlights the therapeutic potential of enhanced antioxidant protection in the maternal environment during gestation (Figure 3.7). Increased hydroperoxide scavenging through this approach can provide protection for offspring into adulthood from the deleterious effects of maternal particulate exposure during gestation, without the need for supplementation by the progeny. Overexpression of mPHGPx in the pregnant dam likely circumvents the initial surge of oxidative stress that is elicited by the xenobiotic exposure, through a mechanism that involves epitranscriptomic reprogramming. 
At the adult stage, maternal ENM exposure during gestation was associated with altered $\mathrm{m}^{6} \mathrm{~A}$ methylation of mPHGPx that contributes to diminished enzymatic activity and persistent cardiac contractile alterations. These findings highlight a specific targeted alteration to the epitranscriptome that may be mechanistically linked to sustained bioenergetic and cardiac dysfunction associated with gestational ENM exposure. Alterations to the epitranscriptome presented in this study provide a new perspective on the role of $\mathrm{m}^{6} \mathrm{~A}$ methylation changes in the fields of cardiovascular ENM inhalation exposure toxicology. Our study introduces a protective strategy that can be implemented to safeguard developing progeny against long-term cardiovascular ramifications. 


\section{Acknowledgements}

We would like to thank Sherri A. Friend and the National Institute for Occupational Safety and Health, Morgantown, WV, USA for contributing in the physicochemical characterization of the nano- $\mathrm{TiO}_{2}$ aerosolized particles.

\section{Disclosure of Interest}

The authors report no conflict of interest.

\section{Funding}

This work was supported by: The National Heart Lung Blood Institute (NHLBI) under Grant [R01 HL-128485] (JMH), the National Institute of Environmental Health Sciences (NIEHS) under Grant [R01 ES-015022] (TRN), American Heart Association under Grant [AHA20PRE35080170] (AK), American Heart Association under Grant [AHA-17PRE33660333] (QAH), National Institute on Aging (NIA) under Grant [5 T32 AG 52375-3] (KLG),WVU Genomics Core Facility support by CTSI Grant [U54GM104942], WVU Animal Models \& Imaging Facility supported by the WVU Cancer Institute and NIH grants [P20 RR016440] and [P30 RR032138/GM103488], and the Community Foundation for the Ohio Valley Whipkey Trust (JMH). 


\section{References:}

1. Amzulescu MS, De Craene M, Langet H, Pasquet A, Vancraeynest D, Pouleur AC, Vanoverschelde JL, and Gerber BL. Myocardial strain imaging: review of general principles, validation, and sources of discrepancies. Eur Heart J Cardiovasc Imaging 20: 605-619, 2019.

2. Anjilvel S, and Asgharian B. A multiple-path model of particle deposition in the rat lung. Fundam Appl Toxicol 28: 41-50, 1995.

3. Ashish K, Faisaluddin M, Bandyopadhyay D, Hajra A, and Herzog E. Prognostic value of global longitudinal strain in heart failure subjects: A recent prototype. Int J Cardiol Heart Vasc 22: 48-49, 2019.

4. Barrientos A, Fontanesi F, and Diaz F. Evaluation of the mitochondrial respiratory chain and oxidative phosphorylation system using polarography and spectrophotometric enzyme assays. Curr Protoc Hum Genet Chapter 19: Unit19 13, 2009.

5. Barros-Silva D, Lobo J, Guimaraes-Teixeira C, Carneiro I, Oliveira J, MartensUzunova ES, Henrique $\mathbf{R}$, and Jeronimo C. VIRMA-Dependent N6-Methyladenosine Modifications Regulate the Expression of Long Non-Coding RNAs CCAT1 and CCAT2 in Prostate Cancer. Cancers (Basel) 12: 2020.

6. Baseler WA, Dabkowski ER, Jagannathan R, Thapa D, Nichols CE, Shepherd DL, Croston TL, Powell M, Razunguzwa TT, Lewis SE, Schnell DM, and Hollander JM. Reversal of mitochondrial proteomic loss in Type 1 diabetic heart with overexpression of phospholipid hydroperoxide glutathione peroxidase. Am J Physiol Regul Integr Comp Physiol 304: R553-565, 2013.

7. Baseler WA, Dabkowski ER, Williamson CL, Croston TL, Thapa D, Powell MJ, Razunguzwa TT, and Hollander JM. Proteomic alterations of distinct mitochondrial subpopulations in the type 1 diabetic heart: contribution of protein import dysfunction. Am $J$ Physiol Regul Integr Comp Physiol 300: R186-200, 2011.

8. Batista PJ. The RNA Modification N(6)-methyladenosine and Its Implications in Human Disease. Genomics Proteomics Bioinformatics 15: 154-163, 2017.

9. Berulava T, Buchholz E, Elerdashvili V, Pena T, Islam MR, Lbik D, Mohamed BA, Renner A, von Lewinski D, Sacherer M, Bohnsack KE, Bohnsack MT, Jain G, Capece V, Cleve N, Burkhardt S, Hasenfuss G, Fischer A, and Toischer K. Changes in m6A RNA methylation contribute to heart failure progression by modulating translation. Eur J Heart Fail 22: 54-66, 2020.

10. Bide RW, Armour SJ, and Yee E. Estimation of Human Toxicity From Animal Inhalation Toxicity Data:1. Minute Volume-Body Weight Relationships Between Animals And Man Defence Research Establishment Suffield, 1997.

11. Bommarito PA, Martin E, and Fry RC. Effects of prenatal exposure to endocrine disruptors and toxic metals on the fetal epigenome. Epigenomics 9: 333-350, 2017.

12. Bradford MM. A rapid and sensitive method for the quantitation of microgram quantities of protein utilizing the principle of protein-dye binding. Anal Biochem 72: 248-254, 1976.

13. Castellanos-Rubio A, Santin I, Olazagoitia-Garmendia A, Romero-Garmendia I, Jauregi-Miguel A, Legarda M, and Bilbao JR. A novel RT-QPCR-based assay for the relative quantification of residue specific m6A RNA methylation. Sci Rep 9: 4220, 2019.

14. Cayir A, Barrow TM, Guo L, and Byun HM. Exposure to environmental toxicants reduces global N6-methyladenosine RNA methylation and alters expression of RNA methylation modulator genes. Environ Res 175: 228-234, 2019. 
15. Crispi F, Miranda J, and Gratacos E. Long-term cardiovascular consequences of fetal growth restriction: biology, clinical implications, and opportunities for prevention of adult disease. Am J Obstet Gynecol 218: S869-S879, 2018.

16. Dabkowski ER, Williamson CL, and Hollander JM. Mitochondria-specific transgenic overexpression of phospholipid hydroperoxide glutathione peroxidase (GPx4) attenuates ischemia/reperfusion-associated cardiac dysfunction. Free Radic Biol Med 45: 855-865, 2008.

17. Department of Health and Human Services CfDCaP, National Institute for Occupational Safety and Health. Occupational Exposure to Titanium Dioxide. 2011.

18. Dominissini D, Moshitch-Moshkovitz S, Schwartz S, Salmon-Divon M, Ungar L, Osenberg S, Cesarkas K, Jacob-Hirsch J, Amariglio N, Kupiec M, Sorek R, and Rechavi G. Topology of the human and mouse m6A RNA methylomes revealed by m6A-seq. Nature 485: 201-206, 2012.

19. Engel M, Eggert C, Kaplick PM, Eder M, Roh S, Tietze L, Namendorf C, Arloth J, Weber P, Rex-Haffner M, Geula S, Jakovcevski M, Hanna JH, Leshkowitz D, Uhr M, Wotjak CT, Schmidt MV, Deussing JM, Binder EB, and Chen A. The Role of m(6)A/m-RNA Methylation in Stress Response Regulation. Neuron 99: 389-403 e389, 2018.

20. Ersboll M, Valeur N, Mogensen UM, Andersen MJ, Moller JE, Velazquez EJ, Hassager C, Sogaard P, and Kober L. Prediction of all-cause mortality and heart failure admissions from global left ventricular longitudinal strain in patients with acute myocardial infarction and preserved left ventricular ejection fraction. J Am Coll Cardiol 61: 2365-2373, 2013.

21. Ferrari L, Carugno M, and Bollati V. Particulate matter exposure shapes DNA methylation through the lifespan. Clin Epigenetics 11: 129, 2019.

22. Fletcher JE, Copeland PR, Driscoll DM, and Krol A. The selenocysteine incorporation machinery: interactions between the SECIS RNA and the SECIS-binding protein SBP2. RNA 7: 1442-1453, 2001.

23. Hathaway QA, Durr AJ, Shepherd DL, Pinti MV, Brandebura AN, Nichols CE, Kunovac A, Goldsmith WT, Friend SA, Abukabda AB, Fink GK, Nurkiewicz TR, and Hollander JM. miRNA-378a as a key regulator of cardiovascular health following engineered nanomaterial inhalation exposure. Nanotoxicology 13: 644-663, 2019.

24. Hathaway QA, Nichols CE, Shepherd DL, Stapleton PA, McLaughlin SL, Stricker JC, Rellick SL, Pinti MV, Abukabda AB, McBride CR, Yi J, Stine SM, Nurkiewicz TR, and Hollander JM. Maternal-engineered nanomaterial exposure disrupts progeny cardiac function and bioenergetics. Am J Physiol Heart Circ Physiol 312: H446-H458, 2017.

25. Hathaway QA, Roth SM, Pinti MV, Sprando DC, Kunovac A, Durr AJ, Cook CC, Fink GK, Cheuvront TB, Grossman JH, Aljahli GA, Taylor AD, Giromini AP, Allen JL, and Hollander JM. Machine-learning to stratify diabetic patients using novel cardiac biomarkers and integrative genomics. Cardiovasc Diabetol 18: 78, 2019.

26. Hollander JM, Lin KM, Scott BT, and Dillmann WH. Overexpression of PHGPx and HSP60/10 protects against ischemia/reoxygenation injury. Free Radic Biol Med 35: 742-751, 2003.

27. Hougaard KS, Campagnolo L, Chavatte-Palmer P, Tarrade A, Rousseau-Ralliard D, Valentino S, Park MV, de Jong WH, Wolterink G, Piersma AH, Ross BL, Hutchison GR, Hansen JS, Vogel U, Jackson P, Slama R, Pietroiusti A, and Cassee FR. A perspective on the developmental toxicity of inhaled nanoparticles. Reprod Toxicol 56: 118-140, 2015.

28. Ingold I, Berndt C, Schmitt S, Doll S, Poschmann G, Buday K, Roveri A, Peng X, Porto Freitas F, Seibt T, Mehr L, Aichler M, Walch A, Lamp D, Jastroch M, Miyamoto S, 
Wurst W, Ursini F, Arner ESJ, Fradejas-Villar N, Schweizer U, Zischka H, Friedmann Angeli JP, and Conrad M. Selenium Utilization by GPX4 Is Required to Prevent HydroperoxideInduced Ferroptosis. Cell 172: 409-422 e421, 2018.

29. Janssen BG, Madhloum N, Gyselaers W, Bijnens E, Clemente DB, Cox B, Hogervorst J, Luyten L, Martens DS, Peusens M, Plusquin M, Provost EB, Roels HA, Saenen ND, Tsamou M, Vriens A, Winckelmans E, Vrijens K, and Nawrot TS. Cohort Profile: The ENVIRonmental influence ON early AGEing (ENVIRONAGE): a birth cohort study. Int $J$ Epidemiol 46: 1386-1387m, 2017.

30. Kalam K, Otahal P, and Marwick TH. Prognostic implications of global LV dysfunction: a systematic review and meta-analysis of global longitudinal strain and ejection fraction. Heart 100: 1673-1680, 2014.

31. Karlsen S, Dahlslett T, Grenne B, Sjoli B, Smiseth O, Edvardsen T, and Brunvand H. Global longitudinal strain is a more reproducible measure of left ventricular function than ejection fraction regardless of echocardiographic training. Cardiovasc Ultrasound 17: 18, 2019.

32. Kessler R. Engineered nanoparticles in consumer products: understanding a new ingredient. Environ Health Perspect 119: a120-125, 2011.

33. Kietzmann T, Petry A, Shvetsova A, Gerhold JM, and Gorlach A. The epigenetic landscape related to reactive oxygen species formation in the cardiovascular system. $\mathrm{Br} J$ Pharmacol 174: 1533-1554, 2017.

34. Knuckles TL, Yi J, Frazer DG, Leonard HD, Chen BT, Castranova V, and Nurkiewicz TR. Nanoparticle inhalation alters systemic arteriolar vasoreactivity through sympathetic and cyclooxygenase-mediated pathways. Nanotoxicology 6: 724-735, 2012.

35. Kunovac A, Hathaway QA, Pinti MV, Goldsmith WT, Durr AJ, Fink GK, Nurkiewicz TR, and Hollander JM. ROS promote epigenetic remodeling and cardiac dysfunction in offspring following maternal engineered nanomaterial (ENM) exposure. Part Fibre Toxicol 16: 24, 2019.

36. Kunovac A, Hathaway QA, Pinti MV, Taylor AD, and Hollander JM. Cardiovascular adaptations to particle inhalation exposure: molecular mechanisms of the toxicology. Am J Physiol Heart Circ Physiol 319: H282-H305, 2020.

37. Leonardi A, Evke S, Lee M, Melendez JA, and Begley TJ. Epitranscriptomic systems regulate the translation of reactive oxygen species detoxifying and disease linked selenoproteins. Free Radic Biol Med 143: 573-593, 2019.

38. Li Y, Wang J, Huang C, Shen M, Zhan H, and Xu K. RNA N6-methyladenosine: a promising molecular target in metabolic diseases. Cell Biosci 10: 19, 2020.

39. Linder B, and Jaffrey SR. Discovering and Mapping the Modified Nucleotides That Comprise the Epitranscriptome of mRNA. Cold Spring Harb Perspect Biol 11: 2019.

40. Liu J, Li K, Cai J, Zhang M, Zhang X, Xiong X, Meng H, Xu X, Huang Z, Peng J, Fan J, and Yi C. Landscape and Regulation of m(6)A and m(6)Am Methylome across Human and Mouse Tissues. Mol Cell 77: 426-440 e426, 2020.

41. Mani A. Global longitudinal strain imaging and its utility in assessing risk in early stages of hypertension. J Clin Hypertens (Greenwich) 21: 1711-1712, 2019.

42. Marmisolle FE, Garcia ML, and Reyes CA. RNA-binding protein immunoprecipitation as a tool to investigate plant miRNA processing interference by regulatory proteins of diverse origin. Plant Methods 14: 9, 2018.

43. Meyer KD. m(6)A-mediated translation regulation. Biochim Biophys Acta Gene Regul Mech 1862: 301-309, 2019. 
44. Min KW, Zealy RW, Davila S, Fomin M, Cummings JC, Makowsky D, McDowell CH, Thigpen H, Hafner M, Kwon SH, Georgescu C, Wren JD, and Yoon JH. Profiling of m6A RNA modifications identified an age-associated regulation of AGO2 mRNA stability. Aging Cell 17: e12753, 2018.

45. Nichols CE, Shepherd DL, Hathaway QA, Durr AJ, Thapa D, Abukabda A, Yi J, Nurkiewicz TR, and Hollander JM. Reactive oxygen species damage drives cardiac and mitochondrial dysfunction following acute nano-titanium dioxide inhalation exposure. Nanotoxicology 12: 32-48, 2018.

46. Nichols CE, Shepherd DL, Knuckles TL, Thapa D, Stricker JC, Stapleton PA, Minarchick VC, Erdely A, Zeidler-Erdely PC, Alway SE, Nurkiewicz TR, and Hollander JM. Cardiac and mitochondrial dysfunction following acute pulmonary exposure to mountaintop removal mining particulate matter. Am J Physiol Heart Circ Physiol 309: H2017-2030, 2015.

47. Nurkiewicz TR, Porter DW, Hubbs AF, Cumpston JL, Chen BT, Frazer DG, and Castranova V. Nanoparticle inhalation augments particle-dependent systemic microvascular dysfunction. Part Fibre Toxicol 5: 1, 2008.

48. Palmer JW, Tandler B, and Hoppel CL. Biochemical properties of subsarcolemmal and interfibrillar mitochondria isolated from rat cardiac muscle. J Biol Chem 252: 8731-8739, 1977.

49. Papp LV, Lu J, Striebel F, Kennedy D, Holmgren A, and Khanna KK. The redox state of SECIS binding protein 2 controls its localization and selenocysteine incorporation function. Mol Cell Biol 26: 4895-4910, 2006.

50. Park SY, Pekas EJ, Headid RJ, 3rd, Son WM, Wooden TK, Song J, Layec G, Yadav SK, Mishra PK, and Pipinos, II. Acute mitochondrial antioxidant intake improves endothelial function, antioxidant enzyme activity, and exercise tolerance in patients with peripheral artery disease. Am J Physiol Heart Circ Physiol 319: H456-H467, 2020.

51. Pelclova D, Barosova H, Kukutschova J, Zdimal V, Navratil T, Fenclova Z, Vlckova S, Schwarz J, Zikova N, Kacer P, Komarc M, Belacek J, and Zakharov S. Raman microspectroscopy of exhaled breath condensate and urine in workers exposed to fine and nano TiO2 particles: a cross-sectional study. J Breath Res 9: 036008, 2015.

52. Pietroiusti A, Stockmann-Juvala H, Lucaroni F, and Savolainen K. Nanomaterial exposure, toxicity, and impact on human health. Wiley Interdiscip Rev Nanomed Nanobiotechnol 2018.

53. Ponikowski P, Voors AA, Anker SD, Bueno H, Cleland JGF, Coats AJS, Falk V, Gonzalez-Juanatey JR, Harjola VP, Jankowska EA, Jessup M, Linde C, Nihoyannopoulos P, Parissis JT, Pieske B, Riley JP, Rosano GMC, Ruilope LM, Ruschitzka F, Rutten FH, van der Meer P, and Group ESCSD. 2016 ESC Guidelines for the diagnosis and treatment of acute and chronic heart failure: The Task Force for the diagnosis and treatment of acute and chronic heart failure of the European Society of Cardiology (ESC)Developed with the special contribution of the Heart Failure Association (HFA) of the ESC. Eur Heart J 37: 2129-2200, 2016.

54. Ribeiro Junior RF, Dabkowski ER, Shekar KC, KA OC, Hecker PA, and Murphy MP. MitoQ improves mitochondrial dysfunction in heart failure induced by pressure overload. Free Radic Biol Med 117: 18-29, 2018.

55. Robichaud CO, Uyar AE, Darby MR, Zucker LG, and Wiesner MR. Estimates of upper bounds and trends in nano-TiO2 production as a basis for exposure assessment. Environ Sci Technol 43: 4227-4233, 2009.

56. Ross-Innes CS, Stark R, Teschendorff AE, Holmes KA, Ali HR, Dunning MJ, Brown GD, Gojis O, Ellis IO, Green AR, Ali S, Chin SF, Palmieri C, Caldas C, and Carroll JS. 
Differential oestrogen receptor binding is associated with clinical outcome in breast cancer. Nature 481: 389-393, 2012.

57. Roundtree IA, Evans ME, Pan T, and He C. Dynamic RNA Modifications in Gene Expression Regulation. Cell 169: 1187-1200, 2017.

58. Sager TM, Kommineni C, and Castranova V. Pulmonary response to intratracheal instillation of ultrafine versus fine titanium dioxide: role of particle surface area. Part Fibre Toxicol 5: 17, 2008.

59. Shepherd DL, Nichols CE, Croston TL, McLaughlin SL, Petrone AB, Lewis SE, Thapa D, Long DM, Dick GM, and Hollander JM. Early detection of cardiac dysfunction in the type 1 diabetic heart using speckle-tracking based strain imaging. J Mol Cell Cardiol 90: 7483, 2016.

60. Shetty SP, and Copeland PR. Selenocysteine incorporation: A trump card in the game of mRNA decay. Biochimie 114: 97-101, 2015.

61. Shi H, Wang X, Lu Z, Zhao BS, Ma H, Hsu PJ, Liu C, and He C. YTHDF3 facilitates translation and decay of N(6)-methyladenosine-modified RNA. Cell Res 27: 315-328, 2017.

62. Squires JE, Stoytchev I, Forry EP, and Berry MJ. SBP2 binding affinity is a major determinant in differential selenoprotein mRNA translation and sensitivity to nonsense-mediated decay. Mol Cell Biol 27: 7848-7855, 2007.

63. Stapleton PA, Hathaway QA, Nichols CE, Abukabda AB, Pinti MV, Shepherd DL, McBride CR, Yi J, Castranova VC, Hollander JM, and Nurkiewicz TR. Maternal engineered nanomaterial inhalation during gestation alters the fetal transcriptome. Part Fibre Toxicol 15: 3, 2018.

64. Stapleton PA, Minarchick VC, Cumpston AM, McKinney W, Chen BT, Sager TM, Frazer DG, Mercer RR, Scabilloni J, Andrew ME, Castranova V, and Nurkiewicz TR. Impairment of coronary arteriolar endothelium-dependent dilation after multi-walled carbon nanotube inhalation: a time-course study. Int J Mol Sci 13: 13781-13803, 2012.

65. Starkov AA. Measurement of mitochondrial ROS production. Methods Mol Biol 648: 245$255,2010$.

66. Stebounova LV, Morgan H, Grassian VH, and Brenner S. Health and safety implications of occupational exposure to engineered nanomaterials. Wiley Interdiscip Rev Nanomed Nanobiotechnol 4: 310-321, 2012.

67. Stolwijk JM, Falls-Hubert KC, Searby CC, Wagner BA, and Buettner GR. Simultaneous detection of the enzyme activities of GPx1 and GPx4 guide optimization of selenium in cell biological experiments. Redox Biol 32: 101518, 2020.

68. Sukjamnong S, Chan YL, Zakarya R, Nguyen LT, Anwer AG, Zaky AA, Santiyanont R, Oliver BG, Goldys E, Pollock CA, Chen H, and Saad S. MitoQ supplementation prevent long-term impact of maternal smoking on renal development, oxidative stress and mitochondrial density in male mice offspring. Sci Rep 8: 6631, 2018.

69. Sun J, Zhang Q, Wang Z, and Yan B. Effects of nanotoxicity on female reproductivity and fetal development in animal models. Int J Mol Sci 14: 9319-9337, 2013.

70. Swanson JM, Entringer S, Buss C, and Wadhwa PD. Developmental origins of health and disease: environmental exposures. Semin Reprod Med 27: 391-402, 2009.

71. Tanwar V, Gorr MW, Velten M, Eichenseer CM, Long VP, 3rd, Bonilla IM, Shettigar V, Ziolo MT, Davis JP, Baine SH, Carnes CA, and Wold LE. In Utero Particulate Matter Exposure Produces Heart Failure, Electrical Remodeling, and Epigenetic Changes at Adulthood. J Am Heart Assoc 6: 2017. 
72. Vance ME, Kuiken T, Vejerano EP, McGinnis SP, Hochella MF, Jr., Rejeski D, and Hull MS. Nanotechnology in the real world: Redeveloping the nanomaterial consumer products inventory. Beilstein J Nanotechnol 6: 1769-1780, 2015.

73. Wan Y, Tang K, Zhang D, Xie S, Zhu X, Wang Z, and Lang Z. Transcriptome-wide high-throughput deep $\mathrm{m}(6) \mathrm{A}$-seq reveals unique differential $\mathrm{m}(6)$ A methylation patterns between three organs in Arabidopsis thaliana. Genome Biol 16: 272, 2015.

74. Wei CM, and Moss B. Nucleotide sequences at the N6-methyladenosine sites of HeLa cell messenger ribonucleic acid. Biochemistry 16: 1672-1676, 1977.

75. Xuan JJ, Sun WJ, Lin PH, Zhou KR, Liu S, Zheng LL, Qu LH, and Yang JH. RMBase v2.0: deciphering the map of RNA modifications from epitranscriptome sequencing data. Nucleic Acids Res 46: D327-D334, 2018.

76. Zeng Y, Wang S, Gao S, Soares F, Ahmed M, Guo H, Wang M, Hua JT, Guan J, Moran MF, Tsao MS, and He HH. Refined RIP-seq protocol for epitranscriptome analysis with low input materials. PLoS Biol 16: e2006092, 2018.

77. Zhong X, Yu J, Frazier K, Weng X, Li Y, Cham CM, Dolan K, Zhu X, Hubert N, Tao Y, Lin F, Martinez-Guryn K, Huang Y, Wang T, Liu J, He C, Chang EB, and Leone V. Circadian Clock Regulation of Hepatic Lipid Metabolism by Modulation of m(6)A mRNA Methylation. Cell Rep 25: 1816-1828 e1814, 2018. 
Table 3.1: M-mode echocardiography for adult progeny

\begin{tabular}{|c|c|c|c|c|c|c|c|c|}
\hline Parameter & $\begin{array}{c}\text { PPME } \\
\text { WT } \\
\text { Sham }_{\text {a }}\end{array}$ & $\begin{array}{c}\text { PPME } \\
\text { WT } \\
\mathrm{TiO}_{2 \mathrm{~b}}\end{array}$ & $\begin{array}{c}\text { PPME } \\
\text { Tg } \\
\text { Sham }_{c}\end{array}$ & $\begin{array}{c}\text { PPME } \\
\text { Tg } \\
\mathrm{TiO}_{2 \mathrm{~d}}\end{array}$ & $\begin{array}{c}\text { MPME } \\
\text { WT } \\
\text { Sham } \\
\text { e }\end{array}$ & $\begin{array}{c}\text { MPME } \\
\text { WT } \\
\text { TiO }_{2 \mathrm{f}}\end{array}$ & $\begin{array}{c}\text { MPME } \\
\text { Tg } \\
\text { Sham }_{g}\end{array}$ & $\begin{array}{c}\text { MPME } \\
\text { Tg } \\
\mathrm{TiO}_{2 \mathrm{~h}}\end{array}$ \\
\hline $\begin{array}{l}\text { Diameter;s } \\
\quad(\mathbf{m m})\end{array}$ & $\begin{array}{c}0.61 \pm \\
0.05\end{array}$ & $\begin{array}{l}0.85 \pm \\
0.08 \\
a, d\end{array}$ & $\begin{array}{c}0.66 \pm \\
0.07\end{array}$ & $\begin{array}{c}0.51 \pm \\
0.06\end{array}$ & $\begin{array}{c}0.63 \pm \\
0.05\end{array}$ & $\begin{array}{c}0.60 \pm \\
0.02\end{array}$ & $\begin{array}{c}0.57 \pm \\
0.02\end{array}$ & $\begin{array}{c}0.72 \pm \\
0.06\end{array}$ \\
\hline $\begin{array}{l}\text { Diameter;d } \\
\quad(\mathbf{m m})\end{array}$ & $\begin{array}{c}2.12 \pm \\
0.04\end{array}$ & $\begin{array}{c}2.27 \pm \\
0.08\end{array}$ & $\begin{array}{c}2.15 \pm \\
0.09\end{array}$ & $\begin{array}{c}2.07 \pm \\
0.07\end{array}$ & $\underline{\underline{1.98 \pm}} \underline{\underline{0.08}}$ & $\frac{1.98 \pm}{\underline{0.07}}$ & $\frac{1.88 \pm}{\underline{0.06}}$ & $\frac{2.07 \pm}{\underline{0.07}}$ \\
\hline Volume;s (uL) & $\begin{array}{c}0.58 \pm \\
0.13\end{array}$ & $\begin{array}{l}1.47 \pm \\
0.35_{\mathrm{a}, \mathrm{c}, \mathrm{d}}\end{array}$ & $\begin{array}{c}0.73 \pm \\
0.19\end{array}$ & $\begin{array}{c}0.38 \pm \\
0.11\end{array}$ & $\begin{array}{c}0.60 \pm \\
0.11\end{array}$ & $\begin{array}{c}0.56 \pm \\
0.02\end{array}$ & $\begin{array}{c}0.46 \pm \\
0.05\end{array}$ & $\begin{array}{c}0.94 \pm \\
0.24\end{array}$ \\
\hline Volume;d (uL) & $\begin{array}{l}14.78 \\
\pm 0.61\end{array}$ & $\begin{array}{c}17.85 \pm \\
1.66\end{array}$ & $\begin{array}{c}15.63 \pm \\
1.56\end{array}$ & $\begin{array}{c}14.09 \pm \\
1.25\end{array}$ & $\frac{12.61 \pm}{\underline{1.31}}$ & $\frac{12.65 \pm}{\underline{1.11}}$ & $\frac{11.00 \pm}{\underline{0.92}}$ & $\frac{14.21 \pm}{\underline{1.31}}$ \\
\hline $\begin{array}{c}\text { Stroke Volume } \\
\text { (uL) }\end{array}$ & $\begin{array}{l}14.19 \\
\pm 0.63\end{array}$ & $\begin{array}{c}16.38 \pm \\
1.34\end{array}$ & $\begin{array}{l}14.90 \pm \\
1.43\end{array}$ & $\begin{array}{l}13.71 \pm \\
1.16\end{array}$ & $\frac{12.01 \pm}{\underline{1.21}}$ & $\frac{12.08 \pm}{\underline{1.12}}$ & $\frac{10.54 \pm}{\underline{0.87}}$ & $\frac{13.27 \pm}{\underline{1.50}}$ \\
\hline $\begin{array}{c}\text { Ejection } \\
\text { Fraction }(\%)\end{array}$ & $\begin{array}{c}96.02 \pm \\
0.94\end{array}$ & $\begin{array}{c}92.22 \pm \\
1.29 \\
\mathrm{a}, \mathrm{d}\end{array}$ & $\begin{array}{c}95.55 \pm \\
0.91\end{array}$ & $\begin{array}{c}97.48 \pm \\
0.59\end{array}$ & $\begin{array}{c}95.34 \pm \\
0.41\end{array}$ & $\begin{array}{c}95.43 \pm \\
0.53\end{array}$ & $\begin{array}{c}95.82 \pm \\
0.13\end{array}$ & $\begin{array}{c}93.35 \pm \\
2.30\end{array}$ \\
\hline $\begin{array}{c}\text { Fractional } \\
\text { Shortening (\%) }\end{array}$ & $\begin{array}{l}71.25 \pm \\
2.37\end{array}$ & $\begin{array}{c}62.99 \pm \\
2.24_{a, d}\end{array}$ & $\begin{array}{l}69.84 \pm \\
2.37\end{array}$ & $\begin{array}{c}75.72 \pm \\
2.37\end{array}$ & $\begin{array}{l}68.64 \pm \\
1.24\end{array}$ & $\begin{array}{c}69.64 \pm \\
1.92\end{array}$ & $\begin{array}{c}69.52 \pm \\
0.35\end{array}$ & $\begin{array}{c}65.40 \pm \\
4.27\end{array}$ \\
\hline $\begin{array}{c}\text { Cardiac Output } \\
(\mathrm{mL} / \mathrm{min})\end{array}$ & $\begin{array}{c}10.08 \pm \\
0.56\end{array}$ & $\begin{array}{c}10.32 \pm \\
0.77\end{array}$ & $\begin{array}{c}9.67 \pm \\
1.07\end{array}$ & $\begin{array}{c}9.06 \pm \\
0.81\end{array}$ & $\frac{7.60 \pm}{\underline{1.44}}$ & $\frac{8.00 \pm}{\underline{0.71}}$ & $\frac{6.80 \pm}{\underline{0.78}}$ & $\frac{9.19 \pm}{\underline{1.20}}$ \\
\hline $\begin{array}{c}\text { Relative Wall } \\
\text { Thickness }\end{array}$ & $\begin{array}{l}1.23 \pm \\
0.06\end{array}$ & $\begin{array}{c}1.20 \pm \\
0.06\end{array}$ & $\begin{array}{c}1.17 \pm \\
0.12\end{array}$ & $\begin{array}{l}1.36 \pm \\
0.06\end{array}$ & $\begin{array}{l}1.18 \pm \\
0.06\end{array}$ & $\begin{array}{l}1.27 \pm \\
0.06\end{array}$ & $\begin{array}{l}1.35 \pm \\
0.05\end{array}$ & $\begin{array}{c}1.15 \pm \\
0.10\end{array}$ \\
\hline
\end{tabular}


Table 3.1: M-mode echocardiography was performed in adult offspring (11 weeks of age) following maternal inhalation exposure. Bold text indicates significant data defined by $P \leq 0.05$. A two-way ANOVA determined statistical difference between PPME and MPME denoted with underlined values for that parameter. A letter next to a given group denotes statistical significance between the marked group and the group represented by each letter based on a Tukey's multiplecomparisons test. All data are presented as the mean \pm the standard error of the mean (SEM). PPME WT Sham, n = 7; PPME WT TiO $2, \mathrm{n}=6$; PPME Tg Sham, n = 6; PPME Tg TiO $2, \mathrm{n}=5$; MPME WT Sham, $\mathrm{n}=4$; MPME WT TiO $2, \mathrm{n}=5$; MPME Tg Sham, $\mathrm{n}=5 ;$ MPME Tg TiO, $\mathrm{n}=$ 4. $\mathrm{PPME}=$ Paternal mPHGPx maternal exposure, $\mathrm{MPME}=$ Maternal mPHGPx maternal exposure, WT Sham = wild-type offspring whose dam was exposed to control air, Tg Sham $=$ mPHGPx transgenic offspring whose dam was exposed to control air, $\mathrm{WT} \mathrm{TiO}_{2}=$ wild-type offspring whose dam was exposed to nano- $\mathrm{TiO}_{2}, \mathrm{Tg} \mathrm{TiO}_{2}=$ mPHGPx transgenic offspring whose dam was exposed to nano- $\mathrm{TiO}_{2}, \mathrm{~s}=$ systolic, $\mathrm{d}=$ diastolic. 
Table 3.2: Adult progeny systolic stress-strain in the long-axis

\begin{tabular}{|c|c|c|c|c|c|c|c|c|c|}
\hline Parameter & Units & $\begin{array}{c}\text { PPME } \\
\text { WT } \\
\text { Sham }_{a}\end{array}$ & $\begin{array}{c}\text { PPME } \\
\text { WT } \\
\text { TiO }_{2 \text { b }}\end{array}$ & $\begin{array}{l}\text { PPME } \\
\text { Tg } \\
\text { Sham }_{c}\end{array}$ & $\begin{array}{c}\text { PPME } \\
\text { Tg } \\
\mathrm{TiO}_{2 \mathrm{~d}}\end{array}$ & $\begin{array}{c}\text { MPME } \\
\text { WT } \\
\text { Sham }_{e}\end{array}$ & $\begin{array}{c}\text { MPME } \\
\text { WT } \\
\text { TiO }_{2 \mathrm{f}}\end{array}$ & $\begin{array}{c}\text { MPME } \\
\text { Tg } \\
\text { Sham }_{g}\end{array}$ & $\begin{array}{c}\text { MPME } \\
\text { Tg } \\
\mathrm{TiO}_{2 \mathrm{~h}}\end{array}$ \\
\hline $\begin{array}{c}\text { Radial } \\
\text { Velocity }\end{array}$ & $\begin{array}{c}\mathrm{Pk} \\
\mathrm{cm} / \mathrm{s}\end{array}$ & $\begin{array}{c}2.01 \pm \\
0.17\end{array}$ & $\begin{array}{c}1.89 \pm \\
0.12\end{array}$ & $\begin{array}{c}1.82 \pm \\
0.10\end{array}$ & $\begin{array}{c}2.52 \pm \\
0.16_{c}\end{array}$ & $\begin{array}{c}2.03 \pm \\
0.21\end{array}$ & $\begin{array}{c}2.46 \pm \\
0.23\end{array}$ & $\begin{array}{c}2.23 \pm \\
0.15\end{array}$ & $\begin{array}{c}2.08 \pm \\
0.26\end{array}$ \\
\hline $\begin{array}{c}\text { Radial } \\
\text { Displacement }\end{array}$ & $\begin{array}{l}\mathrm{Pk} \\
\mathrm{mm}\end{array}$ & $\begin{array}{l}0.47 \pm \\
0.03\end{array}$ & $\begin{array}{l}0.43 \pm \\
0.03\end{array}$ & $\begin{array}{l}0.44 \pm \\
0.04\end{array}$ & $\begin{array}{l}0.61 \pm \\
0.02 \\
\text { a,b,c }\end{array}$ & $\begin{array}{l}0.40 \pm \\
0.00\end{array}$ & $\begin{array}{c}0.55 \pm \\
0.04\end{array}$ & $\begin{array}{l}0.47 \pm \\
0.05\end{array}$ & $\begin{array}{c}0.52 \pm \\
0.03\end{array}$ \\
\hline Radial Strain & $\mathrm{Pk} \%$ & $\begin{array}{l}27.82 \\
\pm 1.84\end{array}$ & $\begin{array}{l}25.95 \\
\pm 2.85\end{array}$ & $\begin{array}{l}25.54 \\
\pm 3.37\end{array}$ & $\begin{array}{l}31.55 \pm \\
2.74\end{array}$ & $\begin{array}{c}26.48 \pm \\
2.58\end{array}$ & $\begin{array}{c}32.90 \pm \\
2.72\end{array}$ & $\begin{array}{c}30.69 \pm \\
3.08\end{array}$ & $\begin{array}{c}23.67 \pm \\
1.49\end{array}$ \\
\hline $\begin{array}{c}\text { Radial Strain } \\
\text { Rate }\end{array}$ & $\begin{array}{l}\mathrm{Pk} \\
1 / \mathrm{s}\end{array}$ & $\begin{array}{c}9.10 \pm \\
0.83\end{array}$ & $\begin{array}{c}8.20 \pm \\
0.67\end{array}$ & $\begin{array}{c}8.62 \pm \\
1.13\end{array}$ & $\begin{array}{l}11.12 \pm \\
1.16\end{array}$ & $\frac{11.34 \pm}{\underline{1.55}}$ & $\frac{11.80 \pm}{\underline{1.02}}$ & $\frac{11.31 \pm}{\underline{0.34}}$ & $\frac{8.50 \pm}{\underline{0.97}}$ \\
\hline $\begin{array}{l}\text { Longitudinal } \\
\text { Velocity }\end{array}$ & $\begin{array}{c}\mathrm{Pk} \\
\mathrm{deg} / \mathrm{s}\end{array}$ & $\begin{array}{l}1.14 \pm \\
0.16\end{array}$ & $\begin{array}{l}1.19 \pm \\
0.18\end{array}$ & $\begin{array}{c}1.00 \pm \\
0.18\end{array}$ & $\begin{array}{c}1.07 \pm \\
0.20\end{array}$ & $\begin{array}{c}1.16 \pm \\
0.36\end{array}$ & $\begin{array}{c}1.09 \pm \\
0.28\end{array}$ & $\begin{array}{c}1.28 \pm \\
0.60\end{array}$ & $\begin{array}{c}0.95 \pm \\
0.15\end{array}$ \\
\hline $\begin{array}{l}\text { Longitudinal } \\
\text { Displacement }\end{array}$ & $\begin{array}{c}\mathrm{Pk} \\
\mathrm{deg}\end{array}$ & $\begin{array}{c}0.18 \pm \\
0.01\end{array}$ & $\begin{array}{c}0.12 \pm \\
0.04\end{array}$ & $\begin{array}{c}0.15 \pm \\
0.06\end{array}$ & $\begin{array}{c}0.11 \pm \\
0.02\end{array}$ & $\frac{0.04 \pm}{\underline{0.01}}$ & $\frac{0.06 \pm}{\underline{0.01}}$ & $\frac{0.06 \pm}{\underline{0.01}}$ & $\frac{0.12 \pm}{\underline{0.04}}$ \\
\hline $\begin{array}{l}\text { Longitudinal } \\
\text { Strain }\end{array}$ & $\mathrm{Pk} \%$ & $\begin{array}{l}-10.99 \\
\pm 2.13\end{array}$ & $\begin{array}{l}-9.51 \\
\pm 2.00\end{array}$ & $\begin{array}{l}-9.16 \\
\pm 0.90\end{array}$ & $\begin{array}{l}-15.81 \\
\pm 3.41\end{array}$ & $\begin{array}{c}-5.38 \pm \\
2.61\end{array}$ & $\begin{array}{c}-7.98 \pm \\
1.52\end{array}$ & $\begin{array}{l}-12.99 \\
\pm 2.78\end{array}$ & $\begin{array}{l}-10.68 \\
\pm 4.73\end{array}$ \\
\hline $\begin{array}{l}\text { Longitudinal } \\
\text { Strain Rate }\end{array}$ & $\begin{array}{l}\mathrm{Pk} \\
1 / \mathrm{s}\end{array}$ & $\begin{array}{l}-7.63 \\
\pm 0.58\end{array}$ & $\begin{array}{l}-6.86 \\
\pm 0.76\end{array}$ & $\begin{array}{l}-7.06 \\
\pm 1.01\end{array}$ & $\begin{array}{l}-9.34 \pm \\
0.76\end{array}$ & $\frac{-7.45 \pm}{\underline{0.85}}$ & $\frac{-8.93 \pm}{\underline{1.35}}$ & 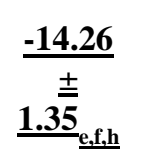 & $\frac{-7.49 \pm}{\underline{1.18}}$ \\
\hline $\begin{array}{c}\text { Global } \\
\text { Longitudinal } \\
\text { Strain (GLS) }\end{array}$ & $\mathrm{AU}$ & $\begin{array}{l}24.26 \\
\pm 1.54\end{array}$ & $\begin{array}{c}16.49 \\
\pm \\
1.97_{\mathrm{a}, \mathrm{d}}\end{array}$ & $\begin{array}{l}19.85 \\
\pm 2.20\end{array}$ & $\begin{array}{c}28.51 \pm \\
1.88_{c}\end{array}$ & $\begin{array}{l}20.07 \pm \\
2.25\end{array}$ & $\begin{array}{c}23.58 \pm \\
3.52\end{array}$ & $\begin{array}{c}22.67 \pm \\
1.86\end{array}$ & $\begin{array}{c}22.29 \pm \\
2.44\end{array}$ \\
\hline
\end{tabular}


Table 3.2: Peak strain and strain-rate values acquired from B-mode images for longitudinal and radial dimensions in adult progeny (11 weeks of age) following maternal inhalation exposure. Bold text indicates significant data defined by $P \leq 0.05$. A two-way ANOVA determined statistical difference between PPME and MPME denoted with underlined values for that parameter. A letter next to a given group denotes statistical significance between the marked group and the group represented by each letter based on a Tukey's multiple-comparisons test. All data are presented as the mean \pm the standard error of the mean $(\mathrm{SEM})$. PPME WT Sham, $\mathrm{n}=7$; PPME WT TiO, $\mathrm{n}=$ 6; PPME Tg Sham, n = 6; PPME Tg TiO $2, \mathrm{n}=5$; MPME WT Sham, n = 4; MPME WT TiO, $\mathrm{n}=$ 5; MPME Tg Sham, $\mathrm{n}=5$; MPME Tg TiO, $\mathrm{n}=4$. PPME = Paternal mPHGPx maternal exposure, MPME $=$ Maternal mPHGPx maternal exposure, WT Sham $=$ wild-type offspring whose dam was exposed to control air, Tg Sham $=$ mPHGPx transgenic offspring whose dam was exposed to control air, WT $\mathrm{TiO}_{2}=$ wild-type offspring whose dam was exposed to nano- $\mathrm{TiO}_{2}, \mathrm{Tg} \mathrm{TiO}_{2}=$ mPHGPx transgenic offspring whose dam was exposed to nano- $\mathrm{TiO}_{2}, \mathrm{GLS}=$ global longitudinal strain, $\mathrm{Pk}=$ peak. 
Figure 3.1:

A

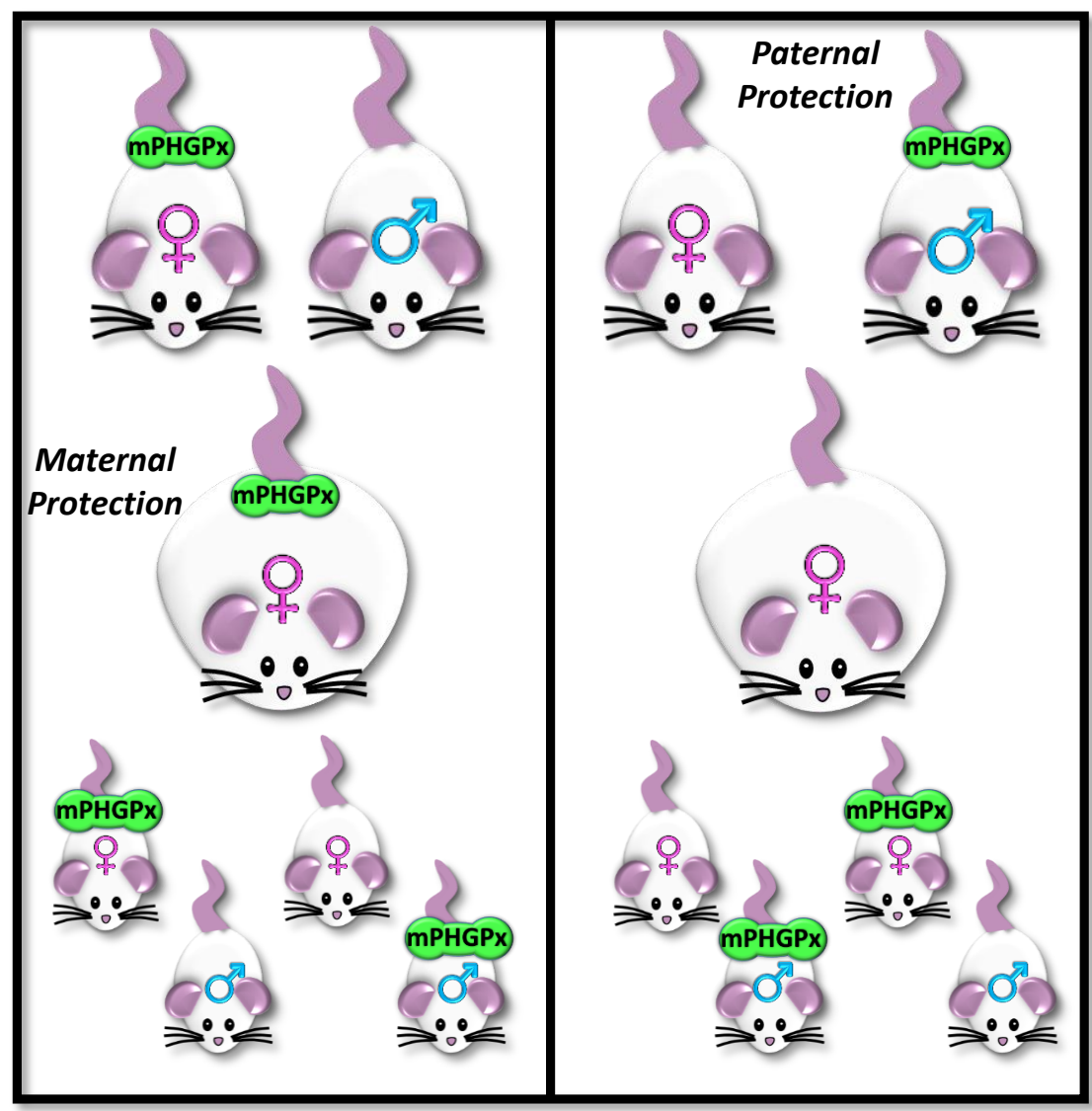


Figure 3.1:

B

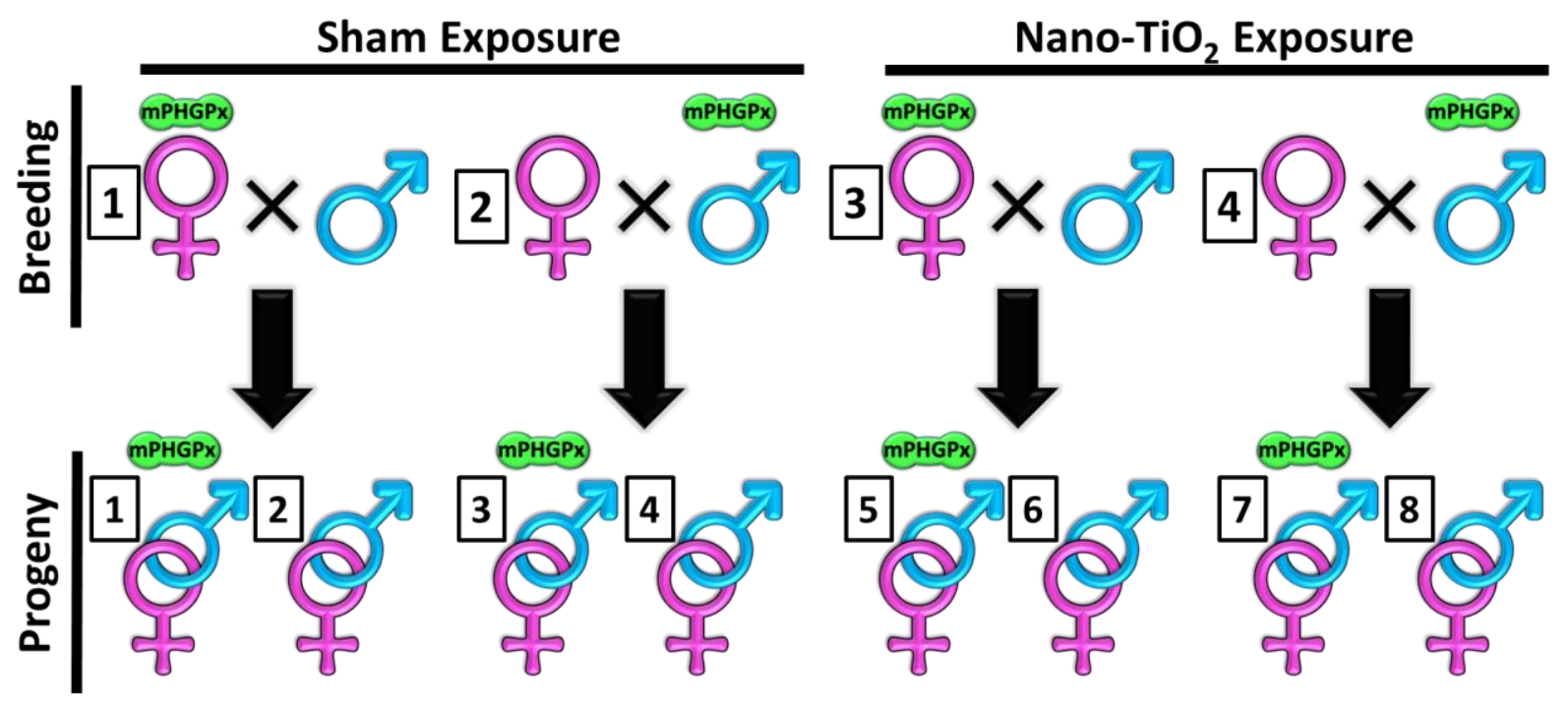

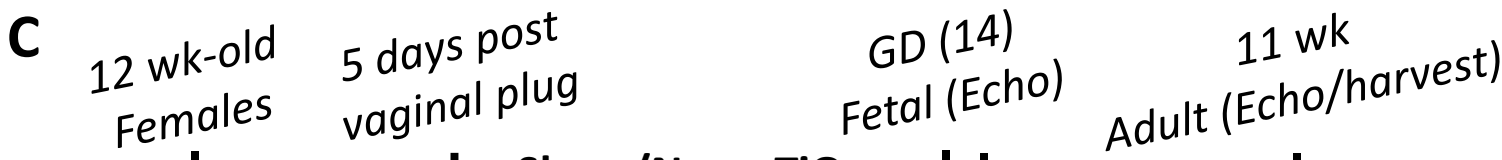

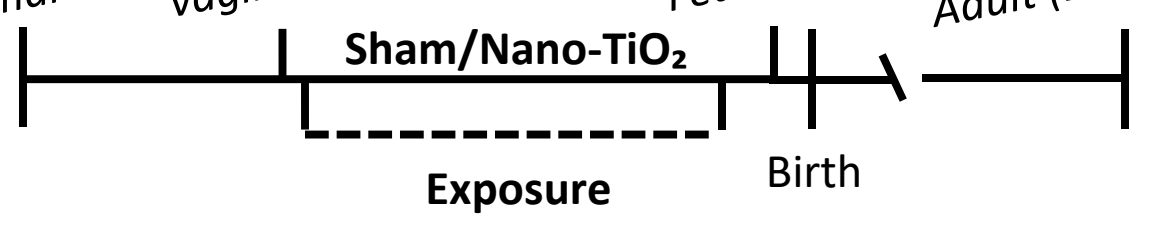

(6 non-consecutive days/8 day period) 
Figure 3.1: MPHGPx mouse breeding strategy. (A) Schematic of mPHGPx breeding strategies with transgene effect on offspring from maternal (left) or paternal (right) transgene. (B) Schematic of exposure paradigm that was implemented for each group, representing all groups that were utilized in the study. (C) A timeline of the study. MPHGPx = mitochondrial phospholipid hydroperoxide glutathione peroxidase. 
Figure 3.2:

A

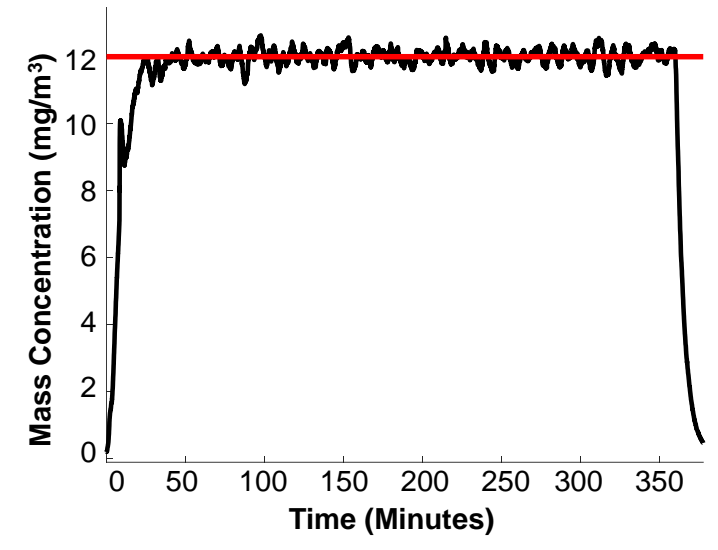

C

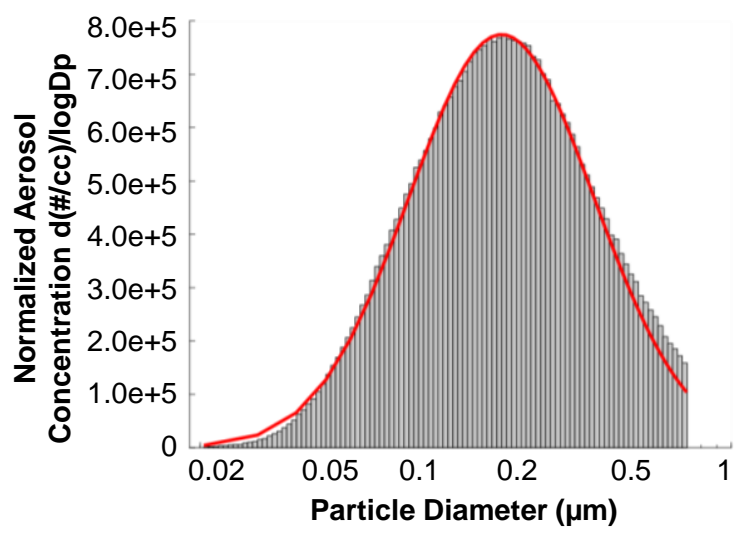

B

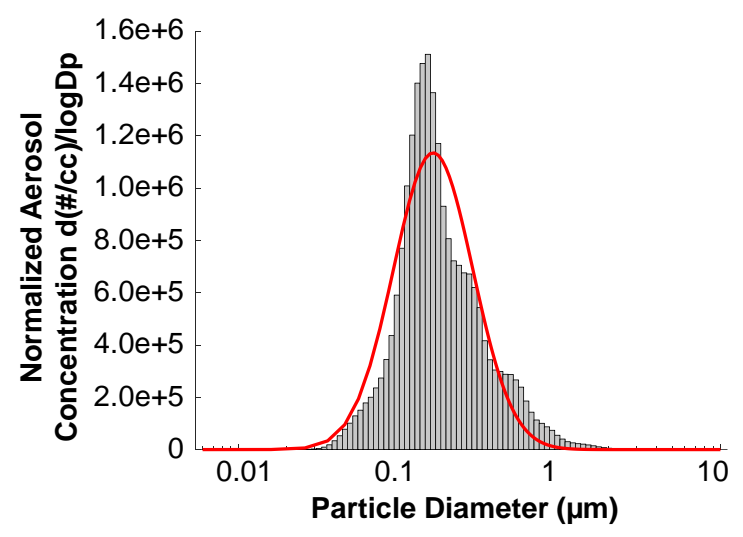

D

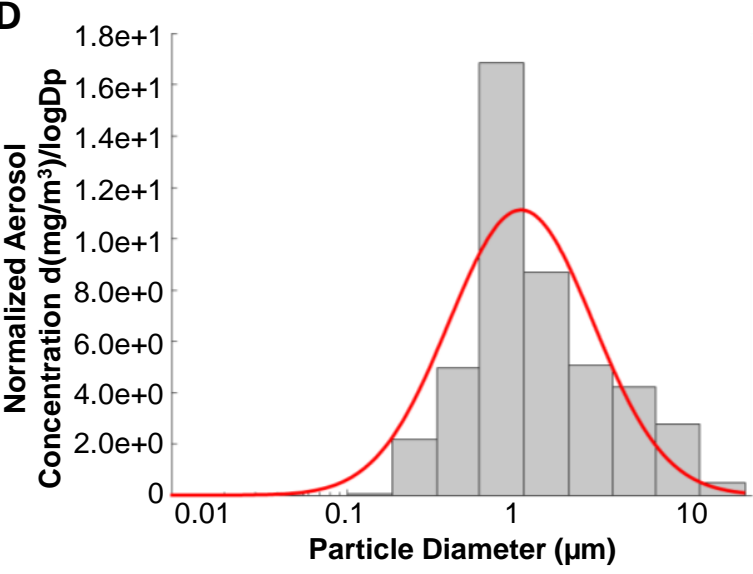


Figure 3.2: Maternal nano-TiO 2 inhalation exposure characteristics. (A) Real-time (black line) aerosol mass concentration measurements with the red line indicating the target concentration $\left(12 \mathrm{mg} / \mathrm{m}^{3}\right)$ of a typical $360 \mathrm{~min}$ maternal nano- $\mathrm{TiO}_{2}$ inhalation exposure. (B) Count size distribution of the nano- $\mathrm{TiO}_{2}$ aerosols measured with a high resolution electric low-pressure impactor (ELPI+). The red line designates the log normal distribution obtained with the log probability plot method $(\mathrm{CMD}=0.163 \mu \mathrm{m}$, with a $\mathrm{GSD}=1.77)$. (C) Count size distribution of nano- $\mathrm{TiO}_{2}$ aerosols measured with a scanning mobility particle sizer (SMPS) with the red line representing a $\log$ normal fit of the data $(\mathrm{CMD}=0.190 \mu \mathrm{m}, \mathrm{GSD}=1.97)$. (D) Mass size distribution of nano- $\mathrm{TiO}_{2}$ aerosols measured with a Nano Micro-Orifice Uniform Deposit Impactor (MOUDI). The red line represents a log normal fit of the data indicating a mass median aerodynamic diameter (MMAD) of $0.968 \mu \mathrm{m}$ and a GSD of 2.56. CMD = Count Median Diameter, GSD $=$ Geometric Standard Deviation. 
Figure 3.3
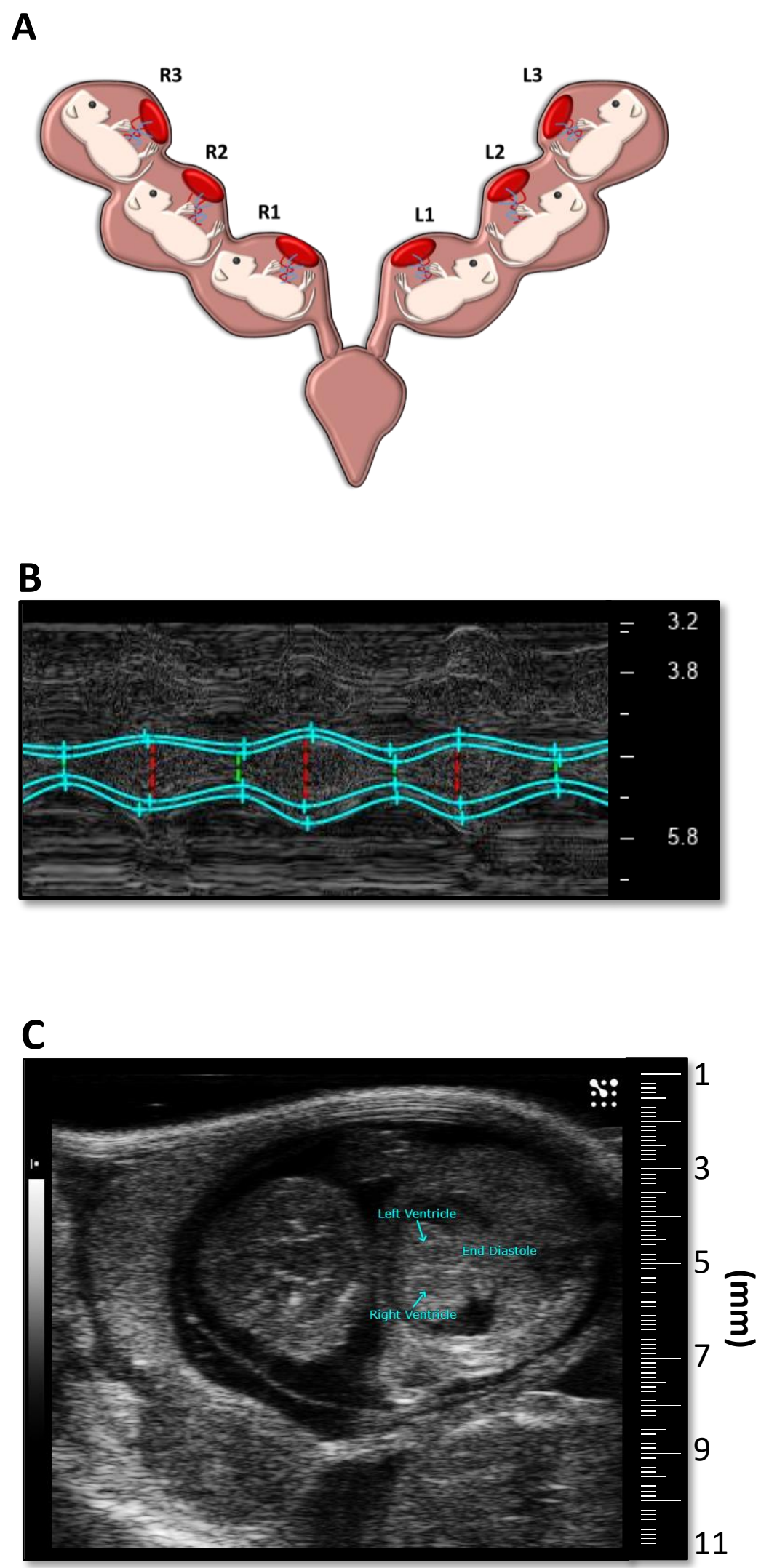
Figure 3.3:
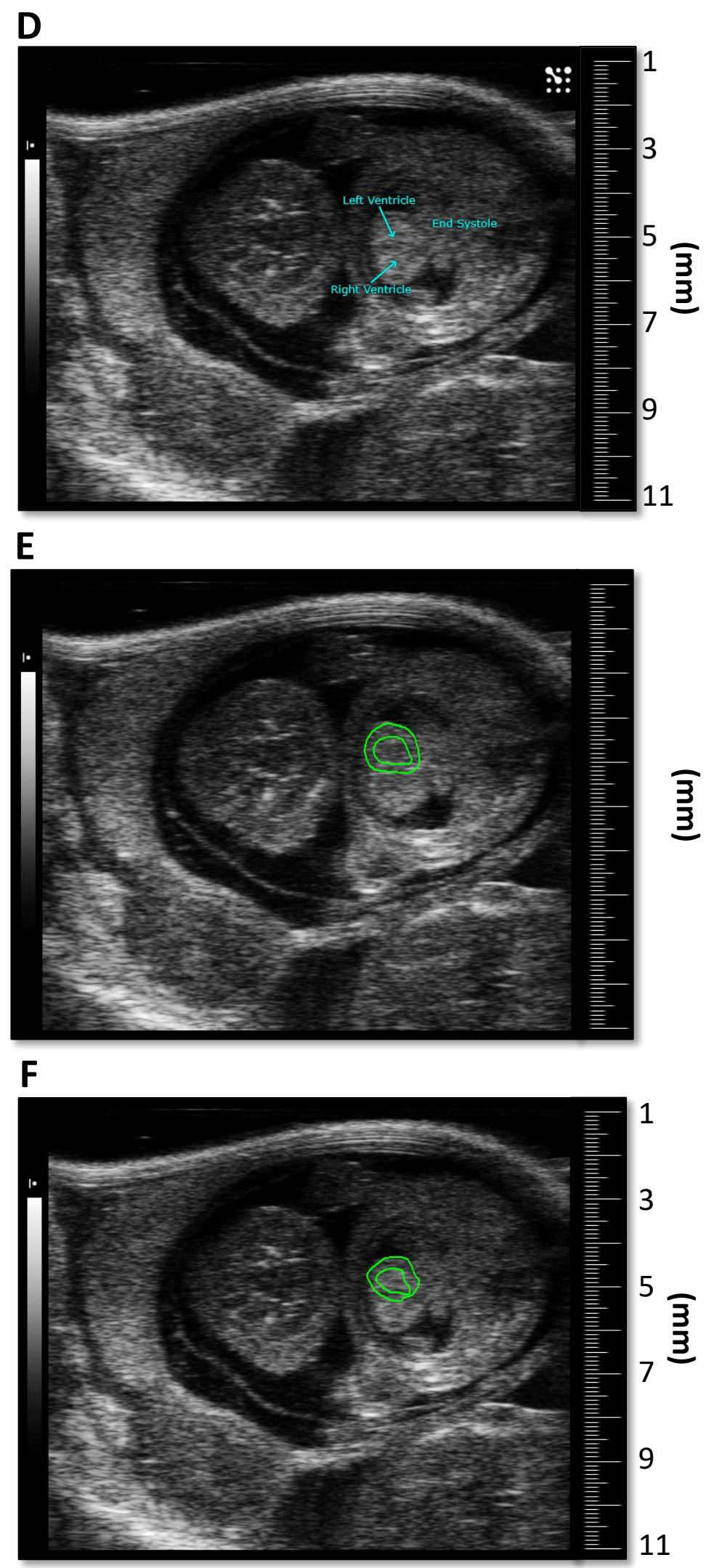
Figure 3.3: Assessment of fetal pup cardiac function in utero. (A) Graphical depiction of the uterine horn and the pup identification system. (B) Representative M-mode echocardiographic scan of a fetal pup with the short-axis left ventricular trace (blue). (C-D) Representative B-mode scan of a fetal pup with the left and right ventricles identified by blue arrows at end diastole (C) and end systole (D). (E-F) Representative B-mode scan in the short-axis of a fetal pup at with green outlines indicating tracking of the epicardium and endocardium borders through (E) end diastole and (F) end systole. $\mathrm{R}=$ right, $\mathrm{L}=$ left. 
Figure 3.4

A

Complex I

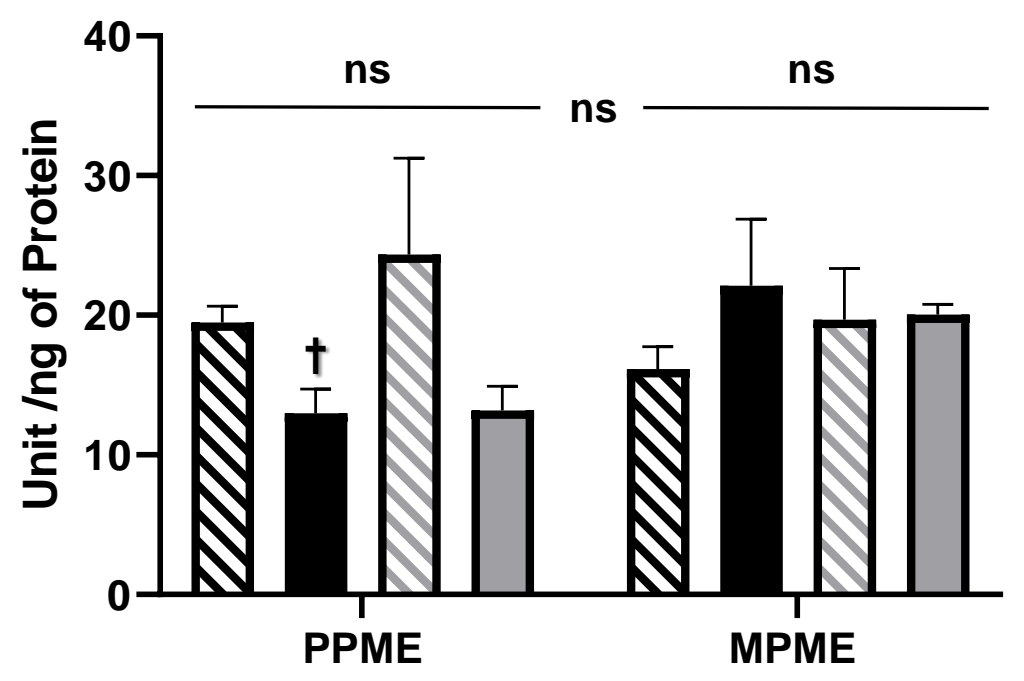

凶WT Sham $\mathrm{WT} \mathrm{TiO}_{2} \square \mathrm{Tg}$ Sham $\square \mathrm{Tg} \mathrm{TiO}_{2}$

B

Complex III

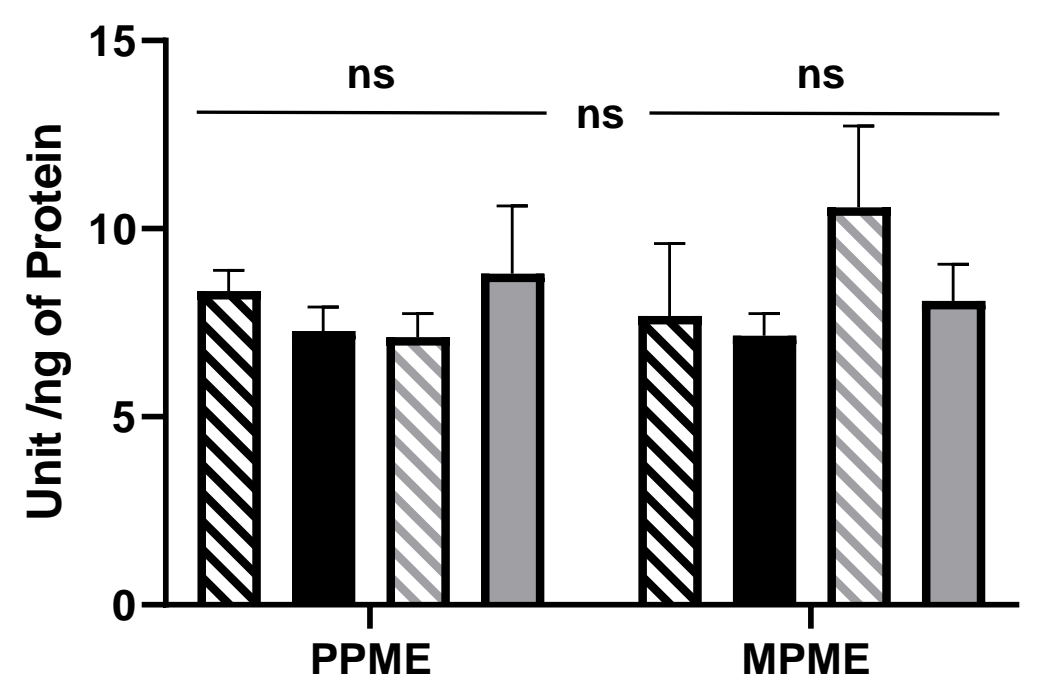


Figure 3.4

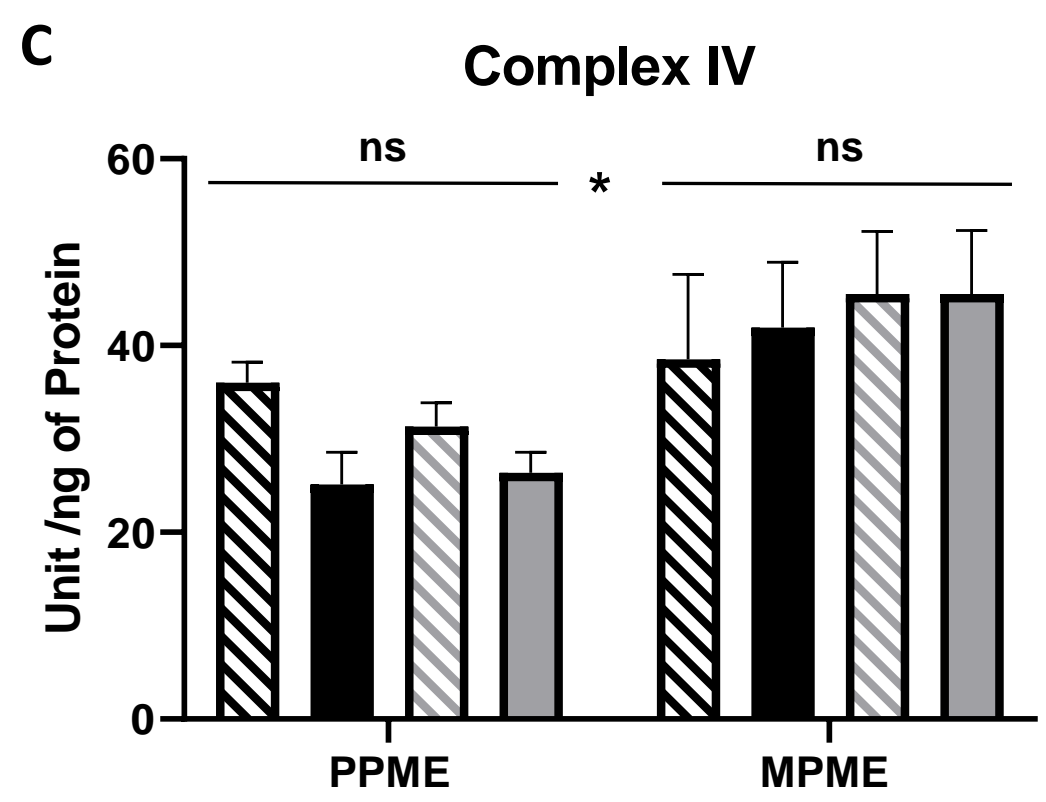

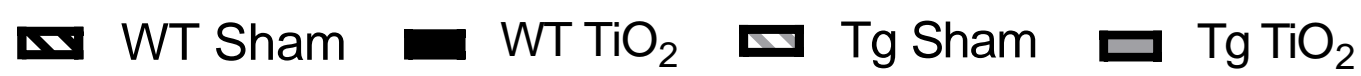

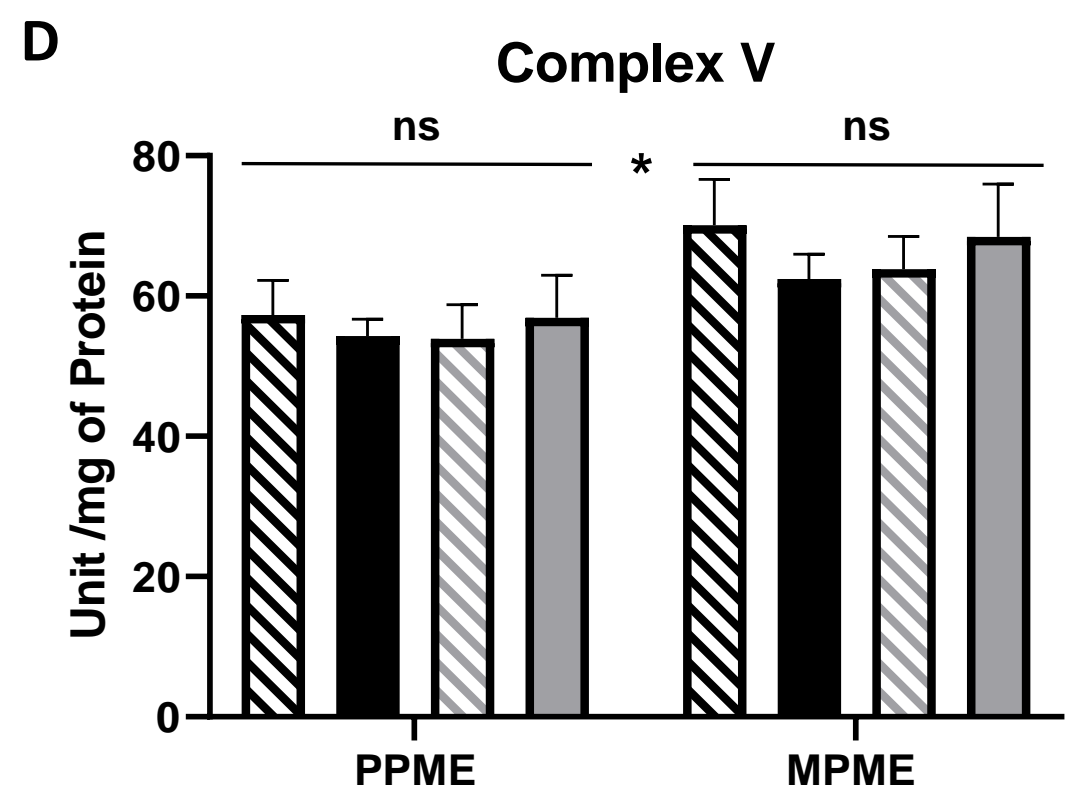


Figure 3.4: Electron transport chain (ETC) complex activities of adult PPME and MPME offspring. (A-D) Electron transport chain (ETC) activities assessed in cardiac protein lysate of adult offspring for (A) complex I, (B) complex III, (C) complex IV, and (D) complex V (ATP Synthase). PPME WT Sham, $\mathrm{n}=$ 7; PPME WT TiO $2, \mathrm{n}=6$; PPME Tg Sham, n = 6; PPME Tg $\mathrm{TiO}_{2}, \mathrm{n}=5$; MPME WT Sham, $\mathrm{n}=4$; MPME WT TiO, $\mathrm{n}=5$; MPME Tg Sham, n = 7; MPME $\mathrm{Tg} \mathrm{TiO}_{2}, \mathrm{n}=4$. Adult $=11$ weeks old. Statistical difference was defined by $P \leq 0.05$. * $=$ group difference determined by a two-way ANOVA and ns = no statistical difference. A letter above a group denotes statistical significance between those groups based on a Tukey's multiplecomparisons test. A dagger ( $\mathbf{\dagger}$ ) above a group indicates statistical significance between WT Sham and $\mathrm{WT}_{\mathrm{TiO}}$ or $\mathrm{Tg}$ Sham and $\mathrm{Tg} \mathrm{TiO}_{2}$ of the same maternal genetic group (MPME or PPME) based on a Student's t-test. All data are presented as the mean \pm the standard error of the mean $(\mathrm{SEM})$. Adult $=11$ weeks of age, $\operatorname{mPHGPx}=$ mitochondrial phospholipid hydroperoxide glutathione peroxidase, $\mathrm{PPME}=$ Paternal mPHGPx maternal exposure, $\mathrm{MPME}=$ Maternal mPHGPx maternal exposure, WT Sham = wild-type offspring whose dam was exposed to control air, Tg Sham $=$ mPHGPx transgenic offspring whose dam was exposed to control air, $\mathrm{WT} \mathrm{TiO}_{2}=$ wild-type offspring whose dam was exposed to nano- $\mathrm{TiO}_{2}, \mathrm{Tg} \mathrm{TiO}_{2}=\mathrm{mPHGPx}$ transgenic offspring whose dam was exposed to nano- $\mathrm{TiO}_{2}$, Unit $=$ nanomoles of substrate oxidized $\cdot$ minute ${ }^{-}$ 1 . 
Figure 3.5

A

GPx Activity

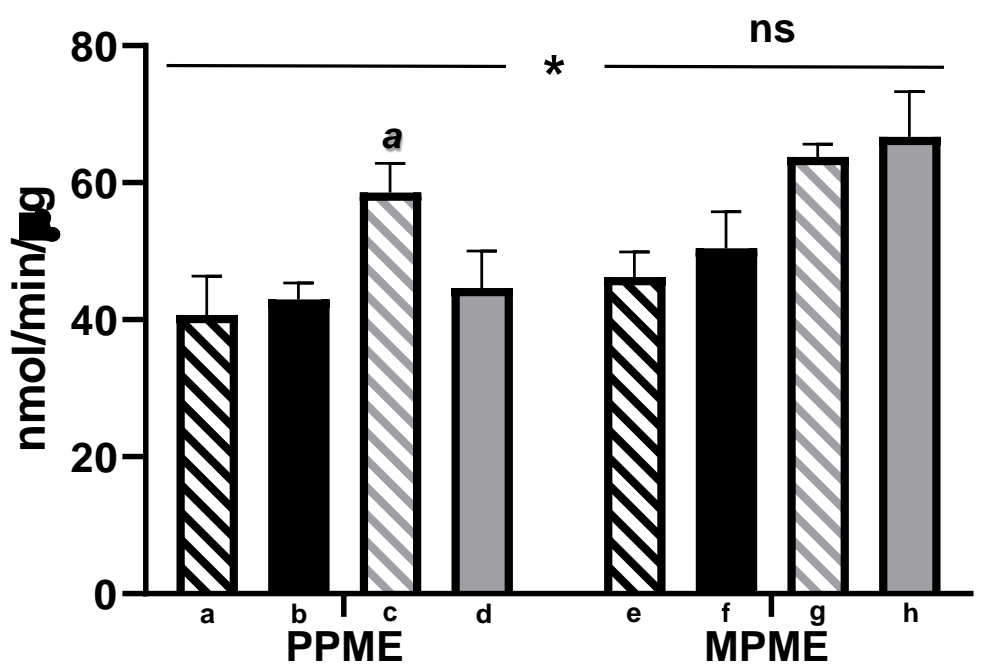

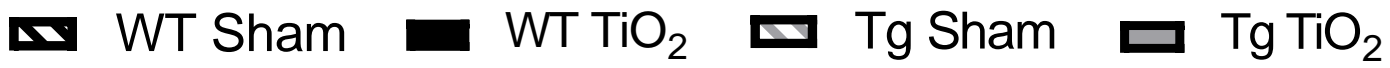

B mPHGPx Activity

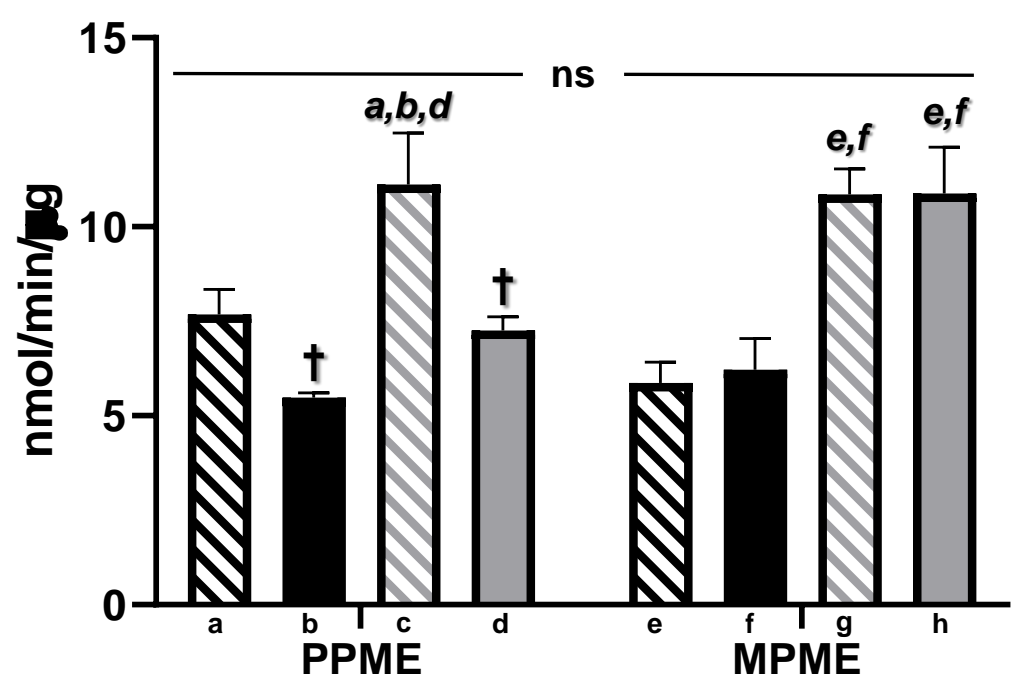


Figure 3.5:

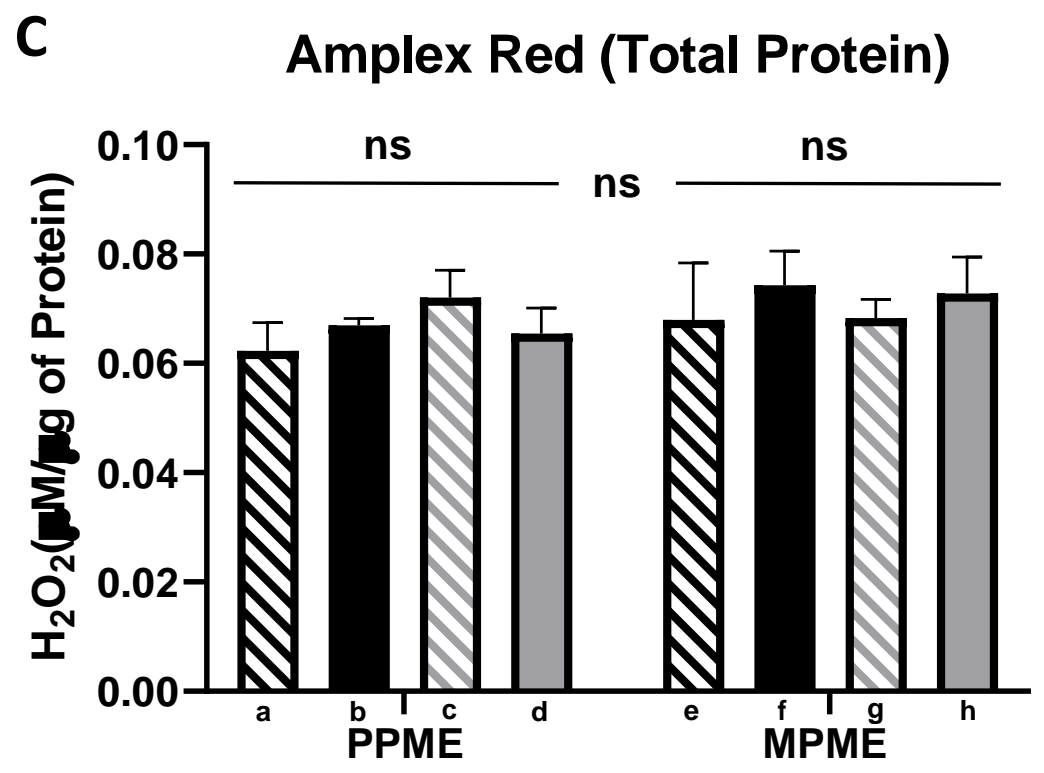

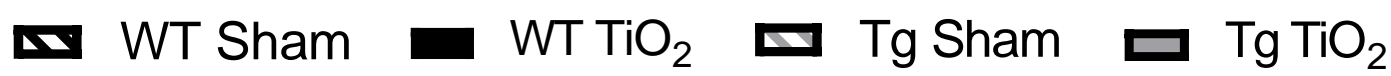

D Amplex Red (Mitochondria)

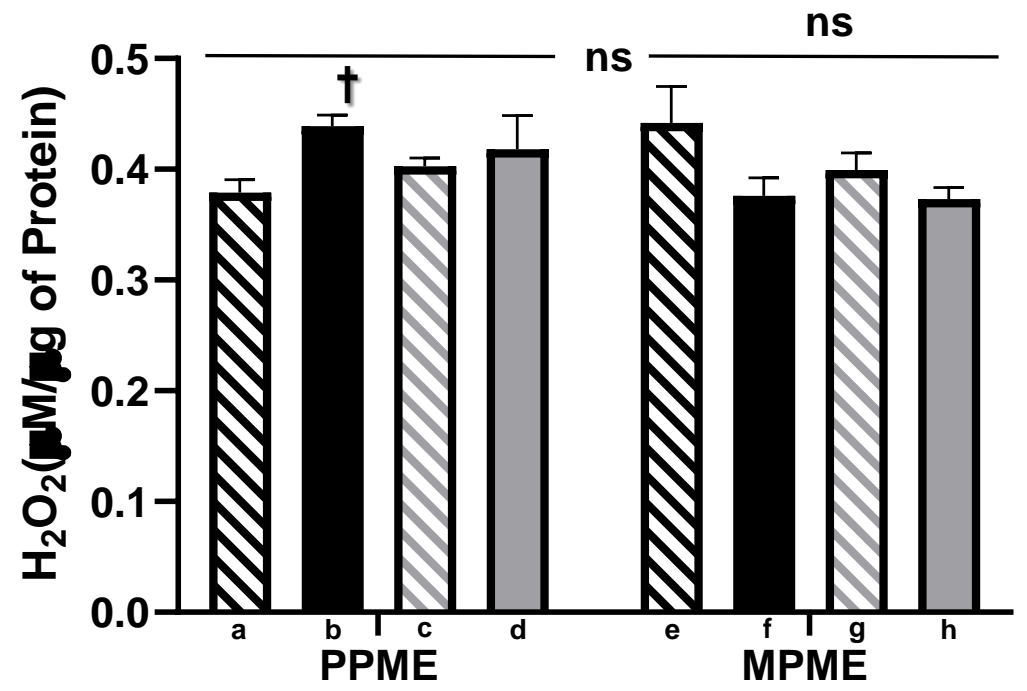


Figure 3.5: Antioxidant activity and $\mathrm{H}_{2} \mathrm{O}_{2}$ production in adult offspring following gestational inhalation exposure. (A) Total GPx activity in cardiac protein lysate determined by cumene hydroperoxide as substrate and normalized to protein content. (B) Mitochondrial GPx (mPHGPx) activity in cardiac protein lysate determined by phosphatidylcholine hydroperoxide $(\mathrm{PCOOH})$ as substrate and normalized to protein content. (C) Total hydrogen peroxide $\left(\mathrm{H}_{2} \mathrm{O}_{2}\right)$ concentration in cardiac protein lysate normalized to protein content. (D) Hydrogen peroxide $\left(\mathrm{H}_{2} \mathrm{O}_{2}\right)$ concentration in cardiac isolated mitochondria of adult offspring normalized to protein content. PPME WT Sham, $\mathrm{n}=7$ (protein) and $\mathrm{n}=6$ (mitochondria); PPME WT TiO, $\mathrm{n}=6$; PPME Tg Sham, $\mathrm{n}=6$ (protein) and $\mathrm{n}=5$ (mitochondria); PPME Tg $\mathrm{TiO}_{2}, \mathrm{n}=5$; MPME WT Sham, $\mathrm{n}=4$; MPME WT $\mathrm{TiO}_{2}, \mathrm{n}=5 ;$ MPME Tg Sham, $\mathrm{n}=7 ;$ MPME Tg $\mathrm{TiO}_{2}, \mathrm{n}=4$. Statistical difference was defined by $P \leq 0.05 . *$ group difference determined by a two-way ANOVA and ns = no statistical difference. A letter above a group denotes statistical significance between those groups based on a Tukey's multiple-comparisons test. A dagger $(\boldsymbol{\dagger})$ above a group indicates statistical significance between WT Sham and WT $\mathrm{TiO}_{2}$ or $\mathrm{Tg}$ Sham and $\mathrm{Tg} \mathrm{TiO}_{2}$ of the same maternal genetic group (MPME or PPME) based on a Student's t-test. All data are presented as the mean \pm the standard error of the mean $(\mathrm{SEM})$. Adult $=11$ weeks of age, $\mathrm{mPHGPx}=$ Mitochondrial phospholipid hydroperoxide glutathione peroxidase, PPME = Paternal mPHGPx maternal exposure, MPME = Maternal mPHGPx maternal exposure, WT Sham = wild-type offspring whose dam was exposed to control air, Tg Sham = mPHGPx transgenic offspring whose dam was exposed to control air, $\mathrm{WT} \mathrm{TiO}_{2}=$ wild-type offspring whose dam was exposed to nano- $\mathrm{TiO}_{2}, \mathrm{Tg} \mathrm{TiO}_{2}=\mathrm{mPHGPx}$ transgenic offspring whose dam was exposed to nano- $\mathrm{TiO}_{2}$. 
Figure 3.6:

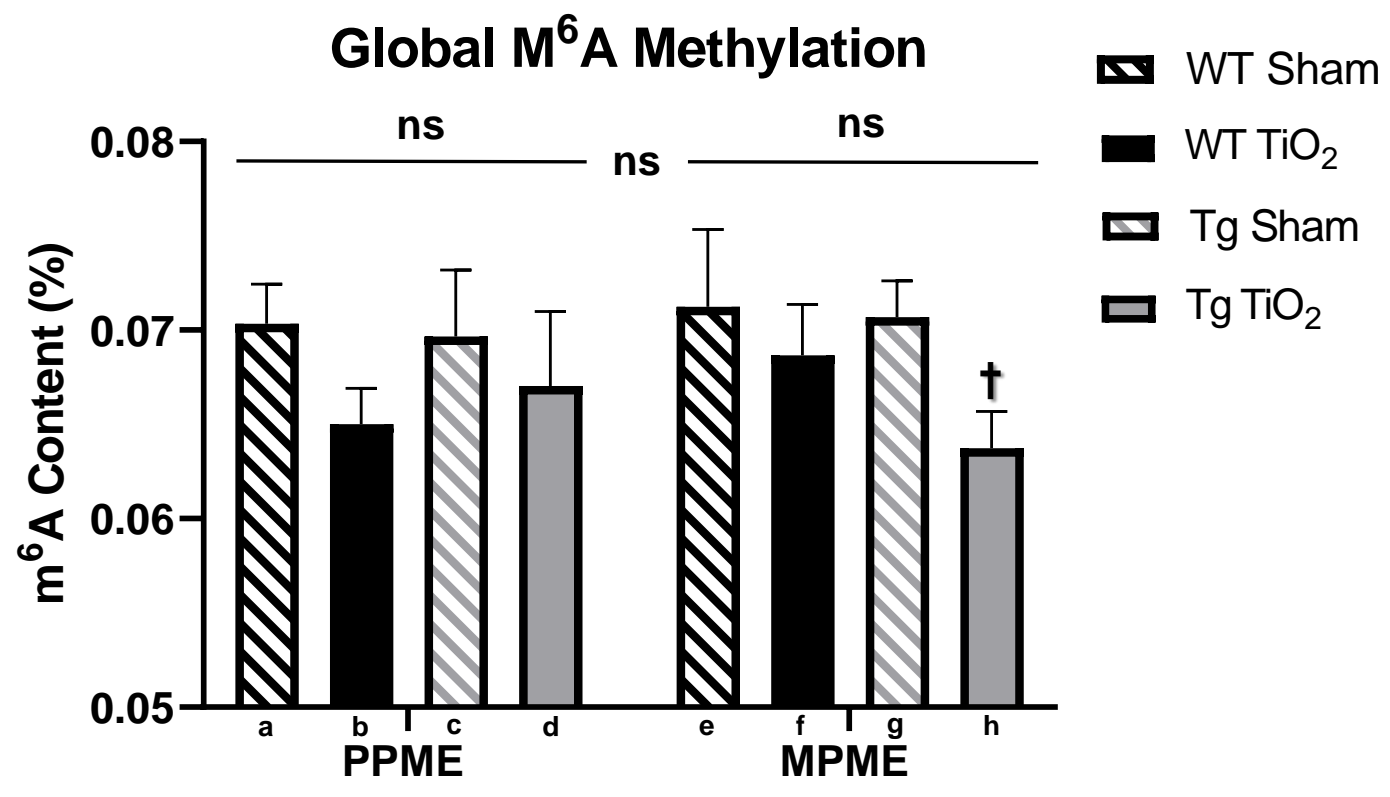

B 3 min fragmentation RIN: 2.40
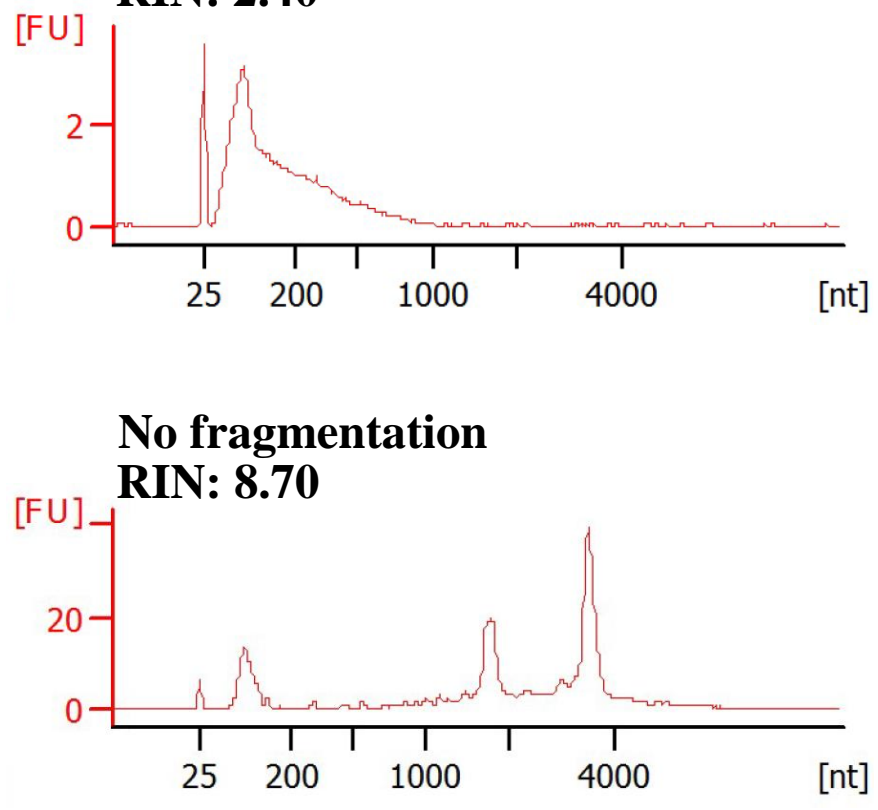
Figure 3.6:

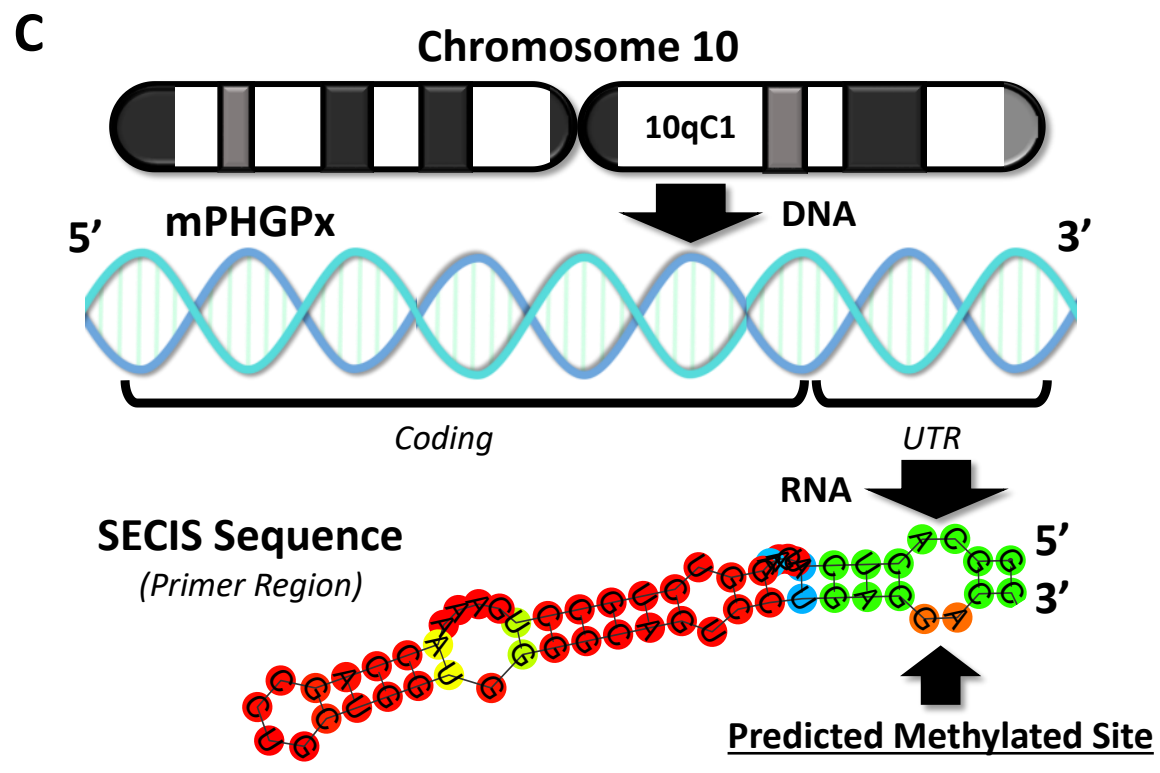

D

\section{$M^{6}$ A-RIP-qPCR}

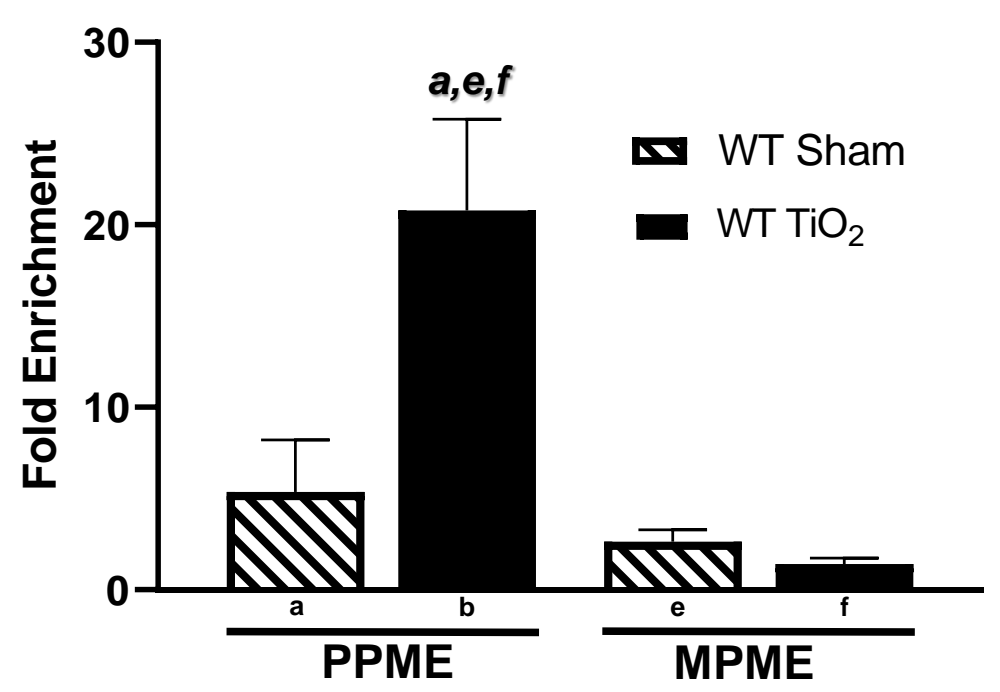


Figure 3.6: Epitranscriptomic mechanism contributing to diminished antioxidant scavenging ability following maternal nano- $\mathrm{TiO}_{2}$ inhalation exposure. (A) Global $\mathrm{m}^{6} \mathrm{~A}$ content was determined as a percentage $(\%)$ of total RNA isolated from adult offspring cardiac tissue. PPME WT Sham, n = 6; PPME WT TiO $2, \mathrm{n}=5$; PPME Tg Sham, n = 6; PPME Tg TiO $2, \mathrm{n}=5$; MPME WT Sham, $\mathrm{n}=4$; MPME WT TiO $2, \mathrm{n}=5$; MPME Tg Sham, $\mathrm{n}=6$; MPME Tg TiO $2, \mathrm{n}=$ 4. (B) Isolated RNA with 3 min fragmentation utilized to achieve $130 \mathrm{nt}$ fragments (top) compared to no fragmentation (bottom). (C) Schematic of the predicted $\mathrm{m}^{6} \mathrm{~A}$ site in the 3'-UTR of the mouse mPHGPX mRNA, specifically within the SECIS region. (D) $\mathrm{M}^{6} \mathrm{~A}-\mathrm{RIP}-\mathrm{qPCR}$ for mPHGPx (3'-UTR region including potential $\mathrm{m}^{6} \mathrm{~A}$ site). $\mathrm{N}=4$ per group (ran in triplicate). Statistical difference was defined by $P \leq 0.05$ (ns = no significance) based on a one or two-way ANOVA, where appropriate. A letter above a group denotes statistical significance between those groups based on a Tukey's multiple-comparisons test. A dagger ( $\boldsymbol{\dagger}$ ) above a group indicates statistical significance between WT Sham and $\mathrm{WT} \mathrm{TiO}_{2}$ or $\mathrm{Tg}$ Sham and $\mathrm{Tg} \mathrm{TiO}_{2}$ of the same maternal genetic group (MPME or PPME) based on a Student's t-test. All data are presented as the mean \pm the standard error of the mean $(\mathrm{SEM})$. Adult $=11$ weeks old, $\mathrm{mPHGPx}=$ mitochondrial phospholipid hydroperoxide glutathione peroxidase, $\mathrm{M}^{6} \mathrm{~A}=\mathrm{N}^{6}$-Methyladenosine, $\mathrm{PPME}=$ Paternal mPHGPx maternal exposure, MPME = Maternal mPHGPx maternal exposure, WT Sham = wild-type offspring whose dam was exposed to control air, Tg Sham $=$ mPHGPx transgenic offspring whose dam was exposed to control air, $\mathrm{WT} \mathrm{TiO}_{2}=$ wild-type offspring whose dam was exposed to nano- $\mathrm{TiO}_{2}, \mathrm{Tg} \mathrm{TiO}_{2}=\mathrm{mPHGPx}$ transgenic offspring whose dam was exposed to nano$\mathrm{TiO}_{2}, \mathrm{RIN}=$ RNA integrity number, SECIS = selenocysteine insertion sequence. 
Figure 3.7:

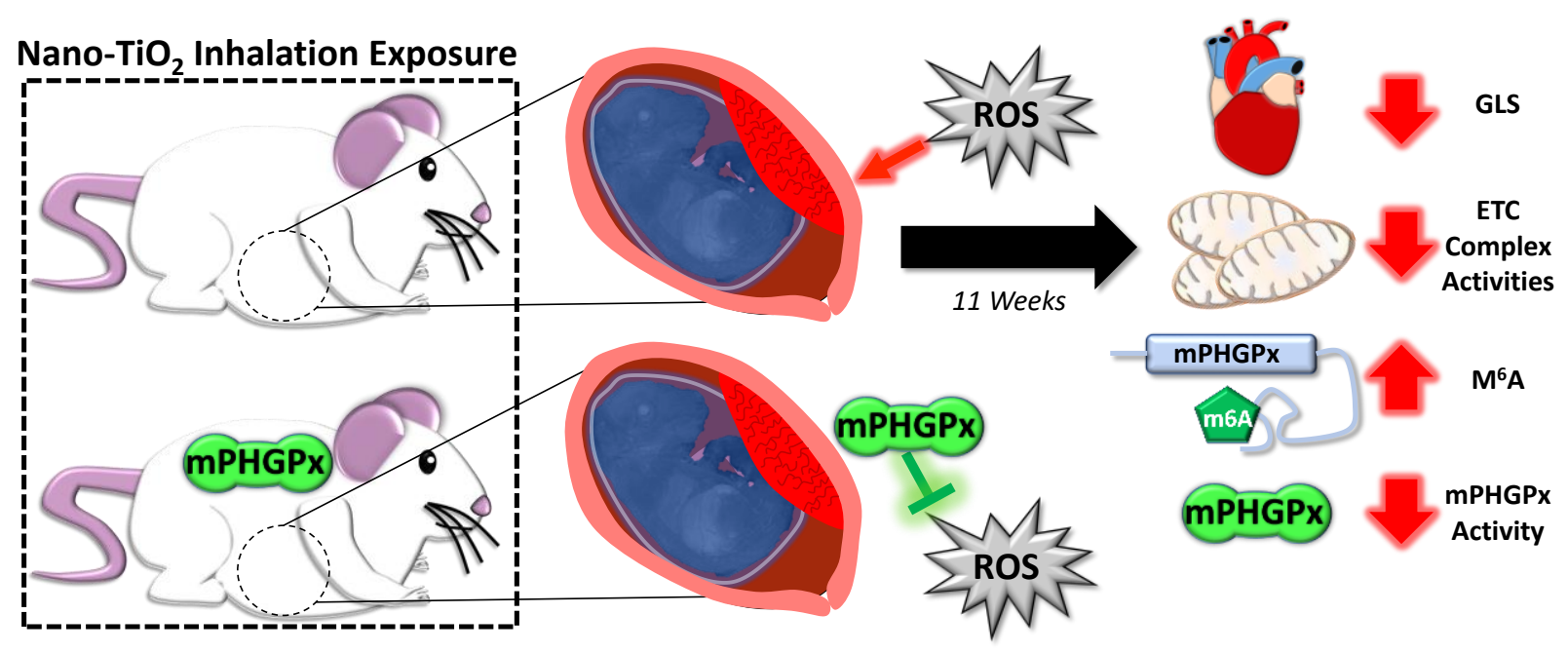


Figure 3.7: Physiological and molecular consequences of gestational nano- $\mathrm{TiO}_{2}$ inhalation exposure in adult offspring. Following gestational exposure, elevated ROS levels in the progeny are concomitant with cardiac functional alterations that can be mitigated by overexpression of maternal mPHGPx. Augmented mitochondrial ROS plays a key role in the persistence of deficits into adulthood (11 weeks of age) characterized by diminished GLS and ETC complex activities. A mechanism that could promote the sustained consequences is initiated by high oxidative stress, which increases $\mathrm{m}^{6} \mathrm{~A}$ methylation at the SECIS in the 3'-UTR of mPHGPx. Ultimately, this may tamper with the SECIS binding region for the SBP2 that is vital for the incorporation of selenocysteine and the catalytic activity of mPHGPx. Decreased mPHGPx activity then propagates mitochondrial bioenergetic deficits, limiting overall cardiac performance in the adult offspring. MPHGPx $=$ mitochondrial phospholipid hydroperoxide glutathione peroxidase, $\mathrm{ROS}=$ reactive oxygen species, GLS $=$ global longitudinal strain, ETC $=$ electron transport chain, $\mathrm{m}^{6} \mathrm{~A}=\mathrm{N}^{6}-$ methyladenosine, SECIS $=$ Selenocysteine insertion sequence, $\mathrm{SBP} 2=$ SECIS binding protein 2. 
Supplemental Table 3.1: Primer sequences

\begin{tabular}{ccc}
\hline Gene Name & Forward $\left(\mathbf{5}^{\prime}, \mathbf{3}\right.$ ') & \multicolumn{1}{c}{ Reverse $\left(\mathbf{5}^{\prime}, \mathbf{3} \mathbf{3}^{\prime}\right)$} \\
\hline GPx4 & CCUACAAGUGUGUGCCCCUA & AGGCCUCUGGACCUUCCUC \\
\hline GAPDH & AACTTTGGCATTGTGGAAGG & ACACATTGGGGGTAGGAACA \\
\hline
\end{tabular}


Supplemental Table 3.1: Primers were designed for $\mathrm{m}^{6} \mathrm{~A}-\mathrm{RIP}-\mathrm{qPCR}$ using Primer-BLAST through NCBI and Primer3. Sequence information was obtained from the University of Santa Cruz (UCSC) genome browser from the mouse GRCm38/mm10 assembly. 
Supplemental Table 3.2: Adult and fetal progeny heart rates following maternal inhalation exposure

\begin{tabular}{|c|c|c|c|c|c|c|c|c|}
\hline $\begin{array}{l}\text { Heart } \\
\text { Rate } \\
(\text { BPM) }\end{array}$ & $\begin{array}{c}\text { PPME } \\
\text { WT } \\
\text { Sham }_{a}\end{array}$ & $\begin{array}{c}\text { PPME } \\
\text { WT } \\
\text { TiO }_{2 b}\end{array}$ & $\begin{array}{c}\text { PPME } \\
\text { Tg } \\
\text { Sham }_{c}\end{array}$ & $\begin{array}{c}\text { PPME } \\
\mathrm{Tg} \mathrm{TiO}_{2} \\
\text { d }\end{array}$ & $\begin{array}{c}\text { MPME } \\
\text { WT } \\
\text { Sham }_{\text {e }}\end{array}$ & $\begin{array}{c}\text { MPME } \\
\text { WT } \\
\mathrm{TiO}_{2 \mathrm{f}}\end{array}$ & $\begin{array}{c}\text { MPME } \\
\text { Tg } \\
\text { Sham }_{g}\end{array}$ & $\begin{array}{c}\text { MPME } \\
\mathrm{Tg} \mathrm{TiO}_{2}\end{array}$ \\
\hline Fetal & $\begin{array}{c}85.67 \pm \\
5.98\end{array}$ & $\begin{array}{c}127.92 \pm \\
5.85\end{array}$ & $\begin{array}{c}107.07 \pm \\
17.75\end{array}$ & $\begin{array}{c}155.22 \pm \\
6.87\end{array}$ & $\frac{140.26 \pm}{\underline{13.73}}$ & $\frac{163.17 \pm}{\underline{41.65}}$ & $\begin{array}{l}145.040 \\
\pm 12.40 \\
\end{array}$ & $\frac{160.60 \pm}{\underline{26.36}}$ \\
\hline Adult & $\begin{array}{c}716.68 \pm \\
13.74\end{array}$ & $\begin{array}{c}666.99 \pm \\
14.29\end{array}$ & $\begin{array}{c}666.37 \pm \\
17.91\end{array}$ & $\begin{array}{c}661.19 \pm \\
21.95\end{array}$ & $\begin{array}{c}676.38 \pm \\
50.98\end{array}$ & $\begin{array}{c}676.14 \pm \\
8.66\end{array}$ & $\begin{array}{c}641.98 \pm \\
39.60\end{array}$ & $\begin{array}{c}691.58 \pm \\
18.90\end{array}$ \\
\hline
\end{tabular}


Supplemental Table 3.2: Heart rates were obtained for adult (11 weeks) and fetal (GD 14) offspring during echocardiographic assessment. Bold and underlined values indicate a statistically significant difference between fetal PPME and MPME offspring heart rates as determined by a two-way ANOVA and defined by $P \leq 0.05$. All data are presented as the mean \pm the standard error of the mean (SEM). Adult offspring: PPME WT Sham, $\mathrm{n}=7$; PPME WT TiO, $\mathrm{n}=6$; PPME Tg Sham, $\mathrm{n}=$ 6; PPME Tg TiO, $\mathrm{n}=5$; MPME WT Sham, n = 4; MPME WT TiO, $\mathrm{n}=5 ;$ MPME Tg

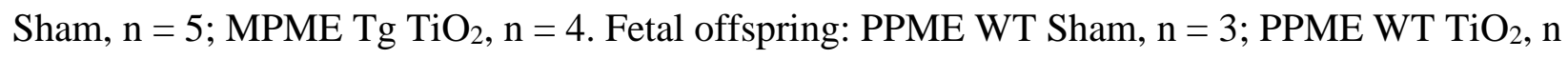
= 7; PPME Tg Sham, $\mathrm{n}=3$; PPME Tg TiO $2, \mathrm{n}=7$; MPME WT Sham, $\mathrm{n}=7 ;$ MPME WT TiO $2, \mathrm{n}$ = 4; MPME Tg Sham, $\mathrm{n}=6$; MPME Tg $\mathrm{TiO}_{2}, \mathrm{n}=6$. PPME = Paternal mPHGPx maternal exposure, MPME = Maternal mPHGPx maternal exposure, WT Sham = wild-type offspring whose dam was exposed to control air, Tg Sham = mPHGPx transgenic offspring whose dam was exposed to control air, WT $\mathrm{TiO}_{2}=$ wild-type offspring whose dam was exposed to nano- $\mathrm{TiO}_{2}, \mathrm{Tg} \mathrm{TiO}_{2}=$ mPHGPx transgenic offspring whose dam was exposed to nano- $\mathrm{TiO}_{2}, \mathrm{GD}=$ gestational day. 
Supplemental Table 3.3: M-mode echocardiography for pregnant dams

\begin{tabular}{|c|c|c|c|c|}
\hline Parameter & WT Sham $_{\mathbf{a}}$ & WT TiO $_{\mathbf{2}}$ & Tg Sham $_{\mathbf{c}}$ & Tg TiO $_{\mathbf{2}}$ \\
\hline Diameter;s (mm) & $0.89 \pm 0.05$ & $0.82 \pm 0.07$ & $0.70 \pm 0.04$ & $0.80 \pm 0.09$ \\
Diameter;d (mm) & $2.62 \pm 0.08$ & $\mathbf{2 . 3 0} \pm \mathbf{0 . 0 8}_{\mathbf{a}}$ & $2.51 \pm 0.02$ & $2.46 \pm 0.06$ \\
Volume;s (uL) & $1.58 \pm 0.20$ & $1.41 \pm 0.30$ & $0.86 \pm 0.16$ & $1.41 \pm 0.30$ \\
Volume;d (uL) & $25.60 \pm 1.93$ & $\mathbf{1 8 . 7 0} \pm \mathbf{1 . 5 7}_{\mathbf{a}}$ & $22.8 \pm 0.54$ & $21.70 \pm 1.32$ \\
Stroke Volume (uL) & $23.30 \pm 1.60$ & $\mathbf{1 7 . 3 0} \pm \mathbf{1 . 3 6}_{\mathbf{a}}$ & $21.9 \pm 0.41$ & $20.40 \pm 1.21$ \\
Ejection Fraction (\%) & $93.00 \pm 0.76$ & $92.90 \pm 1.15$ & $96.3 \pm 0.61$ & $93.60 \pm 1.25$ \\
Fractional Shortening (\%) & $64.60 \pm 1.58$ & $64.90 \pm 2.18$ & $72.40 \pm 1.53$ & $67.50 \pm 3.55$ \\
Cardiac Output (mL/min) & $15.50 \pm 1.04$ & $\mathbf{1 1 . 4 0} \pm \mathbf{0 . 9 8}_{\mathbf{a}}$ & $14.00 \pm 0.37$ & $13.50 \pm 0.72$ \\
\hline Relative Wall Thickness & $0.81 \pm 0.03$ & $\mathbf{1 . 1 2} \pm \mathbf{0 . 0 9}_{\mathbf{a}}$ & $0.930 \pm 0.03$ & $0.97 \pm 0.06$ \\
\hline
\end{tabular}


Supplemental Table 3.3: M-mode echocardiography was performed in pregnant dams (GD 14) following gestational inhalation exposure to control air or ENM aerosols. Bold text indicates a statistically significant difference between the highlighted group and the group referenced by the letter next to it, as determined by a one-way ANOVA with a Tukey's multiple comparisons test and defined by $P \leq 0.05$. WT Sham, $\mathrm{n}=11 ; \mathrm{WT} \mathrm{TiO}_{2}, \mathrm{n}=12 ; \mathrm{Tg}$ Sham, $\mathrm{n}=11 ; \mathrm{Tg} \mathrm{TiO}_{2}, \mathrm{n}=10$. $\mathrm{WT}=$ wild-type, $\mathrm{Tg}=\mathrm{mPHGPx}$ transgenic, $\mathrm{s}=$ systolic, $\mathrm{d}=$ diastolic, $\mathrm{GD}=$ gestational day . 
Supplemental Table 3.4: Maternal heart rates following gestational inhalation exposure

\begin{tabular}{|c|c|c|c|c|}
\hline Heart Rate (BPM) & WT Sham $_{\mathbf{a}}$ & WT TiO $_{\mathbf{2 ~}}$ & Tg Sham $_{\mathbf{c}}$ & ${\text { Tg } \mathbf{T i O}_{\mathbf{2}}}$ \\
\hline Maternal & $667.90 \pm 10.50$ & $655.56 \pm 13.40$ & $638.44 \pm 17.20$ & $667.39 \pm 17.80$ \\
\hline
\end{tabular}


Supplemental Table 3.4: Heart rates were obtained for pregnant dams (GD 14) during echocardiographic assessment, following gestational inhalation exposure. WT Sham, $\mathrm{n}=11$; WT $\mathrm{TiO}_{2}, \mathrm{n}=12 ; \mathrm{Tg}$ Sham, $\mathrm{n}=11 ; \mathrm{Tg} \mathrm{TiO}_{2}, \mathrm{n}=10 . \mathrm{WT}=$ wild-type, $\mathrm{Tg}=$ mPHGPx transgenic. GD $=$ gestational day. 
Supplemental Table 3.5: M-mode echocardiography for fetal progeny

\begin{tabular}{|c|c|c|c|c|c|c|c|c|}
\hline Parameter & $\begin{array}{c}\text { PPME } \\
\text { WT } \\
\text { Sham }_{a}\end{array}$ & $\begin{array}{c}\text { PPME } \\
\text { WT } \\
\text { TiO }_{2 b}\end{array}$ & $\begin{array}{c}\text { PPME } \\
\text { Tg } \\
\text { Sham }_{c}\end{array}$ & $\begin{array}{c}\text { PPME } \\
\text { Tg } \\
\text { TiO }_{2 \mathrm{~d}}\end{array}$ & $\begin{array}{c}\text { MPME } \\
\text { WT } \\
\text { Sham }_{e}\end{array}$ & $\begin{array}{c}\text { MPME } \\
\text { WT } \\
\text { TiO }_{2 \mathrm{f}}\end{array}$ & $\begin{array}{c}\text { MPME } \\
\text { Tg } \\
\text { Sham }_{g}\end{array}$ & $\begin{array}{c}\text { MPME } \\
\text { Tg } \\
\mathrm{TiO}_{2 \mathrm{~h}}\end{array}$ \\
\hline $\begin{array}{l}\text { Diameter;s } \\
\quad(\mathbf{m m})\end{array}$ & $\begin{array}{c}0.31 \pm \\
0.02\end{array}$ & $\begin{array}{l}0.27 \pm \\
0.02\end{array}$ & $\begin{array}{c}0.33 \pm \\
0.07\end{array}$ & $\begin{array}{l}0.34 \pm \\
0.03\end{array}$ & $\begin{array}{c}0.29 \pm \\
0.02\end{array}$ & $\begin{array}{c}0.43 \pm \\
0.08\end{array}$ & $\begin{array}{c}0.30 \pm \\
0.01\end{array}$ & $\begin{array}{c}0.35 \pm \\
0.03\end{array}$ \\
\hline $\begin{array}{l}\text { Diameter;d } \\
\quad(\mathbf{m m})\end{array}$ & $\begin{array}{c}0.76 \pm \\
0.04\end{array}$ & $\begin{array}{l}0.70 \pm \\
0.05\end{array}$ & $\begin{array}{c}0.78 \pm \\
0.07\end{array}$ & $\begin{array}{c}0.78 \pm \\
0.04\end{array}$ & $\frac{0.80 \pm}{\underline{0.05}}$ & $\frac{0.87 \pm}{\underline{0.08}}$ & $\frac{0.82 \pm}{\underline{0.06}}$ & $\frac{0.92 \pm}{\underline{0.04}}$ \\
\hline Volume;s (uL) & $\begin{array}{c}0.08 \pm \\
0.01\end{array}$ & $\begin{array}{c}0.06 \pm \\
0.01\end{array}$ & $\begin{array}{c}0.11 \pm \\
0.06\end{array}$ & $\begin{array}{c}0.12 \pm \\
0.03\end{array}$ & $\begin{array}{l}0.07 \pm \\
0.02\end{array}$ & $\begin{array}{c}0.22 \pm \\
0.08\end{array}$ & $\begin{array}{c}0.08 \pm \\
0.01\end{array}$ & $\begin{array}{c}0.13 \pm \\
0.03\end{array}$ \\
\hline Volume;d (uL) & $\begin{array}{c}0.98 \pm \\
0.12\end{array}$ & $\begin{array}{l}0.83 \pm \\
0.15\end{array}$ & $\begin{array}{c}1.09 \pm \\
0.26\end{array}$ & $\begin{array}{c}1.10 \pm \\
0.19\end{array}$ & $\frac{1.18 \pm}{\underline{0.22}}$ & $\frac{1.48 \pm}{\underline{0.32}}$ & $\frac{1.30 \pm}{\underline{0.23}}$ & $\frac{1.72 \pm}{\underline{0.24}}$ \\
\hline $\begin{array}{c}\text { Stroke Volume } \\
(\mathrm{uL})\end{array}$ & $\begin{array}{c}0.89 \pm \\
0.11\end{array}$ & $\begin{array}{c}0.77 \pm \\
0.14\end{array}$ & $\begin{array}{c}0.98 \pm \\
0.20\end{array}$ & $\begin{array}{c}0.98 \pm \\
0.16\end{array}$ & $\frac{1.11 \pm}{\underline{0.20}}$ & $\frac{1.26 \pm}{\underline{0.24}}$ & $\frac{1.22 \pm}{\underline{0.22}}$ & $\frac{1.60 \pm}{\underline{0.21}}$ \\
\hline $\begin{array}{c}\text { Ejection } \\
\text { Fraction }(\%)\end{array}$ & $\begin{array}{c}91.45 \pm \\
0.32\end{array}$ & $\begin{array}{c}92.68 \pm \\
1.22\end{array}$ & $\begin{array}{l}90.97 \pm \\
3.02\end{array}$ & $\begin{array}{c}89.85 \pm \\
1.41\end{array}$ & $\begin{array}{c}94.07 \pm \\
0.70\end{array}$ & $\begin{array}{l}86.66 \pm \\
3.677_{\text {e,g,h }}\end{array}$ & $\begin{array}{c}93.56 \pm \\
0.44\end{array}$ & $\begin{array}{c}93.13 \pm \\
1.12\end{array}$ \\
\hline $\begin{array}{c}\text { Fractional } \\
\text { Shortening (\%) }\end{array}$ & $\begin{array}{c}58.86 \pm \\
.58\end{array}$ & $\begin{array}{c}61.36 \pm \\
2.20\end{array}$ & $\begin{array}{l}58.46 \pm \\
5.58\end{array}$ & $\begin{array}{l}56.70 \\
\pm 2.35\end{array}$ & $\begin{array}{c}63.60 \pm \\
1.34\end{array}$ & $\begin{array}{c}52.30 \pm \\
5.30\end{array}$ & $\begin{array}{c}63.09 \pm \\
1.56\end{array}$ & $\begin{array}{l}62.040 \\
\pm 2.21\end{array}$ \\
\hline $\begin{array}{l}\text { Cardiac Output } \\
(\mathbf{m L} / \mathrm{min})\end{array}$ & $\begin{array}{c}0.05 \pm \\
0.00\end{array}$ & $\begin{array}{c}0.05 \pm \\
0.01\end{array}$ & $\begin{array}{c}0.06 \pm \\
0.01\end{array}$ & $\begin{array}{c}0.06 \pm \\
0.01\end{array}$ & $\frac{0.09 \pm}{\underline{0.02}}$ & $\frac{0.11 \pm}{\underline{0.02}}$ & $\frac{0.09 \pm}{\underline{0.02}}$ & $\frac{0.10 \pm}{\underline{0.01}}$ \\
\hline $\begin{array}{c}\text { Relative Wall } \\
\text { Thickness }\end{array}$ & $\begin{array}{c}0.59 \pm \\
0.11\end{array}$ & $\begin{array}{c}0.46 \pm \\
0.07\end{array}$ & $\begin{array}{c}0.35 \pm \\
0.01\end{array}$ & $\begin{array}{c}0.57 \pm \\
0.09\end{array}$ & $\begin{array}{c}0.42 \pm \\
0.08\end{array}$ & $\begin{array}{c}0.40 \pm \\
0.06\end{array}$ & $\begin{array}{c}0.40 \pm \\
0.08\end{array}$ & $\begin{array}{c}0.48 \pm \\
0.03\end{array}$ \\
\hline
\end{tabular}


Supplemental Table 3.5: M-mode echocardiography was performed in fetal offspring (GD 14) following maternal inhalation exposure. Bold text indicates significant data defined by $P \leq 0.05$. A two-way ANOVA determined statistical difference between PPME and MPME denoted with underlined values for that parameter. A letter next to a given group denotes statistical significance between the marked group and the group represented by each letter based on a Tukey's multiplecomparisons test. All data are presented as the mean \pm the standard error of the mean (SEM). PPME WT Sham, $\mathrm{n}=3$; PPME WT TiO $2, \mathrm{n}=7$; PPME Tg Sham, $\mathrm{n}=3$; PPME Tg $\mathrm{TiO}_{2}, \mathrm{n}=7$; MPME WT Sham, $\mathrm{n}=7$; MPME WT TiO $2, \mathrm{n}=4$; MPME Tg Sham, $\mathrm{n}=6$; MPME $\mathrm{Tg}^{\mathrm{T}} \mathrm{TiO}_{2}, \mathrm{n}=$ 6. $\mathrm{PPME}=$ Paternal $\mathrm{mPHGPx}$ maternal exposure, $\mathrm{MPME}=$ Maternal $\mathrm{mPHGPx}$ maternal exposure, WT Sham $=$ wild-type offspring whose dam was exposed to control air, Tg Sham $=$ mPHGPx transgenic offspring whose dam was exposed to control air, $\mathrm{WT} \mathrm{TiO}_{2}=$ wild-type offspring whose dam was exposed to nano- $\mathrm{TiO}_{2}, \mathrm{Tg}_{\mathrm{TiO}}=\mathrm{mPHGPx}$ transgenic offspring whose dam was exposed to nano- $\mathrm{TiO}_{2}, \mathrm{~s}=$ systolic, $\mathrm{d}=$ diastolic . 
Supplemental Table 3.6: Adult progeny systolic stress-strain in the short-axis

\begin{tabular}{|c|c|c|c|c|c|c|c|c|c|}
\hline Parameter & Units & $\begin{array}{c}\text { PPME } \\
\text { WT } \\
\text { Sham }\end{array}$ & $\begin{array}{c}\text { PPME } \\
\text { WT } \\
\text { TiO }_{2 b}\end{array}$ & $\begin{array}{c}\text { PPME } \\
\text { Tg } \\
\text { Sham }_{c}\end{array}$ & $\begin{array}{c}\text { PPME } \\
\text { Tg } \\
\mathrm{TiO}_{2 \mathrm{~d}}\end{array}$ & $\begin{array}{l}\text { MPM } \\
\text { EWT } \\
\text { Sham }_{e}\end{array}$ & $\begin{array}{l}\text { MPM } \\
\text { E WT } \\
\mathrm{TiO}_{2 \mathrm{f}}\end{array}$ & $\begin{array}{c}\text { MPM } \\
\text { E Tg } \\
\text { Sham }_{g}\end{array}$ & $\begin{array}{c}\text { MPM } \\
\text { E Tg } \\
\text { TiO }_{2 h}\end{array}$ \\
\hline Radial Velocity & $\begin{array}{c}\mathrm{Pk} \\
\mathrm{cm} / \mathrm{s}\end{array}$ & $\begin{array}{c}2.69 \pm \\
0.22\end{array}$ & $\begin{array}{c}2.82 \pm \\
0.33\end{array}$ & $\begin{array}{c}2.58 \pm \\
0.14\end{array}$ & $\begin{array}{c}2.74 \pm \\
0.12\end{array}$ & $\begin{array}{c}2.35 \pm \\
0.21\end{array}$ & $\begin{array}{c}2.34 \pm \\
0.27\end{array}$ & $\begin{array}{c}2.60 \pm \\
0.30\end{array}$ & $\begin{array}{c}2.62 \pm \\
0.30\end{array}$ \\
\hline $\begin{array}{c}\text { Radial } \\
\text { Displacement }\end{array}$ & $\mathrm{Pk} \mathrm{mm}$ & $\begin{array}{c}0.61 \pm \\
0.04\end{array}$ & $\begin{array}{c}0.65 \pm \\
0.06\end{array}$ & $\begin{array}{c}0.57 \pm \\
0.06\end{array}$ & $\begin{array}{c}0.67 \pm \\
0.05\end{array}$ & $\frac{0.47 \pm}{\underline{0.07}}$ & $\frac{0.47 \pm}{\underline{0.03}}$ & $\frac{\underline{0.50 \pm}}{\underline{0.08}}$ & $\frac{0.57 \pm}{\underline{0.03}}$ \\
\hline Radial Strain & $\begin{array}{l}\mathrm{Pk} \\
\%\end{array}$ & $\begin{array}{l}43.42 \\
\pm 3.68\end{array}$ & $\begin{array}{l}45.16 \\
\pm 3.27\end{array}$ & $\begin{array}{l}38.74 \\
\pm 4.65\end{array}$ & $\begin{array}{l}45.45 \\
\pm 2.66\end{array}$ & $\frac{37.72}{ \pm 2.52}$ & $\begin{array}{r}\underline{30.35} \\
\pm \underline{3.13} \\
\end{array}$ & $\frac{32.33}{\underline{ \pm 5.05}}$ & $\begin{array}{r}\underline{35.54} \\
\pm 5.31\end{array}$ \\
\hline $\begin{array}{c}\text { Radial Strain } \\
\text { Rate }\end{array}$ & $\mathrm{Pk} 1 / \mathrm{s}$ & $\begin{array}{l}15.24 \\
\pm 1.08\end{array}$ & $\begin{array}{c}17.48 \\
\pm 1.10\end{array}$ & $\begin{array}{c}14.21 \\
\pm 0.79\end{array}$ & $\begin{array}{l}15.08 \\
\pm 0.70\end{array}$ & $\begin{array}{l}15.48 \\
\pm 0.54\end{array}$ & $\begin{array}{l}12.35 \\
\pm 1.86\end{array}$ & $\begin{array}{l}14.01 \\
\pm 0.90\end{array}$ & $\begin{array}{c}14.21 \\
\pm 2.58\end{array}$ \\
\hline $\begin{array}{l}\text { Circumferentia } \\
\text { I Velocity }\end{array}$ & $\begin{array}{c}\mathrm{Pk} \\
\mathrm{deg} / \mathrm{s}\end{array}$ & $\begin{array}{c}736.92 \\
\pm \\
150.19\end{array}$ & $\begin{array}{c}506.27 \\
\pm \\
32.36\end{array}$ & $\begin{array}{c}596.50 \\
\pm \\
121.12\end{array}$ & $\begin{array}{c}611.58 \\
\pm \\
41.31\end{array}$ & $\begin{array}{c}867.56 \\
\pm \\
154.99\end{array}$ & $\begin{array}{c}724.07 \\
\pm \\
132.03\end{array}$ & $\begin{array}{c}583.47 \\
\pm \\
86.97\end{array}$ & $\begin{array}{c}612.95 \\
\pm \\
43.03\end{array}$ \\
\hline $\begin{array}{l}\text { Circumferentia } \\
\text { I Displacement }\end{array}$ & Pk deg & $\begin{array}{c}7.37 \pm \\
1.67\end{array}$ & $\begin{array}{l}7.24 \pm \\
2.92\end{array}$ & $\begin{array}{c}7.08 \pm \\
2.87\end{array}$ & $\begin{array}{c}7.05 \pm \\
1.89\end{array}$ & $\begin{array}{c}9.43 \pm \\
4.52\end{array}$ & $\begin{array}{c}8.37 \pm \\
2.07\end{array}$ & $\begin{array}{c}4.88 \pm \\
1.12\end{array}$ & $\begin{array}{c}6.30 \pm \\
1.56\end{array}$ \\
\hline $\begin{array}{c}\text { Circumferentia } \\
\text { I Strain }\end{array}$ & $\begin{array}{l}\mathrm{Pk} \\
\%\end{array}$ & $\begin{array}{l}-46.81 \\
\pm 3.53\end{array}$ & $\begin{array}{l}-55.29 \\
\pm 2.82\end{array}$ & $\begin{array}{l}-43.68 \\
\pm 1.50\end{array}$ & $\begin{array}{l}-52.79 \\
\pm 2.88\end{array}$ & $\begin{array}{l}-38.49 \\
\pm 8.83\end{array}$ & $\frac{-42.26}{ \pm 6.94}$ & $\begin{array}{r}-35.29 \\
\pm 4.32\end{array}$ & $\begin{array}{r}-42.69 \\
\pm 6.94 \\
\end{array}$ \\
\hline $\begin{array}{l}\text { Circumferentia } \\
\text { I Strain Rate }\end{array}$ & $\mathrm{Pk} 1 / \mathrm{s}$ & $\begin{array}{l}-42.28 \\
\pm 3.95\end{array}$ & $\begin{array}{l}-52.41 \\
\pm 7.85\end{array}$ & $\begin{array}{l}-37.53 \\
\pm 5.26\end{array}$ & $\begin{array}{l}-49.63 \\
\pm 8.50\end{array}$ & $\begin{array}{l}-38.61 \\
\pm 1.97\end{array}$ & $\begin{array}{l}-42.40 \\
\pm 9.65\end{array}$ & $\begin{array}{l}-45.37 \\
\pm 6.64\end{array}$ & $\begin{array}{l}-51.42 \\
\pm 3.43\end{array}$ \\
\hline
\end{tabular}


Supplemental Table 3.6: Peak strain and strain-rate values acquired from B-mode images for circumferential and radial dimensions in adult progeny (11 weeks of age) following maternal inhalation exposure. Bold and underlined values indicate a statistically significant difference between fetal PPME and MPME offspring values for that parameter as determined by a two-way ANOVA and defined by $P \leq 0.05$. All data are presented as the mean \pm the standard error of the mean (SEM). PPME WT Sham, $n=7$; PPME WT TiO $2, n=6$; PPME Tg Sham, $n=6$; PPME Tg $\mathrm{TiO}_{2}, \mathrm{n}=5$; MPME WT Sham, $\mathrm{n}=4$; MPME WT TiO $2, \mathrm{n}=5$; MPME Tg Sham, $\mathrm{n}=5$; MPME $\mathrm{Tg} \mathrm{TiO}_{2}, \mathrm{n}=4$. PPME $=$ Paternal $\mathrm{mPHGPx}$ maternal exposure, MPME $=$ Maternal $\mathrm{mPHGPx}$ maternal exposure, WT Sham = wild-type offspring whose dam was exposed to control air, $\mathrm{Tg}$ Sham $=$ mPHGPx transgenic offspring whose dam was exposed to control air, $\mathrm{WT} \mathrm{TiO}_{2}=$ wildtype offspring whose dam was exposed to nano- $\mathrm{TiO}_{2}, \mathrm{Tg} \mathrm{TiO}_{2}=\mathrm{mPHGPx}$ transgenic offspring whose dam was exposed to nano- $\mathrm{TiO}_{2}, \mathrm{Pk}=$ peak. 
Supplemental Table 3.7: Fetal progeny systolic stress-strain in the short-axis

\begin{tabular}{|c|c|c|c|c|c|c|c|c|c|}
\hline Parameter & Units & $\begin{array}{c}\text { PPME } \\
\text { WT } \\
\text { Sham }_{a}\end{array}$ & $\begin{array}{c}\text { PPME } \\
\text { WT } \\
\text { TiO }_{2 \text { b }}\end{array}$ & $\begin{array}{c}\text { PPME } \\
\text { Tg } \\
\text { Sham }_{c}\end{array}$ & $\begin{array}{c}\text { PPME } \\
\text { Tg } \\
\text { TiO }_{2 \mathrm{~d}}\end{array}$ & $\begin{array}{l}\text { MPM } \\
\text { E WT } \\
\text { Sham }\end{array}$ & $\begin{array}{l}\text { MPM } \\
\text { E WT } \\
\text { TiO }_{2 \mathrm{f}}\end{array}$ & $\begin{array}{c}\text { MPM } \\
\text { E Tg } \\
\text { Sham } \\
\mathrm{g} \\
\end{array}$ & $\begin{array}{c}\text { MPM } \\
\text { E Tg } \\
\text { TiO }_{2 h}\end{array}$ \\
\hline Radial Velocity & $\begin{array}{c}\mathrm{Pk} \\
\mathrm{cm} / \mathrm{s}\end{array}$ & $\begin{array}{c}0.23 \pm \\
0.02\end{array}$ & $\begin{array}{l}0.12 \pm \\
0.02 \\
\mathrm{a}, \mathrm{c}\end{array}$ & $\begin{array}{l}0.22 \pm \\
0.05\end{array}$ & $\begin{array}{l}0.12 \pm \\
0.02\end{array}$ & $\begin{array}{c}0.19 \pm \\
0.02\end{array}$ & $\begin{array}{l}0.16 \pm \\
0.02\end{array}$ & $\begin{array}{c}0.16 \pm \\
0.02\end{array}$ & $\begin{array}{c}0.17 \pm \\
0.01\end{array}$ \\
\hline $\begin{array}{c}\text { Radial } \\
\text { Displacement }\end{array}$ & $\begin{array}{l}\mathrm{Pk} \\
\mathrm{mm}\end{array}$ & $\begin{array}{c}0.13 \pm \\
0.01\end{array}$ & $\begin{array}{l}0.06 \pm \\
0.01 \\
a, c\end{array}$ & $\begin{array}{c}0.12 \pm \\
0.04\end{array}$ & $\begin{array}{l}0.05 \pm \\
0.01_{\mathrm{a}, \mathrm{c}}\end{array}$ & $\frac{0.06 \pm}{\underline{0.01}}$ & $\frac{0.05 \pm}{\underline{0.01}}$ & $\frac{0.04 \pm}{\underline{0.01}}$ & $\frac{\underline{0.04 \pm}}{\underline{0.01}}$ \\
\hline Radial Strain & $\mathrm{Pk} \%$ & $\begin{array}{l}18.95 \\
\pm 3.65\end{array}$ & $\begin{array}{l}9.92 \pm \\
2.22\end{array}$ & $\begin{array}{l}19.96 \\
\pm 6.92\end{array}$ & $\begin{array}{c}8.72 \pm \\
1.33\end{array}$ & $\begin{array}{l}21.03 \\
\pm 5.08\end{array}$ & $\begin{array}{c}16.21 \\
\pm 2.49\end{array}$ & $\begin{array}{c}14.07 \\
\pm 3.10\end{array}$ & $\begin{array}{r}22.38 \\
\pm 6.19\end{array}$ \\
\hline $\begin{array}{c}\text { Radial Strain } \\
\text { Rate }\end{array}$ & $\begin{array}{l}\mathrm{Pk} \\
1 / \mathrm{s}\end{array}$ & $\begin{array}{l}13.16 \\
\pm 3.10\end{array}$ & $\begin{array}{c}3.75 \pm \\
0.65\end{array}$ & $\begin{array}{l}7.58 \pm \\
3.13\end{array}$ & $\begin{array}{c}3.37 \pm \\
\mathbf{0 . 3 4}\end{array}$ & $\frac{9.30 \pm}{\underline{0.67}}$ & $\frac{11.75}{ \pm 3.45}$ & $\begin{array}{l}11.07 \\
\pm 1.61\end{array}$ & $\frac{10.55}{ \pm 3.12}$ \\
\hline $\begin{array}{l}\text { Circumferentia } \\
\text { I Velocity }\end{array}$ & $\begin{array}{c}\mathrm{Pk} \\
\mathrm{deg} / \mathrm{s}\end{array}$ & $\begin{array}{c}389.31 \\
\pm \\
62.28\end{array}$ & $\begin{array}{c}213.06 \\
\pm \\
29.75\end{array}$ & $\begin{array}{c}425.89 \\
\pm \\
170.71\end{array}$ & $\begin{array}{c}298.10 \\
\pm \\
67.32\end{array}$ & $\begin{array}{l}\frac{466.39}{ \pm} \\
\underline{42.24}\end{array}$ & $\begin{array}{l}\frac{442.01}{ \pm} \\
\underline{79.04}\end{array}$ & $\frac{\underline{401.68}}{\underline{ \pm}}$ & $\begin{array}{c}\frac{507.34}{ \pm} \\
\underline{56.69}\end{array}$ \\
\hline $\begin{array}{l}\text { Circumferentia } \\
\text { I Displacement }\end{array}$ & $\begin{array}{c}\mathrm{Pk} \\
\mathrm{deg}\end{array}$ & $\begin{array}{r}13.47 \\
\pm 1.97\end{array}$ & $\begin{array}{c}5.36 \pm \\
1.35_{\mathrm{a}}\end{array}$ & $\begin{array}{l}11.74 \\
\pm 2.11\end{array}$ & $\begin{array}{c}7.91 \pm \\
0.84\end{array}$ & $\frac{15.34}{\underline{ \pm 1.83}}$ & $\begin{array}{l}11.66 \\
\pm 1.00 \\
\end{array}$ & $\begin{array}{r}13.86 \\
\pm 0.91 \\
\end{array}$ & $\begin{array}{r}11.38 \\
\pm 1.72 \\
\end{array}$ \\
\hline $\begin{array}{l}\text { Circumferentia } \\
\text { I Strain }\end{array}$ & $\mathrm{Pk} \%$ & $\begin{array}{l}-36.36 \\
\pm 3.16\end{array}$ & $\begin{array}{c}-21.07 \\
\pm \\
3.09 \\
a, c\end{array}$ & $\begin{array}{l}-37.92 \\
\pm 6.78\end{array}$ & $\begin{array}{c}-20.79 \\
\pm \\
0.88 \\
a, c\end{array}$ & $\begin{array}{l}-29.53 \\
\pm 2.68\end{array}$ & $\begin{array}{l}-26.04 \\
\pm 3.70\end{array}$ & $\begin{array}{l}-23.51 \\
\pm 0.81\end{array}$ & $\begin{array}{l}-24.53 \\
\pm 4.69\end{array}$ \\
\hline $\begin{array}{l}\text { Circumferentia } \\
\text { I Strain Rate }\end{array}$ & $\begin{array}{l}\mathrm{Pk} \\
1 / \mathrm{s}\end{array}$ & $\begin{array}{l}-16.47 \\
\pm 1.82\end{array}$ & $\begin{array}{l}-10.23 \\
\pm 2.81\end{array}$ & $\begin{array}{l}-13.68 \\
\pm 3.19\end{array}$ & $\begin{array}{c}-9.50 \pm \\
1.77\end{array}$ & $\frac{-18.25}{ \pm 1.71}$ & $\frac{-17.42}{ \pm 1.08}$ & $\begin{array}{l}-14.70 \\
\pm 1.54\end{array}$ & $\begin{array}{l}-18.48 \\
\pm 2.85\end{array}$ \\
\hline
\end{tabular}


Supplemental Table 3.7: Peak strain and strain-rate values acquired from B-mode images for circumferential and radial dimensions in fetal progeny (GD 14) following maternal inhalation exposure. Bold text indicates significant data defined by $P \leq 0.05$. A two-way ANOVA determined statistical difference between PPME and MPME denoted with underlined values for that parameter. A letter next to a given group denotes statistical significance between the marked group and the group represented by each letter based on a Tukey's multiple-comparisons test. All data are presented as the mean \pm the standard error of the mean (SEM). PPME WT Sham, $n=3$; PPME WT TiO $2, \mathrm{n}=7$; PPME Tg Sham, $\mathrm{n}=3$; PPME Tg TiO $2, \mathrm{n}=7$; MPME WT Sham, $\mathrm{n}=7$; MPME WT $\mathrm{TiO}_{2}, \mathrm{n}=4$; MPME Tg Sham, $\mathrm{n}=6$; MPME Tg $\mathrm{TiO}_{2}, \mathrm{n}=6$. PPME $=$ Paternal $m$ PHGPx maternal exposure MPME $=$ Maternal mPHGPx maternal exposure, WT Sham $=$ wild-type offspring whose dam was exposed to control air, Tg Sham = mPHGPx transgenic offspring whose dam was exposed to control air, $\mathrm{WT} \mathrm{TiO}_{2}=$ wild-type offspring whose dam was exposed to nano$\mathrm{TiO}_{2}, \mathrm{Tg} \mathrm{TiO}_{2}=$ mPHGPx transgenic offspring whose dam was exposed to nano- $\mathrm{TiO}_{2}, \mathrm{GD}=$ gestational day, $\mathrm{Pk}=$ peak . 


\title{
Chapter 4: Specific Aim 3
}

\section{Increased $\mathbf{N}^{6}$-Methyladenosine in Fetal Offspring following Gestational Nano- $\mathrm{TiO}_{2}$ Inhalation Exposure Decreases Mitochondrial Transcript and Protein \\ Expression}

\author{
Amina Kunovac, $\mathrm{PhD}^{1,2,3}$, Quincy A. Hathaway, $\mathrm{PhD}^{4}$, Dharendra Thapa, $\mathrm{PhD}^{1,2}$, Andrya J. Durr, BS ${ }^{1,2}$, \\ Andrew D. Taylor, BS ${ }^{1,2}$, Saira Rizwan, BS ${ }^{1,2}$, Daud Sharif, BS ${ }^{5}$, Stephen J. Valentine, PhD ${ }^{5}$, Timothy R. \\ Nurkiewicz, $\mathrm{PhD}^{3,6}$, and John M. Hollander, $\mathrm{PhD}^{1,2,3}$ \\ ${ }^{1}$ Division of Exercise Physiology, West Virginia University School of Medicine, Morgantown, WV, USA. \\ ${ }^{2}$ Mitochondria, Metabolism \& Bioenergetics Working Group, West Virginia University School of Medicine, \\ Morgantown, WV, USA. ${ }^{3}$ Center for Inhalation Toxicology (iTOX), West Virginia University School of Medicine, \\ Morgantown, WV, USA. ${ }^{4}$ Heart and Vascular Institute, West Virginia University School of Medicine, Morgantown, \\ WV, USA. ${ }^{5}$ Department of Chemistry, West Virginia University, Morgantown, WV, USA. ${ }^{6}$ Department of Physiology \\ \& Pharmacology, Morgantown, WV, USA.
}

\section{Corresponding Author:}

John M. Hollander, Ph.D., F.A.H.A.

Division of Exercise Physiology

West Virginia University School of Medicine

1 Medical Center Drive, PO Box 9227

Morgantown, WV 26506

Tel: 1-(304) 293-3683; Fax: 1-(304) 293-7105

Email: jhollander@hsc.wvu.edu

Word Count: 8873 


\begin{abstract}
Background: $\mathrm{N}^{6}$-methyladenosine $\left(\mathrm{m}^{6} \mathrm{~A}\right)$ is the most prominent epitranscriptomic modification in eukaryotes, but it's implications on adaptive changes within the gestational environment are poorly understood. We propose that cardiac $\mathrm{m}^{6} \mathrm{~A}$ methylation in fetal offspring exposed gestationally to nano- $\mathrm{TiO}_{2}$ alters mitochondrial bioenergetics through changes in mRNA and protein stability.
\end{abstract}

Methods: 10-week-old female FVB/NJ wild type mice $(n=14)$ were purchased. Mice were mated and on gestational day (GD) 5 underwent 6 non-consecutive days of whole-body inhalation exposure. Mice were exposed to filtered room air or nano- $\mathrm{TiO}_{2}$ with a target aerosol mass concentration of $12 \mathrm{mg} / \mathrm{m}^{3}$. At GD 15 mice were sacrificed and cardiac RNA and mitochondrial proteins extracted. Immunoprecipitation with $\mathrm{m}^{6} \mathrm{~A}$ antibodies was performed followed by sequencing of immunoprecipitant $\left(\mathrm{m}^{6} \mathrm{~A}\right)$ and input (mRNA) on the Illumina NextSeq 2000. Protein extraction, preparation, and LC-MS/MS was used for mitochondrial protein quantification.

Results: There were no differences in maternal or fetal pup weights, number of pups, or pup heart weight between exposure groups. Transcriptomic sequencing revealed 3,648 differentially expressed genes in nano- $\mathrm{TiO}_{2}$ exposed mice $(\mathrm{Padj} \leq 0.05)$. Genes involved in mitochondrial bioenergetics were significantly downregulated ( 83 or 85 genes). 921 genes revealed significant $\mathrm{m}^{6} \mathrm{~A}$ methylation sites (Padj $\left.\leq 0.10\right)$. 311 genes were identified to have significantly altered gene expression (mRNA) as well as differentially methylated sites. Pathway analysis of these genes revealed that mRNA degradation and ubiquitin-mediated proteolysis were common pathways. Mitochondrial proteomics showed decreased ATP Synthase expression in the exposed group.

Conclusions: $\mathrm{M}^{6} \mathrm{~A}$ methylation likely affects the longevity of transcripts and translated proteins in fetal progeny following nano- $\mathrm{TiO}_{2}$ exposure, ultimately affecting mitochondrial function.

Keywords: Epitranscriptomics; Bioenergetics; Heart, 3' UTR; m6 A; Bioinformatics 


\section{Introduction}

Epigenetic reprogramming is one of the main mechanisms responsible for adverse effects on long-term health outcomes following environmental exposure to toxicants $(1,43)$. While studies of transient DNA and histone modifications have provided significant insight into the field of toxicology, the advent of chemical modifications at the level of mRNA has introduced a new layer of complexity. The study of mRNA chemical modifications, otherwise known as epitranscriptomics, provides a new perspective for understanding how alterations in the stability of mRNA transcripts can impact the maternal environment, shaping the health of the offspring. $\mathrm{N}^{6}$-methyladenosine $\left(\mathrm{m}^{6} \mathrm{~A}\right)$ is the most abundant mRNA modification in eukaryotes $(52)$ and has the capacity to alter the translational capacity of transcripts. There is currently very little understanding if/how $\mathrm{m}^{6} \mathrm{~A}$ modifications impact fetal development following gestational particulate or ENM exposure.

The epigenetic modifications that were implicated in the long-term effects of environmental exposure thus far have centered primarily around oxidative stress, DNA methylation, and histone post-translational modifications $(37,39)$. However post-transcriptional modifications and their role in regulating RNA function have recently gained traction. Methylation of bases can alter RNA structure, folding, stability, degradation, localization, and thereby its interactions with other RNAs or proteins $(21,52)$. Recently, $\mathrm{N}^{6}$-methyladenosine $\left(\mathrm{m}^{6} \mathrm{~A}\right)$ has been suggested to play a prominent role in epitranscriptomic reprogramming following particle inhalation exposure $(7,8,23)$. $\mathrm{M}^{6} \mathrm{~A}$, which is the most prevalent internal, post-transcriptional RNA modification, occurs in $\sim 30 \%$ of transcripts, and plays a pivotal role in numerous physiological systems (51). In addition to being highly abundant in mammalian mRNA, it is also vastly conserved across eukaryotic species including, yeast, plants, and mammals $(10,13)$.

To understand the effects of $\mathrm{m}^{6} \mathrm{~A}$ in disease, one must first understand the regulators involved in writing, erasing, and reading these prevalent modifications. The writers are responsible for the co-transcriptional addition of a methyl group at the N6 position of the adenosine in the consensus sequence DRACH ( $\mathrm{D}=\mathrm{A} / \mathrm{G} / \mathrm{U} ; \mathrm{R}=\mathrm{A} / \mathrm{G}, \mathrm{H}=\mathrm{A} / \mathrm{C} / \mathrm{U})(21,22,52)$. Methyltransferase-like protein 3 (METTL3) is the main player in the writer complex which also includes adaptor proteins. The two predominant demethylases in mammals that are responsible for removing the $\mathrm{m}^{6} \mathrm{~A}$ marks are fat mass and obesity-associated protein (FTO) and $\alpha$-ketoglutarate-dependent dioxygenase 
homolog 5 (ALKBH5) (52). However, $\mathrm{m}^{6} \mathrm{~A}$ is not the primary target for FTO as has been recently discovered, rather the primary target of FTO is $\mathrm{N}^{6}, 2^{\prime}$-O-dimethyladenosine $\left(\mathrm{m}^{6} \mathrm{~A}_{\mathrm{m}}\right)$ (28). Lastly, the $\mathrm{m}^{6} \mathrm{~A}$ reader proteins include YTH domain (YT521-B homology) containing proteins, YTHDC1 and YTHDF1/2/3, which appear to each play their own individual role in mRNA processing based on the presence or absence of $\mathrm{m}^{6} \mathrm{~A}$ marks. When YTHDC1 binds to the $\mathrm{m}^{6} \mathrm{~A}$ mark (mainly in the nucleus), it can affect splicing and/or mRNA export, whereas YTHDF1 promotes mRNA translation (22). On the other hand, the reader protein YTHDF2 favors mRNA decay. YTHDF3 works with both YTHDF1 and YTHDF2 to enhance each respective activity (40). Dysregulation of $\mathrm{m}^{6} \mathrm{~A}$ can thereby alter gene expression that can lead to changes in cellular function and the onset of cancer, psychiatric disorders, metabolic diseases, and cardiovascular disease $(51,52)$.

The overall landscape of $\mathrm{m}^{6} \mathrm{~A}$ remains to be elucidated in offspring hearts following maternal ENM inhalation exposure during gestation. In this study we implement transcriptomewide mapping of $\mathrm{m}^{6} \mathrm{~A}$ by combining RNA immunoprecipitation and RNA sequencing ( $\mathrm{m}^{6} \mathrm{~A}-\mathrm{RIP}$ seq) to elucidate the role of $\mathrm{m}^{6} \mathrm{~A}$ methylation on diminished cardiac and mitochondrial function in fetal offspring following gestational exposure to nano- $\mathrm{TiO}_{2}(23,24)$. MRNA and $\mathrm{m}^{6} \mathrm{~A}$ analyses revealed genes with overlapping pathways, such as regulation of RNA degradation and ubiquitinmediated proteolysis. Both transcriptomic and mitochondrial proteomic data highlighted how significant decreases in mitochondrial genes were found following exposure. Our data emphasize how gestational exposure to ENMs can alter $\mathrm{m}^{6} \mathrm{~A}$ methylation and indirectly regulate critical cellular processes, such as mitochondrial bioenergetics. 


\section{Materials and Methods}

\section{Animal Model}

Friend Virus B NIH Jackson (FVB/NJ) wild type mice (14 females, 7 males at 10 weeks) were purchased from Jackson Laboratory (Bar Harbor, ME). Animals were housed in the West Virginia University Health Sciences Center Animal Facility with access to a standard chow diet and water ad libitum. All animals were allowed a 48-hour acclimation period before being handled. Females were housed in groups of 4 per cage and introduced to male bedding three days prior to being introduced to the males for breeding. This was implemented to take advantage of the Whitten effect, which states that females are most receptive to mating on the third night after exposure to male pheromones that are found in urine (47). This allows us to synchronize the females' estrous cycles prior to mating and therefore increases the number of females becoming pregnant at similar time points and leading to well age-matched cohorts.

A harem breeding strategy was utilized with two females and one male per cage set up on the third night following exposure to male bedding. Females were checked for vaginal plugs in the early morning after they were set-up with the males. Pregnancy was verified with identification of a vaginal plug at which point females were randomly separated into sham (7 pregnant dams) and nano- $\mathrm{TiO}_{2}$ (7 pregnant dams) groups. On approximately gestational day (GD) 5, maternal inhalation exposure was initiated for each respective exposure group (sham or nano- $\mathrm{TiO}_{2}$ ) that occurred for 6 hours/day, for 6 days over an 8-day period. Pregnant dams (7 Sham, 7 nano-TiO 2 ) were euthanized on GD 15 and the pups were removed from the uteri. The dams, pups, and pup hearts were weighed and weights recorded (Table 4.1). The hearts of fetal offspring were pooled per each litter which was considered $n=1$. The hearts of offspring of 3 sham and 3 nano- $\mathrm{TiO}_{2-}$ exposed dams were saved in RNAprotect Tissue Reagent (Item no. 76105; Qiagen, Hilden, Germany) in cryotubes, flash frozen, and stored in $-80^{\circ} \mathrm{C}$ for future analysis. The hearts of offspring of the other 4 sham and 4 nano- $\mathrm{TiO}_{2}$-exposed dams were immediately processed for mitochondrial isolation as described below. The West Virginia University Animal Care and Use Committee approved all animal studies which conform to the most current National Institutes of Health (NIH) Guidelines for the Care and Use of Laboratory Animals ( $8^{\text {th }}$ edition) manual. 


\section{Engineered Nanomaterial (ENM) Inhalation Exposure}

Our laboratory has previously detailed the engineered nanomaterial (ENM) inhalation exposure paradigm implemented in this study $(14,23,24)$. Nano- $\mathrm{TiO}_{2} \mathrm{P} 25$ powder was purchased from Evonik (Aeroxide $\mathrm{TiO}_{2}$, Parsipanny, $\mathrm{NJ}$ ) which was composed of anatase $(80 \%)$ and rutile $(20 \%) \mathrm{TiO}_{2}$. Prior to aerosolization, the nano- $\mathrm{TiO}_{2}$ powder was prepared by drying, sieving, and storing $(14,18,23,24,31)$. Previous studies from our laboratory and colleagues have outlined the primary particle characteristics including the size $(21 \mathrm{~nm})$, Zeta potential $(-56.6 \mathrm{mV})$, and the specific surface area $\left(48.08 \mathrm{~m}^{2} / \mathrm{g}\right)(30,31,38)$.

A high-pressure acoustical generator (HPAG; IEStechno, Morgantown, WV) was utilized for nano- $\mathrm{TiO}_{2}$ aerosolization as has been previously done for rodent inhalation exposure studies $(14,23,24)$. Figure 4.1 outlines the details of nano- $\mathrm{TiO}_{2}$ aerosol characterization. Using a wholebody exposure chamber, a target aerosol mass concentration of $12 \mathrm{mg} / \mathrm{m}^{3}$ of engineered nano- $\mathrm{TiO}_{2}$ was implemented for a period of 360 minutes per day for 6 non-consecutive days, over an 8-day period (23). The relevance of this concentration lies in its ability to recapitulate the lung burden of a person who works in a manufacturing setting, based on the human equivalent alveolar doses during pregnancy and has been previously detailed by our laboratory (23). Alveolar deposition fraction $(\mathrm{F})$, minute ventilation based on body weight $(\mathrm{V})$, the mass concentration $(\mathrm{C})$, and exposure duration ( $\mathrm{T}$ ) were used with the equation $\mathrm{D}=\mathrm{F} \times \mathrm{V} \times \mathrm{C} \times \mathrm{T}$. This allowed us to determine that the daily deposited nano- $\mathrm{TiO}_{2}$ alveolar dose was $6.92 \mu \mathrm{g}$ (total six exposure dose $=41.55 \mu \mathrm{g}$ ).

The real-time $\mathrm{TiO} 2$ aerosol mass concentration readings were sampled from the exposure chamber during a typical exposure day (Figure 4.1A). These concentrations were verified by gravimetric measurements during each exposure, which resulted in an average mass concentration of $12 \mathrm{mg} / \mathrm{m}^{3}$ during the 360-minute period. To determine the size distribution of the nano-TiO2 aerosols, a high-resolution electrical low-pressure impactor (ELPI+; Dekati, Tampere, Finland), and a scanning particle mobility sizer (SMPS 3938; TSI Inc., St. Paul, MN) were employed. The ELPI+ data indicated a geometric count median diameter (CMD) of $172 \mathrm{~nm}$ with a geometric standard deviation (GSD) of 1.96 (Figure 4.1B). The SMPS data indicated a CMD of $112 \mathrm{~nm}$ with a GSD of 2.14 (Figure 4.1C). The exposure chamber contained bedding material that was soaked in water to maintain a comfortable humidity level during exposure. Control animals (sham) were 
exposed to HEPA filtered air with similar chamber conditions in a designated control chamber. The final exposure was administered 48 hours prior to sacrifice and tissue harvesting.

\section{RNA Isolation and Fragmentation}

Total RNA was extracted from pooled fetal heart samples (sham, $\mathrm{n}=3$; nano- $\mathrm{TiO}_{2}, \mathrm{n}=3$ ) using QIAzol lysis reagent (item no. 79306, Qiagen). Samples were homogenized in QIAzol using a rotor-stator homogenizer and further processed using the miRNeasy Mini Kit (item no. 217004, Qiagen) per manufacturer's protocol. Concentrations were determined for each sample using the NanoDrop ND-100 (Thermo Fisher Scientific, Waltham, MA). Spike-in controls obtained from the EpiMark N6-Methyladenosine Enrichment Kit (item no. E1610S; NEB) were prepared following the manufacturer's protocol. Briefly, the $\mathrm{m}^{6} \mathrm{~A}$ control RNA contains $\mathrm{m}^{6} \mathrm{~A}$ modified RNA (Gaussia luciferase), which was transcribed in the presence of $20 \% \mathrm{~m}^{6} \mathrm{ATP}$ and $80 \%$ ATP and the unmodified control RNA (Cypridina luciferase) contains no modifications. $1 \mu \mathrm{L}$ of the $\mathrm{m}^{6} \mathrm{~A}$ control RNA and $1 \mu \mathrm{L}$ of the unmodified control RNA were added to each sample prior to fragmentation. The fetal cardiac total RNA samples $(3 \mu \mathrm{g})$ were fragmented into $\sim 250-350$ nucleotide fragments using the NEBNext Magnesium RNA Fragmentation kit (item no. E6150S; New England Biolabs (NEB), Ipswich, MA) at $65^{\circ} \mathrm{C}$ for 5 minutes, followed by addition of the stop solution (26, 53), previously shown (23). The Monarch RNA Cleanup Kit (item no T2030L; NEB) was performed per manufacturer's protocol. Samples were eluted with $20 \mu \mathrm{L}$ of nucleasedree water and concentrations were determined using the NanoDrop ND-100 (Thermo Fisher Scientific). $2 \mu \mathrm{L}$ of fragmented total RNA was saved from each sample to be used as input and the rest was used for $\mathrm{m}^{6} \mathrm{~A}$ RNA immunoprecipitation followed by sequencing ( $\mathrm{m}^{6} \mathrm{~A}-\mathrm{RIP}$-seq).

\section{Immunoprecipitation $\left(m^{6} A-R I P\right)$ with Low Input Samples}

The protocol used in our study was adapted from $\mathrm{m}^{6} \mathrm{~A}-\mathrm{RIP}$ protocols described in "Refined RIP-seq protocol for epitranscriptome analysis with low input materials" (53) and "Landscape and Regulation of $\mathrm{m}^{6} \mathrm{~A}$ and $\mathrm{m}^{6} \mathrm{Am}$ Methylome across Human and Mouse Tissues" (26), with modifications. In a $1.5 \mathrm{~mL}$ microcentrifuge tube (per sample), $30 \mu \mathrm{L}$ of protein-A magnetic beads (item no. 10002D; Thermo Fisher Scientific) and $30 \mu \mathrm{L}$ of protein-G magnetic beads (item no. 
10004D; Thermo Fisher Scientific) were mixed, magnetic field applied, and supernatant removed. The mixture of beads was washed twice with $400 \mu \mathrm{L}$ of IPP buffer (10 mM Tris-HCl, $150 \mathrm{mM}$ $\mathrm{NaCl}, \mathrm{pH} 7.5 ; 0.1 \%$ IGEPAL CA-630) and resuspended in $500 \mu \mathrm{L}$ of IPP buffer. $5 \mu \mathrm{g}$ of affinity purified anti-m ${ }^{6} \mathrm{~A}$ polyclonal antibody (item no. ABE572-I; MilliporeSigma, Burlington, MA) was added to the beads and incubated overnight at $4^{\circ} \mathrm{C}$. An additional tube with the mixture of beads received $5 \mu \mathrm{g}$ of the normal rabbit IgG control antibody (item no. 2729; Cell Signaling Technology (CST), Danvers, MA) and was also incubated overnight at $4{ }^{\circ} \mathrm{C}$. The magnetic field was applied and supernatant removed, followed by washing the antibody-bead mixture twice with IPP buffer. In a $1.5 \mathrm{~mL}$ microcentrifuge tube, a $500 \mu \mathrm{L}$ mixture was prepared containing $100 \mu \mathrm{L}$ of $5 \mathrm{X}$ IPP buffer, fragmented total RNA (diluted with nuclease-free water to a volume of $395 \mu \mathrm{L}$ ), and $5 \mu \mathrm{L}$ of RNasin Plus RNase Inhibitor (item no. N2611; Promega, Madison, WI).

The antibody-bead mixture was resuspended in the $500 \mu \mathrm{L}$ mixture containing the fragmented RNA and incubated with orbital rotation at $4{ }^{\circ} \mathrm{C}$ for 2 hours, followed by application of the magnetic field, removal of the supernatant, and two washes with 1,000 $\mu \mathrm{L}$ of IPP buffer. The bead-antibody-RNA mixture was then washed twice with 1,000 $\mu \mathrm{L}$ of low-salt IPP buffer (10 $\mathrm{mM}$ Tris- $\mathrm{HCl}, 50 \mathrm{mM} \mathrm{NaCl}, \mathrm{pH}$ 7.5; 0.1\% IGEPAL CA-630) and twice with 1,000 $\mu \mathrm{L}$ of highsalt IPP buffer (10 mM Tris-HCl, $500 \mathrm{mM} \mathrm{NaCl}, \mathrm{pH}$ 7.5; 0.1\% IGEPAL CA-630). A competitive elution buffer was then prepared containing $6.7 \mathrm{mM} \mathrm{N}^{6}$-methyladenosine 5 '- monophosphate sodium salt (item no. M2780, Sigma-Aldrich) in IPP buffer. Each immunoprecipitation (IP) sample was resuspended in $100 \mu \mathrm{L}$ of the $\mathrm{m}^{6} \mathrm{~A}$ competitive elution buffer with continuous shaking at $4^{\circ} \mathrm{C}$ for 1 hour. The magnetic field was applied, which allowed us to collect the supernatant (eluted $\mathrm{m}^{6} \mathrm{~A}$ RNA) into a new tube. The eluted RNA was further purified using the RNeasy MinElute Cleanup Kit (item no. 74204; Qiagen) following manufacturer's protocol. The $\mathrm{m}^{6} \mathrm{~A}$ enriched RNA was eluted by adding $14 \mu \mathrm{L}$ of ultrapure $\mathrm{H}_{2} \mathrm{O}$ directly to the center of the membrane and centrifuging for 1.5 mins at full speed. Samples were stored at $-80^{\circ} \mathrm{C}$ until initiation of the library preparation procedure.

\section{Library Prep and Sequencing}

Library preparation was performed on immunoprecipitated (IP) and total (input) RNA samples from sham $(n=3)$ and nano- $\mathrm{TiO}_{2}(\mathrm{n}=3)$ gestationally-exposed fetal offspring hearts 
using the $\mathrm{NEB}^{\circledR}$ Single Cell/Low Input RNA Library Prep kit for Illumina ${ }^{\circledR}$ (item no. E6420S, NEB) and Illumina ${ }^{\circledR}$ compatible NEB $^{\circledR}$ UDIs (item no. E6440S, NEB), which mitigate sample misassignment due to index-hopped reads. The Agilent 2100 BioAnalyzer (Agilent Technologies, Santa Clara, CA) was employed to determine the size distribution of RNA. Libraries were PCR amplified for 10 cycles and NEB UDIs were used for indexing by amplifying for 8 cycles. The RNA sample concentrations were quantified using a Qubit Fluorometer (Thermo Fisher Scientific). The samples were sequenced using the Illumina NextSeq 2000 (Illumina Inc., San Diego, CA) at Marshall University as paired end (PE) 2x50 bp reads.

Analysis of RNA-Seq Data

Adapters were trimmed from Fastq files through Flexbar v3.5 (36). The trimmed Fastq files were processed using paired-end alignment with HISAT2 v2.2.1 and the resulting BAM files were aligned to the mouse reference genome (Mus musculus, GRCm39, Ensemble version 104) for input and IP samples. Peaks showing significant enrichment in the IP samples vs. corresponding input samples for all submitted replicates were detected using RADAR v0.2.1 (56), with a fragment length of 297 base pairs and bin size of 25 base pairs. Peak reads coverage for transcripts were visualized with RADAR and the Integrative Genome Browser (IGV) browser (5, 12, 25, 35).

Input mRNA samples were further processed for full decoy-aware transcriptomic analyses using Salmon v1.5.2 (33) on the mouse reference genome (Mus musculus, GRCm39, Ensemble version 104) and processed in R using tximport v1.22.0 (41). Differential gene expression was performed through DESeq2 v1.34.0 (27). Visualization of data was accomplished through ggpolt2 v3.3.5 (48) and pheatmap v1.0.12. Pathway analysis was performed through PathFindR v1.6.3 (44).

\section{Mitochondrial Isolation}

Fetal pups were sacrificed at GD 15 and their hearts were excised through a midsagittal cut in the thoracic cavity. Mitochondria were isolated as previously described (32), with modifications

by our laboratory $(2,3,9)$. The two subpopulations of mitochondria (subsarcolemmal and 
interfibrillar) were combined at the end of the protocol to achieve a total mitochondrial population. Samples were resuspended in KME buffer $(100 \mathrm{mM} \mathrm{KCl,} \mathrm{50mM} \mathrm{MOPS} \mathrm{and} \mathrm{0.5mM} \mathrm{EGTA} \mathrm{pH}$ 7.4) with protease inhibitor cocktail (PIC).

\section{Sample Preparation for Mitochondrial Proteomics}

Label-free proteomics sample preparation was performed on fetal cardiac isolate mitochondria (sham, $\mathrm{n}=4$; nano- $\mathrm{TiO}_{2}, \mathrm{n}=4$ ) based off the "Plasma protein digestion" protocol described by Valentine et. al. with several modifications (45). $37 \mu \mathrm{L}$, containing about $24 \mu \mathrm{g}$ of protein, as measured by the Bradford assay, of isolated fetal cardiac mitochondria (in KME+PIC) was placed in a SpeedVac for 3.5 hours to dry out the sample. Samples were resuspended in 20 $\mu \mathrm{L}$ of Dissolution buffer (8 M Urea, $50 \mathrm{mM}$ Tris- $\mathrm{HCl}-\mathrm{pH} 8.2$ )) and their protein concentrations were determined using the NanoDrop ${ }^{\mathrm{TM}}$ One Microvolume UV-Vis Spectrophotometer (Thermo Fisher Scientific). $12 \mu \mathrm{g}$ of protein per sample was used for the rest of the sample preparation procedure. 1.2 $\mu \mathrm{L}$ of DTT reducing agent (100 mM DTT (item no. V3151, Promega) in $8 \mathrm{M}$ urea and $100 \mathrm{mM}$ ammonium bicarbonate - $\mathrm{pH}$ 8.2) was added to each sample followed by a 2-hour incubation at $37^{\circ} \mathrm{C}$, with gentle agitation. After reducing the disulfide bonds, samples were placed on ice. Protein alkylation was then achieved using $1.2 \mu \mathrm{L}$ of iodoacetamide (225 $\mathrm{mM}$ iodoacetamide (item no. I6125, Sigma-Aldrich) in $8 \mathrm{M}$ urea and $100 \mathrm{mM}$ ammonium bicarbonate $-\mathrm{pH}$ 8.2), which was made fresh.

The reaction was allowed to proceed in darkness, on ice for 2 hours. Next, $1.2 \mu \mathrm{L}$ of cysteine blocking reagent (100 mM L-cysteine (item no. 168149, Sigma-Aldrich) in $8 \mathrm{M}$ urea and $100 \mathrm{mM}$ ammonium bicarbonate $-\mathrm{pH}$ 8.2) was added to the mixture to remove any remaining reagent, followed by a 30-minute incubation at room temperature with gentle agitation. Following this reaction, enough Dilution solution (100 mM ammonium bicarbonate - $\mathrm{pH}$ 8.2) was added to each sample to bring the urea to a $2 \mathrm{M}$ concentration. Protein digestion was initiated by the addition of Trypsin solution (appropriate amount of trypsin in $2 \mathrm{M}$ urea, $100 \mathrm{mM}$ ammonium bicarbonate $-\mathrm{pH} 8.2$ ) to a final concentration of 50:1 protein:trypsin and incubated for 24 hours at $37^{\circ} \mathrm{C}$, with gentle agitation. Peptide cleanup was performed using Thermo Scientific Pierce ${ }^{\mathrm{TM}}$ C18 Spin

Columns (item no. 89873) per manufacturer's instructions and samples were eluted using acetonitrile. Samples were dried using a centrifugal concentrator (Labconco) and stored at $-20^{\circ} \mathrm{C}$ 
for LC-MS/MS analysis. Prior to LC-MS/MS analysis, each sample was resuspended in $100 \mu \mathrm{L}$ of formic acid buffer. Due to limited quantities of protein, the four samples in each group were pooled to produce sham $(\mathrm{n}=2)$ and nano- $\mathrm{TiO}_{2}(\mathrm{n}=2)$.

\section{LC Separation}

$20 \mu \mathrm{L}$ of digest solution was injected onto a reversed phase liquid chromatography (column (10 $\mathrm{cm} \times 2.1 \mathrm{~mm}$ ID, $5 \mu \mathrm{m}$ particle dia). A flow rate of $300 \mu \mathrm{L} / \mathrm{min}$ was employed for the reversedphase separation. Gradient elution was performed using two buffers. Buffer A consisted of HPLCgrade water with $1 \%$ formic acid and Buffer B was acetonitrile with $1 \%$ formic acid. During LC separations the solvent contribution from Buffer B was $0.1 \%, 0.1 \%, 25 \%, 80 \%, 90 \%, 90 \%$, and $0.1 \%$ at $0,2,27,37,42,52$, and 57 minutes, respectively.

\section{Mass Spectrometer}

Data were collected on an orbitrap mass spectrometer (Q-Exactive, Thermo Scientific). Experiments were conducted in positive ion mode and data dependent analysis was employed. Throughout the LC separation, a full MS scan was collected followed by 5 MS2 scans. Resolving power settings of 70,000 and 17,500 were utilized for the precursor and MS2 scans, respectively. The respective AGC settings were 1E6 and 1E5. A normalized collision energy of 30 was employed for MS2 analyses. Finally, a dynamic exclusion time of $10 \mathrm{~s}$ was employed for the separations.

\section{Data Processing}

Raw data files from the Q-Exactive mass spectrometer were imported into the Proteome Discoverer software suite (Thermo Scientific). The SEQUEST search engine was employed for peptide identification. The SwissProt (v2017-10-25) database for Mus musculus was employed for peptide ion identification. The search employed a minimum peptide length of 5 residues and allowed for 3 missed cleavages using Trypsin as the enzyme used for digestion. A precursor mass tolerance of $12 \mathrm{ppm}$ and a fragment ion mass tolerance of $0.03 \mathrm{Da}$ was employed. A static 
modification of 57.021 Da (C, carbamidomethyl)) was employed in the searches. A value of 0.1 was used for protein and peptide validation settings.

\section{Proteomic Analysis}

After the results were obtained, analysis was performed using an exponentially modified protein abundance index (emPAI) to estimate absolute protein amounts based on the number of sequenced peptides per protein (16). Briefly, only high quality peptides were selected based on the Score Sequest HT: A Sequest HT and mitochondrial proteins were identified using MitoCarta3.0 (34). The protein abundance index (PAI) was calculated with Equation 1 using the "total peptides" count per protein for $N_{\text {observed }}$ and the $N_{\text {observable }}$ was determined using ExPASy server (49). The emPAI was then calculated as shown in Equation 2. The emPAI values for the two samples per group was averaged for each respective group (sham and nano- $\mathrm{TiO}_{2}$ ) and compared.
Equation 1

$$
P A I=\frac{N_{\text {observed }}}{N_{\text {observable }}}
$$

Equation 2

$$
\text { emPAI }=10^{\mathrm{PAI}}-1
$$

\section{Data Code Availability}

All code used in the bioinformatic processing of samples is provided https://github.com/qahathaway/mRNA-m6A-Proteomics. Additionally, supplementary data files are included as XLSX files included in the manuscript, as well as provided on the GitHub account. Raw sequencing files have been uploaded to Gene Expression Omnibus (GEO) under accession:

\section{Statistics}

Statistical analyses were conducted in the R v4.1.1 environment. DESeq2 implements the Wald Test, using the Benjamini-Hochberg procedure. The FDR for this study was set to 0.05 for the transcriptomic analyses and 0.10 for $\mathrm{m}^{6} \mathrm{~A}$ peak calling. All measures of significance are 
reported as adjusted $P$-values $(P a d j)$. The RADAR package used for peak calling implements a Gamma-Poisson Distribution Model, which is a type of random effect model. 


\section{Results}

Study Design

The study design (Figure 4.1D) highlights the use of mRNA and $\mathrm{m}^{6} \mathrm{~A}$ sequencing on whole heart tissue and proteomics on isolated mitochondria. Maternal dams were euthanized at gestational day (GD) 15. Each dam was considered an $n=1$. No significant differences were observed between maternal and fetal pup weights, pup number, or pup heart weights (Table 4.1).

\section{Transcriptomics}

In performing the $\mathrm{m}^{6} \mathrm{~A}-\mathrm{RIP}-\mathrm{Seq}$, the input controls provided overall transcript abundance, which showcases the changes to mRNA seen following gestational nano- $\mathrm{TiO}_{2}$ exposure in fetal offspring. Sample distances were projected both using multidimensional scaling (MDS) (Figure 4.2A) as well as distribution with variance stabilizing transformation (VST) (Supplemental Figure 4.1A). Both techniques illustrate distinct stratification between the two groups. An illustration of the VST, as well as $\log _{2}$ normalized counts and regularized-logarithm (rlog) transformations, are provided (Supplemental Figure 4.1B). Differential expression analysis was performed and revealed a total of 3,648 genes that were significantly changed following exposure (Figure 4.2B). Examining the top 1,000 genes, sorted by Padj value, we see that two-thirds are upregulated, while 1/3 is downregulated between groups (Figure 4.2C). Additionally, Figure 2C shows that the sham and nano- $\mathrm{TiO}_{2}$ groups hierarchically cluster separately.

Our previous investigations have shown that mitochondrial dysfunction, specifically alterations to bioenergetics, have correlated with cardiovascular functional impairments, such as reduced ejection fraction, changes to left ventricular size, and alterations of strain of the heart (15, 23, 24). Electron transport chain proteins were significantly decreased for all mitochondrial complexes (Figure 4.2D). When examining all mitochondrial genes, decreased expression was seen across most categories of mitochondrial genes (Supplemental Figure 4.2). Interestingly, mitochondrial electron transport chain genes (Figure 4.2D) and mitochondrial ribosomal metabolism (Supplemental Figure 4.2) were the two pathways most significantly impacted following nano- $\mathrm{TiO}_{2}$ exposure. Also of interest, mitochondrial glutathione peroxidase 4 (Gpx4) 
(Supplemental Figure 4.1C) was significantly decreased, which we have previously shown to be an important mediator of ROS levels in gestationally and directly exposed mice $(23,30)$.

\section{Epitranscriptomics through $N^{6}$-methyladenosine $\left(m^{6} A\right)$}

Using both the input (unmodified mRNA) and immunoprecipitated RNA with our $\mathrm{m}^{6} \mathrm{~A}$ antibodies, we wanted to examine if specific sites were being methylated, or demethylated, following nano- $\mathrm{TiO}_{2}$ exposure (Figure 4.3). Principal Component Analysis (PCA) revealed distinct separation of the sham and nano- $\mathrm{TiO}_{2}$ groups (Figure 4.4A). Through differential peak analyses, we were further able to determine that the majority of $\mathrm{m}^{6} \mathrm{~A}$ sites were occurring in the $3^{\text {' }}$ untranslated regions (UTRs) (Figure 4.4B), which is supported by previous literature (29). We then plotted all the differentially methylated sites, revealing significant upregulating of $\mathrm{m}^{6} \mathrm{~A}$ methylation following exposure (Figure 4.4C).

Our next step was to assess if the mRNA identified in the input samples and the differentially methylated sites overlapped. Of the 3,648 differentially expressed genes and 921 unique genes containing significant $\mathrm{m}^{6} \mathrm{~A}$ modifications, 311 overlapped (Figure 4.4D). The mRNA expression was primarily increased in these genes, suggesting a predominately activating effect of $\mathrm{m}^{6} \mathrm{~A}$ on gene expression/transcript longevity.

$m R N A / m^{6} A$ Shared Features

We next wanted to understand how the 311 genes identified in both mRNA and $\mathrm{m}^{6} \mathrm{~A}$ were related to cellular and molecular pathways. Using gene ontology through KEGG, we hierarchically clustered the pathways and represented the top genes within the pathways for the 3,648 differentially expressed genes (Figure 4.5A) as well as the 311 shared genes (Figure 4.5B). The shared pathway revealed significant overlap with the pathway containing all genes in a few notable ways, including ubiquitin-mediated proteolysis, RNA degradation, spliceosome, and HIF-1 signaling. Interestingly, we see that in the all-gene ontology pathway (Figure 4.5A), oxidative phosphorylation is one of the top pathways, though not represented in the shared analysis (Figure 4.5B). 
The common pathways between the two groups are mainly larger regulator pathways, controlling the transcription, translation, and turnover of proteins. We include the detailed molecular pathway for RNA degradation in the all-gene (Supplemental Figure 4.3A) and shared (Supplemental Figure 4.3B) analyses that highlight genes, such as CCR4-NOT transcription complex subunit 1 (Cnot1) and 5'-3' exoribonuclease 2 (Xrn2), likely upregulated through $\mathrm{m}^{6} \mathrm{~A}$ modification. We also provide an illustration of the entire gene (Supplemental Figure 4.4A-B) and specific region (Supplemental Figure 4.4C-D) that are differentially methylated.

\section{Mitochondrial Proteomics}

Our last objective was to analyze the mitochondrial proteome to define if transcriptional alterations directly aligned with protein level expression. Our workflow included isolating mitochondrion from fetal heart tissue, isolating the protein, and processing the peptides through LC-MS/MS (Figure 4.6A). The protein abundance index (emPAI) was calculated only for mitochondrial proteins identified with a high confidence in both the sham and nano- $\mathrm{TiO}_{2}$ groups. Of the mitochondrial proteins, those belonging to ATP Synthase, including Atp5a1, Atp5b, Atp5c1, Atp5pb, and complex I, Nudufs1 and Nudufv2, showed the most consistent downregulation in the nano- $\mathrm{TiO}_{2}$ exposure group (Figure 4.6B). Additionally, peroxiredoxin 3 (Prdx3), a critical mitochondrial antioxidant, revealed the largest decrease between the sham and exposed groups (Figure 4.6B). 


\section{Discussion}

Fetal development is an intricate process that requires a significant number of regulatory processes. A baleful gestational environment can result in disease predisposition, in addition to immediate consequences of fetal development. $\mathrm{M}^{6} \mathrm{~A}$ methylation can transiently alter cellular function and may play a significant role in the response to toxicants during gestation. The results of our study emphasize the impact of $\mathrm{m}^{6} \mathrm{~A}$ methylation on regulatory pathways within the heart, largely involved with the transcription, translation, and longevity of proteins within the cell. Along with changes to oxidative phosphorylation, acute changes to the $\mathrm{m}^{6} \mathrm{~A}$ methylome may predispose offspring to future adverse outcomes.

Exposure to environmental toxicants is associated with developmental reprogramming that alters normal physiological responses and thereby leads to disease susceptibility including metabolic diseases $(43,46)$. Specifically, prenatal maternal exposure to benzene, diesel exhaust, and fine particulate matter lead to glucose intolerance and elevated insulin resistance (20), weight gain (6), and metabolic syndrome (50), respectively, in adulthood. As cardiovascular disease remains the leading cause of death worldwide, researchers have begun investigating whether $\mathrm{m}^{6} \mathrm{~A}$ mRNA modifications can serve as diagnostic or therapeutic targets $(19,42)$. Transcriptome-wide assessments of cardiac samples from human and murine models of dilated cardiomyopathy were assessed by Kmietczyk et. al (17). They found that hypermethylation was prominent in failing human hearts and confirmed the dynamic and regulatory capabilities of $\mathrm{m}^{6} \mathrm{~A}$ in this diseased state.

Furthermore, research has also shown that $\mathrm{m}^{6} \mathrm{~A}$ is a novel stress-response mechanism in the heart that attempts to maintain normal cardiac function (11). Specifically, Dorn and colleagues implemented genetic tools to modulate $\mathrm{m}^{6} \mathrm{~A}$ levels via METTL3 levels, thereby generating cardiac-restricted gain- and loss-of-function mouse models that allowed them to identify $\mathrm{m}^{6} \mathrm{~A}$ methylation by METTL3 as a dynamic response that is enhanced with cardiac hypertrophy. Contrarily, they determined that $\mathrm{m}^{6} \mathrm{~A}$ hypomethylation drives eccentric cardiomyocyte remodeling and dysfunction (11). Another group examined the $\mathrm{m}^{6} \mathrm{~A}$ landscape in heart hypertrophy and heart failure as well (4). In addition to confirming that cardiac hypertrophy and failure are accompanying by $\mathrm{m}^{6} \mathrm{~A}$ methylation changes, the authors found that hypomethylated transcripts played a role in mitochondrial function and metabolic processes, while hypermethylated transcripts were also associated with metabolic processes as well as response to growth factor and muscle stretch (4). 
Similarly, in patients with heart failure with preserved ejection fraction, the $\mathrm{m}^{6} \mathrm{~A}$ landscape and its regulators were altered such that the several methyltransferase complex constituents, including METTL3, were up-regulated, in addition to demethylase FTO, and reader YTHDF2 (54). Despite an increased interest in the role of $\mathrm{m}^{6} \mathrm{~A}$ methylation in cardiovascular disease, studies have mainly focused on heart failure specifically and have yet to elucidate in depth the contribution from ALKBH5 (22).

Although recent studies have determined that $\mathrm{m}^{6} \mathrm{~A}$ is easily altered by stress and other external stimuli (11), its status particularly in the heart, following exposure to environmental toxicants remains to be elucidated. Following exposure to fine particulate matter (PM2.5), there was a global decrease in $\mathrm{m}^{6} \mathrm{~A}$ methylation, concomitant with elevated expression of methyltransferase complex components (METTL3 and WTAP), demethylases (FTO and ALKBH5), and the reader protein HNRNPC (7). However, this study involved a short-term exposure on A549 cells, which still leaves the question of how different tissue types respond to environmental exposures and how long-term exposure may alter this response. Recent work from our laboratory has demonstrated that maternal inhalation exposure to ENM during a critical point in fetal development results in cardiac dysfunction, mitochondrial bioenergetic disruption, and an increase in global $\mathrm{m}^{6} \mathrm{~A}$ content (23).

Notably, $\mathrm{m}^{6} \mathrm{~A}$ levels were ameliorated in the presence of enhanced antioxidant capacity that was mitochondrially targeted in the pregnant mother. It is has become clear that a specific and balanced $\mathrm{m}^{6} \mathrm{~A}$ RNA distribution is crucial to maintain homeostasis and evade disease, though the precise mechanisms underpinning the process remain unknown. Zhang et. al. similarly investigated the effects of carbon black nanoparticle exposure during pregnancy on $\mathrm{m}^{6} \mathrm{~A}$ status in offspring, but specifically in the case of neurobehavior deficits (55). The authors determined that the exposure decreased $\mathrm{m}^{6} \mathrm{~A}$ modification in the cortex, along with neurobehavioral deficits and cortex injuries in the offspring. These studies substantiate the idea that $\mathrm{m}^{6} \mathrm{~A}$ methylation status is likely disease and tissue specific.

Our current study forwards the concept that differential $\mathrm{m}^{6} \mathrm{~A}$ methylation of genes can have untoward effects of cardiac function. While our model uses transcriptomics, epitranscriptomics, and proteomics to provide a multi-omics approach toward mechanistically detailing fetal cardiac changes, the approach was limited by the amount of tissue available. In our proteomics approach, 
we needed to pool our groups to further condense the protein for adequate analyses, losing the ability to make true statistical inferences on the data. Additionally, the proteins found to be decreased in both the ATP Synthase complex and complex I do not consist of the same transcripts shown to be decreased in the transcriptomic analyses. Though, there is evidence to support that $\mathrm{m}^{6} \mathrm{~A}$ methylation is acting at an indirect, rather than direct, level to modify transcript and protein expression.

The analyses indicate that $\mathrm{m}^{6} \mathrm{~A}$ methylation is predominately occurring in pathways altering transcription of mRNA (spliceosome pathway), stability of transcripts (RNA degradation pathway), and protein longevity (ubiquitin-mediated proteolysis pathway). While the same mRNA and protein changes may not completely align, this could be explained through these different indirect mechanisms decreasing abundance. Further, of the differentially expressed mRNA genes, Mettl14, a key regulatory writer of $\mathrm{m}^{6} \mathrm{~A}$ methylation marks, is shown to be increased and supports the findings of significantly increased $\mathrm{m}^{6} \mathrm{~A}$ methylation overall in the nano- $\mathrm{TiO}_{2}$ group.

We provide for the first time a comprehensive, multi-omics approach that includes epitranscriptomics in the investigation of fetal progeny following toxicant exposure. This framework helped to identify how $\mathrm{m}^{6} \mathrm{~A}$ methylation can be globally increased in the heart following exposure, and how the pathways, such as RNA degradation and ubiquitin-mediated proteolysis, play a role in regulating mitochondrial bioenergetics. These data substantiate the need to further investigate RNA modifications as a mechanism for adaptive fetal responses. Future work should seek to identify the persistence of these marks, and whether other RNA modifications also contribute to modifying the fetal transcriptome and proteome. 


\section{Acknowledgments}

We would like to acknowledge the WVU Genomics Core Facility, Morgantown WV for support provided to help make this publication possible and CTSI Grant \#U54 GM104942 which in turn provides financial support to the Core Facility. We would like to thank Sherri A. Friend and the National Institute for Occupational Safety and Health, Morgantown, WV, USA for contributing to the physicochemical characterization of the nano- $\mathrm{TiO}_{2}$ aerosolized particles.

\section{Funding}

This work was supported by The National Heart, Lung, and Blood Institute (NHLBI) under Grant [R01 HL-128485] (JMH), the National Institute of Environmental Health Sciences (NIEHS) under Grant [R01 ES-015022] (TRN), American Heart Association under Grant [AHA20PRE35080170] (AK), American Heart Association under Grant [AHA-17PRE33660333] (QAH), and the Community Foundation for the Ohio Valley Whipkey Trust (JMH)

\section{Conflict of Interest}

Quincy A. Hathaway is the Chief Science Officer for Aspirations LLC. No other potential conflicts of interest are reported by the author(s).

\section{Author Contributions}

AK, QAH, DT, SJV, and JMH conceived and planned the experiments. AK, QAH, DT, AJD, ADT, SR, and DS carried out the experiments. AK, QAH, AJD, ADT, and SR contributed to sample preparation. DS and SJV processed samples for proteomic analyses. AK, QAH, DT, and JMH contributed to the interpretation of the results. AK took the lead in writing the manuscript. All authors provided critical feedback and helped shape the research, analysis, and manuscript.

\section{Contribution to the Field}


The current study helps to expand our understanding of how environmental exposures impact our health. Importantly, this study uses a gestational model where we want to understand how exposure to toxicants during pregnancy can impact the developing fetus. We know that changes to the fetus can occur at the level of DNA, through temporary modifications known as "epigenetics". What is unknown, is whether other changes, outside of DNA modifications, can also cause the growing fetus to have adverse outcomes. One of the major adverse outcomes of environmental exposure is cardiovascular complications. We have previously shown that these cardiovascular complications can be linked to changes at the level of mitochondria, with decreased ability to produce energy. "Epitranscriptomics" is a term used to described temporary changes at the level of mRNA. Our goal in the current study was to fully detail the impact of these RNA modifications on shaping fetal health following exposure. Our novel approach inspected both mRNA abundance as well as the amount of mRNA modifications present. We then coupled this information with protein level changes in the mitochondrion. Our result suggests that RNA modifications can influence expression of RNA and protein of mitochondrial genes. 


\section{References}

1. Barouki R, Melen E, Herceg Z, Beckers J, Chen J, Karagas M, Puga A, Xia Y, Chadwick L, Yan W, Audouze K, Slama R, Heindel J, Grandjean P, Kawamoto T, and Nohara K. Epigenetics as a mechanism linking developmental exposures to long-term toxicity. Environ Int 114: 77-86, 2018.

2. Baseler WA, Dabkowski ER, Jagannathan R, Thapa D, Nichols CE, Shepherd DL, Croston TL, Powell M, Razunguzwa TT, Lewis SE, Schnell DM, and Hollander JM. Reversal of mitochondrial proteomic loss in Type 1 diabetic heart with overexpression of phospholipid hydroperoxide glutathione peroxidase. Am J Physiol Regul Integr Comp Physiol 304: R553-565, 2013.

3. Baseler WA, Dabkowski ER, Williamson CL, Croston TL, Thapa D, Powell MJ, Razunguzwa TT, and Hollander JM. Proteomic alterations of distinct mitochondrial subpopulations in the type 1 diabetic heart: contribution of protein import dysfunction. Am $J$ Physiol Regul Integr Comp Physiol 300: R186-200, 2011.

4. Berulava T, Buchholz E, Elerdashvili V, Pena T, Islam MR, Lbik D, Mohamed BA, Renner A, von Lewinski D, Sacherer M, Bohnsack KE, Bohnsack MT, Jain G, Capece V, Cleve N, Burkhardt S, Hasenfuss G, Fischer A, and Toischer K. Changes in m6A RNA methylation contribute to heart failure progression by modulating translation. Eur J Heart Fail 22: 54-66, 2020.

5. Berulava T, Buchholz E, Elerdashvili V, Pena T, Islam MR, Lbik D, Mohamed BA, Renner A, von Lewinski D, Sacherer M, Bohnsack KE, Bohnsack MT, Jain G, Capece V, Cleve N, Burkhardt S, Hasenfuss G, Fischer A, and Toischer K. Changes in m6A RNA methylation contribute to heart failure progression by modulating translation. Eur $J$ Heart Fail 2019.

6. Bolton JL, Smith SH, Huff NC, Gilmour MI, Foster WM, Auten RL, and Bilbo SD. Prenatal air pollution exposure induces neuroinflammation and predisposes offspring to weight gain in adulthood in a sex-specific manner. FASEB J 26: 4743-4754, 2012.

7. Cayir A, Barrow TM, Guo L, and Byun HM. Exposure to environmental toxicants reduces global N6-methyladenosine RNA methylation and alters expression of RNA methylation modulator genes. Environ Res 175: 228-234, 2019.

8. Cui YH, Yang S, Wei J, Shea CR, Zhong W, Wang F, Shah P, Kibriya MG, Cui X, Ahsan H, He C, and He YY. Autophagy of the m(6)A mRNA demethylase FTO is impaired by low-level arsenic exposure to promote tumorigenesis. Nat Commun 12: 2183, 2021.

9. Dabkowski ER, Baseler WA, Williamson CL, Powell M, Razunguzwa TT, Frisbee JC, and Hollander JM. Mitochondrial dysfunction in the type 2 diabetic heart is associated with alterations in spatially distinct mitochondrial proteomes. Am J Physiol Heart Circ Physiol 299: H529-540, 2010.

10. Dominissini D, Moshitch-Moshkovitz S, Schwartz S, Salmon-Divon M, Ungar L, Osenberg S, Cesarkas K, Jacob-Hirsch J, Amariglio N, Kupiec M, Sorek R, and Rechavi G. Topology of the human and mouse m6A RNA methylomes revealed by m6A-seq. Nature 485: 201-206, 2012.

11. Dorn LE, Lasman L, Chen J, Xu X, Hund TJ, Medvedovic M, Hanna JH, van Berlo JH, and Accornero F. The N(6)-Methyladenosine mRNA Methylase METTL3 Controls Cardiac Homeostasis and Hypertrophy. Circulation 139: 533-545, 2019.

12. Engel M, Eggert C, Kaplick PM, Eder M, Roh S, Tietze L, Namendorf C, Arloth J, Weber P, Rex-Haffner M, Geula S, Jakovcevski M, Hanna JH, Leshkowitz D, Uhr M, 
Wotjak CT, Schmidt MV, Deussing JM, Binder EB, and Chen A. The Role of m(6)A/m-RNA Methylation in Stress Response Regulation. Neuron 99: 389-403 e389, 2018.

13. Fu Y, Dominissini D, Rechavi G, and He C. Gene expression regulation mediated through reversible m(6)A RNA methylation. Nat Rev Genet 15: 293-306, 2014.

14. Hathaway QA, Durr AJ, Shepherd DL, Pinti MV, Brandebura AN, Nichols CE, Kunovac A, Goldsmith WT, Friend SA, Abukabda AB, Fink GK, Nurkiewicz TR, and Hollander JM. miRNA-378a as a key regulator of cardiovascular health following engineered nanomaterial inhalation exposure. Nanotoxicology 13: 644-663, 2019.

15. Hathaway QA, Nichols CE, Shepherd DL, Stapleton PA, McLaughlin SL, Stricker JC, Rellick SL, Pinti MV, Abukabda AB, McBride CR, Yi J, Stine SM, Nurkiewicz TR, and Hollander JM. Maternal-engineered nanomaterial exposure disrupts progeny cardiac function and bioenergetics. Am J Physiol Heart Circ Physiol 312: H446-H458, 2017.

16. Ishihama Y, Oda Y, Tabata T, Sato T, Nagasu T, Rappsilber J, and Mann M. Exponentially modified protein abundance index (emPAI) for estimation of absolute protein amount in proteomics by the number of sequenced peptides per protein. Mol Cell Proteomics 4: 1265-1272, 2005.

17. Kmietczyk V, Riechert E, Kalinski L, Boileau E, Malovrh E, Malone B, Gorska A, Hofmann C, Varma E, Jurgensen L, Kamuf-Schenk V, Altmuller J, Tappu R, Busch M, Most P, Katus HA, Dieterich C, and Volkers M. m(6)A-mRNA methylation regulates cardiac gene expression and cellular growth. Life Sci Alliance 2: 2019.

18. Knuckles TL, Yi J, Frazer DG, Leonard HD, Chen BT, Castranova V, and Nurkiewicz TR. Nanoparticle inhalation alters systemic arteriolar vasoreactivity through sympathetic and cyclooxygenase-mediated pathways. Nanotoxicology 6: 724-735, 2012.

19. Komal S, Zhang LR, and Han SN. Potential regulatory role of epigenetic RNA methylation in cardiovascular diseases. Biomed Pharmacother 137: 111376, 2021.

20. Koshko L, Debarba LK, Sacla M, de Lima JBM, Didyuk O, Fakhoury P, and Sadagurski M. In Utero Maternal Benzene Exposure Predisposes to the Metabolic Imbalance in the Offspring. Toxicol Sci 180: 252-261, 2021.

21. Kumar S, and Mohapatra T. Deciphering Epitranscriptome: Modification of mRNA Bases Provides a New Perspective for Post-transcriptional Regulation of Gene Expression. Front Cell Dev Biol 9: 628415, 2021.

22. Kumari R, Ranjan P, Suleiman ZG, Goswami SK, Li J, Prasad R, and Verma SK. mRNA modifications in cardiovascular biology and disease: with a focus on m6A modification. Cardiovasc Res 2021.

23. Kunovac A, Hathaway QA, Pinti MV, Durr AJ, Taylor AD, Goldsmith WT, Garner KL, Nurkiewicz TR, and Hollander JM. Enhanced antioxidant capacity prevents epitranscriptomic and cardiac alterations in adult offspring gestationally-exposed to ENM. Nanotoxicology 1-20, 2021.

24. Kunovac A, Hathaway QA, Pinti MV, Goldsmith WT, Durr AJ, Fink GK, Nurkiewicz TR, and Hollander JM. ROS promote epigenetic remodeling and cardiac dysfunction in offspring following maternal engineered nanomaterial (ENM) exposure. Part Fibre Toxicol 16: 24, 2019.

25. Liu J, Li K, Cai J, Zhang M, Zhang X, Xiong X, Meng H, Xu X, Huang Z, Peng J, Fan J, and Yi C. Landscape and Regulation of m(6)A and m(6)Am Methylome across Human and Mouse Tissues. Mol Cell 2019. 
26. Liu J, Li K, Cai J, Zhang M, Zhang X, Xiong X, Meng H, Xu X, Huang Z, Peng J, Fan J, and Yi C. Landscape and Regulation of m(6)A and m(6)Am Methylome across Human and Mouse Tissues. Mol Cell 77: 426-440 e426, 2020.

27. Love MI, Huber W, and Anders S. Moderated estimation of fold change and dispersion for RNA-seq data with DESeq2. Genome Biol 15: 550, 2014.

28. Mauer J, Luo X, Blanjoie A, Jiao X, Grozhik AV, Patil DP, Linder B, Pickering BF, Vasseur JJ, Chen Q, Gross SS, Elemento O, Debart F, Kiledjian M, and Jaffrey SR. Reversible methylation of m(6)Am in the 5' cap controls mRNA stability. Nature 541: 371-375, 2017.

29. Meyer KD, Saletore Y, Zumbo P, Elemento O, Mason CE, and Jaffrey SR. Comprehensive analysis of mRNA methylation reveals enrichment in 3' UTRs and near stop codons. Cell 149: 1635-1646, 2012.

30. Nichols CE, Shepherd DL, Hathaway QA, Durr AJ, Thapa D, Abukabda A, Yi J, Nurkiewicz TR, and Hollander JM. Reactive oxygen species damage drives cardiac and mitochondrial dysfunction following acute nano-titanium dioxide inhalation exposure. Nanotoxicology 12: 32-48, 2018.

31. Nurkiewicz TR, Porter DW, Hubbs AF, Cumpston JL, Chen BT, Frazer DG, and Castranova V. Nanoparticle inhalation augments particle-dependent systemic microvascular dysfunction. Part Fibre Toxicol 5: 1, 2008.

32. Palmer JW, Tandler B, and Hoppel CL. Biochemical properties of subsarcolemmal and interfibrillar mitochondria isolated from rat cardiac muscle. J Biol Chem 252: 8731-8739, 1977.

33. Patro R, Duggal G, Love MI, Irizarry RA, and Kingsford C. Salmon provides fast and bias-aware quantification of transcript expression. Nat Methods 14: 417-419, 2017.

34. Rath S, Sharma R, Gupta R, Ast T, Chan C, Durham TJ, Goodman RP, Grabarek Z, Haas ME, Hung WHW, Joshi PR, Jourdain AA, Kim SH, Kotrys AV, Lam SS, McCoy JG, Meisel JD, Miranda M, Panda A, Patgiri A, Rogers R, Sadre S, Shah H, Skinner OS, To TL, Walker MA, Wang H, Ward PS, Wengrod J, Yuan CC, Calvo SE, and Mootha VK. MitoCarta3.0: an updated mitochondrial proteome now with sub-organelle localization and pathway annotations. Nucleic Acids Res 49: D1541-D1547, 2021.

35. Robinson JT, Thorvaldsdottir H, Winckler W, Guttman M, Lander ES, Getz G, and Mesirov JP. Integrative genomics viewer. Nat Biotechnol 29: 24-26, 2011.

36. Roehr JT, Dieterich C, and Reinert K. Flexbar 3.0 - SIMD and multicore parallelization. Bioinformatics 33: 2941-2942, 2017.

37. Ruiz-Hernandez A, Kuo CC, Rentero-Garrido P, Tang WY, Redon J, Ordovas JM, Navas-Acien A, and Tellez-Plaza M. Environmental chemicals and DNA methylation in adults: a systematic review of the epidemiologic evidence. Clin Epigenetics 7: 55, 2015.

38. Sager TM, Kommineni C, and Castranova V. Pulmonary response to intratracheal instillation of ultrafine versus fine titanium dioxide: role of particle surface area. Part Fibre Toxicol 5: 17, 2008.

39. Seo MY, Kim SH, and Park MJ. Air pollution and childhood obesity. Clin Exp Pediatr 63: 382-388, 2020.

40. Shi H, Wang X, Lu Z, Zhao BS, Ma H, Hsu PJ, Liu C, and He C. YTHDF3 facilitates translation and decay of N(6)-methyladenosine-modified RNA. Cell Res 27: 315-328, 2017.

41. Soneson C, Love MI, and Robinson MD. Differential analyses for RNA-seq: transcriptlevel estimates improve gene-level inferences. F1000Res 4: 1521, 2015. 
42. Sweaad WK, Stefanizzi FM, Chamorro-Jorganes A, Devaux Y, Emanueli C, and CA EU-CCA. Relevance of N6-methyladenosine regulators for transcriptome: Implications for development and the cardiovascular system. J Mol Cell Cardiol 160: 56-70, 2021.

43. Trevino LS, Dong J, Kaushal A, Katz TA, Jangid RK, Robertson MJ, Grimm SL, Ambati CSR, Putluri V, Cox AR, Kim KH, May TD, Gallo MR, Moore DD, Hartig SM, Foulds CE, Putluri N, Coarfa C, and Walker CL. Epigenome environment interactions accelerate epigenomic aging and unlock metabolically restricted epigenetic reprogramming in adulthood. Nat Commun 11: 2316, 2020.

44. Ulgen E, Ozisik O, and Sezerman OU. pathfindR: An R Package for Comprehensive Identification of Enriched Pathways in Omics Data Through Active Subnetworks. Front Genet 10: $858,2019$.

45. Valentine SJ, Kurulugama RT, Bohrer BC, Merenbloom SI, Sowell RA, Mechref Y, and Clemmer DE. Developing IMS-IMS-MS for rapid characterization of abundant proteins in human plasma. International Journal of Mass Spectrometry 283: 149-160, 2009.

46. Walker CL. Epigenomic reprogramming of the developing reproductive tract and disease susceptibility in adulthood. Birth Defects Res A Clin Mol Teratol 91: 666-671, 2011.

47. Whitten WK. Modification of the oestrous cycle of the mouse by external stimuli associated with the male. J Endocrinol 13: 399-404, 1956.

48. Wickham H. ggplot2: Elegant Graphics for Data Analysis. New York: Springer-Verlag New York, 2016.

49. Wilkins MR, Gasteiger E, Bairoch A, Sanchez JC, Williams KL, Appel RD, and Hochstrasser DF. Protein identification and analysis tools in the ExPASy server. Methods Mol Biol 112: 531-552, 1999.

50. Wu G, Brown J, Zamora ML, Miller A, Satterfield MC, Meininger CJ, Steinhauser CB, Johnson GA, Burghardt RC, Bazer FW, Li Y, Johnson NM, Molina MJ, and Zhang R. Adverse organogenesis and predisposed long-term metabolic syndrome from prenatal exposure to fine particulate matter. Proc Natl Acad Sci U S A 116: 11590-11595, 2019.

51. Yang C, Hu Y, Zhou B, Bao Y, Li Z, Gong C, Yang H, Wang S, and Xiao Y. The role of m(6)A modification in physiology and disease. Cell Death Dis 11: 960, 2020.

52. Zaccara S, Ries RJ, and Jaffrey SR. Reading, writing and erasing mRNA methylation. Nat Rev Mol Cell Biol 20: 608-624, 2019.

53. Zeng Y, Wang S, Gao S, Soares F, Ahmed M, Guo H, Wang M, Hua JT, Guan J, Moran MF, Tsao MS, and He HH. Refined RIP-seq protocol for epitranscriptome analysis with low input materials. PLoS Biol 16: e2006092, 2018.

54. Zhang B, Xu Y, Cui X, Jiang H, Luo W, Weng X, Wang Y, Zhao Y, Sun A, and Ge J. Alteration of m6A RNA Methylation in Heart Failure With Preserved Ejection Fraction. Front Cardiovasc Med 8: 647806, 2021.

55. Zhang S, Meng P, Cheng S, Jiang X, Zhang J, Qin X, Tang Q, Bai L, Zou Z, and Chen C. Pregnancy exposure to carbon black nanoparticles induced neurobehavioral deficits that are associated with altered m(6)A modification in offspring. Neurotoxicology 81: 40-50, 2020.

56. Zhang Z, Zhan Q, Eckert M, Zhu A, Chryplewicz A, De Jesus DF, Ren D, Kulkarni RN, Lengyel E, He C, and Chen M. RADAR: differential analysis of MeRIP-seq data with a random effect model. Genome Biol 20: 294, 2019. 
Table 4.1: Maternal and Fetal Pup Characteristics

\begin{tabular}{|c|c|c|c|c|}
\hline Sample & $\begin{array}{c}\text { Maternal } \\
\text { Weight (g) }\end{array}$ & $\begin{array}{l}\text { Number of Pups } \\
\text { in Litter }\end{array}$ & $\begin{array}{l}\text { Average Pup } \\
\text { Weight (g) }\end{array}$ & $\begin{array}{c}\text { Average Pup Heart } \\
\text { Weight (g) }\end{array}$ \\
\hline \multicolumn{5}{|c|}{ Sham Exposure } \\
\hline 1 & 31.9 & 8 & 0.61 & 0.0038 \\
\hline 2 & 34.1 & 10 & 0.56 & 0.0030 \\
\hline 3 & 34.1 & 10 & 0.56 & 0.0026 \\
\hline 4 & 33.8 & 10 & 0.60 & 0.0036 \\
\hline 5 & 32.0 & 9 & 0.39 & 0.0023 \\
\hline Average & $33.2 \pm 0.51$ & $9.4 \pm 0.40$ & $0.54 \pm 0.04$ & $0.0031 \pm 0.0003$ \\
\hline \multicolumn{5}{|c|}{ Nano- $\mathrm{TiO}_{2}$ Exposure } \\
\hline 1 & 34.7 & 10 & 0.61 & 0.0038 \\
\hline 2 & 36.0 & 10 & 0.66 & 0.0043 \\
\hline 3 & 35.6 & 9 & 0.66 & 0.0039 \\
\hline 4 & 31.7 & 10 & 0.34 & 0.0026 \\
\hline 5 & 35.7 & 9 & 0.61 & 0.0037 \\
\hline Average & $33.7 \pm 0.79$ & $9.6 \pm 0.24$ & $0.58 \pm 0.06$ & $0.0037 \pm 0.0003$ \\
\hline
\end{tabular}


Table 4.1: Maternal and fetal pup characteristics. Dams from sham $(n=5)$ and nano- $\mathrm{TiO}_{2}(\mathrm{n}=5)$ inhalation exposure were assessed. All weights given are wet weights. 


\section{Graphical Abstract:}

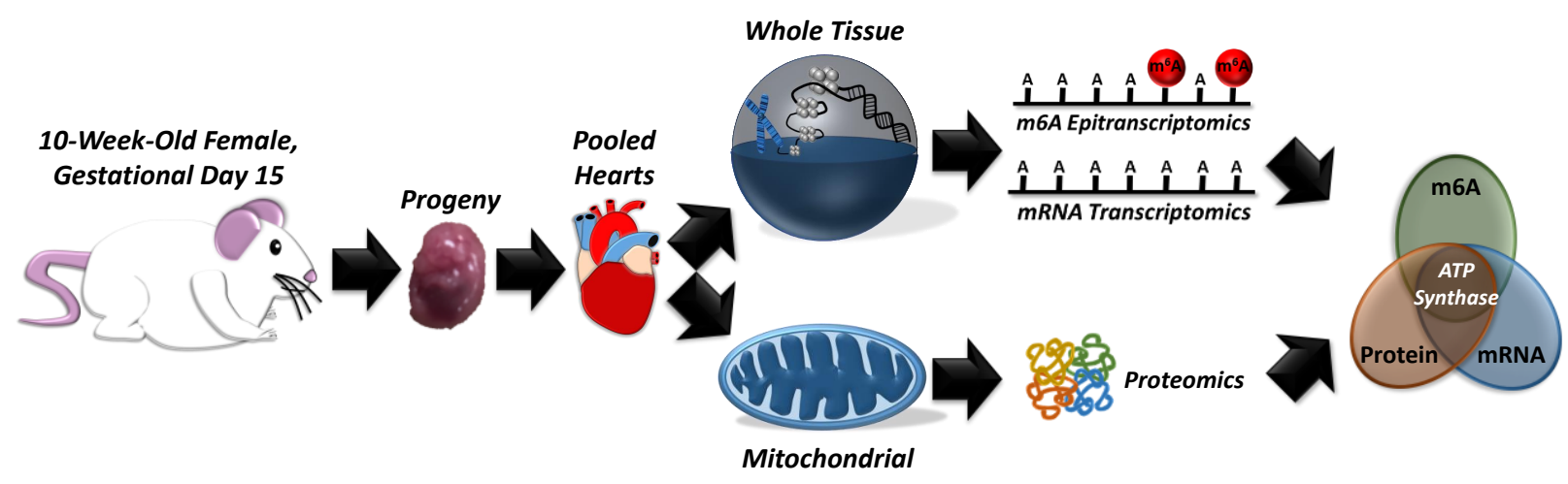


Figure 4.1:
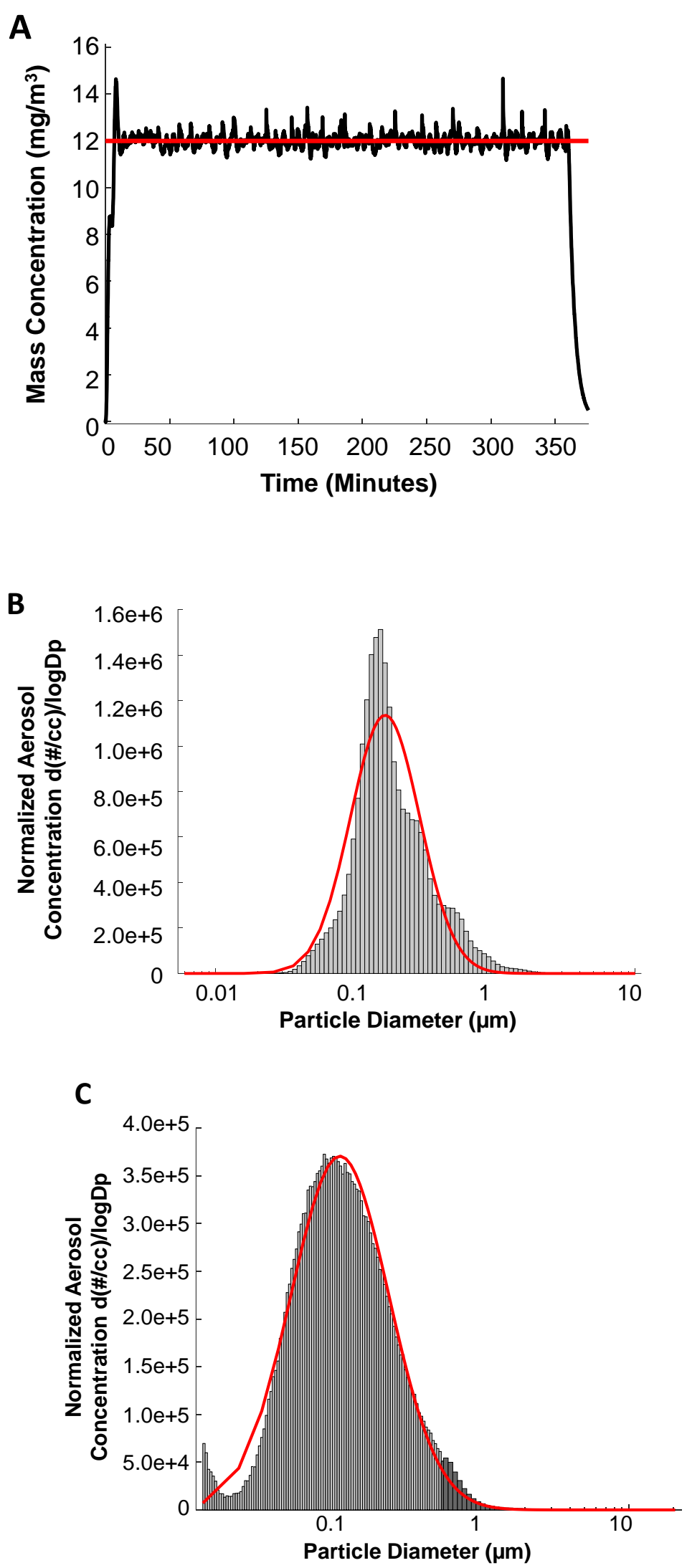
Figure 4.1:

D

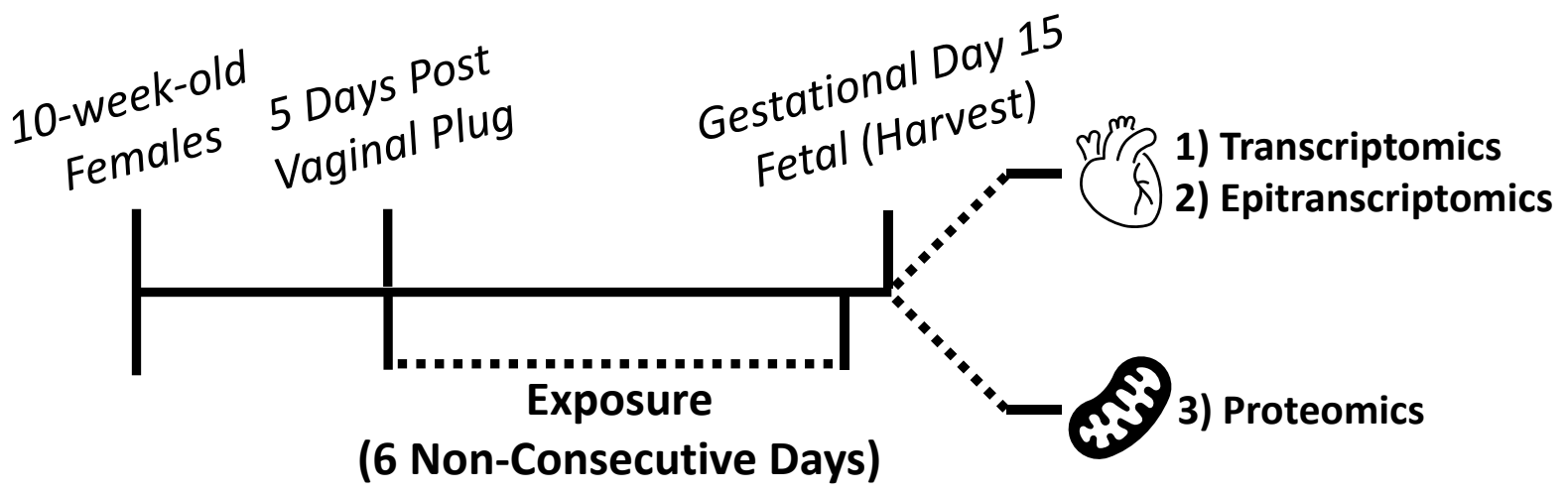


Figure 4.1: Characteristics of maternal whole-body inhalation exposure. (A) A target aerosol mass concentration of $12 \mathrm{mg} / \mathrm{m}^{3}$ of engineered nano- $\mathrm{TiO}_{2}$ was implemented for a period of 360 minutes per day for 6 non-consecutive days, over an 8-day period. These concentrations were verified by gravimetric measurements during each exposure, which resulted in an average mass concentration of $12 \mathrm{mg} / \mathrm{m}^{3}$ during the 360-minute period. (B) High-resolution electrical lowpressure impactor (ELPI+) indicated a geometric count median diameter (CMD) of $172 \mathrm{~nm}$ with a geometric standard deviation (GSD) of 1.96. (C) Scanning particle mobility sizer (SMPS) indicated a CMD of $112 \mathrm{~nm}$ with a GSD of 2.14. (D) Exposure model paradigm including the allocation of tissue on gestational day (GD) 15 . 
Figure 4:2:
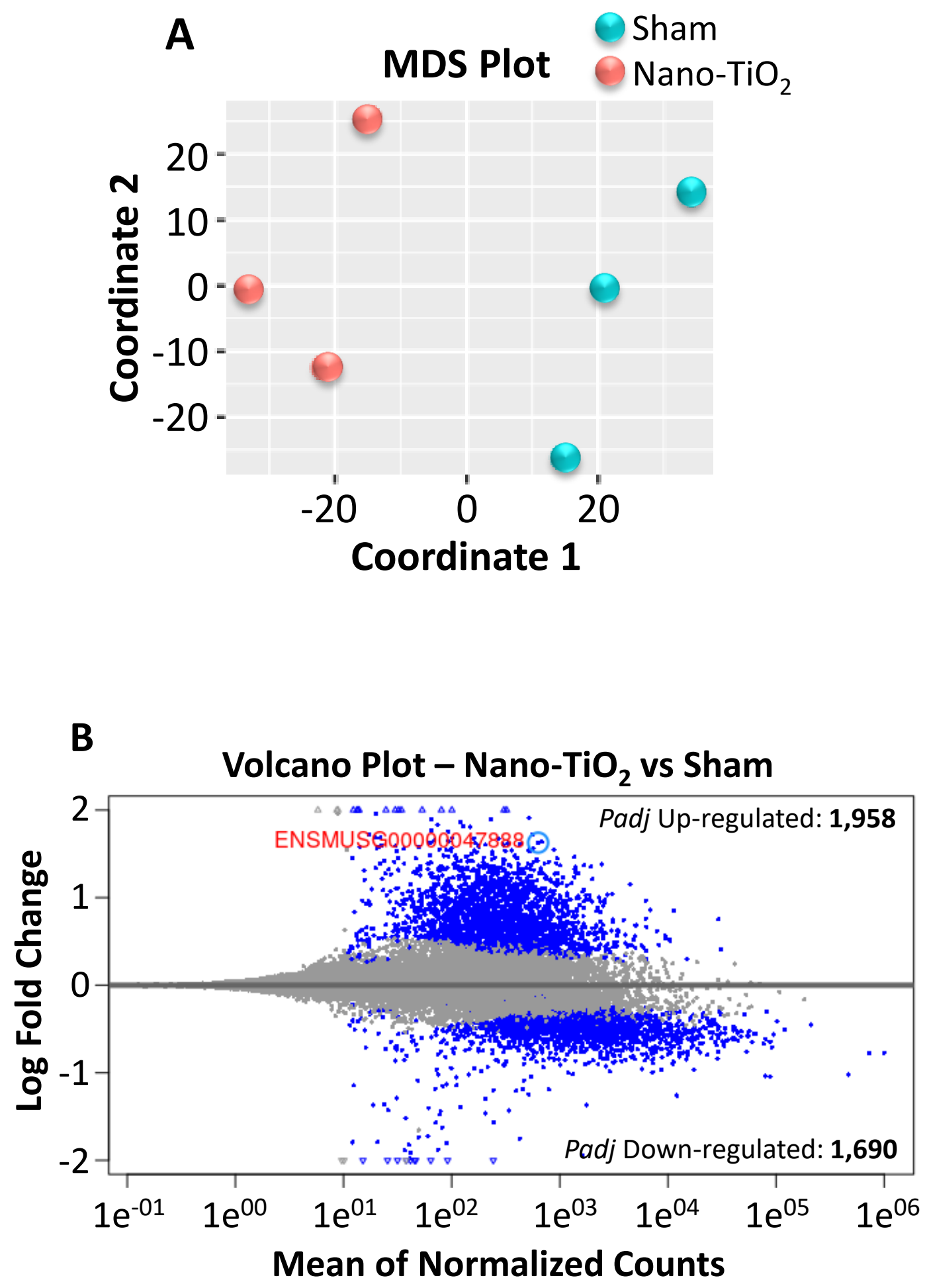
Figure 4.2:

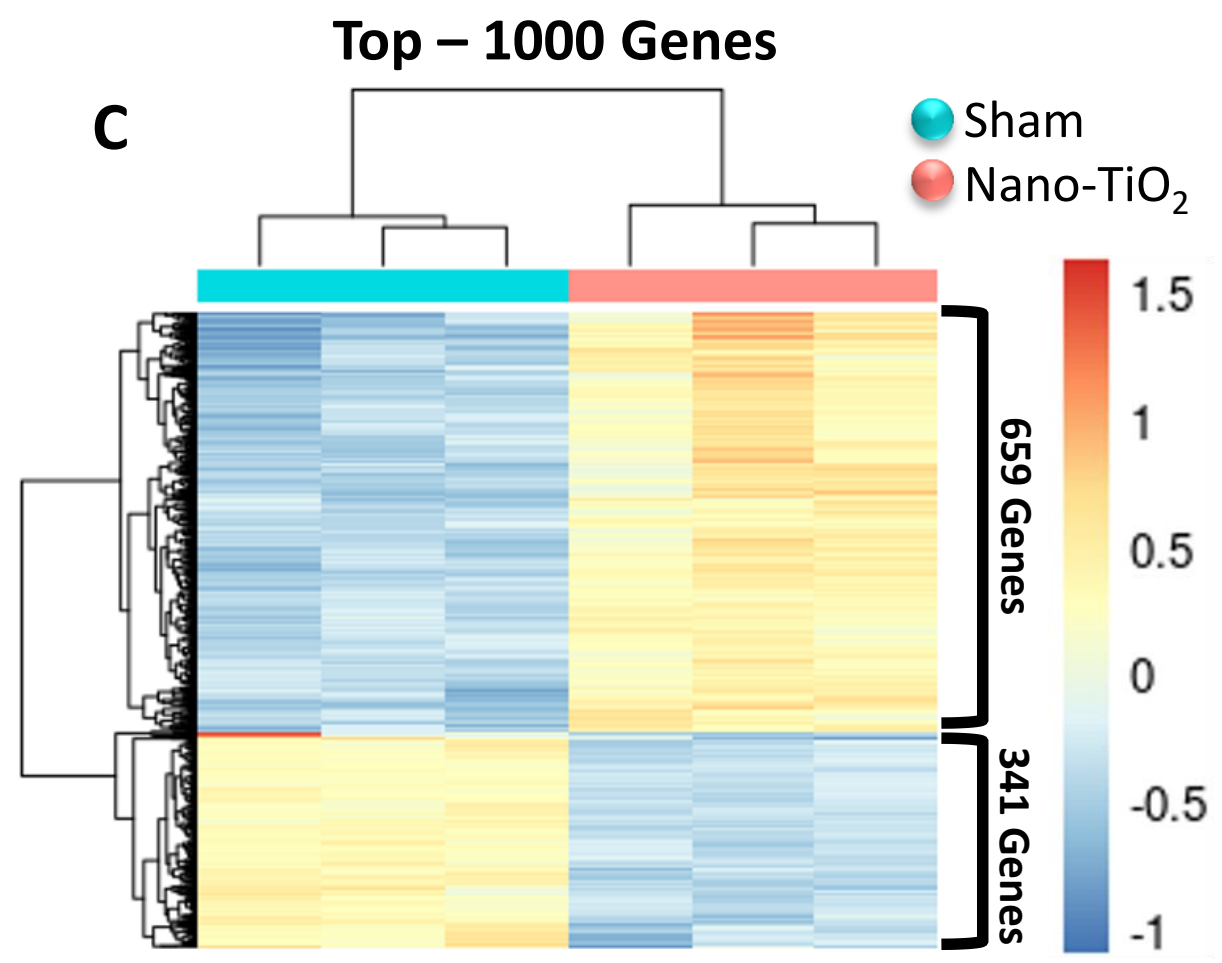

D Complex I

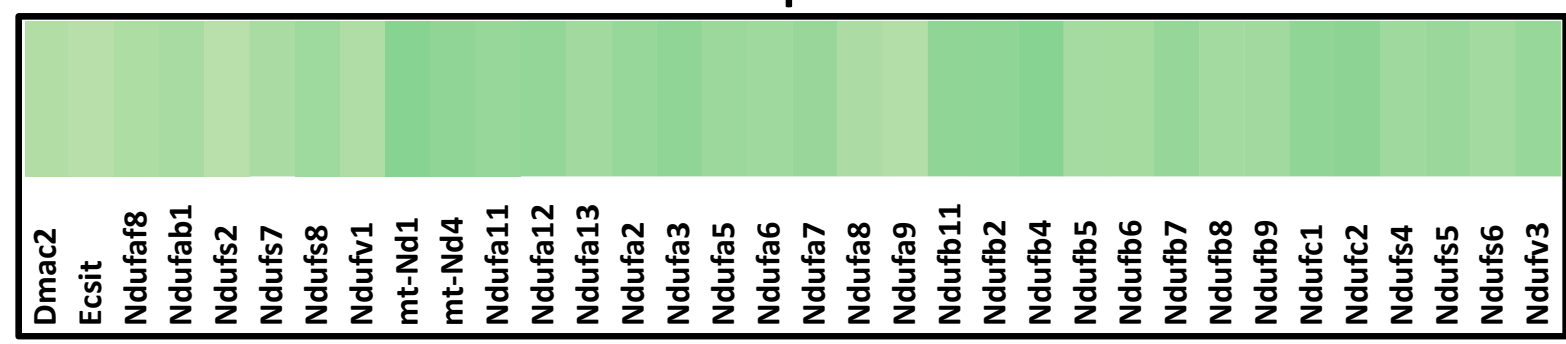

Complex II Complex III
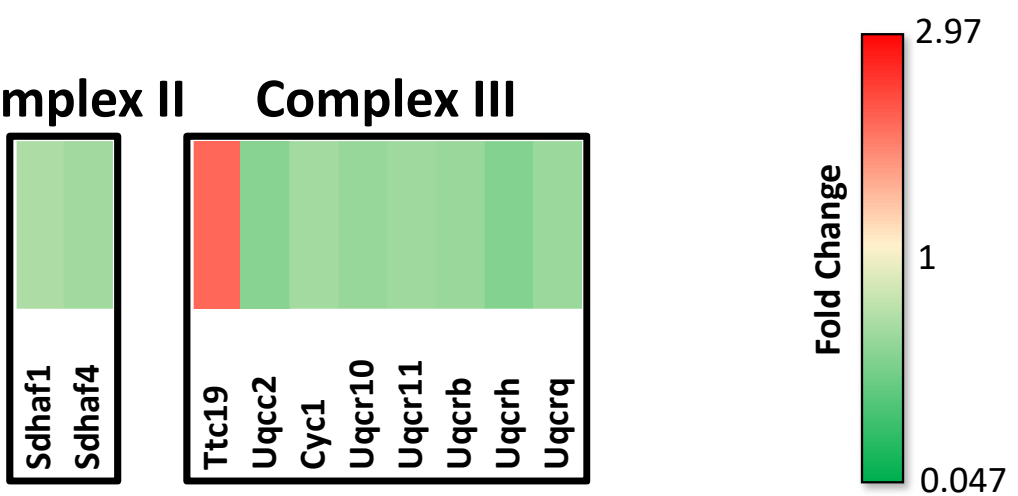
Figure 4.2D:

Complex IV

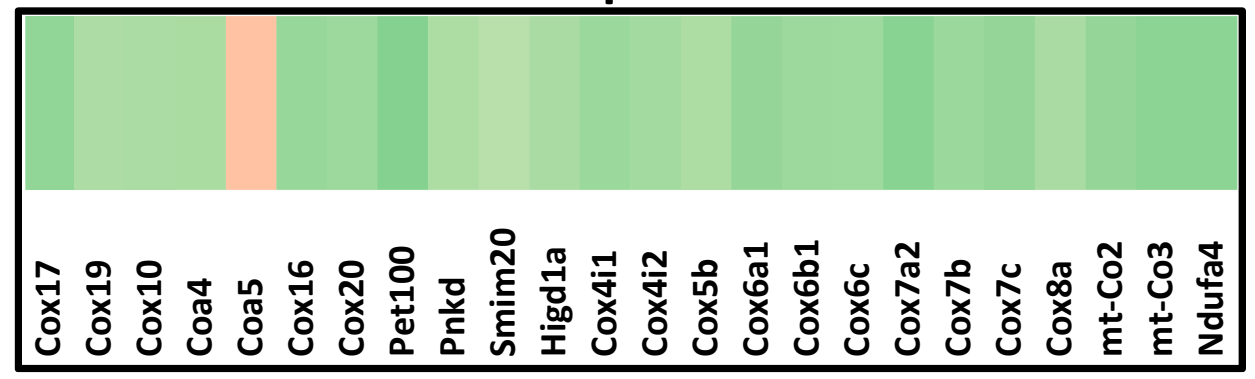

ATP Synthase
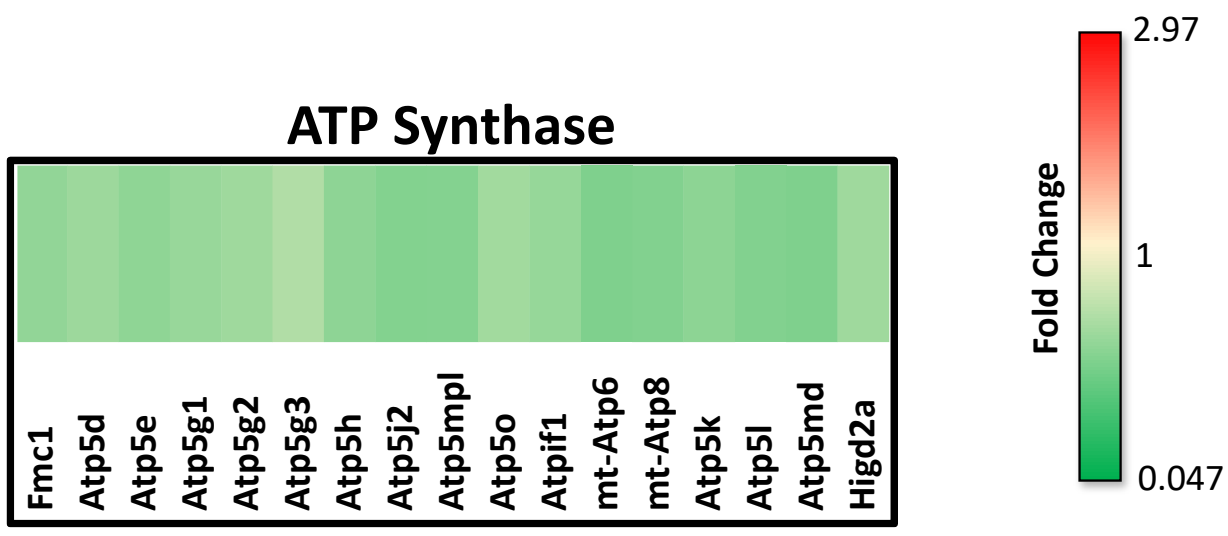
Figure 4.2: Transcriptomic analysis of fetal cardiac tissue. (A) Multidimensional Scaling (MDS) plot of sham $(n=3)$ and nano- $\mathrm{TiO}_{2}(\mathrm{n}=3)$ gestationally exposed fetal progeny. (B) Volcano plot depicting the $\log _{2}$ fold change observed following differential expression analysis. The top gene (lowest Padj value) is listed. (C) Heatmap depicting the top 1,000 genes, as sorted in ascending order by Padj value. The provided scale is in $\log _{2}$ fold change. (D) Heatmap of differentially expressed mitochondrial genes within the electron transport chain oxidative phosphorylation pathway. Genes were classified based on MitoCarta3.0 (34). The provided scale is in fold change. Genes were differentially expressed if $P a d j \leq 0.05, \mathrm{FDR}=0.05$. Differences are illustrated as nano- $\mathrm{TiO}_{2}(\mathrm{n}=3)$ compared to sham $(\mathrm{n}=3)$. Sham = fetal progeny of maternal dams exposed to filtered air, $\mathrm{Nano}_{-} \mathrm{TiO}_{2}=$ fetal progeny of maternal dams exposed to $12 \mathrm{mg} / \mathrm{m}^{3}$ of nano$\mathrm{TiO}_{2}$ for 360-minute periods for 6 days, Complex I = NADH:ubiquinone oxidoreductase, Complex II = succinate dehydrogenase, Complex III = coenzyme Q - cytochrome $\mathrm{c}$ reductase, Complex IV $=$ cytochrome $\mathrm{c}$ oxidase, ATP Synthase $=$ mitochondrial electron transport chain complex V. 
Figure 4.3:

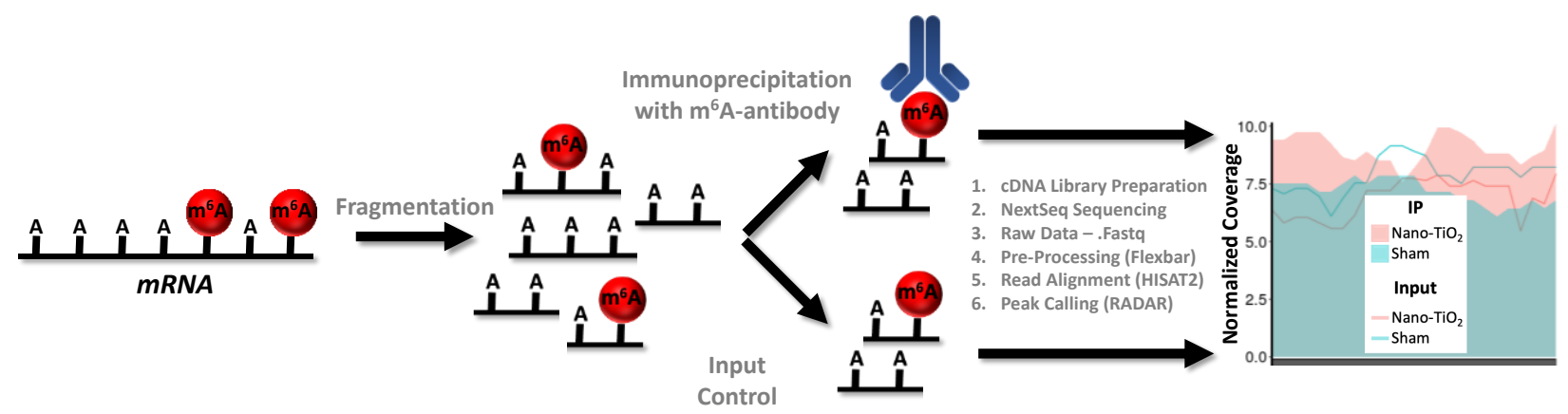


Figure 4.3: Schematic overview of $\mathbf{N}^{6}$-methyladenosine $\left(\mathrm{m}^{6} \mathrm{~A}\right)$ analyses. First, RNA was isolated from fetal pup hearts. Next, RNA was fragmented, with an average fragment size of 297 base pairs. $10 \%$ of each sample was saved as an input control while $90 \%$ of the sample was immunoprecipitated with $\mathrm{m}^{6} \mathrm{~A}$ antibodies. RNA was barcoded and reverse transcribed into cDNA. Sequencing was performed on the Illumina NextSeq with paried-end (PE) 2x50 reads. Adapters were trimmed from Fastq files, files were aligned to the mouse genome, and differential peak calling was performed. Sham $=$ fetal progeny of maternal dams exposed to filtered air, $\mathrm{Nano}^{-\mathrm{TiO}_{2}}$ $=$ fetal progeny of maternal dams exposed to $12 \mathrm{mg} / \mathrm{m}^{3}$ of nano- $\mathrm{TiO}_{2}$ for 360 -minute periods for 6 days, Input $=$ unprocessed $\mathrm{mRNA}, \mathrm{IP}=$ mRNA derived from immunoprecipitation with $\mathrm{m}^{6} \mathrm{~A}$ antibodies. 
Figure 4.4:

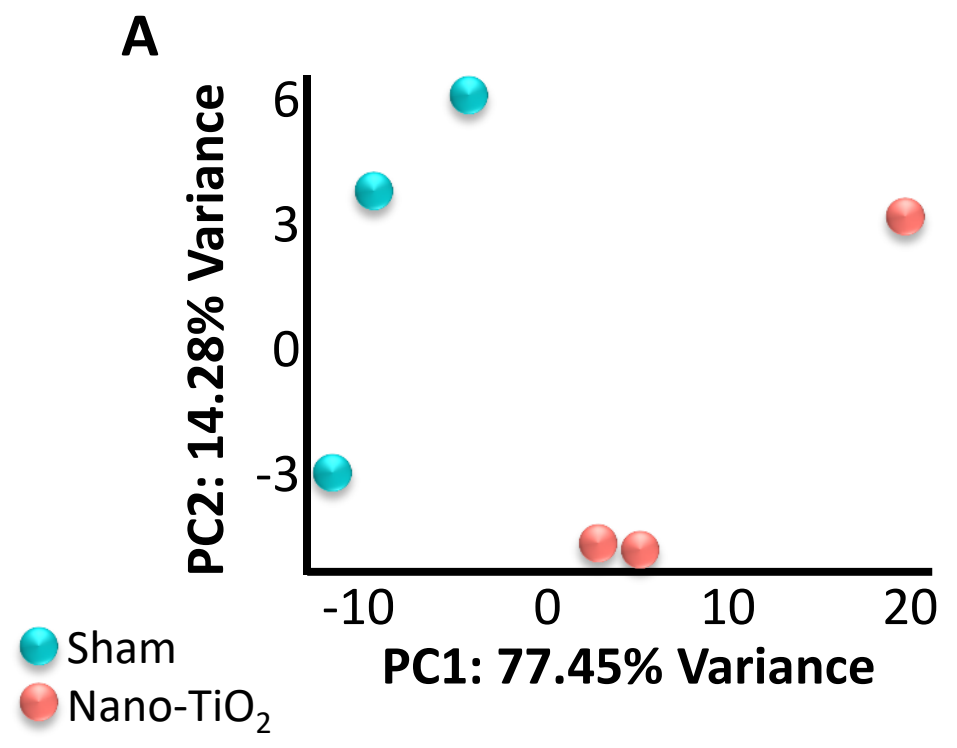

B m6A Methylation Sites

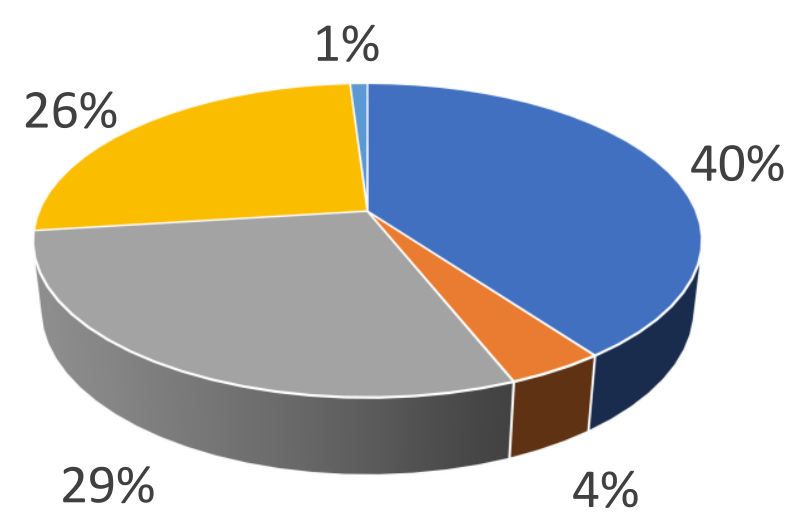

- 3' UTR $\approx 5^{\prime}$ UTR $\approx$ CDS $\approx$ ncRNA $\approx$ Other 
Figure 4.4:

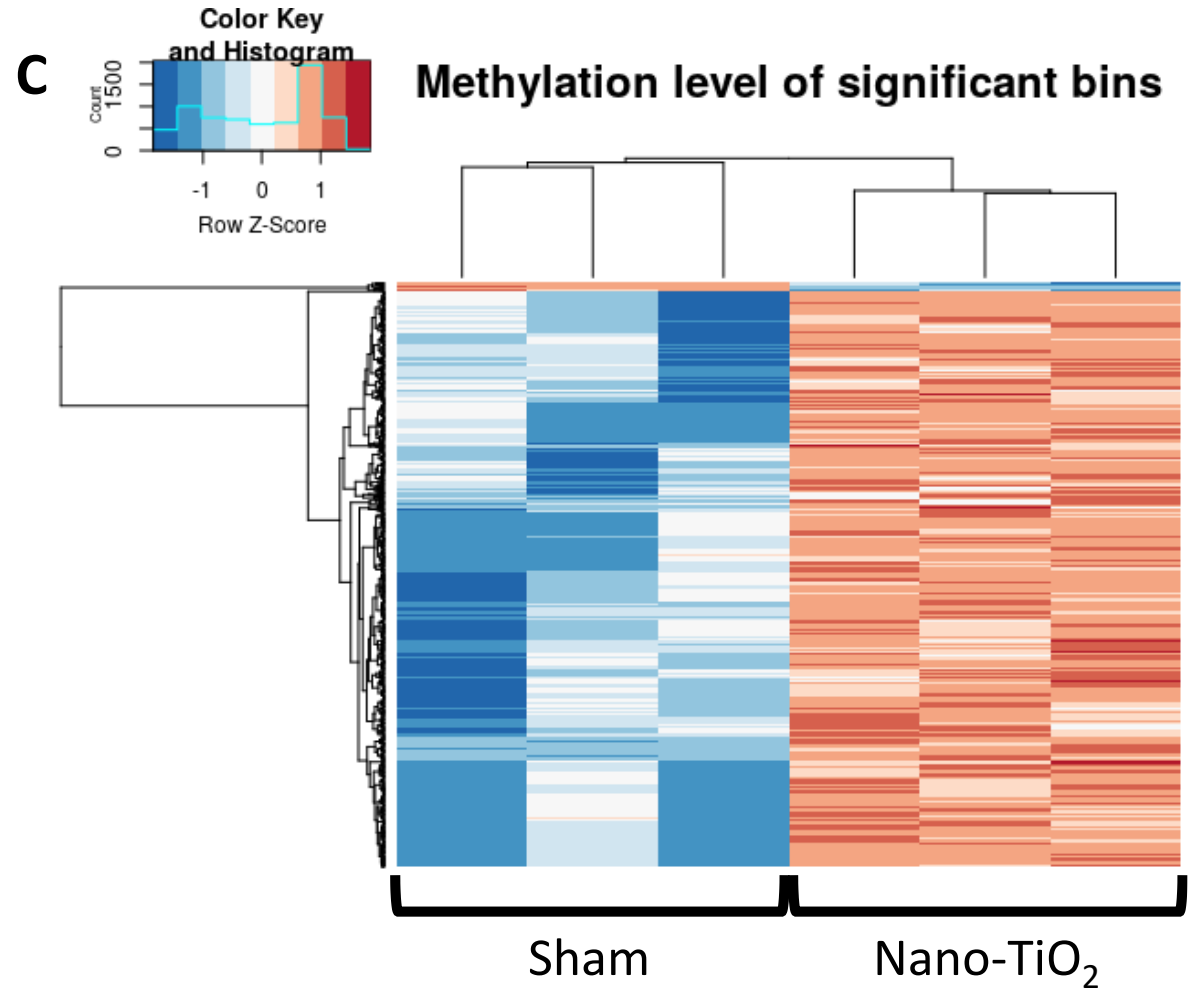


Figure 4.4D:

Number of m6A Sites

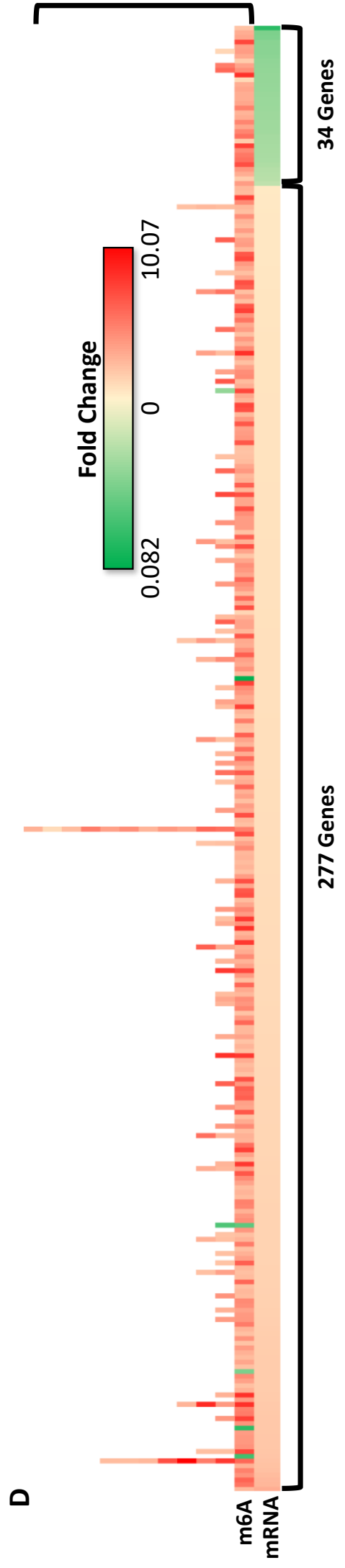


Figure 4.4: Epitranscriptomic analysis of fetal cardiac tissue. (A) Principal Component Analysis (PCA) plot of sham $(\mathrm{n}=3)$ and nano- $\mathrm{TiO}_{2}(\mathrm{n}=3)$ gestationally exposed fetal progeny. $(\mathbf{B})$

Pie chart depicting the distribution of $\mathrm{m}^{6} \mathrm{~A}$ sites identified by location across genomic space. (C) Heatmap of the 1,135 differentially $\mathrm{m}^{6} \mathrm{~A}$ methylated sites across 921 genes. Z-Score is defined as (gene expression value in sample of interest) - (mean expression across all samples)/standard deviation. Bins were defined as 25 base-pair regions. (D) Heatmap of the shared 331 genes that were both identified in the transcriptomic and epitranscriptomic analyses. The provided scale is in fold change. Genes were differentially expressed if $P a d j \leq 0.10, F D R=0.10$. Sham $=$ fetal progeny of maternal dams exposed to filtered air, $\mathrm{Nano}^{-\mathrm{TiO}_{2}}=$ fetal progeny of maternal dams exposed to $12 \mathrm{mg} / \mathrm{m}^{3}$ of nano- $\mathrm{TiO}_{2}$ for 360 -minute periods for 6 days, $3^{\prime}$ ' UTR = 3' untranslated region of a gene, $5^{\prime}$ UTR $=5^{\prime}$ untranslated region of a gene, $\mathrm{CDS}=$ coding DNA sequence, $\mathrm{ncRNA}=$ noncoding RNA, Other $=$ other regions in genomic space not specified. 
Figure 4.5:

A

mRNA

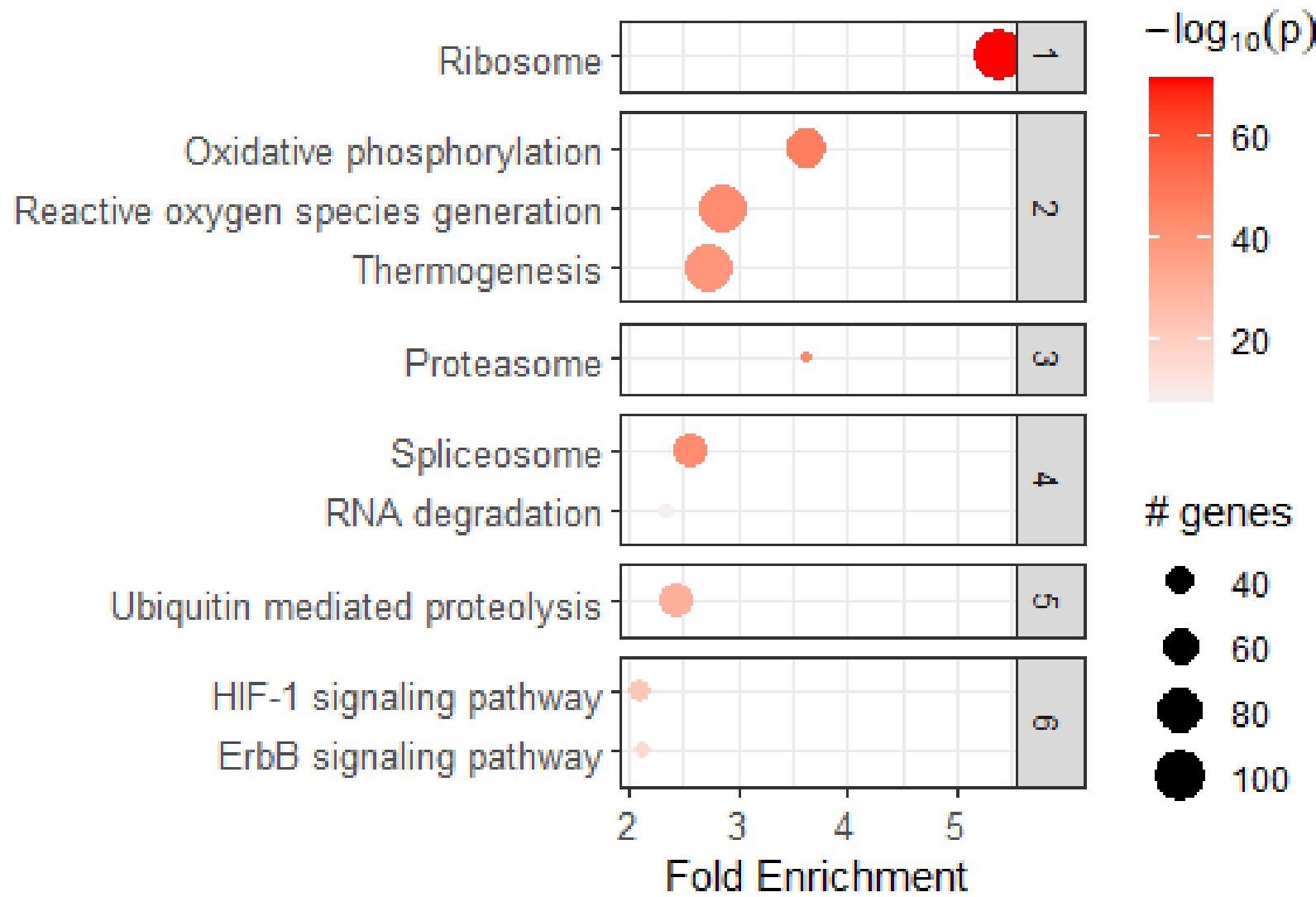


Figure 4.5:

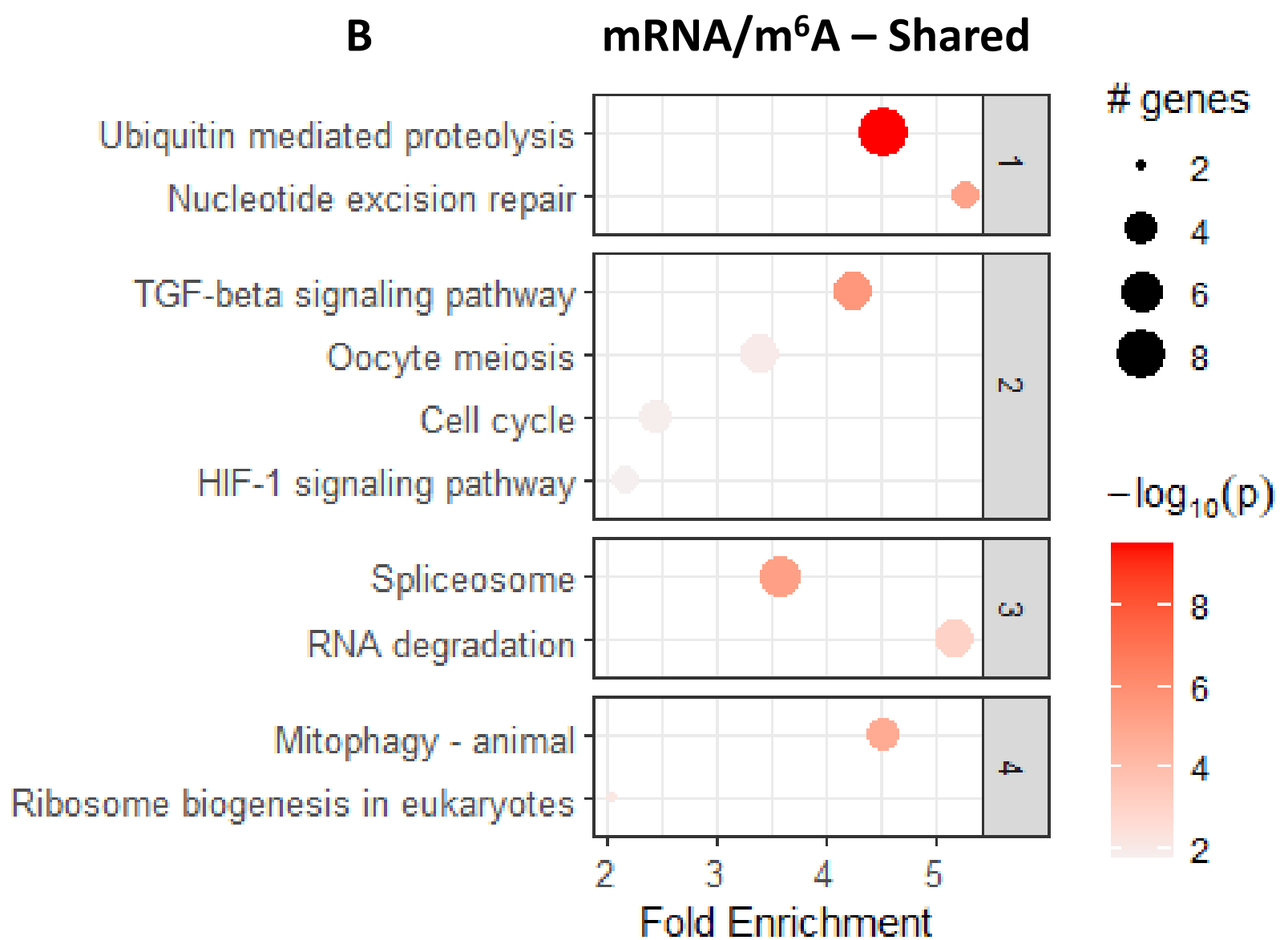


Figure 4.5: Pathway analysis of differentially expressed genes. (A) Pathway analysis of the 3,648 genes differentially expressed in the transcriptomic analysis. (B) Pathway analysis of those genes (311) that also coincided with differentially methylated sites. Both pathways are presented as hierarchically clustered pathways, with the top (A) six and (B) four pathways represented along with other similar pathways within each clustered group. Genes were differentially expressed if $\operatorname{Padj} \leq 0.05, \mathrm{FDR}=0.05$ 
Figure 4.6:
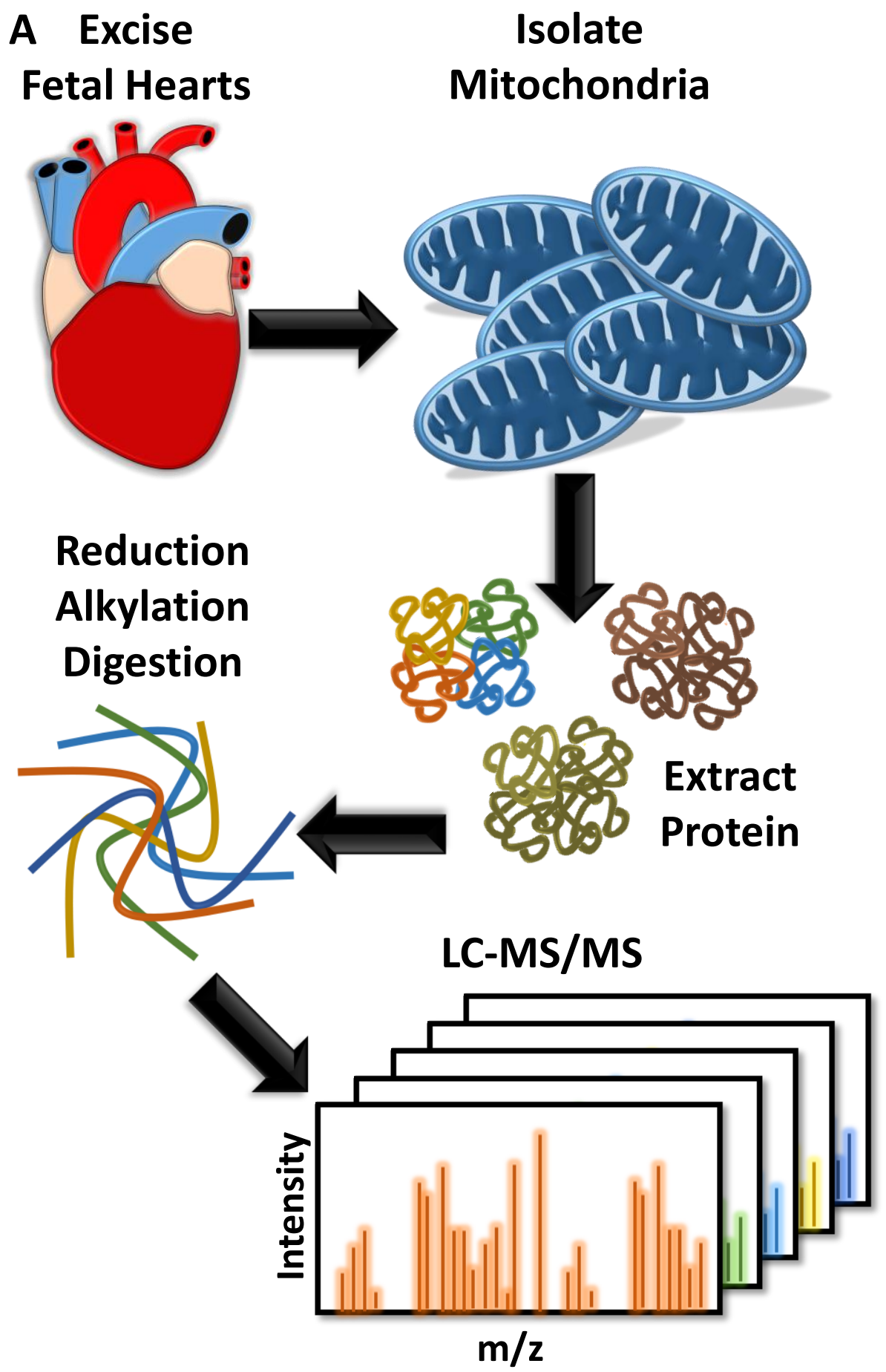
Figure 4.6:

B

\begin{tabular}{|c|c|c|c|c|}
\hline Protein & emPAl - Sham & emPAl - Exp & Exp vs. Sham & Pathway \\
\hline Got2 & 0.0922 & 0.0684 & & Metabolism > Amino acid metabolism \\
\hline Pdha1 & 0.0416 & 0.0576 & & Metabolism > Pyruvate metabolism \\
\hline Pdhb & 0.0795 & 0.0969 & & Metabolism > Pyruvate metabolism \\
\hline Cs & 0.1134 & 0.1202 & & Metabolism > TCA cycle \\
\hline Fh1 & 0.0661 & 0.0938 & & Metabolism > TCA cycle \\
\hline Ogdh & 0.0373 & 0.0472 & & Metabolism > TCA cycle \\
\hline Prdx3 & 0.0890 & 0.0437 & & Metabolism > ROS and glutathione metabolism \\
\hline Hadha & 0.0756 & 0.0852 & & Metabolism > Lipid metabolism \\
\hline Slc25a4 & 0.2119 & 0.2047 & & Metabolism > Nucleotide metabolism \\
\hline Slc25a5 & 0.2284 & 0.2284 & & Metabolism > Nucleotide metabolism \\
\hline Tufm & 0.0558 & 0.0732 & & Mitochondrial central dogma $>$ Translation \\
\hline Ndufs1 & 0.0862 & 0.0759 & & OXPHOS $>$ Complex I \\
\hline Ndufs7 & 0.0446 & 0.0444 & & OXPHOS > Complex I \\
\hline Ndufv2 & 0.0840 & 0.0715 & & OXPHOS > Complex I \\
\hline Ndufa13 & 0.1498 & 0.1906 & & OXPHOS > Complex I \\
\hline Sdha & 0.0730 & 0.0581 & & OXPHOS > Complex II \\
\hline Cox6b1 & 0.1152 & 0.1152 & & OXPHOS > Complex IV \\
\hline Atp5a1 & 0.2627 & 0.2440 & & OXPHOS > Complex V \\
\hline Atp5b & 0.3457 & 0.3169 & & OXPHOS > Complex V \\
\hline Atp5c1 & 0.1112 & 0.0827 & & OXPHOS > Complex V \\
\hline Atp5pb & 0.0952 & 0.0841 & & OXPHOS > Complex V \\
\hline Hspd1 & 0.1077 & 0.1082 & & Protein import, sorting and homeostasis \\
\hline Hspe1 & 0.2702 & 0.3567 & & Protein import, sorting and homeostasis \\
\hline $\mathrm{Phb}$ & 0.0961 & 0.1073 & & Protein import, sorting and homeostasis \\
\hline Phb2 & 0.1365 & 0.1277 & & Protein import, sorting and homeostasis \\
\hline Vdac1 & 0.1309 & 0.1015 & & Mitochondrial permeability transition pore \\
\hline \multirow[t]{3}{*}{ Vdac3 } & 0.0622 & 0.0703 & & Mitochondrial permeability transition pore \\
\hline & & & & emPAl \\
\hline & & & & -0.045 \\
\hline
\end{tabular}


Figure 4.6: Mitochondrial proteomics. (A) Schematic depicting the processes of mitochondrial isolation, protein extraction, peptide preparation, and peak identification. (B) Mitochondrial proteins that were identified with high confidence in the analyses. The provided scale is the difference between emPAI values between the sham and nano- $\mathrm{TiO}_{2}$ groups. Proteins are organized based on MitoCarta3.0 designations (34). Sham = fetal progeny of maternal dams exposed to filtered air, Exp = fetal progeny of maternal dams exposed to $12 \mathrm{mg} / \mathrm{m}^{3}$ of nano- $\mathrm{TiO}_{2}$ for $360-$ minute periods for 6 days, LC-MS/MS = liquid chromatography with tandem mass spectrometry. 
Supplemental Figure 4.1:
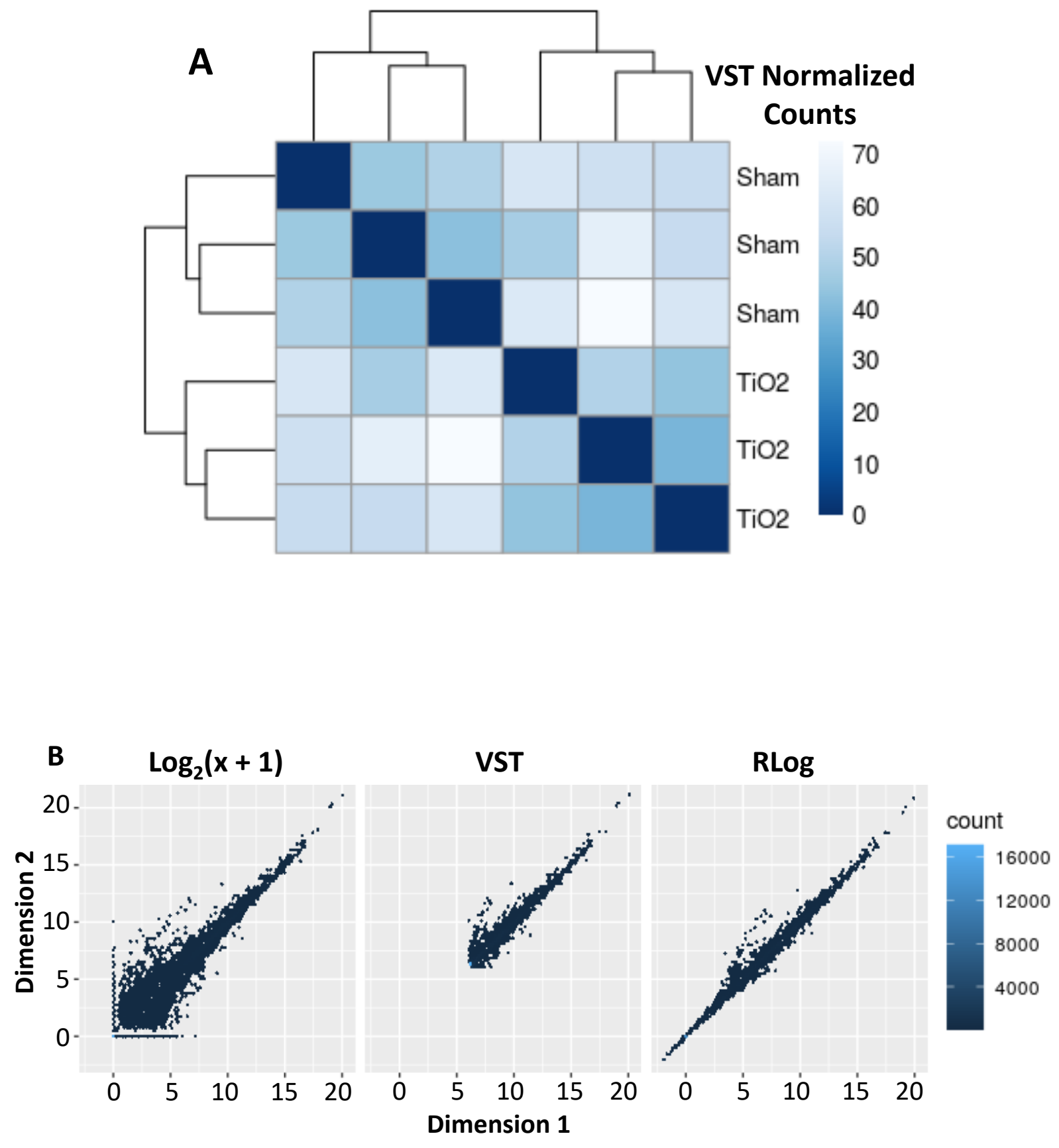
Supplemental Figure 4.1:

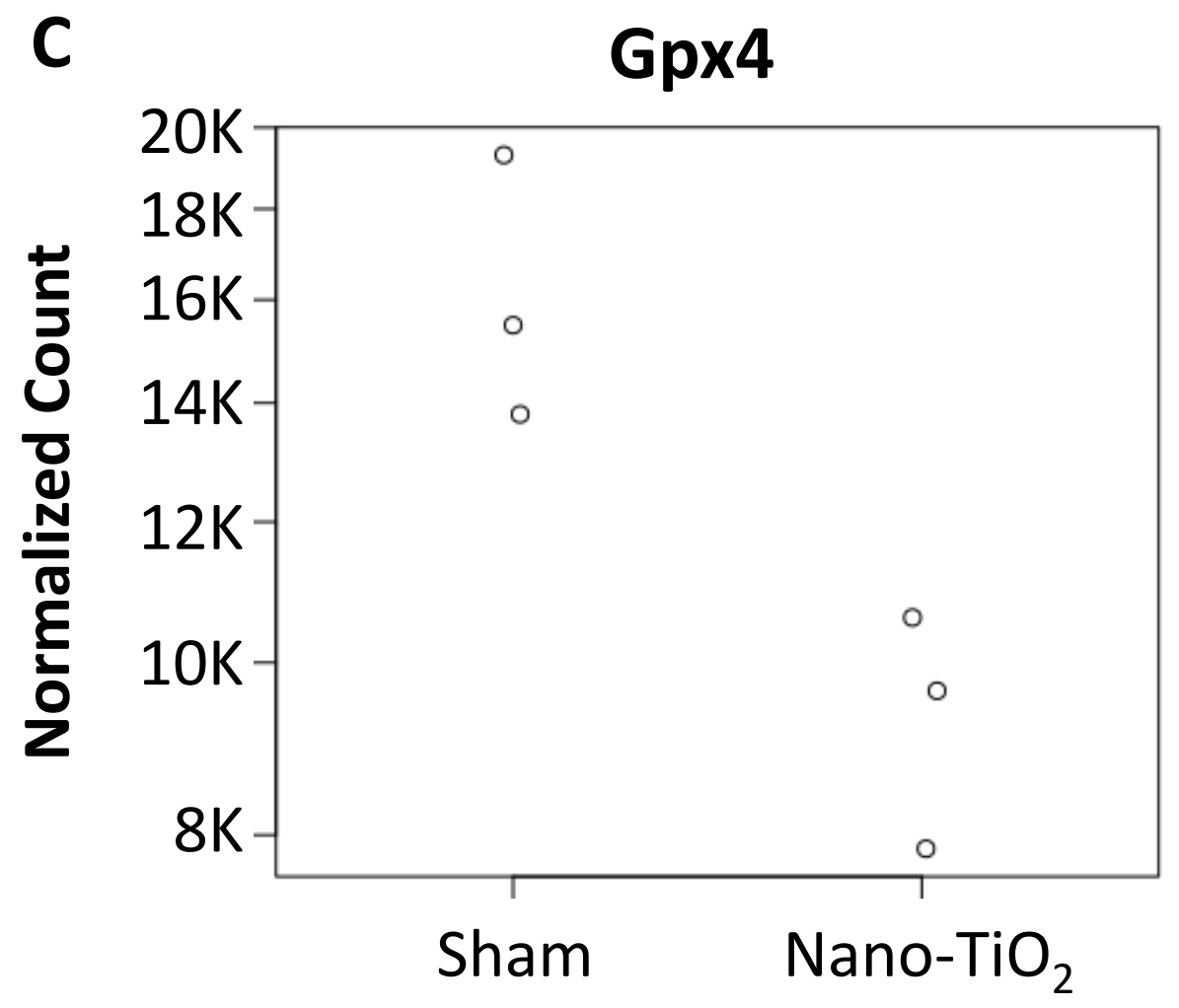




\section{Supplemental Figure 4.1: Transcriptomic processing and pre-processing. (A) Sample}

distribution heatmap using variance stabilizing transformation (VSD) normalized counts. (B) Multidimensional Scaling (MDS) of counts that $\operatorname{are} \log _{2}$ transformations of normalized counts

(left), VST (middle), and regularized-logarithm (rlog) transformations (right). (C) An example of normalized counts for $\mathrm{Gpx} 4$ in the sham $(\mathrm{n}=3)$ and nano- $\mathrm{TiO}_{2}(\mathrm{n}=3)$ groups. Genes were differentially expressed if $\operatorname{Padj} \leq 0.05, \mathrm{FDR}=0.05$. Sham $=$ fetal progeny of maternal dams exposed to filtered air, Nano- $\mathrm{TiO}_{2}=$ fetal progeny of maternal dams exposed to $12 \mathrm{mg} / \mathrm{m}^{3}$ of nano- $\mathrm{TiO}_{2}$ for 360-minute periods for 6 days, Gpx4 = mitochondrial glutathione peroxidase 4 . 
Supplemental Figure 4.2:

Amino Acid Metabolism

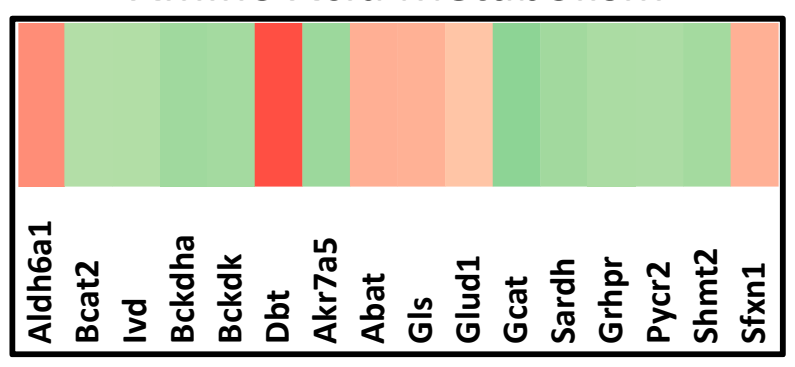

ROS and Glutathione

Carbohydrate Metabolism

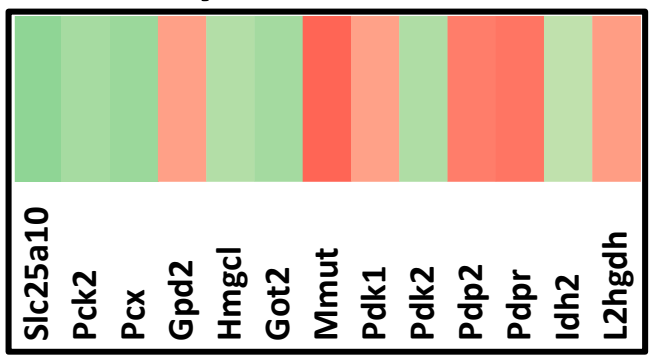

Metabolism

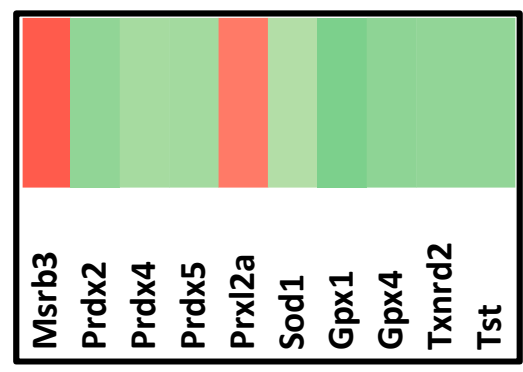

Lipid Metabolism

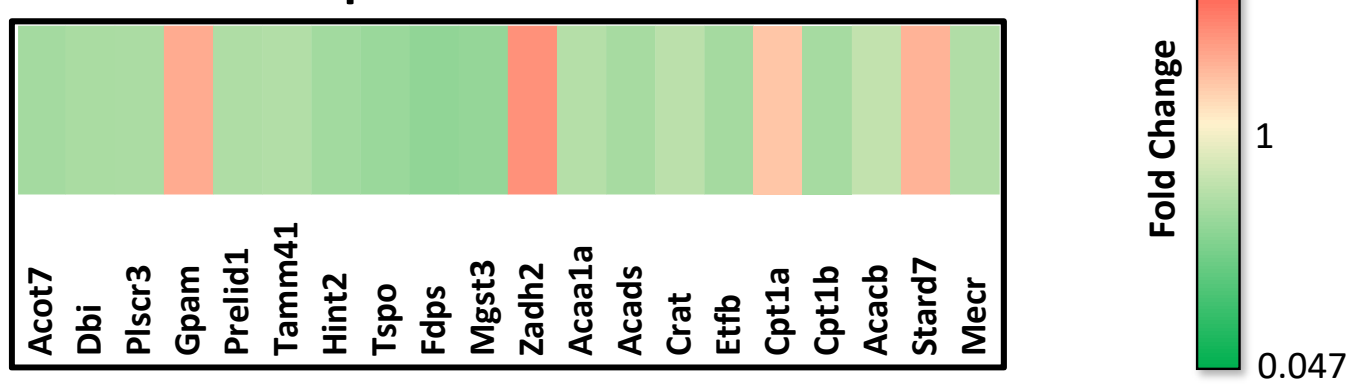

Metals and Cofactors

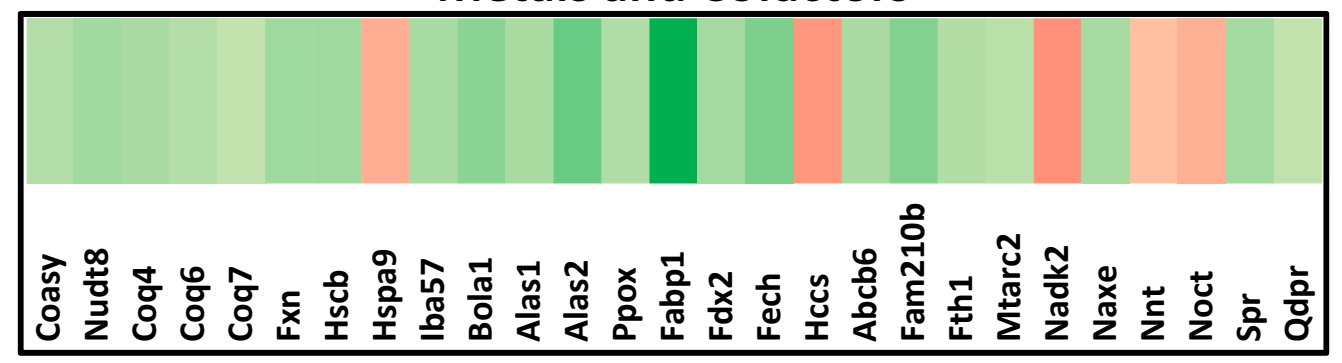


Supplemental Figure 4.2:
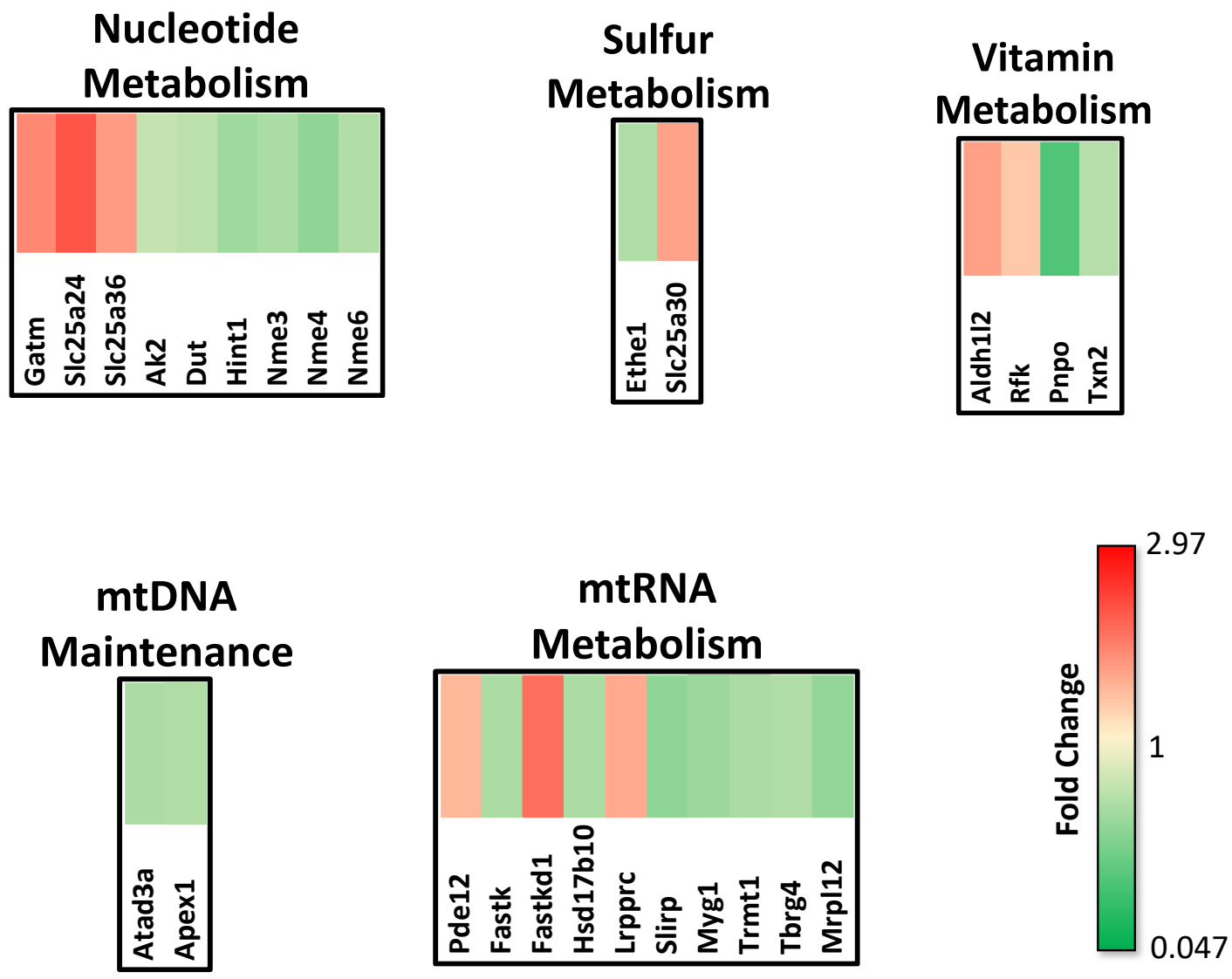

Mitochondrial Ribosome Metabolism

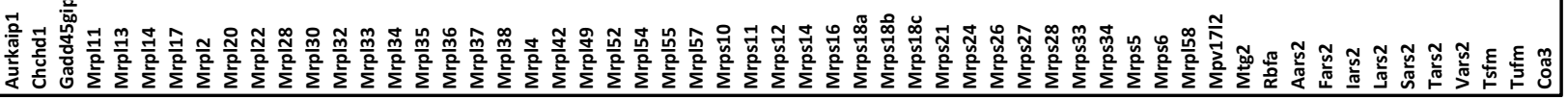

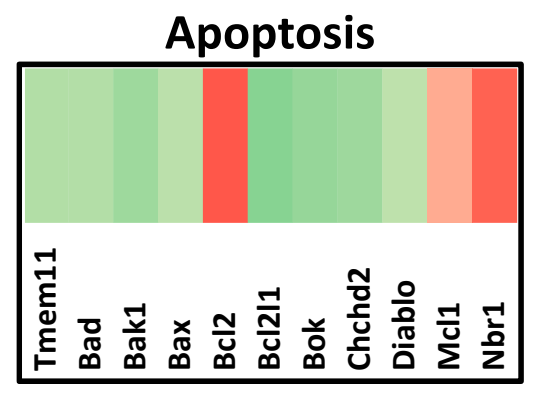

\section{Cristae}

Formation

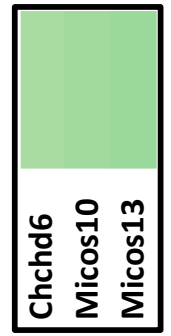


Supplemental Figure 4.2:
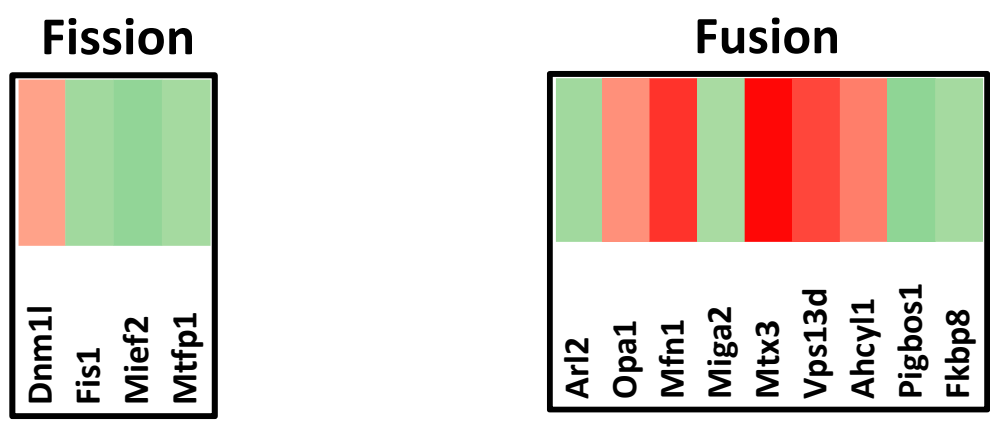

Protein Import, Sorting, and Homeostasis

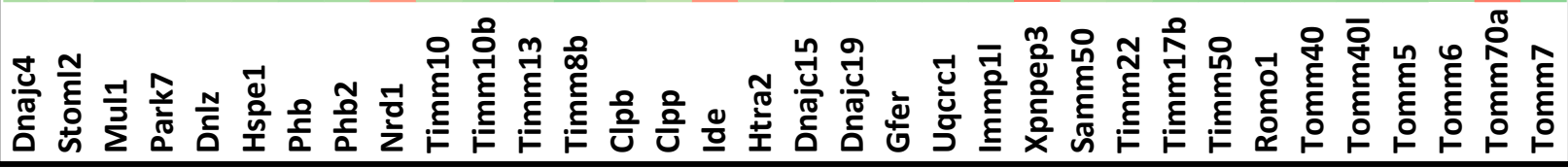
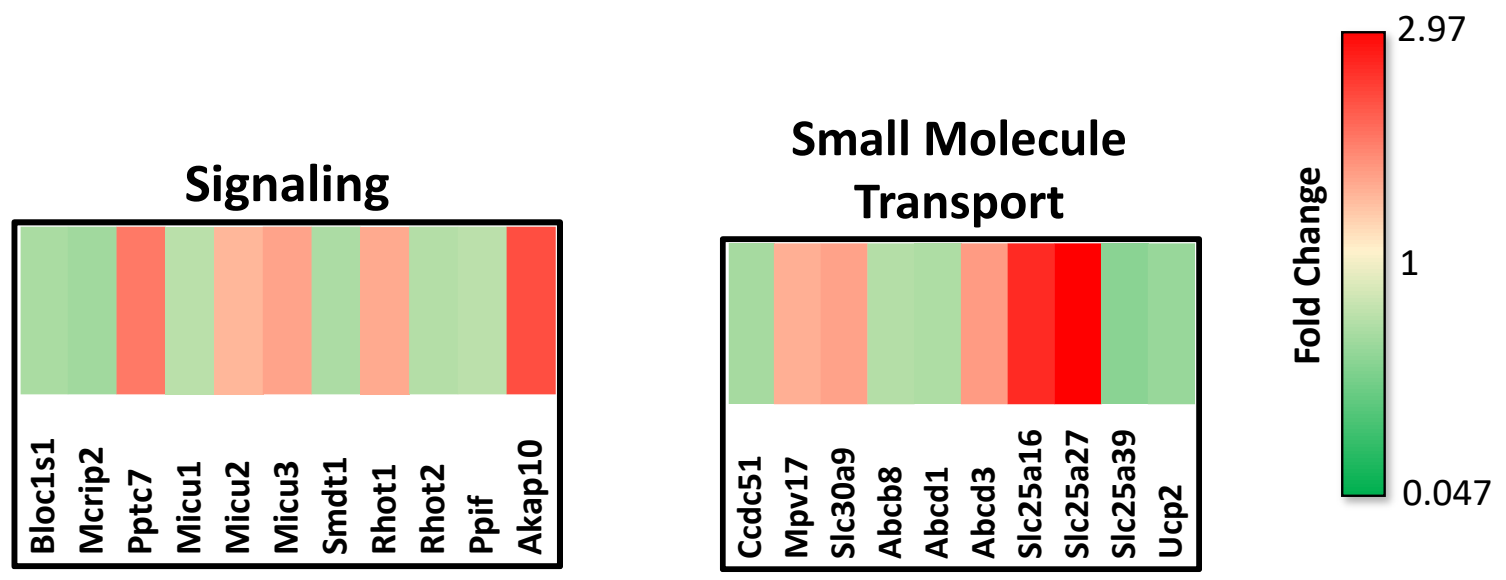


\section{Supplemental Figure 4.2: Differentially expressed mitochondrial genes not belonging to}

oxidative phosphorylation. (A) Heatmap of differentially expressed mitochondrial genes. Genes were classified based on MitoCarta3.0. The provided scale is in fold change. Genes were differentially expressed if $P a d j \leq 0.05, \mathrm{FDR}=0.05$. Differences are illustrated as nano- $\mathrm{TiO}_{2}(\mathrm{n}=3)$ compared to sham $(n=3)$. Sham = fetal progeny of maternal dams exposed to filtered air, Nano$\mathrm{TiO}_{2}=$ fetal progeny of maternal dams exposed to $12 \mathrm{mg} / \mathrm{m}^{3}$ of nano- $\mathrm{TiO}_{2}$ for 360 -minute periods for 6 days. 
Supplemental Figure 4.3:

\section{A RNA Degradation Pathway - mRNA}

- Upregulated Input Genes

- Downregulated Input Genes

- Other

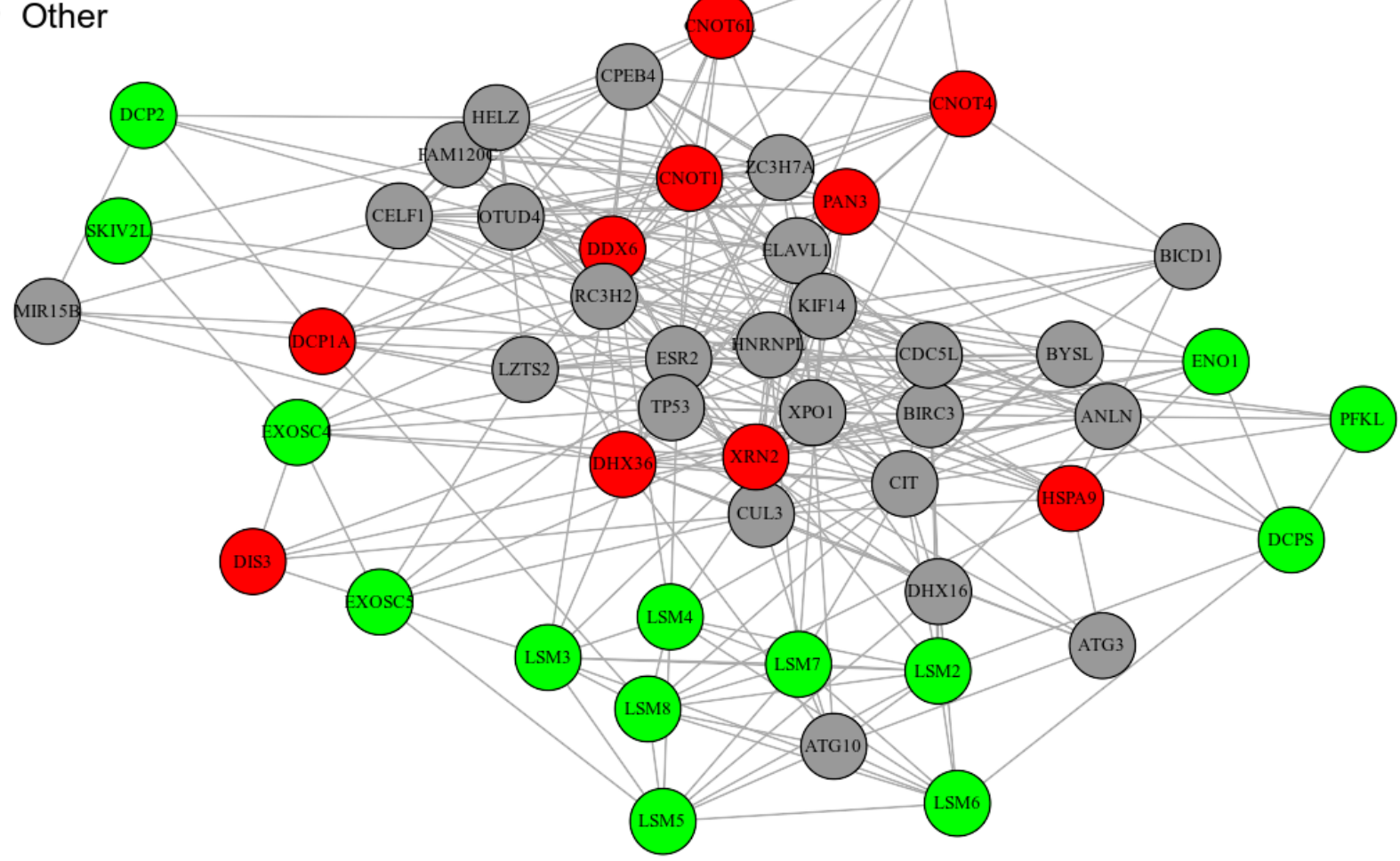


Supplemental Figure 4.3:

B RNA Degradation Pathway - mRNA/m6A Shared

- Upregulated Input Genes

- Downregulated Input Genes

- Other

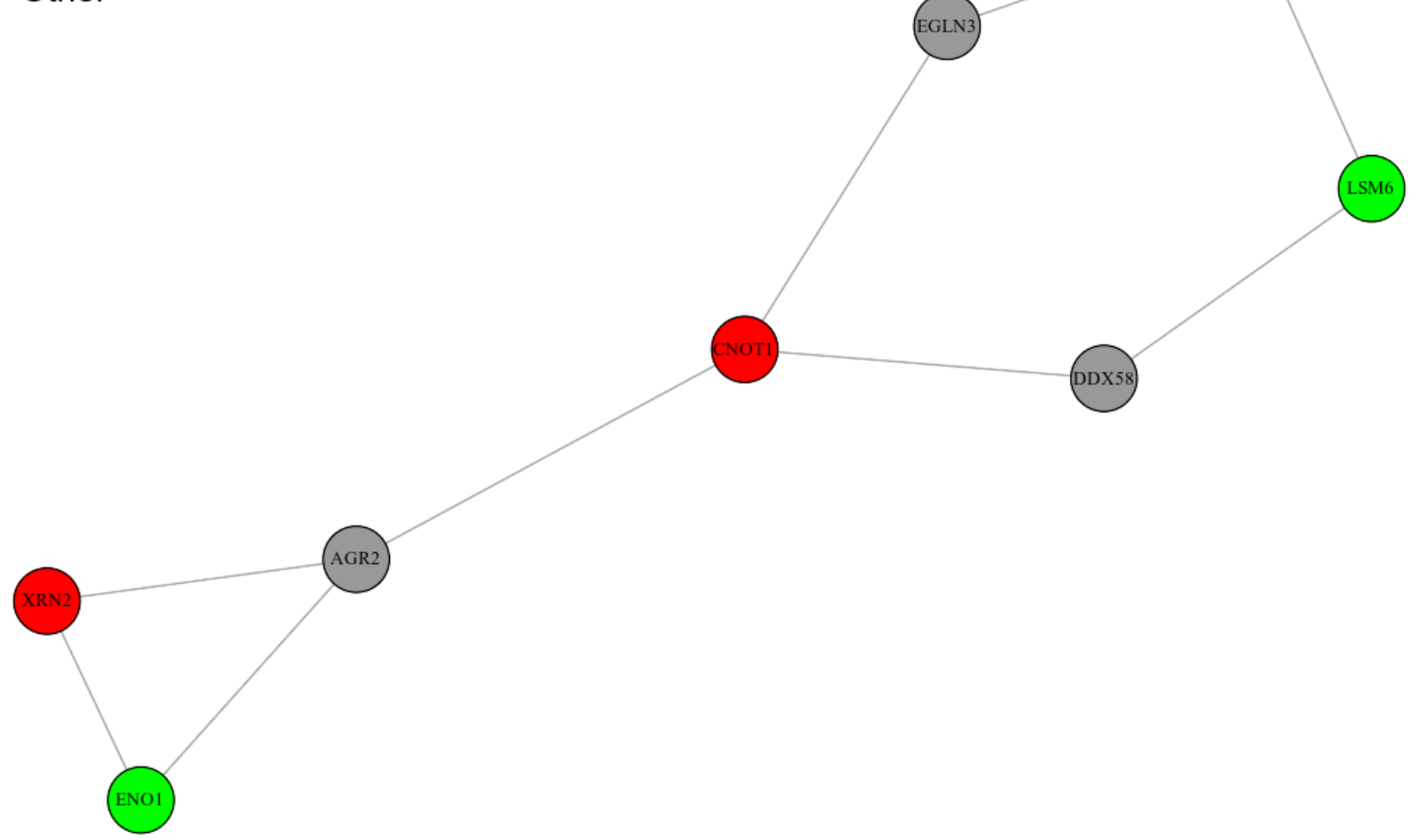




\section{Supplemental Figure 4.3: RNA Degradation pathway identified through PathFindR. (A) Of}

the 3,648 genes differentially expressed in the transcriptomic data between sham $(n=3)$ and nano$\mathrm{TiO}_{2}(\mathrm{n}=3)$, the highlighted genes were identified in the RNA degradation pathway. (B) Of the shared 311 genes between the mRNA and $\mathrm{m}^{6} \mathrm{~A}$ peak analysis, the highlighted genes were identified in the RNA degradation pathway. "Other" indicates genes not shown to be differentially expressed between sham and nano- $\mathrm{TiO}_{2}$. Genes were differentially expressed if $\operatorname{Padj} \leq 0.05, \mathrm{FDR}=0.05$. Sham

$=$ fetal progeny of maternal dams exposed to filtered air, Nano- $\mathrm{TiO}_{2}=$ fetal progeny of maternal dams exposed to $12 \mathrm{mg} / \mathrm{m}^{3}$ of nano- $\mathrm{TiO}_{2}$ for 360 -minute periods for 6 days. 
Supplemental Figure 4.4:
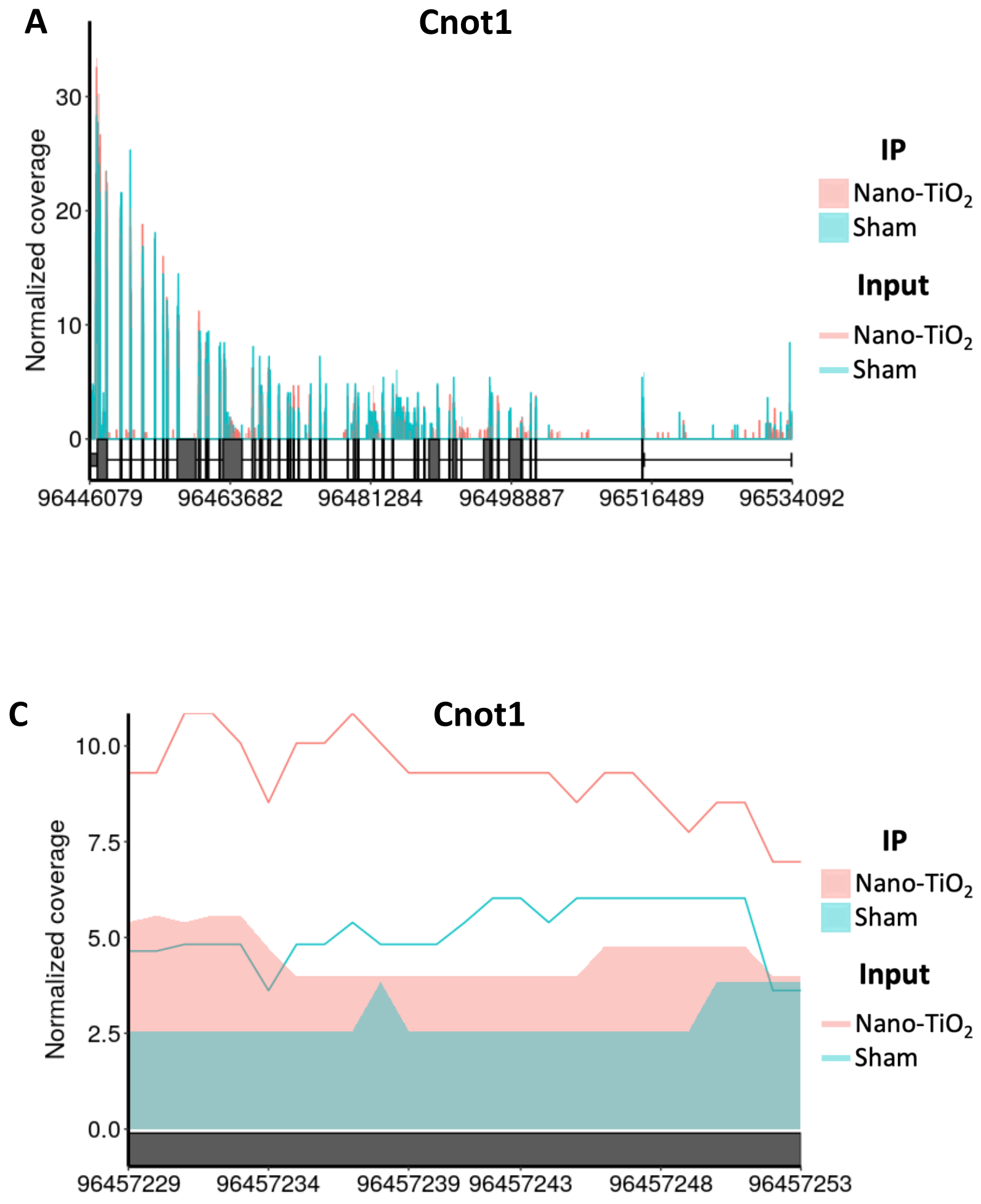
Supplemental Figure 4.4:
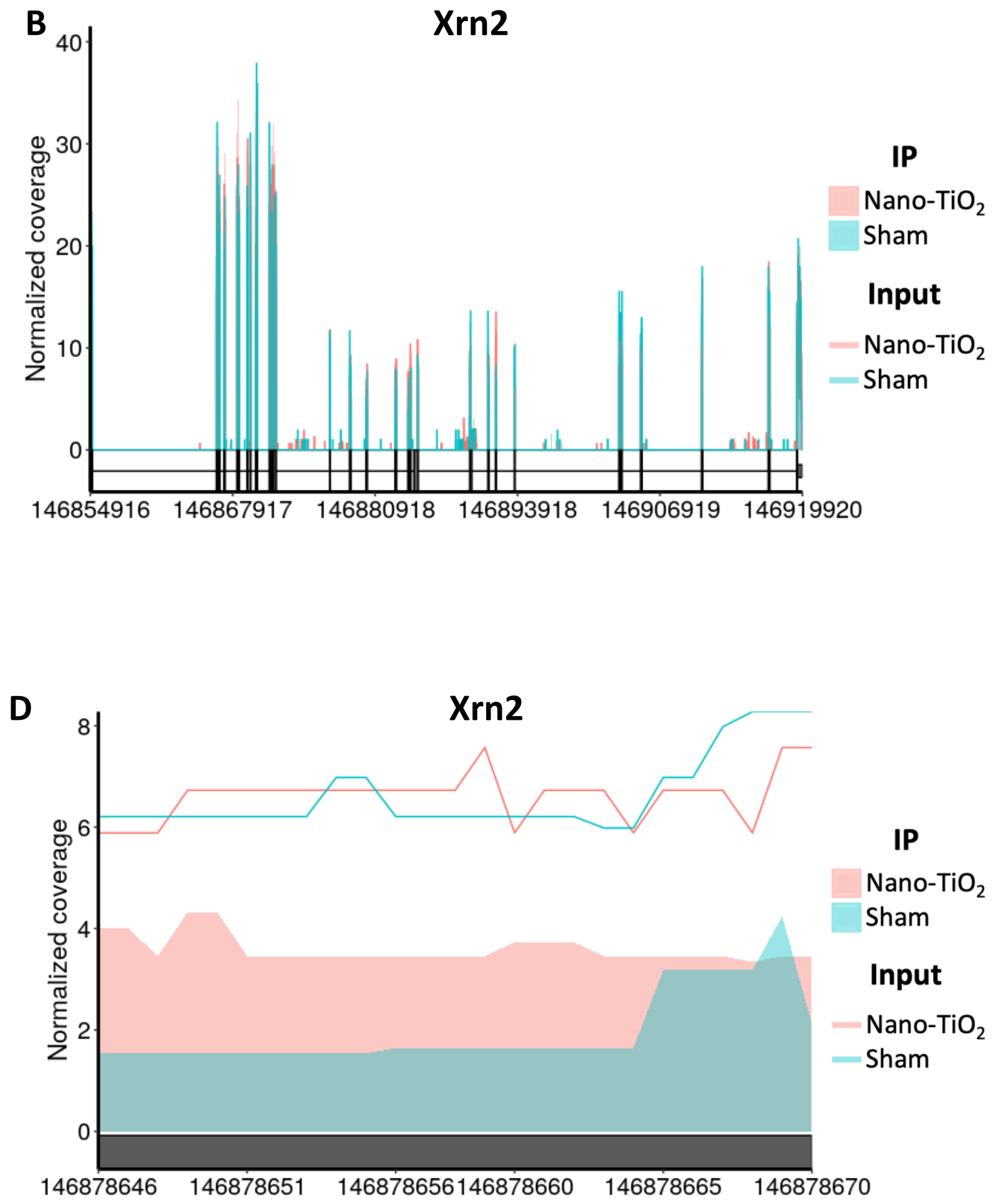


\section{Supplemental Figure 4.4: $\mathrm{N}^{6}$-methyladenosine $\left(\mathrm{m}^{6} \mathrm{~A}\right)$ peak calling of RNA Degradation}

pathway genes. The entire gene region of (A) Cnot 1 and (B) $\mathrm{Xrn} 2$ reveals $\mathrm{m}^{6} \mathrm{~A}$ methylation across the gene. Normalized coverage to input samples was gated across samples to display regions were $\mathrm{m}^{6} \mathrm{~A}$ was significantly increased for $(\mathbf{C})$ Cnot1 and (D) Xrn2. IP expression is designated by filled boxes while input samples are represented by lines. The $\mathrm{x}$-axis represents the genomic location. Genes were differentially expressed if $\operatorname{Padj} \leq 0.10, \mathrm{FDR}=0.10$. Sham $=$ fetal progeny of maternal dams exposed to filtered air, $\mathrm{Nano}-\mathrm{TiO}_{2}=$ fetal progeny of maternal dams exposed to $12 \mathrm{mg} / \mathrm{m}^{3}$ of nano- $\mathrm{TiO}_{2}$ for 360-minute periods for 6 days, Input $=$ unprocessed $\mathrm{mRNA}, \mathrm{IP}=\mathrm{mRNA}$ derived from immunoprecipitation with $\mathrm{m}^{6} \mathrm{~A}$ antibodies. 


\section{Chapter 5: General Discussion}

The work within this dissertation aims to ascertain the repercussions of inhalation exposure to engineered nanomaterials (ENM), particularly nano- $\mathrm{TiO}_{2}$, during gestation on offspring cardiac function, the epigenetic and epitranscriptomic mechanism that contribute to these detriments, as well as the potential for therapeutic prevention with the implementation of an antioxidant defense strategy. With the proliferative increase in nanoparticle applicability in multiple industries, comes also the necessity for thorough evaluation and understanding of any adverse effects that such ubiquitous exposure can emanate. The research herein, attempts to ascertain these adverse effects through approaches that include examination of functional cardiac effects, down to the organelle that plays a pivotal role in heart contraction, the mitochondrion, and furthermore the chemical modifications that likely contribute to sustained dysfunction into later stages of life in a mouse model. The long-term goal of the research performed was to identify mechanisms contributing to the pathological effects of xenobiotic exposure as a prerequisite to developing strategies for reducing risks to public health.

The central hypothesis is that changes in the $\mathrm{m}^{6} \mathrm{~A}$ methylome, concomitant with an altered mitochondrial proteome at the fetal stage, precipitate cardiac contractile dysfunction that is sustained into adulthood following maternal ENM inhalation exposure. Sustained dysfunction may be averted through limiting ROS via overexpression of mPHGPx. The particularly intriguing aspect of this central hypothesis is the idea of epitranscriptomic remodeling and the implications this holds. Within my research, the focus really does not stray from understanding the effects of maternal toxicant inhalation exposure during gestation on the offspring heart function and mitochondrial function. However, the concept of reprogramming may have even more detrimental outcomes that include inclining the system to be more susceptible to diseases that also alter similar pathways such as metabolism. To date, this possibility has not been explored, but may, in part, explain the simultaneous increasing rates of childhood obesity and applications of nanoparticles and increased air pollutants. The changes seen in mitochondrial function, specifically with decreased electron transport chain complex activities, in both fetal and adult progeny of dams exposed to nano- $\mathrm{TiO}_{2}$ during gestation, is similar to what our laboratory has previously seen with a type 2 diabetic mouse model (6). It is therefore plausible that even if ETC complex activities are 
only diminished as an immediate response (at the fetal stage) or minimally altered at the adult stage following gestational ENM exposure, the offspring's capacity to manage a secondary insult, such as high-fat diet-(HFD) induced obesity, is significantly limited. This may result in a more severe and rapidly progressing type 2 diabetic phenotype. Nevertheless, the research described within this dissertation lays the basic groundwork necessary for further research in the field of inhalation toxicology and both the short and long-term repercussions of it.

The objective of Specific Aim 1 was to elucidate the effects of maternal nano- $\mathrm{TiO}_{2}$ inhalation exposure during gestation on cardiac contractile function and mitochondrial function in fetal offspring and whether these detriments persist into adulthood. The evidence provided in this study pointed towards a connection between elevated ROS, specifically hydrogen peroxide $\left(\mathrm{H}_{2} \mathrm{O}_{2}\right)$, levels and cardiac bioenergetic and contractile dysfunctions at the acute (fetal) and chronic (adult) stages. Based off the data acquired during this project, we postulated that elevated ROS in the maternal gestational environment affected the fetal epigenome such that when combined with a decrease in mitochondrial ROS scavenging capacity via diminished GPX4 protein levels, results in a positive feed-back loop. The mitigation of antioxidant capacity thus perpetuates increased ROS levels in fetal mitochondria and is concomitant with an increase in Hifl $\alpha$, which can transcriptionally activate Dnmt1. Through augmented Dnmt1 levels, global $5 \mathrm{mC}$ methylation in the fetal offspring is increased and thereby may be further diminishing GPX4 levels, resulting in a sustained effect into adulthood. The chronic effect seen however cannot be explained by the same epigenetic modification nor diminished GPX4 protein levels that are seen at the fetal stage. Notably however, mitochondrial bioenergetics, size, and internal complexity were all affected negatively. This brings to light the potential of mitochondrial reprogramming as a result of enhanced ROS, which although not discussed or investigated in this work, is a plausible hypothesis. It is also unlikely that $5 \mathrm{mC}$ methylation of GPX4 is solely responsible for the changes in mitochondrial structure and function and ultimately cardiac dysfunction that persist long-term. Moreover, evaluating the role of selenium is also critical in explicating diminished GPX4 content at the fetal stage.

As a result of the maternal inhalation exposures occurring at a critical timepoint in fetal development, the consequential phenotype may therefore be pathological. During mouse embryonic cardiac development, the mitochondrial permeability transition pore (mPTP) closes 
when the cardiomyocyte is maturing, which occurs between embryonic day 9.5 and 13.5 (45). The purpose of this closure is to increase mitochondrial membrane potential to promote aerobic respiration and to decrease ROS levels in the cardiomyocytes. It is possible that the increased ROS levels seen in the fetal progeny may be occurring as a consequence of a high-stress state in the maternal environment as the nano- $\mathrm{TiO}_{2}$ inhalation exposure occurs during this specific time in gestation. This may alter the ability of the mPTP to close as is necessary, making it unable to lower the ROS levels which instead remain high for an extended period. In turn, the mitochondria may be reprogrammed in an attempt to overcompensate for the deficiency, which could alter heart development in the vulnerable population (22).

It is important to note that the mechanism by which the effects of gestational nano- $\mathrm{TiO}_{2}$ exposure are being transferred to the fetus and sustained into adulthood remains relatively elusive. While our studies are able to establish the presence of mitochondrial and cardiac changes, concomitant with a high ROS environment in the cardiac tissue, there are a multitude of possibilities in terms of how this occurs. While the research presented in this dissertation mainly investigated $\mathrm{H}_{2} \mathrm{O}_{2}$ and mitochondrial dysfunction as the key source of ROS, there are other cellular mechanisms that may play a role in the resultant oxidative stress seen following exposure. Some of those pathways include xanthine oxidase, NADPH oxidase, and uncoupling of NO synthase. Nano-sized particulate matter can exert its effects through both direct and indirect mechanisms. Recent studies have proposed the ability of certain particles including black carbon (28) and nanopolystyrene (2) to cross the placental barrier and potentially induce direct effects to the developing fetus. However, the prevailing theory suggests that the consequences of particle exposure generally arise from lung inflammation and an associated ROS increase, in conjunction with other indirect effects elicited by the maternal exposure $(5,31)$. On the other hand, if particles are indeed translocating across the placental barrier, the quantities are likely incredibly limited and practically inconsequential. It is therefore unlikely that such minimal amounts could be behind such a significant impact on the progeny at both the acute and chronic stages. Consequently, one of the main possibilities goes back to inflammation $(17,25,27)$. A case could be made that there is an initial interaction between the particles and lung tissue that precipitates an inflammatory response that causes both free radical and inflammatory cytokine release, along with other mediators of inflammation into the circulation. Even though primary inflammation occurs in the lungs, there are immune cells and inflammatory mediators that regain access to the blood and 
continue perpetuating an inflammatory reaction. Higher amounts of macrophages, neutrophils, and other immune cells may then increase ROS levels in the blood and furthermore result in a hostile gestational environment due to the maternal systemic distribution of $\operatorname{ROS}(17,25)$. Previous studies have determined that nano- $\mathrm{TiO}_{2}$ inhalation exposure during gestation results in impaired vascular reactivity of the umbilical vein, umbilical artery, as well as increases placental vascular resistance $(1,9,10)$. This may be another consequence of the perpetuating inflammatory reaction that can occur when alveolar macrophages interact with particulate matter is a change in endothelial cells. Particularly, studies of ENM inhalation exposure during gestation have shown altered endothelium-dependent placental hemodynamics, while endothelium-independent placental hemodynamics were not impacted. It is possible that a kisspeptin-dependent mechanism is the culprit when it comes to disruption of the normal gestational endocrine vascular axis following gestational ENM exposure. Specifically, nano- $\mathrm{TiO}_{2}$ exposure augmented the effects of kisspeptin on vasoconstriction (3). Kisspeptin is a neuropeptide that binds to its respective Gcoupled receptor (Kiss1R) and triggers a cascade that results in release of intracellular calcium, leading to smooth muscle contraction. Therefore, a potential repercussion of these findings is an increase in reactivity to this vasoconstrictor, which may be responsible for insufficient placental perfusion and increased resistance, mitigating oxygen availability for the pups in utero. Notably, unpublished data from our laboratory showed a decrease in Prdx1 mRNA expression (Padj $=$ 0.002), which has been established as a form of protection against excessive endothelial activation. Diminished Prdx1 levels in mice resulted in a model that is susceptible to chronic inflammation (18). These studies emphasize the real possibility that there are several pathways that work in a cooperative manner to ensue the damage that is seen in offspring following maternal ENM inhalation exposure. Nevertheless, it is clear that more work remains to fully elucidate the source of the ROS and the connection between the elevated levels and sustained cardiac and mitochondrial effects in mice gestationally exposed to nano- $\mathrm{TiO}_{2}$. As this field of research continues to grow, the truth will likely lie in the possibility that multiple pathways are simultaneously at play.

Regardless of the mechanism by which the fetus is impacted, we still recognize the importance of the sustained alterations that are carried into adulthood. Unlike at the fetal stage, young adult offspring whose dams were gestationally exposed to ENM presented with a decrease in $5 \mathrm{mC}$ methylation (21). This is an interesting finding such that it suggests that other epigenetic and/or epitranscriptomic mechanisms are involved. While the research presented in Specific Aim 
1 of this dissertation investigated Dnmt levels and global $5 \mathrm{mC}$ methylation status, other investigators have looked at histone modifications associated with disease following environmental exposure as well as altered miRNA and other non-coding RNA levels (13). The first evidence that maternal ENM inhalation exposure contributes to modifications to the fetal epigenome identified changes in histone 3 lysine 4 tri-methylation (H3K4me3) and histone 3 lysine 27 tri-methylation (H3K27me3) in the fetal offspring hearts (37). Our laboratory has also published data that indicates changes to miRNA levels following inhalation exposure, specifically miRNA-378a that were associated with mitochondrial functional diminutions (11). The possibility of other non-coding RNAs however has not been investigated in this dissertation or otherwise. As mentioned earlier, it is highly unlikely that one specific DNA modification is responsible for both the fetal and adult mitochondrial and cardiac detriments that are associated with maternal inhalation exposure to particulate matter during gestation. Further research is required to determine whether long non-coding RNA (lncRNA) distribution, for example, is altered as lncRNA has multiple regulatory roles including regulating translation, miRNA sequestration, guiding chromatin remodeling, and inhibiting or promoting binding of transcription factors and cofactors to gene promoters and thus control the transcription of target genes (16). It is thereby possible that several of these mechanisms are working together to result in a globally altered and sustained mitochondrial profile and ultimately chronically diminished cardiac function.

Although the focus of our research and others in the field of inhalation toxicology has prominently been epigenetics, there is an increasing amount of interest surrounding the epitranscriptome $(4,24,44)$. While both epigenetics and epitranscriptomics play a role in influencing gene expression, there is a distinct difference between the two. Epigenetics encompasses DNA modifications, histone modifications, and nucleosome occupancy, which can influence the structure of chromatin as well as the function of the genes that are affected (8). The most prevalently studied epigenetic modification is 5-methylcytosine $(5 \mathrm{mC})$, which was studied in Specific Aim 1 as mentioned previously. Epitranscriptomics, on the other hand, refers to posttranscriptional modifications in both coding and non-coding RNAs, with the most prominent modification being $\mathrm{N}^{6}$-methyladenosine $\left(\mathrm{m}^{6} \mathrm{~A}\right)$ (7). The study of the epitranscriptome is gaining traction as discoveries have verified that post-transcriptional modifications such as $\mathrm{m}^{6} \mathrm{~A}$ have their own set of writers (responsible for addition of the methylation mark(s)), erasers (responsible for removal of the methylation mark(s)), and readers (responsible for determining the fate of the 
mRNA with the methylation mark(s)). This has initiated a burgeoning field of possibilities in terms of researching and elucidating the effects that modifications have on gene expression, regulation, and furthermore their roles in diseases. This provides a new opportunity to understand not only the role of DNA modifications or RNA modifications individually, but the combined role they may be playing in disease and how one may influence the other (15). Because recent discoveries have established the link between environmental toxicant exposure and the most abundant mRNA modification, $\mathrm{m}^{6} \mathrm{~A}$, in the second part of my dissertation we wanted to determine whether this modification played a role in the acute and chronic repercussions on progeny gestationally exposed to ENM.

The objective of Specific Aim 2 was to determine whether enhanced mPHGPx expression preserves cardiac contractile function and bioenergetics in adult offspring following maternal ENM inhalation exposure, and whether $\mathrm{m}^{6} \mathrm{~A}$ methylation contributes to altered antioxidant capacity. Our study specifically focused on the mPHGPx mRNA and whether $\mathrm{m}^{6} \mathrm{~A}$ modifications played a role in the diminished mPHGPx activity found in adult offspring hearts following maternal ENM inhalation exposure. The reasoning behind the focus on the 3'UTR of mPHGPx specifically is two-fold; (1) the 3'UTR of mPHGPx contains the selenocysteine (Sec) incorporation machinery, which is vital for the catalytic activity of this enzyme to promote $\mathrm{H}_{2} \mathrm{O}_{2}$ scavenging and evade damage to the mitochondrial membrane, and (2) $\mathrm{m}^{6} \mathrm{~A}$ is highly enriched in the 3'UTR and around stop codons. Notably, this is of interest as changes to the Sec incorporation sequence (SECIS), the critical region located in the 3'UTR of mPHGPx, can alter the binding ability for the complex that recodes a "Stop" codon to a "Sec" codon and allows for the catalytic activity to be viable $(14,35)$. $\mathrm{M}^{6} \mathrm{~A}-\mathrm{RIP}-\mathrm{qPCR}$ for this particular region determined that there in fact was an increased amount of $\mathrm{m}^{6} \mathrm{~A}$ methylation occurring in wild-type offspring gestationally exposed to nano- $\mathrm{TiO}_{2}$, concomitant with decreased mPHGPx activity. These findings, though limited in terms of sample size, highlight the value of understanding the role of $\mathrm{m}^{6} \mathrm{~A}$ as it relates to epitranscriptomic reprogramming associated with sustained effects. However, a more broad scale approach would be beneficial in detailing other aspects of mPHGPx that may be altered through this prominent modification and whether these modifications are detrimental (as in the case presented in Specific Aim 2) or the possibility that the modification is actually necessary for proper function as is the case with the Sec tRNA. The epitranscriptomic writer, alkylation repair homolog 8 (ALKBH8), is a tRNA methyltransferase that adds methylation marks to the wobble 
uridine of the Sec tRNA to allow for synthesis of selenoproteins. (40) Without this methylation mark, selenoprotein levels are diminished and mitochondrial reprogramming ensues. Not investigated in this study is the likelihood that modulator proteins (readers and writers) are altered, but other studies have shown that environmental exposure to toxicants alters expression of RNA methylation modulator genes including METTL3, WTAP, FTO and ALKBH5. It is also of utmost importance that other genes be investigated that are required for mitochondrial function and ROS regulation. This can provide new targets for the prevention or treatment of ROS-induced cardiac effects in fetal and adult offspring of mother exposed to nanoparticulate matter during pregnancy.

As the importance of antioxidant defense and limiting ROS levels became abundantly clear through our preliminary studies, the potential of alleviating the adverse effects on fetal and adult offspring gestationally exposed to nano- $\mathrm{TiO}_{2}$ became of interest. Based off our laboratories previous work with the mPHGPx mouse models, this model was chosen at it increases $\mathrm{H}_{2} \mathrm{O}_{2}$ scavenging and thereby decreases mitochondrial ROS levels. This endeavor required implementation of a novel breeding strategy that would allow us to test the benefits of increased antioxidant capacity from several points of origin; (1) fetal, (2) maternal, as well as (3) fetal and maternal. Interestingly, our original prediction that the combined maternal environment mPHGPx overexpression and fetal pup mPHGPx overexpression protection would be the most protective profile, as compared to wild type pups from wild type mothers that were gestationally exposed to ENM was not supported. We did not expect to see that there was a trivial difference between the protection provided by just the maternal environment providing increased antioxidant defense and the combined maternal and fetal mPHGPx overexpression. This was therefore the first study to show that enhancing antioxidant defense in the mother during pregnancy may suffice for limiting cardiac and mitochondrial deficits associated with gestational nano- $\mathrm{TiO}_{2}$ inhalation exposure. Furthermore, the offspring of mPHGPx ENM-exposed mothers did not present with increased $\mathrm{m}^{6} \mathrm{~A}$ methylation in the mPHGPx 3'UTR region, unlike the offspring of wild type ENM-exposed dams. Despite the limitations associated with using a transgenic mouse model, this study unlocks the possibility that supplementation with a mitochondrially-targeted antioxidant therapeutic during pregnancy may be able to provide the same beneficial protection in humans, in regards to avoiding the repercussions of acute and sustained cardiac detriments, in offspring gestationally exposed to ENM. Mitigating ROS in the mother and gestational environment using a supplement, such as mitoquinol (a mitochondrially targeted form of CoQ10), is the next step in protecting future 
generations from the consequences of particulate matter exposure $(30,39)$. Furthermore, other antioxidant supplements may be of benefit, however, our study supports the beneficial role of targeting the mitochondrion specifically to protect from dysregulation and diminished bioenergetic function.

The objective of Specific Aim 3 was to determine whether disruption of mitochondrial bioenergetics and cardiovascular dysfunction elicited by maternal exposure can be attributed to epitranscriptomic remodeling that is associated with an altered mitochondrial proteome that is incapable of managing high levels of ROS. To gain a better understanding of the broad-scale $\mathrm{m}^{6} \mathrm{~A}$ changes that may be occurring at the fetal stage that result in long-term dysfunction, we performed $\mathrm{m}^{6} \mathrm{~A}-\mathrm{RIP}$-sequencing as well as label-free mitochondrial proteomics on fetal cardiac samples obtained following maternal inhalation exposure of sham air and nano- $\mathrm{TiO}_{2}$ aerosolized particles. The novelty of this study lies in the application of multi-omics approaches including epitrasncriptomics, transcriptomics, and proteomics. Such an approach is vital in moving the field forward, towards a more integrative approach that allows researchers to see the bigger picture while also understanding the detailed mechanisms involved with pathologies of not only the heart but all the organ systems. The connection between mitochondrial bioenergetic dysregulation and the mRNA expression levels presented in Figure 4.2D is apparent. All, but 2, mRNAs that are part of the electron transport chain complexes were significantly decreased in the nano- $\mathrm{TiO}_{2}$ gestationally exposed offspring. The possibility that this was an experimental fluke is rejected by the data presented in Supplemental Figure 4.2 which demonstrates the dynamic expression changes seen within other pathways. These data further substantiate the notion that there is a dysregulation of expression levels to pivotal genes, which then results in mitigation of mitochondrial activity previously reported by our laboratory (12, 20, 21, 26). Markedly, GPX4 mRNA expression was significantly decreased in fetal offspring gestationally exposed to ENM (Supplemental Figure 4.1). This is consistent with previously published data from our laboratory which determined that GPX4 activity (20) and GPX4 protein expression (21) were decreased in fetal and adult offspring, respectively, that were gestationally exposed to ENM.

As GPX proteins are selenoproteins, it is a reasonable assumption that the diminishment of GPX4 may be attributed to a decrease in selenium. Notably, unpublished data from our laboratory determined that following gestational ENM exposure, the only glutathione peroxidase 
proteins that were altered were GPX1 $(P a d j=0.005)$ and GPX8 $(P a d j=0.024)$. Although this is interesting, it leads us to believe that a limitation in selenium is likely not responsible for diminished GPX4 levels. The reason for that lies in the discovery that selenium is prioritized for synthesis of GPX4, therefore if selenium concentrations were the issue in this situation, we would expect all of the other GPX proteins to be decreased significantly as well (33). However, based on our unpublished data mRNA expression of other selenoproteins were significantly decreased including selenoprotein M (Padj=0.001), selenoprotein H $($ Padj $=0.029)$, and selenoprotein $\mathrm{W}$ $($ Padj $=0.005)$, but others were increased such as selenoprotein $\mathrm{T}($ Padj $=0.025)$, suggesting dynamic changes that are likely unrelated to selenium availability. This further indicates that a potential limited availability of selenium was not responsible for decreased GPX4 mRNA and activity. Other constituents of the oxidative stress pathway that should be considered are glutathione (GSH), catalase (CAT), superoxide dismutase (SOD), and peroxiredoxins (PRDX). Environmental stress, such as exposure to particulate matter can derive free radicals that react with oxygen, thereby producing superoxide, which can then result in either production of peroxynitrite (superoxide interacting with nitric oxide) or $\mathrm{H}_{2} \mathrm{O}_{2}$ via a dismutase reaction catalyzed by SOD (29). The antioxidant activities of CAT and GSH/GPX are then responsible for detoxifying the $\mathrm{H}_{2} \mathrm{O}_{2}$ produced in the previous step, otherwise hydroxyl radicals are produced via the Fenton reaction. It is therefore necessary to understand whether expression of these antioxidant enzymes is diminished following gestational ENM exposure, or if this suppression is only limited to GPX4. Unpublished data from our laboratory indicated that mRNA expression of the catalase was not changed $($ Padj $=0.060)$, while glutathione synthetase expression $($ Padj $=0.004)$ and SOD1 expression were significantly decreased $(P a d j=0.017)$. These data may therefore suggest that decreased GPX4 is not the only contributor to elevated ROS in offspring maternally exposed to ENM. However, protein expression levels of these members of the oxidative stress pathway were not examined due to the limitation that our proteomic assessments were performed on isolated mitochondria from cardiac tissue of fetal offspring. Nevertheless, protein expression data, presented in Chapter 4, highlights the apparent decrease in PRDX3 (Figure 4.6), which also scavenges $\mathrm{H}_{2} \mathrm{O}_{2}$ in mitochondria, as well as lipid peroxides and peroxynitrites, and is required to maintain normal mitochondrial function $(41,43)$. It is necessary that this pathway be further examined in order to truly be able to delineate if there is one specific antioxidant enzyme that can 
be supplemented in a mother during pregnancy to avoid the detriments to mitochondrial and contractile function seen in offspring.

Evaluation of the shared pathways seen between the genes with altered mRNA expression and $\mathrm{m}^{6} \mathrm{~A}$ levels determined that ubiquitin mediated proteolysis was the top pathway. This unexpected finding is intriguing as a recent study reported that YTHDF3 is involved in ubiquitin mediated proteolysis (42). As mentioned earlier, YTHDF3 affects translation and decay of methylated mRNAs depending on whether it is interacting with YTHDF1 (translation) or YTHDF2 (decay) (36). Modulating expression of YTHDF3 can therefore affect the RNA binding activity of the other two proteins, changing the fate of the $\mathrm{m}^{6} \mathrm{~A}$ methylated $\mathrm{mRNA}$ by altering stability. As part of the study done in Chapter 4, we found that YTHDF3 mRNA expression was significantly increased ( $\mathrm{Padj}=0.002)$ in offspring whose dams were exposed gestationally. Although this mechanism is far from elucidated, our research as well as research from other laboratories mentioned herein, suggest that explicating this connection may be valuable in better understanding how the fate of $\mathrm{m}^{6} \mathrm{~A}$ methylated mRNAs is regulated.

\section{Limitations}

The work presented within this dissertation contributes to the understanding of the shortcomings associated with increased ENM utilization and the possibility of circumventing these shortcomings using an accessible supplement during pregnancy. Nevertheless, there are limitations that must be taken into consideration. The inhalation exposure protocol utilized in all three Specific Aims involve a whole-body exposure, which results in not only inhalation exposure, but also dermal exposure. Additionally, as the mice continue to groom themselves throughout the exposure, ingestion of nano- $\mathrm{TiO}_{2}$ becomes a concern. Future studies should attempt to compare the difference in lung burden between a nose-only and whole-body exposure, as well as the presence of particles in the gastrointestinal tract. Furthermore, working with fetal samples presents the limitation of fetal tissue size. Tissue size resulted in restrictions in terms of the experiments we were able to run principally for understanding mitochondrial bioenergetics with the mPHGPx transgenic and wild type offspring. 
In Specific Aims 2 and 3, $\mathrm{m}^{6} \mathrm{~A}$ RNA immunoprecipitation ( $\mathrm{m}^{6} \mathrm{~A}(\mathrm{me})$-RIP) was employed in order to capture $\mathrm{m}^{6} \mathrm{~A}$ modified mRNAs. $\mathrm{M}^{6} \mathrm{~A}-\mathrm{RIP}$ is one of the most used methodologies for this purpose, but comes with limitations of its own. In general, this method does not have the ability to differentiate $\mathrm{N}^{6}$-methyladenosine $\left(\mathrm{m}^{6} \mathrm{~A}\right)$ from 6,2'-O-dimethyladenosine $\left(\mathrm{m}^{6} \mathrm{Am}\right)(19)$. Although $\mathrm{m}^{6} \mathrm{Am}$ is very limited, it still introduces an aspect of uncertainty as to what we are actually capturing with the RNA immunoprecipitation procedure. Future studies would benefit from utilizing $\mathrm{m}^{6} \mathrm{~A}$ individual-nucleotide resolution cross-linking and immunoprecipitation (miCLIP), which can accurately differentiate between the two modifications. This method still requires further development to accommodate for small sample sizes though. Lastly, $\mathrm{m}^{6} \mathrm{~A}-\mathrm{RIP}$ qPCR, which was used in Specific Aim 2, is restricted by the fact that the it has high variation among biological replicates and therefore requires a greater number of replicates for reliable data (19). Similarly, $\mathrm{m}^{6} \mathrm{~A}-\mathrm{RIP}$-seq, which was used in Specific Aim 3, is limited by the high risk of false positive results. Further validation of the results with either a more reliable method such as miCLIP or with a greater sample size is needed in ordered to definitively be able to confirm the reprogramming phenotype seen in the fetal offspring.

The proteomics analysis performed in Specific Aim 3, though interesting, is limited by sample size and therefore statistical analyses were not possible. To achieve the protein concentrations necessary to perform label-free proteomics, fetal cardiac mitochondrial samples were pooled from 2 mother's litters per each exposure group (sham/nano- $\mathrm{TiO}_{2}$ ). In order to verify the findings presented in our study, it is of utmost importance that these studies be repeated with a greater sample size that will allow for more tangible answers.

\section{Future Directions}

In the US between 2011 and 2012, 5,300 children and adolescents (10-19 years old) were diagnosed with type 2 diabetes and $\sim 90 \%$ of adults diagnosed with type 2 diabetes were overweight or obese (38). With the growing prevalence of obesity and metabolic syndromes such as type 2 diabetes, assessment of prominent environmental risk factors must be elucidated. Like the suggested effects of ENMs on $\mathrm{m}^{6} \mathrm{~A}$, recent studies have reported that in type 2 diabetic patients, $\mathrm{m}^{6} \mathrm{~A}$ was significantly reduced in peripheral blood RNA, concomitant with an upregulation of the demethylase FTO (34). Based on the similarities in metabolic pathways that are altered by both 
inhaled particle exposure and high-fat diet-induced obesity (27), future investigations should focus on understanding whether maternal exposure to inhaled particles during pregnancy predisposes offspring to type 2 diabetes in young adulthood. A potential starting point for such studies would likely include "omics" based approaches that include epitrasncriptomics, proteomics, metabolomics, and epigenomics profiling which will allow for a better understanding of the mechanisms (i.e. inflammation and oxidative stress) that are activated due to inhaled particle exposure and play instrumental roles in eliciting cardiovascular deficits. Specifically, future studies should investigate the role of NF-KB in offspring whose dams were gestationally exposed. NF-KB is associated with insulin resistance, obesity, and atherosclerosis, which have overlapping pathways with what is seen following exposure (23). $\mathrm{H}_{2} \mathrm{O}_{2}$ has the ability to result in translocation of NF-KB so understanding how ROS influences this pivotal mediatory of inflammatory responses and how the two work hand in hand, will allow for a better understanding of different mechanisms driving ROS accumulation and long term mitochondrial and cardiac health effects.

As previously discussed, blood flow to the placenta may plays a critical role in initiation of the series of events that occur leading to long term cardiac contractile and mitochondrial dysfunction. Future studies should attempt to assess blood flow and the inflammatory pathways that likely contribute to elevated ROS levels as well as potential endothelial dysfunction. A thorough examination of other forms of ROS such as nitric oxide and xanthine oxidase may also provide more insight into the mechanisms involved. Understanding these key aspects will allow for a more complete picture of the mechanisms in place, thereby making a more clear path for treatment and prevention.

As indicated by the findings from our laboratory and others, enhancing antioxidant defense is a plausible route to investigate as a prophylactic and/or therapeutic strategy. Although our studies used genetic modification to overexpress the ROS scavenging antioxidant protein, mPHGPx, there are other forms of mitochondrially targeted antioxidants that should be evaluated in the context of inhaled particle exposure and its associated mechanisms. As indicated by our recent study (Chapter 3) (20), increasing maternal antioxidant defense was sufficient to protect the offspring from long-term adverse cardiac and mitochondrial functional alterations. The clinical relevance of this study is one that is highlighted by the suggestion that a antioxidant strategy that is delivered to the pregnant mother may allow for complete evasion of pollutant-associated long- 
term cardiovascular defects in offspring. One example of a deliverable antioxidant strategy that has recently gained traction is mitoquinone mesylate (Mito-Q). A recent study that investigated the effects of vehicle exhausted exposure as a form of toxicological stress that leads to behavioral deficits utilized Mito-Q to ameliorate oxidative stress levels that were triggering mitochondrial impairment in the brain (32). Treating the mother during pregnancy with Mito-Q may serve a similar protective profile for the progeny as the mPHGPx overexpression, thereby limiting ROS upsurges during inhaled particle exposure and avoiding mitochondrial bioenergetic dysregulation. This would likely allow for the maintenance of normal cardiac function at both the fetal and adult stages in progeny.

\section{Conclusions}

Overall, the data presented within this dissertation strongly support the idea that maternal inhalation exposure to ENM results in differentially altered epigenetic and epitranscriptomic methylation status in progeny cardiac tissue at both the fetal and adult stages of life. These changes culminate in a mitochondrial phenotype that is associated with a high ROS environment, bioenergetic dysregulation, and ultimately, cardiac dysfunction. These studies also demonstrate a potential supplemental preventative measure that can be administered to mitigate the effects of gestational toxicant inhalation exposure. Based on the data presented within this dissertation, we accept the hypothesis that changes in the $\mathrm{m}^{6} \mathrm{~A}$ methylome, concomitant with an altered mitochondrial proteome at the fetal stage, precipitate cardiac contractile dysfunction that is sustained into adulthood following maternal ENM inhalation exposure. The novelty of epitranscriptomic and epigenetic modifications studied herein advances the field such that it provides a stepping stone for future studies to assess the interactions of these modifications and how they can be exploited for therapeutic strategies. A summary of the overall conclusions and findings within this dissertation is illustrated in Figure 5.1. 
Figure 5.1: Specific Aims Overview

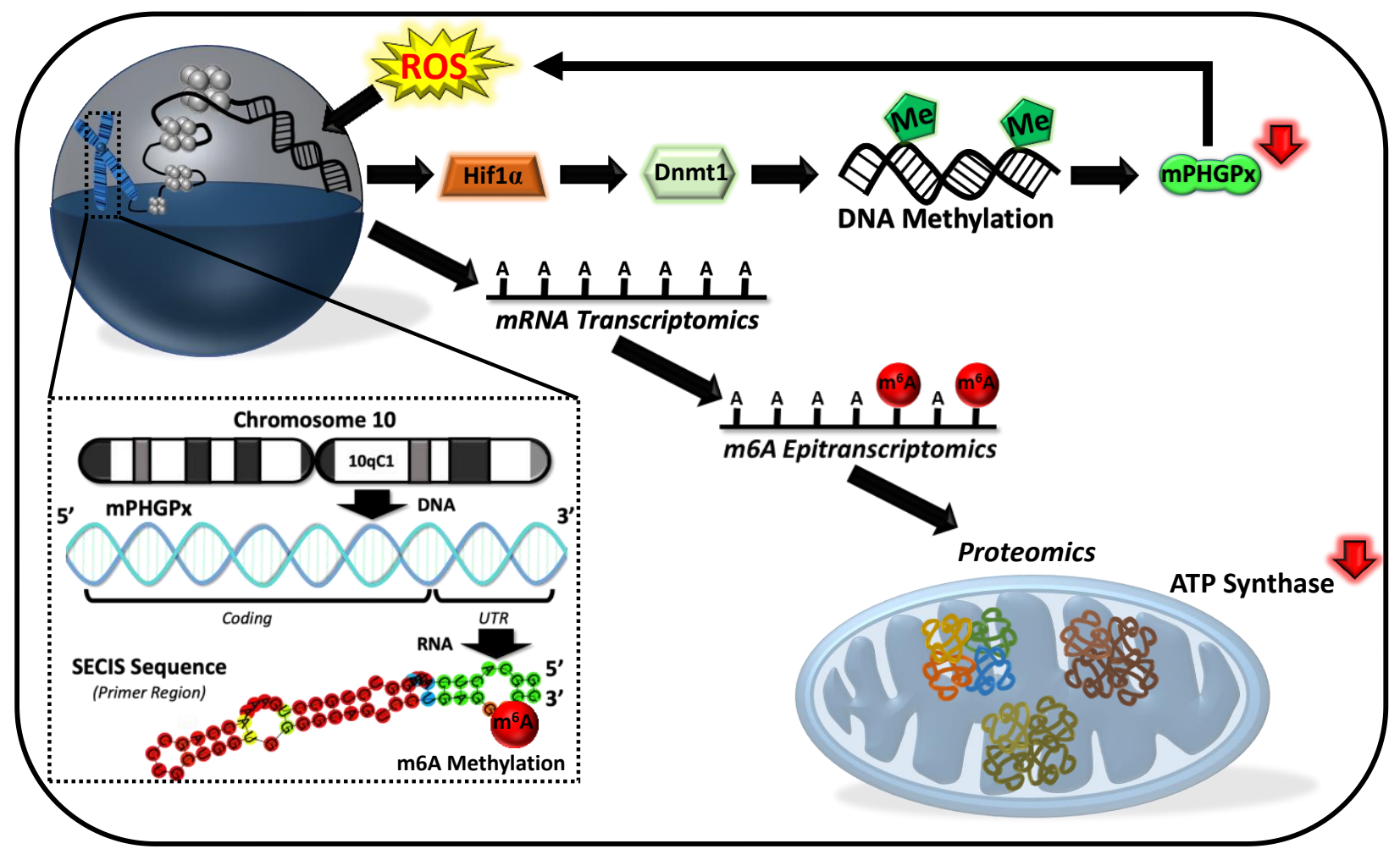




\section{References}

1. Abukabda AB, Bowdridge EC, McBride CR, Batchelor TP, Goldsmith WT, Garner KL, Friend S, and Nurkiewicz TR. Maternal titanium dioxide nanomaterial inhalation exposure compromises placental hemodynamics. Toxicol Appl Pharmacol 367: 51-61, 2019.

2. Bommarito PA, Martin E, and Fry RC. Effects of prenatal exposure to endocrine disruptors and toxic metals on the fetal epigenome. Epigenomics 9: 333-350, 2017.

3. Bowdridge EC, Abukabda AB, Engles KJ, McBride CR, Batchelor TP, Goldsmith WT, Garner KL, Friend S, and Nurkiewicz TR. Maternal Engineered Nanomaterial Inhalation During Gestation Disrupts Vascular Kisspeptin Reactivity. Toxicol Sci 169: 524-533, 2019.

4. Cayir A, Barrow TM, Guo L, and Byun HM. Exposure to environmental toxicants reduces global N6-methyladenosine RNA methylation and alters expression of RNA methylation modulator genes. Environ Res 175: 228-234, 2019.

5. Crispi F, Miranda J, and Gratacos E. Long-term cardiovascular consequences of fetal growth restriction: biology, clinical implications, and opportunities for prevention of adult disease. Am J Obstet Gynecol 218: S869-S879, 2018.

6. Dabkowski ER, Baseler WA, Williamson CL, Powell M, Razunguzwa TT, Frisbee JC, and Hollander JM. Mitochondrial dysfunction in the type 2 diabetic heart is associated with alterations in spatially distinct mitochondrial proteomes. Am J Physiol Heart Circ Physiol 299: H529-540, 2010.

7. Dominissini D, Moshitch-Moshkovitz S, Schwartz S, Salmon-Divon M, Ungar L, Osenberg S, Cesarkas K, Jacob-Hirsch J, Amariglio N, Kupiec M, Sorek R, and Rechavi G. Topology of the human and mouse m6A RNA methylomes revealed by m6A-seq. Nature 485: 201-206, 2012.

8. Fico A, Di Croce L, and Matarazzo MR. Interplay between DNA and RNA Modifications: A Constantly Evolving Process. Epigenomes 4: 26, 2020.

9. Fournier SB, D'Errico JN, and Stapleton PA. Uterine Vascular Control Preconception and During Pregnancy. Compr Physiol 11: 1871-1893, 2021.

10. Fournier SB, Kallontzi S, Fabris L, Love C, and Stapleton PA. Effect of Gestational Age on Maternofetal Vascular Function Following Single Maternal Engineered Nanoparticle Exposure. Cardiovasc Toxicol 19: 321-333, 2019.

11. Hathaway QA, Durr AJ, Shepherd DL, Pinti MV, Brandebura AN, Nichols CE, Kunovac A, Goldsmith WT, Friend SA, Abukabda AB, Fink GK, Nurkiewicz TR, and JM aH. miRNA-378a as a key regulator of cardiovascular health following engineered nanomaterial inhalation exposure. Nanotoxicology 1-20, 2019.

12. Hathaway QA, Durr AJ, Shepherd DL, Pinti MV, Brandebura AN, Nichols CE, Kunovac A, Goldsmith WT, Friend SA, Abukabda AB, Fink GK, Nurkiewicz TR, and Hollander JM. miRNA-378a as a key regulator of cardiovascular health following engineered nanomaterial inhalation exposure. Nanotoxicology 1-20, 2019.

13. Hou L, Zhang X, Wang D, and Baccarelli A. Environmental chemical exposures and human epigenetics. Int J Epidemiol 41: 79-105, 2012.

14. Ingold I, Berndt C, Schmitt S, Doll S, Poschmann G, Buday K, Roveri A, Peng X, Porto Freitas F, Seibt T, Mehr L, Aichler M, Walch A, Lamp D, Jastroch M, Miyamoto S, Wurst W, Ursini F, Arner ESJ, Fradejas-Villar N, Schweizer U, Zischka H, Friedmann Angeli JP, and Conrad M. Selenium Utilization by GPX4 Is Required to Prevent HydroperoxideInduced Ferroptosis. Cell 172: 409-422 e421, 2018. 
15. Kan RL, Chen J, and Sallam T. Crosstalk between epitranscriptomic and epigenetic mechanisms in gene regulation. Trends Genet 2021.

16. Karlsson O, and Baccarelli AA. Environmental Health and Long Non-coding RNAs. Curr Environ Health Rep 3: 178-187, 2016.

17. Kelley AS, Banker M, Goodrich JM, Dolinoy DC, Burant C, Domino SE, Smith YR, Song PXK, and Padmanabhan V. Early pregnancy exposure to endocrine disrupting chemical mixtures are associated with inflammatory changes in maternal and neonatal circulation. Sci Rep 9: 5422, 2019.

18. Kisucka J, Chauhan AK, Patten IS, Yesilaltay A, Neumann C, Van Etten RA, Krieger M, and Wagner DD. Peroxiredoxin1 prevents excessive endothelial activation and early atherosclerosis. Circ Res 103: 598-605, 2008.

19. Kumari R, Ranjan P, Suleiman ZG, Goswami SK, Li J, Prasad R, and Verma SK. mRNA modifications in cardiovascular biology and disease: with a focus on m6A modification. Cardiovasc Res 2021.

20. Kunovac A, Hathaway QA, Pinti MV, Durr AJ, Taylor AD, Goldsmith WT, Garner KL, Nurkiewicz TR, and Hollander JM. Enhanced antioxidant capacity prevents epitranscriptomic and cardiac alterations in adult offspring gestationally-exposed to ENM. Nanotoxicology 1-20, 2021.

21. Kunovac A, Hathaway QA, Pinti MV, Goldsmith WT, Durr AJ, Fink GK, Nurkiewicz TR, and Hollander JM. ROS promote epigenetic remodeling and cardiac dysfunction in offspring following maternal engineered nanomaterial (ENM) exposure. Part Fibre Toxicol 16: 24, 2019.

22. Lee MY, Leonardi A, Begley TJ, and Melendez JA. Loss of epitranscriptomic control of selenocysteine utilization engages senescence and mitochondrial reprogramming(). Redox Biol 28: 101375, 2020.

23. Liu T, Zhang L, Joo D, and Sun SC. NF-kappaB signaling in inflammation. Signal Transduct Target Ther 2: 2017.

24. Malovic E, Ealy A, Kanthasamy A, and Kanthasamy AG. Emerging Roles of N6Methyladenosine (m6A) Epitranscriptomics in Toxicology. Toxicol Sci 181: 13-22, 2021.

25. Miller MR, Shaw CA, and Langrish JP. From particles to patients: oxidative stress and the cardiovascular effects of air pollution. Future Cardiol 8: 577-602, 2012.

26. Nichols CE, Shepherd DL, Hathaway QA, Durr AJ, Thapa D, Abukabda A, Yi J, Nurkiewicz TR, and Hollander JM. Reactive oxygen species damage drives cardiac and mitochondrial dysfunction following acute nano-titanium dioxide inhalation exposure. Nanotoxicology 12: 32-48, 2018.

27. Niemann B, Rohrbach S, Miller MR, Newby DE, Fuster V, and Kovacic JC. Oxidative Stress and Cardiovascular Risk: Obesity, Diabetes, Smoking, and Pollution: Part 3 of a 3-Part Series. J Am Coll Cardiol 70: 230-251, 2017.

28. Pietroiusti A, Stockmann-Juvala H, Lucaroni F, and Savolainen K. Nanomaterial exposure, toxicity, and impact on human health. Wiley Interdiscip Rev Nanomed Nanobiotechnol 2018.

29. Redza-Dutordoir M, and Averill-Bates DA. Activation of apoptosis signalling pathways by reactive oxygen species. Biochim Biophys Acta 1863: 2977-2992, 2016.

30. Ribeiro Junior RF, Dabkowski ER, Shekar KC, KA OC, Hecker PA, and Murphy MP. MitoQ improves mitochondrial dysfunction in heart failure induced by pressure overload. Free Radic Biol Med 117: 18-29, 2018. 
31. Robichaud CO, Uyar AE, Darby MR, Zucker LG, and Wiesner MR. Estimates of upper bounds and trends in nano-TiO2 production as a basis for exposure assessment. Environ Sci Technol 43: 4227-4233, 2009.

32. Salvi A, Liu H, and Salim S. Involvement of oxidative stress and mitochondrial mechanisms in air pollution-related neurobiological impairments. Neurobiol Stress 12: 100205, 2020 .

33. Schriever SC, Barnes KM, Evenson JK, Raines AM, and Sunde RA. Selenium requirements are higher for glutathione peroxidase-1 mRNA than gpx1 activity in rat testis. Exp Biol Med (Maywood) 234: 513-521, 2009.

34. Shen F, Huang W, Huang JT, Xiong J, Yang Y, Wu K, Jia GF, Chen J, Feng YQ, Yuan BF, and Liu SM. Decreased N(6)-methyladenosine in peripheral blood RNA from diabetic patients is associated with FTO expression rather than ALKBH5. J Clin Endocrinol Metab 100: E148-154, 2015.

35. Shetty SP, and Copeland PR. Selenocysteine incorporation: A trump card in the game of mRNA decay. Biochimie 114: 97-101, 2015.

36. Shi H, Wang X, Lu Z, Zhao BS, Ma H, Hsu PJ, Liu C, and He C. YTHDF3 facilitates translation and decay of N(6)-methyladenosine-modified RNA. Cell Res 27: 315-328, 2017.

37. Stapleton PA, Hathaway QA, Nichols CE, Abukabda AB, Pinti MV, Shepherd DL, McBride CR, Yi J, Castranova VC, Hollander JM, and Nurkiewicz TR. Maternal engineered nanomaterial inhalation during gestation alters the fetal transcriptome. Part Fibre Toxicol 15: 3, 2018.

38. Statistics NCfH. 2011-2014 National Health and Nutrition Examination Survey (NHANES). edited by Prevention CfDCa.

39. Sukjamnong S, Chan YL, Zakarya R, Nguyen LT, Anwer AG, Zaky AA, Santiyanont R, Oliver BG, Goldys E, Pollock CA, Chen H, and Saad S. MitoQ supplementation prevent long-term impact of maternal smoking on renal development, oxidative stress and mitochondrial density in male mice offspring. Sci Rep 8: 6631, 2018.

40. Truitt ML, and Ruggero D. New frontiers in translational control of the cancer genome. Nat Rev Cancer 17: 332, 2017.

41. Wonsey DR, Zeller KI, and Dang CV. The c-Myc target gene PRDX3 is required for mitochondrial homeostasis and neoplastic transformation. Proc Natl Acad Sci U S A 99: 66496654, 2002.

42. Xu D, Shao J, Song H, and Wang J. The YTH Domain Family of N6-Methyladenosine "Readers" in the Diagnosis and Prognosis of Colonic Adenocarcinoma. Biomed Res Int 2020: 9502560, 2020.

43. Zhang H, Go YM, and Jones DP. Mitochondrial thioredoxin-2/peroxiredoxin-3 system functions in parallel with mitochondrial GSH system in protection against oxidative stress. Arch Biochem Biophys 465: 119-126, 2007.

44. Zhang S, Meng P, Cheng S, Jiang X, Zhang J, Qin X, Tang Q, Bai L, Zou Z, and Chen C. Pregnancy exposure to carbon black nanoparticles induced neurobehavioral deficits that are associated with altered m(6)A modification in offspring. Neurotoxicology 81: 40-50, 2020.

45. Zhao Q, Sun Q, Zhou L, Liu K, and Jiao K. Complex Regulation of Mitochondrial Function During Cardiac Development. J Am Heart Assoc 8: e012731, 2019. 


\section{Chapter 6: Supplemental}

\section{Left Ventricular Segmental Stress-Strain Identifies Unique Myocardial Deformation Patterns Following Intrinsic and Extrinsic Stressors in Mice}

Amina Kunovac, BS ${ }^{1,2}$, Quincy A. Hathaway, $\mathrm{PhD}^{3}$, Emily N. Burrage, BS ${ }^{4}$, Tyler Coblentz, BS ${ }^{1}$, Eric E. Kelley, $\mathrm{PhD}^{5}$, Partho P. Sengupta, MD, DM ${ }^{3,6}$, John M. Hollander, $\mathrm{PhD}^{1,2}$, Paul D. Chantler, $\mathrm{PhD}^{1,2,4}$

Manuscript Under Review at Ultrasound in Medicine and Biology (Manuscript Number: UMB-

D-21-00654)

\footnotetext{
${ }^{1}$ Division of Exercise Physiology, West Virginia University, School of Medicine, Morgantown, WV, USA, ${ }^{2}$ Mitochondria, Metabolism \& Bioenergetics Working Group, West Virginia University, Morgantown, WV, USA, ${ }^{3}$ Heart and Vascular Institute, West Virginia University, Morgantown, WV, USA, ${ }^{4}$ Department of Neuroscience, West Virginia University, School of Medicine, Morgantown, WV, USA, ${ }^{5}$ Department of Physiology and Pharmacology, West Virginia University, School of Medicine, Morgantown, WV, USA, ${ }^{6}$ Rutgers Robert Wood Johnson University Hospital, New Brunswick, NJ, USA.
}

Running Title: Identifying Unique Patterns of Myocardial Deformation

\section{Corresponding Author}

Quincy A. Hathaway, PhD

PO Box 9227

Room 3033-A HSC North

1 Medical Center Drive, Morgantown, WV 26506.

Phone: 724-255-4637

Email: qahathaway@mix.wvu.edu 


\begin{abstract}
We utilized segmental stress strain analysis to evaluate whether intrinsic (diet-induced obesity (DIO)) and extrinsic (unpredictable chronic mild stress (UCMS)) stressors can alter deformational patterns of the left ventricle and act as a unique "fingerprint" for characterization. 6-week-old, male C57BL/6J mice were randomized into lean or obese groups ( $\mathrm{N}=24 /$ group). The obese group underwent 12 weeks of DIO with a high-fat diet (HFD). At 18 weeks, lean and obese mice were further randomized into UCMS and non-UCMS groups to elicit a chronically stressed phenotype (UCMS; 7 hrs/day, 5 days/week, for 8 weeks). M-Mode, Pulse-Wave Doppler, and speckle tracking echocardiography were assessed at baseline (6 weeks), post-HFD (18 weeks), and post-UCMS (26 weeks). Supervised machine learning with 10-fold cross validation was applied to the DIO and UCMS groups. Comparing obese to lean mice, the machine learning model provided robust prediction (AUC: 0.921), radial strain of the lateral wall and anterior free wall being most important. Changes in radial strain of the lateral wall $(-64 \%, \mathrm{P} \leq 0.001)$ and anterior free wall $(-53 \%, \mathrm{P}<0.001)$ were more dramatically altered than ejection fraction $(-9 \%, \mathrm{P}<0.001)$ and global longitudinal strain $(-16 \%, \mathrm{P}=0.08)$. The ability to predict mice that underwent UCMS, irrespective of diet, was assessed (AUC: 0.886) revealing longitudinal strain rate of the anterior mid wall and radial strain of the posterior septal wall as the top features. The wall segments indicate a predilection for changes in deformation patterns to the free wall (DIO) and septal wall (UCMS), indicating disease-specific alterations to the myocardium.
\end{abstract}




\section{Introduction}

Cardiovascular diseases contribute to nearly one-third of all deaths in the world, accounting for 17.9 million deaths in 2019 (2). Left ventricular (LV) dysfunction plays a major role in precipitating mortality in the context of cardiovascular diseases, which heightens the need for a better understanding of LV pathology. In general, overt functional and/or structural modifications of the LV begin as subclinical modifications at the molecular and cellular level that further culminate into adverse clinical outcomes (5). Being able to predict how stressors will modify the LV is important in both a basic understanding of the disease and how to model treatment options.

The initial clinical findings of pathological changes to the LV can be observed using stressstrain parameters. Speckle tracking stress-strain can identify deformation patterns across a variety of regions within the LV, including the longitudinal, circumferential, and radial axes. Global longitudinal strain (GLS) has been used as a marker for predicting outcomes, such as all-cause mortality (24) and morbidity (4), as well as cardiovascular disease (22). The measurement of stress-strain parameters, such as GLS, has also been shown to be more reproducible than left ventricular ejection fraction, regardless of the level of expertise of the technician (11). While GLS is a powerful measurement for modeling the early changes in deformation patterns of the LV, it does not address how varying insults could preferentially affect certain areas of the LV myocardium, and if these regions can act as a "fingerprint" in the identification of an insult retrospectively.

The current study investigates a novel concept that suggests a role for different forms of physiological stressors to cause unique deformational patterning of the LV. We investigate how diet-induced obesity (DIO) and unpredictable chronic mild stress (UCMS) alter stress-strain parameters in the murine LV and if they can be differentiated from one another. Our findings highlight how segmental stress-strain parameters, when compared to other common echocardiographic techniques, provide superior predictive power in correctly identifying DIO and UCMS animals. Additionally, segmental patterns of deformation are unique across these physiological insults, with changes in segmental stress-strain clearly identifiable even in animals that have already undergone LV remodeling (i.e., DIO). 


\section{Methods}

Murine Model and Diet-Induced Obesity (DIO) Protocol

6-week-old male C57BL/6J mice (Stock No: 000664; The Jackson laboratory. ME, USA) were randomized into lean $(\mathrm{N}=24)$ or obese $(\mathrm{N}=24)$ groups. Mice in the obese group underwent 12 weeks of diet induced obesity (DIO) (Research Diet D12492; NJ, USA) with a caloric composition of $20 \mathrm{kcal} \%$ protein, $20 \mathrm{kcal} \%$ carbohydrate, and $60 \mathrm{kcal} \%$ fat. To elicit a chronically stressed phenotype at 18 weeks of age, mice in the lean and obese groups were further randomized into unpredictable chronic mild stress (UCMS) and non-UCMS groups. The final groups reflect lean non-UCMS $(\mathrm{N}=12)$, lean-UCMS $(\mathrm{N}=12)$, obese-non-UCMS $(\mathrm{N}=12)$, and obese-UCMS $(\mathrm{N}=12)$ at 26 weeks old. Body weight was measured in the morning at 6,18 and 26 weeks of age. At 26 weeks of age, mice were euthanized. All experiments used only male mice. All animal studies, including animal housing, sedation, euthanasia, and experimentation were approved by The West Virginia University Animal Care and Use Committee and conformed to the most current National Institutes of Health (NIH) Guidelines for the Care and Use of Laboratory Animals manual.

\section{Unpredictable Chronic Mild Stress (UCMS) Protocol}

The UCMS protocol is a well-defined model to induce a depressive state in rodents (29). Rodents undergoing UCMS manifest with clinically relevant depressive symptoms such as anhedonia and learned helplessness (29) with alterations in brain structure and function parallel to clinical depression (16). Mice were singly housed in UCMS groups, and exposed to the following mild environmental stressors in randomly chosen sequences for 8 hours each day, 5 days/week, over the course of 8 weeks:

1. Damp bedding - 10 oz. of water was added to each standard cage.

2. Bath - all bedding was removed and $\sim 0.5$ inches of water was added to empty cage. Water temperature was room temperature, $\sim 24^{\circ} \mathrm{C}$.

3. Cage Tilt - cage was tilted to 45 degrees without bedding.

4. Social stress - each rat was switched into a cage of a neighboring mouse.

5. No bedding - all bedding was removed from the cage.

6. Alteration of light/dark cycles -turning lights off/on in random increments for scheduled 
period.

\section{Echocardiography}

Mice were anesthetized with inhaled isoflurane at $2.5 \%$ in combination with $100 \%$ oxygen (25). Imaging was performed while mice were maintained under anesthesia using $1 \%$ isoflurane. Vital signs were measured using a rectal probe to monitor temperature and limb leads for electrocardiogram. A $32-55 \mathrm{MHz}$ linear array transducer was used to acquire ultrasound images with the Vevo2100 Imaging System (Visual Sonics, Toronto, Canada) at a frame rate of 200-425 frames/second. A trained, ultrasound technician at the West Virginia University Animal Models and Imaging Facility performed all imaging. M-mode images were acquired at the mid-papillary level of the LV in the parasternal short axis, with LV volumes and masses calculated through the Vevo2100 system. Measurements in M-mode were calculated over four consecutive cardiac cycles and averaged. M-Mode and pulse-wave (PW) Doppler tracings were divided between two skilled technicians who were blinded to the assigned groups.

\section{Speckle Tracking Echocardiography}

Strain analysis was applied to B-Mode videos captured in the parasternal short and long axes using the Visual Sonics VevoStrain software (Toronto, Canada) (25). Using speckle tracking software, points were designated along with endocardium and epicardium of the LV. The LV in parasternal short axis was segmented into six regions of interest: anterior free (AF), lateral (L), posterior (P), inferior free (IF), posterior septum (PS), and anterior septum (AS). Additionally, the $\mathrm{LV}$ in parasternal long axis was segmented into six regions of interest: anterior base (AB), anterior mid (AM), anterior apex (AA), posterior apex (PA), posterior mid (PM), and posterior base (PB). All of the individual segments were used in the proceeding analyses. Strain and strain rate were used for subsequent analyses. Doppler tracings were divided between two skilled technicians who were blinded to the assigned groups.

\section{Machine Learning Pipeline}

Features from M-Mode ( $\mathrm{N}=14)$, PW Doppler ( $\mathrm{N}=13)$, strain analysis $(\mathrm{N}=57)$, as well as features including heart rate, root mean square of successive difference between heart beats (RMSSD), and dyssynchrony were used for analyses. Multicollinearity of features were assessed 
using corrplot (v.0.90) (27) in R (v4.0.3). Machine learning was performed using BigML (https://bigml.com. BigML, Inc. Corvallis, Oregon, USA, 2011) using a mixed supervised/unsupervised platform (AutoML). A 75\% training/testing and 25\% holdout spilt was implemented to separate the data along with 10 -fold cross validation. The top 3 most predictive models built on the $75 \%$ training/testing set were combined into a fusion model that was evaluated on the $25 \%$ holdout data. The evaluation data was extracted from BigML and used in the $\mathrm{R}$ environment to generate receiver operating characteristic (ROC) curves using pROC (v1.17.0.1) (21) and ggplot2 (v3.3.3) (28). Feature importance was assessed using packages randomForest (v.4.6-14) (12) and rfUtilities (v.2.1-5) (9) in R. All code can be found here: https://github.com/qahathaway/DIO_and_UCMS.

\section{Statistics}

All statistical analyses were performed using GraphPad Prism v9.1.0 (GraphPad Software). Outliers were first removed using a ROUT test prior to analyses. On clean data, the D'AgostinoPearson omnibus (K2) test was implemented to determine whether the data were normally distributed. Correlation tests were implemented to determine whether normalization of hemodynamic parameters using body weights or LV mass was necessary. For normally distributed data, the Pearson correlation coefficients were computed whereas the nonparametric Spearmen correlation was applied to non-normally distributed data. Normally distributed data were then analyzed using either a one-way analysis of variance test (ANOVA) (Tukey's post hoc test) or a two-sided unpaired Student's t-test. Data that did not follow Gaussian distribution were analyzed using either a Kruskal-Wallis test (Dunn's post hoc test) or a Mann Whitney test, depending on the number of groups being compared. Significant differences between paired ROC curves were evaluated using DeLong's test $(7,21,26)$. Results were considered statically significant if $P \leq$ 0.05. All data are reported as the means \pm the standard error of the mean (SEM). 


\section{Results}

Study Paradigm

An overview of the study design is provided to illustrate the three timepoints that were assessed in our analyses (Figure 6.1A). Briefly, echocardiography was performed at weeks 6, 18, and 26. High fat diet (HFD) was administered for 12 weeks followed by 8 weeks of unpredictable chronic mild stress (UCMS). Body weights were assessed at each time point (Figure 6.1B). As expected, in the presence of a 12-week HFD regime the obese group gained 18.72 grams while the lean group only gained 7.33 grams compared to their baseline assessments. In the presence of UCMS, the HFD mice failed to gain more weight, unlike their non-UCMS counterparts. Additionally, the weight lost by the lean group of mice was statistically significant in the UCMS group, but not the non-UCMS group (Figure 6.1B).

\section{Traditional Echocardiographic Assessments}

First, we wanted to understand if functional and structural changes of the LV would be observed following HFD. Measures of systolic and diastolic function for the baseline (6-week-old) and post-diet (18-week-old) animals are provided for M-Mode (Table 6.1) and PW Doppler (Table 6.2). The lean group of animals (18-week-old) compared to their baseline assessments (6week-old) revealed increased ejection fraction (EF) (88.33\% vs. 81.80\%) and fractional shortening (FS) $(60.11 \%$ vs. $50.88 \%)$ and decreased systolic volumes $(3.828 \mu 1$ vs. $7.997 \mu 1)$ (Table 6.1), but did not exhibit significant changes in left ventricle (LV) mass (120.5 mg vs $109.8 \mathrm{mg})$. The obese group of animals (18-week-old) presented with a significantly decreased EF (76.38\% vs. 88.33\%) and FS (45.32\% vs. $60.11 \%)$ compared to the lean cohort (18-week-old) with a significantly elevated LV mass (150.7 mg vs. $120.5 \mathrm{mg}$ ) and stroke volume (38.35 $\mu \mathrm{l}$ vs. $26.72 \mu \mathrm{l})$ (Table 6.1). PW Doppler also revealed other poorly adaptive functional changes in the obese group (Table 6.2). This included decreases in the obese groups MV A $(333.0 \mathrm{~mm} / \mathrm{s}$ vs. $395.6 \mathrm{~mm} / \mathrm{s})$ and increased E/A ratio (1.869 vs. 1.583) compared to their baseline. These data suggest that the obese cohort (18-week-old) has both LV functional impairments, through decreased pump efficiency (lower EF and FS), as well as changes in atrial function (lower MV A and higher E/A ratio). The functional changes, along with increased LV mass and stroke volume, indicate the burden of the 
HFD on cardiovascular function in the obese animals. Comparisons not discussed (Table 6.1 and Table 6.2) as well as the individual data points (Additional File 6.1) are provided.

\section{Speckle Tracking Echocardiography and Data Discovery Pathway}

Our next step was to apply the stress strain workflow to the B-Mode videos in the parasternal short and long axes (Figure 6.2A), which included segmental strain analysis. The LV segments are anatomically defined regions of the myocardium in both the short (Figure 6.2A) and long (Figure 6.2B) axes. The raw data obtained from these analyses are included (Additional File 6.1). Now, with data including M-Mode, PW Doppler, and segmental strain for the baseline (6week-old) and the lean (18-week-old) and obese (18-week-old) cohorts, we applied our machine learning pipeline (Figure 6.2C). We first examined the data for the existence of strong collinearity within our feature sets (Supplemental Figure 6.1) and removed features with strong correlations $(>0.85)$ to decrease selection bias within the machine learning algorithms. Our machine learning pipeline included a mixed supervised/unsupervised platform that allowed for discovery of unique connections (unsupervised) and objective evaluations of the model (supervised).

\section{Machine Learning - Obese versus Non-Obese}

Our objective was to compare non-obese animals ( $\mathrm{N}=72$, baseline + lean groups) with obese animals ( $\mathrm{N}=24$, obese group) to determine the predictive accuracy of our features for correctly identifying each animal into its respective group. Compiling all features together from M-Mode, PW Doppler, and strain analysis, there was a strong predictive accuracy (AUC: 0.969) for correctly delineating between obese and non-obese animals (Figure 6.3A, line 1). We then wanted to elucidate whether specific echocardiographic assessments (i.e. M-Mode, PW Doppler, or strain analysis) provided additional insights. There were no differences when comparing the compiled dataset to M-Mode (AUC: 0.969 vs. 0.968, $P=0.99$ ) (Figure 6.3A, line 2) and strain analysis (AUC: 0.969 vs. $0.938, P=0.25$ ), (Figure 6.3A, line 4) but a significant difference when only PW Doppler was used (AUC: 0.969 vs. 0.746, $P=0.05$ ) (Figure 6.3A, line 3). We further wanted to understand what features were most important in the construction of the machine learning model. 
Using feature importance through randomForest, we show that the top two most important features in predicting obese vs. non-obese animals were radial strain of the anterior free wall and LV mass (Figure 6.3B). We also include the statistics for the top five most important features, as defined by randomForest (Figure 6.3C). Of note, four of the five top features were strain-based parameters, with only one parameter from M-Mode. Also, strain features offer a greater percent difference between groups (radial strain of the anterior free wall, -54\%, radial strain of all segments, $-45 \%$, radial strain of the lateral wall, $-64 \%$, and radial strain rate of the anterior free wall, $-35 \%$ ) compared to M-Mode (LV mass, $+33 \%$ ). To better understand which features were important in the prediction of obese vs. non-obese mice, we further investigated the top five most important features in M-Mode (Supplemental Figure 6.2A), PW Doppler (Supplemental Figure 6.3A), and strain analysis (Supplemental Figure 6.4A) individually. This also included the traditional statistical analyses for M-Mode (Supplemental Figure 6.2B), PW Doppler (Supplemental Figure 6.3B), and strain analysis (Supplemental Figure 6.4B). These analyses suggest that a clear distinction is present between obese and non-obese animals when assessments derived from M-Mode and/or strain analysis are implemented. Additionally, the anterior free wall and lateral wall are disproportionately impacted by the obese phenotype.

\section{Machine Learning - Post-Unpredictable Chronic Mild Stress (UCMS)}

With an interest in understanding how a unique patterning may present following different insults, we further followed these animals throughout an 8-week UCMS protocol. We assessed if, irrespective of diet, we would be able to determine which animals received the UCMS protocol $(\mathrm{N}=22)$, compared to those that $\operatorname{did} \operatorname{not}(\mathrm{N}=22)$. Again, we first examined the data for the existence of strong collinearity within our feature sets (Supplemental Figure 6.2) and removed features with strong correlations $(>0.85)$ to decrease selection bias within the machine learning algorithms. The prediction of stressed (UCMS) versus non-stressed (non-UCMS) animals was robust (AUC: 0.868) (Figure 6.4A). RandomForest was used to select the top five most important features (Figure 6.4B) and the statistical representation of the features are also provided (Figure 6.4C). As expected, heart rate variability (HRV) was also significantly reduced post-UCMS (-49\%) (Figure 6.4D). The averages of velocity, displacement, strain, and strain rate calculated in the parasternal short axis for the radial and circumferential dimensions (Supplemental Table 6.1) and in the long 
axis for the longitudinal and circumferential dimensions (Supplemental Table 6.2) are included, along with all data used in the machine learning pipeline (Additional File 6.1).

Using the information gained from the post-diet and post-stress cohorts, we provide an illustration of the myocardial regions most significantly impacted by the stressors (Figure 6.5). We illustrate how the normal (Figure 6.5A) parasternal short and long axis segments compare to the post-diet (Figure 6.5B) and post-stress (Figure 6.5C) groups. While the anterior free and lateral wall are consistently altered between groups, the induction of stress (UCMS) appears to cause a more global impact on the myocardium. Conversely, high-fat diet feeding appeared to specifically affect the anterior free and lateral walls. 


\section{Discussion}

Recognizing the early markers of myocardial deformation is critical in alleviating the morbidity and mortality rates associated with cardiovascular disease. In recent years, the applications of speckle-tracking echocardiography have expanded significantly $(10,15,19,23)$. The sensitivity and specificity associated with strain imaging plays a crucial role in its increasingly prevalent use. Numerous studies have demonstrated the predictive value of strain echocardiography in terms of morbidity and mortality in the context of various cardiovascular diseases, particularly when compared to the prognostic information provided by ejection fraction alone (13). Although the ability of speckle-tracking to identify subclinical left ventricular dysfunction in many disease states is becoming more recognized, there is a scarcity of information on its potential to distinguish multiple insults via regional alterations. This study highlights the abilities of segmental stress-strain to identify specific regions of the LV that undergo wall motion abnormalities. Further, independent of diet, segmental stress-strain acts as a sensitive diagnostic marker for mapping additional insults, such as chronic stress (UCMS).

In 2018, 34.2 million Americans over the age of 18, were diagnosed with type 2 diabetes mellitus (T2DM). This number continuous to grow and affect younger populations as the rate of individuals with high-fat diet induced obesity continuously increases (1). Cardiovascular disease, is a major cause of mortality in patients with T2DM around the world, affecting about $32 \%$ of those individuals (8). Detection of myocardial changes prior to overt dysfunction is therefore critical in reducing the number of cardiovascular related deaths. Notably, wall motion abnormalities can be detected prior to complications or changes in ejection fraction as previously demonstrated on a cohort of T2DM patients, with normal ejection fractions (6). The study revealed that conventional parameters could not detect LV dysfunction as early as global longitudinal strain (GLS) could, which was calculated using speckle-tracking echocardiography. Similarly, a study on obese children and adolescents without other comorbidities revealed that, although there were no difference between the ejection fractions of the obese and non-obese groups, GLS correlated negatively with body mass index (BMI) (3).

Furthermore, speckle-tracking echocardiography has been utilized to look at characteristic changes that occur in type 1 diabetes mellitus (T1DM) as compared to the changes seen in T2DM (14). The authors demonstrated that strain and strain rate parameters are valuable in describing the 
dynamic changes in contractility, active relaxation, and LV stiffness between T1DM and T2DM animal models. Subclinical myocardial dysfunction can also be detected by speckle-tracking echocardiography in T1DM patients as evidenced by several previous studies $(18,20,25)$. A previous study from our laboratory, performed on a T1DM animal model, assessed speckle tracking stress-strain, particularly using segmental analysis in both the short and long axes. Changes in myocardial strain were detected after only 1-week post diabetic onset, while conventional measures and diastolic dysfunction were not seen until 6 weeks post diabetic-onset. Segmental stress-strain analyses highlighted region-specific changes, specifically in the posterior and free wall regions throughout T1DM progression (25), while our data suggest that the anterior free and lateral walls are most significantly impacted with diet-induced obesity.

Although there has been a recent increase in literature relating to the usefulness of speckletracking echocardiography, there is a limited number of studies that investigate region specific changes as they correlate to specific insults. Nevertheless, a recent study that investigated the progression of T1DM in an animal model attempted to elucidate region specific changes after discovering decreases in both GLS and GLS rate (18). This study is of great importance as it verified segmental changes with MALDI-Imaging mass spectrometry. However, this study does not demonstrate how this information is applicable in a clinical setting for promoting early detection and intervention of cardiovascular diseases. Further, traditional statistical approaches are limited in their ability to provide information regarding generalizability and predictive accuracy. Zhang et. al., applied machine learning to speckle-tracking echocardiography features to create a predictive model for coronary heart disease (30). This is one example of how stress-strain imaging can play a pivotal role in the development of early detection screening tools using artificial intelligence approaches, which continues to hold promising future clinical applications.

Our study explores the implications of multiple insults on cardiovascular health, though we did not follow the animals for cardiovascular outcomes (i.e. stroke, heart failure, etc.). While we acknowledge the importance of tangible, outcome-based assessments, both the protocols involving diet-induced obesity (validated with body weight, LV mass, and ejection fraction) and unpredictable chronic mild stress (UCMS) (validated previously, $(16,29)$ ) included objective standards. Additionally, the machine learning pipeline did not identify any regions within the parasternal long axis as significantly contributing to the differentiation of obese from non-obese 
as well as UCMS from non-UCMS mice. The parasternal long axis view of the LV is perpendicular to the transducer, making it the best angle for reflection of the ultrasound beam (17). This suggests that the collection of longitudinal strain data should result in less noise and signal disturbance, further heightening our conclusions that no substantial alterations are occurring within that axis. 


\section{Conclusion}

This is the first study to present speckle-tracking echocardiography as a tool for uniquely "fingerprinting" multiple cardiovascular insults through segmental strain analysis. These insults included intrinsic (diet-induced obesity) and extrinsic (chronic stress) stressors to cardiovascular function that were correctly stratified using a combination of strain-based analyses with machine learning algorithms. The data presented highlight how clinical applications should consider evaluating if known contributors of cardiovascular dysfunction, such as diabetes, obesity, stress, and others, have distinctive, regional patterns that can be identified using segmental strain-based analyses. In this way, the multifaceted contribution leading to cardiovascular disease can be better understood, and targeted interventions applied. 


\section{Declarations}

Consent for publication

Not applicable

Availability of Data and Materials

The datasets and computer code produced in this study are available in the following databases

- Source Code: Github: https://github.com/qahathaway/DIO_and_UCMS

- Datasets: Supplemental Data: Additional File 1

\section{Competing Interests}

Partho P. Sengupta is a consultant to Heart Sciences, Ultromics, and Kencor Health. The other authors have nothing to disclose.

\section{Funding}

This work was supported by: 20PRE35080170/AK/2020 (AK), NSF: \#1920920 (PPS), R01 HL-128485 (JMH), 17PRE33660333/QAH/2017 (QAH), NIH, BINP R56 NS117754-01 (PDC), and the Community Foundation for the Ohio Valley Whipkey Trust (JMH).

\section{Authors' contributions}

Designing research studies (AK, QAH, ENB, EEK, PPS, JMH, PDC), conducting experiments (AK, QAH, ENB, TC), acquiring data (AK, QAH, ENB, TC), analyzing data (AK, QAH, EEK, PPS, JMH, PDC), writing the manuscript (AK, QAH, PPS, JMH, PDC). The author Quincy A. Hathaway had full access to all the data in the study and takes responsibility for the integrity of the data and the accuracy of the data analysis. All authors read and approved the final manuscript. 


\section{Acknowledgements}

We would like to acknowledge and thank Sarah L. McLaughlin (Biological Technician Animal Models and Imaging Facility) who performed echocardiography. 


\section{References}

1. (CDC) CfDCaP. Diabetes Fast Facts https://www.cdc.gov/diabetes/basics/quickfacts.html. [July 122021.

2. (WHO) WHO. Cardiovascular diseases (CVDs) WHO. https://www.who.int/en/newsroom/fact-sheets/detail/cardiovascular-diseases-(cvds). [10 July 2021.

3. Barbosa JA, Mota CC, Simoes ESAC, Nunes Mdo C, and Barbosa MM. Assessing pre-clinical ventricular dysfunction in obese children and adolescents: the value of speckle tracking imaging. Eur Heart J Cardiovasc Imaging 14: 882-889, 2013.

4. Biering-Sorensen T, Biering-Sorensen SR, Olsen FJ, Sengelov M, Jorgensen PG, Mogelvang R, Shah AM, and Jensen JS. Global Longitudinal Strain by Echocardiography Predicts Long-Term Risk of Cardiovascular Morbidity and Mortality in a Low-Risk General Population: The Copenhagen City Heart Study. Circ Cardiovasc Imaging 10: 2017.

5. Burchfield JS, Xie M, and Hill JA. Pathological ventricular remodeling: mechanisms: part 1 of 2. Circulation 128: 388-400, 2013.

6. Conte L, Fabiani I, Barletta V, Bianchi C, Maria CA, Cucco C, De Filippi M, Miccoli R, Prato SD, Palombo C, and Di Bello V. Early Detection of Left Ventricular Dysfunction in Diabetes Mellitus Patients with Normal Ejection Fraction, Stratified by BMI: A Preliminary Speckle Tracking Echocardiography Study. J Cardiovasc Echogr 23: 73-80, 2013.

7. DeLong ER, DeLong DM, and Clarke-Pearson DL. Comparing the areas under two or more correlated receiver operating characteristic curves: a nonparametric approach. Biometrics 44: 837-845, 1988.

8. Einarson TR, Acs A, Ludwig C, and Panton UH. Prevalence of cardiovascular disease in type 2 diabetes: a systematic literature review of scientific evidence from across the world in 2007-2017. Cardiovasc Diabetol 17: 83, 2018.

9. Evans JS, Murphy MA, Holden ZA, and Cushman SA. Modeling species distribution and change using Random Forests. New York: Springer, 2011.

10. Gupta K, Kakar TS, Gupta A, Singh A, Gharpure N, Aryal S, Hawi R, Lloyd SG, Booker J, Hage FG, Prabhu SD, Nanda NC, and Bajaj NS. Role of left ventricle deformation analysis in stress echocardiography for significant coronary artery disease detection: A diagnostic study meta-analysis. Echocardiography 36: 1084-1094, 2019.

11. Karlsen S, Dahlslett T, Grenne B, Sjoli B, Smiseth O, Edvardsen T, and Brunvand H. Global longitudinal strain is a more reproducible measure of left ventricular function than ejection fraction regardless of echocardiographic training. Cardiovasc Ultrasound 17: 18, 2019.

12. Liaw A, and Wiener M. Classification and Regression by randomForest. $R$ News 2: 18 22, 2002.

13. Luis SA, Chan J, and Pellikka PA. Echocardiographic Assessment of Left Ventricular Systolic Function: An Overview of Contemporary Techniques, Including Speckle-Tracking Echocardiography. Mayo Clin Proc 94: 125-138, 2019.

14. Matyas C, Kovacs A, Nemeth BT, Olah A, Braun S, Tokodi M, Barta BA, Benke K, Ruppert M, Lakatos BK, Merkely B, and Radovits T. Comparison of speckle-tracking echocardiography with invasive hemodynamics for the detection of characteristic cardiac dysfunction in type-1 and type-2 diabetic rat models. Cardiovasc Diabetol 17: 13, 2018.

15. Meng S, Guo L, and Li G. Early changes in right ventricular longitudinal function in chronic asymptomatic alcoholics revealed by two-dimensional speckle tracking echocardiography. Cardiovasc Ultrasound 14: 16, 2016. 
16. Mineur YS, Belzung C, and Crusio WE. Functional implications of decreases in neurogenesis following chronic mild stress in mice. Neuroscience 150: 251-259, 2007.

17. Mitchell C, Rahko PS, Blauwet LA, Canaday B, Finstuen JA, Foster MC, Horton K, Ogunyankin KO, Palma RA, and Velazquez EJ. Guidelines for Performing a Comprehensive Transthoracic Echocardiographic Examination in Adults: Recommendations from the American Society of Echocardiography. J Am Soc Echocardiogr 32: 1-64, 2019.

18. Pappritz K, Grune J, Klein O, Hegemann N, Dong F, El-Shafeey M, Lin J, Kuebler WM, Kintscher U, Tschope C, and Van Linthout S. Speckle-tracking echocardiography combined with imaging mass spectrometry assesses region-dependent alterations. Sci Rep 10: 3629, 2020.

19. Parsaee M, Saedi S, Joghataei P, Azarkeivan A, and Alizadeh Sani Z. Value of speckle tracking echocardiography for detection of clinically silent left ventricular dysfunction in patients with beta-thalassemia. Hematology 22: 554-558, 2017.

20. Ringle A, Dornhorst A, Rehman MB, Ruisanchez C, and Nihoyannopoulos $\mathbf{P}$. Evolution of subclinical myocardial dysfunction detected by two-dimensional and threedimensional speckle tracking in asymptomatic type 1 diabetic patients: a longterm follow-up study. Echo Res Pract 4: 73-81, 2017.

21. Robin X, Turck N, Hainard A, Tiberti N, Lisacek F, Sanchez JC, and Muller M. pROC: an open-source package for $\mathrm{R}$ and $\mathrm{S}+$ to analyze and compare ROC curves. $B M C$ Bioinformatics 12: 77, 2011.

22. Romano S, Mansour IN, Kansal M, Gheith H, Dowdy Z, Dickens CA, Buto-Colletti C, Chae JM, Saleh HH, and Stamos TD. Left Ventricular global longitudinal strain predicts heart failure readmission in acute decompensated heart failure. Cardiovasc Ultrasound 15: 6, 2017.

23. Saccheri MC, Cianciulli TF, Morita LA, Mendez RJ, Beck MA, Guerra JE, Cozzarin A, Puente LJ, Balletti LR, and Lax JA. Speckle tracking echocardiography to assess regional ventricular function in patients with apical hypertrophic cardiomyopathy. World J Cardiol 9: 363370, 2017.

24. Sengelov M, Jorgensen PG, Jensen JS, Bruun NE, Olsen FJ, Fritz-Hansen T, Nochioka K, and Biering-Sorensen T. Global Longitudinal Strain Is a Superior Predictor of AllCause Mortality in Heart Failure With Reduced Ejection Fraction. JACC Cardiovasc Imaging 8: 1351-1359, 2015.

25. Shepherd DL, Nichols CE, Croston TL, McLaughlin SL, Petrone AB, Lewis SE, Thapa D, Long DM, Dick GM, and Hollander JM. Early detection of cardiac dysfunction in the type 1 diabetic heart using speckle-tracking based strain imaging. J Mol Cell Cardiol 90: 7483, 2016.

26. Sun X, and Xu W. Fast Implementation of DeLong's Algorithm for Comparing the Areas Under Correlated Receiver Operating Characteristic Curves. IEEE Signal Processing Letters 21: 1389-1393, 2014.

27. T. W, and V.S. R package 'corrplot': Visualization of a Correlation Matrix. 2021.

28. Wickham H. ggplot2: Elegant Graphics for Data Analysis. New York: Springer-Verlag New York, 2016.

29. Willner P. Validity, reliability and utility of the chronic mild stress model of depression: a 10-year review and evaluation. Psychopharmacology (Berl) 134: 319-329, 1997. 
30. Zhang J, Zhu H, Chen Y, Yang C, Cheng H, Li Y, Zhong W, and Wang F. Ensemble machine learning approach for screening of coronary heart disease based on echocardiography and risk factors. BMC Med Inform Decis Mak 21: 187, 2021. 
Tables

Table 6.1 - M-Mode Parameters

\begin{tabular}{|c|c|c|c|}
\hline Parameter & Baseline $^{\text {a }}$ & Lean $^{b}$ & Obese $^{c}$ \\
\hline Heart Rate (BPM) & $475.2 \pm 16.57$ & $581.1 \pm 25.83^{a}$ & $474.3 \pm 21.43^{\mathbf{b}}$ \\
\hline Diameter; s (mm) & $1.547 \pm 0.073$ & $1.166 \pm 0.103^{\mathrm{a}}$ & $1.948 \pm 0.101^{\mathbf{a , b}}$ \\
\hline Diameter; d (mm) & $3.079 \pm 0.067$ & $2.823 \pm 0.075$ & $3.468 \pm 0.098^{\mathbf{a , b}}$ \\
\hline Volume; s $(\boldsymbol{\mu L})$ & $7.997 \pm 0.864$ & $3.828 \pm 0.727^{a}$ & $13.41 \pm 1.430^{\mathbf{a , b}}$ \\
\hline Volume; $d(\mu L)$ & $38.71 \pm 1.960$ & $31.06 \pm 2.125$ & $51.76 \pm 3.156^{\mathbf{a , b}}$ \\
\hline Stroke Volume $(\mu \mathrm{L})$ & $30.71 \pm 1.240$ & $26.72 \pm 1.316$ & $38.35 \pm 1.892^{\mathbf{a , b}}$ \\
\hline Ejection Fraction (\%) & $81.80 \pm 1.323$ & $88.33 \pm 1.667^{\mathrm{a}}$ & $76.38 \pm 1.743^{\mathbf{a , b}}$ \\
\hline Fractional Shortening (\%) & $50.88 \pm 1.510$ & $60.11 \pm 2.708^{a}$ & $45.32 \pm 1.770^{b}$ \\
\hline Cardiac Output (mL/min) & $14.00 \pm 0.497$ & $15.12 \pm 0.730$ & $17.29 \pm 0.853^{\mathrm{a}}$ \\
\hline LV Mass (mg) & $109.8 \pm 3.198$ & $120.5 \pm 4.632$ & $150.7 \pm 5.765^{\mathbf{a}, \mathbf{b}}$ \\
\hline LVAW; s (mm) & $1.717 \pm 0.031$ & $1.938 \pm 0.046^{\mathrm{a}}$ & $1.858 \pm 0.044^{\mathrm{a}}$ \\
\hline LVAW; d (mm) & $1.051 \pm 0.025$ & $1.213 \pm 0.031^{\mathrm{a}}$ & $1.186 \pm 0.048^{\mathrm{a}}$ \\
\hline LVPW; s (mm) & $1.378 \pm 0.409$ & $1.635 \pm 0.058^{a}$ & $1.401 \pm 0.051^{\mathbf{b}}$ \\
\hline LVPW; d (mm) & $0.969 \pm 0.037$ & $1.112 \pm 0.054$ & $1.051 \pm 0.044$ \\
\hline
\end{tabular}


Table 6.1: M-Mode assessments for the baseline (6-week-old) (N=48), lean (18-week-old) $(\mathrm{N}=24)$, and obese (18-week-old) $(\mathrm{N}=24)$. Outliers were removed using a ROUT test, the D’Agostino-Pearson omnibus (K2) test was implemented to determine normal distribution, and an ANOVA/Tukey's post hoc test (normally distributed) or Kruskal-Wallis test/Dunn's post hoc test (non-normally distributed) were used to determine significance. Results were considered statically significant if $P \leq 0.05$. All data are reported as the means \pm the standard error of the mean (SEM). $\mathbf{a}=$ statistically different than the baseline group,$^{\mathbf{b}}=$ statistically different than the lean group, $\mathrm{s}=$ systolic, $\mathrm{d}=$ diastolic, $\mathrm{LV}=$ left ventricle, $\mathrm{AW}=$ anterior wall, $\mathrm{PW}=$ posterior wall. 
Table 6.2 - Pulse Wave (PW) Doppler

\begin{tabular}{|cccc}
\hline Parameter & Baseline $^{\mathbf{a}}$ & Lean $^{\mathbf{b}}$ & Obese $^{\mathbf{c}}$ \\
\hline AET (ms) & $41.09 \pm 0.948$ & $31.30 \pm 1.559^{\mathbf{a}}$ & $39.98 \pm 1.444^{\mathbf{b}}$ \\
\hline IVCT (ms) & $17.10 \pm 1.096$ & $11.28 \pm 0.775^{\mathbf{a}}$ & $18.19 \pm 0.691^{\mathbf{b}}$ \\
\hline IVRT (ms) & $19.21 \pm 0.509$ & $20.31 \pm 1.194$ & $19.09 \pm 0.641$ \\
\hline MV A (mm/s) & $395.6 \pm 13.48$ & $380.9 \pm 16.22$ & $333.0 \pm 11.97^{\mathbf{a}}$ \\
\hline MV Decel (mm/s $)$ & $-26523 \pm 1067$ & $-35276 \pm 2315^{\mathbf{a}}$ & $-24536 \pm 1190^{\mathbf{b}}$ \\
\hline MV Decel (ms) & $22.93 \pm 0.747$ & $18.53 \pm 0.769^{\mathbf{a}}$ & $24.78 \pm 1.220^{\mathbf{b}}$ \\
\hline MV E (mm/s) & $614.9 \pm 18.43$ & $659.5 \pm 27.85$ & $606.9 \pm 19.71$ \\
\hline NFT (ms) & $77.77 \pm 1.767$ & $63.22 \pm 1.525^{\mathbf{a}}$ & $76.60 \pm 1.813^{\mathbf{b}}$ \\
\hline LV MPI IV & $0.898 \pm 0.030$ & $1.094 \pm 0.090$ & $0.965 \pm 0.053$ \\
\hline LV MPI NFT & $0.908 \pm 0.032$ & $1.107 \pm 0.090$ & $0.954 \pm 0.055^{\mathbf{b}}$ \\
\hline MV Area (mm $\left.{ }^{\mathbf{b}}\right)$ & $35.12 \pm 1.383$ & $41.80 \pm 2.110^{\mathbf{a}}$ & $32.41 \pm 1.645^{\mathbf{b}}$ \\
\hline MV E/A & $1.583 \pm 0.037$ & $1.768 \pm 0.078$ & $1.869 \pm 0.088^{\mathbf{a}}$ \\
\hline MV PHT (ms) & $6.649 \pm 0.216$ & $5.373 \pm 0.223^{\mathbf{a}}$ & $7.186 \pm 0.354^{\mathbf{b}}$ \\
\hline
\end{tabular}


Table 6.2: PW Doppler assessments for the baseline (6-week-old) (N=48), lean (18-week-old) $(\mathrm{N}=24)$, and obese (18-week-old) $(\mathrm{N}=24)$. Outliers were removed using a ROUT test, the D’Agostino-Pearson omnibus (K2) test was implemented to determine normal distribution, and an ANOVA/Tukey's post hoc test (normally distributed) or Kruskal-Wallis test/Dunn's post hoc test (non-normally distributed) were used to determine significance. Results were considered statically significant if $P \leq 0.05$. All data are reported as the means \pm the standard error of the mean (SEM). $\mathbf{a}=$ statistically different than the baseline group, ${ }^{\mathbf{b}}=$ statistically different than the lean group, LV $=$ left ventricle, $\mathrm{AET}=$ aortic ejection time, $\mathrm{MV}=$ mitral valve, $\mathrm{IVCT}=$ isovolumetric contraction time, IVRT, isovolumetric relaxation time, Decel $=$ deceleration, MPI = myocardial performance index, NFT $=$ no flow time, PHT $=$ pressure half-time. 
Figure 6.1

A
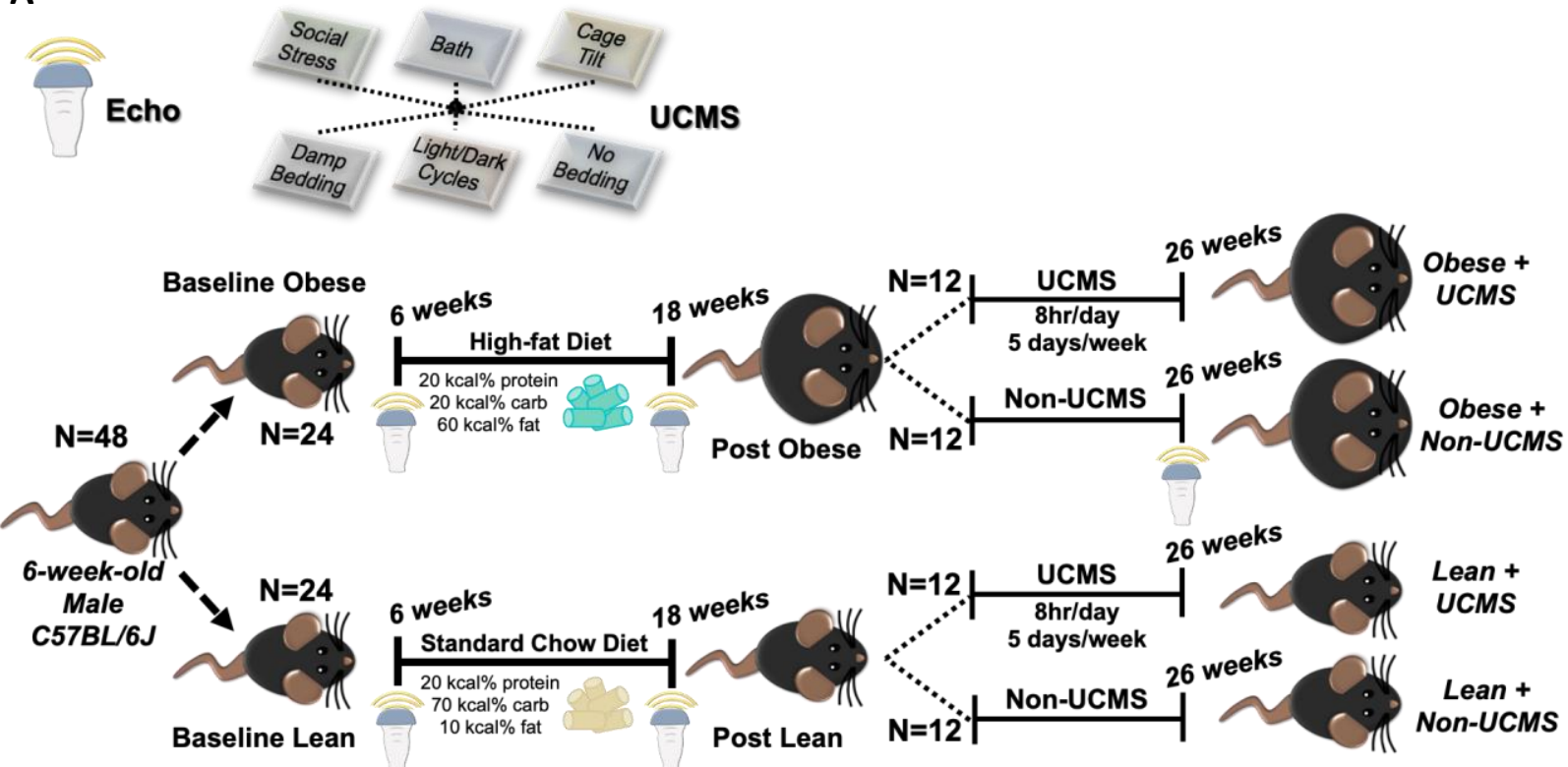

B

Body Weights

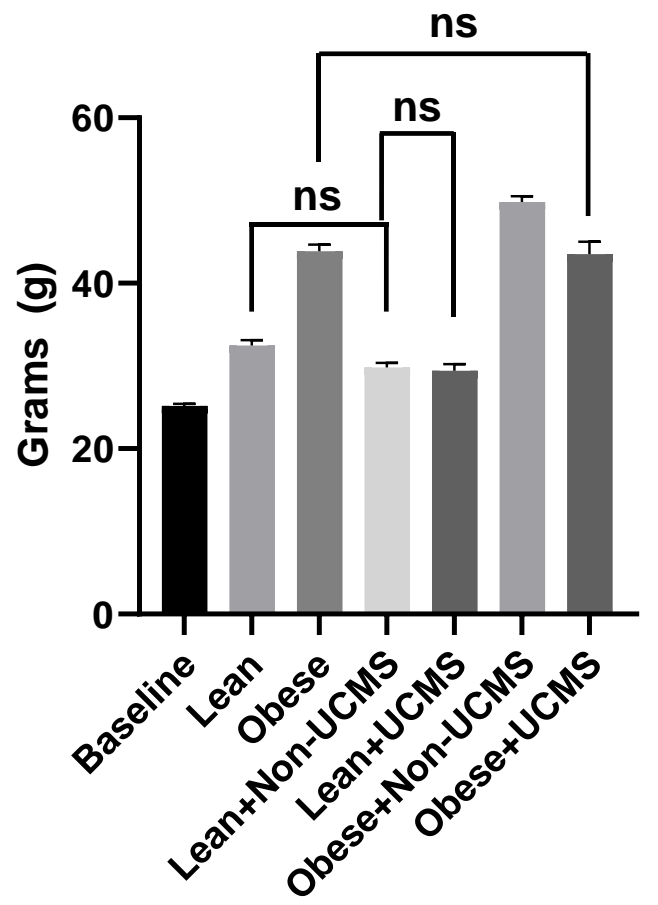


Figure 6.1: Experimental paradigm and body weights. (A) High-fat diet (HFD) feeding and stress protocol: 6-weekold, male C57BL/6J mice were randomized into lean $(\mathrm{N}=24)$ and obese $(\mathrm{N}=24)$ groups. Mice in the obese group underwent 12 weeks of diet induced obesity (DIO), while the lean group consumed standard chow. At 18 weeks of age, mice in the lean and obese groups were further randomized into unpredictable chronic mild stress (UCMS) (N=22) and non-UCMS $(\mathrm{N}=22)$ groups to elicit a chronically stressed phenotype over an 8-week period. Echocardiography was performed at baseline ( 6 weeks, $\mathrm{N}=48$ ), post-diet (18 weeks, $\mathrm{N}=48$ ), and post-stress ( 26 weeks, $\mathrm{N}=44$ ) time points. (B) Body weights in grams for each cohort. All comparisons are statistically significant except for those labeled "ns". The D'Agostino-Pearson omnibus (K2) test was implemented to determine normal distribution, and an ANOVA/Tukey's post hoc test (normally distributed) was used to determine significance. Results were considered statically significant if $P$ $\leq 0.05$. All data are reported as the means \pm the standard error of the mean $(\mathrm{SEM}) . \mathrm{Ns}=$ not significantly different. 
Figure 6.2:

A

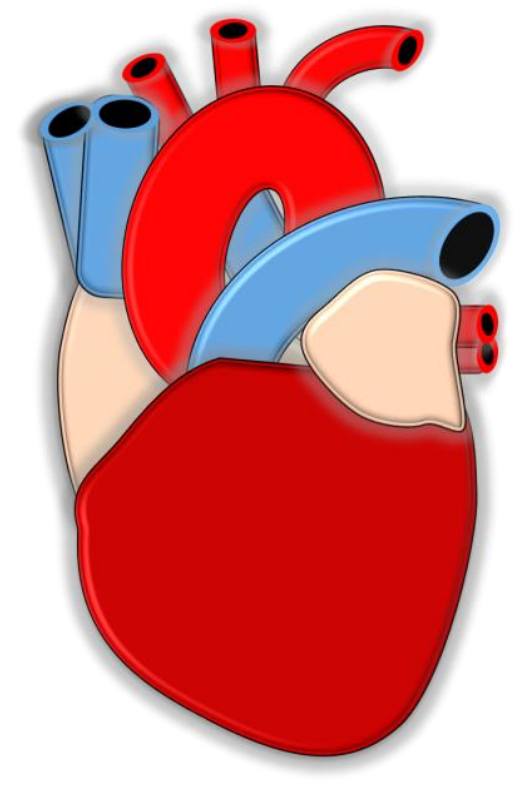

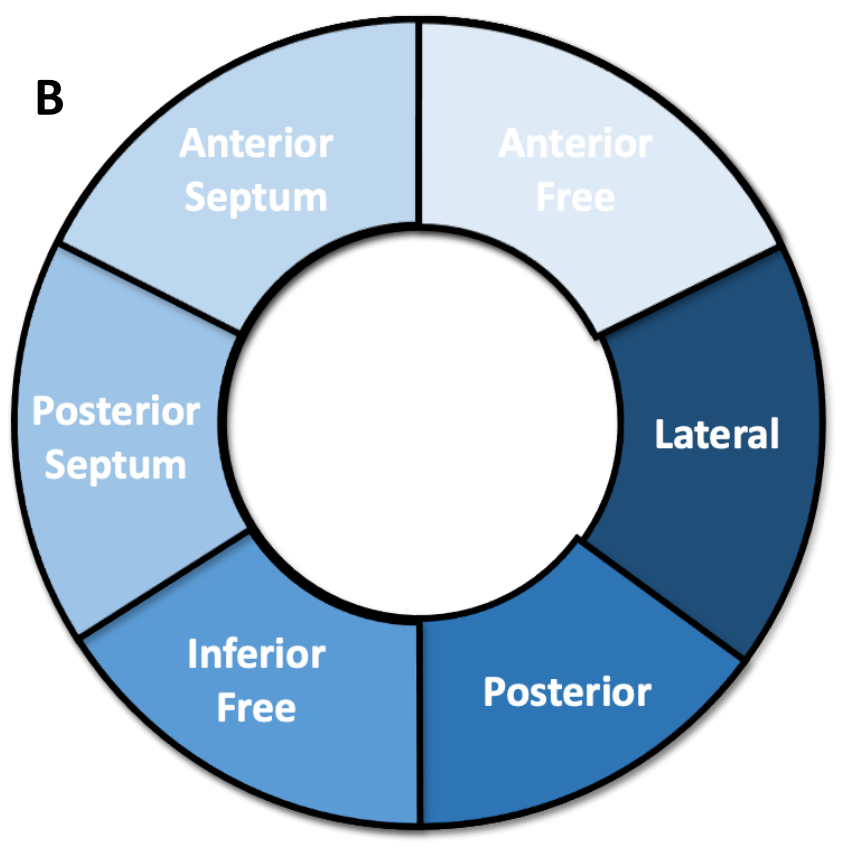
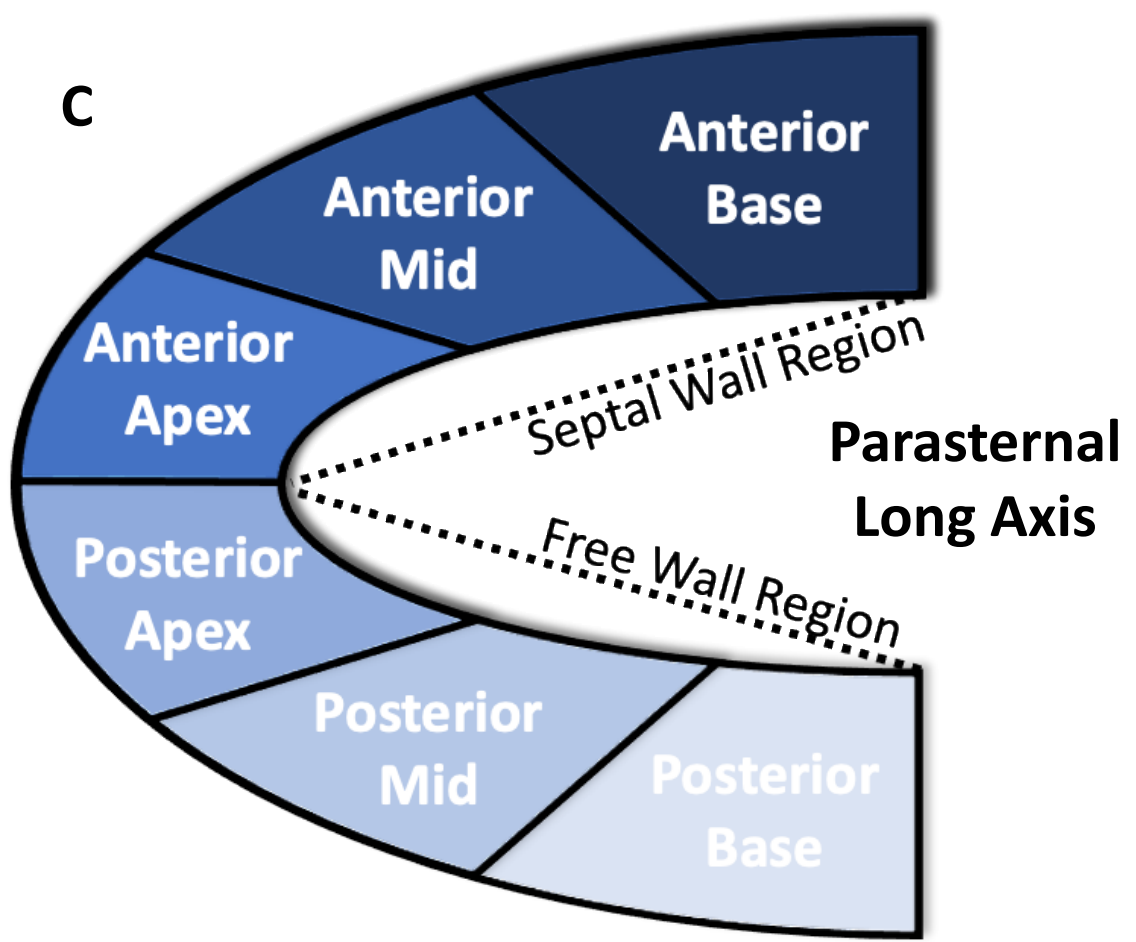
Figure 6.2:

D
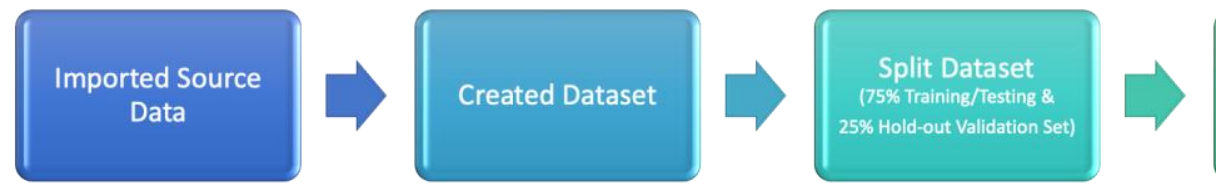

AutoML

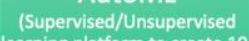

foarning plattorm to create 10 -

assessments of the

training/testing dataset)
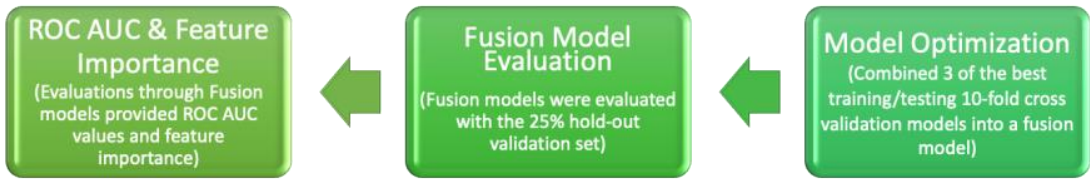
Figure 6.2: Segmental strain and machine learning pipeline. (A) The LV in parasternal short axis was segmented into six regions of interest: anterior free (AF), lateral (L), posterior $(\mathrm{P})$, inferior free (IF), posterior septum (PS), and anterior septum (AS). Additionally, (B) the LV in parasternal long axis was segmented into six regions of interest: anterior base (AB), anterior mid (AM), anterior apex (AA), posterior apex (PA), posterior mid (PM), and posterior base (PB). (C) Data were imported and used to create a dataset containing segmental speckle tracking stress-strain, MMode, and Pulse Wave Doppler, that were then split (75\% Training/Testing and 25\% Hold-out validation sets). A mixed supervised/unsupervised machine learning model was used through the BigML platform that provided 10-cross validation models of the Training/Testing dataset. The top 3 models for each analysis were then fused to create a more holistic model. The data were evaluated using the AUC generated from the hold-out dataset, as an indication of the accuracy of the model for predicting the desired outcome (HFD or UCMS). 
Figure 6.3:

ROC
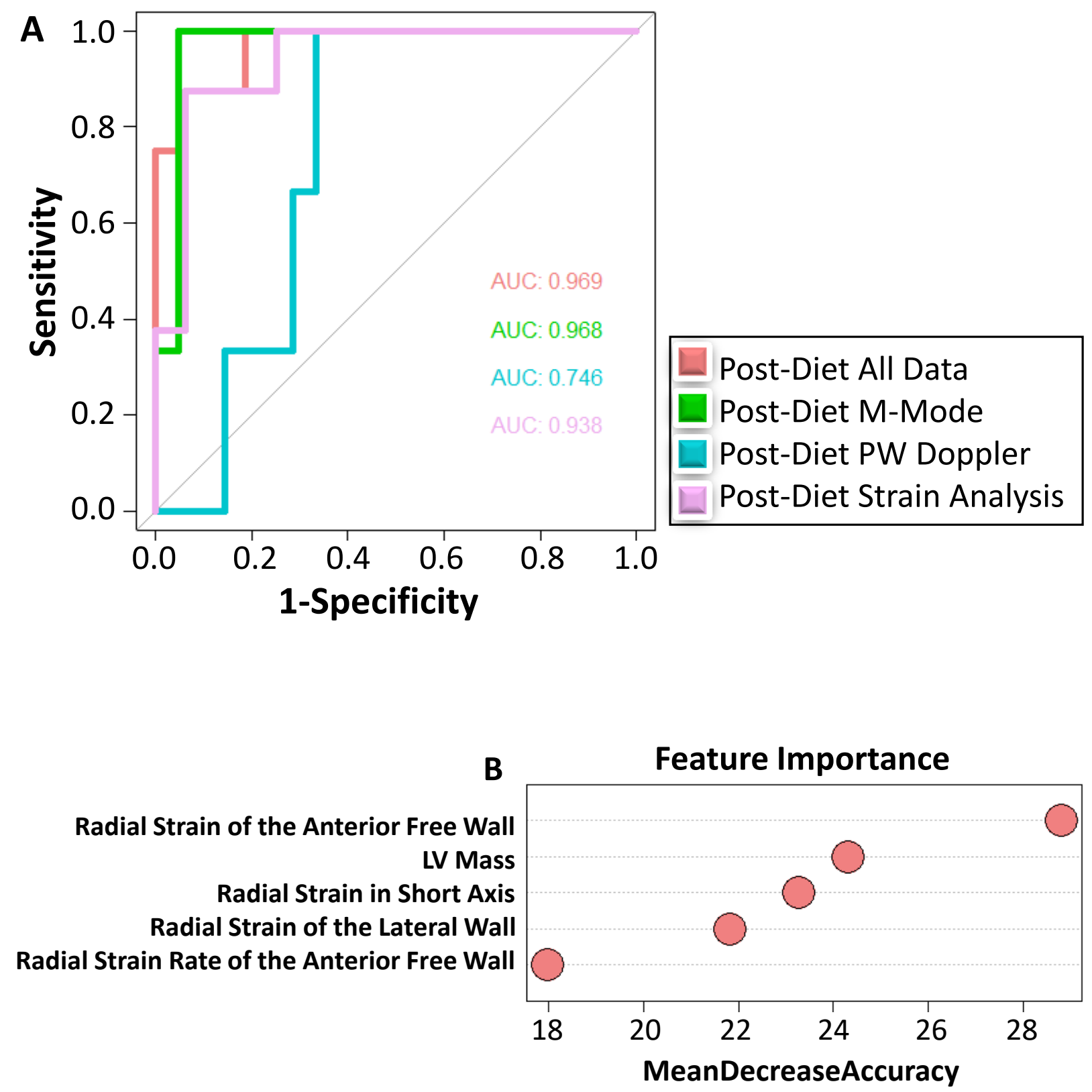
Figure 6.3:

C Radial Strain of the

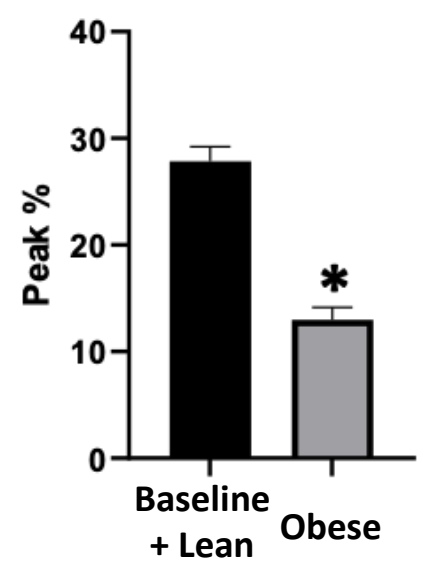

Radial Strain in

Short Axis

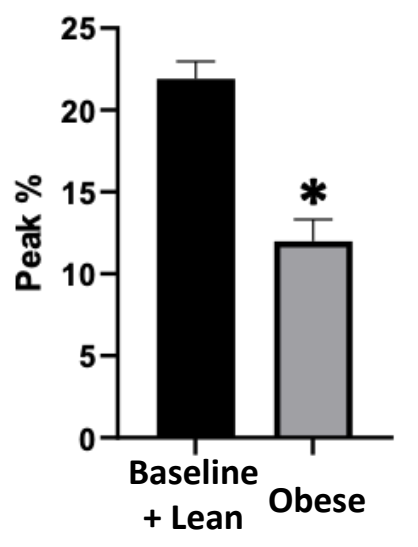

LV Mass

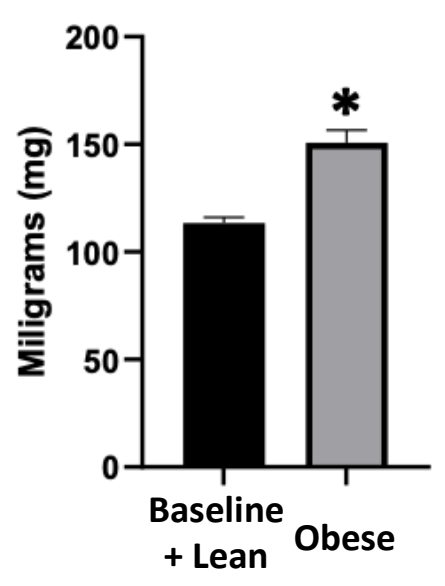

Radial Strain of the Lateral Wall

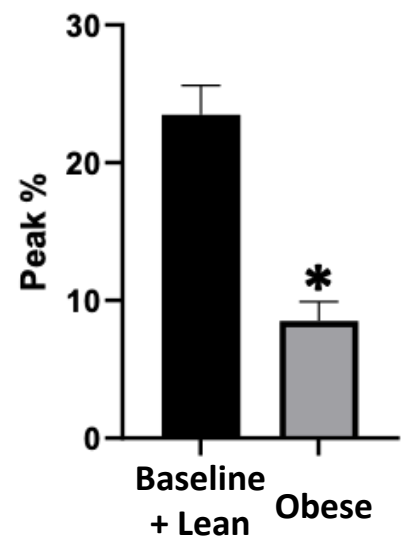

Radial Strain Rate of the Anterior Free Wall

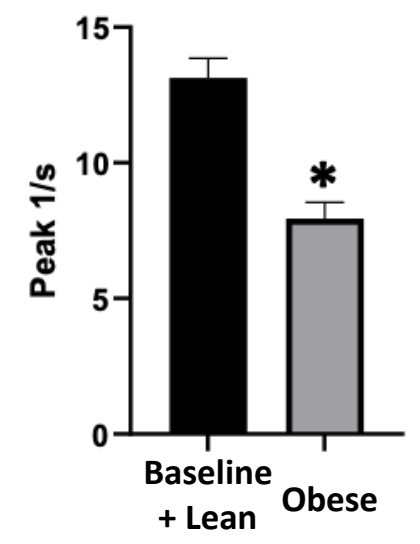


Figure 6.3: Obese versus non-obese analyses. Features derived from M-mode, Pulse Wave (PW) Doppler, and strain analyses were used in machine learning applications for non-obese (baseline and lean, $\mathrm{N}=72$ ) and obese $(\mathrm{N}=24)$ mice. Implementation of AutoML, model optimization, and fusion model evaluation were performed. (A) ROC curves were graphed, and AUC scores calculated. (B) Feature importance was determined using randomForest and evaluated based on MeanDecreaseAccuracy. (C) The top five most important features are provided with their values. Outliers were removed using a ROUT test, the D'Agostino-Pearson omnibus (K2) test was implemented to determine normal distribution, and a two-sided unpaired Student's t-test (normally distributed) or Mann Whitney test (non-normally distributed) were used to determine significance. Results were considered statically significant if $P \leq 0.05$ and indicated by “*”. All data are reported as the means \pm the standard error of the mean $(\mathrm{SEM})$. Post-Diet $=$ post high-fat diet induced obesity. 
Figure 6.4:
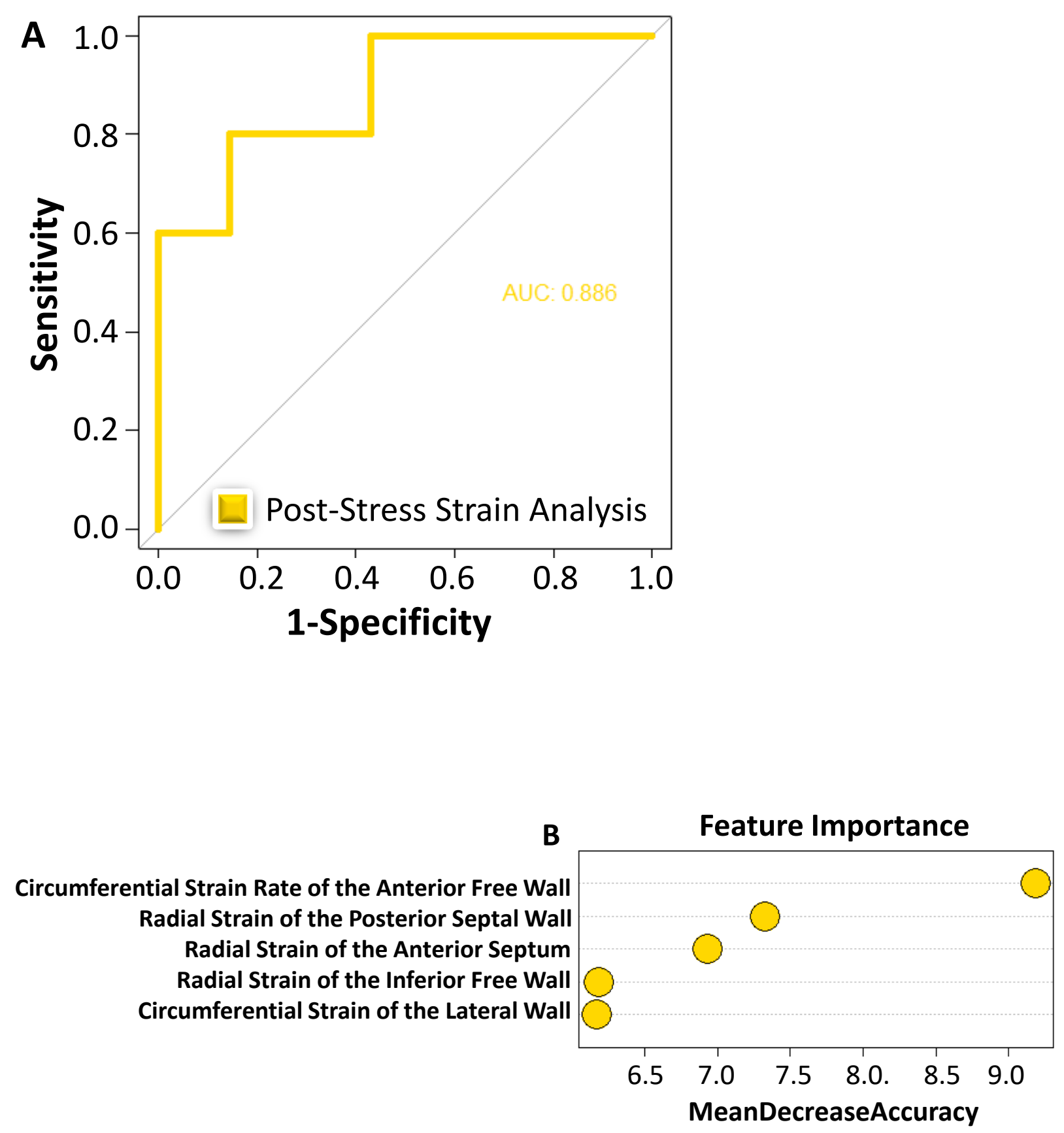
Figure 6.4:

C Circumferential Strain Rate of the Anterior Free Wall

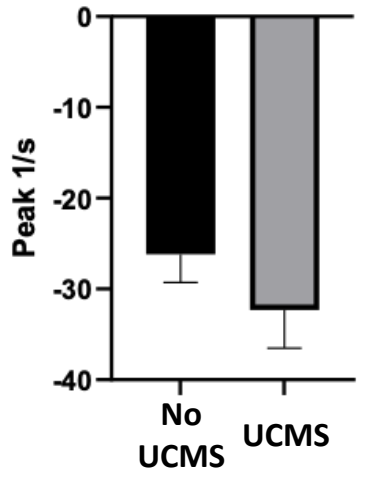

Posterior Septal Wall

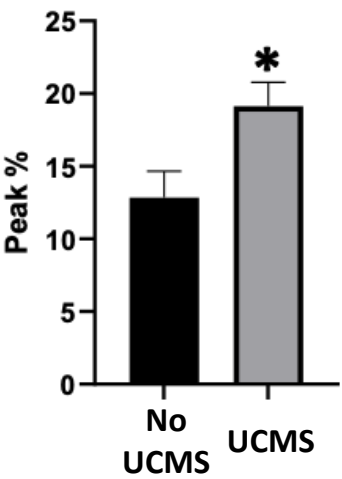

Radial Strain of the Radial Strain of the Anterior Septum Inferior Free Wall
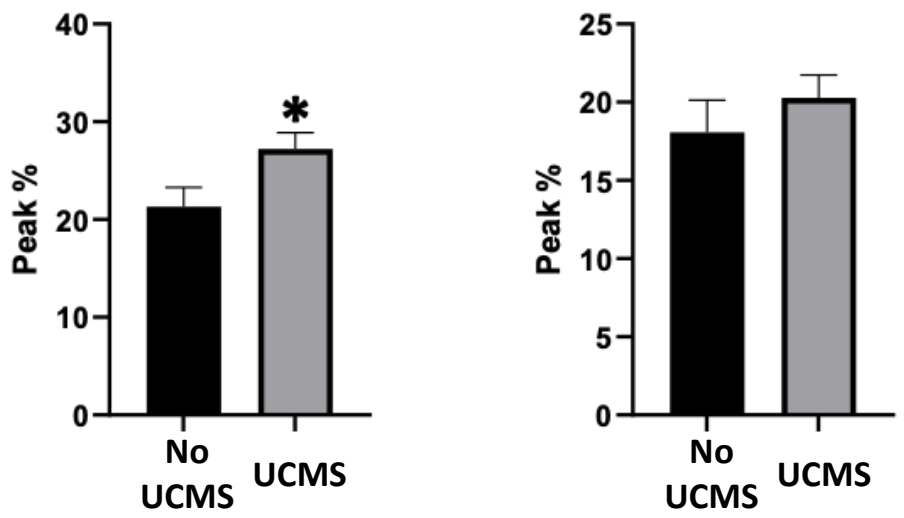

Circumferential

Strain of the Lateral

Wall

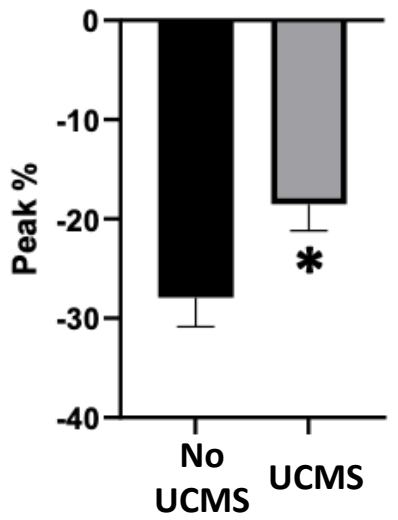


Figure 6.4:

D

$$
\text { HRV }
$$

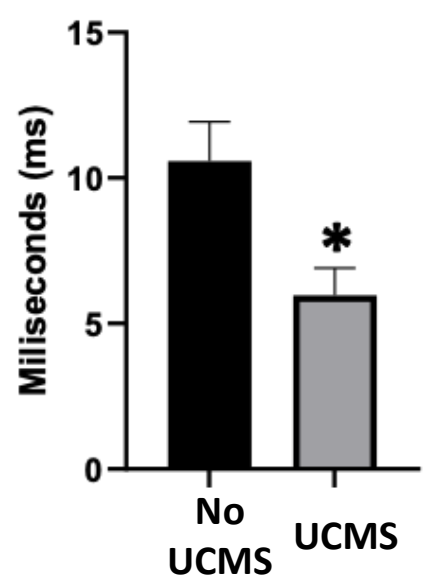


Figure 6.4: UCMS versus non-UCMS analyses, irrespective of diet. Features derived from strain analyses were used in machine learning applications for non-UCMS (N=22) and UCMS (N=22) mice at 26 weeks. Implementation of AutoML, model optimization, and fusion model evaluation were performed. (A) The ROC curve was graphed, and AUC score calculated. (B) Feature importance was determined using randomForest and evaluated based on MeanDecreaseAccuracy. (C) The top five most important features are provided with their values. (D) Heart rate variability (HRV) is also shown for comparison. Outliers were removed using a ROUT test, the D'Agostino-Pearson omnibus (K2) test was implemented to determine normal distribution, and a two-sided unpaired Student's t-test (normally distributed) or Mann Whitney test (non-normally distributed) were used to determine significance. Results were considered statically significant if $P \leq 0.05$ and indicated by "**". All data are reported as the means \pm the standard error of the mean (SEM). 
Figure 6.5:
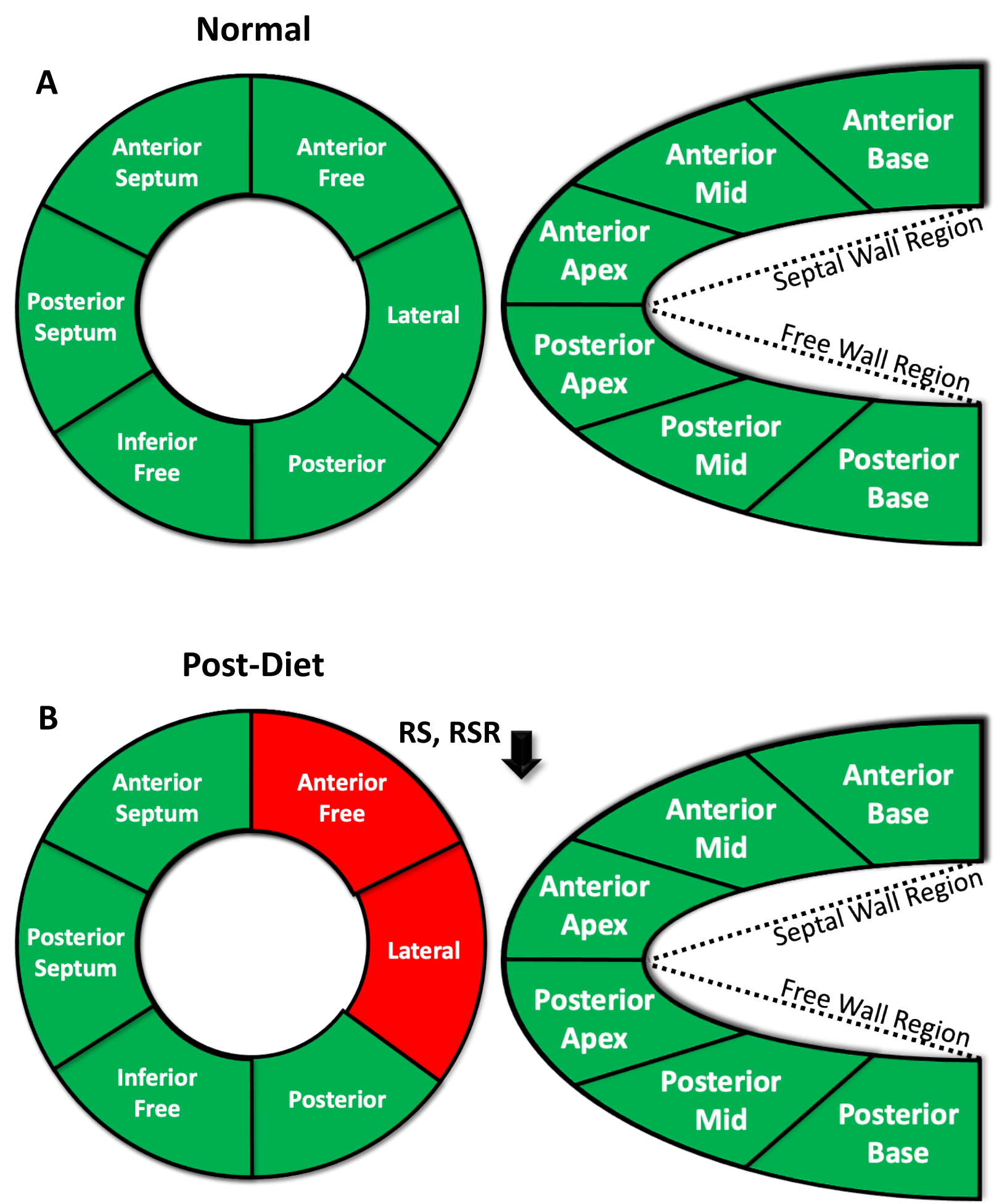
Figure 6.5:
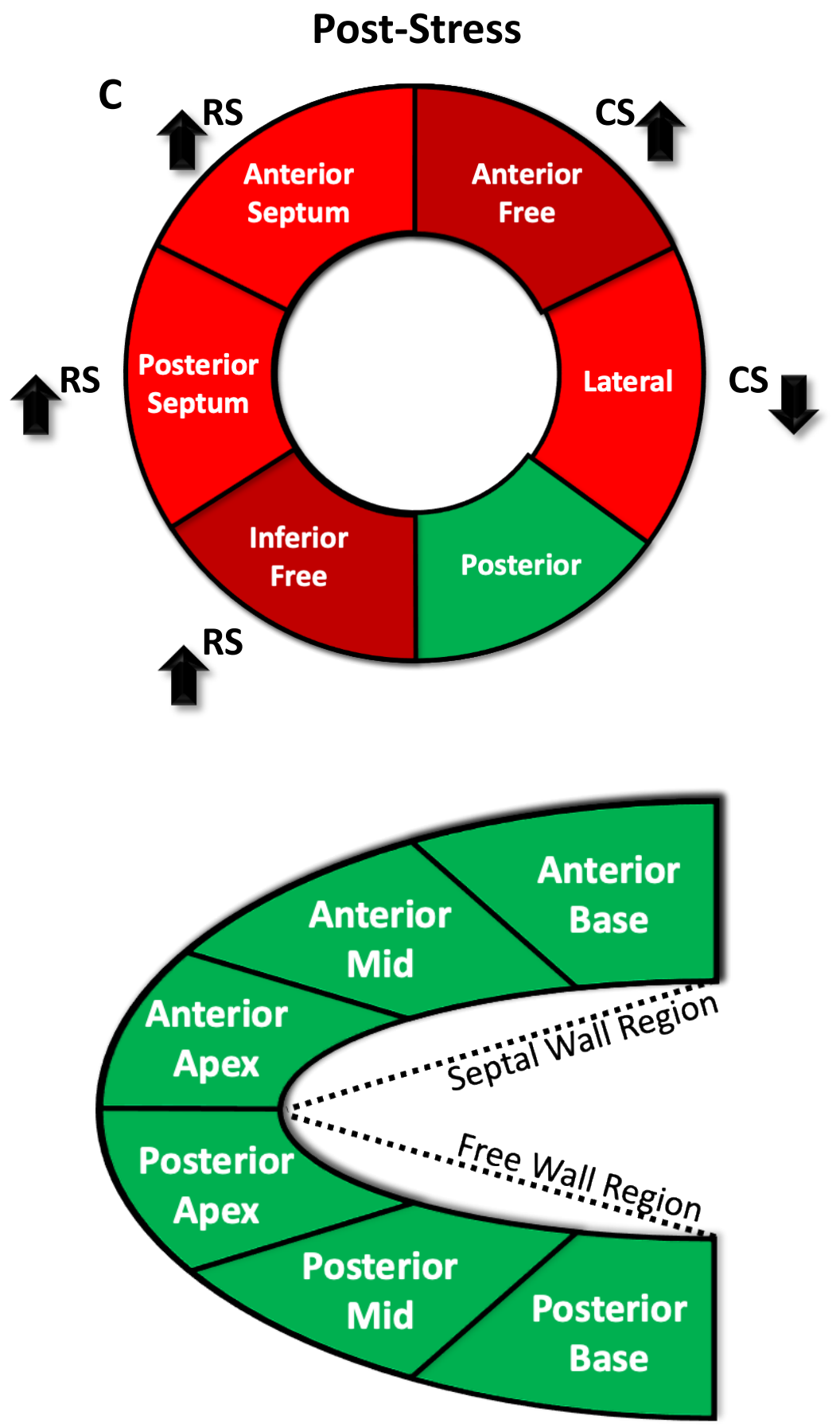
Figure 6.5: Overview of regional impacts of diet-induced obesity (DIO) and unpredictable chronic mild stress (UCMS). The (A) normal, (B) post-diet, and (C) post-stress segmental strain profiles are shown. Green indicates baseline strain function for the indicated left ventricular (LV) region. Bright red indicates a region identified as important by one or more of the top predictive features that is also statistically significantly different. Dark red indicates a region identified as important by one or more of the top predictive features, but that is not statistically significantly different. $\mathrm{RS}=$ radial strain, $\mathrm{RSR}=$ radial strain rate, $\mathrm{CS}=$ circumferential strain . Post-Diet $=$ post high-fat diet induced obesity. 


\section{Supplemental Tables}

Supplemental Table 6.1 - Short-Axis Systolic Stress-Strain

\begin{tabular}{|c|c|c|c|c|c|c|}
\hline Parameter & Units & Baseline $^{a}$ & Lean ${ }^{b}$ & Obese $^{c}$ & $\begin{array}{c}\text { Non- } \\
\text { UCMS d }^{\mathrm{d}}\end{array}$ & UCMS \\
\hline Radial Velocity & $\begin{array}{c}\mathbf{P k} \\
\mathbf{c m} / \mathbf{s}\end{array}$ & $\begin{array}{c}1.663 \pm \\
0.067\end{array}$ & $\begin{array}{l}2.200 \pm \\
0.094^{a}\end{array}$ & $\begin{array}{l}1.680 \pm \\
0.060^{b}\end{array}$ & $\begin{array}{l}2.159 \pm \\
0.120^{\mathrm{a}, \mathrm{c}}\end{array}$ & $\begin{array}{l}2.285 \pm \\
0.110^{a, c}\end{array}$ \\
\hline Radial Displacement & $\begin{array}{c}\mathbf{P k} \\
\mathbf{m m}\end{array}$ & $\begin{array}{c}0.398 \pm \\
0.016\end{array}$ & $\begin{array}{l}0.474 \pm \\
0.014^{\text {a }}\end{array}$ & $\begin{array}{l}0.313 \pm \\
0.023 \text { a,b }\end{array}$ & $\begin{array}{l}0.353 \pm \\
0.029^{b}\end{array}$ & $\begin{array}{c}0.395 \pm \\
0.017\end{array}$ \\
\hline Radial Strain & Pk \% & $\begin{array}{c}20.33 \pm \\
1.279\end{array}$ & $\begin{array}{l}25.55 \pm \\
1.039\end{array}$ & $\begin{array}{l}11.99 \pm \\
1.334^{\text {a,b }}\end{array}$ & $\begin{array}{l}17.29 \pm \\
1.875^{b, c}\end{array}$ & $\begin{array}{l}19.30 \pm \\
1.043^{c}\end{array}$ \\
\hline Radial Strain Rate & Pk 1/s & $\begin{array}{c}8.561 \pm \\
0.401\end{array}$ & $\begin{array}{l}12.96 \pm \\
0.4911^{a}\end{array}$ & $\begin{array}{l}8.019 \pm \\
0.624^{b}\end{array}$ & $\begin{array}{l}17.25 \pm \\
3.183^{\text {a,c }}\end{array}$ & $\begin{array}{l}17.86 \pm \\
3.485^{\mathrm{a}, \mathrm{c}}\end{array}$ \\
\hline $\begin{array}{l}\text { Circumferential } \\
\text { Velocity }\end{array}$ & $\begin{array}{c}\text { Pk } \\
\text { deg/s }\end{array}$ & $\begin{array}{c}324.6 \pm \\
20.31\end{array}$ & $\begin{array}{l}607.2 \pm \\
79.89^{\text {a }}\end{array}$ & $\begin{array}{l}292.7 \pm \\
24.17^{b}\end{array}$ & $\begin{array}{l}489.0 \pm \\
38.41^{\text {a,c }}\end{array}$ & $\begin{array}{l}600.3 \pm \\
71.32^{a, c}\end{array}$ \\
\hline $\begin{array}{c}\text { Circumferential } \\
\text { Displacement }\end{array}$ & Pk deg & $\begin{array}{c}3.584 \pm \\
0.363\end{array}$ & $\begin{array}{l}6.055 \pm \\
0.635^{a}\end{array}$ & $\begin{array}{l}2.238 \pm \\
0.419^{b}\end{array}$ & $\begin{array}{l}6.263 \pm \\
0.789^{\text {a,c }}\end{array}$ & $\begin{array}{l}5.570 \pm \\
0.840^{c}\end{array}$ \\
\hline Circumferential Strain & Pk \% & $\begin{array}{c}-22.78 \pm \\
1.255\end{array}$ & $\begin{array}{c}-23.64 \pm \\
1.151\end{array}$ & $\begin{array}{l}-16.79 \pm \\
0.956^{\text {a,b }}\end{array}$ & $\begin{array}{c}-20.49 \pm \\
1.982\end{array}$ & $\begin{array}{c}-22.20 \pm \\
1.788\end{array}$ \\
\hline $\begin{array}{c}\text { Circumferential Strain } \\
\text { Rate }\end{array}$ & Pk 1/s & $\begin{array}{c}-13.83 \pm \\
1.010\end{array}$ & $\begin{array}{c}-17.24 \pm \\
1.526\end{array}$ & $\begin{array}{c}-12.16 \pm \\
1.276\end{array}$ & $\begin{array}{l}-20.29 \pm \\
1.850^{\mathrm{a}, \mathrm{c}}\end{array}$ & $\begin{array}{l}-21.12 \pm \\
1.912^{\mathrm{a}, \mathrm{c}}\end{array}$ \\
\hline
\end{tabular}


Supplemental Table 6.1: Short-axis systolic stress-strain assessments for the baseline (6-weekold) ( $\mathrm{N}=48)$, lean (18-week-old) $(\mathrm{N}=24)$, obese (18-week-old) $(\mathrm{N}=24)$, non-UCMS (26-week-old) $(\mathrm{N}=24)$, UCMS (26-week-old) $(\mathrm{N}=24)$. Outliers were removed using a ROUT test, the D'Agostino-Pearson omnibus (K2) test was implemented to determine normal distribution, and an ANOVA/Tukey's post hoc test (normally distributed) or Kruskal-Wallis test/Dunn's post hoc test (non-normally distributed) were used to determine significance. Results were considered statically significant if $P \leq 0.05$. All data are reported as the means \pm the standard error of the mean (SEM). ${ }^{\mathbf{a}}=$ statistically different than the baseline group, ${ }^{\mathbf{b}}=$ statistically different than the lean group, ${ }^{\mathbf{c}}=$ statistically different than the obese group, ${ }^{\mathbf{d}}=$ statistically different than the non-UCMS group. $\mathrm{Pk}=$ peak, $\mathrm{UCMS}=$ unpredictable chronic mild stress. 
Supplemental Table 6.2 - Long-Axis Systolic Stress-Strain

\begin{tabular}{|c|c|c|c|c|c|c|}
\hline Parameter & Units & Baseline a & Lean ${ }^{b}$ & Obese $^{c}$ & $\underset{d}{\text { Non-UCMS }}$ & UCMS \\
\hline Radial Velocity & $\begin{array}{c}\mathrm{Pk} \\
\mathrm{cm} / \mathrm{s}\end{array}$ & $\begin{array}{c}1.348 \pm \\
0.064\end{array}$ & $\begin{array}{l}1.952 \pm \\
0.112 \text { a }\end{array}$ & $\begin{array}{c}1.557 \pm \\
0.080\end{array}$ & $\begin{array}{l}1.957 \pm \\
0.129^{a}\end{array}$ & $\begin{array}{l}1.965 \pm \\
0.102^{a}\end{array}$ \\
\hline Radial Displacement & $\begin{array}{c}\mathbf{P k} \\
\mathbf{m m}\end{array}$ & $\begin{array}{c}0.297 \pm \\
0.015\end{array}$ & $\begin{array}{c}0.354 \pm \\
0.022\end{array}$ & $\begin{array}{l}0.255 \pm \\
0.022^{b}\end{array}$ & $\begin{array}{c}0.296 \pm \\
0.026\end{array}$ & $\begin{array}{c}0.336 \pm \\
0.020\end{array}$ \\
\hline Radial Strain & Pk \% & $\begin{array}{c}13.72 \pm \\
0.938\end{array}$ & $\begin{array}{c}15.06 \pm \\
1.454\end{array}$ & $\begin{array}{l}8.300 \pm \\
1.161^{a, b}\end{array}$ & $\begin{array}{c}11.31 \pm \\
1.412\end{array}$ & $\begin{array}{c}13.04 \pm \\
1.140\end{array}$ \\
\hline Radial Strain Rate & Pk 1/s & $\begin{array}{c}7.184 \pm \\
0.409\end{array}$ & $\begin{array}{l}9.932 \pm \\
0.6481^{a}\end{array}$ & $\begin{array}{l}7.343 \pm \\
\mathbf{0 . 5 0 7}\end{array}$ & $\begin{array}{l}12.34 \pm \\
2.513^{a}\end{array}$ & $\begin{array}{c}18.04 \pm \\
6.371\end{array}$ \\
\hline $\begin{array}{l}\text { Longitudinal } \\
\text { Velocity }\end{array}$ & $\begin{array}{c}\text { Pk } \\
\operatorname{deg} / \mathbf{s}\end{array}$ & $\begin{array}{c}0.973 \pm \\
0.063\end{array}$ & $\begin{array}{c}0.851 \pm \\
0.064\end{array}$ & $\begin{array}{c}0.975 \pm \\
0.082\end{array}$ & $\begin{array}{l}1.327 \pm \\
0.139^{\text {a,b }}\end{array}$ & $\begin{array}{c}1.146 \pm \\
0.098\end{array}$ \\
\hline $\begin{array}{l}\text { Longitudinal } \\
\text { Displacement }\end{array}$ & Pk deg & $\begin{array}{c}0.120 \pm \\
0.014\end{array}$ & $\begin{array}{c}0.083 \pm \\
0.013\end{array}$ & $\begin{array}{c}0.091 \pm \\
0.011\end{array}$ & $\begin{array}{c}0.119 \pm \\
0.015\end{array}$ & $\begin{array}{c}0.120 \pm \\
0.016\end{array}$ \\
\hline Longitudinal Strain & Pk \% & $\begin{array}{c}-9.665 \pm \\
0.714\end{array}$ & $\begin{array}{c}-9.236 \pm \\
1.040\end{array}$ & $\begin{array}{c}-8.658 \pm \\
0.870\end{array}$ & $\begin{array}{c}-7.621 \pm \\
1.229\end{array}$ & $\begin{array}{c}-8.732 \pm \\
1.063\end{array}$ \\
\hline $\begin{array}{c}\text { Longitudinal Strain } \\
\text { Rate }\end{array}$ & Pk 1/s & $\begin{array}{l}-6.602 \pm \\
0.355\end{array}$ & $\begin{array}{c}-8.329 \pm \\
0.611\end{array}$ & $\begin{array}{c}-6.934 \pm \\
0.612\end{array}$ & $\begin{array}{l}-12.74 \pm \\
1.3844^{\text {a,b,c }}\end{array}$ & $\begin{array}{r}-10.25 \pm \\
1.207^{\mathrm{a}}\end{array}$ \\
\hline
\end{tabular}


Supplemental Table 6.2: Long-axis systolic stress-strain assessments for the baseline (6-weekold) ( $\mathrm{N}=48)$, lean (18-week-old) $(\mathrm{N}=24)$, obese (18-week-old) $(\mathrm{N}=24)$, non-UCMS (26-week-old) $(\mathrm{N}=24)$, UCMS (26-week-old) $(\mathrm{N}=24)$. Outliers were removed using a ROUT test, the D'Agostino-Pearson omnibus (K2) test was implemented to determine normal distribution, and an ANOVA/Tukey's post hoc test (normally distributed) or Kruskal-Wallis test/Dunn's post hoc test (non-normally distributed) were used to determine significance. Results were considered statically significant if $P \leq 0.05$. All data are reported as the means \pm the standard error of the mean (SEM). ${ }^{\mathbf{a}}=$ statistically different than the baseline group, ${ }^{\mathbf{b}}=$ statistically different than the lean group, ${ }^{\mathbf{c}}=$ statistically different than the obese group, ${ }^{\mathbf{d}}=$ statistically different than the non-UCMS group. $\mathrm{Pk}=$ peak, $\mathrm{UCMS}=$ unpredictable chronic mild stress. 


\section{Supplemental Figure 6.1:}

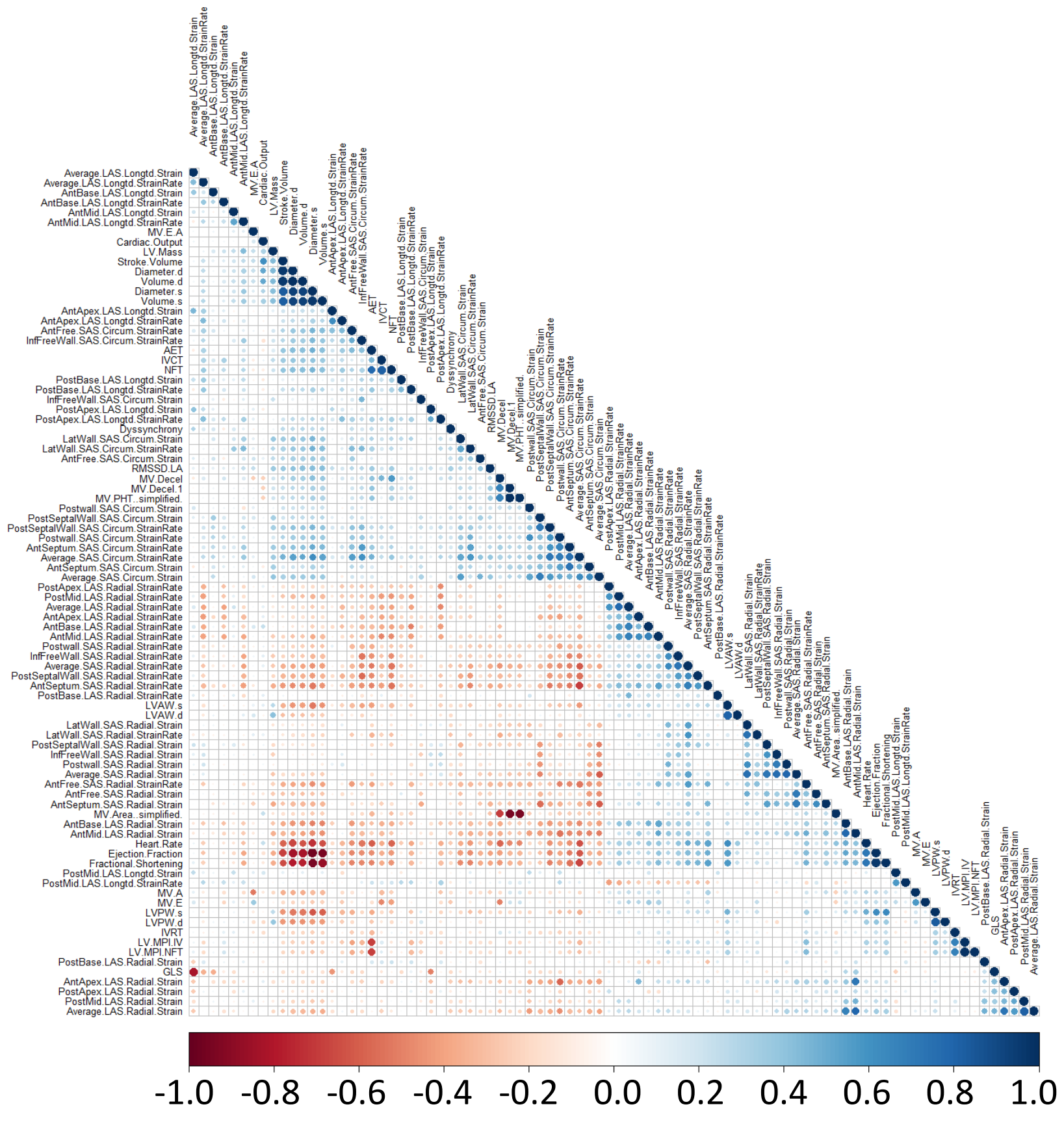


Supplemental Figure 6.1: Multicollinearity - Post-Diet. Features derived from M-mode, Pulse Wave (PW) Doppler, and strain analyses were used in machine learning applications for non-obese (baseline and lean, $\mathrm{N}=72)$ and obese $(\mathrm{N}=24)$ mice. Multicollinearity of features was assessed using corrplot (v.0.90) to prevent data bias. Highly correlated variables were removed to eliminate the possibility of impacting our machine learning algorithms. 
Supplemental Figure 6.2:

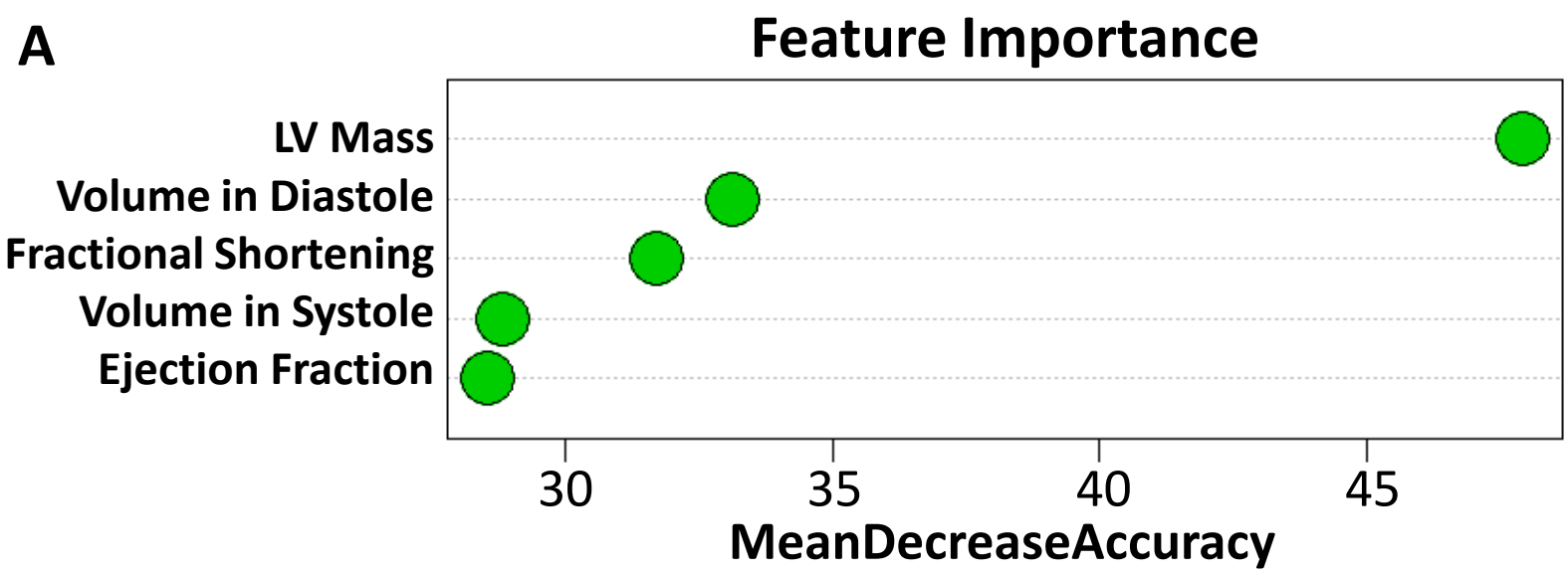

B

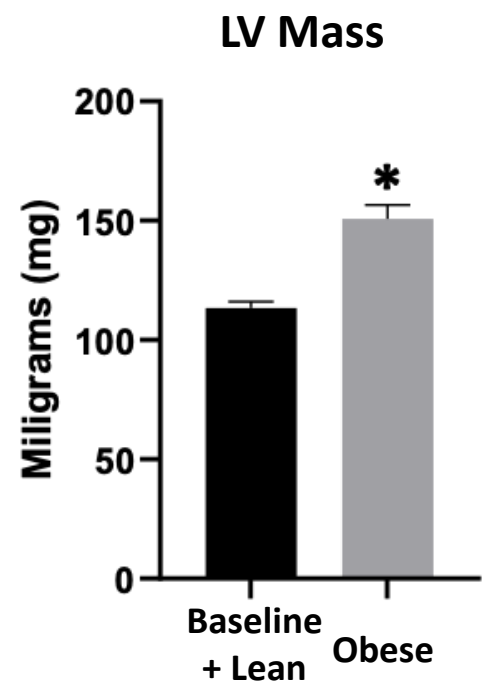

Volume in Diastole

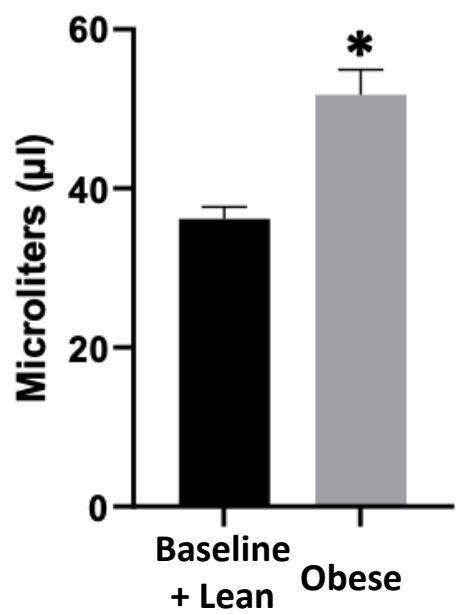


Supplemental Figure 6.2:

Fractional Shortening

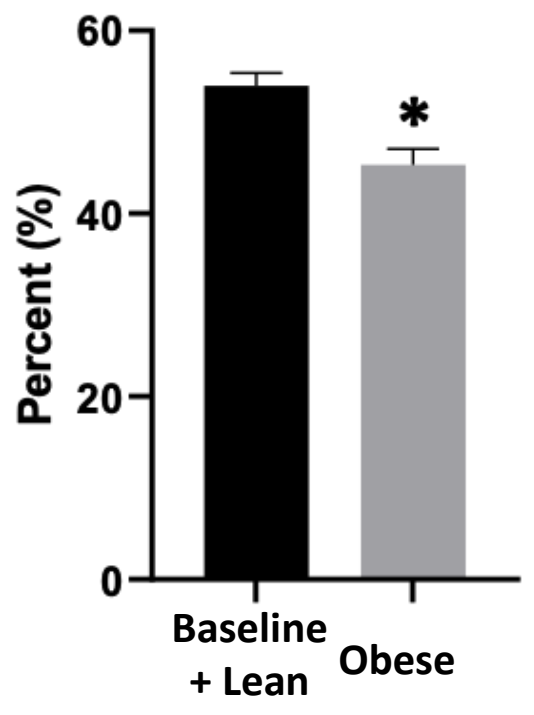

Volume in Systole

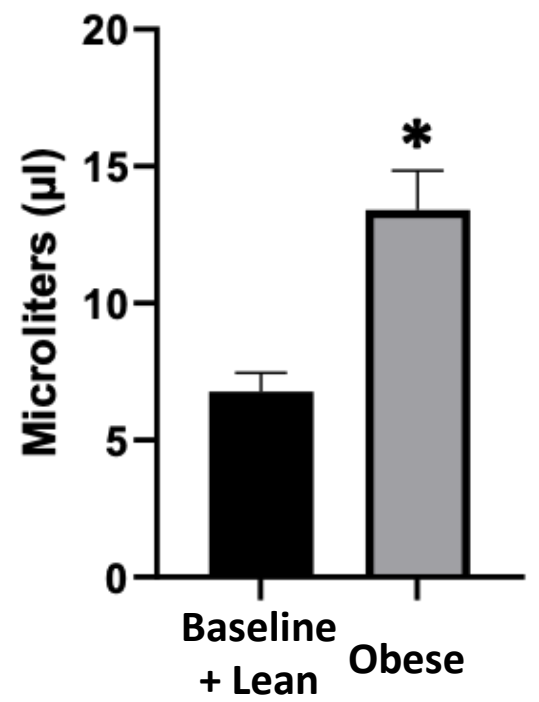

Ejection Fraction

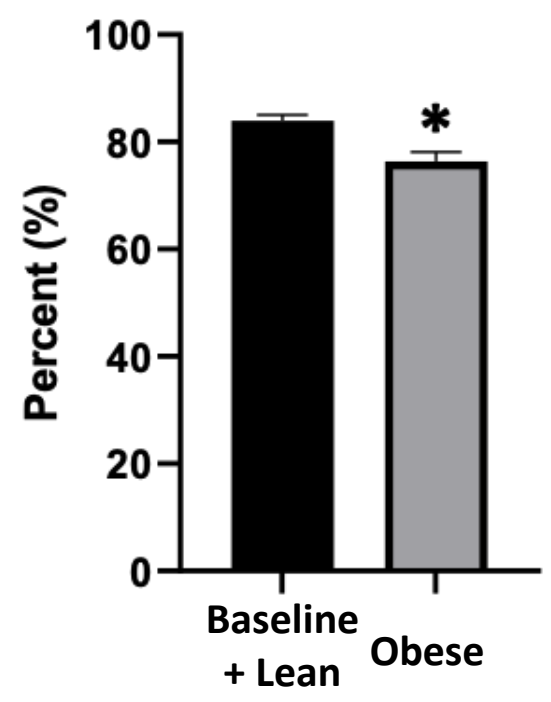


Supplemental Figure 6.2: Feature Importance Post-Diet M-Mode. Features derived from Mmode for non-obese (baseline and lean, $\mathrm{N}=72$ ) and obese (N=24) mice. (A) Feature importance was determined using randomForest and evaluated based on MeanDecreaseAccuracy. (B) The top five most important features are provided with their values. Outliers were removed using a ROUT test, the D'Agostino-Pearson omnibus (K2) test was implemented to determine normal distribution, and a two-sided unpaired Student's t-test (normally distributed) or Mann Whitney test (non-normally distributed) were used to determine significance. Results were considered statically significant if $P \leq 0.05$ and indicated by “*”. All data are reported as the means \pm the standard error of the mean $(\mathrm{SEM})$. Post-Diet $=$ post high-fat diet induced obesity, $L V=$ left ventricle. 
Supplemental Figure 6.3:

A

Feature Importance

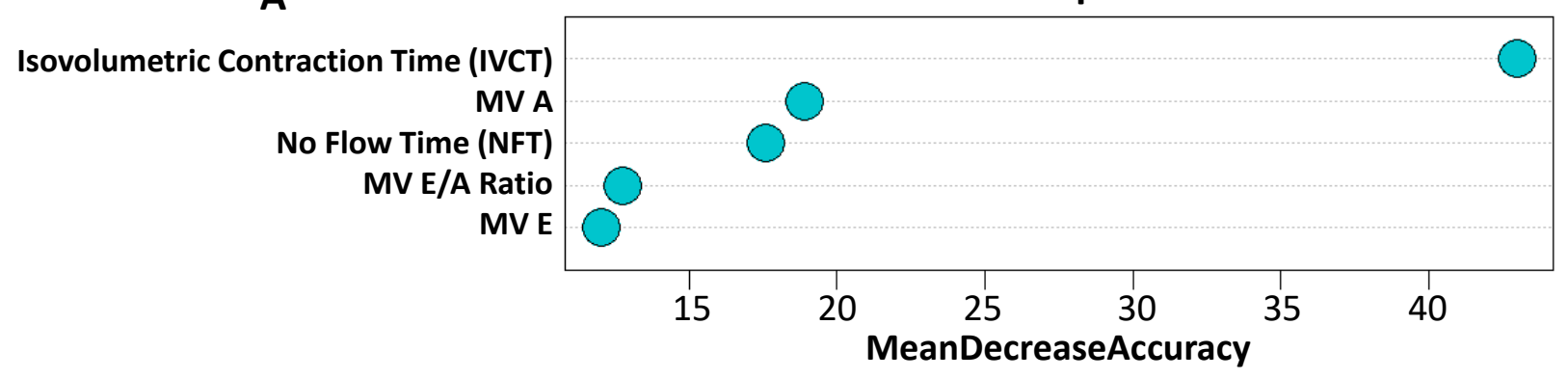

B Isovolumetric

MV A

(IVCT)
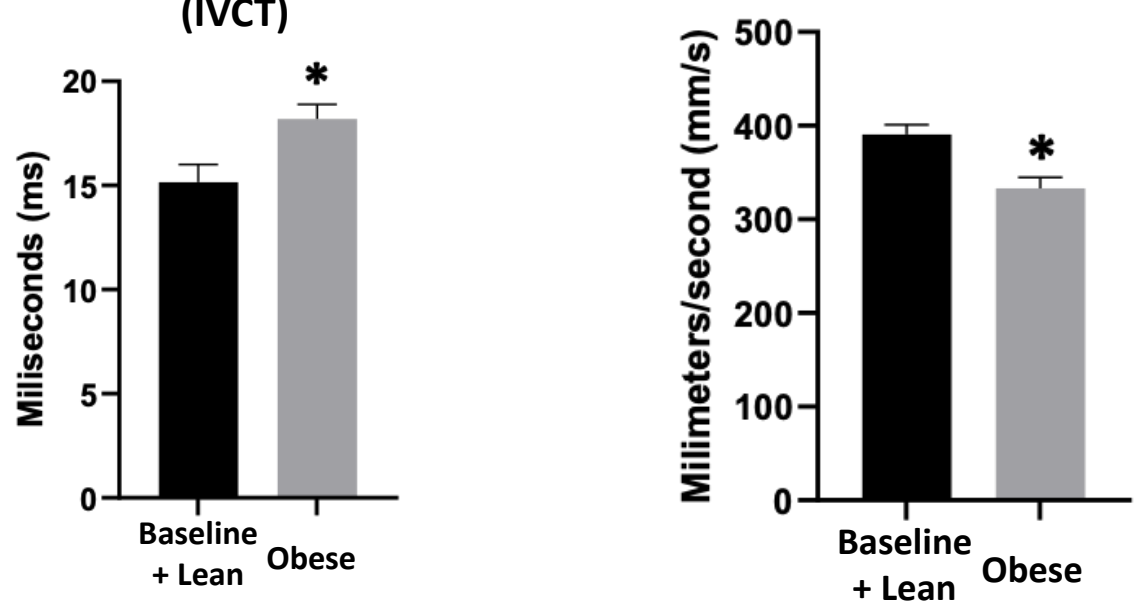
Supplemental Figure 6.3B

No Flow Time (NFT)

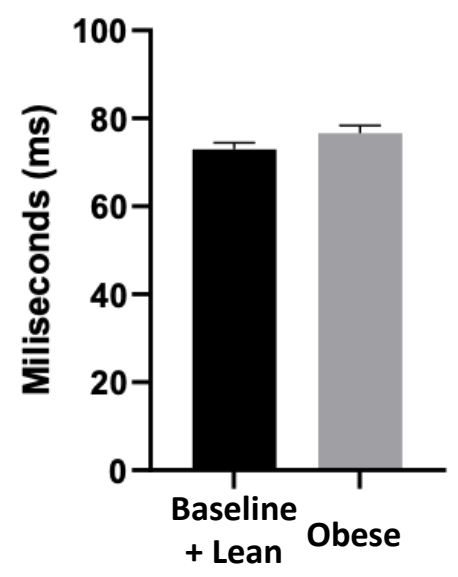

MV E/A Ratio

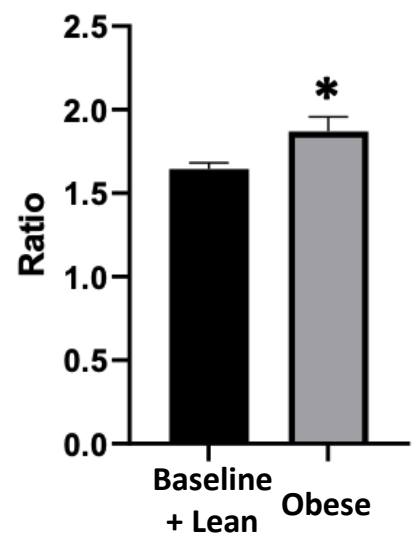

MVE

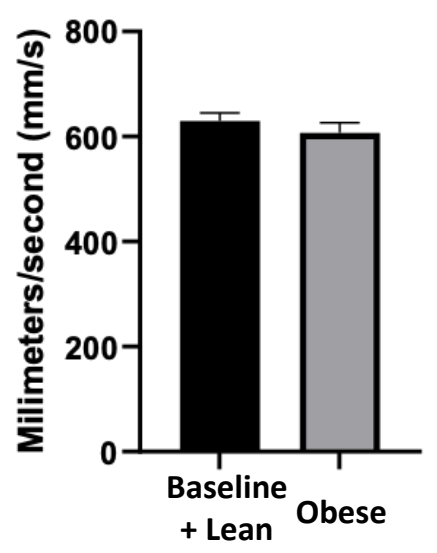


Supplemental Figure 6.3: Feature Importance Post-Diet PW Doppler. Features derived from Pulse Wave (PW) Doppler for non-obese (baseline and lean, $\mathrm{N}=72$ ) and obese (N=24) mice. (A) Feature importance was determined using randomForest and evaluated based on MeanDecreaseAccuracy. (B) The top five most important features are provided with their values. Outliers were removed using a ROUT test, the D'Agostino-Pearson omnibus (K2) test was implemented to determine normal distribution, and a two-sided unpaired Student's t-test (normally distributed) or Mann Whitney test (non-normally distributed) were used to determine significance. Results were considered statically significant if $P \leq 0.05$ and indicated by “*”. All data are reported as the means \pm the standard error of the mean $(\mathrm{SEM})$. Post-Diet $=$ post high-fat diet induced obesity, MV = mitral valve. 
Supplemental Figure 6.4:

A

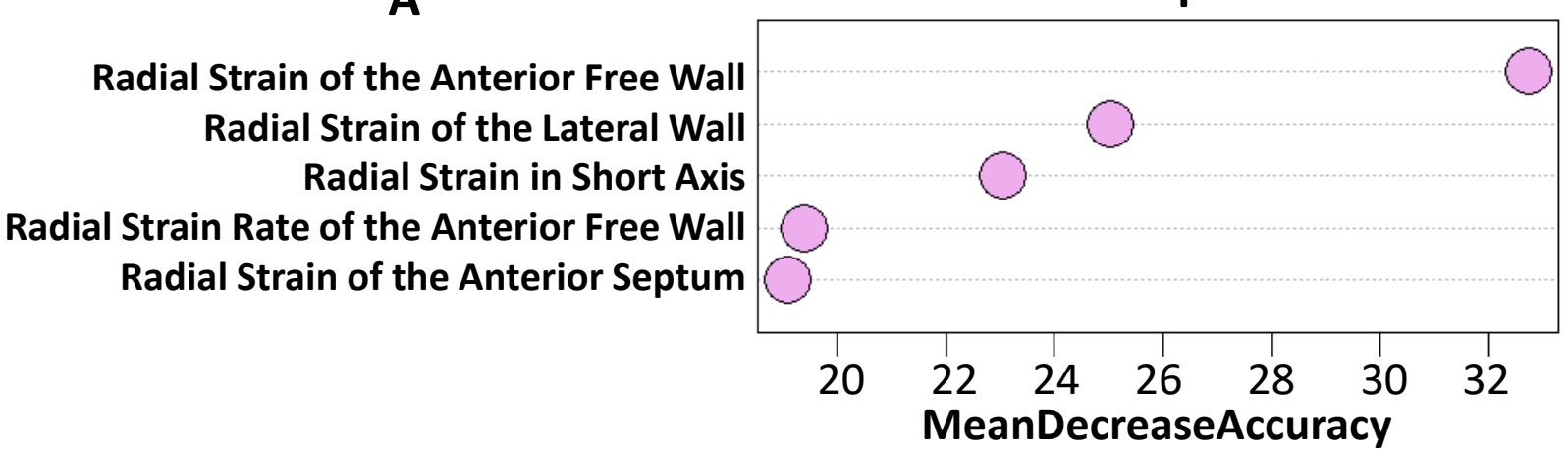

B

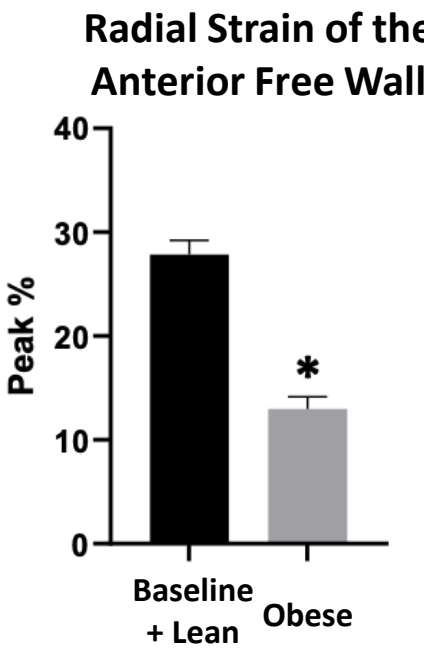

Feature Importance

MeanDecreaseAccuracy

\section{B}


Supplemental Figure 6.4B:

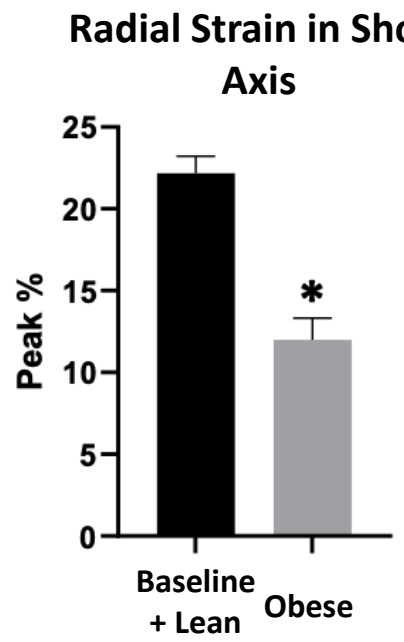

Radial Strain Rate of the Anterior Free Wall

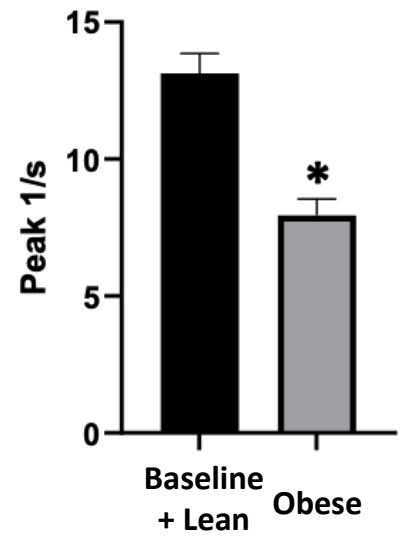

Radial Strain of the

Anterior Septum

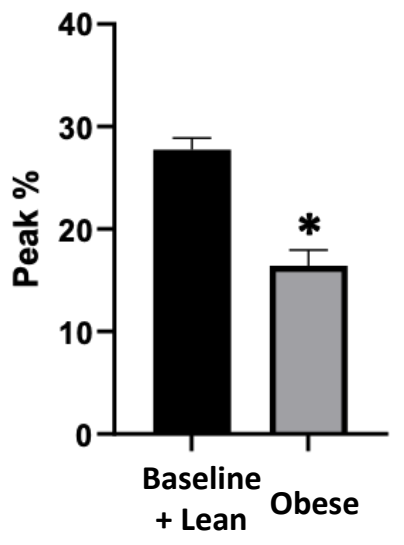


Supplemental Figure 6.4: Feature Importance Post-Diet Stress-Strain. Features derived from stress-strain analyses for non-obese (baseline and lean, N=72) and obese (N=24) mice. (A) Feature importance was determined using randomForest and evaluated based on MeanDecreaseAccuracy. (B) The top five most important features are provided with their values. Outliers were removed using a ROUT test, the D'Agostino-Pearson omnibus (K2) test was implemented to determine normal distribution, and a two-sided unpaired Student's t-test (normally distributed) or Mann Whitney test (non-normally distributed) were used to determine significance. Results were considered statically significant if $P \leq 0.05$ and indicated by “*”. All data are reported as the means \pm the standard error of the mean (SEM). Post-Diet $=$ post high-fat diet induced obesity. 


\section{Supplemental Figure 6.5:}

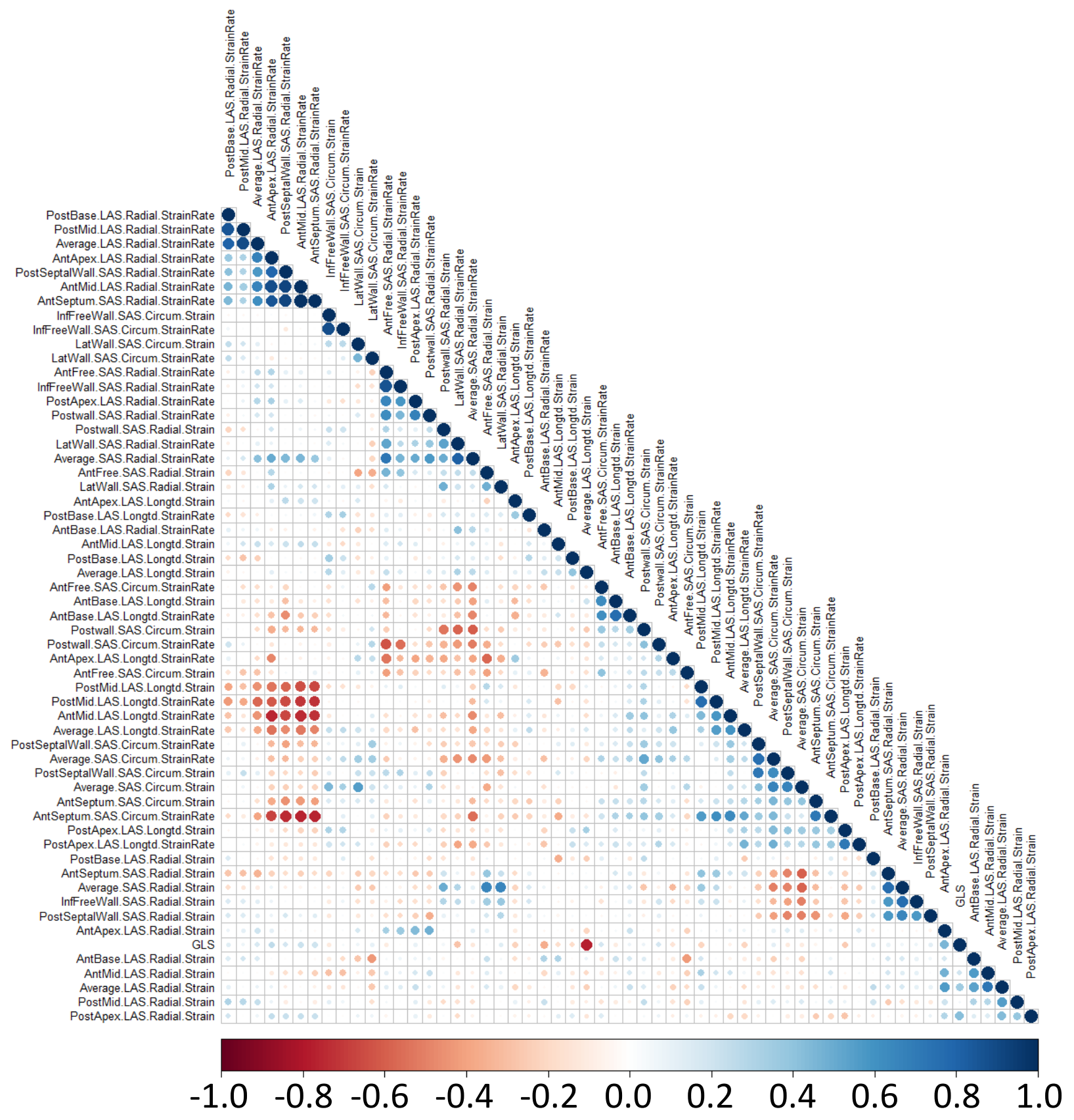


Supplemental Figure 6.5: Multicollinearity - Post-Stress. Features derived from stress-strain analyses were used in machine learning applications for non-UCMS (N=22) and UCMS (N=22) mice at 26 weeks of age. Multicollinearity of features was assessed using corrplot (v.0.90) to prevent data bias. Highly correlated variables were removed to eliminate the possibility of impacting our machine learning algorithms. 


\title{
Curriculum Vitae
}

\section{Amina Kunovac}

\author{
ak0086@mix.wvu.edu
}

\section{Education}

DOCTOR OF PHIOLOSOPHY | AUGUST 2021 | WEST VIRGINIA UNIVERSITY

- Applied and Molecular Pathophysiology (Division of Exercise Physiology)

- Graduate Research Assistant: GPA - 3.87

- Graduate student member of the American Heart Association

- Member of the WVU Mitochondria, Metabolism \& Bioenergetics Working Group

- Member of the WVU Center of Inhalation Toxicology

- Experiential Learning (1 Credit Hour): Online Review Course in Medical Genetics and Genetic Counseling

- Morgantown, WV

\section{BACHELOR OF SCIENCE | MAY 2016 | UNIVERSITY OF NEW HAVEN}

- B.S. Biology - Pre-Med (Magna Cum Laude)

- B.S. Forensic Science - Forensic Biology (Magna Cum Laude); Minor: Chemistry

- Member of Alpha Lambda Delta National Honor Society

- Member of Honor Society for Experiential Education

- Resident Assistant

- West Haven, CT

\section{Manuscripts (In Preparation/Under Review)}

Synergistic Transcriptomic and Mitochondrial Function Alterations after Single and Repeated Carbon Black and Ozone Inhalation Co-exposures.

Hathaway QA*, Majumder N*, Goldsmith WT, Kunovac A, Pinti MV, Harkema JR, Castranova V, Hollander JM, Hussain S. Submitted to Particle and Fibre Toxicology: April 14, 2021.

Primary Sequence and Secondary Structure of Nuclear-Encoded Long Non-Coding RNAs Predict Binding to Mitochondrial PNPase.

Hathaway QA, Taylor AD, Kunovac A, Pinti MV, Newman MS, Cook CC, Winters MT, Westemeier E, Fink GK, Durr AJ, Shepherd DL, Robart AR, Martinez I, Hollander JM. Submitted to Journal of Biological Chemistry: April 22, 2021. 
Genome-wide expression reveals potential biomarkers in breast cancer bone metastasis. Singh Y, Subbarao N, Jamini A, Hathaway QA, Kunovac A, Erickson B, Swarup V, and Narayan Singh H. In preparation.

Left Ventricular Segmental Stress-Strain Identifies Unique Myocardial Deformation Patterns Following Intrinsic and Extrinsic Stressors in Mice.

Kunovac A, Hathaway QA, Burrage EN, Coblentz T, Kelley EE, Sengupta PP, Hollander JM, Chantler PD Manuscript Under Review at Ultrasound in Medicine and Biology (Manuscript Number UMB-D-21-00654). Submitted September 1, 2021.

\section{Peer-Reviewed Publications}

Enhanced Antioxidant Capacity Prevents Epitranscriptomic and Cardiac Alterations in Adult Offspring Gestationally-Exposed to ENM. Kunovac A, Hathaway QA, Pinti MV, Durr AJ, Taylor AD, Goldsmith WT, Garner KL, Nurkiewicz TR, Hollander JM. Nanotoxicology. 2021 May 8:1-20. doi: 10.1080/17435390.2021.1921299. Online ahead of print. PMID: 33969789

Cardiovascular Adaptations to Particle Inhalation Exposure: Molecular Mechanisms of the Toxicology. Kunovac A, Hathaway QA, Pinti MV, Taylor AD, Hollander JM. Am J Physiol Heart Circ Physiol. 2020 Jun 12; 1;319(2):H282-H305. doi: 10.1152/ajpheart.00026.2020. PMID: 32559138

ROS Promote Epigenetic Remodeling and Cardiac Dysfunction in Offspring Following Maternal Engineered Nanomaterial (ENM) Exposure.

Kunovac A, Hathaway QA, Pinti MV, Goldsmith WT, Durr AJ, Fink GK, Nurkiewicz TR, Hollander JM. Part Fibre Toxicol. 2019 Jun 18;16(1):24. doi: 10.1186/s12989-019-0310-8. PMID: 31215478

Machine Learning, Diabetes Mellitus, and Cardiovascular Risk: A Personalized Medicine Approach to Disease Diagnosis.

Hathaway QA, Roth SM, Pinti PV, Sprando DC, Kunovac A, Durr AJ, Cook CC, Fink GK, Cheuvront TB, Grossman JH, Aljahli GA, Taylor AD, Giromini AP, Allen JL, Hollander JM. Cardiovascular Diabetology. 2019 June 11; 18(1):78. doi: 10.1186/s12933-019-0879-0. PMID: 31185988

miRNA-378a as a key regulator of cardiovascular health following engineered nanomaterial inhalation exposure.

Hathaway QA, Durr AJ, Shepherd DL, Pinti MV, Brandebura AN, Nichols CE, Kunovac A, Goldsmith WT, Friend SA, Abukabda AB, Fink GK, Nurkiewicz TR, Hollander JM. Nanotoxicology. 2019 Feb 1:1-20. doi: 10.1080/17435390.2019.1570372. PMID: 30704319

Mitochondrial Dysfunction in Type 2 Diabetes Mellitus: An Organ-Based Analysis. Pinti MV, Fink GK, Hathaway QA, Durr AJ, Kunovac A, Hollander JM. Am J Physiol Endocrinol Metab. 2019 Feb 1;316(2):E268-E285. doi: 10.1152/ajpendo.00314.2018. Epub 2019 Jan 2. PMID: 30601700

Mitochondrial proteome disruption in the diabetic heart through targeted epigenetic regulation at the mitochondrial heat shock protein 70 (mtHsp70) nuclear locus. 
Shepherd DL*, Hathaway QA*, Nichols CE, Durr AJ, Pinti MV, Hughes KM, Kunovac A, Stine SM, Hollander JM. J Mol Cell Cardiol. 2018 Jun;119:104-115. doi: 10.1016/j.yjmcc.2018.04.016. Epub 2018 May 4. PMID: 29733819

*These authors contributed equally

\section{Relevant Skills and Techniques}

Four years of experience designing and executing experiments involving a wide variety of molecular biology techniques including, but not limited to: Microbiome-sequencing analysis, RNA-seq analysis, Statistics, Bioinformatics, Genotyping, RT-qPCR, Animal Colony Maintenance, Western Blotting, ELISAs, Gel Electrophoresis, Mitochondrial Isolations, Mitochondrial Bioenergetic Assays, Mitochondrial Respiration, and Clinical Specimen Handling (including right atrial appendage).

Other skills and experiences include training in the following:

- Echocardiographic analyses on fetal and adult mouse hearts

- Data Science

- Grant writing

- Manuscript writing, editing, and preparing for publication

- Coordinating and collaborating with other laboratories

- Presenting at various conferences

- Training and teaching other graduate students (laboratory techniques, writing, and how to collaborate with other laboratories)

- Didactic Teaching

\section{Research Presentations}

\section{Experimental Biology (EB), Virtual: 2021}

Poster Presentation, abstract entitled "Identifying Unique Patterns of Myocardial Deformation through Segmental Speckle Tracking Stress Strain Following High-Fat Diet” (April 27-30, 2021)

Cardiopulmonary Physiology (EXPH 787) - Guest Lecturer - West Virginia University, Morgantown, WV: 2020

A 1-hour lecture how to perform speckle-tracking stress strain and conventional echocardiography and in human and mouse cohorts and the applications of each modality (September 11, 2020)

NHLBI Mitochondrial Biology Symposium, Bethesda, MD: 2019

Poster presentation, abstract entitled "Antioxidant Protection Attenuates Cardiac and Mitochondrial Dysfunction in Offspring Following Maternal Engineered Nanomaterial Exposure" (September 27, 2019)

Experimental Biology (EB), Orlando, FL: 2019 
Poster presentation, abstract entitled "Elevated ROS and Epigenetic Remodeling Disrupt Cardiac Function in Offspring Following Maternal Engineered Nanomaterial (ENM) Exposure" (April 9, 2019)

West Virginia University, Van Liere Research Day, Morgantown, WV: 2019

Poster presentation entitled "Maternal Engineered Nanomaterial (ENM) Exposure Augments ROS Inciting Epigenetic Remodeling and Cardiac Dysfunction in Offspring" (March 22, 2019)

West Virginia University Center for Inhalation Toxicology (iTOX), Morgantown, WV - WINTER MEETING.

Oral Presentation talk entitled "Maternal Engineered Nanomaterial (ENM) Exposure Augments ROS and Epigenetic Remodeling Inciting Cardiac Dysfunction in Offspring" (November 28, 2018)

\section{Honors and Distinctions}

\section{Outstanding Doctoral Student Award - Exercise Physiology}

Background: Award bestowed on individuals in the Exercise Physiology doctoral program who exhibit exemplary performance in academic and professional standards, such as publications, GPA, collaborations, teaching, etc.

Awarded: May 15, 2021

\section{American Heart Association Predoctoral Fellowship}

Background: Two-year predoctoral award received for project entitled "Cardiac Epitranscriptomic and Mitochondrial Remodeling in Progeny Following Maternal Engineered Nanomaterial Exposure".

Awarded: January 31, 2020 - December 31, 2021

\section{Mitochondria, Metabolism \& Bioenergetics Working Group Travel Award - EB 2020}

Background: Award designed to monetarily support conference registration costs for mitochondrial research. The work presented included a poster presentation entitled "Glutathione Peroxidase Influence on Cardiac Remodeling in Progeny of Dams Exposed to Engineered Nanomaterials During Gestation"

Awarded: February 3, 2020

\section{WVU Center for Inhalation Toxicology (iTOX) Travel Award - SOT 2020}

Background: Award designed to monetarily support toxicology research. The work presented included a poster entitled "Transient and Sustained Antioxidant Protection in Progeny Following Gestational Engineered Nanomaterial Inhalation Exposure".

Awarded: February 11, 2020

\section{Peer-Reviewed Accepted Abstracts}

IDENTIFYING UNIQUE PATTERNS OF MYOCARDIAL DEFORMATION THROUGH SEGMENTAL SPECKLE TRACKING STRESS STRAIN FOLLOWING HIGH-FAT DIET 
Kunovac A, Burrage EN, Coblentz T, Kelley EE, Sengupta PP, Hollander JM, Hathaway QA, Chantler PD. Experimental Biology (EB), Virtual: 2021

MODELLING THE PULMONARY TRANSCRIPTOME IN A DOSE AND SUBSTRATE-DEPENDENT MANNER: CARBON BLACK AND OZONE CO-EXPOSURE

Hathaway QA, Majumder N, Kunovac A, Xie Z, Pinti MV, Harkema JR, Nurkiewicz TR, Hollander JM, and Hussain S. - Society of Toxicology (SOT), Virtual: 2021

GLUTATHIONE PEROXIDASE INFLUENCE ON CARDIAC REMODELING IN PROGENY OF DAMS EXPOSED TO ENGINEERED NANOMATERIALS DURING GESTATION

Kunovac A, Hathaway QA, Taylor AD, Durr AJ, Goldsmith WT, Pinti MV, Fink GK, Nurkiewicz TR, and Hollander JM. - Experimental Biology (EB), San Diego, CA: 2020

MICRORNA-378A LOSS ENHANCES MITOCHONDRIAL BIOENERGETICS AND LESSENS CARDIAC CONTRACTILE DYSFUNCTION IN THE TYPE 2 DIABETIC HEART

Durr AJ, Hathaway QA, Kunovac A, Taylor AD, Pinti MV, McLaughlin SL, Shepherd DL, Singh AK, and Hollander JM. - Experimental Biology (EB), San Diego, CA: 2020

LOSS OF FUNCTIONAL NON-CODING RNA DIVERSITY IN DIABETIC CARDIAC MITOCHONDRIA

Taylor AD, Hathaway QA, Kunovac A, Pinti MV, Cook CC, Fink GK, Durr AJ, and Hollander JM. Experimental Biology (EB), San Diego, CA: 2020

TRANSIENT AND SUSTAINED ANTIOXIDANT PROTECTION IN PROGENY FOLLOWING GESTATIONAL ENGINEERED NANOMATERIAL INHALATION EXPOSURE

Kunovac A, Hathaway QA, Taylor AD, Pinti MV, Goldsmith WT, Fink GK, Durr AJ, Nurkiewicz TR, and Hollander JM. - Society of Toxicology (SOT), Anaheim, CA: 2020

ANTIOXIDANT PROTECTION ATTENUATES CARDIAC AND MITOCHONDRIAL DYSFUNCTION IN OFFSPRING FOLLOWING MATERIAL ENGINEERED NANOMATERIAL EXPOSURE

Kunovac A, Hathaway QA, Durr AJ, Goldsmith WT, Taylor AD, Pinti MV, Fink GK, Nurkiewicz TR, and Hollander JM. - NHLBI Mitochondrial Biology Symposium, Bethesda, MD: 2019

\section{APPLYING MACHINE-LEARNING TO DISEASE DIAGNOSIS THROUGH PATIENT-MATCHED OMICS PROFILES \\ Hathaway QA, Roth SM, Pinti, MV, Sprando DC, Kunovac A, Durr AJ, Cook CC, Fink GK, Cheuvront TB, Grossman JH, Aljahli GA, Taylor AD, Giromini AP, Allen JL, and Hollander JM. - NHLBI Mitochondrial Biology Symposium, Bethesda, MD: 2019}

LOSS OF MICRORNA-378A FUNCTION RESTORES MITOCHONDRIAL BIOENERGETICS IN A TYPE 2 DIABETIC MOUSE MODEL

Durr AJ, Hathaway QA, Taylor AD, Kunovac A, Pinti MV, Shepherd DL, Fink GK, and Hollander JM. - NHLBI Mitochondrial Biology Symposium, Bethesda, MD: 2019

IMPACT OF DIABETES MELLITUS ON MITOCHONDRIAL MIRNA DIVERSITY AND RELATED CELLULAR PATHWAYS

Taylor AD, Hathaway QA, Kunovac A, Pinti MV, Cook CC, Fink GK, Durr AJ, Shepherd DL, Robart AR, and Hollander JM. - NHLBI Mitochondrial Biology Symposium, Bethesda, MD: 2019 
ELEVATED ROS AND EPIGENETIC REMODELING DISRUPT CARDIAC FUNCTION IN OFFSPRING FOLLOWING MATERNAL ENGINEERED NANOMATERIAL (ENM) EXPOSURE

Kunovac A, Hathaway QA, Pinti MV, Durr AJ, Fink GK, Goldsmith WT, Nurkiewicz TR, and Hollander JM. Experimental Biology (EB), Orlando, FL: 2019

USING MACHINE LEARNING TO PREDICT THE DEVELOPMENT OF DIABETES AND POTENTIAL BIOMARKERS LINKED TO CARDIAC RISK

Hathaway QA, Pinti MV, Roth SM, Sprando DC, Kunovac A, Durr AJ, Cook CC, Fink GK, Cheuvront TB, Grossman JH, Aljahli GA, Roberts HG, Salman M, Giromini AP, and Hollander JM. - Experimental Biology (EB), Orlando, FL: 2019

MICRORNA CHANGES IN DIABETIC CARDIAC MITOCHONDRIA: WHAT ARE THEY DOING THERE?

Pinti MV, Hathaway QA, Kunovac A, Durr AJ, Cook CC, Roberts HG, Salman M, and Hollander JM. Experimental Biology (EB), Orlando, FL: 2019

STRESS STRAIN SPECKLE-TACKING SEGMENTAL ANALYSIS REVEALS EARLY INDICATIONS OF DIASTOLIC DYSFUNCTION IN A TYPE 2 MOUSE MODEL OF DIABETES MELLITUS

Durr AJ, Hathaway QA, Pinti MV, Shepherd DL, Kunovac A, and Hollander JM. - Experimental Biology (EB), Orlando, FL: 2019

MATERNAL ENGINEERED NANOMATERIAL (ENM) EXPOSURE AUGMENTS ROS INCITING EPIGENETIC REMODELING AND CARDIAC DYSFUNCTION IN OFFSPRING

Kunovac A, Hathaway QA, Pinti MV, Fink GK, Goldsmith WT, Durr AJ, Nurkiewicz TR, and Hollander JM. West Virginia University Van Liere, Morgantown, WV: 2019

\section{Mentorship}

West Virginia University | Graduate Research Assistant | January 2017 - Current

- Summer Students

Dylan Holland (2019) - Medical school summer research rotation

- Currently: Medical student class of 2022 at West Virginia University

- Undergraduate Students

Matt Knauff (Fall 2019 - Present) - Undergraduate part-time research

- Currently: Undergraduate student in Exercise Physiology

Garrett Fink (Spring 2018 - Present) - Undergraduate part-time research

- Currently: Undergraduate student in Exercise Physiology

- Research Rotations

Joseph Agba (Fall 2019) - Graduate research rotations

- Currently: Undifferentiated graduate student in the Biomedical Sciences program

Andrew Giromini (Fall 2018) - Graduate research rotations

- Currently: Undifferentiated graduate student in the Biomedical Sciences program

- Graduate Students 
Saira Rizwan (Fall 2020-Present)-Graduate research rotations

- Currently: Graduate Research Assistant for Dr. John Hollander, West Virginian University, Department of Exercise Physiology

Andrew Taylor (Fall 2018-Present) - Graduate research rotations

- Currently: Graduate Research Assistant for Dr. John Hollander, West Virginian University, Department of Exercise Physiology

\section{Community Outreach and Volunteer Work}

Smokey Mountain Home for Children - Severiville, TN | Greene Valley Church of God | July 2018

- 7-day trip to volunteer at a home for foster children and neglected youth. Approximately 50-80 children living at the facility, with a widow's center housing 30-40 women.

- Work included painting, sanding, cleaning, drywall work, remodeling, moving furniture and equipment, etc.

- Outreach activities included talking and interacting with the youth through sports and while working within the living quarters.

Volunteer, Yale New Haven Hospital -Children's Surgical Unit- New Haven, CT | 2013-2015

Provided help and human connection necessary to ease the stress of the patients going through difficult times.

\section{Undergraduate Work Experience}

Forensic Science Study Abroad Program-Chaperone - July 2016

- Assisted in coordinating a trip to Sydney, Australia and the University of Technology, Sydney-Bodies Farm.

Resident Assistant - Office of Residential Life, University of New Haven - 2013-2016

- Develop community between 70 residents through creative programming while implementing University policies

Resident Assistant - Forensic Science Living Learning Community-Office of Residential Life, University of New Haven

2014-2015

- Developed community between 40 residents by creating programs involving Forensic Science topics to introduce first-year Forensic Science students to possible career paths, while also implementing University policies.

\section{Undergraduate Honors and Distinctions}

Inductee of the Honor Society for Experiential Education-Gold Level

April 2016 
Summer Undergraduate Research Fellow

Summer 2015

Inductee of Alpha Lambda Delta Honor Society

Spring 2013

Dean's List, University of New Haven

2012-2016

Distinguished Scholar Award (\$12,000 per academic year)

2012-2016

SAT Writing Award ( $\$ 1,000$ per academic year)

2012-2016

\section{Language}

Fluent

English

Written and Spoken

Bosnian

Written and Spoken

Croatian

Written and Spoken 